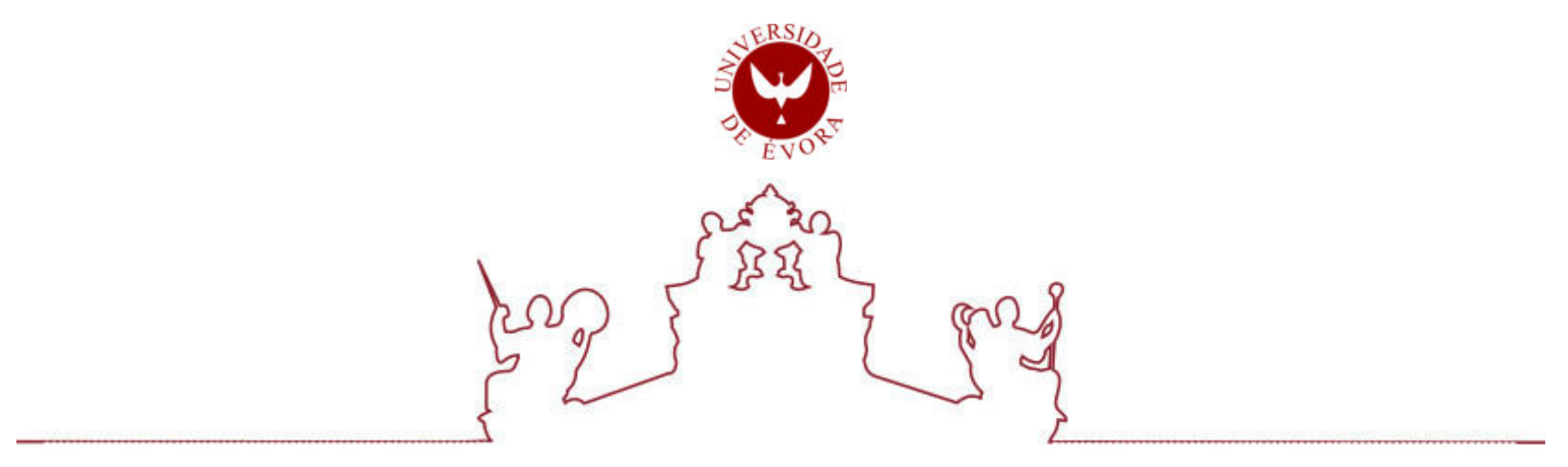

Universidade de Évora - Instituto de Investigação e Formação Avançada

Programa de Doutoramento em História e Filosofia da Ciência Área de especialização | Museologia

Tese de Doutoramento

\title{
Biodiversidade Musealizada: Formas que Comunicam
}

\author{
Mariana Galera Soler \\ Orientador(es) | Maria Margaret Lopes \\ Maria de Fátima Nunes Ferreira
}




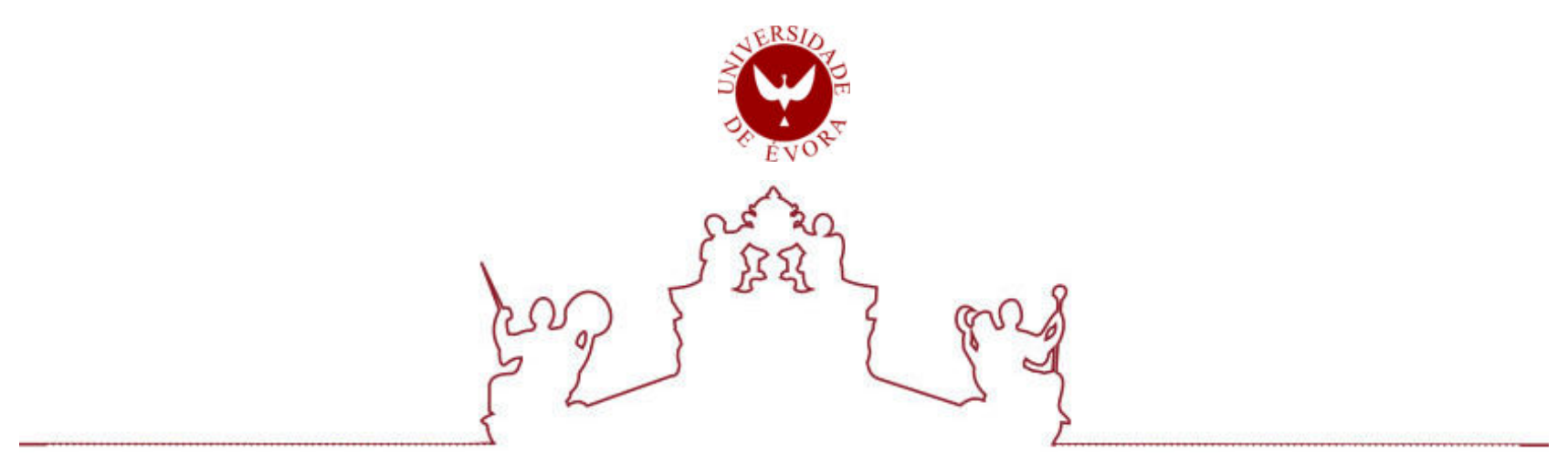

Universidade de Évora - Instituto de Investigação e Formação Avançada

Programa de Doutoramento em História e Filosofia da Ciência Área de especialização | Museologia

Tese de Doutoramento

Biodiversidade Musealizada: Formas que Comunicam

\author{
Mariana Galera Soler \\ Orientador(es) | Maria Margaret Lopes \\ Maria de Fátima Nunes Ferreira
}




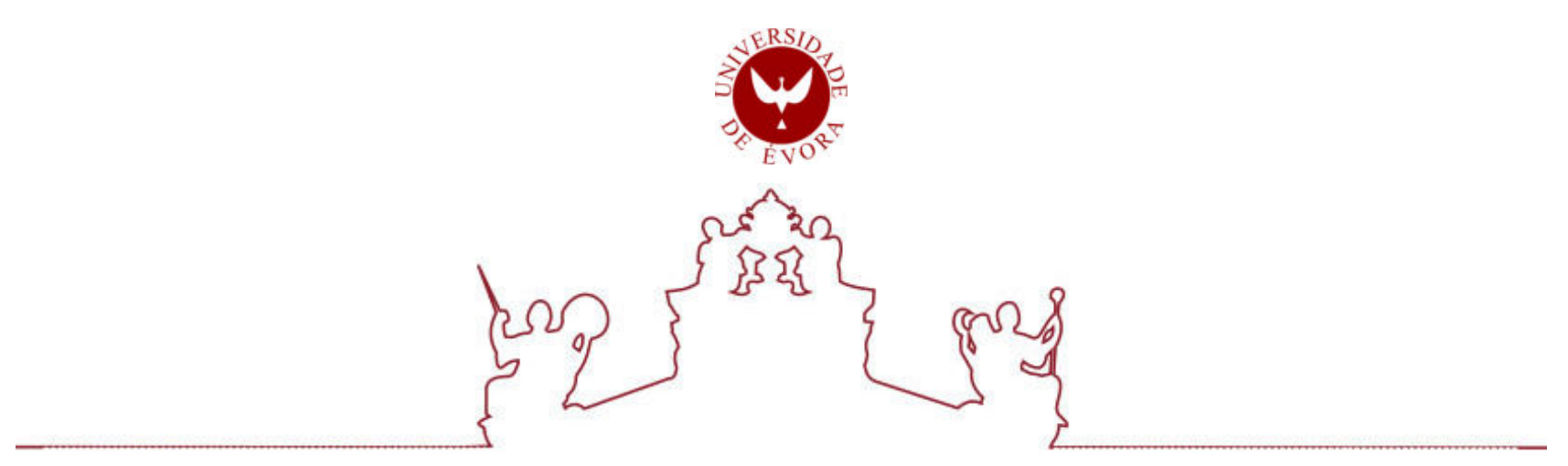

A tese de doutoramento foi objeto de apreciação e discussão pública pelo seguinte júri nomeado pelo Diretor do Instituto de Investigação e Formação Avançada:

- Presidente | Filipe Manuel Miranda Themudo Barata (Universidade de Évora)

- Vogal | Ana Carvalho (Universidade de Évora)

- Vogal | Ignacio Pereda Garcia (Universidade de Lisboa)

- Vogal | Mariana de Jesus Pereira Valente (Universidade de Évora)

- Vogal | Marta Catarino Lourenço (Universidade de Lisboa)

- Vogal | Pedro Casaleiro (Universidade de Coimbra)

- Vogal | Tiago Brandão (Universidade Nova de Lisboa - Faculdade de Ciências Sociais e Humanas)

- Vogal-orientador | Maria de Fátima Nunes Ferreira (Universidade de Évora) 


\section{Quniversidade de évora}

Dedico estas reflexões a todos aqueles que se

fizeram presentes, não importa o lado do Oceano Atlântico.

Em especial para Aurora Rodrigues, por ser uma inspiração sobre o que é ser mulher. 


\section{RESUMO}

Nesta tese discutimos a museografia de museus de história natural como meio de registo de práticas científicas e museológicas. A partir de ampla revisão na literatura, fontes documentais e visitas técnicas, foi construído um modelo teórico de padrões museográficos, formas de expor acervos científicos associadas ao design, tipo de acervo, textos, iluminação, recursos audiovisuais e multimédia e o posicionamento do acervo e do visitante perante o discurso museológico, desde o século XIX até a atualidade. Embora os padrões tenham sido desenvolvidos em contextos específicos, estes podem ser contemporâneos, sendo possível diferentes modos de expor numa mesma instituição e/ou exposição. Encontramos ainda padrões semelhantes em diferentes museus, evidenciando o contacto entre instituições e a circulação de conhecimentos, ideias e objetos. Os padrões propostos foram aplicado a cinco exposições de museus de história natural, contemporâneas, lusófonas (Brasil e Portugal) e que abordaram biodiversidade "Conchas Corais e Borboletas"; "Biodiversidade: conhecer para preservar"; "Galeria da Biodiversidade"; "Reis da Europa Selvagem" e "Specere". Utilizamos o conceito "biodiversidade", como marcador temporal e garantia de um ponto de articulação entre os discursos das exposições analisadas. Partimos de uma Matriz que sumarizou em indicadores os padrões e a características das exposições. Entre as questões que identificamos como determinantes (objetivo, tipo de instituição, tema e acervo), a constituição da equipa curatorial foi crucial. A ausência de algumas práticas científicas e museológicas, a invisibilidades de determinados profissionais e conhecimentos reafirmam a autoridade das ciências naturais e dos museus, por conseguinte, dos investigadores perante a assistência. Constatamos que ainda mais recente que a conceção de biodiversidade são modos de expor que permitam experienciá-la, uma vez que viabilizar exposições sobre tal conceito implica em também interagir com as múltiplas perspetivas de sua crise e permitir o posicionamento crítico do visitante.

PALAVRAS-CHAVE: museus de história natural; exposições; biodiversidade; museografia; coleções zoológicas 


\section{Musealized Biodiversity: Forms and Ways that Comunicate}

\section{ABSTRACT}

In this thesis we discuss a natural history museum as a means of recording scientific and museum practices. Based on broad literature review, archives and technical visits, we propose a theoretical model of museographic pattern: forms of exportation of scientific objects related to design, type of collection, texts, lighting, audiovisual and multimedia resources and the role of the collection and the visitor in museological discourse, from the nineteenth century to the present. Although patterns have been developed in specific contexts, they may be contemporary, with different ways of exhibition being possible within the same institution and / or exhibition. It also found similar patterns in different museums, evidence or contact between institutions and circulation of knowledge, ideas and objects. Our theorical model were applied to five exhibitions of museums of natural history, contemporary, Lusophone (Brazil and Portugal) that addressed the biodiversity: "Conchas Corais e Borboletas"; "Biodiversidade: conhecer para preservar"; "Galeria da Biodiversidade"; "Reis da Europa Selvagem" e "Specere". We use the concept "biodiversity" as a temporal marker and a point of articulation among the exhibitions analyzed. We started the analysis from a Matrix that summarized in indicators the patterns and characteristics of the exhibitions. The curatorial team constitution was crucial among the issues that identify as determinants to the way and forms in exhibition (other issue identified: objective, type of institution, theme and collection). The lack of some scientific and museological practices, the invisibility of professionals and knowledge reaffirm the authority of the natural sciences and museums, that is researchers authority on visitors. We have found that even more recent than the conception of biodiversity are ways of exposing that allow to experience it. Since enabling biodiversity exhibitions also means interacting with the multiple perspectives of its crisis and allowing critical visitor positioning

KEY WORDS: natural history museums; exhibitions; biodiversity; museography; zoological collections. 


\section{ÍNDICE DE ILUSTRAÇÕES}

FIGURA 1: Comparação entre o aspeto geral do espaço expositivo contemporâneo de museus britânicos construídos no século XIX.

FIGURA 2: Prancha publicada em 1806 por Pitt Rivers, associada ao texto em que explica suas conceções sobre evolução da cultura humana.

FIGURA 3: Exemplo que identificamos como representante do subpadrão museográfico "Série Evolutiva/Progressista" na exposição Mammals, do NHM.

FIGURA 4: Exemplos de grupos biológicos, ainda presentes em exposições contemporâneas.

FIGURA 5: Dioramas inaugurados em 2012, para a exposição Las Aves, no Museu Argentino de Ciencias Naturales Bernardino Rivadavia (Buenos Aires, Argentina).

FIGURA 6: Imagem do recebimento da Transparent Woman do German Health Museum (Colônia) para a construção do Biology of Man Hall, no AMNH, em 1951.

FIGURA 7: Painéis da exposição "Can Man Survive?", inaugurada em 1969, no Theodore Roosevelt Memorial Hall, AMNH.

FIGURA 8: Exemplos da inclusão de elementos que consideramos característicos do subpadrão museográfico Public Understanding of Science presentes em exposições contemporâneas de museus de história natural.

FIGURA 9: Exemplos da inclusão de elementos característicos do padrão museográfico Espetacular.

FIGURA 10. Exemplo de exposição que promove o Padrão Museográfico Espetacular. Spectrum of Life Wall, vitrine com destaque para as espécies ameaçadas de extinção na Terra. Parte do Hall of Biodiversity, no AMNH

FIGURA 11: Exemplos da utilização do padrão museográfico inspirado em gabinetes de curiosidades, em museus de Madrid (Espanha).

FIGURA 12: Exemplos do padrão museográfico "Retorno à Curiosidade".

FIGURA 13: As reservas técnicas visitáveis são consideradas uma das representações do padrão museográfico "Retorno à Curiosidade". Spirit Collection, no Darwin Centre, NHM.

FIGURA 14: Vista geral da exposição Treasures, no NHM.

Figura 15: Planta baixa do Hintze Hall, NHM.

FIGURA 16: Objetos destacados no Hintze Hall, saguão central do NHM.

FIGURA 17: Espécime "Vaca Ñata" em exposição na sala Osteología Comparada, no Museo de La Plata.

FIGURA 18: Vitrine com reprodução de um paleta de aquarela.

FIGURA 19: Exemplo de uma Ficha de Catalogação de Material em Exposição. 
FIGURA 21: Uma das perspetivas que faziam parte do projeto expositivo de "Conchas, corais e borboletas”, com distribuição do mobiliário e alguns objetos do acervo, na segunda galeria.

FIGURA 22: Exposição "Conchas, corais e borboletas" - Setor Porifera. $\quad 148$

FIGURA 23: Exposição “Conchas, corais e borboletas” - Setor Cnidaria. $\quad 149$

FIGURA 24: Dioramas da exposição "Conchas, corais e borboletas”. 150

FIGURA 25: Exposição “Conchas, corais e borboletas” - Setor Mollusca. 151

FIGURA 26: Exposição “Conchas, corais e borboletas" - Setor Echinodermata. 152

FIGURA 27: Exposição "Conchas, corais e borboletas" - Visão geral da segunda galeria. 153

FIGURA 28: Exposição "Conchas, corais e borboletas" - Setor Arachnida. 154

FIGURA 29: Exposição “Conchas, corais e borboletas” - Setor Crustacea. 166

FIGURA 30: Exposição "Conchas, corais e borboletas" - Setor Crustacea. Comparação entre vitrine "zonação do ambiente marinho" (A) e ilustração do livro "Marine Biology: an ecological approach" de

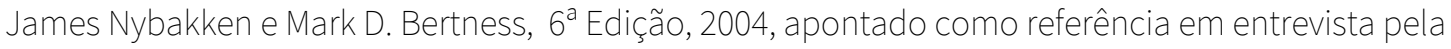
curadora Irene Azevedo Cardoso (B).

FIGURA 31: Exposição “Conchas, corais e borboletas” - Setor Insecta.

FIGURA 32: Exposição "Conchas, corais e borboletas" - Setor Insecta.

FIGURA 33: Algumas das fantasias doada pela Escola de Samba Imperatriz Leopoldinense e associadas ao acervo exposto em Exposição "Conchas, corais e borboletas".

FIGURA 34: Planta-baixa da exposição "Reis da Europa Selvagem”.

FIGURA 35: Painéis na entrada da exposição “Reis da Europa Selvagem”.

FIGURA 36: Primeiro módulo da exposição “Reis da Europa Selvagem”. Em A, painel de apresentação. 166

FIGURA 37: Segundo módulo da exposição “Reis da Europa Selvagem”. Em A, vista geral dos animais 169

FIGURA 38: Palco com os espécimes naturalizados de presas dos grandes carnívoros europeus. 170

FIGURA 39: Dioramas da exposição "Reis da Europa Selvagem”.

FIGURA 40: Módulo final da exposição "Reis da Europa Selvagem".

FIGURA 41: Realidade aumentada, com fêmea de urso-pardo e sua cria.

FIGURA 42: Painel de abertura da exposição “Specere” e visão geral dos armários e painéis.

FIGURA 43: Mapa do Museu Nacional de História Natural e da Ciência, Universidade de Lisboa. 
FIGURA 46: Conjunto de armários que apresentam as coleções preservadas em via húmida.

FIGURA 47: Conjunto de armários que apresentam as coleções entomológicas.

FIGURA 48: Conjunto de armários que apresentam as coleções ornitológicas.

FIGURA 49: Exemplos de objetos apresentados fora de armários.

FIGURA 50: Armários com museografias e abordagens diferentes.

188

FIGURA 51: "O desejo de Sophia" é como ficou conhecida um dos mais icónicos objetos em exposição na Galeria da Biodiversidade, o esqueleto de baleia que pertencia a Faculdade de Ciências da Universidade do Porto.

FIGURA 52: Planta baixa dos espaços expositivos nos Pisos O e 1 da Casa de Andresen.

Figura 53: Os esqueletos da Galeria da Biodiversidade.

Figura 54: Os quatro princípios para preservação da biodiversidade.

Figura 55: Módulos de grande apelo estético, baseados na conceção da "museologia total".

Figura 56: Módulos Diversidade de Formas.

Figura 57: Módulos Por Terra, Mar e Ar. Duas perspetivas diferentes.

201

Figura 58: Módulos Comer e Não ser Comida.

202

Figura 59: Módulos relacionados à teorias seletivas.

202

Figura 60: Módulos Analogia e Homologia.

203

Figura 61: Módulos Especiação, duas perspetivas do módulo.

205

Figura 62: Módulos Gabinete de Curiosidades, diversas perspetivas do módulo.

207

Figura 63: Módulos Diversidade Humana.

208

Figura 64: Módulos Diversidade da Língua.

Figura 65: Vista Geral do átrio com o esqueleto de cetáceo.

Figura 66: Hall de entrada da exposição "Biodiversidade: conhecer para preservar", com destaque para o chimpanzé Chico.

FIGURA 67: Planta baixa da exposição "Biodiversidade: conhecer para preservar".

FIGURA 68: Quatro perspetivas diferentes do hall de entrada da exposição "Biodiversidade: conhecer para preservar"

FIGURA 69: Paredes laterias do hall de entrada da exposição "Biodiversidade: conhecer para preservar". 
FIGURA 70: Módulo 1 da exposição "Biodiversidade: conhecer para preservar", cujo tema é a história geológica da biodiversidade.

FIGURA 71: Fechamento do Módulo 1 da exposição "Biodiversidade: conhecer para preservar", com representantes da megafauna, que foram extintos na mais recente grande extinção.

FIGURA 72: Módulo 2 - "Paisagens da Biodiversidade".

222

FIGURA 73: Módulo 2 - Paisagens humanas, com destaque para fotografia aérea de São Paulo e alguns animais distribuídos de acordo com os locais na metrópole que podem (raramente) ser encontrados.

FIGURA 74: Módulo 3 - "Todos parentes, todos diferentes" traz exemplos de histórias evolutivas de diversos grupos.

FIGURA 75: Sala da Descoberta.

FIGURA 76: Equipamentos museográficos destinados à crianças em “Conchas, corais e borboletas”. 228

FIGURA 77: Vitrine com bivalves em "Conchas, corais e Borboletas".

229

FIGURA 78: Vitrine com artefactos indígenas e joias construídos com insetos, na parte de Entomologia Cultural do Setor Insecta

FIGURA 79: Espécimes de poríferos que narram seus procedimentos de recol ha em ambiente natural

FIGURA 80: Detalhe do terceiro módula da exposição "Reis da Europa Selvagem"

FIGURA 81: Dois ambientes imersivos criados pela museografia de Reis da Europa Selvagem. Em A, os dioramas construídos em paralelo e sem vidros, permitem que o visitante literalmente transite por dois diferentes ecossistemas.

FIGURA 82: No segundo módulo da exposição "Reis da Europa Selvagem" encontramos o uso de imagens pictóricas (projeção e painéis), gráficos (projeção), frases curtas (painéis) e com formatação diferenciada, uma estética similar a utilizada em jornais e revistas

FIGURA 83: Detalhes exposição "Reis da Europa Selvagem" em que podem ser vistas estruturas de montagem simples e que não afetam a arquitetura do edifício.

FIGURA 84: Armário da exposição "Specere", cujo mobiliário foi reaproveitado das estantes da biblioteca do Instituto Bacteriológico, contendo espécimes histórica de botânica que atualmente fazem parte do Herbário LISC.

FIGURA 85: Visão comparada de duas museografias inspiradas em "typological exuberance".

FIGURA 86: Armário da exposição "Specere" contendo réplicas de fósseis relacionados à evolução de dinossauros e outros fósseis autênticos, com destacada qualidade de preservação ou tamanho. Fotografia: Mariana Galera Soler, obtida em visita técnica em Julho de 2018.

FIGURA 87: No Módulo Diversidade de Formas, destaque para a forma "Esfera", que é descrita em texto (na parede à esquerda), demonstrada em aparato interativo que cria bolhas de ar em gel e ilustrada por objetos (bola de futebol, pérolas e formações rochosas). 
FIGURA 88: Uma das vitrines mais aclamadas pelas publicações na abertura da exposição permanente da Galeria da Biodiversidade é aquela que ilustra a diversidade de ovos na natureza. Nessa vitrine uma coleção de ovos preservados em via seca (apenas a casca) são distribuídos de acordo com sua cor X tamanho X presença de ornamentações.

FIGURA 89: Exemplos de recursos interativos da Galeria da Biodiversidade.

FIGURA 90: Vitrines com coleções do MZUSP, na exposição "Biodiversidade: conhecer para preservar".

FIGURA 91: Vitrines "novinhos em folha", na Sala de Descobertas da exposição "Biodiversidade: conhecer para preservar".

FIGURA 92: Imagens de referência para a arquitetura e museografia da exposição "Biodiversidade: conhecer para preservar". 259

FIGURA 93: Módulo 3 da exposição "Biodiversidade: conhecer para preservar". 261

FIGURA 94: Dioramas, no Módulo 2 da exposição "Biodiversidade: conhecer para preservar". 264

FIGURA 95: Módulo 2 e 3 da exposição "Biodiversidade: conhecer para preservar", com destaque para iluminação focal e opção por manter spots de luz e calhas com fios elétricos evidentes. 


\section{ÍNDICE DE TABELAS}

Tabela 1: Tabela que resume os indicadores compartilhados por exposições do padrão museográfico "Centrado em objetos", que serão aplicados na análise das exposições estudadas nessa tese.

Tabela 2: Tabela que sistematiza os indicadores que definem o subpadrão museográfico "Séries Taxonómicas", que serão aplicados na análise das exposições estudadas nesse trabalho.

Tabela 3: Tabela que resume os indicadores que definem o subpadrão museográfico "Séries Evolutivas / Progressistas", que serão aplicados na análise das exposições estudadas nesse trabalho.

Tabela 4: Tabela que resume os indicadores que definem o subpadrão museográfico "Dioramas", que serão aplicados na análise das exposições estudadas nesse trabalho.

Tabela 5: Tabela que resume os indicadores compartilhados pelos padrões museográficos "Centrados numa narrativa", que serão aplicados na análise das exposições estudadas nesse trabalho.

Tabela 6: Tabela que resume os indicadores compartilhados pelo subpadrão museográfico "Quotidiano", que serão aplicados na análise das exposições estudadas nesse trabalho.

Tabela 7: Tabela que resume os indicadores compartilhados pelo subpadrão museográfico "Ecológico", que serão aplicados na análise das exposições estudadas nesse trabalho.

Tabela 8: Tabela que resume os indicadores compartilhados pelo subpadrão museográfico "Public Understanding of Science, que serão aplicados na análise das exposições estudadas nesse trabalho.

Tabela 9: Tabela que resume os indicadores compartilhados pelo Padrão Museográfico "Espetacular", que serão aplicados na análise das exposições estudadas nesse trabalho.

Tabela 10: Tabela que resume os indicadores compartilhados pelo subpadrão museográfico "Blockbuster", que serão aplicados na análise das exposições estudadas nesse trabalho.

Tabela 11: Tabela que resume os indicadores compartilhados pelo padrão museográfico "Retorno à Curiosidade", que serão aplicados na análise das exposições estudadas nesse trabalho.

Tabela 12: Tabela que resume os indicadores compartilhados pelo subpadrão museográfico "Biografia dos Objetos", que serão aplicados na análise das exposições estudadas nesse trabalho.

Tabela 13: Tabela que resume os valores de EPM (Enquadramento em Padrão Museográfico), um índice numérico calculado de acordo com a presença ou ausência dos indicadores. 


\section{LISTA DE ABREVIATURAS E SIGLAS}

AMNH: American Museum of Natural History (Nova lorque, EUA)

EPM: Enquadramento em Padrão Museográfico

FCT: Fundação para a Ciência e a Tecnologia

GBIF: Global Biodiversity Information Facility

ICOM International Council of Museums

MNHN: Muséum National d'Histoire Naturelle (Paris, França)

MNRJ: Museu Nacional do Rio de Janeiro (Rio de Janeiro, Brasil)

MoMA: Metropolitan Museum of Modern Art (Nova Iorque, EUA)

MP: Museu de História Natural e da Ciência da Universidade do Porto (Porto, Portugal)

MUHNAC: Museu Nacional de História Natural e da Ciência da Universidade de Lisboa (Lisboa, Portugal)

MZUSP: Museu de Zoologia da Universidade de São Paulo (São Paulo, Brasil)

NES: New Exhibition Scheme

NHM: Natural History Museum (Londres, Inglaterra)

NMNH: National Museum of Natural History - Smithsonian Institute (Washington D.C., EUA)

PUS: Public Understanding of Science

UNESCO: United Nations Educational, Scientific and Cultural Organization

USP: Universidade de São Paulo (São Paulo, Brasil) 


\section{SUMÁRIO}

1. INTRODUÇÃO

2. CAPÍTULO 1 - A diversidade normalizada: padrões museográficos de museus de história natural

2.1 "Infinitas formas de grande beleza" inseridas em categorias 13

2.2 Principais referenciais 14

2.3 Formas de Organizar Acervos e Discursos: Padrões Museográficos 20

2.4 Padrão Museográfico: Centrado em Objetos 23

2.4.1 Subpadrão: Séries Taxonómicas 26

2.4.2 Subpadrão: Séries Evolutivas / Progressistas 34

2.4.3 Dioramas 42

2.5 Centrado numa narrativa _______________ 53

2.5.1 Subpadrão Museográfico Quotidiano ____________________________ 67

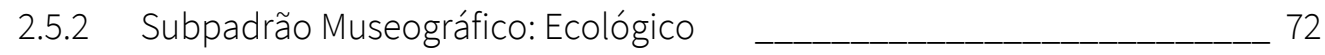

2.5.3 Subpadrão Museográfico Public Understanding of Science ou "Exploratorium Effect" 84

2.6 Padrão Museográfico Espetacular _______________________________ 95

2.6.1 Padrão Museográfico baseado em exposições blockbuster 105

2.7 Padrão "Retorno à Curiosidade" 114

2.7.1 Biografia dos Objetos 126

2.8 Exposições e padrões museográficos: outras interpretações 135

3. CAPÍTULO II: Análise das exposições: museografia categorizada por padrões 141

3.1 Métodos de investigação 141

3.2 Estudos de Caso: descrição de exposições e enquadramento nos diferentes padrões museográficos 143

3.2.1 Museu Nacional do Rio de Janeiro: "Conchas, corais e borboletas" 143

3.2.1.1 Contextualização: 143

3.2.1.2 Tratamento Museográfico 147

3.2.2 Museu Nacional de História Natural e da Ciência - Universidade de Lisboa 161

3.2.2.1 Reis da Europa Selvagem: os nossos últimos carnívoros ______ 161

3.2.2.2 "Specere" 175 
3.2.3 Museu de História Natural e da Ciência da Universidade do Porto - Galeria da Biodiversidade 189

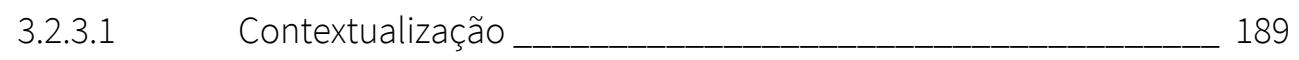

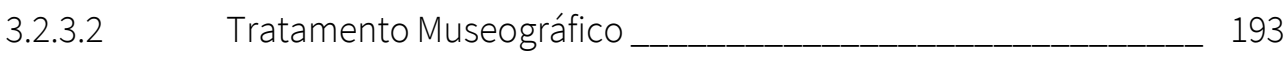

3.2.4 Museu de Zoologia da Universidade de São Paulo - Biodiversidade: conhecer para preservar 210

3.2.4.1 Contextualização 210

3.2.4.2 Tratamento Museográfico 216

4. CAPÍTULO III - Enquadramento em Padrão Museográfico (EPM): números que ajudam explicar padrões 226

4.1 Discussão dos Padrões Identificados 227

4.1.1 "Conchas, corais e borboletas" (MNRJ) _____________________________ 227

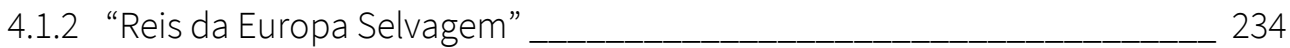

4.1.3 "Specere" ___________________________ 243

4.1.4 "Galeria da Biodiversidade" ________________________________ 249

4.1.5 "Biodiversidade: conhecer para preservar" ________________________ 255

4.2 Entre padrões: aproximações e distanciamentos entre realidade observada, documentos e entrevistas 267

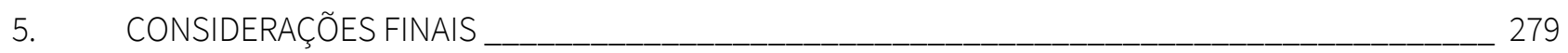

6. REFERÊNCIAS BIBLIOGRÁFICAS _______________________ 286

7. ÍNDICE REMISSIVO _______________________ 303

8. APÊNDICES

8.1 APÊNDICE 1: Tabela de Indicadores e respetivos autores

8.2 APÊNDICE 2: Matriz de Indicadores

8.3 APÊNDICE 3: Entrevistas

9. ANEXOS

9.1 ANEXO 1: Ficha Técnica da exposição "Conchas, corais e borboletas"

9.2 ANEXO 2: Ficha Técnica da exposição "Reis da Europa Selvagem"

9.3 ANEXO 3: Ficha Técnica da exposição "Specere"

9.4 ANEXO 4: Ficha Técnica da exposição "Galeria da Biodiversidade"

9.5 ANEXO 5: Ficha Técnica da exposição "Biodiversidade: conhecer para preservar" 


\title{
1. INTRODUÇÃO
}

\author{
"And dioramas are meaning-machines. Machines are time slices into the social \\ organisms that made them. Machines are maps of power, arrested moments of social \\ relations that in turn threaten to govern the living"
}

(Haraway, 1984, p. 52)

Esta tese discute as transformações da museografia ${ }^{1}$ de museus de história natural como meio de registo de práticas científicas e museológicas. A partir de um modelo teórico concebido por meio de exaustiva revisão na literatura cientifica, nos domínios da História da Ciência e da Museologia, missões de investigação que permitiram o contacto e registo de imagens de mais de duas dezena de museus europeus e brasileiros e experiência profissional da autora, foi possível delinear panoramas dos diferentes modos de expor acervos nos grandes museus científicos ocidentais, desde o século XIX até à contemporaneidade.

Destacamos que nesta tese empregamos a definição de museus científicos utilizada por Delicado (2009)“optou-se pelo termo 'museu científico' para nomear os museus que têm uma vertente científica, como temática principal ou como uma entre outras temáticas, ou ainda apresentando os resultados ou os processos de um trabalho de investigação científica" (Delicado, 2009, p. 10). Excluímos as instituições primordialmente constituídas por coleções vivas, como os aquários e os zoológicos, embora sejam utilizadas eventualmente como exemplos comparativos. Assim, o foco de nossas considerações está sobre os museus de história natural, museus de ciência e técnica e centros de ciências (em menor escala). Tais instituições, como definido por Desvallées \& Mairesse (2013): "Não se trata de contemplar, mas de ver: o museu científico não apresenta somente os objetos belos, mas convida à compreensão dos seus sentidos” (Desvallées \& Mairesse, 2013, p. 58).

Fundamentados em variadas fontes, propomos quatro padrões museográficos (divididos em subpadrões, totalizando dez categorias) que sumarizam indicadores relativos ao design, tipo de

${ }^{1}$ De acordo com a publicação eletrônica "Conceitos Chaves da Museologia" - dicionário de palavras-chave da Museologia, produzido no âmbito do International Council of Museums (ICOM) e que apresenta a discussão sobre a definição e diferentes traduções e abordagens - na França, o termo expographie (expografia) foi proposto para designar as técnicas ligadas às exposições, estejam elas situadas dentro de um museu ou em espaços não-museais. Contudo, atualmente tende-se a ser utilizada a palavra "museografia", em português (assim como muséographie, no francês), para designar a arte da exposição (Desvallées \& Mairesse, 2013). 
acervo, textos e legendas, iluminação, recursos audiovisuais e multimédia, além do posicionamento do visitante perante o discurso museológico. Destacamos que a bibliografia disponível é, em geral, específica para uma instituição ou período temporal. Portanto, um importante contributo dessa investigação é a proposição de uma série de padrões museográficos histórica e socialmente constituídos em exposições de museus de história natural, os quais são transversais. Um vez que tais padrões podem ser identificados na museografia de diferentes instituições e lugares, servem também como sinalizadores do contacto, intercâmbios e reproduções entre instituições científicas.

Sendo assim, embora o modelo teórico proposto reconheça modos de expor concebidos ao longo dos últimos dois séculos, os mesmos puderam ser identificados ainda em exposições atuais, sendo tradicionais instituições portuguesas e brasileiras analisadas como estudos de caso.

Partimos da premissa de que os museus de história natural são espaços urbanos cruciais para definições sociais de natureza e cultura (Alberti, 2008) e influenciados por outras instituições culturais que também possuem orientação racional, como as bibliotecas e parques públicos. Numa abordagem histórico-social, as mudanças registadas no funcionamento dos museus são condicionadas pelo contexto social que os envolvem e estão assinaladas em suas formas de expressão, marcadamente nas exposições (Tony Bennett, 1995).

Diante da análise de exposições sob uma perspetiva crítica, a museografia é inerentemente problemática, uma vez que se trata de construções em que os objetos são retirados dos seus contextos originais para a contemplação (ou interação controlada), onde são projetados significados e valores por diferentes atores e que não estão necessariamente relacionados aos objetos em si (Barker, 1999b). Tal qual as obras de arte, as exposições revelam também o que pode ser descrito como "objetivos inconscientes", ou seja, questões e agendas ideológicas. De modo que mesmo os aspetos menos obviamente visíveis refletem manifestações de limitações históricas e códigos sociais (Staniszewski, 2001).

A partir da citação que abre esse capítulo, os dioramas são os recursos museográficos mais característicos dos museus de história natural e compõem representações pacificadas de paisagens naturais, onde todos os organismos parecem exercer funções específicas para o perfeito funcionamento do ambiente exibido. No entanto, ainda na década de 1980, Donna Haraway nos alerta que essa aparentemente simples e harmônica representação da natureza trata-se de uma "meaning-machine", ou seja, um recurso produtor de significados e relações de poder, que é 
suportado por ideologias, políticas e contexto histórico-social do período e instituição em que é produzido. Para tanto, Haraway analisou os tradicionais dioramas realizados por Carl Akeley no American Museum of Natural History (AMNH), desde as expedições para a recolha do acervo até as escolhas para elaboração da taxidermia e construção da cenografia (Haraway, 1984).

As mudanças de paradigmas pedagógicos, crises políticas, sociais e/ou económicas, associadas às influências da arquitetura e do design, das estratégias de marketing e das constantemente dinâmicas ideias e teorias científicas obrigam os museus a reconfigurarem sua aparência e taxonomias institucionais. Em resposta, tais instituições desenvolvem novos conjuntos de práticas expositivas, educativas, valores e objetivos (Karen A. Rader \& Cain, 2014).

Por conseguinte concordamos também com Alberti (2008) ao considerar a inseparabilidade da produção do conhecimento e a sua representação. O autor afirma que os museus científicos não são simplesmente canais para disseminação, mas locais pró-ativos para a construção de ideias sobre a natureza ( Alberti, 2008).

Igualmente as exposições não são apenas um grupo aleatório de objetos dispostos numa opulente galeria (Dolák \& Šobáňová, 2018) ou a expressão de um tema sob uma narrativa determinada e diagramada em normas técnicas museográficas (Corral-Guillé, 2015). As exposições são construções coletivas, refletem pontos de vista de seus autores cuja informação é necessariamente o produto de disputa e seleção. Além dos conteúdos e objetos, o modo como os objetos são dispostos refletem conceções científicas; estão presentes determinadas representações de ciência e investigadores, que são produto da estruturação do campo científico subjacente e destinadas a exercer influência sobre as perceções e atitudes do público. Tais representações procuram gerar confiança, interesse e apoio face à ciência (Delicado, 2008).

Museus, objetos, acervos e exposições são focos de estudos de diferentes áreas do conhecimento. Porém, quando comparados com a produção científica sobre museus de Arte, História e Antropologia, ainda é marginal a investigação realizada sobre museus e coleções de História Natural (Alberti, 2008). No que tange a História da Ciência, os últimos trinta anos marcaram o crescimento expressivo de investigações históricas em museus, coleções e exposições, especialmente após o simpósio de comemoração de 300 anos do Ashmolean Museum (1983) e a publicação dos respetivos trabalhos (Impey \& MacGregor, 1985), que congregaram diferentes perspetivas e corroboraram a construção de um novo campo de conhecimento (J. Bennett, 2005). 
Enquanto os museus, coleções e exposições estabelecem-se como agendas de investigação na História da Ciência, paralelamente, a História da Arte têm produzido substancialmente mais sobre o tópico "exposição" - e, portanto, também sobre a sua história. Adequadamente estabelecido como objeto de pesquisa apenas nos últimos vinte anos, e particularmente na última década, o interesse sobre a história das exposições também pode ser incluído nos domínios da chamada "nova" História da Arte, em que são consideradas as abordagens específicas do contexto socio-histórico² (J. Bennett, 2005).

Cypriano e Oliveira (2017) defendem a existência de um campo disciplinar História das Exposições que "tem como enfoque fundamental o momento no qual produção artística e o público têm contato, perspectiva que diferencia da História da Arte tradicional e também dos estudos curatoriais".

Das publicações em História da Arte e também da História das Exposições, destaca-se a série de livros Exhibition Histories, lançada em 2010 e em constante desenvolvimento. A série publicada pelo Afterall (Centro de Investigação da University of the Arts London) aborda as mudanças em como a arte é exibida e realizada na segunda metade do século XX. Cada título da série (dez até o momento) discute um tema diferente na história da produção de exposições, com referência a um determinada mostra ou conjunto de mostras consideradas "paradigmáticas"3.

Iniciam os estudos sobre os modos de expor o questionamento sobre a disposição do acervo na organização espacial. Datam da segunda metade do século XIX e referem-se à distribuição dos espaços expositivos e fluxos de público nas exposições universais (Hebert Bayer, 1961). Tais estudos iniciais remetem para duas questões fundamentais no período: (i) a abertura das exposições/museus ao público, servindo como espaço de emulação de comportamentos e práticas, de modo a fomentar o caráter civilizador dessas instituições (seja pela museografia, seja pela própria visibilidade que é dada para aqueles que visitam, promovendo uma "cidadania autorregulável"); e (ii) os princípios da classificação e especialização, ou seja, o desenvolvimento de museus e exposições especializados

2 O interesse na história das exposições artísticas e antropológicas reflete também a profissionalização e a subsequente formalização do campo curatorial nas Artes, que pressupunham um sentido de sua própria história (Vogel, 2014).

3 Tais estudos são realizados por meio de ensaios e entrevistas, textos produzidos na altura das respetivas exposições (resenhas e materiais dos museus e jornalístico) e abundante documentação visual (mais informações em: https://mww.afterall.org/books/exhibition.histories/.Acesso em 14 de Novembro de 2019). 
em que os objetos estão organizados em séries racionais, buscando tornar inteligível uma determinada visão científica do mundo e a posição da humanidade diante da diversidade (Tony Bennett, 1995).

Se princípios classificatórios (taxonómicos e sociais) fundamentaram a museografia do final do século XIX e início do XX, o histórico da museografia associada às coleções biológicas pode também demonstrar a natureza e a amplitude das transformações intelectuais e institucionais que ocorreram nos séculos XX e XXI (Karen A. Rader \& Cain, 2014), uma vez que é fortemente influenciada por agendas pessoais, por políticas institucionais e/ou governamentais e critérios de seleção para recolha e investigação (Paddon, 2014).

Estudos que relacionam o desenvolvimentos das ciências naturais e sua representação em exposições de museus de história natural demonstram articulações entre o histórico e a modo de expor desta área do conhecimento (Porcedda, Landry, \& Lepage, 2006). Contudo, Alberti (2008) em editorial da publicação Museum and Society é contundente ao afirmar que pouco conhecemos para além das histórias institucionais dos museus e coleções de história natural, especialmente ao longo do século XX: "studies of US museums notwithstanding histories of twentieth-century natural history museums in Europe are marked by their absence" (Alberti, 2008, p. 77).

A ausência sentida há mais de uma década por Alberti (2008) ainda se faz presente na literatura científica, embora já existam alguns trabalhos com perspetivas comparadas e/ou contextualizada, que foram fundamentais para a construção dessa tese, tais como: Nyhart (2009) ao descrever como se constituía a investigação em ciências biológicas, particularmente nos museus de história natural (entre outras instituições) alemães no final do século XIX e início do XX; as alterações dos museus estadunidenses nas primeiras décadas do século XX analisadas por Karen Rader e Victoria Cain (2008), um panorama geral da museografia dos museus científicos estadunidenses no século XX, também publicado por Rader e Cain (2014); uma análise das exposições do Museu Nacional do Rio de Janeiro nos anos 1940, proposta por Aranha Filho (2011); as modificações realizadas na museografia dos museus de história natural ingleses, após a mudança do seu financiamento na década de 1980, estudadas por Paddon (2014); ou o "novo" esquema de exposições proposto no Natural History Museum (NHM) nos anos 1970-80 e descritos por Corral-Guilé (2015). 
A partir de histórias institucionais e dos intercâmbios entre museus, profissionais, bibliografias e objetos é ainda possível construir também a história das exposições dos museus científicos, visto que a circulação de ideias é um fator constitutivo dessas instituições. Tais museus têm origem ocidental e foram disseminados globalmente porém, sem negligenciar a forma de apropriação de cada cultura, mesmo as entidades mais recentes em geral se inspiram, em princípio, nos modelos originalmente europeus e norte-americanos (Valente, 2014).

Contudo, ainda pouco foi investigado sobre a criação e replicação dos modos de expor, especialmente no que diz respeito aos objetos de história natural. Enquanto as exposições artísticas possuem paradigmas definidos, como o "cubo branco" proposto por Alfred Bar no Museum of Modern Art (Nova Iorque, EUA), na década de 1920 - influenciado pela Escola Bauhaus (Cypriano \& Oliveira, 2017); os experimentos em caóticas exposições surrealistas e dadaístas, em que os visitantes interagiam em todas as dimensões, puxavam e carregavam botões e luzes, entre 1930 - 1940, nas exposições de arte de vanguardas alemãs (Staniszewski, 2001); ou o pioneirismo Hebert Bayer, com estudos de fluxo e a integração do design e produção industrial na construção de espaços expositivos nos anos 1960 (Herbert Bayer, 1961), apenas para citar alguns exemplos, poucos são os estudos que trazem uma perspetiva panorâmica das exposições científicas ao longo do tempo, especialmente no século XX. Nas palavras de Dominique Poulot: "uma história cruzada das museografias e de sua circulação internacional ainda está por se escrever (...)” (Poulot, 2013, p. 142).

Nesta investigação, além da constante revisão e ampliação dos estudos teóricos, agregaramse experiências académicas e profissionais prévias para orientar a realização de missões de investigação. Tal investigação "em campo" permitiu a melhor definição dos estudos de caso (escolha das exposições em museus), bem como a recolha de exemplos de diferentes museografias, registados por imagens e apresentados ao longo desta investigação.

Ao total, foram visitados mais de uma dezena de museus europeus e brasileiros, dos quais destacamos para a construção da presente tese: Mauritshuis (Haia), Natural History Museum (Londres), Science Museum (Londres), National Maritime Museum (Londres), British Museum (Londres), Oxford University Museum of Natural History (Oxford), History of Science Museum University of Oxford (Oxford), Museo Nacional de Ciencias Naturales (Madrid), Museo de America (Madrid), Museo Arqueologico Nacional (Madrid), La Specola - Museo di storia naturale (Firenze), Museu Nacional de História Natural e da Ciência - Universidade de Lisboa (Lisboa), Aquário Vasco da 
Gama (Lisboa), Oceanário de Lisboa (Lisboa), Pavilhão do Conhecimento - Ciência Viva (Lisboa), Museu de História Natural e da Ciência da Universidade do Porto (Porto), Museu Nacional Frei Manuel do Cenáculo (Évora), Museu Interactivo do Megalitismo (Mora), Museu de Zoologia da Universidade de São Paulo (São Paulo), Catavento Cultural e Educacional (São Paulo), Museu da Vida - Fundação Oswaldo Cruz (Rio de Janeiro) e Museu Nacional do Rio de Janeiro (Rio de Janeiro).

Sobre o Museu Nacional do Rio de Janeiro (MNRJ) ressalta-se que a missão de investigação foi realizada em 2018, em sequência a contactos estabelecidos ainda em 2014 (durante a realização do Mestrado da autora em Museologia, pela Universidade de São Paulo). Durante a primeira semana do mês de Agosto de 2018, na instituição foi possível realizar entrevistas a diferentes membros das equipas científicas e do Setor de Museologia, além de ter acesso a documentos sobre a museografia e efetuar o registo fotográfico detalhado das exposições contemporâneas com acervo zoológico. Menos de um mês depois dessa visita, na noite de 2 de Setembro de 2018 um nefasto incêndio destruiu grande parte da instituição, especialmente a exposição de longa duração e exposições temporárias, as coleções de etnologia e etnografia, as coleções de entomologia e parte dos invertebrados, os arquivos do centro de documentação em línguas indígenas, as coleções de Antropologia Biológica, as coleções de Arqueologia, documentos históricos da Seção de Memória e arquivos e a Biblioteca de Antropologia Francisca Keller do Programa de Pós-graduação em Antropologia Social (Cândido, Mendes, Andrade, \& Rosa, 2019)4.

Diante desse sombrio cenário de perda patrimonial, científica e histórica, finalizar esta tese ganha ainda mais significados emocionais e estratégicos, servindo como o testemunho mais recente tanto de parte da exposição e coleção zoológica do MNRJ, como também um registo detalhado de parte de suas práticas curatoriais. Para além do registo fotográfico, as informações recolhidas em entrevistas e cópias de documentos foram colocadas à disposição das equipas de resgate do MNRJ

${ }^{4}$ Importante ressaltar o momento em que o incêndio ocorreu foi agravado por dois fatores: em 2018 celebravam-se os 200 anos do MNRJ e foram realizados diversos eventos e anúncios, onde existia um tom esperançoso devido a um substancial investimento financeiro, fundamental para se restabelecer a instituição e estar à altura da sua história e seu papel na produção e disseminação científicas brasileiras. Outro aspeto que inflacionou os danos do incêndio foram os conturbados contextos político e social instáveis e polarizados sob o qual o Brasil passava (e que tem se confirmado na atualidade) (Cândido, Mendes, Andrade, \& Rosa, 2019). 
e foram parcialmente publicadas num volume especial da publicação eletrônica "Ventilando Acervos", do Instituto Brasileiro de Museus (Soler, 2019).

Em síntese, no presente estudo partimos da revisão detalhada da literatura ativa de variadas áreas do conhecimento - como: História da Ciência, Museologia, Arquitetura e Design, História da Arte, Biologia - bem como determinada literatura cinzenta - por exemplo publicações internas de museus: relatórios, boletins, resumos de palestras, panfletos - e de investigações em campo, com missões de investigação em mais de 20 museus, o que permitiu compreender e propor modos de expor organizados em padrões, os quais são concebidas as exposições de museus de história natural.

Assim, no Capítulo I desta tese apresentamos os pressupostos teóricos que subsidiaram a construção de padrões museográficos para exposições de museu de história natural, a saber:

Padrão Centrado em Objetos

Subpadrão: Taxonómico

Subpadrão: Séries Evolutivas / Progressistas

Subpadrão: Dioramas

Padrão Centrado numa narrativa

Subpadrão: Quotidiano

Subpadrão: Ecológico

Subpadrão: Public Undestanding of Science

Padrão Espetacular

Subpadrão: Blockbuster

Padrão "Retorno à Curiosidade"

Subpadrão: Biografia dos objetos

A proposição destes padrões museográficos estabeleceu um modelo teórico que associa características específicas dos modos de expor (design, iluminação, texto, acervo, entre outros) com os contextos sociais, políticos e institucionais em que foram criados, além de sugerir conceções de ciência, do investigador, da instituição.

Os padrões "Centrado em Objetos" e "Centrado numa Narrativa” já são citados por outros autores na literatura, desde o início do século XX (Gregory, 1936). No entanto, agregamos a estes dois padrões museográficos: "Espetacular" e "Retorno à Curiosidade", que assinalam novidades desta 
tese. Enquanto expressões como "exposições espetaculares" e "exposições blockbuster" são termos correntes nos estudos culturais e críticos sobre as exposições de museus de arte e história depois do anos 1970, inspirados por estes elencamos um conjunto de características destas exposições que chegaram também aos museus de história natural, incutindo novas museografias.

Já o padrão museográfico "Retorno à Curiosidade", utilizando o termo proposto por Michelle Henning (2006), consiste numa proposta de articulação de bibliografias recentes do campo da Museologia e Museografia, como Adamopoulou e Solomon (2016), associada à "biografia dos objetos", uma das atuais linhas de investigação da História da Ciência.

Para além do modelo teórico proposto, demonstramos a construção da ferramenta de análise "Matriz de Indicadores". Dos padrões museográficos caracterizados emergiram indicadores, num total de 116. Os indicadores foram organizadas numa tabela que conta com suas descrições e respetivas fontes bibliográficas (APÊNDICE 1). Os dados recolhidos nas exposições estudadas foram cruzados com tais indicadores, tornando a tabela numa matriz e ferramenta de análise (APÊNDICE 2). Trata-se de um primeiro instrumento, que pôde ser utilizado ainda "em campo" e que poderá também subsidiar futuros trabalhos.

Encerra o Capítulo I as discussões sobre os padrões museográficos do modelo teórico proposto sob a perspetiva dos medias contemporâneos e de documentos fundamentais da Museologia, nomeadamente cartas e declarações do ICOM, que versam sobre a função social dos museus e sua responsabilidades perante ao público.

No Capítulo II aplicamos a Matriz de Indicadores como ferramenta para análise de cinco exposições contemporâneas de museus de história natural. Tendo em vista que os objetivos propostos e os ainda escassos estudos sobre a circulação dos modos de expor coleções científicas, selecionamos para esta investigação museus de Portugal e do Brasil, uma vez que são países de mesma língua, tradição (e intercâmbios) na investigação em ciência naturais e avanços científicos recentes rumo a internacionalização (publicações e colaborações com países não-lusófonos), mas que não são as "tradicionais superpotências científicas" (embora tenha havido um aumento na pesquisa recente no Brasil e Portugal e existam colaborações entre esses países e os demais, suas respetivas produções científicas são consideradas periféricas, em termos numéricos, quando comparado com países como EUA, Japão, França, Alemanha, Reino Unido, Holanda e Bélgica) (Royal Society Science Policy Centre, 2011). 
Elegemos museus universitários e museus nacionais de história natural (também associados a universidades), que estão em importantes centros urbanos portugueses (Lisboa e Porto) e brasileiros (São Paulo e Rio de Janeiro): Museu Nacional de História Natural e da Ciência da Universidade de Lisboa, Museu de História Natural e da Ciência da Universidade do Porto, Museu de Zoologia da Universidade de São Paulo e Museu Nacional do Rio de Janeiro.

Optou-se por exposições com acervos zoológicos uma vez que os animais estão entre os tipos de objetos de história natural mais comuns presentes em coleções científicas ${ }^{5}$ e a experiência profissional e em estudos já publicados da autora sobre o tema (Soler, 2015, 2019; Soler \& Landim, 2017a, 2018; Soler, Nunes, \& Lopes, 2018).

A seleção de exposições com menos dez anos de inauguração pode ser justificada por aspetos técnicos e epistemológicos. No primeiro caso, as exposições estudadas foram desenvolvidas depois de 2010, o que possibilitou o acesso a maior número de documentos e dados (projetos museográficos, guiões expositivos, folders, panfletos, relatórios internos, trocas de e-mails, reportagens) e a possibilidade de realizar o registo fotográfico e entrevista com as equipas curatoriais (membros da equipa científica e profissionais associados a museografia). Além disso, retratam quase uma década de produção museográfica portuguesa e brasileira.

Quanto à abordagem epistemológica, as exposições selecionadas foram desenvolvidas por instituições científicas inseridas em redes internacionais de intercâmbios, o que possibilita que essas possuam o mesmo arcabouço científico e que esse seja o mais recente possível. Para tanto, selecionamos exposições cujo discurso estivesse centrado no conceito "biodiversidade".

O termo "diversidade biológica" apareceu na literatura científica, em 1968, no livro A Different Kind of Country, de Raymond F. Dasmann (Franco, 2013). Já o conceito Biodiversidade foi considerado um marcador da contemporaneidade do discurso, tendo em vista a sua recente origem na comunidade académica: idealizado por Walter G. Rosen, do National Research Council / National Academy of Sciences (NRC/NAS), em 1985, durante o planeamento de um fórum sobre crise da diversidade biológica. O evento foi realizado em Washington, de 21 a 24 de Setembro de 1986, com

${ }^{5}$ Como exemplo, podemos utilizar a base de dados GBIF (Global Biodiversity Information Facility), uma rede internacional de instituições que produzem dados sobre biodiversidade. Nessa base de dados é possível verificar a existência de mais de um bilhão de espécimes animais, contra pouco mais de 8 milhões de bactérias, 16 milhões de fungos e 255 milhões de plantas. Fonte: https://muw.gbif.org/species/search. Dados referentes há Abril de2019. 
o nome de National Forum on BioDiversity. Em 1988, a publicação dos trabalhos e discussões deste evento por Edward Wilson ratificava o neologismo proposto por Rosen, sendo o título Biodiversity (sem o destaque para o D em maiúscula)(Sarkar, 2002; Wilson, 1988).

Ainda que o uso do termo "biodiversidade seja recente, é importante ressaltar que conceções sobre a diversidade dos organismos estão presente em discussões desde a Antiguidade, passando por diferentes escolas de pensamento e sociedades humanas (Caseta et al., 2018), sendo um dos aspetos fundadores das natural science (Nordenskiold, 1929) e, portanto, serve como um conceito norteador de análises comparativas, mesmo em exposições concebidas em diferentes contextos históricos.

Assente nos critérios supracitados, elegemos as seguintes exposições para estudo: "Conchas, Corais e Borboletas" (MNRJ, inaugurada em 2013 e completamente perdida no incêndio de 2 de Setembro de 2018); "Biodiversidade: conhecer para preservar" (MZUSP, inaugurada em 28 de Agosto de 2015); "Reis da Europa Selvagem: os nossos últimos grandes carnívoros" (MUHNAC, inaugurada em 2 de Março 2017 e encerrada em 29 de Setembro de 2019), "Galeria da Biodiversidade" (MP, inaugurada em 30 de Junho de 2017) e "Specere" (MUHNAC, inaugurada em 28 de Março de 2018).

O Capítulo II é descritivo. Construímos narrativas dos contextos de produção das exposições, a partir dos dados recolhidos por meio de entrevistas com as equipas curatoriais e diferentes documentos. Ainda nesta etapa, descrevemos a museografia de cada exposição, utilizando como referência fotografias, plantas e esboços do espaço expositivo e montras que, juntamente com os documentos, foram recolhidos em visitas técnicas nos museus e nos respetivos arquivos institucionais.

O Capítulo III consiste na identificação dos padrões museográficos propostos nas exposições descritas no Capítulo anterior. Para tanto aplicamos os valores de 0 e 1, respetivamente a ausência ou presença dos indicadores na construção da Matriz de Indicadores. A seguir, calculamos o índice EPM (Enquadramento em Padrão Museográfico), um teste estatístico de propensão concebido nesta investigação, com o qual avaliamos como cada uma das exposições aderiram ("são similares") aos padrões propostos no modelo teórico.

A partir do índice numérico EPM foram desenvolvidas discussões, em que consideramos fundamental a problemática apontada por Achiam e Marandino (2014): 
"One issue that may confound attempts to understand the exhibitions and their diversity is the disjunction between the exhibition itself and the process of creating it. (...)In other words, the represented and disseminated science content is strongly dependent upon (although not identical with) the process by which that science content was constructed. Efforts to understand exhibitions must therefore include efforts to understand exhibition production" (Achiam \& Marandino, 2014, pp. 66-67)

Associamos ao índice o conjunto de outros dados recolhidos em documentos e entrevistas, para então discutirmos a aproximação e distanciamento aos padrões museográficos elaborados em nosso modelo teórico, ou seja, quais os elementos das exposições caracterizam epistemologias e práticas científicas e museológicas concebidos em diferentes momentos e instituições, mas que estão dispostos em exposições contemporâneas portuguesas e brasileiras.

Nas Considerações Finais evidenciamos as ideias fundamentais elaboradas na tese e associamos o modelo teórico proposto com o conceito de biodiversidade. Neste caso "biodiversidade" serve tanto como um conceito comum às exposições elegidas, como um tema que transcende as diferentes escolas da História Natural, portanto, como um conceito norteador de análises comparativas para além das balizas temporais ou locais que os padrões museográficos foram inicialmente concebidos.

Nesta etapa, para além de questões relativas ao design ou temáticas dos discursos, consideramos que os padrões propostos permitiram verificar como as escolhas na forma de expor coleções científicas, em nosso caso zoológicas, reafirmam a autoridade dos museus e, particularmente, dos investigadores, impondo suas respetivas epistemologias e práticas. De modo que fundamentamos em nosso debate a partir da seguinte citação de Tony Bennett: "The museum 's reordering of things needs to be seen as an event that was simultaneously epistemic and governmental" (Tony Bennett, 1995, p. 33).

As páginas que encerram esta tese contêm as referências bibliográficas que nos apoiaram na construção do modelo teórico e discussões realizadas. Na sequência, em APÊNDICES apresentamos documentos produzidos, como a Tabela e Matriz de Indicadores completa e guiões das entrevistas semiestruturadas. Os ANEXOS encerram este trabalho, com documentos que serviram de apoio para a investigação, como as Fichas Técnicas das exposições. 


\title{
2. CAPÍTULO 1 - A diversidade normalizada: padrões museográficos de museus de história natural
}

\section{1 "Infinitas formas de grande beleza" inseridas em categorias}

\author{
"Em qualquer aspeto da vida, a sua característica fundamental é sua ilimitada \\ diversidade. Não existem dois indivíduos, nas populações sexualmente reproduzíveis, \\ que sejam iguais, nem duas populações da mesma espécie, nem duas espécies, nem \\ dois taxa superiores, nem quaisquer associações, e assim ad infinitum. Independente \\ do nivel hierárquico que observamos encontrarmos a singularidade, e a \\ singularidade acarreta a diversidade" (Mayr, 1998, pp. 161, grifo nosso)
}

Ernst Mayr, um dos principais evolucionistas e divulgador da teoria evolutiva do século XX, mostra-nos como a diversidade é uma característica essencial da vida em nosso planeta. Charles Darwin termina seu mais famoso livro, The Origins of Species (1859), utilizando a expressão "infinitas formas de grande beleza" ("endless forms most beauty") como resultado do contínuo processo evolutivo por ele descrito.

A categorização da diversidade de formas em grupos sob os mais diferentes critérios é recorrente desde as primeiras publicações sobre a história da História Natural e da Biologia, quando ainda nas civilizações clássicas ocidentais (gregos) são reconhecidas categorias taxonómicas e os aspetos fundadores do que seria chamado ciências naturais (Nordenskiold, 1929).

Tony Bennett considera que os museus do século XIX institucionalizaram o ato de classificar, tanto os objetos como os públicos (Tony Bennett, 1995). A produção e comunicação do conhecimento científico nesses espaços assinalam diferentes conceções da ordem do mundo natural e as nossas relações com ele, como apontado por Golinski: "Museums thus encode and shape particular configurations of knowledge; they display objects but they are never simply windows to the world beyond. The place in which the display occurs is crucial" (Golinski, 2005, p. 98).

Assim, nos museus de história natural a diversidade está salvaguardada em coleções organizadas taxonomicamente e é apresentada ao público por meio das exposições, quando forma e conteúdos interagem criando uma miríade de possibilidades argumentativas. Nesta investigação 
temos como objetos de análise as exposições de museus de história natural e aplicamos a estas as práticas comuns das respetivas instituições: descrição, caracterização, classificação e ordenamento. De forma que nossa investigação reflete a diversidade das coleções de história natural normalizada dentro de determinados tipos de exposição; e, as exposições, diante da diversidade de discursos e modos de apresentar, normalizada em padrões museográficos que são criados em contextos culturais, sociais, políticos, por um grupo de profissionais (investigadores que imprimem seu arcabouço teórico para representação do conhecimento, técnicos, arquitetos e designers que transmitem esse conhecimento em forma, patronos e administradores que usam as exposições como respostas a demandas político-económicas) e apresentadas para público determinado.

Para além de questões relativas design ou temáticas dos discursos, visamos verificar como as escolhas na forma de expor coleções científicas, em nosso caso zoológicas, estão associadas às epistemologias e às práticas científicas e museológicas que se pretendem comunicar. Bann (2003) suporta nossa hipótese de investigação, ao considerar a progressão direta das coleções dos gabinetes de curiosidades renascentistas até os museus do final do século XIX uma falácia, uma vez que os paradigmas do conhecimento têm mudado. Tendo em vista que cada tipo de coleções de objetos possui status epistemológico, que é simultaneamente adaptado a novas formas de exposição (museografia), os objetos e classificações precisam ser analisados à luz no contexto em que foram dispostos.

\subsection{Principais referenciais}

Partimos do estudo pioneiro Whitehead (1971), um dos primeiros zoólogos contemporâneos a relacionar a importância dos museus de história natural com a história da Zoologia, destacando o papel dessas instituições e suas coleções na investigação e na disseminação do conhecimento. Em um texto já com mais de meio século (embora publicado em 1971, o texto refere-se a uma palestra ministrada por na Linnean Society, em 5 de Novembro de 1968), com uma abordagem ampliada e sem precisos marcos cronológicos, Whitehead propõe divisões na história dos museus de história natural, relacionando-as com o modo como as coleções e exposições estavam organizadas em cada período. Embora vago, esse tem sido amplamente citado por outros autores e utilizado como ponto 
de partida para estudos que referenciamos nesse trabalho, como Rader e Cain (2014), Paddon (2014) e Corral-Guillé (2015).

No cenário europeu contemporâneo, uma das exposições paradigmáticas é a Grande Galerie d'Evólution, aberta no Muséum National d'Histoire Naturelle de Paris (MNHN), em 1994 (M. Henning, 2006; Paddon, 2014). O desenvolvimento dessa exposição exigiu diversos estudos das equipas da instituição, desde aspetos históricos das exposições até avaliações da receção do público a diferentes recursos museográficos. Entre as muitas publicações produzidas, destacamos Eidelman \&Van-Praet (2000) que revisitam as exposições permanentes do MNHN, a procura do "esprit du lieu", como fonte fundamental para o processo de desenvolvimento da Grande Galerie d'Evólution e sua relação com o público. Tal "arqueologia de exposições” parisienses permitiu relacionar as mudanças nas práticas científicas da instituição, os profissionais, as exposições e o os diferentes públicos que tiveram acesso a instituição nos últimos três séculos.

Seguindo ainda os museus franceses, o arquiteto e museógrafo franco-suíço Pierre-Henri Magnin destaca exemplos paradigmáticos de museus de ciências e tecnologia em Paris, ao longo do século XX, e projetos em que esteve envolvido. Numa visão panorâmica, o autor destaca a revolução contemporânea (pós II-Grande Guerra) na forma de comunicação dos museus com seus públicos, que "acompanha la aparición de la sociedad del espectáculo anunciada em 1967 por Guy Debord" (Magnin, 2011, p. 9).

No contexto museológico português, as funções de investigação (salvaguarda de acervos científicos e suporte a investigadores), ensino (formação de novos profissionais) e difusão do conhecimento científico têm tido maior ou menor proeminência nos museus de história natural, desde o final do século XVIII até o início do século XXI. Esses movimentos foram identificados em outros museus europeus, como os museus de história natural britânico e francês, mas também promoveram transformações na realidade museal portuguesa (Delicado, 2010b).

Já na contemporaneidade, Delicado (2010) destacou o caráter finalista das exposições científicas portuguesas, destacando abordagens que legitimam as instituições científicas, suas práticas e cientistas, com a apresentação de resultados prontos e "verdades inquestionáveis". No caso dos museu de história natural: 
"conferem uma importância central à apresentação dos resultados da investigação, na medida em que exibem os objetos recolhidos e organizados segundo classificações, interpretações e teorias em voga. A estruturação das exposições, segundo critérios tipológicos, evolutivos ou ecológicos, reflete os paradigmas teóricos dominantes nas disciplinas" (Delicado, 2008, p. 83).

As obras de Delicado (2008; 2010) inserem Portugal em um contexto global de transformações dos museus científicos ao longo do século XX, o que foi retomado mais recentemente por Lourenço e Dias (2017).

Ainda considerando exposições mais contemporâneas de museus de história natural, Paddon (2014) revisa museografias e destaca três exposições de coleções biológicas que considera icónicas, por "illustrate a combination of ground-breaking design and interpretation from the world's leading designers and innovative, dynamic museum teams that have set high standards in the display of biological collections" (Paddon, 2014, p. 118). São elas: Grande Galerie de l'Evólution, pela combinação de uma abordagem simbólica/filosófica das diversas formas de vida, forma inovadora do uso do espaço do museu, coleções biológicas abertas a visitação e intensidade sensorial e emotiva (MNHN, Paris); Naturalis, com um museu construído sobre o conceito de conectar o conhecimento biológico e geológico, com exposições sobre a diversidade e sobre os processos naturais (Nationaal Natuurhistorisch Museum, Leiden, atualmente fechado a visitação); e Hall of Biodiversity, onde os curadores apresentam questões relativas à compreensão e à preservação da diversidade da vida na Terra, utilizando variadas estratégias de design, multimédia (incluindo luz e som ambiente) e medias que exibem um "bio-boletim", com informações sempre atualizadas sobre questões ambientais, tornando a exposição sempre atual e dinâmica (American Museum of Natural History, Nova lorque) (Paddon, 2014).

O amplo espectro temporal e a visão comparada dos museus científicos foram os critérios que nos levaram a utilizar os estudos de Rader e Cain (2008; 2014) como um dos principais referenciais em nossa investigação. As autoras analisaram o processo de reformulação das exposições em instituições estadunidenses, seguindo uma cronologia que relaciona as alterações ocorridas na museografia das exposições com movimentos educacionais e as mudanças nas identidades institucionais dos museus científicos, diante das mudanças impostas pelas 
transformações sociais e económicas ocorridas no século XX. Tendo como fontes arquivos institucionais de grandes museus, como American Museum of Natural History (AMNH), Smithsonian Institute e Museum of Science, as autoras apresentam diversos e detalhados exemplos dos interesses frequentemente conflituantes de equipas científicas, designers, educadores, administradores, patronos e diretores de museus nas negociações de novas abordagens e o reconhecimento da necessidade de diversificar e aumentar as audiências dessas instituições.

De modo que, Rader e Cain (2014) propõem uma contínua e contenciosa relação entre os museus de história natural, de ciências, os science centres e a educação e discutem como entraves orçamentais levaram a busca de patronos em instituições privadas, gestão de exposições baseadas em "sucessos de bilheteria" e edutainment (Trofanenko, 2015).

Das análises críticas dos museus científicos contemporâneos, destacam-se duas autoras fundamentais: Sharon MacDonald e Fiona Cameron. Em MacDonald (2004), a autora contextualiza a influência dos science centres nos demais museus científicos, especialmente a partir dos anos 1980. Embora as exposições desses espaços, ou por eles influenciados, estejam baseadas em leis naturais e princípios científicos, na opinião da autora, os science centres não fornecem uma melhoria na compreensão de ciências de seus visitantes, servindo, provavelmente, mais ao estímulo pelo interesse geral pela ciência e, por vezes, reforçando uma visão "mágica" da ciência. Conceção essa que tem "contaminado" outros espaços museológicos, dado especialmente ao grande apelo visual e impacto mediáticos de tais science centres.

Além disso, exposições que seguem a museografia dos science centres tendem a ser onerosas financeiramente (alto custo de montagem e manutenção, especialmente de equipamentos multimédia), o que implica muitas vezes em parcerias com instituições privadas e uma série de interesses comerciais e negociações entre os museus e seus patronos (MacDonald, 1998, 2004).

Preocupada em formar uma sociedade mais cientificamente alfabetizada, então MacDonald (2004) aponta que narrativas mais fluídas e menos estruturadas num único caminho ou conceito sejam mais adequadas ao momento atual, tendo em vista que o público deve ser capaz de se apropriar do debate público sobre questões ligadas a ciência.

Nessa perspetiva, os assuntos controversos podem alterar as práticas museológicas e questionar a autoridade dos museus, como apontado pelos resultados de uma ampla investigação sobre a responsabilidade social dos museus em representar e contribuir para questões da 
contemporaneidade (Cameron, 2005). Por exemplo, nas discussões sobre alterações climáticas, a autoridade científica dos museus, sem um diálogo aberto, multiescalar e plural torna-se improdutivo. O grupo de investigação de Cameron destaca a importância da heterogeneidade de práticas científicas e públicos que visitam os museus para promover debates atualizados, dinâmicos e que possam ser até mesmo conflituantes. Esses investigadores também sugerem que as representações científicas presentes nos museus não podem estar separadas das suas dimensões sociais e culturais, uma vez que as relações entre natureza, ciência, práticas sociais e visões de mundo precisam ser reformuladas, a partir do reconhecimentos das complexas relações e envolvimentos entre todos esses elementos ${ }^{6}$.

Assim como MacDonald (2004), Cameron e colaboradores chegam a seguinte conclusão: "the role of museums and science centres is not to prove the science of climate change but to improve the communication of climate change" (Cameron, Hodge, \& Salazar, 2013, p. 18).

Considerando que grande parte dos autores investigam histórias institucionais ou exposições em determinada faixa temporal e/ou espacial, para essa tese foram utilizados também referenciais que partem essencialmente de museus de arte e históricos, mas que traçam paralelos e discutem suas proposições também embasadas em exposições de museus de história natural (contemporâneas ou históricas). Staniszewski (2001) parte da premissa que a museografia de exposições é uma produção cultural geralmente "esquecida", mas que manifesta ideologias,

${ }^{6}$ As discussões sobre a inserção das questões científicas e dos museus nos problemas sociais não são novidade no campo museológico. Já na década de 1930, em Viena, Otto Neurath foi o primeiro diretor do Gesellschafts- und Wirtschaftsmuseum (Museu da Economia e Sociedade), onde visava explicar questões econômicas e sociais a classe trabalhadora de cidadãos, utilizando um sistema visual simples e acessível. Para tanto, desenvolveu com grande sucesso séries de painéis com gráficos e pictogramas, que foram visitadas por designers estadunidenses e de outros museus europeus (Perks, 2015).

A função social dos museus também é tema de ampla discussão do ICOM, especialmente nos últimos 40 anos e com o desenvolvimento da Nova Museologia. Alguns marcadores podem ser identificados nas declarações dessa instituição, tais como: a função educativa dos museus, defendida na reunião da UNESCO no Rio de Janeiro, em 1958; função social dos museus, reivindicada pela Declaração de Santiago (1972); movimento da Nova Museologia, reconhecido pela Declaração de Québec (1984); e o papel dos museus na formação de identidades e reconhecimento do património, como defendido Declaração de Caracas (1992). Na Conferência Geral de 2019, em Kyoto, discute-se uma nova definição de museu, em que podemos destacar palavras como "justiça social”, "igualdade”, "democracia”" e "inclusão". 
políticas, padrões estéticos e que influencia e é influenciada pelo contexto político, económico e social em que está inserida.

Já Michelle Henning (2006) aborda museus estadunidenses e europeus como forma de media e espaços reprodutores de ideologias e controle social (uma tese defendida inicialmente por Tony Bennett, 1995). Assim, discute as relações entre audiência e objeto, cujo afastamento e, mais recentemente, aproximação, são dadas via museografia. Henning analisa tradicionais museus de arte e científicos dentro de uma perspetiva histórica e identifica dois importantes pontos de viragem na museografia: as exposições do vanguarda do período entre guerras (especialmente as soviéticas, entre os anos 1920-30) (corroborado por Perks, 2015) e os novos empreendimentos expositivos influenciados pela "culture of curiosity" característica dos séculos XVI e XVII, o que a autora define como "return of curiosity" (tratado ao longo do texto em versão traduzida como "Retorno à Curiosidade"), que são também encontrados nas exposições de museus de história natural (corroborado por Adamopoulou \& Solomon, 2016).

Buscamos identificar formas de expor acervos científicos que estão associadas às práticas científicas e museológicas, que possuem contextos específicos de produção (e reprodução, no caso de intercâmbios e influências sob outras instituições), autoria e públicos a que se destinam, o que referimos nesse trabalho como "padrões museográficos". Cabe ressaltar que não se trata de uma cronologia linear de substituições de padrões e sim evidenciar as interfaces entre conceções e práticas científicas e museológicas e relacioná-las com o espaço, tempo e comunidade em que estão inseridas.

De forma que foi possível construir e caracterizar uma série de padrões de museografia, desde o século XIX, ao longo do século XX e a contemporaneidade, revisitando algumas propostas já feitas, corroboradas por diferentes autores, e indicando novos padrões, a partir da revisão de literatura e dados recolhidos em campo. Então, elaboramos um modelo teórico de padronização da museografia de exposições de museus de história natural.

No decorrer do texto apontamos indicadores que traçam as características que definem cada um dos modos de expor. Tais indicadores são sumarizados em tabelas ao final de cada seção do capítulo. No final desse trabalho, uma tabela completa é apresentada (APÊNDICE 1). 


\title{
2.3 Formas de Organizar Acervos e Discursos: Padrões Museográficos
}

\author{
"Over the past century, natural history museum exhibitions have seen significant shifts \\ in tone and approach - augmenting the tradition of labeled specimens with stories, \\ context and relevance. (...) The dynamic tension between celebration iconic objects \\ and giving them relevance is at the heart of imagining the future of natural history \\ museum exhibition" (Blond, 2018, p. 103)
}

No exercício de pensar o futuro das exposições de museus de história natural, Kara Blond traz a histórica tensão desses espaços: foco nos objetos e coleções, que embora sejam centrais nos museus muitas vezes são de difícil interpretação por não-especialistas, ou utilizar narrativas que contextualizam os acervos, mas que reduzem os objeto a ilustrações tridimensionais de conceitos expostos em suporte textual ou multimédia (Blond, 2018).

Diferentes estratégias de organização dos acervos têm sido propostas ao longo do último século, sendo a dicotomia entre as proposição de que os museus de história natural deveriam dar mais expressão a comunicação de ideias (conceitos) ou de factos (objetos) já circula na literatura científica desde o final do século XIX, como por exemplo nos guias propostos por George Brown Goode, secretário do United States Nacional Museum (posteriormente denominado Smithsonian Institute) (Schaeffer \& Patsuris, 1958).

Gregory (1936) sumarizou a questão em um artigo intitulado "The museum of things versus the museum of ideas", em que relaciona as distintas organizações do acervo com o histórico da própria prática científica, com o acúmulo de grande quantidade de objetos e acervos anatómicos advindo de dissecções, em uma tendência contra generalizações. Nesta conceção, as exposição foram tidas como "dictionaries of references" e cabia aos curadores elaborar séries cada vez mais completas. Contudo, tal acúmulo promovia o tédio e o cansaço do visitante leigo ao visitar longas e monótonas galerias. Em contrapartida, as lojas de departamento e os jornais do mesmo período mostravam resultados melhores: "the window-dressers in the better department stores long since discovered the fundamental importance of unity, emphasis and coherence, and they have also hit upon the high value of the rest, or interval of empty space, for the bewildered eye" (Gregory, 1936, p. 588). De modo que o autor propõe que o "museum of ideas" representa a modernidade das exposições diante do conhecimento científico e uma abordagem que permite melhora na educação pública. 
O debate sobre modos de expor continua até mais recentemente na literatura. Por exemplo, Dias (1994) analisa exposições antropológicas, inseridas em museus de história natural, e distingue duas formas de exposição para essas coleções ao longo do século XIX: organizações tipológicas e organizações geográficas, como dois arranjos distintos de exibir o conhecimento.

Séries tipológicas tendem a privilegiar as formas externas, que são mais acessíveis pela visão. Em geral, são apresentadas desde as formas mais simples até as formas mais complexas ou classificar de acordo com sua semelhança (técnica ou morfológica) com outros objetos, independentemente do seu contexto de uso ou procedência geográfica (panóplia) (Dias, 1994). A proposição de organização da coleção arqueológica e etnográfica realizada por Pitt Rivers (que deram origem ao Pitt Rivers Museum, em Oxford) foi fundamental para consolidação deste arranjo dos objetos em exposição (Chapman, 1985).

As organizações geográficas permitem uma visão dos modos de vida característicos de uma determinada região, promovendo uma visão sinóptica. Inseridos no contexto particular determinada área, esse tipo de arranjo dos objetos preocupa-se com o seu significado dentro de uma cultura particular. Nesse modo de arranjo de coleções, o espaço de um grupo social não é atemporal e abstrato como nas séries tipológicas, mas um espaço concreto, que é geograficamente e temporalmente localizado (Dias, 1994).

McLean (2007) ao rever as publicações dos primeiros 50 anos da publicação Curator aponta que também na literatura museológica da segunda metade do século XX está presente discussão sobre museografias centradas nos objetos e centradas nas narrativas. De acordo com a autora, a tensão entre esses modos de expor foi motivada, em parte, pelo entendimento de que exposições baseadas em objetos funcionavam para enfatizar as particularidades de um objeto ou de um espécime, mas por si só não eram adequadas para transmitir as ideias mais relevantes e abstratas, como os conceitos relacionados à Ecologia, Biogeografia e Evolução.

No entanto, essa última conceção da autora é questionável, a medida que as séries tipológicas de Pitt Rivers são caracterizadas pelo sentido evolutivo/progressista que oferecem em conjunto, por meio de sua observação. O espécime ou objeto representam categorias, que são dependes da relação com as categorias seguintes (Dias, 1994).

Gregory (1936), Dias (1994) e McLean (2007) são autores que diante de uma análise comparada de exposições propostas em diferentes momentos do século XX evidenciam a existência 
de dois padrões museográficos: "Centrado em objetos" e "Centrado numa narrativa", o que nos sugere que estes são padrões museográficos consolidados na literatura museológica.

Porém, as quatro últimas décadas do século XX assistiram o surgimento de duas novas formas de expor os acervos: o espetáculo e o retorno à matriz estética dos gabinetes de curiosidades. Diferente das abordagens educacionais das décadas anteriores, centrada na transmissão de conhecimento para o visitante-aprendiz, tais novas formas questionam o que o visitante quer aprender, uma abordagem ideologicamente diferente das anteriores (Karen Ann Rader \& Cain, 2014).

Além disso, a emergência do novo e formas económicas baseadas na "experiência" são uma clara tendência contemporânea. A tradicional oferta de produtos e serviços agora vem com um importante ingrediente: o "e-factor" ou "entertainment factor". Esse é o contexto do surgimento do movimento "edutainment", que se refere a uma tendência das instituições culturais incorporarem elementos do entretenimento e da educação em suas ofertas, de modo a atrair novas audiências, particularmente jovens (Balloffet, Courvoisier, \& Lagier, 2014).

Também os estudos culturais pós-modernos evidenciam que a cultura contemporânea opera por meio do espetáculo e da reprodução incessante de práticas de mass media. Exposições com grandes audiências e museografias elegantes e imersivas funcionam em conjunto com o marketing e a publicidade para produzir uma cultura do espetáculo e para que o espetáculo possa ser comercializado com legitimidade cultural, os museus representam um local único para esse processo (Sherman \& Rogoff, 2003). É nesse panorama que estão inseridas as exposições centradas no espetáculo, tendo com um dos principais exemplos das exposições do tipo blockbuster.

Em outra abordagem desse panorama, o papel socialmente responsável que os museus assumiram, bem como posições mais criticamente comprometida dos curadores permitiram novas práticas museográficas. Esse movimento tem sido definido por autores como Bann (2003), Henning (2006) e Adamapoulou \& Solomon (2016a) como o "retorno à curiosidade", uma vez que questionam as tradicionais ordenações hierárquicas de objetos e/ou informações científicas para promoção de formas novas e interativas de comunicar as coleções ao público. Propõe-se o "reencantamento" com as coisas, com intuito de libertar os objetos de suas rígidas estruturas explicativas ou didáticas e permitir que eles possam recuperar seus atributos de maravilhamento e curiosidade, tornando o museu mais dialógico e seus objetos polissêmicos (M. Henning, 2006). 
Diante das perspetivas museológica e histórica dos museus de história natural e suas exposições, construídas por meio da revisão de ampla literatura e recolha de dados em visitas técnicas, propomos quatro padrões museográficos, e seus respetivos subpadrões, caracterizados e discutidos em detalhe ao longo desse capítulo:

Padrão Centrado em Objetos

Subpadrão: Séries Taxonómicas

Subpadrão: Séries Evolutivas / Progressistas

Subpadrão: Dioramas

Padrão Centrado numa Narrativa

Subpadrão: Quotidiano

Subpadrão: Ecológico

Subpadrão: Public Understanding of Science

Padrão Espetacular

Subpadrão: Blockbuster

Padrão "Retorno à Curiosidade"

Subpadrão: Biografia dos Objetos

\subsection{Padrão Museográfico: Centrado em Objetos}

De acordo com uma conceção empirista, a natureza é atomista, ou seja, um conjunto infinito de formas indivisíveis que circulam no vazio, e o único conhecimento possível é derivado de uma miríade de impressões sensoriais e operados pela recolha, comparação e classificação desses impressões que são, essencialmente, visuais e experimentais (Cypriano \& Oliveira, 2017).

Tal conceção é característica das práticas científicas do século XVIII e início do XIX, conforme descrito por Daston e Galison (2007). No período, os naturalistas deveriam ter outras qualidades para além dos sentidos aguçados: grande memória, capacidade de analisar e sintetizar impressões, bem como paciência e talento para extrair o típico do que adivinha das particularidades naturais. 0 
naturalista modelo (e, portanto, investigador ideal) é um "genious of observation", sendo Carl Nilsson Linnæus $^{7}$ seu principal exemplo (Lorraire Daston \& Galison, 2007).

É a partir desse contexto, que o interesse não estava mais concentrado no "exótico" e sim no lugar em que este ocupava numa estrutura conceitual maior. De acordo com Dias (1994), no caso da Antropologia, pela primeira vez os artefactos foram exibidos de modo sistemático, dentro de quadros que eram simultaneamente visuais, legíveis e espaciais.

Considerando que a função educativa dos objetos e coleções está implícita desde as coleções renascentistas (Findlen, 1994), o papel dos objetos era comum entre as escolas e os museus, uma vez que essas instituições compartilhavam o interesse no objeto como fonte de conhecimento e de sua importância nas “lições das coisas” (Van Praët \& Poucet, 1992).

Não apenas como fonte de conhecimento, mas também o conteúdo acerca dos objetos é suposto ser visível e organizado no espaço. Adicionalmente, a retórica utilizada para o ensino desse conhecimento tornava-se o modo de organizar as coleções de objetos, ordenando o saber, estruturado em tabelas, séries e diagramas (Fabian, 2014).

Nas última décadas do século XIX, há a consolidação das “lições das coisas”, o que Podgorny (1995) denominou "imaginería escolar", contrapondo no ensino baseado em livros e exposição oral de um mestre ao ensino considerado mais "útil e agradável”, baseada no método intuitivo, por meio da observação e comparação de objetos (García \& Podgorny, 2001) [INDICADOR 1, Tabela 1].

Em poucas palavras, o método intuitivo fundamenta-se na ideia de que o pensamento pessoal do aluno é estimulado e promovido pela visão e manuseio de objetos. Esse tipo de ensino reproduz o modo científico de conhecer e a crença de que a inteligência do sujeito, confrontada diretamente com objetos, permite lhe descobrir sua natureza. Esse é o ponto de justificação e partida para todas as iniciativas pedagógicas baseadas em "coisas" e objetos9 (García \& Podgorny, 2001).

${ }^{7}$ Nesse trabalho utilizaremos "Lineu”, nome do naturalista adaptado para o Português.

8 "Encauzar los sentidos hacia lo bello y moralmente util constituia uno de los objetivos de una nueva especie que se dio en llamar "imagineria escolar" (Podgorny, 1995, p. 93)

${ }^{9} \mathrm{O}$ método intuitivo esteve em circulação conferências, congressos e exposições internacionais, sendo as últimas um importante meio de sua divulgação. Já na primeira Exposição Internacional realizada em Londres, em 1851, o método é discutido na temática do ensino elementar do desenho. Cartas geográficas e geológicas, desenhos, coleções de minerais, plantas e madeira, atlas para o estudo de física, química etc., foram exibidos durante a segunda Exposição Universal em Londres, de 1862, e atestavam o uso de coleções de objetos para o ensino intuitivo, mostrando que esse tipo de evento (grandes feiras internacionais), se a temática do método intuitivo não foi objeto 
Desse modo, longas séries, peças e esqueletos completos eram consideradas fundamentais também para atrair o público aos museus, que se supunha incapaz de compreender globalmente um animal ou uma cultura apenas pela observação dos fragmentos, que bastavam ao especialista. Numa época, em que a "lição das coisas" se colocava como condição indispensável para a educação da juventude e das populações urbanas iletradas, os museus ressaltaram a importância também dos fins educativos de suas exposições (Lopes \& Murriello, 2005).

Em 11 de Setembro de 1889, em Newcastle-Upon-Tyne, Sir William H. Flower inaugurou sua presidência na British Association for the Advancement of Science com um discurso sobre os papéis que cabiam aos museus de história natural, no século que se avizinhava. Nesse famoso discurso, publicado no dia seguinte no Times, traduzido para o francês apenas uma semana depois de sua apresentação, e no ano seguinte para o espanhol, publicado pela revista Revista del Museo de La Plata (1890-1) destaca o papel educacional dos objetos:

"Every specimen exhibited should be good of its kind, and all available skill and care should be spent upon its preservation and rendering it capable of teaching the lesson it is intended to convey" ((Flower, 1898, p. 17)

O museu cultivava o poder da observação, para que o visitante casual pudesse fazer descobertas por ele mesmo [INDICADOR 1, Tabela 1] e sob o guia das etiquetas e rótulos para formular as suas próprias impressões [INDICADOR 4, Tabela 1] (Karen Ann Rader \& Cain, 2014). No entanto, reduzido a sua expressão morfológica, o objeto é consumido nele mesmo, como se a sua superfície externa correspondesse a sua essência interior (Dias, 1994) [INDICADOR 2, Tabela 1].

Em outras palavras, ao observar a forma externa do objeto, o "visível", o visitante pode atingir o "invisível”, por meio da leitura horizontal do conjunto dos objetos organizados (Dias, 1994). Uma perceção horizontal é possível por meio da observação da organização de séries justapostas, que implicam que o conhecimento de cada forma depende da relação com as formas seguintes. Então, além do conhecimento sobre um único espécime, é relevante perceber o que ele representa em relação aos demais [INDICADOR 3, Tabela 1] (Dias, 1994).

de conferências e estudos específicos, ao menos foi retratada na exibição (e comércio) dos objetos destinados àquele ensino (Schelbauer, 2005). 
Esse tipo de organização de exposições científicas são claramente tipológicas, ou seja, os espécimes representam tipos. Tal organização pressupõe uma ordenação inicialmente taxonómica, mas que derivou mais tarde para séries evolutivas (ou, progressistas): do mais simples para o mais complexo, do mais necessário a vida humana (alimentação, habitação, vestuário ou defesa) até o "mais supérfluo" (como instrumentos musicais), sendo Pitt Rivers, no final do século XIX, seu principal promotor (Dias, 1994).

\begin{tabular}{|c|c|c|c|c|}
\hline \multirow{5}{*}{ 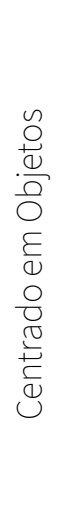 } & $\begin{array}{l}\mathrm{N}^{\circ} \text { do } \\
\text { Indicador }\end{array}$ & $\begin{array}{c}\text { Padrão } \\
\text { Museográfico }\end{array}$ & Indicador & Autor - Fonte \\
\hline & 1 & $\begin{array}{l}\text { Características } \\
\text { comuns }\end{array}$ & $\begin{array}{l}\text { Promover o aprendizado por meio da observação } \\
\text { dos objetos ("lição das coisas") }\end{array}$ & $\begin{array}{l}\text { Dias, 1994; Holzmeyer, } \\
\text { 2012; Rader e Cain, 2014; } \\
\text { García e Podgorny, } 2001\end{array}$ \\
\hline & 2 & $\begin{array}{l}\text { Características } \\
\text { comuns }\end{array}$ & Privilégio das formas anatómicas externas & Dias, 1994; Fabian, 2014 \\
\hline & 3 & $\begin{array}{l}\text { Características } \\
\text { comuns }\end{array}$ & $\begin{array}{l}\text { Conhecimento de cada forma depende da relação } \\
\text { com as formas seguintes }\end{array}$ & Dias, 1994 \\
\hline & 4 & $\begin{array}{l}\text { Características } \\
\text { comuns }\end{array}$ & Espaços e objetos identificados por etiquetas & $\begin{array}{l}\text { Henson, 2017; Rader e } \\
\text { Cain, 2014; Flower, } 1898\end{array}$ \\
\hline
\end{tabular}

Tabela 1: Tabela que resume os indicadores compartilhados por exposições do padrão museográfico "Centrado em objetos", que serão aplicados na análise das exposições estudadas nessa tese. As "características comuns" são indicadores compartilhados por todos os subpadrões dentro desse padrão museográfico.

\subsubsection{Subpadrão: Séries Taxonómicas}

"As long as an exhibition hall is conceived to be primarily a dictionary for references, the curators will naturally try to make it as complete as possible a will not only exclude everything not directly pertaining to the dictionary function but will cram their shelves to the limit of capacity" (Gregory, 1936, p. 586)

O subpadrão museográfico "Séries Taxonómicas" relaciona-se com à própria constituição da História Natural como disciplina científica. Diante da quase inconcebível riqueza dos tipos de organismos, o mundo científico ocidental buscou leis e o primeiro modo de detetar tais leis foi a ordenação, mediante a sua classificação. Isso explica por que os naturalistas dos séculos XVII, XVIII e XIX eram tão obsessivos pela classificação, uma vez que lhes permitia colocar a desconcertante diversidade pelo menos numa espécie de ordem (Mayr, 1998). Tão importante se afigurava esse 
proceder de ordenação aos naturalistas do século XVIII, que a classificação era tratada como sinônimo de ciência (Lopes, 2009).

As classificações biológicas constituem um depósito de informação, uma fonte sintética de informação sobre a ordem da diversidade biológica e podem ser reconhecidos como sistema geral de referências sobre a diversidade biológica, como definido por Willi Henning (1966). Como sistema de informação sobre a ordem, por sua vez, lança luz sobre o grupo em foco, e permite a compreensão tanto do grupo como do todo (Amorim, 2005).

Entre os diversos sistemas de classificação biológica correntes ao longo do século XVIII, predominou o sistema de classificação lineano. Proposto por Lineu, em Systema naturae, cuja primeira versão foi publicada em 1735 (embora a versão mais corrente seja de 1758), teve importante recetividade na comunidade científica, especialmente por seu caráter enciclopédico e tipológico, que permitia:

\begin{abstract}
"enabled the collector and the museum worker to find a logical place for each new specimen. In its turn, this framework stimulated the search for an ever more complete series, so that the enthusiasm of the explorer-collector harmonized with that of the museum classifier to produce an increasingly rich and complex but orderly picture" (Whitehead, 1971, pp. 155-156).
\end{abstract}

Em Systema naturae, Lineu criou um método empírico de nomeação (sistema binomial) para construir uma taxonomia ideal de formas puras. Nesse sistema, a natureza manifestava-se em certas formas irredutíveis (eidos) e poderia ser entendida dentro de uma organização sincrônica e lógica ${ }^{10}$. Nas palavras de Amorim (2005), o que chamamos de sistema lineano de classificação contém duas estruturas distintas: o sistema de táxons e o sistema de categorias. O sistema de táxons corresponde ao agrupamento de espécies com base em semelhanças compartilhadas. Nomes são atribuídos a tais grupos, isto é, o conhecimento sobre características compartilhadas permite visualizar uma certa ordem na natureza biológica, o que gera os agrupamentos, que recebem nomes.

\footnotetext{
${ }^{10}$ O sistema de Lineu é fundamentado na lógica aristotélica, facto pouco enfatizado na literatura. No campo da Zoologia, Systema naturae é central e sua décima edição, publicada em 1758, foi adotada oficialmente pelo Código Internacional de Nomenclatura Zoológica como a primeira publicação válida para fins de prioridade (Amorim, 2005).
} 
A outra parte da classificação lineana é a hierarquia dos táxons, que é o sistema de categorias. O sistema de categorias lineano é baseado no conceito aristotélico de genus (do grego: origem, tribo, descendência, género) e eidos (do grego: aspeto exterior, forma, classe, modo de ser). Esses termos indicam, num sentido lógico as posições numa hierarquia: um nível mais geral, que inclui vários elementos, é um genus (plural, genera), enquanto que um nível mais restrito, incluído em um nível maior é um eidos. Esses são conceitos relativos, e o que é um genus em um nível pode ser um eidos em outro. Portanto, as categorias indicam se um grupo está mais abaixo ou acima na hierarquia dos táxons (Amorim, 2005).

A principal oposição enfrentada por Lineu foi realizada por Gerges-Louis LeClerc, conde de Buffon, responsável pelo Jardin du Roi (compreendido como o jardim botânico associado ao MNHN) que, mesmo que por fim tendo aceito a utilização da nomenclatura binomial, considerava falaciosa a tentativa lineana de criar um sistema de classificação capaz de abranger todo o funcionamento da natureza (Sloan, 1976).

Buffon jamais aceitou a ideia de Lineu sobre a natureza da categoria "género" (genus) (Mayr, 1998). A crítica de Buffon a Lineu parte de alguns pressupostos associados as suas conceções. $O$ primeiro argumento de Buffon era que qualquer tentativa de hierarquizar a ordem da natureza é algo arbitrário, uma vez que considerava "it is to impose on the reality of the Creator's works the abstractions of our mind" (Buffon, 1749 apud Sloan, 1976). O segundo argumento parte de uma conceção metafísica, em que a natureza consiste apenas em indivíduos e não é possível agrupá-los dado ao infinito contínuo do mundo natural. Por fim, o terceiro argumento é de ordem epistemológica, afirmando que todo o conhecimento é relacional e não fundamentado nas essências reais ou causas essenciais (o que não era compartilhado por outros taxonomistas contemporâneos), de modo que a ordem mais "natural" que poderia ser seguida para organizar os animais deveria seguir seu grau de relação a espécie humana (Sloan, 1976).

Contudo, a partir o estudo de documentos e publicações de outros investigadores parisienses contemporâneos a Buffon, Sloan (1976) evidencia que a crítica e reputação científica de Buffon não foram impeditivos para que outros naturalistas utilizassem as categorias lineanas de classificação - como classes, ordens, famílias e gêneros - em suas publicações e que, depois de 1760, o próprio Buffon reconhecia como grupos naturais os quadrúpedes e as aves, dentro de gêneros e 
famílias (embora os critérios de classificação estivessem associados a modos de alimentação e locomoção desses grupos, que eram critérios aceitos por Buffon).

A proliferação dos museus de história natural na Europa, a partir do século XVIII, enraízam a consolidação da História Natural como parte da ciência moderna ${ }^{11}$. E é nesse contexto que Domenico Vandelli, em meados de 1780, discutindo a utilidade dos museus de história natural, identifica a "História Natural" e a "ciência dos museus" como algo único (Brigola, 2008; Lopes, 2009).

Constituindo um legado centralizado no entusiamo pela classificação e pelo conhecimento enciclopédico do século XVIII, os museus configuravam-se como espaços de articulação e formação do olhar dos naturalistas, transformando-se em instituições de produção e disseminação de conhecimentos, nos moldes que lhes exigiam as conceções científicas vigentes (Tony Bennett, 2004).

No contexto português, o primeiro museu de história natural relacionado à prática científica foi fundado em 1772, com a criação da Faculdade de Filosofia da Universidade de Coimbra. 0 primeiro estatuto da universidade já descreve a distribuição física das coleções do seu museu, organizado também em categorias: três salas devotadas aos três reinos da natureza e um jardim botânico. Essa organização é associada ao naturalista italiano Domenico Vandelli, contratado inicialmente para o ensino no Colégio dos Nobres (o que nunca foi efetivado) e depois para organização do Real Gabinete de História Natural (posteriormente transferido para o Palácio da Ajuda) e indicado à Universidade de Coimbra, pela administração pombalina. Catedrático em História Natural, Vandelli correspondia-se com Lineu (além de outros investigadores internacionais) e alinhava-se com seu sistema de classificação (Brigola, 2008)

Apesar das diferenças na compreensão das espécies e classificação Buffon e Lineu, bem como outros defensores da História Natural, tiveram um impacto significativo na forma como os objetos naturais foram concebidos e organizados (Chicone \& Kissel, 2014). A exposição de

${ }^{11}$ De acordo com Lopes (2005): "A História Natural do Renascimento foi abandonando seus antigos quadros conceituais, e foi assumindo novas práticas e se constituindo nas tradições da História Natural do século XVIII. Em um processo, em que tanto a botânica, a zoologia, a mineralogia se individualizam como áreas de conhecimentos, apoiadas em práticas locais e coleções globais, indo além de sua subordinação à utilidade médica; como em que, áreas de conhecimento se organizaram por começarem a se colocar questões relativas à origem e à historicidade dos seres e processos naturais, pelo avanço das temáticas classificatórias e das discussões envolvendo temporalidades" (Lopes, 2005 p. 459). 
"regularidades" taxonomicamente ordenadas [INDICADOR 5; INDICADOR 9, Tabela 2], em vez do singular (ou as anomalias), pretendia revelar a ordem e a racionalidade - as leis da natureza (Holzmeyer, 2012) [INDICADOR 8, Tabela 2].

De modo que as primeiras exposições reconstruíam um inventário geral dos seres vivos, reproduzindo a ordem dos livros e tratado. Portanto, a partir dos conhecimentos reconhecidos pela academia, a exposição funcionava como uma biblioteca de espécimes preservados (Delicado, 2010). É a essa busca por séries completas - a Grande Cadeia dos Seres - e a criação de um catálogo tridimensional da ordem da natureza que é descrita William Gregory (1936), no trecho que inicia esse texto.

No entanto, quanto ao conceito de espécie e sua hierarquização baseada em grupos naturais (e não unicamente tipológicos ou operacionais), poucos progressos foram feitos na classificação animal, durante os séculos XVII e XVIII (Mayr, 1998).

Já na virada do século XVIII - XIX e nos primeiros anos do século XIX, Georges Cuvier, autoridade científica no MNHN, traz uma nova luz a classificação, a partir da sua descoberta do grande conteúdo informativo da anatomia interna dos invertebrados. Ao dissecar numerosos animais marinhos, o naturalista encontrou abundantes caracteres novos e de tipos de organização corporal. Então, uma das principais contribuições científicas de Cuvier foi seu método comparativo consistente e de ampla aplicabilidade, em que a forma dos órgãos estava em primeiro plano (Mayr, 1998). Por exemplo, Cuvier sustenta que a respiração - cujo papel na renovação da substância é a mesma em todo o reino animal - é realizada dentro das classes de animais separadas por meio de órgãos, que de tão diferentes uns dos outros não era possível nenhuma comparação entre eles (para Cuvier, esse também é o caso dos órgãos do movimento) (Nordenskiold, 1929).

As suas descobertas permitiram-lhe, pela primeira vez, o reconhecimento de um número de taxa muito maior do que aqueles reconhecidos por Lineu. Em seu livro Le Règne Animal Distribué d'Après Son Organisation, Pour Servir de Base à l'Histoire Naturelle des Animaux et d'Introduction à l'Anatomie Compare, publicado em 1812, Cuvier descreveu os quatro "embranches" (sub-reinos) como entidades muito distintas, que não podiam ser unidas: vertebrados, moluscos, articulata (artrópodes) e zoófitos ou radiata (Mayr, 1998). 
Cuvier considerava os sistemas fisiológicos com tamanha importância que controlariam a conformação de todos os outros caracteres. Isso representava um novo ponto de partida conceitual, cuja investigação prescreveu a forma de expor as coleções de história natural ${ }^{12}$ (Taquet, 2008).

Assim, Cuvier organizou os objetos herdados da coleção de Buffon, além de muitos outros que foram angariados em sua gestão, de acordo com sistemas orgânicos:

"Les préparations ont été faites avec des visions physiologiques, c'est-à-dire que'elles ont été réparties non pas d'abord dans l'ordre des animaux dont elles sont issues, plus dans l'ordre des organes dont els clarifient la la structure"

Para Cuvier o estudo dos animais estendia-se para além da classificação baseada na morfologia externa. Nessa perspetiva, assim como a química, as combinações e as propriedades dos elementos servirem para explicar a estrutura e os processos, a variedade e sua classificação (Pickstonene 20011). No entanto, isso não significou comparar órgãos em diferentes grupos zoológicos, como a complexidade do olho de um cefalópode com a de um mamífero, mas mostrar que dentro de grupos taxonómicos os órgãos compartilham funções, de modo a provar uma distribuição natural de espécies, gêneros e famílias, dentro das diferentes classes. De forma que, os resultados do grande esforço de preparar, estudar e organizar as coleções zoológicas de acordo com a sua proposta poderiam ser vistos no Cabinet d’Anatomie Comparée, aberto 1806, (e que serviu de base para sua "remontagem" na Galerie de Paléontologie et d’Anatomie Comparée), além de suas publicações impressas (Taquet, 2008).

As exposições taxonómicas adentraram o século XIX, expressando a proeminência intelectual das ciências naturais (Kulik, 1989). Não era a abundância e generosidade da criatividade da natureza que os museus e seus profissionais buscavam celebrar, mas a racionalidade e a ordem sob a profusão e a confusão das formas (Asma, 2001). No período, as exposições evidenciavam as

12 Cabe destacar também que a linha de investigação em Anatomia Comparada desenvolvida por Cuvier era essencialmente diferente de seus antecessores, homens da medicina como Louis-Jean-Marie Daubenton ou Johann Friedrich Blumenbach, em que a espécie humana era o objeto primário de estudo com os quais todos os demais organismos eram comparados. Cuvier, entretanto, partiu do estudo de animais marinhos, como anelídeos, moluscos e peixes (Nordenskiold, 1929). 
epistemologias dos profissionais dos museus, naturalistas-taxonomistas. Nas palavras de Daston e Galison (2007) sábios, pacientes, com capacidade de memória, de analisar e sintetizar informações, bem como paciência e talento para extrair o que é típico e regular.

Além disso, as práticas científicas e de disseminação do conhecimento da Antropologia e Etnografia espelharam-se na História Natural, de modo que a ênfase na coleta e classificação, adotando uma "lista taxonómica" de "raças" e "artefactos" como forma de estruturar e ordenar os dados (Dias, 1994).

A ordenação taxonómica transcendeu as vitrinas e prateleiras e também orientou a distribuição espacial dos museus, ao longo do século XIX. Forgan (1994) discute a arquitetura de museus britânicos e destaca como as classificações taxonómicas influenciaram o layout dos espaços [INDICADOR 6, Tabela 2], destacando duas formas de organização: uma similar as bibliotecas, onde as séries taxonómicas estavam organizadas ao redor de um espaço aberto, em que o visitante poderia circular. Outro tipo de organização taxonómica dispõe as séries ao longo de um eixo central, dividido por baias de igual tamanho, com espaços estão logicamente conectados, de modo que ao observá-lo pode-se ter uma noção "one complete classificatory table" (Forgan, 1994, p. 148), ou como índex, em referência ao projeto de Richard Owen (Figura 1).
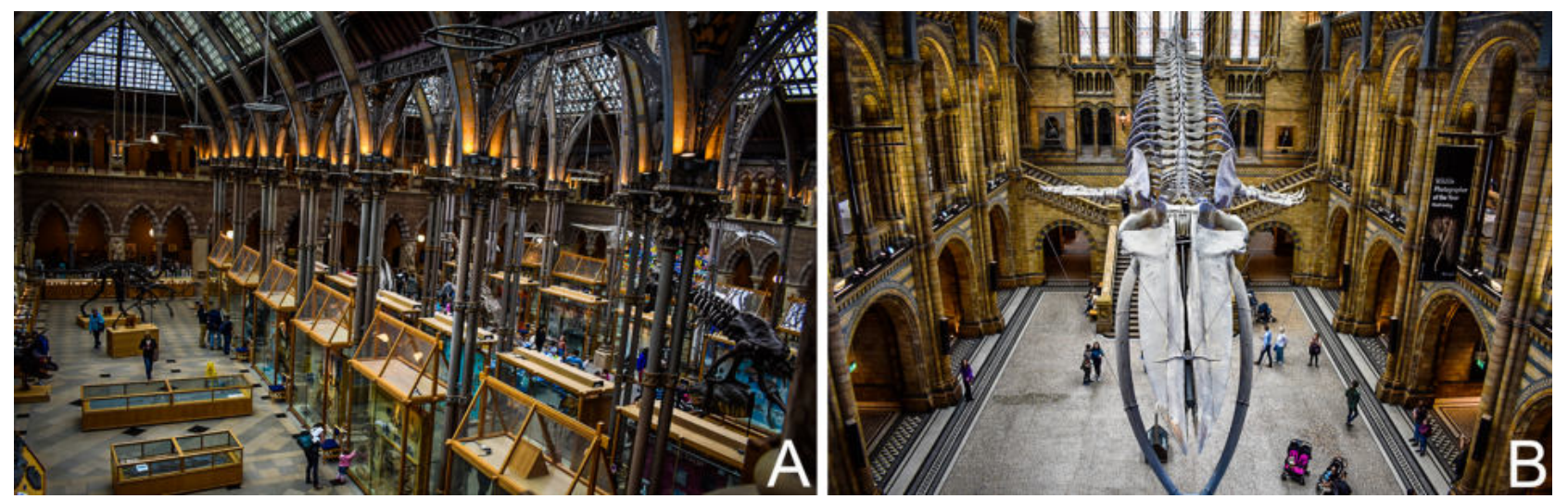

FIGURA 1: Comparação entre o aspeto geral do espaço expositivo contemporâneo de museus britânicos construídos no século XIX. Em A, Oxford University Museum of Natural History, onde séries taxonómicas estão organizadas em corredores paralelos e estruturas de pilares ao redor de um hall central (esses pilares, inclusive, são decorados com amostras de rochas do Reino Unido). Em B, Hintze Hall no NHM, em que há um esqueleto de baleia-azul eixo central e pequenas salas de exposição laterias. Atualmente, a exposição dessa galeria visa exaltar as coleções da instituição, portanto, em cada um desses espaços há um objeto icónico de algumas das principais coleções, como por exemplo: duas girafas taxidermizadas, um meteorito, uma amostra de rocha com bandas de ferro, um esqueleto completo de dinossauro encontrado na Inglaterra, fósseis de troncos e algas. Fotos: Mariana Galera Soler, obtidas durante visita técnica em Maio de 2018. 
De acordo com Orosz (1990) a ausência de uma longa e artística tradição associada aos museus estadunidenses foi um dos motivos das organizações taxonómicas serem as primeiras formas de museografia nos EUA. Na Europa, as coleções dos monarcas e aristocratas poderiam ser facilmente transformadas em museus. Contudo, no Novo Mundo, as coleções deveriam primeiro ser formadas e dada a necessidade urgente de recursos para o desenvolvimento, os museus foram criados principalmente para propósitos práticos e úteis. Em países com grande abundância de espécies não descritas de flora e fauna, era inevitável que a taxonomia fosse um propósito dos gabinetes iniciais. Lopes (2009) descreve um movimento similar no Brasil, em que os primeiros museus foram os espaços de institucionalização da ciência e o inventário dos recursos naturais a prática científica vigente, o que também levou a primeiras exposições organizadas dentro de categorias taxonómicas. Lopes e Podgorny (2000) caracterizam a necessidade de inventariamento dos recursos naturais e do território como uma das principais motrizes para o desenvolvimento dos primeiros museus latino-americanos.

Ainda o caso dos EUA, a classificação taxonómica foi a primeira forma organizar as exposições do United States National Museum (atualmente, Smithsonian Institute), aberto em 1881 (tais formas de expor perduraram por todo século XIX-XX). Promovida essencialmente por seus dois primeiros secretários e que também eram taxonomistas, George Brown Goode e Spencer Fullerton Baird, esperava-se apresentar e descrever os recursos da jovem nação. As organizações taxonómicas impulsionaram a exposição de todos os objetos da instituição, incluindo os artefactos da humanidade, de modo que exposição deveria capturar a classificação, fornecendo uma ordem para a museografia (Henson, 2017) [INDICADOR 7, Tabela 2].

A classificação taxonómica forneceu as bases para o que se tornou conhecido como sistemática biológica, em que são analisadas as relações entre os organismos, incluindo a trajetória evolutiva das espécies e dos ecossistemas (Holzmeyer, 2012). No entanto, ao longo do século XIX, a conceção de formas fixas e Grande Cadeia dos Seres foram substituídas por novos campos de conhecimento sobre a mudança da forma (Kulik, 1989), sendo a teoria evolutiva proposta por Charles Darwin, decisiva tanto no campo científico, como na organização das exposições. 


\begin{tabular}{|c|c|c|c|c|}
\hline \multirow{6}{*}{ 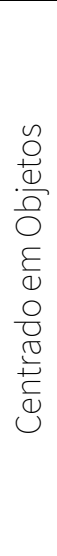 } & $\begin{array}{c}\mathrm{N}^{\circ} \text { do } \\
\text { Indicador }\end{array}$ & $\begin{array}{l}\text { Subpadrão } \\
\text { Museográfico }\end{array}$ & Indicador & Autor - Fonte \\
\hline & 5 & $\begin{array}{c}\text { Séries } \\
\text { Taxonómicas }\end{array}$ & $\begin{array}{l}\text { Organização das coleções dentro categorias } \\
\text { taxonómicas lineanas }\end{array}$ & $\begin{array}{ll}\text { Whitehead, } & 1971 ; \\
\text { Holzmeyer, } 2012\end{array}$ \\
\hline & 6 & $\begin{array}{c}\text { Séries } \\
\text { Taxonómicas }\end{array}$ & $\begin{array}{l}\text { Espaços organizados de acordo com categorias } \\
\text { taxonómicas }\end{array}$ & Forgan, 1994 \\
\hline & 7 & $\begin{array}{c}\text { Séries } \\
\text { Taxonómicas }\end{array}$ & Museografia associada as categorias taxonómicas & Henson, 2017 \\
\hline & 8 & $\begin{array}{c}\text { Séries } \\
\text { Taxonómicas }\end{array}$ & $\begin{array}{l}\text { Expressão de leis da natureza a partir de séries } \\
\text { ordenadas }\end{array}$ & Holzmeyer, 2012 \\
\hline & 9 & $\begin{array}{c}\text { Séries } \\
\text { Taxonómicas }\end{array}$ & $\begin{array}{l}\text { Apresentação de espécimes representativos e } \\
\text { regulares, não anomalias }\end{array}$ & Holzmeyer, 2012 \\
\hline
\end{tabular}

Tabela 2: Tabela que sistematiza os indicadores que definem o subpadrão museográfico "Séries Taxonómicas", que serão aplicados na análise das exposições estudadas nesse trabalho.

\subsubsection{Subpadrão: Séries Evolutivas / Progressistas}

"Progress is like a game of dominoes - like fits on to like. In neither case can we tell beforehand what will be the ultimate figure produced by the adhesions; all we know is that the fundamental rule of the game is sequence" (Pitt Rivers, 1874, p. 308, grifo nosso)

Embora a evolução não possa ser vista diretamente, uma questão já pontuada por Darwin, pode se tornar evidente pela ordenação dos objetos em que semelhanças são apresentadas como descendência [INDICADOR 15, Tabela 3] (Tony Bennett, 2004).

Os princípios evolutivos de classificação e exposições desenvolvidos nos museus de história natural marcaram as últimas décadas do século XIX. Diante de uma ótica evolucionista, as homologias que pareciam contrariar a adaptação passaram a fazer sentido, uma vez que representavam as condições ancestrais que ainda estão presentes no seus descendentes. Já as adaptações nas quais Cuvier havia se concentrado, após 1859 e a publicação de The Origins of Species, puderam ser associadas ao processo de seleção natural. O próprio sistema de classificação, ainda que primariamente lineano (portanto fixista), ao incorporar a perspetiva evolutiva passa a representar o conjunto de características compartilhadas por espécies ou grupos, tornando-se um subproduto da árvore evolutiva (Amorim, 2005; Asma, 2001). 
Os princípios evolutivos presentes nas exposições de museus também tiveram um papel fundamental em tornar o passado visível e reconhecível, o que pode ser evidenciado por dois aspetos (Tony Bennett, 2004). O primeiro preocupa-se com a investigação científica, uma vez que os museus eram os espaços de práticas das disciplinas científicas, fornecendo contexto e evidências para que os "novos passados" fossem percetíveis e passíveis de compreensão: Zoologia, Geologia, Botânica e Antropologia são, nas palavras de Pickstone (1994), museological sciences. O segundo diz respeito a função desempenhada pelas práticas museográficas em traduzir o passado num componente significativo para cultura pública. Em ambos aspetos, os museus serviram de incubadoras para avanços científicos, afetando a própria gramática do campo artefactual (como abaixo descrevemos as séries tipológicas de Pitt Rivers), fornecendo novas regras para a classificação e combinação de objetos, além de novas estratégias de governança cultural e controle social13 (Tony Bennett, 1995). Diretamente associado ao setor museológico, tais aspetos também afetaram as práticas dos museus de arte e coleções arqueológicas clássicas (Tony Bennett, 2004).

O typological system (sistema tipológico ou séries tipológicas), proposto pelo General August Lane-Fox Pitt Rivers, representa um marcante exemplo de como a museografia registou as ideias evolutivas e progressistas da ciência, na segunda metade do século XIX. O arqueólogo britânico mudou o paradigma das exposições de artefactos antropológicos e etnográficos, até então organizadas de acordo com a localidade de coleta, por padrões estéticos ou de curiosidades, para apresentar os objetos em séries dispostas em esquemas lógicos.

Nesse sistema, o que era considerado "mais primitivo" deveria ser disposto junto com outros "mais desenvolvidos", de modo que o visitante pudesse fazer comparações entre os diferentes tipos em um mesmo horizonte, mais do que uma ver uma seleção da cultura material de uma única sociedade ou a observação das peculiaridades de um objeto (Chapman, 1985).

${ }^{13}$ As tecnologias para exposições evolutivas de museus podem ser entendidas, em parte, como uma resposta as ameaças de mudanças políticas e ideológicas. A tarefa do museu era refrear uma nova ordem emergente, agrupando os objetos (ossos, fósseis, minerais, ferramentas, cerâmica etc.) em linhas graduais e contínuas de desenvolvimento evolutivo. A retórica central das exposições poderia mostrar o ordenamento da natureza e da cultura e as relações entre elas, de maneira a regular o progresso, fornecendo um modelo para seu avanço suave e ininterrupto (Tony Bennett, 2004). 
Como descrito na seguinte passagem:

"For this purpose ordinary and typical specimens, rather than rare objects, have been selected and arranged in sequence, so as to trace, as far as practicable, the succession of ideas by which the minds of men in a primitive condition of culture have progressed from the simple to the complex, and from the homogeneous to the heterogeneous."

(Pitt Rivers, 1874, p. 294)

Dias (1994) descreve esse arranjo expositivo como "panóplias", por oferecer evidências visuais das semelhanças de diferentes objetos e uma confirmação visual da evolução biológica ou tecnológica. Tal arranjo encaminha o olhar do visitante ao longo dos estágios evolutivos, começando com a forma original, o protótipo ou ancestral, colocado no centro ou em uma das extremidades da panóplia, seguindo para sua forma final (Dias, 1994)(Figura 2)[INDICADOR 14, Tabela 3].

Pitt Rivers foi claramente um evolucionista (Chapman, 1985) e utilizava autores como Charles Darwin e, principalmente, as teorias evolucionistas progressistas de Hebert Spencer ${ }^{14}$ para justificar suas séries tipológicos e a conceção do desenvolvimento gradual ${ }^{15}$, lento e progressivo das sociedades humanas e respetiva cultura material, como no trecho destacado a seguir:

"So in natural history, invertebrate and vertebrate animals and mammalia are all found living side by side in the same localities, although we know that they represent successive stages in the development of species. Typological sequence, or typological continuity, may be said to be established when the true succession of forms have been brought out. This is the object of an educational museum" (Pitt Rivers, 1891, p. 118)

${ }^{14}$ A teoria evolutiva progressista de Hebert Spencer pode ser sintetizada no seguinte excerto: "Assim, propomo-nos demonstrar, em primeiro lugar, que esta lei do progresso orgânico é a lei de todo o progresso; quer se trate das transformações da Terra, do desenvolvimento da vida à sua superfície ou do desenvolvimento das instituições políticas, da indústria, do comércio, da língua, da literatura, da ciência, da arte, dá-se sempre a mesma evolução do simples para o complexo, mediante sucessivas diferenciações" (Spencer, 1939, p. 5).

${ }^{15}$ A conceção de que a natureza "no makejumps" já está presente desde as primeiras classificações de Buffon (Tony Bennett, 2004). No entanto, já era questionada por Cuvier, ao classificar os animais em quatro grupos que o investigador considerava impossível uma origem comume, mais recentemente, na segunda metade do século XX, por paleontólogos como Stephen Jay Gold e Niles Eldredge (Mayr, 1998). 
Desse modo, Pitt River propõe a organização dos objetos (espécimes ou artefactos) de modo a referir esquemas lógicos (evolutivos), ao invés de destacar unicamente as próprias características do objeto (Figura 2) [INDICADOR 12, Tabela 3].

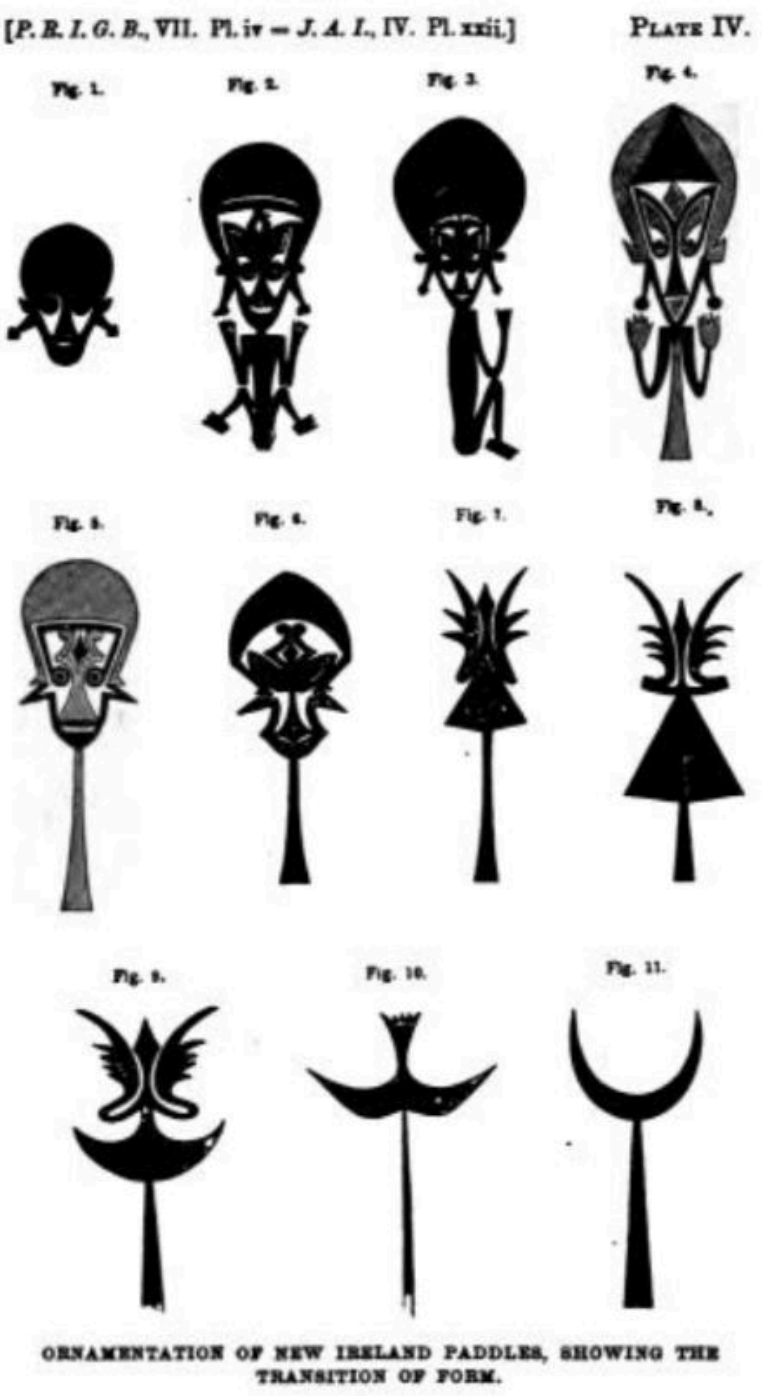

FIGURA 2: Prancha publicada em 1806 por Pitt Rivers, associada ao texto em que explica suas conceções sobre evolução da cultura humana. Na primeira linha (Fig. 1 - Fig 4) notamos a progressão de formas mais simples para mais complexas. Esse tipo de arranjo foi reproduzido nas monstras da exposição do museu em Oxford. Fonte: PittRivers, A. Lane-Fox. 1906 [1875]. On the evolution of culture. In J. L. Myres ed., The evolution of culture and other essays. Oxford: Clarendon Press, Plate IV.

Inserido no proposto subpadrão museográfico "Séries Evolutivas / Progressistas", identificamos exposições em que o curador agrupa os objetos de diversas regiões geográficas e os classifica de acordo com seus critérios relacionados à semelhança hereditária [INDICADOR 15, Tabela 3] (Tony Bennett, 2004; Richards, 1993). Nesse contexto, o objeto (ou espécime) é uma evidência, que 
serve de testemunho e oferece reconhecimento das pressuposições e pressupostos dos curadores científicos [INDICADOR 11, Tabela 3] (Delicado, 2008; Dias, 1994) (Figura 3).
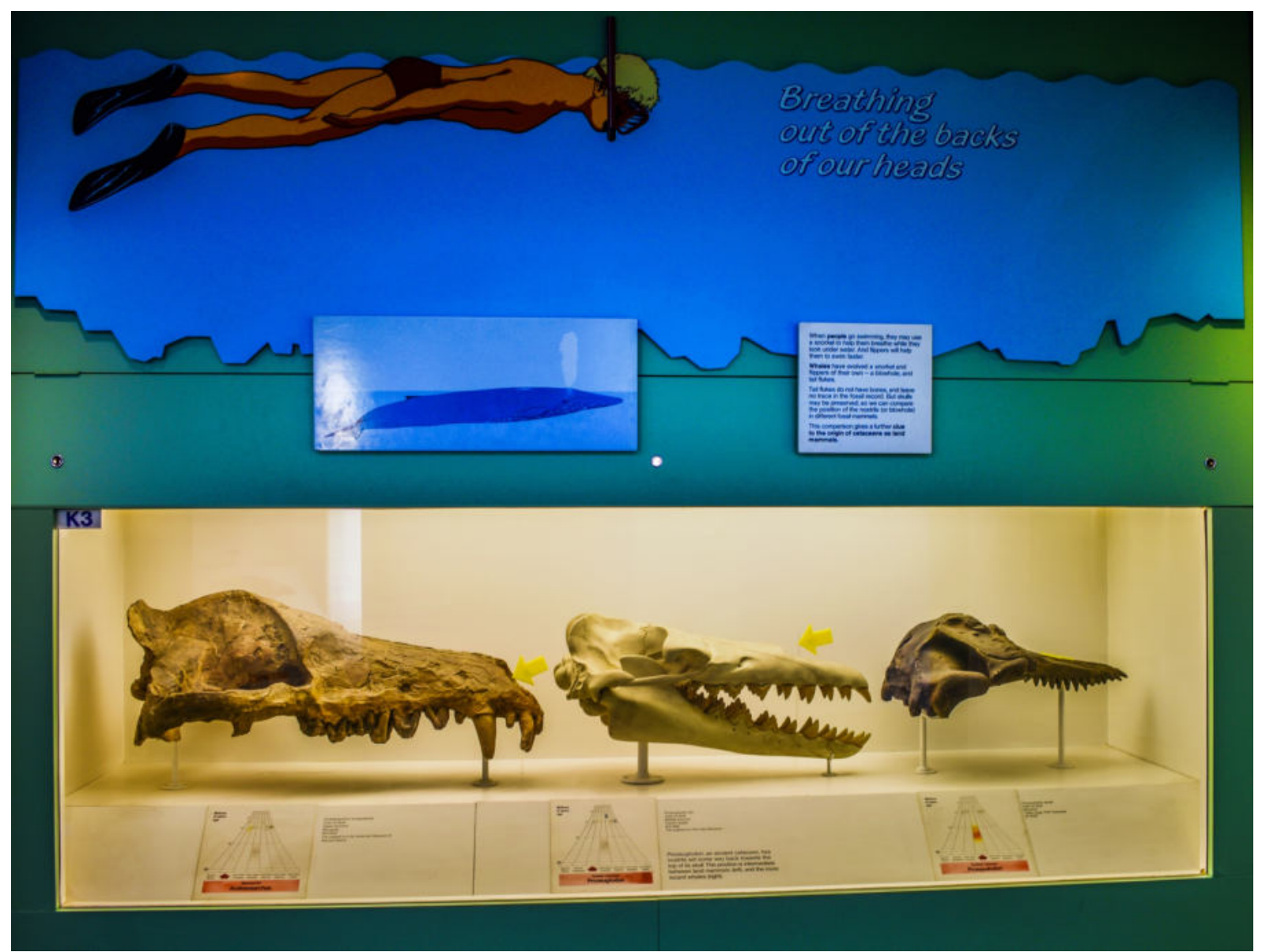

FIGURA 3: Exemplo que identificamos como representante do subpadrão museográfico "Série Evolutiva/Progressista” na exposição Mammals, do NHM. Na sequência de réplicas de crânios fósseis de ancestrais das baleias é apontado o deslocamento da abertura nasal, com o mais antigo a esquerda e o mais recente a direita. Foto: Mariana Galera Soler, visita técnica em Maio de 2018.

Propomos também como um exemplo elucidativo desse subpadrão museográfico o projeto original do Museo de La Plata. Francisco Moreno foi o primeiro diretor e concebeu o plano da instituição considerando o desenvolvimento de dois tipos de coleções: uma série destinada a exibição pública e outra para ser utilizada por estudiosos e especialistas, seguindo as ideias do britânico William Flower e seu discurso de 1889 (Farro, 2009).

O Museo de La Plata iniciou suas obras em 1894, com os conteúdos das salas organizados a partir de um espiral, composto por quinze salas que se comunicam entre si, sendo a primeira destinada aos recursos minerais (matéria inanimada) e culminando em uma sala de osteologia 
comparada de mamíferos (no rés de chão; o segundo andar do edifício foi destinado as salas de antropologia e etnologia) (Podgorny, 1995).

\begin{abstract}
"Dicho plan consiste en desarrollar el cuadro mas completamente posible de la Naturaleza, en la parte Sud-Americana y principalmente Argentina, según los métodos de la ciencia moderna, y reunir en sus galerías, sin solución de continuidad, a través de las edades geológicas, las formas tangibles de la vida en las regiones citadas"
\end{abstract}

(Notas sobre o Museo de La Plata (Marzo 1885), Archivo Histórico del Museo de La Plata, LCC 1, f7 - 24 apud Farro, 2009)

Para além da hereditariedade, uma das essenciais inovações metodológicas das ciências do século XIX foi considerar a temporalidade nas análises, o que pode ser exemplificado pelos estudos estratigráficos e biogeográficos. Isso também está refletido na museografia das séries evolutivas: numa sequência linear, o tempo é traduzido num contínuo de eventos únicos e organizados [INDICADOR 13, Tabela 3] (Tony Bennett, 1995; Tony Bennett, 2004).

O reconhecimento dos fósseis como formas de vida extintas e relacionados às formas presentes dentro das árvores evolutivas, estendeu as séries evolutivas para o passado profundo (Richards, 1993). Também no espaço do museu, o visitante é convidado a observar o desenvolvimento linear e único de ideias [INDICADOR 12, Tabela 3]. Embora o sentido estimulado seja a visão, o visitante ao andar por galerias organizadas em Séries Evolutivas Progressistas é motivado a transcender o tempo e o espaço dos objetos para situar-se no atemporal, analítico e abstrato espaço museal (Dias, 1994).

No entanto, há um aspeto característico no tempo e espaço “musealizados” nas exposições evolutivas, desde a segunda metade do século XIX: a acumulação de objetos a partir de diferentes locais possibilitou que essas instituições pudessem propor novas perceções do tempo. Os acervos de museus permitem superar a distância temporal e espacial. Contudo, justificam o que está ausente no presente pela sua ocorrência há muito tempo ou por estar localizado longe. Nessa estratégia, há uma sobreposição entre o que está distante com o passado, em uma rede de pressupostos que correspondiam a distância da Europa com a Pré-História. Tais pressupostos foram aplicados tanto a história natural como a antropologia e podem ser exemplificado pelas explorações marítimas inglesas no Pacífico, que permitiam aos europeus "to overcome both space and time in bringing back 
the past - the living past of form of life that were extinct in Europe - from faraway" (Tony Bennett, 2004, p. 22).

Tony Bennett (2004) resume:

"The telling of each time in the form of a unilinear developmental sequence provided the conditions for their amalgamation in a totalising narrative, in which the history of the earth supplied the master time which calibrated the histories of life on earth, and those of human civilisations, cultures and technologies" (Tony Bennett, 2004, p. 24)

Considerando que as séries evolutivas iniciais buscavam conectar formas de vida umas às outras dentro de sequências de descendência linear (portanto, progressistas), algumas das formas consideradas "monstruosas" poderiam também ser recuperadas como ancestrais, entendidos como elos de sequências evolutivas, integrados a uma ordem científica [INDICADOR 12; INDICADOR 15, Tabela 3]. O mesmo aconteceu com o exótico: o canguru, bem como outros elementos da fauna australiana, deixaram de ser uma "maravilha" ou "exótico" descobertos pelos exploradores europeus, e foram enquadrados dentro de um estágio dentro da evolução dos mamíferos (Tony Bennett, 2004; Richards, 1993). Em resumo: "the order of things went from being the order of ordered things to being the order of all things that had ever existed" (Richards, 1993, p. 48).

A influência darwiniana na museografia ficou registrada na organização dos objetos dentro de grupos únicos organizados de modo a evidenciar a evolução dentro de uma família ou categoria taxonómica mais elevada [INDICADOR 10, Tabela 3] (Whitehead, 1971). Nas primeiras décadas do século XX, o ambiente museológico estava significativamente reorganizado, não mais como os museus do lluminismo, quando a racionalidade da ordem da natureza que era exibida, mas de acordo com a sequência, direção e temporalidade do desenvolvimento da diversidade (Tony Bennett, 2004).

No entanto, cabe destacar que as séries evolutivas ou as séries tipológicas de Pitt Rivers eram carregadas de estereótipos e preconceitos e muitas vezes não se adequavam a todas as audiências dos museus, especialmente as classes trabalhadoras. Chapman (1985) cita que:

"Despide Pitt River's hopes that typological arrangements might close working class mind to 'scatter-brained revolutionary ideas', one suspects that those three hundred local agricultural workers (...) may have been attracted more by exotic animals and band concerts than by typology" (Chapman, 1985, p. 43). 
Nos EUA, no final do século XIX, ainda eram vistas séries de animais e plantas dentro de categorias taxonómicas, mas ordenadas internamente de modo a refletir uma visão evolutiva progressista daqueles grupos. A maioria dos objetos estava disposto numa associação lógica com outros grupos taxonómicos (ou sequências tecnológicas, no caso de instrumentos e máquinas). Cada espécime ou artefacto tinha que ser cuidadosamente identificado por uma etiqueta escrita e cada vitrina possuía um pequeno ensaio fornecendo uma visão geral daquela montra (Henson, 2017).

Exemplificado pelo United States National Museum, os museus estadunidenses para cumprir sua função educativa entendiam que cada espécime deveria ser identificado e posicionado em relação a espécimes similares. Goode, que se tornou um dos mais influentes profissionais de museus estadunidenses na virada do século XIX - XX, em "The Principles of Museum Administration”, evidencia tal importância: "a small exhibition series, complete within its own limits, systematically arranged, fully labeled and effectively displayed, is far more useful than a vast collection exhibited without reference to its teaching power" (Goode, 1895, p. 40).

Assim, ainda no século XIX, o surgimento de novas representações e disciplinas do conhecimento científico relacionadas à história natural alteram profundamente a epistemologia dos museus científicos. A teoria darwiniana é, talvez, o mais notável desenvolvimento do período, mas os avanços na Biologia Celular e a criação do termo "ecologia" também foram fundamentais e trouxeram novas luzes para as práticas científicas e museológicas (Delicado, 2010a).

A tabela abaixo sintetiza as características que identificam as exposições cuja museografia representa as séries evolutivas/progressistas. Cabe destacar que esse subpadrão museográfico (nem os demais) não substituiu as Séries Taxonómicas (Tabela 3). De modo que podem ser identificadas exposições com acervos organizados em categorias lineanas, e dentro desses grupos serem dispostos de acordo sua relação ancestral-descendente. 


\begin{tabular}{|c|c|c|c|c|}
\hline \multirow{7}{*}{ 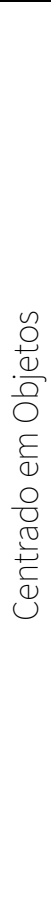 } & $\begin{array}{l}\mathrm{N}^{\circ} \text { do } \\
\text { Indicador }\end{array}$ & $\begin{array}{l}\text { Subbadrão } \\
\text { Museográfico }\end{array}$ & Indicador & Autor - Fonte \\
\hline & 10 & $\begin{array}{l}\text { Séries } \\
\text { Evolutivas / } \\
\text { Progressistas }\end{array}$ & $\begin{array}{l}\text { Grupo de organismos organizados para demonstrar sua } \\
\text { evolução ou hierarquia dentro de grupos taxonómicos } \\
\text { superiores }\end{array}$ & Whitehead, 1971 \\
\hline & 11 & $\begin{array}{c}\text { Séries } \\
\text { Evolutivas / } \\
\text { Progressistas }\end{array}$ & $\begin{array}{l}\text { Espécimes organizados em classificações únicas, } \\
\text { representando o resultado final de uma investigação }\end{array}$ & $\begin{array}{l}\text { Delicado, 2008; Dias, } \\
1994\end{array}$ \\
\hline & 12 & $\begin{array}{c}\text { Séries } \\
\text { Evolutivas / } \\
\text { Progressistas }\end{array}$ & $\begin{array}{l}\text { Espécimes organizados de modo que reflitam uma } \\
\text { narrativa progressista e linear }\end{array}$ & $\begin{array}{l}\text { Silverstone, 1992; Dias, } \\
\text { 1994; Chapman, } 1985\end{array}$ \\
\hline & 13 & $\begin{array}{l}\text { Séries } \\
\text { Evolutivas / } \\
\text { Progressistas }\end{array}$ & Organização do espaço de acordo com a temporalidade & $\begin{array}{l}\text { Bennett, 1995; Bennett, } \\
2004\end{array}$ \\
\hline & 14 & $\begin{array}{c}\text { Séries } \\
\text { Evolutivas / } \\
\text { Progressistas }\end{array}$ & $\begin{array}{l}\text { O arranjo de objetos encaminha o olhar do visitante ao } \\
\text { longo dos estágios evolutivos (horizontalidade } \\
\text { histórica) }\end{array}$ & $\begin{array}{l}\text { Dias, 1994; Delicado, } \\
2010\end{array}$ \\
\hline & 15 & $\begin{array}{c}\text { Séries } \\
\text { Evolutivas / } \\
\text { Progressistas }\end{array}$ & $\begin{array}{l}\text { Apresentação de semelhança entre as espécimes como } \\
\text { resultado da descendência comum }\end{array}$ & $\begin{array}{l}\text { Bennett, 2004; Richards, } \\
1993\end{array}$ \\
\hline
\end{tabular}

Tabela 3: Tabela que resume os indicadores que definem o subpadrão museográfico "Séries Evolutivas / Progressistas", que serão aplicados na análise das exposições estudadas nesse trabalho.

\subsubsection{Dioramas}

"Whereas a single museum object is an instance of reality, a diorama is a depiction of reality" (Reiss, 2015, p. 287).

Um subpadrão museográfico que convive com os demais e ainda hoje é um dos mais emblemáticos associados aos museus de história natural é a composição de exposição de exposição por dioramas, ou Subpadrão Museográfico Dioramas.

Em museus de história natural, os dioramas são representações tridimensionais de paisagem animais, que incluem espécimes reais e/ou modelos artificiais de animais, em combinação com pinturas de fundo e elementos naturais ou artificiais (rochas, solo, vegetação etc.) [INDICADOR 17 e INDICADOR 21, Tabela 4] (Asensio \& Pol, 1996). Entretanto, o significado do termo "diorama" mudou ao longo do tempo, desde pequenas caixas de papelão (como os dioramas de papel japoneses Tatetonka) até as instalações sofisticadas e artísticas presentes nos museus contemporâneos (Kamcke \& Hutterer, 2015). 
O termo "diorama" foi inicialmente utilizado como mais uma das ofertas de entretenimento do século XIX, inspirado nos panoramas. Embora com grande sucesso, os panoramas eram considerados demasiadamente estáticos. Em 1822, Louis Daguerre, um dos principais nomes da fotografia do século XIX, inaugurou um espetáculo popular chamado "diorama", onde os espectadores mantinham-se sentados em uma sala escura, enquanto assistiam uma grande pintura feita em tela opaca ou translúcida, que permitia a passagem da luz, criando a noção de movimento e vida, mudando formas, iluminação e $\operatorname{aspetos}^{16}$. O diorama de Daguerre, bem como outros entretenimentos populares como coleções de curiosidades e mostras de som e luz, ou seja, as maravilhas da técnica para instrução pública e recreação social, influenciaram exposições e museus históricos e museus científicos, ao longo do século XIX (Kamcke \& Hutterer, 2015; Tresch, 2017).

Ainda é incerto como o uso do termo "diorama" foi apropriado para as montagens com objetos tridimensionais em museus e, possivelmente, nos museus de história natural os dioramas não possuam uma origem única (Kamcke \& Hutterer, 2015). No contexto europeu (especialmente na Suécia), seu desenvolvimento foi influenciado pela "beleza pitoresca", pela ideia filosófica do "sublime e belo" e foi um caminho para observar as paisagens com o olhar de um artista que desejava extrair e organizar os componentes do belo, desde o mundo natural até formar um objeto de maravilhamento dentro de um museu (Tresch, 2017).

Wonders (1989) traz uma perspetiva diferente para o contexto estadunidense. A autora relaciona a presença e o crescimento do número de dioramas nos museus de história natural dos EUA, nas décadas finais do século XIX, como um movimento dos museus em busca de audiências e educação popular. Tal movimento é corroborado por outros autores como Conn (1998), Henning (2006), Magnin (2011) e Rader e Cain (2014).

Esse movimento é exemplificado por, em um primeiro momento, grandes museus comprarem dioramas, ou seja, montagens artísticas realizadas fora dos museus e da sua "autoridade científica", mas de reconhecido grande apelo popular. A primeira montagem adquirida e exposta nos EUA foi "Arab Courtier Attacked by Lions", criada pelos irmãos naturalistas e taxidermistas franceses Edouard Verreaux e Jules Verreaux, para a Exposição Internacional de Paris (1867), onde foi

16 Mais informações sobre o histórico e o funcionamento do diorama de Daguerre estão disponíveis em: http://cultureandcommunication.org/deadmedia/index.php/Daguerre\%27s_Diorama. Acesso em 24 de Novembro de 2018. 
premiada. Esse diorama foi inicialmente adquirido pelo AMNH, em 1869, e depois passou ao Carnegie Museum of Natural History, onde está em exposição desde $1899^{17}$ (M. Henning, 2006; Wonders, 1989).

Os contextos diferentes que promoveram a utilização dos dioramas nos EUA e Europa referem-se também ao histórico dos museus dessas regiões e seu papel social. Enquanto na Europa os museus são fruto das coleções reais, ménageries, prestigiados gabinetes e forma de exaltação de um passado humano de glórias (grandes navegações, conquistas de territórios e civilizações, exaltação do poder bélico e de qualidades ilustradas do belo, como nas pinturas e esculturas), nos países do Novo Mundo, tanto os EUA como na América Latina, os museus fazem parte do processo de construção de uma identidade que se afirma nos recursos naturais e na descoberta das riquezas do território. Embora os museus europeus e americanos sejam um dos produtos da maquinaria dos Estados-Nação do século XIX, a conceção de nação e de origem é discrepante: enquanto os europeus afirmam uma visão antropo-europocêntrica no controle dos demais povos e territórios, os países do Novo Mundo constituem sua identidade a partir dos recursos naturais, da afirmação de um território rico e diverso. Nitidamente, quando a América importa o modelo europeu de museus, também produz uma instituição que responde as demandas dos investigadores e autoridades do Velho Mundo, funcionando de índex das riquezas dos seus territórios para os estrangeiros.

Ademais, nos EUA, considerando que os espécimes eram exibidos convencionalmente os arranjos taxonómicos, pois julgava-se atender a uma ordem racional, ou as séries evolutivas como posicionamento dos espécimes (e dos visitantes) no tempo e espaço, outros tipos de museografia, como os dioramas, inicialmente eram vistos como dificuldade por aquelas instituições que buscavam legitimação como instituições científicas. A aquisição desse diorama de uma feira internacional por um importante museu científico estadunidense refletiu a primeira aceitação oficial dos museus científicos de montagens espetaculares (Holzmeyer, 2012; Wonders, 1989).

Os dioramas também refletiram mudanças nas práticas científicas e museológicas dos museus de história natural. Nyhart (2009) afirma o papel decisivo dos curadores científicos no

17 Esse diorama passou por um profundo processo de restauro nos anos 2016/2017, que foi acompanhado pelos medias, especialmente após a descoberta de restos humanos na representação de um homem árabe, presente nessa montagem. Um exemplo é a reportagem "Museum's 'Arab Courier Attacked by Lions' has a real human skull", feita por Karen Graham, em 27/01/2017, disponível em http://mww.digitaljournal.com/tech-and-science/science/museum-s-arab-courier-attacked-by-lions-has-a-real-humanskull/article/484609. Acesso em 7 de Dezembro de 2018. 
controle e definição do posicionamento espacial e conceitual do acervo e conteúdos dos museus, nos museus alemães ao longo do século XIX e XX. No final do século XIX, com a profissionalização dos curadores, agora homens com diploma universitário, bem integrados às redes profissionais de zoólogos e botânicos, cada vez mais os conteúdos passaram a ser biológicos e integradores e não apenas classificatórios (Nyhart, 2009).

Magnin (2011) e Van-Praet (2004) consideram dois fatores fundamentais para a ampla utilização dos dioramas em museus de história natural: desenvolvimento da Ecologia como campo científico e a separação das coleções, em coleções para investigação e coleções destinadas à exposição.

Quanto ao surgimento da especialidade da ecologia, o termo "oekologie" foi proposto em 1866, por Ernst Haeckel, e reunia conhecimentos que permitiam a melhor compreensão da relação entre organismos e seus ambientes. O termo foi inicialmente associada à "economia da natureza" (proposição lineana sobre as funções utilitárias dos organismos) e mesmo a teoria evolutiva, uma vez que Charles Darwin também discutia a interação e compartilhamento de indivíduos e espécies num mesmo ambiente (Gay, 2013). No entanto, as pesquisas iniciais em Ecologia eram baseadas em descrições estáticas de associações entre diversos tipos de organismos e ambientes, ganhando novas perspetivas apenas a partir de 1960 (Mayr, 1998).

No que diz respeito a separação entre as coleções, Kolher (2006) também associa essa prática e a utilização dos dioramas, com importantes mudanças na política de aquisição de acervos e na promoção de expedições científicas para além do continente europeu, no final do século XIX. De acordo com o autor, a melhora das práticas de museografia e de preservação das coleções, exigiu espécimes melhores do que aqueles que já estavam nas antigas reservas. Com isso, curadores científicos e profissionais de museus tinham um forte argumento para realizar expedições científicas por eles organizadas, ao invés da compra de espécimes de amadores, coletores comerciais ou recolha de doações: somente as equipas dos museus sabiam quais as necessidades da mais moderna taxonomia, os dados necessários aos estudos emergentes da Ecologia e à aplicação das novas técnicas de museografia.

Além disso, considerando-se que apenas alguns espécimes iam para a exposição, taxidermistas e outros profissionais dos museus ganharam mais tempo para refinar suas técnicas, o que novamente reafirmava a necessidade desses profissionais realizarem o trabalho de campo: 
exposições que recriavam o ambiente em vida dos animais (como os dioramas) exigiam peles frescas, cuidadosamente preparadas (o que não necessariamente era encontrado nos comerciantes e nos coletores locais); grupos de animais precisavam ser coletados juntos (especialmente famílias) e ao mesmo tempo (para evitar haver variações entre estações do ano, por exemplo) [INDICADOR 22, Tabela 4]; outros elementos de suporte dos dioramas precisavam ser coletados, como rochas, solo e plantas, de modo a garantir ilusão visual e a autenticidade do diorama [INDICADOR 21, Tabela 4]. Também, como os dioramas representavam um local particular em determinado momento [INDICADOR 25, Tabela 4], os profissionais de museus precisavam observar e coletar dados da localidade, fazer desenhos, fotografias e anotações de campo (Kohler, 2006; Karen Ann Rader \& Cain, 2014).

Numa outra perspetiva, se os administradores e patronos dos museus queriam dioramas alinhados com as técnicas mais modernas (demanda do mecenato - patronos das instituições e das audiências), eles tinham que investir em trabalhos de campo e expedições gerenciados por suas próprias equipes científicas, mais do que a simples aquisição inicialmente feita (Kohler, 2006).

De acordo com Conn (1998), embora o diorama tenha introduzido o espetáculo popular nos museus, como ciência, em alguns aspetos já nasceu atrasado. Conn (1998), seguido por Henning (2006), argumenta que, pelo menos nos EUA, os dioramas assinalavam mais as mudanças de museus com um compromisso com a educação popular, no início do século XX, do que com os avanços científicos. Os autores associam o investimento público em exposições de museus de alto custo, como os dioramas, com o afastamento dos museus estadunidenses das pesquisas correntes experimentais e com foco nas formas e funções - que passavam a ser hospedadas nos laboratórios universitários.

A partir desse argumento, Henning (2006) discute os dioramas como forma de museografia que transforma os visitantes de produtores ativos de conhecimento (a partir de séries e arranjos diversos dos organismos), em recipientes de ideias e conhecimentos já formados. Nas palavras de Reiss (2015): "dioramas are usually snapshots: they are a moment frozen in action, so visitors can view, ponder and look again" (Reiss, 2015, p. 287).

Outro aspeto histórico relevante a ser considerado nos dioramas é sua relação com a caça. Wonders (1989) mostra que entre as formas artísticas de taxidermias populares desde o final do 
século XVIII e ao longo do XIX e que influenciaram os dioramas, os troféus de caças contribuíram para manter um mercado ativo.

Além disso, grandes expedições científicas realizadas por museus, no final do século XIX e início do XX, foram financiadas por uma elite masculina de caçadores desportistas (Haraway, 1984). A caça está relacionada com a afirmação do poder antropológico sobre os grandes territórios selvagens, sendo os seus "troféus" (peles, bustos, cornos, entre outros) as evidências da bravura dos caçadores e domínio de territórios. Theodore Roosevelt é o exemplo mais emblemático no patrocínio de expedições e como os espécimes coletados marcaram as exposições do AMNH (Haraway, 1984; M. Henning, 2006; Kohler, 2006).

Contudo, os sofisticados dioramas contemporâneos são resultado de várias formas de montagens com animais que foram utilizadas e aprimoradas. Inicialmente, eram conhecidos os "grupos artificiais", apresentações de paisagens particulares com grupos de animais de diferentes espécies, em número e contextos biológicos não-naturais (Kamcke \& Hutterer, 2015). Exemplifica-se com as taxidermias e montagens criadas por Walter Potter, na Era Vitoriana, e registradas pelo livro "Walter Potter's Curious World of Taxidermy", publicado pelo biógrafo de Potter e especialista em taxidermia Pat Morris, em 2013.

Os "grupos geográficos" organizam animais e plantas de um determinado ambiente ou região geográfica em um mesmo espaço, ainda sem grande preocupação em criar a ilusão de realidade. Enquanto os "grupos biológicos" representam grupos de animais e plantas em seu habitat, porém sem imagens ao fundo, não criando a ilusão de uma paisagem natural. Frequentemente estão protegidos dentro de caixas de madeira ou por vidros e representam uma parte da natureza, como se tivesse acabado de ser tirado do ambiente (Figura 4) (Kamcke \& Hutterer, 2015). 

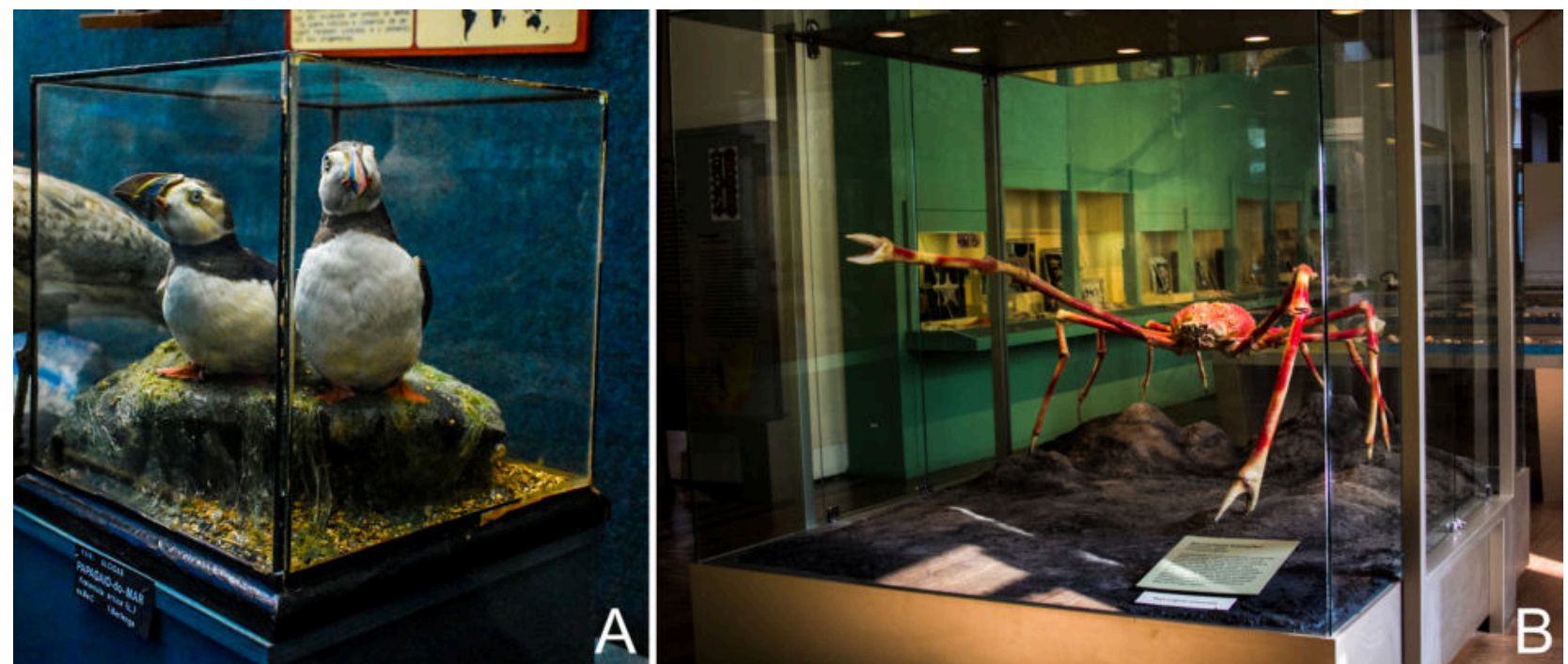

FIGURA 4: Exemplos de grupos biológicos, ainda presentes em exposições contemporâneas. Em A, dois papagaiosdo-mar estão taxidermizados e dispostos como se estivessem em seu ambiente natural. Exposição da "Sala Nova", Aquário Vasco da Gama. Foto: Mariana Galera Soler, durante realização de trabalho de apoio a nova museografia do espaço, em Novembro de 2018. Em B, um caranguejo-gigante (Macrochereia kaempferi) disposto como se estivesse em vida andando pelo solo marinho do Pacífico Oeste. Exposição "Conchas, Corais e Borboletas", Museu Nacional do Rio de Janeiro. Foto: Mariana Galera Soler, visita técnica em Agosto de 2018.

Os "dioramas de habitats" são o resultado do desenvolvimento dos "grupos biológicos", acrescidos de um fundo, geralmente curvo, com uma pintura naturalista (ou, mais recentemente, fotografia ampliada) [INDICADOR 17, Tabela 4], iluminação coerente com o ambiente (dramática) e diferenciada do restante da sala [INDICADOR 19; INDICADOR 26, Tabela 4], componentes dos ambientes naturais, como animais, plantas, rochas, solo entre outros [INDICADOR 21, Tabela 4], e buscam relacionar os animais com os ambientes em que vivem e seu comportamento (clima, relevo e flora) [INDICADOR 24, Tabela 4] (M. Henning, 2006; Kamcke \& Hutterer, 2015; Kohler, 2006; Karen Ann Rader \& Cain, 2014).

Carl Akeley, taxidermista, caçador e escultor estadunidense, foi o pioneiro nesse tipo de representação, no início do século XX. Ele iniciou esse tipo de trabalho profissionalmente Milwaukee Public Museum (Milwaukee, EUA). Em 1902, sua montagem de quatro cenários de uma família de cervídeos ao longo de um ano intitulado "Four Seasons" (ainda exposto no Field Museum of Natural History, em Chicago) é considerado o primeiro "diorama de habitats" produzido para um museu (Kamcke \& Hutterer, 2015; Wonders, 1989). Akeley terminou sua carreira no AMNH, onde deixou seu principal legado: 28 dioramas de ambientes africanos no Akeley Hall of African Mammals, que são 
amplamente ovacionados pelo público e por alguns profissionais de museus (Quinn, 2006). Ressaltase que esses dioramas de habitat também são objeto de análise crítica, como o trabalho seminal de Donna Haraway (1984), que ao discutir como as escolhas dos espécimes em campo, o próprio trabalho de campo e a composição das posturas em vida dos grupos animais evidencia valores do patriarcado, a eugénia e a preservação de determinadas espécies. Em sua análise as relações de poder relacionado ao género, raças e classes sociais estavam implícitas no "monumental reproduction of the Garden of Eden" (Haraway, 1984, p. 20).

Ao longo desse trabalho, ao utilizarmos o termo "diorama (termo mais corrente na literatura), referimo-nos aos "dioramas de habitats”, definidos por Kamcke e Hutterer (2015).

No início do século XX, os dioramas eram também um ponto focal de tensão entre os profissionais de museus, representando a oposição entre museografias sistemáticas ou cênicas, pesquisa ou educação pública, uma visão racional ou maravilhamento, e mesmo entre a verdade e a imaginação seja no contexto europeu (Nyhart, 2009), como décadas depois no estadunidense (Karen Ann Rader \& Cain, 2008, 2014).

Mesmo como montagens elaboradas e a busca pela fidelidade com a natureza, Reiss (2015) afirma que os dioramas podem ser metaforicamente comparados com as telenovelas: os factos que ocorrem nelas todos os dias que, na realidade, acontecem apenas ocasionalmente. A sensação transmitida remete ao "Jardim do Éden": não há doença ou desnutrição; os animais são inevitavelmente mostrados no auge da saúde e da aptidão física: "a diorama is a metaphor for reality not a faithful depiction of it. Metaphors can illuminate but they need to be examined and talked through, otherwise they can seduce unwittingly" (Reiss, 2015, p. 288).

Também não há sinais de presença humana e a paisagem parece intocada, nos dioramas mais tradicionais (M. Henning, 2006) [INDICADOR 18, Tabela 4]. Cabe a ressalva de que essa conceção dos dioramas aplica-se melhor a realidade estadunidense (Karen Ann Rader \& Cain, 2008, 2014), uma vez que Nyhart (2009) demonstra que os dioramas em museus europeus, especialmente nas instituições alemãs, respondem a diferentes agendas e representavam, principalmente, a natureza e suas diferentes relações com a humanidade.

No final dos século XIX, os profissionais de museus tinham como desafio capturar e manter a atenção dos visitantes, diante do problema da acumulação de objetos e das impressões fugazes e espetaculares da modernidade. A introdução de exibições imersivas, miméticas e ambientais, como 
o diorama e a reconstrução histórica, foi uma tentativa de conter a distração e produzir uma atenção extasiada. Movendo as exposições para "dentro" das paredes, o museu encorajava o visitante a ser seletivo e focado, bem como as vitrinas das lojas foram projetadas para prender a atenção do transeunte na rua ${ }^{18}$. As galerias com dioramas possuíam espaços vazios em coloração neutra [INDICADOR 20, Tabela 4] e os dioramas com iluminação destacada e dramática [INDICADOR 19, Tabela 4], exigiam alterações arquitetónicas, como a utilização de vidros curvos e tetos rebaixados [INDICADOR 26, Tabela 4] (M. Henning, 2006; Karen Ann Rader \& Cain, 2014).

O crescimento em escala e complexidade dos dioramas aconteceu especialmente até os anos 1920. Para tanto, administradores de museus contrataram designers de montras de lojas e decoradores de interiores, como consultores das exposições, e artistas e designers que apoiavam os departamentos de produção na construção de sinaléticas e efeitos ilusórios dos espaços (M. Henning, 2006; Karen Ann Rader \& Cain, 2014). Já no final da década de 1910, os dioramas estadunidenses tornaram-se visualmente mais dramáticos, com espécies em expressões e posicionados de modo a provocar associações antropomórficas [INDICADOR 23, Tabela 4] (Karen Ann Rader \& Cain, 2014).

Embora custosos, os diretores de museus acreditavam que os dioramas aumentavam as audiências e permitiam a educação pública, de forma inconsciente. Testemunhavam a crença compartilhada entre diretores, curadores, técnicos e designers de que a trivialidade da experiência humana diante de descrições holísticas da natureza, ou melhor, em face a sua precisa replicação [INDICADOR 16, Tabela 4], pudesse promover suporte público para conservação, simpatia aos animais e exploração dos recursos naturais (Karen Ann Rader \& Cain, 2014).

Desse modo, os dioramas tornaram-se um dos pilares das exposições biológicas até a primeira metade do século XX, quando começaram a ser considerados desatualizados (conceitualmente e esteticamente) (Paddon, 2014; Karen Ann Rader \& Cain, 2008, 2014). Aliado a isso, os grandes investimentos económicos e laborais para sua construção passaram a colocar em causa

${ }^{18}$ A técnica de museografia que mais se assemelham como uma montra de uma loja são os dioramas: ambos produzem uma oscilação entre a proximidade e a distância, entre querer entrar na cena e ou ficar seguro fora dela, algo que é encorajado pelo uso compartilhado de um vidro laminado que separa o objeto de desejo (ou curiosidade) e o consumidor, a utilização de modelos tridimensionais e a iluminação (M. Henning, 2006). As aproximações entre a museografia e o design de lojas são temas de debate constante na literatura, a partir da publicação de Tony Bennett (1995). 
os outros pilares dos museus científicos: salvaguarda e investigação dos acervos. Apesar dos diretores expressarem que nos museus estadunidenses a investigação deveria ter um papel superior, os custos da museografia e dos programas educativos nas primeiras décadas do século XX não permitiam a divisão dos recursos de modo igualitário, levando a conflitos internos e questionamento dos investigadores (Karen Ann Rader \& Cain, 2008, 2014).

Contudo, abordagens educacionais baseadas em hands-on (interatividade), impulsionadas pelas visitas de curadores e investigadores estadunidenses aos museus europeus - destacadamente ao Deutsches Museum (Munique, Alemanha) e as feiras internacionais, propiciaram um ambiente de intensa crítica às exposições estáticas da natureza. Questionava-se a forma, para além do conteúdo que mostrava-se desfasado em relação às investigações mais inovadoras das primeiras décadas do século XX (Etologia, Genética, Ecologia, principalmente) (Karen A. Rader \& Cain, 2014).

Mesmo que ainda presente nos museus de história natural, o que se observa desde os anos 1950 são exposições com grandes dioramas, similares aos dos anos 1920 - 30, eventualmente com o acréscimo de animais vivos (biodioramas), legendas mais explicativas ou inclusão de multimédias (Karen A. Rader \& Cain, 2014) (Figura 5).

Um fator fundamental para a manutenção desse subpadrão museográfico é seu sucesso em termos de audiência, como evidenciado por Asensio e Pol (1996), e seu papel educativo, como descrito por Ash (2004). O histórico e a função educativa dos dioramas são temas da coletânea de trabalhos presentes na publicação "Natural history dioramas: history, construction and educational role", organizada por Tunnicliffe (2015). Ademais, essas montagens são mantidas pois, uma vez que ocorra o desmantelamento dessa museografia, ocorre a perda de sua integridade como obra artística (Paddon, 2014), tornando o subpadrão museográfico Dioramas embora com mais de um século de existência, um dos padrões mais reconhecidos entre as exposições dos museus de história natural. 


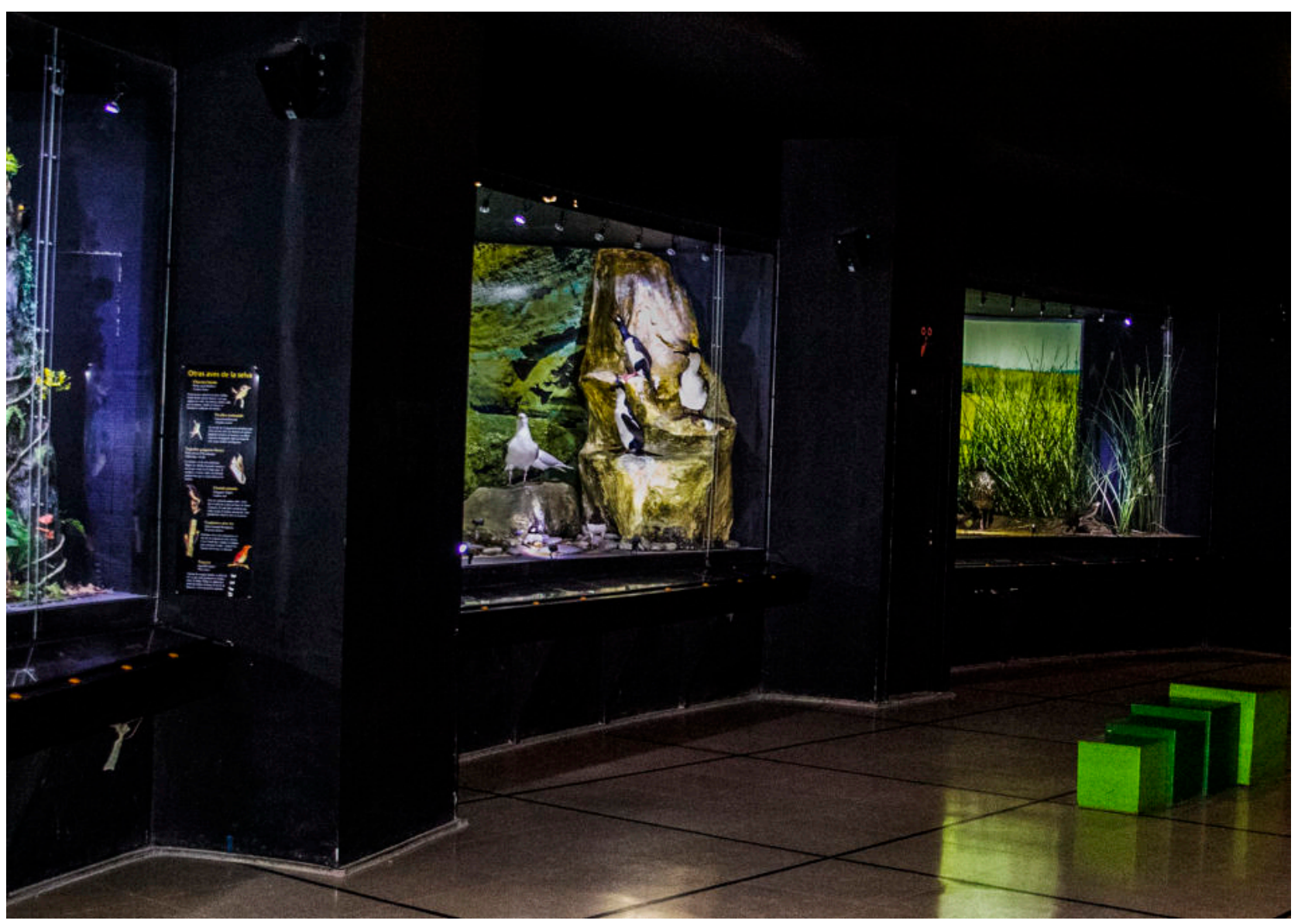

FIGURA 5: Dioramas inaugurados em 2012, para a exposição Las Aves, no Museu Argentino de Ciencias Naturales Bernardino Rivadavia (Buenos Aires, Argentina). Os dioramas estão inseridos nas paredes negras do segundo módula dessa exposição. Foram utilizadas taxidermias históricas da instituição, com os animais dispostos em cenários mais modernos, com ampliações fotográficas ao fundo, iluminação focada e as legendas possuíam botões (na barra abaixo dos dioramas é possível identifica-los por sua cor laranja) que acionavam um sistema de som (detalhe no canto superior direito das divisórias dos dioramas), reproduzindo o canto de cada ave. Painéis laterais traziam informações adicionais, como por exemplo a função do canto das aves ou características peculiares do ambiente representado. Foto: Mariana Galera Soler, obtida durante visita técnica em Fevereiro de 2014 


\begin{tabular}{|c|c|c|c|c|}
\hline \multirow{12}{*}{ 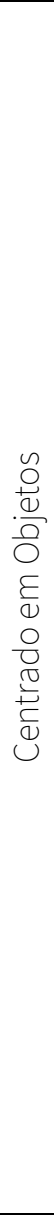 } & $\begin{array}{c}\mathrm{N}^{\circ} \text { do } \\
\text { Indicador }\end{array}$ & $\begin{array}{l}\text { Subpadrão } \\
\text { Museográfico }\end{array}$ & Indicador & Autor - Fonte \\
\hline & 16 & Dioramas & Descrições holísticas do mundo natural & Rader e Cain, 2014 \\
\hline & 17 & Dioramas & $\begin{array}{l}\text { Pintura de fundo (ou fotografias) paisagens que } \\
\text { permitem a noção de um espaço aberto ou } \\
\text { profundidade }\end{array}$ & $\begin{array}{l}\text { Rader e Cain, 2014; Kamcke } \\
\text { e Hutterer, } 2015\end{array}$ \\
\hline & 18 & Dioramas & $\begin{array}{l}\text { Representação da natureza intocada e em perfeita } \\
\text { harmonia (ausência do componente humano) }\end{array}$ & Henning, 2006; Reiss, 2015 \\
\hline & 19 & Dioramas & $\begin{array}{l}\text { Busca concentrar atenção do visitante, com } \\
\text { iluminação destacada do restante do espaço }\end{array}$ & $\begin{array}{l}\text { Henning, 2006; Rader e } \\
\text { Cain, } 2014\end{array}$ \\
\hline & 20 & Dioramas & $\begin{array}{l}\text { Busca concentrar atenção do visitante, com paredes } \\
\text { ao redor com coloração neutra }\end{array}$ & $\begin{array}{l}\text { Henning, 2006; Rader e } \\
\text { Cain, } 2014\end{array}$ \\
\hline & 21 & Dioramas & $\begin{array}{l}\text { Composição elaborada com elementos reais como } \\
\text { animais, plantas, rochas etc. }\end{array}$ & $\begin{array}{l}\text { Rader e Cain, 2014; Kamcke } \\
\text { e Hutterer, 2015; Kohler, } \\
2006\end{array}$ \\
\hline & 22 & Dioramas & $\begin{array}{l}\text { Espécimes representam ações de grupo ou } \\
\text { dinâmicas familiares, como cuidado parental }\end{array}$ & $\begin{array}{l}\text { Rader e Cain, 2014; Kohler, } \\
2006\end{array}$ \\
\hline & 23 & Dioramas & $\begin{array}{l}\text { Espécimes com expressões e posicionados de modo } \\
\text { a provocar associações antropomórficas }\end{array}$ & Rader e Cain, 2014 \\
\hline & 24 & Dioramas & $\begin{array}{l}\text { Relaciona a importância das relações entre os } \\
\text { organismos e o ambiente (clima, relevo e flora) }\end{array}$ & $\begin{array}{l}\text { Rader e Cain, 2014; Kohler, } \\
2006\end{array}$ \\
\hline & 25 & Dioramas & Representa um local específico & $\begin{array}{l}\text { Rader e Cain, 2014; Kohler, } \\
2006\end{array}$ \\
\hline & 26 & Dioramas & $\begin{array}{l}\text { Iluminação diferenciada e alterações arquitetónicas } \\
\text { para melhorar a iluminação (vidros curvos e tetos } \\
\text { rebaixados) }\end{array}$ & $\begin{array}{l}\text { Henning, 2006; Rader e } \\
\text { Cain, } 2014\end{array}$ \\
\hline
\end{tabular}

Tabela 4: Tabela que resume os indicadores que definem o subpadrão museográfico "Dioramas", que serão aplicados na análise das exposições estudadas nesse trabalho.

\subsection{Centrado numa narrativa}

"It was only in the context of late-nineteenth-century evolutionary thought that this gallery structure was translated into a regulative principle that was at work within each of the histories organised by a range of disciplinary museums, and across the relations between them. Dead things had not, of course, been absent from earlier museum contexts. The Muséum National d'Histoire Naturelle under Cuvier's direction was, like the natural history collections of the British Museum under Richard Owen, Hunter's earlier anatomical collections, and William Macleay's 'vicious circles', full of dead things. These were not, however, arranged in accordance with a narrative itinerary"

(Tony Bennett, 2004, p. 23) 
Conn (2010) discute o papel os objetos nos museus ao longo do século XX. De acordo com o autor, no final do século XIX os museus eram concebidos primariamente como lugares para expor objetos, enquanto já virada do século XXI foi possível imaginar museus sem nenhum objeto. De acordo com o autor, diferentes tipos de museus demandam diferentes tipos de objetos e os utilizam de formas diferentes. Todavia, de modo geral, as exposições mais recentes fazem uso de menos objetos. Houve uma mudança de estratégia: museus do final do século XIX usaram a estratégia da abundância visual como suporte para qualquer história que eles queriam contar. Ao longo do século XX, os visitantes são solicitados a examinar em detalhe, mas em menos quantidade, os objetos (Conn, 2010).

Como apresentado no padrão museográfico anteriormente descrito ("Centrado em objetos”), os diferentes arranjos em que os objetos eram dispostos (séries taxonómicas ou evolutivas/progressistas ou dioramas) estavam associados à diferentes práticas científicas e museográficas. A separação das coleções científicas e acervos para exposição também foi fundamental para proposição de novos usos dos objetos em exposição, uma vez que cada vez menos objetos concentravam mais abordagens possíveis (M. Henning, 2006).

Nas décadas finais do século XIX, a investigação pautava-se em métodos científicos cada vez mais técnicos, especializados e restritos. Além disso, com uma contínua especialização do conhecimento, o aumento do uso de tecnologias sofisticadas e escalas infinitamente pequenas ou gigantes, a ciência desenvolvida parecia ser misteriosa e para além do entendimento, embora os museus ainda mantivessem um importante papel na validação da ciência para o público (MacDonald, 1998).

Assim, embora alguns historiadores da ciência mais tradicionais argumentem que a prática científica dos laboratórios universitários substituiu a História Natural investigada nos museus, uma vez que que o desenvolvimento da biologia experimental é relativamente contemporâneo a fundação dos laboratórios universitários (por exemplo Pickstone (1994), Nyhart (19-1966). demonstrou, a partir de exemplos alemães, que o processo de desenvolvimento da História Natural e da Biologia não se trata de uma linear progressão entre campos de conhecimento e instituições. A viragem do século XIX - XX representou um momento complexo, em que houve a diversificação dos espaços de investigação, bem como especialização de algumas áreas anteriormente reconhecidas apenas como História Natural. Kraft e Alberti (2003) corroboram Nyhart (1996) a partir de exemplos ingleses, 
demonstrando que as transformações da Biologia nas últimas décadas do século XIX foram graduais e não-uniformes, dependendo de ações particulares e contextos locais. Eles demonstram que nesse período museus e laboratórios universitários coexistiam e realizavam investigação e ensino: "The reference to the museum and lab traditions as 'equal though different' gives some sense of how far both were valued, at both the institutional level and throughout the emerging profession" (Kraft \& Alberti, 2003, pp. 229-230).

Pickstone (2001), revisando trabalho anterior (Pickstine, 1994), também considera essa uma noção exagerada pois, embora "laboratory biology" tornou-se hegemónica no século XX, a História Natural nunca desapareceu. A segunda metade do século XIX é a grande época dos museus científicos e, mesmo as grandes instituições universitárias desse período, como Oxford e Cambridge, tinham em seus edifícios espaços destinados para museus, onde as principais práticas estavam associadas a História Natural (Pickstone, 2001).

Ademais, os investigadores que trabalhavam em grandes museus de história natural mantinham-se como referências em pesquisas de campo, como Ecologia, Paleontologia e Sistemática. Por vezes ainda estendiam suas pesquisas para Genética, Fisiologia Experimental e Comportamento Animal, especialmente devido aos novos investigadores integrados aos museus, agora com formação superior e parcerias com os laboratórios universitários (Nyhart, 2009).

Em outra perspetiva, desde o final do século XIX os museus eram vistos como "una obra de enseñanza", cujo poder não residia apenas na posse e exposição dos objetos, mas na ação combinada das palavras e das exposições (García \& Podgorny, 2001). Os museus científicos do século XX basearam-se na ênfase em educação pública, colocando-se como especialistas na mediação entre o mundo "exotérico" da ciência e o público.

O discurso de William Flower sobre o papel dos museus como instituições de pesquisa e instrução/ educação pública, apontou o caminho que a ser seguido pelas exposições ao longo do século XX:

"certain propositions to be illustrated, either in the structure, classification, geographical distribution, geological position, habits, or evolution of the subjects dealt with, will be laid down and reduced to definite and concise language. Lastly will come the illustrative specimens, each of which as procured and prepared will fall into its appropriate place” [INDICADOR 27; INDICADOR 29, Tabela 5] (Flower, 1898, p. 18) 
Desde o século XIX os museus operavam sob a arquitetura intelectual de que os objetos permitem o acesso ao conhecimento, possuindo significados próprios desde que observados e estudados cuidadosamente ${ }^{19}$, o que Conn (1998) identificou como "object-based epistemology". Enquanto o museu do final do século XIX buscava dar sentido a um mundo industrial e darwiniano, colocando-o dentro de vitrinas de vidro e organizadas em fileiras de prateleiras lineares, o museu das primeiras décadas do século XX pretende ensinar a relatividade do universo de Einsten (Conn, 1998).

O visual - que se manifestava por objetos - já não era mais considerado uma forma única e confiável de prova, o que significava que a função de museu de fornecer "verdade visual" estava seriamente comprometida. A premissa sobre a qual se basearam os museus e as exposições científicas - olhar os objetos como um caminho robusto para as ciências e tecnologia - tornou-se precária em um mundo governado por eletromagnetismo, relatividade e mecânica quântica (Conn, 1998). Em síntese, o papel dos museus difere daquele predominante anteriormente. Busca não apenas tornar a ciência legível por evidências materiais e seus princípios subjacentes, mas representar a ciência: não simplesmente mostrar ou dizer, mas interpretar (MacDonald, 2004).

Além disso, tais interpretações são centradas no visitantes [INDICADOR 28, Tabela 5] e personalizadas ao público, por exemplo com exposições que dizem "Seu Corpo" ou "Compras", ao invés de títulos apenas com termos científicos [INDICADOR 31, Tabela 5] (MacDonald, 1998).

Assim, se nas primeiras décadas do século XX, os dioramas mesmo que custosos e exigentes de intenso trabalho laboral recebiam grandes elogios e eram considerados permanentes, décadas depois pareciam "fora de moda". Marcadamente após os anos 1930, as equipas dos museus, especialmente estadunidenses, assumiram que os dioramas e os esqueletos de dinossauros, embora populares, falhavam em transmitir os conceitos mais modernos das ciências da vida ${ }^{20,21}$ (Karen Ann Rader \& Cain, 2014).

\footnotetext{
${ }^{19}$ Numa perspetiva diferente do que será abordado no padrão museográfico "Retorno à curiosidade", que tem como referenciais as afterlives de Alberti (2011) ou a história social das coisas de Appadurai (1986), e que será descrito mais à frente.

20 Entretanto, mesmo já desacreditados por parte dos pesquisadores mais jovens, os dioramas ajudaram a manter os museus dos EUA abertos durante a Grande Depressão, pois ainda havia o mecenado de associações de caça que financiavam expedições e exposições (Karen Ann Rader \& Cain, 2014).

${ }^{21}$ Ainda a partir dos anos 1930, os museus de arte e os acervos antropológicos estadunidenses passaram a mudar suas exposições, buscando incorporar padrões e instalações mais estéticos e inspirados nas exposições das vanguardas soviéticas dos anos 1920 - 30 do
} 
A história natural parecia ter poucas conexões com os avanços e preocupações científicos mais divulgados e que receberam mais investimentos desde o período entre guerras: produção industrial bélica, novas tecnologias militares, micróbios e antibióticos (Karen Ann Rader \& Cain, 2008). Não apenas a museografia, mas os conteúdos científicos apresentados pelos museus de história natural pareciam cada vez mais desatualizados. Nos dioramas, as visões esteticamente agradáveis e organizadas da natureza pouco retratavam as investigações sobre a interação entre o ambiente e os organismos e soluções científicas mais contemporâneas para as crises naturais e ambientais. A separação dos acervos científicos em reservas técnicas e coleções de exposição também tirou "das vistas" dos visitantes os objetos de investigação. A literatura traz exemplos que tanto nos museus de história natural estadunidenses (R_ader_ \&_Cain_ 2014) como os alemães (Nyy_hart, 20092), havia um hiato entre o que estava em exposição e os temas de investigação. Evidencia-se o divórcio entre a investigação dos bastidores e o modo de representação da ciência nos museus (Conn $19 \underline{9}$ 요).

Ainda nesse momento histórico, os debates sobre as exposições relacionadas à Biologia estavam centradas na habilidade e responsabilidade do museu em responder as mudanças dramáticas da ciência e da educação pública do período. Nos EUA, a educação científica era matéria cívica necessária e as exposições de museus de história natural deveriam explicar conceitos da Biologia moderna, como a Ecologia ou destacar das aplicações das ciências no quotidiano, com foco em Agricultura, Medicina e Biologia Humana: A Saúde da nação dependia de cidadãos propriamente educados sobre ciência (Karen Ann Rader \& Cain, 2014).

Antes de transformações drásticas na museografia, entre as mudanças que começam a ser registadas no final dos anos 1930, é significativo o aumento do número de programas educativos nas atividades desenvolvidas pelos museus e a contratação e especialistas em educação. A crença na habilidade dos objetos em comunicar mensagens de forma clara e transparente estava desgastada. Nas palavras de Conn (2010) "the objects needed help. As educational programming grew in

que os arranjos baseados em categoria de matérias, tecnologias humanas ou culturas (em uma lógica tipológica e classificatória, como os museus científicos). Alfred Barr, a frente do Museum of Modern Art (MoMA) e um dos mais influentes curadores de museus dos EUA da primeira metade do século XX, foi um dos nomes fundamentais ao reconhecer a museografia como criação estética e autônoma (Staniszewski, 2001). 
institutional importance, objects receded" (Conn, 2010, pp. 25-26). No contexto desse estudo, podemos exemplificar com o primeiro setor educativo de museus no Brasil data de 1927, e foi

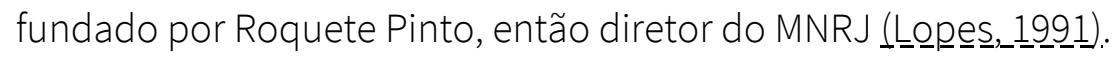

Foram também experimentadas soluções intermédias. Rader e Cain (2014) apontam exemplos pontuais de exposições sobre comportamento animal realizadas no AMNH por Frank E. Lutz (entomólogo) e Gladwyn Kingsley Noble (herpetólogo), nas décadas de 1930-40. Os investigadores não se opunham totalmente aos dioramas, uma vez que poderiam expor noções ecológicas, como cadeia alimentar, mas os consideravam demasiadamente estáticos. Então, Lutz propôs a construção dos biodioramas, em que os animais vivos eram apresentados em montras que recriavam o seu ambiente natural, dentro da exposição do museu (esse tipo de museografia já era conhecido nos menageries e zoológicos, desde o início do século XIX). Além disso, também propôs exposições ao ar livre e itinerantes, em que ele poderia realizar suas investigações (escolhendo sítios de interesse) e ao mesmo tempo mostrar aos visitantes como a ciência é feita, destacando o papel dos insetos na natureza.

Noble seguiu outro caminho, entusiasmado com o uso da tecnologia associado à investigação e a exposição (Karen Ann Rader \& Cain, 2014). O herpetólogo partiu de seus estudos em endocrinologia e neurologia e propôs aparatos interativos, sendo um deles uma caixa sonora que reproduzia o som da cauda de uma cascavel, quando os visitantes apertavam o botão (Myers, 2000). Embora Rader e Cain (2014) utilizem esses como exemplos museográficos pontuais e de pouca circulação em uma fase de transição dos museus de história natural, essas duas formas de museografia foram observadas em exposições do Museu do Instituto Butantan (São Paulo, Brasil), nos anos 1950-60 (Almeida, 1995).

Conn (2010) aponta quatro questões associadas a redução de objetos nas exposições: (i) a reorganização dos espaços dos museus, com a separação do espaços públicos e espaços reservados para pesquisa; (ii) com um menor número de objetos, os objetos em exposição são exigidos a contar mais histórias e menos oportunidades para histórias alternativas competirem (as galerias de museus abarrotadas de objetos certamente transmitiam uma narrativa, mas com tantos objetos preenchendo nosso campo visual, talvez houvesse mais espaço para o acidental ou não-intencional para os visitantes); (iii) o menor número de objetos em museus aponta também a ascensão da profissão de curador, sobre a relação entre curadores de museus e outros profissionais dentro dos 
mesmos campos disciplinares, e sobre a perspetiva das histórias que os museus contam; e (iv) os museus do século XX já possuem menos espaços para a exposição de objetos e os mais antigos tiveram espaços adaptados para a construção de lojas de suvenirs (por exemplo, no Natural History Museum - NHM - a inserção do esqueleto de baleia azul no teto do Hintze Hall deixou o espaço térreo livre, onde foi colocado um quiosque para venda de produtos e caixas para arrecadação de donativos (Soler et al., 2018), cafés temáticos, restaurantes de alta gastronomia (como por exemplo - Great Court Restaurant, no British Museum) e suportar outros espaços devotado para outras funções que não de expor objetos.

Para além das questões relacionadas à epistemologia e representação de práticas científicas e museológicas em exposições, outros fatores interferiram nas transformações da museografia dos museus de história natural na primeira metade do século XX. Por exemplo, regista-se que a Grande Depressão nos EUA de 1929 e a II Grande Guerra erodiram as principais fontes de financiamento para a ciência não diretamente associada a indústria bélica nos EUA e Europa (Pickstone, 2001; Karen Ann Rader \& Cain, 2008).

Se os museus estadunidenses tiveram seus picos de público e financiamentos nas primeiras décadas dos século XX (as décadas finais do século XIX representam o apogeu dos museus científicos europeus), a partir de 1930, as equipas financiavam seu trabalho solicitando doações e buscando patronos. Como os museus de história natural eram instituições comprometidas com a educação pública, muitos curadores viam-se forçados a dedicar seus escassos recursos - dinheiro, tempo e espaço - à captação de recursos, supervisão da preparação de elaborados dioramas ou comunicando informações científicas básicas ao público, ao invés de dedicarem-se a investigação (Karen Ann Rader \& Cain, 2008).

Os obstáculos materiais e financeiros também são relatados por Urbain e Rude (1948) nas coleções de história natural francesas, o que dificultava a renovação de seus espaços expositivos:

\footnotetext{
"(...) Natural History museums will have to modernize the arrangement of the galleries of the Paris Museum, and to five advice on museum operation to provincial institutions.
}

This is a particularly difficult task at a time when material and financial conditions are so unfavorable. (...) The fundamental principle on which the arrangement of natural 
Science Museums, like that of art and science museums, should be based, is the separation of materials which is to be exhibited to the public from series of duplicates and of items without exhibition interest. (...) Our exhibition halls are as a rule too crowded with specimens and the really interesting exhibits are nor shown to advantage"

(Urbain \& Rode, 1948, pp. 111-112)

No contexto português, Nunes (2016) registra na figura de Artur Ricardo Jorge (1886 - 1974), diretor do Museu Bocage (coleções zoológicas e antropológicas que foram integradas ao atual Museu Nacional de História Natural e da Ciência da Universidade de Lisboa) (1927 - 1956), as práticas científicas e culturais de Portugal no período entre guerras:

"É pois na dinâmica de um Congresso Nacional, em 1941, com modelo de funcionamento internacional que o Diretor do Museu Bocage apresenta um relatório intitulado Museus de História Natural, um manifesto em torno da necessidade de Portugal ter um Museu Nacional de História Natural ligado às Universidades assente num tripé de prática museográfica: ensino - investigação - divulgação cultural cientifica"

(Nunes, 2016, p. 278)

Ricardo Jorge foi um médico e naturalista português, cuja investigação e contactos auxiliou o crescimento das coleções de história natural do citado museu (Nunes, 2016), especialmente na primeira metade do século XX. No entanto, a componente expositiva da instituição estava cristalizada desde que o museu foi anexado a Faculdade de Ciências da Universidade e Lisboa, em 1911: o museu abria ao público somente um dia por semana e não era possível distinguir o que era atividade do museu ou da Faculdade (Póvoas, Lopes, Melo, Correia, \& Alves, 2016).

O Museu Nacional do Rio de Janeiro também regista instabilidade no pós II Grande Guerra, como descrito por Aranha Filho (2011):

"Tudo leva a crer que, na trajetória do Museu, há uma rutura sem precedentes nos anos da Segunda Guerra Mundial. Ocorre aí uma mudança de figura, uma descontinuidade no curso do instituto" 
(Aranha Filho, 2011, p. 49)

“(...)[sobre a gestão de Heloísa Alberto Torres, entre os anos 1938 - 1955] Entenda-se bem, não quero dizer que não havia coleções expostas, arrumadas em vitrines limpas e etiquetadas, em salas franqueadas à visitação do público geral. Sim, elas estavam expostas. Na verdade, havia até coleções demais à mostra. Era um excesso de vitrines e de espécimes por vitrine, frequentemente inúmeros exemplares repetidos ou semelhantes de uma mesma espécie taxonómica, e, já no final da década de 30, com o acúmulo explosivo de novas aquisições, não seria raro encontrá-los já um tanto amontoados, obstruindo-se mutuamente e disputando uma nesga da visão dos visitantes. Eaí é que está o problema. Não se tratava de uma exposição propriamente, nos termos que nos acostumamos a conceber, montada a partir de um roteiro intencional e em que cada objeto apresentado cumprisse uma função narrativa. (...) Ali, nos corredores de visitação, o que se mostrava eram os depósitos da casa, organizadas por critérios estritamente classificatórios e para uso de especialistas"

(Aranha Filho, 2011, p. 50)

Diante de um contexto global de transição, incluindo as instituições museológicas, os museus de ciência e de tecnologia passaram a distanciar-se dos museus de história natural, sendo que os primeiros experimentavam mais livremente diferentes formas de museografia e buscando ativamente financiamento junto a indústria e comércio (Pickstone, 2001; Karen Ann Rader \& Cain, 2014). O Palais de la Décoverte, inaugurado em 1927, deliberadamente omitiu coleções permanentes de objetos e sua pesquisa, coleta e conservação, dedicando-se exclusivamente à educação pública (até a palavra "museu" foi omitida de seu nome). Ainda anterior, mas como modelo fundamental dos objetivos institucionais voltados a educação pública, exposições esvaziadas de objetos mas que ofereciam oportunidades de toque ou mesmo operar equipamentos, são as exposições do Deutsches Museum, inaugurado em 1903 (Friedman, 2007).

Nos EUA, Museum of Science and Industry (Chicago) foi uma influência inicial dessa nova abordagem. Inaugurado em 1933, a instituição também representa uma clara influência do Deutsches Museum, um exemplo que o magnata Julius Rosenwald (patrono da instituição) trouxe a partir de sua visita a Europa, dez anos antes. O diretor contratado por esse magnata foi um editor do 
jornal New York Times, Waldemar Kaempffert. Kaempffert possuía controle dos conteúdos e do processo curatorial e, para desempenhar suas funções, realizou uma viagem de quatro meses para visitar os museus científicos europeus em Londres, Viena e Munique e conhecer as técnicas mais modernas de museografia. Depois dessa imersão, a decisão da instituição estadunidense foi de abordar apenas princípios científicos, descobertas recentes e aplicações da ciência no quotidiano (Karen Ann Rader \& Cain, 2014).

Este modelo não foi prontamente aceito, mas contou com o apoio das exposições industriais que, em formato de grandes feiras internacionais, mostravam dramaticamente novas tecnologias e as "maravilhas" dos fenômenos científicos, e permitiam a participação do público (Friedman, 2007).

Temas biológicos estavam presentes nos museus de ciências e da industria, porém focados em biologia experimental e aplicada, variando para biologia celular, microrganismos, desenvolvimento e genética humana, comportamento animal e química hormonal. Tal abordagem desencadeou a resposta de alguns museus de história natural, com a instalação de exposições similares ou idênticas aos museus de ciências, embora não tivessem qualquer conexão com as pesquisas realizadas nessas instituições, como questões relacionadas a saúde humana (Karen Ann Rader \& Cain, 2008).

Um exemplo icónico é a Transparent Woman, um aparato expositivo comum em exposições europeias nos anos 1930, que utilizava sons eletrônicos e luzes para demonstrar o funcionamento dos principais órgãos humanos (Karen Ann Rader \& Cain, 2008) (Figura 6). Esse aparato foi desenvolvido e exibido nos anos 1930 no Deutsches Hygiene-Museum, em Dresden. Chegou aos EUA, sendo inicialmente exposta na Chicago World's Fair, em 1933-34, depois adquirida Museum of Science and Industry (Chicago). Nos anos 1950, o German Health Museum, em Colônia, passou a produzir esse objeto em escala comercial, sendo adquirida pelo Cleveland Health Museum, o primeiro museu dedicado a temática da saúde dos EUA, ainda em 1950 (Janes, 2016); pelo AMNH, em 1951; e pelo Museum of Applied Arts \& Science (Austrália), em 1954 (Dicker, 2007). 


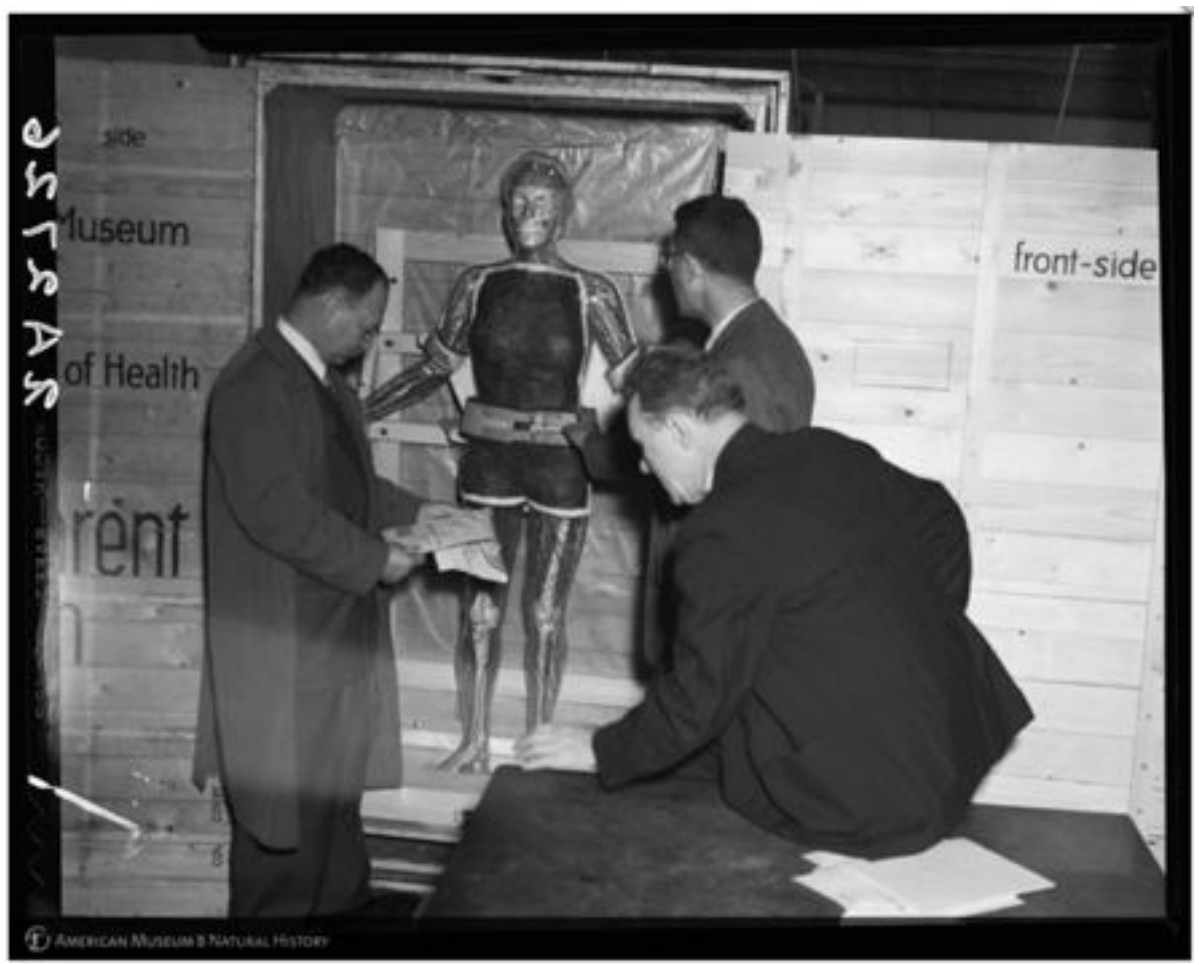

FIGURA 6: Imagem do recebimento da Transparent Woman do German Health Museum (Colônia) para a construção do Biology of Man Hall, no AMNH, em 1951. Fonte: Digital Special Collections. Department of Library Services. American Museum of Natural History. Disponivel em: http://lbry-web007.amnh.org/digital/index.php/items/show/46153. Acesso em 9 de Abril de 2019.

Com o final da II Grande Guerra, os contextos institucionais, políticos e sociais dos museus de história natural eram muito diferentes do início do século XX: os investigadores formavam um grupo de profissionais universitários que traziam novas práticas aos museus; a erosão dos orçamentos públicos exigia a busca por outras fontes de financiamento e patronagem da investigação e das exposições ${ }^{22}$; e a consolidação do caráter público e educacional institucional. No caso da América Latina, destaca-se também a manutenção do caráter nacionalista que marcava os museus do século XIX (Lopes \& Podgorny, 2000).

Nyhart (2009) descreve a virada do século XIX - XX e as primeiras décadas do século XX como um momento de forte transformação dos museus de história natural da Alemanha, indicando os

22 Enquanto Pickstone (2001) fala do grande desenvolvimento dos complexos tecnocientíficos no pós-II Grande Guerra, o que tornou a compreensão pública da ciência como um objetivo corporativo, Rader e Cain (2008) descrevem como a disputa pela divisão do orçamento dos museus estadunidenses entre os anos de 1930 - 1968 refletiu e contribuiu para o processo de negociação do papel dos museus deveriam ter em relação a produção da ciência e seus públicos, promovendo discussões fundamentais sobre o papel da investigação e relação dos museus com seus públicos. 
novos investigadores, homens com formação universitária e parceria com laboratórios experimentais, também nas universidades, como um dos fatores fundamentais para a mudança destas instituições. Aranha Filho (2011) descreve como a mudança da legislação trabalhista brasileira e a necessidade de novos concursos para investigadores do Museu Nacional do Rio de Janeiro, na segunda metade da década de 1930, trouxe para a instituição um corpo de investigadores mais especializado, além do surgimento de novas especialidades na instituição (anos antes), como a Educação em museus e a Museologia.

Outro fator relevante dessa transição é a contratação de outros novos profissionais para os museus: uma nova geração designers, contratados para desenvolver exposições para diversas audiências e reforçar o papel educacional dos museus de história natural (especialmente PósSputnick, em 195723). Esses novos profissionais ficavam a cargo da museografia das exposições, mas possuíam pouca ou nenhuma experiência em trabalho de campo, o que era até então profundamente compartilhado pela estética dos taxidermistas e artistas responsáveis pelos dioramas nas primeiras décadas do século XX (como bem caracterizado na figura de Carl Akeley, descrita por Quinn, 2006, como um naturalista, caçador e também artista) (Karen Ann Rader \& Cain, 2014). Ao invés disso, referenciavam-se nas artes, arquitetura, design industrial e comunicação, alterando a ordem epistemológica severa e orientada das vitrines e quadros imutáveis propostos por académicos, cedendo espaço a uma variedade infinita de forma e géneros discursivos (Magnin, 2011).

A ausência de objetos ou a presença necessariamente contextualizada de objetos em exposições construídas sobre narrativas também é uma influência de áreas da comunicação e da Museologia. Neste sentido, é marcante nos museus o uso de pictogramas e gráficos, que refletem o influxo dos princípios do ISOTYPE (International System of Typographic Picture Education), ou método de Viena, uma linguagem iconográfica simples para museus, proposto pelo filósofo da ciência e sociólogo Otto Neurath, diretor do Gesellschafts - und Wirtschaftsmuseum, em 1925 (atualmente Wirstchaftsmuseum)(Perks, 2015).

${ }^{23}$ Logo após o lançamento do Sputnik pela União Soviética, em 1957, a melhora no ensino de ciências passou a ser uma questão fundamental para os EUA. Diretores de museus de ciências e de história natural aproveitaram esse momento para abordar o papel da educação não-formal em seus espaços (Karen Ann Rader \& Cain, 2014). 
Nos museus científicos, destacamos com um importante exemplo desse novo padrão museográfico a grande reforma da museografia do NHM, na década de 1970, coordenada por Roger Miles e intitulada New Exhibition Squeme (NES): "The Natural History Museum developed a new "Exhibition Scheme" with the broad aim of solving the problems caused by the narrow conceptual basis of the old exhibits and their outmoded approach to the diffusion of knowledge" (R. S. Miles \& Tout, 1978, p. 39).

Processo detalhadamente descrito por Corral-Guillé (2015), em que as novas exposições substituíram de forma significativa os objetos das coleções científicas por modelos e dispositivos interativos e as etiquetas tornaram-se um elemento secundário, naquele momento inseridos numa narrativa simples sobre um tema contemporâneo, ilustrada por alguns espécimes escolhidos ${ }^{24}$. Tais mudanças ocorreram em resposta a uma série de transformações políticas, económicas e culturais britânicas: cortes do financiamento governamental, a perceção de que o museu estava obsoleto à respeito dos avanços da Biologia e da irrupção do movimento ambientalista, além do questionamento da instituição como uma opção cultural e de lazer em Londres (Corral-Guillé, 2015). As relações entre esse processo de reestruturação das exposições e a influência de Otto Neurath são discutidas por Perks (2015).

Nas décadas de 1950 e 1960, designers de exposições dos principais museus estadunidenses utilizavam o suporte das narrativas, alegando que o valor dos espécimes estava em sua habilidade única de ilustrar ideias científicas e que são efetivos apenas se inseridos em uma narrativa estruturada $^{25}$ [INDICADOR 27, Tabela 5]. Dessa forma, os museus deveriam estar atentos às necessidades dos visitantes [INDICADOR 28, Tabela 5] e apresentar objetos e coleções de modo contextualizado e significativo.

Em suma, esse movimento baseado em temas e narrativas era mais mental, cujas abordagens narrativas e por temas ofereciam explicações explícitas e didáticas [INDICADOR 30, Tabela 5] (Karen Ann Rader \& Cain, 2014).

${ }^{24}$ A exposição "Human Biology - an exhibition ofourselves" inaugurou esse processo de transformação da museografia do NHM, em 1977, e continua aberta para visitação na instituição: https://umw.nhm.ac.uk/visit/galleries-and-museum-map/human-biology.html . Acesso em 26 de Dezembro de2018.

${ }^{25}$ Nota-se que esta visão ainda é mantida em exposições de museus de história natural contemporâneos, como demonstrado por Soler e Landim (2017). 
Esses múltiplos fatores levaram a predominância de padrões museográficos baseados em narrativas nos museus de história natural, de modo que essas instituições se tornaram meios e as histórias sobre ciência a sua mensagem (Karen Ann Rader \& Cain, 2014).

As abordagens narrativas, que já eram faladas desde o início do século XX, ganharam especial espaço a partir da sua segunda metade daquele século e algumas temáticas possuem características particulares de serem "museografadas". Nos próximos tópicos discutiremos como narrativas associadas às questões ambientais, à inserção da ciência no quotidiano e aos princípios básicos da ciência foram musealizadas nas exposições de museus de história natural.

\begin{tabular}{|c|c|c|c|c|}
\hline \multirow{6}{*}{ 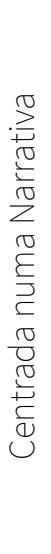 } & $\begin{array}{l}\text { No. Do } \\
\text { Indicador }\end{array}$ & $\begin{array}{c}\text { Padrão } \\
\text { Museográfico }\end{array}$ & Indicador & Autores-Fonte \\
\hline & 27 & $\begin{array}{l}\text { Características } \\
\text { comuns }\end{array}$ & $\begin{array}{l}\text { Objetos selecionados por sua capacidade } \\
\text { de ilustrar um conceito científico }\end{array}$ & Rader e Cain, 2014; Flower, 1898 \\
\hline & 28 & $\begin{array}{l}\text { Características } \\
\text { comuns }\end{array}$ & Abordagem centrada no visitante & $\begin{array}{l}\text { Rader e Cain, 2014; Miles, 2007; } \\
\text { MacDonald, } 1998\end{array}$ \\
\hline & 29 & $\begin{array}{l}\text { Características } \\
\text { comuns }\end{array}$ & $\begin{array}{l}\text { Presença de objetos necessariamente } \\
\text { contextualizados }\end{array}$ & Rader e Cain, 2014; Flower, 1898 \\
\hline & 30 & $\begin{array}{l}\text { Características } \\
\text { comuns }\end{array}$ & $\begin{array}{l}\text { Explicações explícitas das narrativas } \\
\text { propostas }\end{array}$ & Rader e Cain, 2014 \\
\hline & 31 & $\begin{array}{l}\text { Características } \\
\text { comuns }\end{array}$ & Tom personalizado na narrativa & MacDonald, 1998 \\
\hline
\end{tabular}

Tabela 5: Tabela que resume os indicadores compartilhados pelos padrões museográficos "Centrados em narrativas", que serão aplicados na análise das exposições estudadas nesse trabalho. 


\subsubsection{Subpadrão Museográfico Quotidiano}

MacDonald (2004) destaca que exposições sobre a relevância das conquistas científicas, tecnológicas e médicas para o quotidiano têm sido realizadas desde o início do século XX, utilizando diversos temas, como os transportes ou a produção de eletricidade e seus papéis na transformação da vida rotineira.

Trazer temas quotidianos para dentro das exposições também fez parte do programa educativo do Museu Nacional do Rio de Janeiro, priorizado pelo diretor Eduardo Roquete-Pinto, desde o final de década de 1920. Aranha Filho (2011) cita:

"a recomendação da atenção aos seres banais, cotidianos, pretende não é, obviamente, buscar um conhecimento igualmente banal, de segunda ordem. Visa o contrário: elevar os seres comuns, que povoam os cenários do território nacional, e normalmente desdenhados como desinteressantes, a objetos primeiros e prioritários de conhecimento"

(Aranha Filho, 2011, p. 98)

A conceção da Children's Gallery, no Science Museum londrino, ainda na década de 1930, representou também o início da utilização de temas quotidianos, como descrito por MacDonald (2002):

\footnotetext{
"Showing the role of the technologies in everyday life, albeit within a very clear narrative of technological improvement, was at the time considered a daring new dimension to Science Museum display. Although the Children's Gallery contained some objects from the Museum collections, there were by no means as many of them as in other galleries in the Museum".
}

(MacDonald, 2002, p. 29)

No entanto, os contextos e caminhos de tal abordagem mudaram significativamente nas seguintes décadas do século XX, sendo possível identificar um subpadrão museográfico focado em temas quotidianos dos visitantes de forma mais evidente e associado aos movimentos educacionais ocorridos no período entre guerras e, principalmente, pós II Grande Guerra (MacDonald, 2004). 
Nesse sentido, Rader e Cain (2014), apontam que movimento do "life adjustment", entre os anos 1940 - 1950, representou uma resposta dos museus estadunidenses ao movimento progressista na educação formal com o mesmo nome - Life Adjustment Education. Tal movimento educacional tinha por objetivo promover o conhecimento como uma ferramenta de competência cívica, melhorar a conscientização sobre questões relacionadas à saúde e promover aspetos úteis da biologia inserida no quotidiano dos cidadãos: "rather than scientific, experience to 'the better adjustment of the individual to the world around him" " (Karen Ann Rader \& Cain, 2014, p. 141). Ao ser adotado como narrativa museológica, evocava uma visão antropocêntrica do mundo [INDICADOR 33, Tabela 6], mostra aplicações direta da ciência na vida quotidiana [INDICADOR 32, Tabela 6], demonstrando a relevância científica a partir do impacto das pesquisas sendo a humanidade e suas necessidades urbanas e domésticas centrais nas narrativas [INDICADOR 36, Tabela 6].

Na década de 1940, houve a descoberta da penicilina e a devastação promovida pela bomba atômica, o que fomentou as discussões sobre a relevância da ciência para nossos futuros individuais e coletivos (Pickstone, 2001). Com o final da II Grande Guerra, os museus de ciências e os museus de história natural compartilhavam o otimismo [INDICADOR 38, Tabela 6] e a compreensão do seu potencial educativo, contudo seguiram caminhos distintos na busca pela educação científica ${ }^{26}$ (Karen Ann Rader \& Cain, 2014).

Outro movimento educacional, já no pós-guerra, que impulsionou o subpadrão museográfico "Quotidiano" foi o construtivismo²7. De acordo com Hein (1998): "A fundamental attribute of any constructivist position is the need for the learner to be able to associate an educational situation with what is already known" (Hein, 1998, p. 156).

Roschelle (1995) realizou uma importante revisão do construtivismo e aprendizagem em museus, tendo por base os principais teóricos de teoria: Jean Piaget, John Dewey e Lev Vygotsky. De

${ }^{26}$ Tal como as teorias educacionais influenciaram as exposições dos museus de história natural, as exposições tornaram-se uma contribuição única para o ensino de ciências, pois distinguiam os museus das escolas e de outros veículos educacionais. O subpadrão museográfico quotidiano, como um padrão baseado em narrativas, também foi apoiado pelos advogados da alfabetização cientifica, que consideravam as narrativas como um meio efetivo para fins educativos. Os profissionais de museus buscavam construir uma museografia que comunicassem conteúdos científicos claramente, mas que também tivessem um apelo estético e contribuíssem para os debates sobre o ensino de ciências em instituições não-formais (Karen Ann Rader \& Cain, 2014).

${ }^{27}$ O construtivismo também será uma referência fundamental para outro subpadrão museográfico, o Public Understanding of science, elaborado mais a frente no texto. 
acordo com a teoria construtivista cabe aos educadores (e, por consequência, àqueles que desenvolvem exposições) fornecerem modelos socialmente apropriados de atividades (engajados no contexto de vida dos participantes) e a promoção de atividades mais complexas do que os estudantes (ou visitantes) possam lidar individualmente (Roschelle, 1995).

Os museus de ciências investiram na interatividade e basearam sua temáticas em narrativas sobre biologia experimental e medicina humana (MacDonald, 2004). Apostava-se que as crianças e os adultos poderiam aspirar vidas mais saudáveis se entendessem mais sobre o corpo humano e os resultados das pesquisas biológicas. Tais instituições realizavam parcerias com a indústria e o comércio, que tinham interesse em promover os resultados de suas pesquisas e produtos por meio de aparatos interativos, vistos como modernos e pedagogicamente efetivos (Karen Ann Rader \& Cain, 2014).

Já os museus de história natural estadunidenses optaram por priorizar seus programas de pesquisa, especialmente com novos financiamentos federais sobre taxonomia e sistemática e o financiamento de expedições (MacDonald, 2002). Foram elaborados novos programas educacionais e expositivos, mas sem mudanças expressivas na museografia. O uso de narrativas que abordavam temas quotidianos deu-se, por exemplo, pela inserção de painéis didáticos e personalizados sobre os antigos dioramas [INDICADOR 34, Tabela 6] ou ações educativas e correspondeu a uma forma de aproximação dos museus e escolas locais.

Em 1943, Albert Parr²8 em simpósio em comemoração cinquentenário do Field Museum of Natural History (Chicago), declarou que os museus não poderiam contentar-se apenas com os dioramas e os estudos naturais, mas deveriam intensificar seus esforços em educar os americanos sobre conceitos biológicos essenciais, especialmente aqueles que vão de encontro com as suas vidas diárias. Nesse discurso, Parr aponta elementos fundamentais para narrativas expositivas que

\footnotetext{
${ }^{28}$ Albert Eide Parrfoi diretor do AMNH entre os anos de 1942 - 1959. Com formação em oceanografia e uma carreia consagrada em estudos ecológicos de Biologia Marinha, ao assumir a direção da instituição teve o foco claro em mais investir na investigação do que nas exposições, realizando várias medidas para isso: aumento do salário de pesquisadores e os orçamentos dos departamentos científicos que estivessem alinhados com a pesquisa das universidades e instituições de pesquisa (Karen Ann Rader \& Cain, 2014). Parr favoreceu as investigações que não eram baseadas em objetos e coleç̃es, na sequência daquelas que ele próprio realizava. Ele acreditava que a ecologiazoológica era mais importante do que as coleções, especialmente as coleções paleontológicas, chegando a dissolver o tradicional departamento de Paleontologia de Vertebrados (Myers, 2000). Portanto, a escolha de abordagens narrativas para as exposições, com menos objetos e apresentação de conceitos de forma explíita, também refletem a prática científica do investigador esuas escolhas como administrador do American Museum of Natural History.
} 
abordem o subpadrão museográfico Quotidiano: centralidade da espécie humana ${ }^{29}$ [INDICADOR 33, Tabela 6], promoção do estilo de vida estadunidense, ilustração de conceitos científicos básicos relacionados ao dia-a-dia [INDICADOR 32, Tabela 6] e melhoria no entendimento dos avanços e aplicações da ciência [INDICADOR 36, Tabela 6].

Tal discurso foi fortemente influenciado pelo slogan de Vaillant:

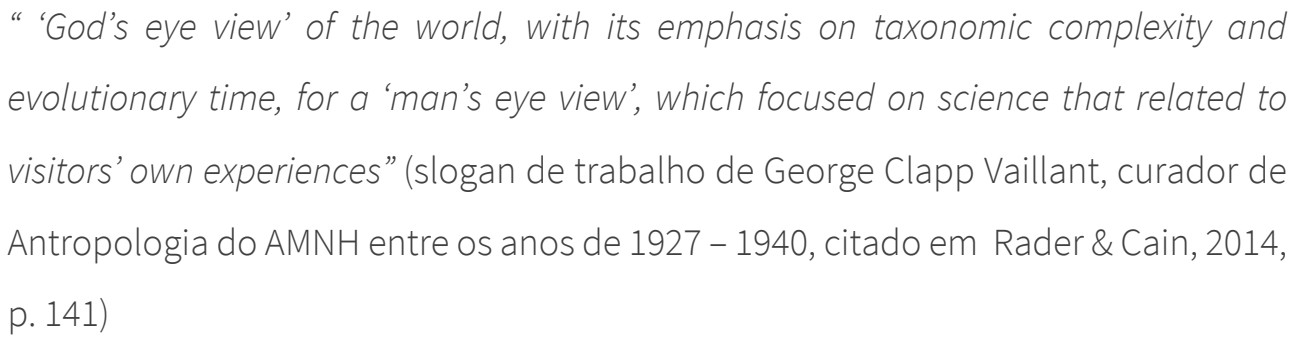

De modo que era esperado que o uso do subpadrão museográfico Quotidiano pudesse dar aos jovens perspetivas otimistas da potencialidade de ciência em transformar a sociedade em caminhos mais positivos [INDICADOR 38, Tabela 6]. Assim, esse subpadrão utilizava questões relacionadas a vida diária dos cidadãos como lentes pelas quais a ciência e a tecnologia eram apresentadas. A premissa era que a maioria dos visitantes consideravam a ciência e a tecnologia "ameaçadoras" e "difíceis", e que isso impediria seu potencial de se interessar pelos assuntos ou aprender sobre eles (MacDonald, 2004).

Em perspetiva, quando olhamos para os museus de história natural entre os anos 1940 1950, encontramos discursos mais radicais, porém práticas ainda conservadoras. Se os dioramas tinham sido determinantes para uma visão estética clara mas nem sempre uma contribuição óbvia para a educação científica e engajamento do público, a museografia do período imediatamente pósII Grande Guerra tinha objetivos educacionais claros, mas não necessariamente ainda correspondia de forma evidente as mudanças para que os museus fossem efetivamente espaços educativos (Karen Ann Rader \& Cain, 2014)

\footnotetext{
${ }^{29}$ A centralidade da espécie humana pode também ser ilustrada pelo seguinte excerto: "the life of a frog or a moose can never compete with the human organism in significant appeal to the public except insofar as the frog the moose contribute to an understanding of the human animal” (Trecho da proposta para o estabelecimento de exposições sobre Biologia Humana e Saúde Pública no AMNH, Council of Scientific Staff, December 11, 1941, destacado por Karen A. Rader \& Cain, 2014).
} 
No final dos anos 1950, os museus de ciência e os de história natural compartilhavam a convicção de que ao apresentar oportunidades de contemplar princípios biológicos, práticas e resultados das pesquisas, poderiam melhorar o entendimento das ciências dos visitantes. Embora os caminhos que estas instituições trilharam tenham sido muito afastados um do outro, dado que prioridades e abordagens pedagógicas eram distantes, os museus científicos estavam certos de que os visitantes deveriam ser expostos aos mais atuais avanços da ciência e da tecnologia e não a exposições sobre história das ciências e tecnologia [INDICADOR 36, Tabela 6] (Karen A. Rader \& Cain, 2014).

Mais recentemente, MacDonald (2004) discutiu a utilização de temas do quotidiano como uma abordagem possível para a ciência em museus. Partindo de um momento histórico mais atual ${ }^{30}$, a investigadora mostra que o subpadrão museográfico Quotidiano também pode ser apresentado por meio de experiências simples ou reproduções de ações, espaços ou objetos do quotidiano que Ihes eram mais familiares [INDICADOR 37, Tabela 6]. De modo que os visitantes podem ter acesso ao conhecimento científico como uma "consequência da visita".

Outra característica apontada pela autora é a utilização de reconstruções cenográficas de espaços e ambientes comuns [INDICADOR 37, Tabela 6] e painéis de textos explicativos [INDICADOR 34, Tabela 6]. São, assim, exposições com ambições educacionais claras e menos propensas a incluir os objetos das coleções do museu. E, quando há exibições de objetos de acervo, estes são encaixados na estrutura educativa geral [INDICADOR 39, Tabela 6] (MacDonald, 2004).

No entanto, uma crítica recorrente a esse modo de expor é que o espaço para a discussão científica tende a ficar reduzido. Quando o quotidiano é a estrutura norteadora de uma exposição, os conteúdos científicos e seus contextos tendem a ficar restritos aos textos [INDICADOR 34, Tabela 6], escritos com o uso de linguagem simples, termos familiares, rotineiros e não-especializados [INDICADOR 35, Tabela 6], de modo a gerar mais confiança no que está sendo apresentado, ao invés de estimular questionamentos sobre o que é apresentado (MacDonald, 2004).

30 Pós anos 1980 e a forte influência dos movimento Public Understanding of Science, e os science centres, discutido na sequência desse texto. 


\begin{tabular}{|c|c|c|c|c|}
\hline \multirow{9}{*}{ 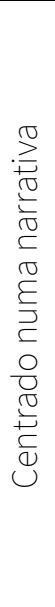 } & $\begin{array}{c}\text { No. Do } \\
\text { Indicador }\end{array}$ & $\begin{array}{l}\text { Subpadrão } \\
\text { Museográfico }\end{array}$ & Indicador & Autores-Fonte \\
\hline & 32 & Quotidiano & $\begin{array}{l}\text { Apresentar conceitos biológicos relacionados ao } \\
\text { quotidiano }\end{array}$ & $\begin{array}{l}\text { MacDonald, 2004; Rader e } \\
\text { Cain, } 2014\end{array}$ \\
\hline & 33 & Quotidiano & Visão antropocêntrica & Rader e Cain, 2014 \\
\hline & 34 & Quotidiano & Conceitos científicos comunicados por textos & MacDonald, 2004 \\
\hline & 35 & Quotidiano & $\begin{array}{l}\text { Uso de linguagem de termos quotidianos, } \\
\text { familiares e não científicos }\end{array}$ & MacDonald, 2004 \\
\hline & 36 & Quotidiano & $\begin{array}{l}\text { Explicações sobre avanços e importância da } \\
\text { ciência }\end{array}$ & $\begin{array}{l}\text { MacDonand, 2004; Rader } \\
\text { e Cain, } 2014\end{array}$ \\
\hline & 37 & Quotidiano & Reproduções cenográficas & MacDonald, 2004 \\
\hline & 38 & Quotidiano & Perspetiva otimista da ciência & Rader e Cain, 2014 \\
\hline & 39 & Quotidiano & Poucos (ou nenhum) objetos históricos & MacDonald, 2004 \\
\hline
\end{tabular}

Tabela 6: Tabela que resume os indicadores compartilhados pelo subpadrão museográfico Quotidiano, que serão aplicados na análise das exposições estudadas nesse trabalho.

\subsubsection{Subpadrão Museográfico: Ecológico}

"The word ecology is widely used today in the normative sense, not in the biological sense. The science of ecology is one that considers energy flows within a closed system. The normative sense of the word has come to mean the belief that severe or drastic change within that system, or indeed any change which can damage any species within it, or that disturbs the system, is seen as wrong" (Bramwell, 1989, p. 4)

Em sentido estrito, o termo "ecologia" está associado à ciência da Ecologia, que tem uma história específica, constituída por investigadores dentro de meios sociais e institucionais definidos. Contudo, desde que a "ecologia científica" (scientific ecology, tradução nossa) tem sido associada aos movimentos sociais - notavelmente ao movimento conservacionista do início do século XX e, mais recentemente, com o movimento ambientalista, nos anos 1960-70 - o significado original de "ecologia" tem sido aplicado em diferentes conotações (Keller \& Golley, 2000) .

O amplo uso do termo "ecologia" tem gerado confusões entre as questões relacionadas a ciência da Ecologia e um pensamento ecológico o que, por vezes, limita o campo científico a um vago sinónimo de "ambientalismo" (Keller \& Golley, 2000). Isso também decore da emergência dos movimento ambientalista e seu grande apelo mediático, quando a Ecologia passou de um campo de conhecimento estritamente académico para um tema de engajamento político e interesse público (Jamison, 2011). 
No entanto, as discussões contemporâneas da Ecologia, não fazem dela uma disciplina científica nova (Worster, 1977). Keller \& Golley (2000) nomeiam de "protoecologia" o legado do pensamento da História Natural iniciado pelos gregos, com destaque para Teofrasto, que reconheceu que a biota ativamente adapta-se ao seu redor, isto é, a adaptação não é apenas uma compulsão externa, e sim uma resposta interna do organismo as condições ambientais.

Em ensaio de 1749, Lineu considerou que todas as interações entre os organismos e o ambiente são controladas por uma precisão mecânica, desenvolvendo a ideia de harmonia e balanço da natureza, por meio da interação das espécies numa "economia da natureza” (Lopes, 2005).

Ainda nos escritos de Alexander von Humboldt são propostas relações entre clima, latitude, altitude e a distribuição das espécies na América, formulando o conceito de geobotânica, em 1805 (Cooper, 2007). Buffon e Lamarck também são considerados "protoecologistas", pois admitiam que as espécies não são categorias estáticas. Buffon reconheceu que os organismos são afetadas pelas condições ambientais em Histoire Naturelle (1749), bem como em 1809, em Philosophie Zoologique, Lamarck afirmou que as espécies mudam pela herança de características determinadas pelo uso ou desuso de órgãos de seus ancestrais (Keller \& Golley, 2000; Worster, 1977).

Contudo, apenas na metade do século XIX, origina-se a palavra ecologia - oekologie -citada pela primeira vez no livro Generelle Morphologie, de Ernst Haeckel, publicado em 1866 (Bramwell, 1989). Haeckel cunhou o termo fortemente influenciado por conceitos evolutivos darwinistas, especialmente a luta pela sobrevivência, e o conceito lineano de economia da natureza, sinalizando transformações epistemológicas para uma Biologia mais contextual e holística (Stauffer, 1957). É a partir desse trabalho que Keller \& Golley (2000) afirmam ser o início da "ecologia científica”.

Haeckel apresentou esse mesmo termo em uma série de outras publicações, fornecendo variadas definições, como descrito por Jax e Schwarz (2011). Em comum, nota-se que a Ecologia é uma parte da Biologia, muitas vezes posicionada como um desdobramento da Zoologia ou da Fisiologia ${ }^{31}$. Além disso, o investigador alemão considerava a Ecologia uma ciência preocupada com

\footnotetext{
${ }^{31}$ A posição da Ecologia como parte da Fisiologia fazia parte das investigações de Haeckel sobre a estrutura da Biologia, que era logicamente relacionada com a teoria darwiniana de evolução, na qual Haeckel extraiu insights sobre a importância das relações entre os organismos e entre os organismos e o ambiente, as quais ele chamou de “ecológicas"(Jax \& Schwarz, 2011).
} 
a fisiologia da relações entre os organismos (fluxo de energia), distinguindo-a da biogeografia, que se preocupava com a distribuição geográfica dos seres (Nucci, 2007).

Nessa etapa inicial, a enfâse dos estudos ecológicos permaneceu centrada na importância dos estudos de Fisiologia e na tentativa de implantação de metodologias experimentais para o estudo das respostas das plantas e animais à ação direta dos fatores ambientais e, em particular, do ambiente físico. O apego dos primeiros ecólogos, originalmente de formação em Botânica e Zoologia, à Fisiologia fundamentada na Física e na Química, sugere que esse movimento emprestava à nova disciplina maior respeitabilidade científica pela introdução de métodos quantitativos e permitia a verificação experimental (Fernandes, 2015).

Em síntese, Keller \& Golley (2000) reconhecem três "ecologias": (i) ecologia romântica (romantic literary ecology, tradução nossa) que surge a partir do movimento de escritores descontentes com as visões de mundo antropocêntricas e mecanicistas da Modernidade, especialmente no século XIX; (ii) ecologia política (political ecology, tradução nossa), fortemente influenciada pela anterior, discute questões morais e éticas do uso do ambiente em prol da humanidade, cujas primeiras discussões datam do final do século XIX e início do século XX; e (iii) ecologia científica (scientific ecology, tradução nossa), em que são realizadas as práticas científicas associadas a investigação ecológica.

Para além da multiplicidade de definições do termo "ecologia", existem também controvérsias filosóficas fundamentais. Em sentido amplo, os estudos ecológicos preocupam-se com a ideia do equilíbrio da natureza (balance of nature). No entanto, esse balanço suscita diversos debates, como a dependência da densidade das populações ou se a competição é o mais importante dos fatores ecológicos. Intrinsecamente relacionado a esses debates, está a questão de quanta ordem é possível ser reconhecida nos fenómenos biológicos e se é possível postular leis (generalizações) sobre os mesmos, uma vez que cada circunstância ecológica é uma constelação única de fatores causais, moldados por contextos históricos idiossincráticos (Cooper, 2007).

Em um estudo clássico sobre a história das ideias ecológicas, Worster (1977) propõe duas principais correntes, desde o final do século XVII até a data de sua publicação. Num primeiro momento, trata-se de uma tradição "imperialista", baseado em uma visão da dominação humana sob a natureza. Essa abordagem é representada pelos escritos de Francis Bacon e, posteriormente, com as investigações de Lineu e Buffon sobre a economia da natureza e a função inequívoca dos 
organismos nos ambientes em que estão inseridos. A natureza é conceitualizada em termos mecânicos e instrumentais, descrita por suas partes, de modo a possibilitar sua efetiva utilização pelos humanos. Essa visão altamente utilitarista da natureza veio a ser promulgada nos séculos XVIII e XIX na Filosofia e na política, mas especialmente nas Ciências Naturais, à medida que assumiam uma forma organizacional mais profissional e disciplinada. O utilitarismo era uma visão que se encaixava bem com o projeto mais geral de industrialização (Jamison, 2001) e essa corrente mostrase alinhada com os primórdios do que Keller e Golley definiram como ecologia política.

Em oposição a essa visão imperialista estão os amantes da natureza, identificados por Worster (1977) como "arcadian" (ou arcadianos), sendo aqueles que associam a Ecologia com o ideal clássico de harmonia entre a natureza e a sociedade. Inseridos dentro do movimento do Romantismo, tais visões de natureza também são fundamentalmente ecológicas, uma vez que se preocupam com as relações, interdependência e holismo. A natureza era um lugar de autenticidade, do bom e do belo (ideias retomadas no movimento ambientalista dos anos 1970) (Worster, 1977), o que se enquadra no que Keller e Golley (2000) definiram como "ecologia romântica".

Jamison (2001) aponta diferenças elementares entre essas correntes ideológicas, sob o papel atribuído aos investigadores e sua prática científica. Enquanto a visão imperialista está inserida no processo de profissionalização e especialização da ciência, em que a ciência se tornou uma vocação, uma forma socialmente aceita de produção de conhecimento, os arcadianos correspondiam aos "gentlemen 's scientists", ou seja, os estudos eram realizados por investigadores individuais e por eles próprios financiados, cujos escritos também foram importantes, especialmente para conceções mais engajadas e holísticas do ambiente.

Worster (1977) argumenta que ambas correntes também contribuíram para a teoria evolutiva de Charles Darwin, mas que, ao longo do século XX, impulsionaram dois modos diferentes de pensar a Ecologia e conduzir a investigação. A abordagem imperialista propunha uma visão mais sistêmica e, portanto, orientada aos ecossistemas e da relação sistemática das espécies, enquanto os arcadianos tinham um foco mais individual, e com estudos orientados para as populações evolutivas e na relação dinâmica entre as espécies e o ambiente. Tais correntes implicaram em diferentes conceções e pressupostos metodológico e teóricos de como investigar e questionar a natureza (Jamison, 2001, 2011). 
Em 1913, ecólogo Arthur Tansley fundou a primeira sociedade de Ecologia a British Ecological Society, reafirmando a constituição desse campo de conhecimento e profissionalização dos investigadores. Em 1935, Tansley sugeriu o termo "ecossistema" como um modelo teórico, salientando além da importância do estudo conjunto dos organismos e dos fatores inorgânicos como sistemas, sendo que os ecossistemas seriam as unidades fundamentais da natureza na face da Terra. Das ideias de Darwin, que propunham que a unidade de sobrevivência seria a espécie, passou-se para um conceito mais sistémico no qual a unidade de sobrevivência seria o organismoem-seu-meio-ambiente (Keller \& Golley, 2000; Nucci, 2007).

Mais recentemente Jamison (2001), revisou o dualismo das correntes ecológicas propostas por Worster (1977). Embora o autor corrobore com essa importante distinção, Jamison (2001; 2011) considera que existe uma terceira e, igualmente, importante corrente dentro do movimento ambientalista. Para Jamison (2001), reafirmado em Jamison (2011), não foi apenas a conservação (ou exploração de novos territórios) da natureza que forneceu o foco para o movimento ambientalista. A ecologia humana (tradução livre do termo "human ecologies", proposto por Jamison, 2001) representou a identificação e a busca por respostas a uma série de problemas sociais identificados no decorrer da industrialização: lixo industrial e poluição, mobilidade urbana, uso de energia e, talvez mais importante, os riscos ambientais do trabalho.

Originada no final do século XIX e nas primeiras décadas do século XX, essa terceira corrente desenvolveu-se particularmente nos EUA, associada aos vários projetos de bem-estar social e saúde, motivada em parte pelas demandas do desenvolvimento da engenharia e da infraestrutura, o crescimento da geografia física e planeamento urbano e como um subcampo da medicina e saúde públicas. A ecologia humana foi também incorporada às jovens ciências sociais, como a Sociologia e a Antropologia, e às ciências políticas e económicas (Jamison, 2011).

Essa vertente da Ecologia ganhou ainda mais força após a II Grande Guerra, uma vez que os testes nucleares e a escalada das armas de destruição em massa levaram a uma preocupação cada vez maior com a "saúde do planeta". Alguns cientistas entenderam que tinham a obrigação moral de alertar a humanidade sobre os perigos que ela e o ambiente corriam (Nucci, 2007).

A crise do petróleo no início dos anos 1970 serviu como argumento fundamental para a noção da importância da finitude dos recursos. Embora essa conceção seja anterior a referida data,, seu escopo cresceu em proporção quase direta à crescente "impotência" sobre os países do chamado 
"Terceiro Mundo". Com o crescente temor das superpopulações, era momento de fazer os dados acadêmicos e publicações internas chegarem ao público. Para isso, os medias tiveram que apresentar questões ecológicas seriamente, o que nunca havia sido realizado pelos medias de massa (Bramwell, 1989).

Worster (1977) cita Barry Commoner, Rachel Carson e Paul Ehrlich, entre outros investigadores que se tornaram autores de best-sellers, conseguiram espaço nos medias, e até mesmo influenciaram politicas governamentais. A realização de eventos emblemáticos também ajudou a popularizar a temática: a divulgação da imagem da Terra vista do espaço, a partir de 1969; a comemoração do primeiro Dia da Terra, em 1970; e a Conferência de Estocolmo, em 1972 (Nucci, 2007), levando alguns autores a caracterizar os últimos cinquenta como "Age of Ecology"32.

Embora muitas das lutas políticas que os levaram a existir sejam datadas, os movimentos ambientais das décadas de 1960 e 1970 continuam a influenciar as ideias científicas e os valores pessoais, bem como os discursos sociopolíticos mais amplos na contemporaneidade (Jamison, 2011).

Diante das diferentes correntes que influenciaram o desenvolvimento do pensamento ecológico, a Ecologia contemporânea compartilha mais debates comuns, provavelmente, com as ciências sociais do que com outras ciências naturais e, portanto, ocupa um espaço único entre a vasta gama de disciplinas científicas (Cooper, 2007). De acordo com Cooper (2007), a função fundamental da Ecologia é delinear e implementar políticas ambientais, tratando-se de uma ciência de elevada importância pratica e social ${ }^{33}$. A visão de Cooper (2007) pode ser entendida como o desdobramento mais recente da "ecologia política” de Keller e Golley (2000).

No âmbito da Museologia, Nair (1996) cita duas publicações que sugerem o impacto dos movimentos ambientalistas e do desenvolvimento do conhecimento científico ecológico nos museus de história natural: (i) Museums and the environment: a handbook for education, publicado em 1971 pela American Association of Museums, serviu como um guião com informações e um

${ }^{32}$ Na descrição do recente livro "The Age of Ecology”, publicado por Joackim Radkau em 2018, é possível identificaro uso da mesma expressão como justificação da obra: "While the history can be traced back several centuries, environmentalism has flourished since the 'environmental revolution' of 1970, spurred on by the Chernobyl nuclear disaster in 1986 and the growing concern about global warming. While environmentalists often opposed the scientific mainstream, they were also often led by scientific knowledge. Environmentalism is the true Enlightenment of our time so much so that we can call our era "the age of ecology' "(Disponivel em: < https://nww.wiley.com/enus/The+Age+of+Ecology-p-9780745679990>. Acesso em 24 de Janeiro de 2019.

33 "Finally, given ecology's fundamental role in the design and implementation of environmental policy, it is hard to imagine a science that has more social and practical relevance" (Cooper, 2007, p. . x) 
conjunto de recursos museográficos, como esquemas, temas, técnicas e ilustrações para instituições interessadas em interpretar os problemas ambientais, iniciar ou expandir suas exposições ou programas educativos; (ii) L'environnement entre au Musée, livro publicado por Jean Davallon e colaboradores em 1992, a partir de uma investigação realizada em dezenas de exposições de instituições museológicas do Hemisfério Norte (especialmente EUA e Europa) que abordam a temática ambiental. Nessa publicação os autores defendem que o meio ambiente sobre o qual nos questionamos na contemporaneidade não é apenas o que os humanos podem extrair dele, mas sim todos os elementos, antes colocados apenas como entorno em representações ordinárias. Essa nova relação (e, consequentemente, forma de representação) assume um caráter patrimonial ao meio ambiente. Desse modo, além da sua dimensão científica, o meio ambiente assume dimensões social e humana, as quais permitem entender a relações das sociedades com a natureza que as rodeia, sendo o museu um espaço privilegiado para evidenciar essa nova conceção (Davallon, Grandmont, \& Schiele, 1992).

De acordo com Davallon e colaboradores (1992), o museu tornou-se um mediador entre o meio ambiente e o público:

"o museu contribui doravante para aparição deste 'ser' que é o meio ambiente - feito
de coisas, de processos e de representações - como um 'bem público' que deve ser
conservado; em suma, como um património. Esta 'patrimonialização' do ambiente
ocorre segundo os modos que, por sua vez, respondem às especificidades da
instituição museal e à sua atual evolução como media. Em suma, face à tempestade
verde, vemos esboçar-se hoje um novo papel do museu: o de ser um 'espaço público'
que oferece ao público a oportunidade de se formar uma opinião sobre o que está
prestes a se tornar o 'património verde’” (Davallon et al., 1992, p. 56, tradução nossa) [INDICADOR 43, Tabela 7].

Ainda de acordo com esses autores, a chegada do ambiente ao museu causa um duplo impacto. Por um lado, trouxe mudanças na Museografia e na Museologia, porque requer uma atualização da apresentação das "coisas" da natureza. Por outro lado, coloca o museu na frente de missões e situações que não lhe são habituais. Ela pede que a instituição trate tópicos pertencentes ao tempo presente e declare um posicionamento (Porcedda et al., 2006). 
No que tange a museografia, progressivamente a sensibilidade para as questões ecológicas promoveu o abandono de apresentações singulares de natureza, estéticas, uníssonas e estáticas, para aderir a representações patrimoniais do meio ambiente. No entanto, a museografia foi confrontada com problemas específicos como, por exemplo, a dificuldade em exibir o caráter dinâmico dos ecossistemas para que fosse possível perceber a degradação sistémica, ou ainda, superar o caráter meramente normativo e prescritivo dos discursos sobre o meio ambiente.

Uma das soluções encontradas foi aproximação do visitante à natureza, por intermédio da observação dos ecossistemas, esperando que esse visitante apreenda a multiplicidade das relações entre a fauna e a flora que os caracterizam. A museografia integrou o visitante ao inseri-lo na cena, na qual ele não só ocupa um espaço, mas também desempenha um papel [INDICADOR 42, Tabela 7], promovendo condições de um refletir e agir sobre suas atitudes [INDICADOR 43, Tabela 7] (Davallon et al., 1992).

A temática do meio ambiente também requalificou a abordagem tradicional de comunicação dos museus, alinhando-a com os médias, em particular com as técnicas de jornalismo, quando os factos são reportados de diversas fontes, mesmo que contraditórias [INDICADOR 47, Tabela 7]. Ao propiciar uma vivência da complexidade das questões ambientais, o museu trabalha as expectativas estruturais da informação pública, compreendendo-as como "um meio de pensar as escolhas" (Rocha, 2015).

Assim, no subpadrão museográfico Ecológico destaca-se o contexto das exposições, com atenção para que não seja reforçado em nenhum aspeto atitudes relativas a superioridade humana e dominação sobre a natureza (especialmente se as pessoas acreditam que os organismos estão sendo exibidos apenas para o prazer do visitante) (Karen A. Rader \& Cain, 2014) [INDICADOR 48, Tabela 7]. São promovidos valores positivos em relação à natureza, como atitudes que incentivem o público a cultivar ao invés de explorar ou controlar a natureza [INDICADOR 43, Tabela 7] (Karen A. Rader \& Cain, 2014). Exemplifica-se com painéis e gráficos que fornecem mais do que factos isolados ou informações técnicas sobre a biodiversidade, mas que também transmitem mensagens empolgantes e propostas factíveis para a conservação [INDICADOR 46, Tabela 7] (Miller, Conway, Reading, Wemmwe, et al., 2004).

São igualmente concebidos novos usos para as coleções, como por exemplo, como etiquetas e pequenos textos explicativos que convertem taxidermias que remetem a estética de troféus em 
ícones do ambientalismo [INDICADOR 40, Tabela 7] e a inclusão de faixas e alertas de "ameaçado de extinção", em animais expostos em dioramas ${ }^{34}$ (Karen A. Rader \& Cain, 2014) [INDICADOR 41, Tabela 7].

Portanto, o papel social dos museus diante da conservação do meio ambiente redireciona as coleções biológicas para o âmbito da comunicação, nas quais as "coisas da natureza" foram mobilizadas para apresentar as mudanças no meio ambiente de forma a ampliar a compreensão da interdependência da vida e de sua diversidade no planeta [INDICADOR 45, Tabela 7](Rocha, 2015).

Outrossim, para Davallon e colaboradores (1992) a instituição museal como um todo passa a ser questionada, exigindo um posicionamento crítico da instituição sobre as discussões ambientais [INDICADOR 44, Tabela 7]:

"como ator social de um debate em que ele se coloca, o museu encerra seu status de neutralidade; ele deve ser protagonista. Ele não encarna mais a objetividade do científico, aquelas representações do passado a que havia se acostumado, e evolui sobre o campo destinado a pertencer àqueles que decidem. Por suas escolhas de programação e de discurso, ele toma a palavra como um corpo constituído da vida civil" (Davallon et al., 1992, p. 138, tradução nossa).

O desenvolvimento do movimento ambientalista, com estreita relação com a Ecologia e a imagem pública desta disciplina, foi determinante para questionar, por exemplo, o investimento nos museus de história natural. O processo de mudanças sociais, provocou, por sua vez, modificações na relação entre o museu e seus visitantes, entre os profissionais a cargo de desenvolvimento das exposições e entre eles e as autoridades do museu ou as técnicas de exibição escolhidas. Dessa forma, como o reflexo de uma sociedade mais preocupada com questões ambientais, as instituições baseadas em coleções (museus, zoológicos, aquários e jardins botânicos) tornaram-se também interessadas em questões relacionadas a conservação (Paddon, 2014).

\footnotetext{
${ }^{34}$ No caso brasileiro, podemos citar a Instrução Normativa n.4 de 4 de Março de 2002 do Instituto Brasileiro do Meio Ambiente e Recursos Naturais Renováveis (IBAMA), sobre o registro de zoológicos públicos e privados, em que exige em seu Artigo $3^{\circ}$, Inciso VIII: “manter, em cada recinto sujeito à visitação pública, uma placa informativa onde conste, no mínimo, os nomes comum e científico das espécies animais ali expostas, a sua distribuição geográfica e a indicação quando se tratar de espécies ameaçadas de extinção”.
} 
Biodiversidade Musealizada: Formas que Comunicam

Tal demanda mostra-se ainda atual e está claramente expressa na Declaração de Taipei, proposta pelo Comitê de Museus de História Natural do Conselho Internacional de Museus (ICOMNatHist), em 2015, e que explicitou o compromisso ético dos museus de história natural com questões relacionadas à conservação ambiental (Dorfman, 2017).

\begin{abstract}
"A major role of natural history museums is to collect and steward natural history objects, generating knowledge regarding these objects and disseminating this knowledge to the community. Natural history museums also engage the public to form deep bonds with the natural world and commit to its preservation. Increased human activities have created catastrophic declines in biodiversity. Both ethics and logic point to a mandate to conserve vulnerable habitats and species. To achieve best practice, natural history museums take action to conserve natural habitats and populations" (Taipei Declaration on NHMs and Biodiversity Conservation. Disponível em: https://icomnathist.wordpress.com/taipei-declaration-on-nhms-and-biodiversityconservation/. Acesso em 17 de Setembro de 2018).
\end{abstract}

Nos EUA e na Europa, desde o final da década de 1960, encontramos exemplos de museus (e suas exposições) possuem objetivos relacionados à conservação dos ambientes, a preservação da natureza, a interdependência entre os organismos viventes [INDICADOR 45, Tabela 7], as consequências da intervenção humana nos ecossistemas e a necessidade de mudanças no comportamento [INDICADOR 43, Tabela 7] (Delicado, 2010).

As autoras Rader e Cain (2014) apontam como marco inicial do subpadrão museográfico Ecológico a exposição “Can Man Survive?”, do AMNH, inaugurada em 1969. Artefactos, aparatos audiovisuais e luzes coloridas apresentavam o argumento que o desperdício do consumo de energia e práticas ecológicas imprudentes poderiam levar a um suicídio coletivo (Figura 7). Embora considerada extremista e criticada pelo público, essa mostra abriu uma série de outras exposições sobre a temática ambientalista nos EUA, que se perpetua até os dias correntes (Karen A. Rader \& Cain, 2014). 


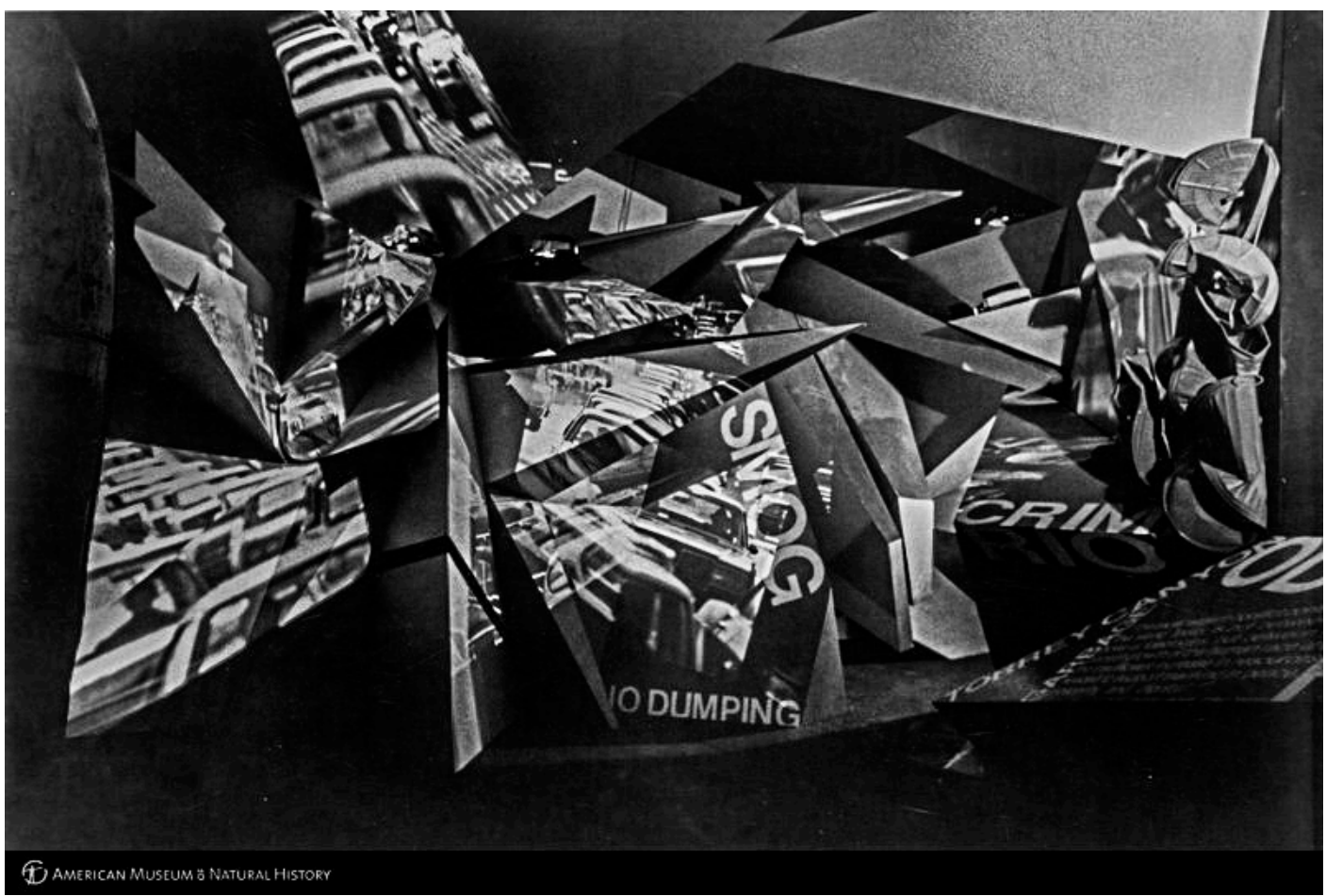

FIGURA 7: Painéis da exposição "Can Man Survive?", inaugurada em 1969, no Theodore Roosevelt Memorial Hall, AMNH. Fonte: Digital Special Collections. Department of Library Services. American Museum of Natural History. Disponível em: http://lbry-web-007.amnh.org/digital/index.php/items/show/26551. Acesso em 9 de Abril de 2019.

Por fim, Miller e colaboradores (2004), ao revisar a missão conservacionista de museus de história natural, zoológicos, aquários e jardins botânicos contemporâneos, declaram que os desafios ambientais transcendem os muros dos museus, mas que a qualificação do espaço expositivo é um "fundamental community service":

"a clear challenge for institutions with a mission of conservation is to find ways to create a new and effective base of political support, financial help, and scientific expertise to save as much of nature as possible in the face of obstacles that are almost unrivaled in complexity. Although statement of a conservation mission recognizes this need, the question we ask is whether collection-based institutions are living up to that mission. (...) Time is short. Conservation is about life, and each day that we dally, more is lost. The degree to which collection-based institutions can successfully re-tool existing facilities, use innovative models when building new facilities, and change their prime function from visitor recreation to the fundamental community service of conservation will have a profound effect on the fate of Earth's marvelous wild creatures." (Miller, Conway, Reading, Wemmer, et al., 2004, pp. 91-92). 
Retomando a citação de Bramwell (1989) que inicia esse capítulo, um posicionamento em prol de questões ecológicas não se trata apenas da assimilação de um conjunto de conhecimentos científicos, mas também um posicionamento cívico e político perante ao ambiente que nos rodeia. Sendo os museus as instituições fundamentais para a construção da cidadania, as exposições constituem-se como o principal meio de comunicação, dado que representam o espaço de encontro da sociedade com a instituição.

\begin{tabular}{|c|c|c|c|c|}
\hline \multirow{10}{*}{ 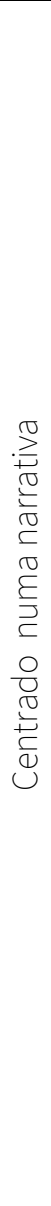 } & $\begin{array}{l}\text { No. Do } \\
\text { Indicador }\end{array}$ & $\begin{array}{l}\text { Subpadrão } \\
\text { Museográfico }\end{array}$ & Indicador & Autores-Fonte \\
\hline & 40 & Ecológico & $\begin{array}{l}\text { Manutenção de museografia e espécimes } \\
\text { antigos, utilizando etiquetas e pequenos textos } \\
\text { com novas contextualizações }\end{array}$ & Rader e Cain, 2014 \\
\hline & 41 & Ecológico & $\begin{array}{l}\text { Indicações de espécies extintas ou ameaçadas } \\
\text { de extinção }\end{array}$ & Rader e Cain, 2014 \\
\hline & 42 & Ecológico & $\begin{array}{l}\text { Integração do visitante com a exposição, na } \\
\text { qual ele é convidado a desempenhar um papel } \\
\text { social na resolução de problemas ambientais }\end{array}$ & Davallon et al, 1992 \\
\hline & 43 & Ecológico & $\begin{array}{l}\text { Promover a reflexão do visitante e condições } \\
\text { para mudanças de atitudes relacionadas aos } \\
\text { problemas ambientais }\end{array}$ & $\begin{array}{l}\text { Davallon et al, 1992; } \\
\text { Delicado, } 2010\end{array}$ \\
\hline & 44 & Ecológico & $\begin{array}{l}\text { Posicionamento crítico dos museus em } \\
\text { questões ambientais }\end{array}$ & Davallon et al, 1992 \\
\hline & 45 & Ecológico & $\begin{array}{l}\text { Ampliar a compreensão da interdependência } \\
\text { da vida e de sua diversidade no planeta }\end{array}$ & $\begin{array}{l}\text { Davallon et al 1992; } \\
\text { Delicado, 2010; Rocha, } \\
2015\end{array}$ \\
\hline & 46 & Ecológico & $\begin{array}{l}\text { Painéis e gráficos que transmitem mensagens } \\
\text { empolgantes e propostas factíveis para a } \\
\text { conservação }\end{array}$ & $\begin{array}{l}\text { Miller et al., 2004; Rader } \\
\text { e Cain, } 2014\end{array}$ \\
\hline & 47 & Ecológico & $\begin{array}{l}\text { Factos reportados de diversas fontes, similar a } \\
\text { linguagem jornalística }\end{array}$ & $\begin{array}{l}\text { Davallon et al, 1992; } \\
\text { Rocha, } 2015\end{array}$ \\
\hline & 48 & Ecológico & $\begin{array}{l}\text { Negação de qualquer discurso ou atitudes } \\
\text { relativas a superioridade humana e dominação } \\
\text { sobre a natureza }\end{array}$ & $\begin{array}{l}\text { Miller et al., 2004; Rader } \\
\text { e Cain, } 2014\end{array}$ \\
\hline
\end{tabular}

Tabela 7: Tabela que resume os indicadores compartilhados pelo subpadrão museográfico Ecológico, que serão aplicados na análise das exposições estudadas nesse trabalho. 


\subsubsection{Subpadrão Museográfico Public Understanding of Science ou "Exploratorium Effect"}

"Hands-on experiments communicate scientific truths"

(Barry, 2001, p. 138)

Simultaneamente as exposições ecológicas, outra tendência evidente do pós-II Grande Guerra são exposições interativas de ciência. Embora proclamadas como exemplos de uma museografia contemporânea e hi-tech, estas mostras não são uma inovação da contemporaneidade. Já nas primeiras décadas do século XX, os museus de ciências e indústria europeus incorporavam aparatos interativos em suas exposições, como máquinas de engenharia em operação, demonstração de experimentos e modelos que se moviam ativados por botões e manivelas. Tais instituições carregam desde suas origens conexões com a promoção dos avanços científicos nacionais e da indústria, além de algumas incorporarem nacionalmente os acervos e museografia das grandes exposições internacionais (como por exemplo, o Science Museum londrino).

Podemos exemplificar com o Deutusches Museum, aberto em 1925 em Munique (que inspirou o departamento de educação do Exploratorium), Children's Gallery do Science Museum, aberto em 1931 em Londres, e as demostrações químicas do Palais de la Découverte ${ }^{35}$ (Paris), inaugurado em 1937 (M. Henning, 2006) ${ }^{36}$. É possível ainda retornar para períodos mais precoces e citar o Urania, como um espaço de divulgação científica que data do final do século XIX, em Berlim (desmantelado em 1928, com a depressão pós I Grande Guerra) (Bragança Gil, 1988).

No entanto, foi na segunda metade do século XX que a preocupação em comunicar ciência tornou-se um movimento social, evidentemente concentrado em assegurar o financiamento público de investigadores e proteger as empresas das adversidades da crítica pública (Pickstone, 2001). Assim, Public Understanding of Science (PUS) emergiu como uma área de estudo e práticas, cujo

${ }^{35}$ O Palais de la Découverte foi inaugurado para a Exposição Internacional de 1937 e propunha a supressão dos objetos da ciência. Desse modo, as coleções não estavam presentes, o foco era mostrar como a ciência era feita e praticar teorias que eram traduzidos em experiências-espetáculos. A particularidade desse espaço era propor experiências mediadas por estudantes ou profissionais, convidando os visitantes a assistir sua demonstração (Magnin, 2011). Ainda em Paris, a Cité des Sciences et l'industrie, fundado em 1986, marca a ascensão de uma Museologia baseada em modelos e inspirada em informação e comunicação (Eidelman \&Van Praët, 2000; Magnin, 2011).

${ }^{36}$ No entanto, algumas destas iniciativas foram descontinuadas (ou mesmo extintas) devido a ll Grande Guerra (Corral-Guillé, 2015). 
conceito está associado à scientific literacy ${ }^{37}$, termo cunhado nos Estados Unidos, no final dos anos 1950 (Entradas, 2015).

Há ampla literatura que discute as origens e definição do termo science literacy, como revisões recentes de Burns e colaboradores (2003), sobre comunicação científica e literacia científica por Entradas (2015). Cabe aqui destacar que o movimento do PUS foi propulsionado pela preocupação da comunidade cientifica estadunidense em garantir o apoio público para a exploração aeroespacial, no início da corrida espacial (por exemplo, a primeira pesquisa nacional dos EUA sobre atitudes em relação à ciência foi realizadas em 1957, antes do lançamento do Sputnik $1)^{38}$ e para corrigir um suposto deficit educacional do país (Ogawa, Loomis, \& Crain, 2009).

Desde o primeiro momento desse movimento, museus e exposições foram aclamados como instituições chaves para sua promoção, uma vez que operam como recursos informais de educação, onde as pessoas podem ir por prazer e em qualquer momento de suas vidas (Barry, 2001).

As instituições e exposições derivadas do PUS estavam atentas a demonstrar os princípios científicos básicos [INDICADOR 51, Tabela 8] e a melhoria dos níveis de educação básica em ciência da população, permitindo que os visitantes conduzir seus experimentos e descobrir os princípios "sozinhos" [INDICADOR 55, Tabela 8] (MacDonald, 2004). A quotidianidade das exibições e a visibilidade de seus trabalhos estavam também ligadas à desmistificação da ciência (M. Henning, 2006) [INDICADOR 62, Tabela 8].

A abertura do Exploratorium - em 1969, em São Francisco (EUA) - por Frank Oppenheimer, é a principal referência das instituições do período (Delicado, 2010; MacDonald, 2004). O discurso expositivo do Exploratorium, e do demais science centres nele inspirados, estava baseado no

${ }^{37}$ De acordo com a investigadora portuguesa Canvalho (2009), o termo "literacia cientifica" surge frequentemente ao Ensino de Ciências, no contexto estadunidense. Tradicionalmente interpretado como a capacidade de ler e escrever, o termo literacia tem sido utilizado em outros contextos como literacia para a saúde, literacia informática, literacia cultural, literacia políica e também literacia científica. Este último termo ("scientific literacy"), tem como sinónimo "compreensão pública da ciência" ("public understanding of science") na Inglaterra e "cultura científica" "'la culture scientifique") em França (Carvalho, 2009, p. 179).

${ }^{38}$ O período da Guerra Fria e a era pós-Sputnik compõe um período crucial para o campo da educação científica nos EUA. 0 lançamento do Sputnik 1, em 1957, promoveu o discurso de que os estadunidenses estariam atrasados em relação a União Soviética, no tocante da ciência e tecnologia. Embora a competição direta com a União Soviética tenha decrescido até o final da década de 1960, o interesse em manter a superioridade internacional científica e tecnológica ainda hoje continua a pautar as reformas na educação científica estadunidense (Ogawa, Loomis, \& Crain, 2009). 
conceito da interatividade ${ }^{39}$ [INDICADOR 49, Tabela 8], o que pode ser exemplificado pela seguinte passagem: "Explaining science and technology without props can resemble an attempt to tell what it is like to swim without ever letting a person near the water" (Oppenheimer, 1968, p. 206).

Antes de receber financiamento do governo americano para conceber o Exploratorium, Frank Oppenheimer visitou diversos museus de ciência e técnica europeus, em uma viagem realizada com o apoio de uma Guggenheim Fellowship para estudar física em Londres, em 1965 (Ogawa et al., 2009). No entanto, se Exploratorium foi influenciado por museus europeus, sua agenda era, pelo menos em teoria, mais radical. Para Oppenheimer, as exposições científicas interativas deveriam ter uma função explicitamente emancipatória - "democratic empowerment" - e não existiriam barreiras entre a arte e a ciência, sendo ambas formas de entenderemos o mundo que nos cerca.

O trabalho de Oppenheimer também estava inserido em uma tendência da educação científica e das exposições dos museus da metade do século XX, uma vez que respondia aos anseios dos educadores progressistas, que defendiam a participação ativa dos estudantes/visitante [INDICADOR 54, Tabela 8](Karen Ann Rader \& Cain, 2014). Contudo, representou a vanguarda das conversas sobre os métodos de educação hands-on em ampla escala e suas ideias cativaram por muito tempo mudanças educacionais e nos museus. Tal reconhecimento pode ser exemplificado pelo convite de Albert Parr, então editor da publicação Curator ${ }^{40}$ e diretor do AMNH, para que Oppenheimer publicasse sua proposta (Oppenheimer, 1968) e pela participação em conferências no

${ }^{39}$ O sociólogo Andrew Barry escreveu sobre a circulação das ideias de interatividade, evidenciando que essa não foi "descoberta" ou "inventada", mas sim desenvolvida em episódios. Considerando que uma das medidas do avanço das economias industriais é, em parte, a posse e aquisição de capital intelectual e científico, então pelo menos uma das funções das tecnologias interativas tem sido melhorar e manter esse capital. Barry aponta que a interatividade surge num contexto em que fica claro que apenas textos científicos não são suficientes para produzir um tipo de cidadania dentro de uma democracia moderna e tecnológica. Entretanto, a circulação da interatividade entre museus científicos não se trata apenas de uma transferência de uma instituição para o outra, mas um processo de tradução e transformação, em que as tecnologias interativas carregam novas formas esignificados (Barry, 2001). Ainda deacordo com Barry (2001), as exposições interativas de ciência também passaram por uma mudança política, desde a associação com o empoderamento político e criatividade nas décadas de 1960 e 1970, até uma tentativa mais prosaica de aumentar o "public understanding of science" e tornar os museus de ciência mais atraentes (M. Henning, 2006). De modo que a interatividade tornou-se "a dominant model of how objects can be used to produce subjects", com a intenção de transformar "unfocused visitor-consumer into the interested, engaded and informed technological citizen" (Barry, 2001, p. 129)

40 "Curator: the museum jornal" é uma das mais importantes publicações do campo da Museologia, escrita e destinada aos profissionais de museus. Sua primeira edição data de 1958 e mantém-se até os dias correntes, pertencendo atualmente ao grupo editorial Wiley. A revista tem acesso aberto e está disponível em:

<https://onlinelibrary.wiley.com/page/journal/21516952/homepage/productinformation.html> Acesso em 5 de Fevereiro de 2019. 
Smithsonian Institute, quando o físico e divulgador evidenciou a pedagogia hands-on como caminho para preencher demandas tanto da alfabetização científica mais geral, como do ensino disciplinar de ciências¹ (Ogawa et al., 2009; Karen A. Rader \& Cain, 2014).

Já no contexto europeu, o movimento do "Public Understanding of Science" ganhou importância a partir dos anos 1980, no Reino Unido, como resultado da preocupação governamental com os caminhos da compreensão da ciência. Em 1985 é publicada uma pesquisa intitulada "The PUS", pela Royal Society of London, cujos resultados foram baseados na premissa de que quanto mais as pessoas soubessem sobre ciência, mais elas iriam gostar e apoiar atividades científicas, declarando que todos deveriam entender ciência e que a ciência deveria estar em pauta na agenda inglesa (Entradas, 2015).

De modo que o entusiasmo pela interatividade, iniciado pelo Exploratorium no final dos anos 1960, subsequentemente, espalhou-se pelos EUA e, finalmente, voltou a Europa, na metade dos anos 1980, marcado pela abertura do Launch Pad no Science Museum e pela Cité des Sciences et de I'Industrie, em Paris (Barry, 2001).

No entanto, tal emergência aumentou a tensão entre os administradores de museus e políticos sobre o significado dos espécimes e coleções na definição e legitimidade de suas instituições (Karen Ann Rader \& Cain, 2008). No lugar das coleções históricas, essas instituições recorriam a séries de aparatos museográficos desenhados para que o visitante pudessem acioná-los [INDICADOR 49, Tabela 8], a fim de demonstrar os fenômenos da ciência e comunicar os princípios básicos que os sustentam [INDICADOR 58, Tabela 8] (Corral Guillé, 2015).

"Hands-on" tornou-se um nome alternativo para exposições organizadas sob a influência do Public Understanding of Science, cuja proposta é auxiliar o visitante a entender alguns princípios científicos básicos, de modo que ele se sentisse capacitado a entender a ciência e o mundo que a rodeia (MacDonald, 2004).

Os recursos interativos desenvolvidos no Exploratorium mudaram o foco dos museus para longe dos objetos de acervos, por meio da demonstração de princípios científicos, processos e fenómenos [INDICADOR 51, Tabela 8] (M. Henning, 2006). Nesse sentido, a museóloga brasileira

${ }^{41}$ A função educativa, mas não escolar, do Exploratorium pode ser descrita em: "A museum should not be a substitute for a school or a classroom but itshould be a place where people come both to teach and to learn. Visitors should be able to find it refreshing and stimulating" (Oppenheimer, 1968, p. 209). 
Waldisa Rússio resume: "Um museu de ciências é aquele que apresenta o experimento científico como seu principal objeto museológico" (Guarnieri, 2010, p. 281).

O uso dos recursos interativos no lugar dos objetos de coleções científicas em exposições também expressa uma mudança na prática científica que se desejava representar. Miles e Tout (1992) argumentam que os objetos não possuem voz própria, apenas etiquetas com informações parceladas e que são facilmente esquecidas, e o foco das "ciências modernas" está mais associado ao significado dos objetos do que na evidência física de que eles existem² ${ }^{42}$

Para além da ênfase na interação do visitante [INDICADOR 50, Tabela 8], mais do que o currículo escolar ou nos roteiros temáticos pré-definidos por curadores, o surgimento do PUS também podem ser interpretados como tendências do movimento contracultura, do final dos anos 1960, celebrando a escolha individual e as mudanças de autoridade do conhecimento [INDICADOR 54, Tabela 8]. Michelle Henning (2006), resume a posição dos visitantes em relação aos objetos em exposição:

\begin{abstract}
"The Victorian glass case exhibits had placed the visitor as an observer, and the 1930s mechanical and chemical displays had positioned the visitor as an operator or user. But the Exploratorium incorporated the visitor into the exhibition, so that the visitor's body and mind become the subject and content. The emphasis on the visitor's own bodily experiences is connected to the view that the process of disseminating scientific knowledge should start with people's own everyday experience" (M. Henning, 2006, p. 85)
\end{abstract}

Analisando em perspetiva, ironicamente, as exposições interativas do Exploratorium seguiam as mesmas diretrizes das premissas educativas das caóticas coleções do final do século XIX, nos museus de história natural. Recusando-se a criar uma narrativa [INDICADOR 54, Tabela 8], Oppenheimer (e seus seguidores) não organizava exposições dentro de linhas taxonómicas, tal qual a museografia tradicional dos museus de história natural, e nem dispunha os objetos em linhas

42 "However the strongestargument against traditional objects-and-label exhibits, in the context of the public understanding of science, is that " the failure to convey relevant concepts will prevent [the visitor] from achieving anything more than an illusion of understanding. So it seems safe to suggest that objects in exhibitions do not, by simply being there, male possible a distinctive (or indeed any) understanding of science. As a post-script to this argument, it is worth pointing out that much of modern science focuses on the significance of things in nature rather than of the physical evidence of their existence" (Roger S. Miles \&Alan F. Tout, 1992, pp. 27-28, grifo nosso) 
progressistas, como uma matéria de civilidade e ajustamento social como apresentado por Tony Bennett (1995), museografias comuns antes e logo depois da II Grande Guerra.

A abordagem pedagógica do Exploratorium era característica do século XIX (cabia ao visitante construir seu próprio conhecimento), em que Oppenheimer contentava-se com a ausência das explicações didáticas deixando os visitantes maravilharem-se com os resultados da investigação, o que ele chamou de "scandalous revelations" [INDICADOR 59, Tabela 8] (Karen Ann Rader \& Cain, 2014).

Assim, mesmo que as exposições científicas baseadas na demonstração/experimentação de conceitos básicos não sejam originais de Oppenheimer, ele atualizou e popularizou o conceito de museu baseado na educação cientifica, tornando-se uma marca característica do movimento dos science centres, nos anos 1970 e início dos anos 1980. A exposição do Exploratorium e sua organização tiveram grande influência no mundo dos museus, capturando valores do aprendizado não-formal e das experiências interativas, forçando os museus a repensarem seus aparatos e redefinirem sua identidade institucional, o que as autoras Karen Rader e Victoria Cain (2004) identificaram como "Exploratorium effect".

Todavia, na perspetiva de Macdonald (2004), as instituições e/ou exposições relacionadas com este movimento promovem o interesse em ciência de forma nebulosa e pouco avaliada, ao invés de fomentarem o conhecimento em ciência básica dos visitantes. Contrariamente ao esperado, estes espaços poderiam (e podem, a medida em que ainda existem) promover um sentido "mágico" das ciências.

Ainda de acordo com Secord (1996) uma questão substantiva é a distância entre o que é demonstrado e o mundo social da investigação. O autor exemplifica que ao vermos ossos de dinossauros, mesmo que modelos, é possível ver um objeto que serviu de evidência para o estudo paleontológico, o que pode gerar dificuldades na interpretação e problemas na reconstrução. Quando, no entanto, é apresentado um modelo robótico o mundo da prática científica torna-se invisível. A imagem criada é de um dinossauro mais vívido, mas a compreensão pública de como o cientista trabalha é empobrecida.

Além disso, como citado início desse tópico, são demonstrações de verdades eternas, ou no máximo fornecem informações sobre suas aplicações tecnológicas. A ciência é apresentada como um conjunto de leis naturais e princípios, sobre os quais existe uma única verdade e que todos 
podemos descobrir [INDICADOR 53, Tabela 8]. Orquestradas para reproduzir respostas padronizadas e corretas, o subpadrão museográfico baseado no Public Understanding of Science pode produzir aparatos eficazes, mas para Macdonald (2004) é improvável que essa abordagem seja capaz de promover a tomada de decisões conscientes sobre questões relacionadas à ciência ${ }^{43}$.

Ademais, entre as exposições concebidas sob a influência do Public Understanding of Science existe uma padronização dos sistemas de comunicação e linguagem, substituindo possibilidades de abordagem de conhecimento populares, indígenas ou outros, o que pode enfraquecer a função cívica dessas instituições (Cameron et al., 2013)[INDICADOR 56, Tabela 8].

Quanto aos museus de história natural, estes mudaram suas museografias buscando simular práticas dos science centres, por meio da inclusão de interativos [INDICADOR 49, Tabela 8], modelos robóticos [INDICADOR 63, Tabela 8], aparatos multimédia [INDICADOR 61, Tabela 8]e jogos [INDICADOR 64, Tabela 8], reconstituições de ambientes naturais onde os visitantes poderiam andar, espaços com animais vivos ${ }^{44}$, discovery rooms [INDICADOR 52, Tabela 8] etc. (Figura 8)(Delicado, 2010).

A importância dos medias, em detrimento dos objetos de coleção pode ser exemplificada na passagem abaixo, feita por Roger Miles e Alan Tout (colaborador externo) em uma publicação que revisitou o programa de remodeloação museográfica do NHM: "selecting media (and combining them in paced sequences) remains once of the big challenges of exhibition design: the act of selection remains an art rather than science" (Roger S. Miles \& Alan F. Tout, 1992, p. 29).

${ }^{43}$ Apresentar a ciência "pura", desassociada das tecnologias resultantes ou seus efeitos e como uma conquista humanística como arte, foi, sem dúvida, também uma tentativa de resgatar a ciência de sua imagem pública manchada, pós bomba atómica, projeto que Frank trabalhou com o irmão Robert Oppenheimer (MacDonald, 2004).

${ }^{44}$ A introdução de temas relacionados à Biologia nos centros de ciência também ocorreu pela tentativa de criar displays com animais vivos, no caso do Exploratorium. Contudo, a interação com esse animais exigia mais expertise científica e material de suporte do que um aparato mecânico, assim como apresentar e controlar fenómenos biológicos de forma confiável e em grande escala exigia gastos excessivos, grande trabalho de manutenção e montagem. Há ainda implicações éticas no desenvolvimento destes dispositivos e nos danos causados a saúde animal para o aprendizado/divertimento humano, embora tenham sido elogiados por pesquisadores da área, dada a sua acurácia e inovação (Karen A. Rader \& Cain, 2014).

Encontramos uma situação similar na "Galeria da Biodiversidade" no MP, em que os terrários e aquários com animais vivos para demonstrações de mimetismo e aposematismo estiveram em manutenção durante praticamente toda a missão de investigação, especialmente por problemas ocasionados pela manutenção da temperatura e umidade. A dificuldade e falta de expertise na equipa técnica da instituição para lidar com esses problemas foi citado na entrevista com a equipa curatorial. 
Cabe destacar que o uso da interatividade como fonte de empoderamento e liberdade dos visitantes, um caráter mais radical das instituições estadunidenses, tornou-se marginal nos museus europeus. Ao invés disso, aplicava-se a interatividade em busca de responder as preocupações da compreensão pública da ciência e a atração de mais visitantes para os museus (Barry, 2001).

Barry (2001) identifica duas tendências: uma exaltação a cultura experimental dos aparatos expositivos, fomentada pelo Exploratorium desde as suas origens; ou a junção do uso de aparatos experimentais com novas tecnologias, o que tornou o design de exposições altamente profissionalizado, sofisticado e, consequentemente, custoso (o Science Museum atualmente oferece consultorias pagas para museus e centros de ciências que desejam desenvolver exposições inteiras ou apenas alguns aparatos interativos), tornando a interatividade um indústria e um commodity.
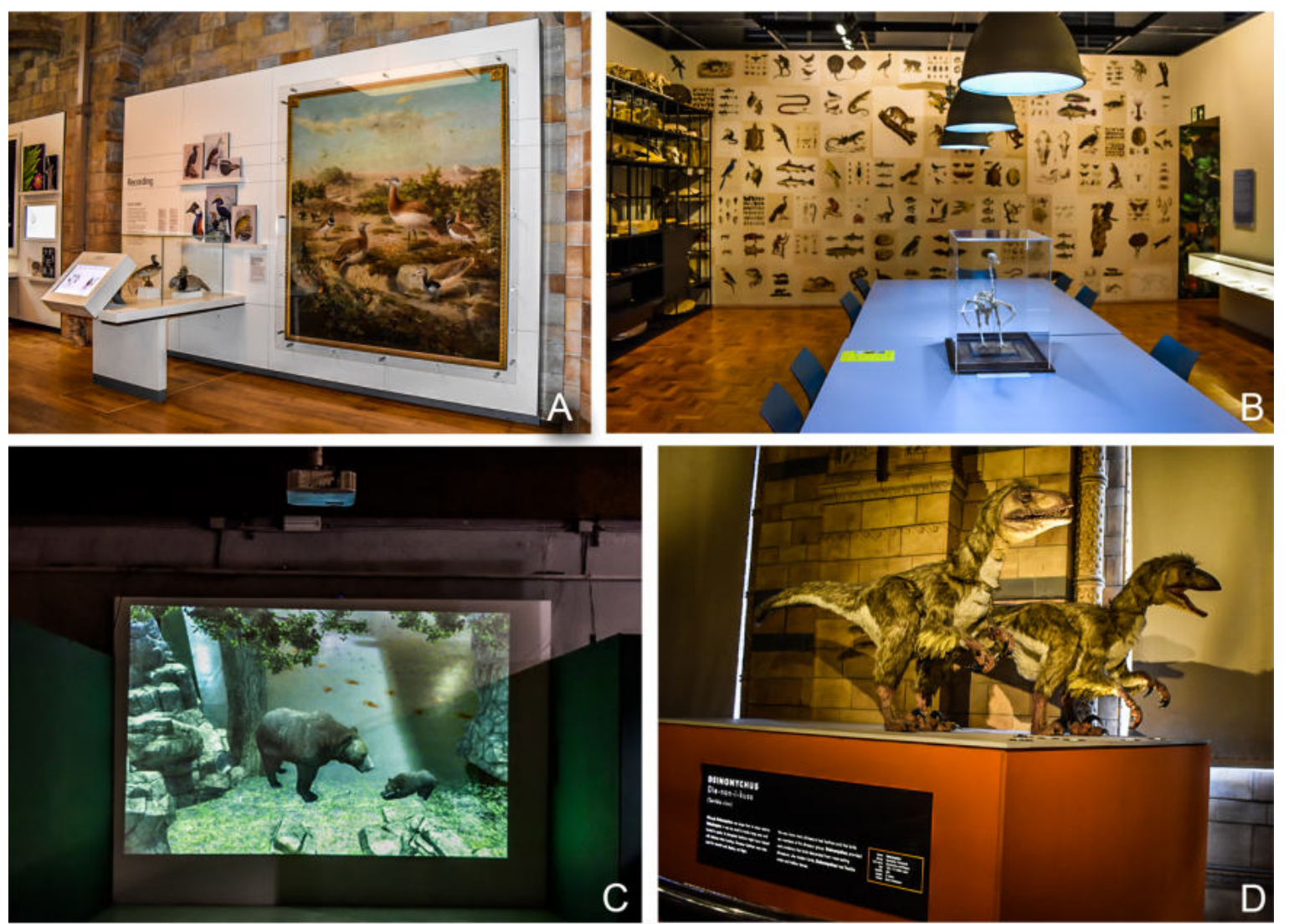

FIGURA 8: Exemplos da inclusão de elementos que consideramos característicos do subpadrão museográfico Public Understanding of Science presentes em exposições contemporâneas de museus de história natural. A. Junto a tradicionais taxidermias em vitrines e imagens de naturalistas, é possível identificar dois ecrãs (sendo o em primeiro plano tátil) na exposição Imagens of Nature, do NHM. B. Sala de Descoberta, na exposição "Biodiversidade: conhecer para preservar" do MZUSP, onde são realizadas atividades educativas e os visitantes tem acesso a uma "simulação" de como são as gavetas e armários das coleções científicas ("bastidores", armários pretos à esquerda da imagem). C. Utilização de realidade aumentada na exposição Reis da Europa Selvagem, no MUHNAC. D. Modelos robóticos de dinossauros emplumandos, na exposição Dinosaurs, no NHM. Fotos: Mariana Galera Soler, obtidas em visitas técnicas. A, C e D, visita técnica em Maio de 2018. B. Visita técnica em Julho de 2018. 
No contexto brasileiro, podemos destacar dois projetos que se adequam claramente ao subpadrão Public Understandin of Scienc. Em ordem cronológica, o Projeto da Estação Ciência, em São Paulo, iniciou na segunda metade da década de 1980. Realizado pela Waldisa Russio Guarnieri, tal instituição parte de uma premissa, bastante similar ao discurso de Oppenheimer quanto a conceção de ciência e arte como práticas humanas:

\begin{abstract}
"Ciência é, também, um complexo artefato humano e, portanto, integra a ricaprofunda e extensa gama das criações culturais. Se a Cultura nada mais é que a vida vivida e experimentada em toda a sua força, a Ciência, enquanto criação cultural, integra essa experiência e essa vivência. A partir dessa premissa geral e considerando o caso particular brasileiro em que o conhecimento científico constitui condição necessária de emancipação económica, política e social "(Guarnieri, 2010, p. 292)
\end{abstract}

“Decorre daí que a exposição não terá 'objetos únicos' sacralizados, mas modelos e protótipos, sobretudo criados por cientistas e mestres brasileiros ou atuando no país"(Guarnieri, 2010, p. 293)

A Estação Ciência foi a criada em 1987 e representou uma das principais instituições do movimento pioneiro que ocorreu no Brasil, na década de 1980, de popularização da ciência (Cavalcanti \& Persechini, 2011). Entretanto, encerrou suas atividades em 2013, quando houve a devolução do edifício onde estava alocada (antiga fábrica de tecelagem) e a dissolução dos acervos institucionais entre outros museus e centros da Universidade de São Paulo (instituição a que fazia parte) (Leão, 2016).

Mais recentemente, o Museu Catavento Cultural e Educacional, ou simplesmente Catavento, tornou-se rapidamente um dos mais expressivos espaços científico-culturais na região central de São Paulo (Brasil).

"Criado com a vocação de ser um espaço interativo que apresente a

ciência de forma instigante para crianças, jovens e adultos" ( "O Catavento". Disponível em:<http://www.cataventocultural.org.br/inf_palacio>. Acesso em 10 de Julho de 2019. Grifo nosso). 
Embora também apresente elementos museográficos do padrão Espetacular (descrito a seguir), o Catavento é atualmente um dos principais centros de ciência brasileiro, com gestão público-privada, e apresenta em seu espaço expositivo todos os indicadores elencados para o subpadrão museográfico Public Understanding of Science. De acordo com Padovan (2016), o Catavento foi criado a partir da visita dos seus proponentes a várias instituições identificadas como science centres e museus de ciências tradicionais, tais como o Papalote na cidade do México, Deutsches Museum, Science Museum.

O programa Ciência Viva, lançado em Portugal em 1996, também representa a influência do subpadrão museográfico Public Understanding of Science na constituição de novas exposições em instituições europeias. José Mariano Gago, então Ministro da Ciência e da Tecnologia após as eleições legislativas de 1995, é consensualmente apontado como o protagonista central da conceção e implementação inicial deste programa. Gago participou ativamente durante a primeira metade da década de 1990 em diversos grupos de trabalho, à escala europeia, cuja agenda centravase em questões como o desenvolvimento da produção científica e tecnológica, nos modos de relação entre ciência e sociedade, no ensino de ciências e na cultura científica dos cidadãos europeus. O confronto com estas problemáticas e o contato com experiências desencadeadas noutros países foram fundamentais para a escolha desse subpadrão museográfico e relevante para - lançamento do programa do Ciência Viva, facilitando, inclusive, a sua posterior projeção internacional (Conceição, 2011). Novamente, nota-se um alinhamento com as ideias de Oppenheimer:

"A maioria dos Centros Ciência Viva é, neste sentido, contrária à realização de visitas organizadas aos espaços expositivos, muito em particular quando se trata de acolher adultos ou famílias em momentos de lazer, na medida em que se entende que a liberdade de movimentos e a possibilidade de descobertas autónomas, orientadas pelos interesses de cada um, são condições intrínsecas ao tipo de oferta que se pretende disponibilizar" (Conceição, 2011, p. 247).

Em linhas gerais, nota-se que, no final da década de 1970, os museus científicos estavam largamente modificados, tendo revisado sua atenção ao público, as características, conteúdos e 
objetivos de suas exposições e seus programas educativos (Corral-Guillé, 2015; Karen A. Rader \& Cain, 2014).

\begin{tabular}{|c|c|c|c|c|}
\hline \multirow{12}{*}{ 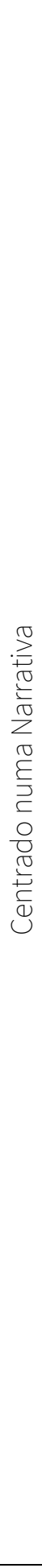 } & $\begin{array}{l}\text { No. Do } \\
\text { Indicador }\end{array}$ & $\begin{array}{c}\text { Subpadrão } \\
\text { Museográfico }\end{array}$ & Indicador & Autores-Fonte \\
\hline & 49 & $\begin{array}{l}\text { Public } \\
\text { Understanding of } \\
\text { Science }\end{array}$ & $\begin{array}{l}\text { Aparatos interativos } \\
\text { (hands-on) }\end{array}$ & $\begin{array}{l}\text { Barry, 2001; MacDonald, } \\
\text { 2004; Henning, 2006; } \\
\text { Delicado, 2010; Rader e } \\
\text { Cain, 2014; }\end{array}$ \\
\hline & 50 & $\begin{array}{l}\text { Public } \\
\text { Understanding of } \\
\text { Science }\end{array}$ & Ênfase no visitante & $\begin{array}{l}\text { Barry, 2001; MacDonald, } \\
\text { 2004; Henning, 2006; } \\
\text { Delicado, 2010; Rader e } \\
\text { Cain, 2014; Corral Guillé, } \\
2015\end{array}$ \\
\hline & 51 & $\begin{array}{c}\text { Public } \\
\text { Understanding of } \\
\text { Science }\end{array}$ & $\begin{array}{l}\text { Ênfase em princípios científicos } \\
\begin{array}{l}\text { (ciência descontextualizada } \\
\text { atemporal) }\end{array}\end{array}$ & $\begin{array}{l}\text { MacDonald, 2004; Henning, } \\
\text { 2006; Corral Guillé, } 2015\end{array}$ \\
\hline & 52 & $\begin{array}{l}\text { Public } \\
\text { Understanding of } \\
\text { Science }\end{array}$ & $\begin{array}{l}\text { Presença de salas de aula ou espaços } \\
\text { reservados para atividades ("discovery } \\
\text { rooms") }\end{array}$ & Delicado, 2010 \\
\hline & 53 & $\begin{array}{c}\text { Public } \\
\text { Understanding of } \\
\text { Science }\end{array}$ & $\begin{array}{l}\text { Ciência apresentada como um conjunto } \\
\text { de leis e com uma única verdade a ser } \\
\text { descoberta }\end{array}$ & $\begin{array}{l}\text { Barry, 2001; MacDonald, } \\
2004\end{array}$ \\
\hline & 54 & $\begin{array}{l}\text { Public } \\
\text { Understanding of } \\
\text { Science }\end{array}$ & $\begin{array}{l}\text { Autonomia do visitante no processo de } \\
\text { compreender a exposição (não há uma } \\
\text { narrativa única e estruturante de toda a } \\
\text { exposição) }\end{array}$ & $\begin{array}{l}\text { Henning, 2006; Delicado, } \\
\text { 2010; Rader e Cain, 2014; }\end{array}$ \\
\hline & 55 & $\begin{array}{l}\text { Public } \\
\text { Understanding of } \\
\text { Science }\end{array}$ & $\begin{array}{l}\text { Promoção de experimentos simples e } \\
\text { caseiros para descoberta auto-guiada }\end{array}$ & $\begin{array}{l}\text { Rader e Cain, 2014; } \\
\text { MacDonald, } 2004\end{array}$ \\
\hline & 56 & $\begin{array}{l}\text { Public } \\
\text { Understanding of } \\
\text { Science }\end{array}$ & $\begin{array}{l}\text { Ausência de diferentes perspetivas de } \\
\text { conhecimento } \\
\text { (conhecimentos locais, visões leigas, } \\
\text { indígenas) }\end{array}$ & Cameron et al., 2013 \\
\hline & 57 & $\begin{array}{c}\text { Public } \\
\text { Understanding of } \\
\text { Science } \\
\end{array}$ & $\begin{array}{l}\text { Painéis explicativos sobre o método } \\
\text { científico ou trabalho de "bastidores" ou } \\
\text { campo }\end{array}$ & $\begin{array}{l}\text { Rader e Cain, 2014; } \\
\text { Delicado, } 2010\end{array}$ \\
\hline & 58 & $\begin{array}{l}\text { Public } \\
\text { Understanding of } \\
\text { Science }\end{array}$ & $\begin{array}{l}\text { Conceitos científicos apresentados por } \\
\text { caminhos pré-definidos de } \\
\text { experimentação e interpretação }\end{array}$ & Rader e Cain, 2014 \\
\hline & 59 & $\begin{array}{c}\text { Public } \\
\text { Understanding of } \\
\text { Science }\end{array}$ & $\begin{array}{l}\text { Promover o "scandalous revelations" } \\
\text { (maravilhamento pelos resultados da } \\
\text { ciência) }\end{array}$ & $\begin{array}{l}\text { Rader e Cain, 2014; } \\
\text { MacDonald, } 2004\end{array}$ \\
\hline
\end{tabular}


Continuação Tabela 8:

\begin{tabular}{|c|c|c|c|c|}
\hline \multirow{6}{*}{ 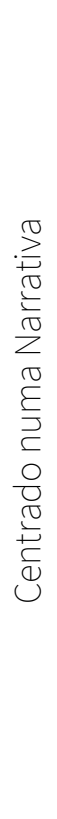 } & $\begin{array}{l}\text { No. Do } \\
\text { Indicador }\end{array}$ & $\begin{array}{l}\text { Subpadrão } \\
\text { Museográfico }\end{array}$ & Indicador & Autores-Fonte \\
\hline & 60 & $\begin{array}{c}\text { Public } \\
\text { Understanding of } \\
\text { Science }\end{array}$ & Promoção do entusiasmo pela ciência & Rader e Cain, 2014 \\
\hline & 61 & $\begin{array}{c}\text { Public } \\
\text { Understanding of } \\
\text { Science }\end{array}$ & $\begin{array}{l}\text { Interação multimédia } \\
\text { (ecrãs, vídeos e ambientes imersivos) }\end{array}$ & $\begin{array}{l}\text { Henning, 2006; Delicado, } \\
\text { 2010; Rader e Cain, 2014; }\end{array}$ \\
\hline & 62 & $\begin{array}{c}\text { Public } \\
\text { Understanding of } \\
\text { Science }\end{array}$ & $\begin{array}{l}\text { Referências ao quotidiano, com temas } \\
\text { ou objetos domésticos ou de uso } \\
\text { comum }\end{array}$ & $\begin{array}{l}\text { MacDonald, 2004; Henning, } \\
2006\end{array}$ \\
\hline & 63 & $\begin{array}{c}\text { Public } \\
\text { Understanding of } \\
\text { Science }\end{array}$ & Modelos de robótica & Delicado, 2010 \\
\hline & 64 & $\begin{array}{c}\text { Public } \\
\text { Understanding of } \\
\text { Science }\end{array}$ & Presença de jogos & Delicado, 2010 \\
\hline
\end{tabular}

Tabela 8: Tabela que resume os indicadores compartilhados pelo subpadrão museográfico Public Understanding of Science, que serão aplicados na análise das exposições estudadas nesse trabalho.

\subsection{Padrão Museográfico Espetacular}

"Spectacular museum design is the dominant trend"(Mairesse, 2015)

Como definido por Pickstone (2001), desde o final do século XIX, mas de forma mais expressiva no período pós-II Grande Guerra no século XX, o conhecimento científico ainda utiliza métodos e responde questões da história natural e das ciências analíticas, mas também tem sido crucial a sistemática produção de novidades para conectar o experimento e a inovação. Para o autor, na contemporaneidade a produção do conhecimento é amplamente dominada pela tecnociência: redes industriais, académicas e governamentais que produzem commodites, baseados em conhecimento científico.

Nas décadas pós- II Grande Guerra os símbolos de "modernidade" são compostos por princípios científicos, modos de produção racionais, estética funcional, proezas na área médica, profissionalismo e políticas de bem-estar. Tais símbolos foram construídos a partir do emprego de cientistas em empresas e agências do governo e por suas associações com as universidades. Sendo 
assim, as redes tecnocientíficas foram fundamentais para formar esta imagem e esta forma de civilidade (Pickstone, 2001).

No que tange os museus científicos, as exposições têm constituído o principal meio de comunicação e são cruciais as circunstâncias nas quais os objetos são apresentados para definição do status do acervo e a posição do visitante (Prior, 2006). Também nas exposições, questões relacionadas ao orçamento dos museus estão historicamente expressas: a Grande Depressão dos anos 1930, trouxe para a pauta a discussão o papel educacional dos custosos dioramas dos museus estadunidenses (Karen Ann Rader \& Cain, 2008), o New Exhibition Scheme do NHM foi uma das respostas institucionais para enfrentar a crise econômica e cortes orçamentais nos anos 1970 (CorralGuillé, 2015), bem como as reformas das exposições de diversos museus de história natural ingleses, descritas por Paddon (2014), estão associadas a mudança na forma de financiamento dessas instituições, com o aporte financeiro vindo das loterias, desde 1994.

Em um primeiro momento, a partir da intrincada relação entre ciência-governo-indústria, o movimento do Public Understanding of Science supracitado respondeu a demandas de "educar a sociedade" ou "interatividade". Todavia, nas últimas décadas do século XX, os profissionais de museus de história natural inseriram-se na lógica da indústria de consumo cultural. O argumento é que também estas instituições têm oferecido um produto - o conhecimento científico - e que poderiam, legitimamente, fazer propagandas, encenações ou utilizar outras estratégias de impacto, esforçando-se para ser mais atrativas para potenciais "consumidores" (novamente tem-se como premissa o conhecimento científico como commodity) (Karen Ann Rader \& Cain, 2014).

Consideramos que o dinheiro é um fator fundamental no desenvolvimento, uso e comunicação da ciência, em todos os níveis e através dos séculos (Andersen, Bek-Thomsen, \& Kjærgaard, 2012). Especificamente nos museus, a questão do financiamento está presente desde as primeiras fases do desenvolvimento da instituição museológica (Mairesse, 2015), sendo as respetivas estratégias de captação e utilização permanentemente contingentes e variáveis (Sherman \& Rogoff, 2003). A perceção do visitante como um consumidor, associada ao esvaziamento dos orçamentos públicos para os museus, concomitante com o entendimento de corporações industriais e comerciais de que o público dos museus também é consumidor de seus produtos, fomentou o 
financiamento privado de diversas exposições ${ }^{45}$. Notoriamente, a busca por mais audiências relaciona-se com o orçamento dos museus, uma vez que os financiamentos dependem dos números de público e há constante pressão dos patronos para manutenção ou aumento das respetivas audiências (Balloffet et al., 2014).

Assim, uma das mais recentes mudanças aparentes nas práticas museológicas é a "comercialização da museografia (tradução nossa para a expressão "commercialization of display", proposto por Prior, 2006, pg.514), com o aumento das exposições blockbuster e a provisão de experiências espetaculares ou de simulações (Prior, 2006). Rader e Cain (2014) citam o exemplo do espaço interativo Insect Zoo, no National Museum of Natural History - Smithsonian Institute (NMNH): a exposição aberta em 1977, foi financiada por um grupo de companhias que produziam e vendiam pesticidas ${ }^{46}$. Macdonald (1998) ao analisar o processo de conceção da exposição Food, no Science Museum, descreve as discussões (muitas vezes de caráter pessoal com os conselheiros e administradores) entre os possíveis patronos da exposição (uma rede de supermercados e uma indústria alimentícia) e as contrapartidas exigidas pelos mesmos, muitas vezes questionáveis para o corpo técnico da instituição.

As mudanças que configuram o padrão museográfico Espetacular são expressas tanto no modo como a museografia é realizada, como no papel da própria curadoria. Uma das mais notáveis mudanças tem sido a expansão de repertório que constitui a organização e arranjo da coleção. Alguns museus começaram a incluir atores e atrizes, cheiros, simuladores e exposições interativas

${ }^{45}$ Cabe destacar que a associação entre a museografia e os commodities tem raízes históricas antigas, ainda anteriores ao traçado por Guy Debord na sociedade do espetáculo, nos anos 1960. O século XIX testemunhou uma explosão massiva de tecnologias visuais e o desenvolvimento inerente de uma cultura de olhar (Prior, 2006). Tony Bennett (1995) evidenciou o caráter civilizador dos museus e exposições universais do século XIX e início do XX, comparando esses espaços com lojas de departamentos, nos seguintes pontos: ambos são abertos e permitem a entrada do público e funcionam como espaços de "emulação", locais de praticas miméticas onde são refinados gostos, valores e normas de conduta, que são amplamente difusas na sociedade.

Além disso, o crescimento das exposições internacionais também relacionou a cultura e o mercado de maneira ainda mais estreita, glorificando as nações e entretendo amplo público (Prior, 2006). As manifestações grandiosas e efémeras desses eventos, com a reconstrução de paisagens e biótopos, atrações vivas e seus grandes panoramas anteciparam a museografia do espetáculo, mais de um século mais tarde (Magnin, 2011).

${ }^{46}$ Na década de 1990, essa mesma exposição recebeu outro financiamento privado para renovações, tendo seu nome alterado para fazer referência a seu patrocinador. Orkin é uma empresa de pesticidas e controle de pragas e a sala agora chama "O. Orkin Insect Zoo" e mantém-se aberta até os dias correntes. Na página do NMNH está disponível um breve descritivo do espaço: <https://naturalhistory.si.edu/education/exhibitions/insectzoo.html. Acesso em 8 de Fevereiro de 2019. 
(Prior, 2006). Entre os anos 1980 e o início dos anos 1990, a similaridade na museografia dos museus científicos e science centres aproximou ainda mais essas instituições de parque temáticos, mercados, shoppings e do cinema blockbuster. Tal hibridização resultava da crescente porosidade entre as esferas culturais, o entretenimento, museus e parques de diversões. Por um lado, museus criavam ambientes inovadores e animados, que incluíam elementos recreativos para mediar conteúdo. Por outro, os parques de diversões buscavam melhorar as experiências recreativas de seus visitantes, incluindo conteúdos que fossem culturalmente mais ricos (Okan, 2003) ${ }^{47,48}$.

Embora ainda existam diferenças fundamentais entre exposições em instituições científicas, museus de arte e centros de património, no padrão museográfico Espetacular afinidades sugerem no mínimo na constituição de exibições mais populares, interativas e uma crescente tendência a dramatização (Prior, 2006).

Data também das últimas décadas do século XX o movimento do "edutainment", relacionado à crescente midiatização dos museus (M. Henning, 2006). Edutainment é um gênero híbrido, que permite relacionar formatos materiais, narrativos e interativos ("game-like format"), de modo informal e não-disciplinar [INDICADOR 74, Tabela 9].

A proposta do "edutainment" é atrair e manter a atenção dos visitantes e suas emoções por meio de aparatos interativos, geralmente eletrônicos, que fornecem animações realistas, promovem ambientes imersivos [INDICADOR 69, Tabela 9] e parte do conceito de que aprender deve ser inevitavelmente "divertido" [INDICADOR 76, Tabela 9] (Okan, 2003). Uma tendência que já vinha sendo observada desde que a linguagem mediática dos science centres impregnaram todo o meio museológico, desde os anos 1960/70 (MacDonald, 2004).

De modo que desde os anos 1980, os museus têm oferecido suas próprias versões do edutainment: lojas e cafés de museus com estoques de produtos licenciados, investimentos em

47 Atrações como Walt Disney World marcam a vida do público repetidamente, desde o final da década de 1960. Não é surpreendente que muitos empreendimentos, incluindo desporto, recreação e o mercado, tenham tentado emular os métodos de instalação deste parque, na esperança de atingir similar assombro e maravilhamento em suas audiências (Counts, 2009), um fenómeno conhecido como "Disneyfication" ou “Disneylandization" (Balloffet, Courvoisier, \& Lagier, 2014).

${ }^{48}$ Além disso, as novas tecnologias de comunicação potencializaram a convergência entre educação e entretenimento, também fora das paredes dos museus. Aplicações multimédia podem ser usadas dentro do contexto da exposição ou no ambientevirtual, recriando a atual exposição, como por exemplo a iniciativa do Google Art Project (Balloffet et al., 2014). 
propaganda, como a utilização de painéis gigantes na suas fachadas e anúncios em letreiros e outdoors da cidade [INDICADOR 74, Tabela 9] (Karen Ann Rader \& Cain, 2014)(Figura 9).

Diante dessa lógica mercadológica e da disputa por audiência, a museografia espetacular é claramente centrada no visitante [INDICADOR 75, Tabela 9], buscando promover o que ele gostaria de aprender [INDICADOR 76, Tabela 9] (e certificar esse aprendizado por meio de estudos de público) e satisfazer a crítica e assegurar o financiamento (Karen Ann Rader \& Cain, 2014).

Os museus e science centres sobrepunham suas missões e práticas, com foco na aplicabilidade da ciência para a sociedade [INDICADOR 72, Tabela 9], embora raramente preocupados com a relevância social e pessoal do conteúdo exposto. Grupos políticos e profissionais reclamavam que essas instituições continuavam a ignorar o complicado legado das descobertas científicas e promoviam uma inequívoca visão positiva e progressista da ciência [INDICADOR 70, Tabela 9](Delicado, 2008; MacDonald, 2004).

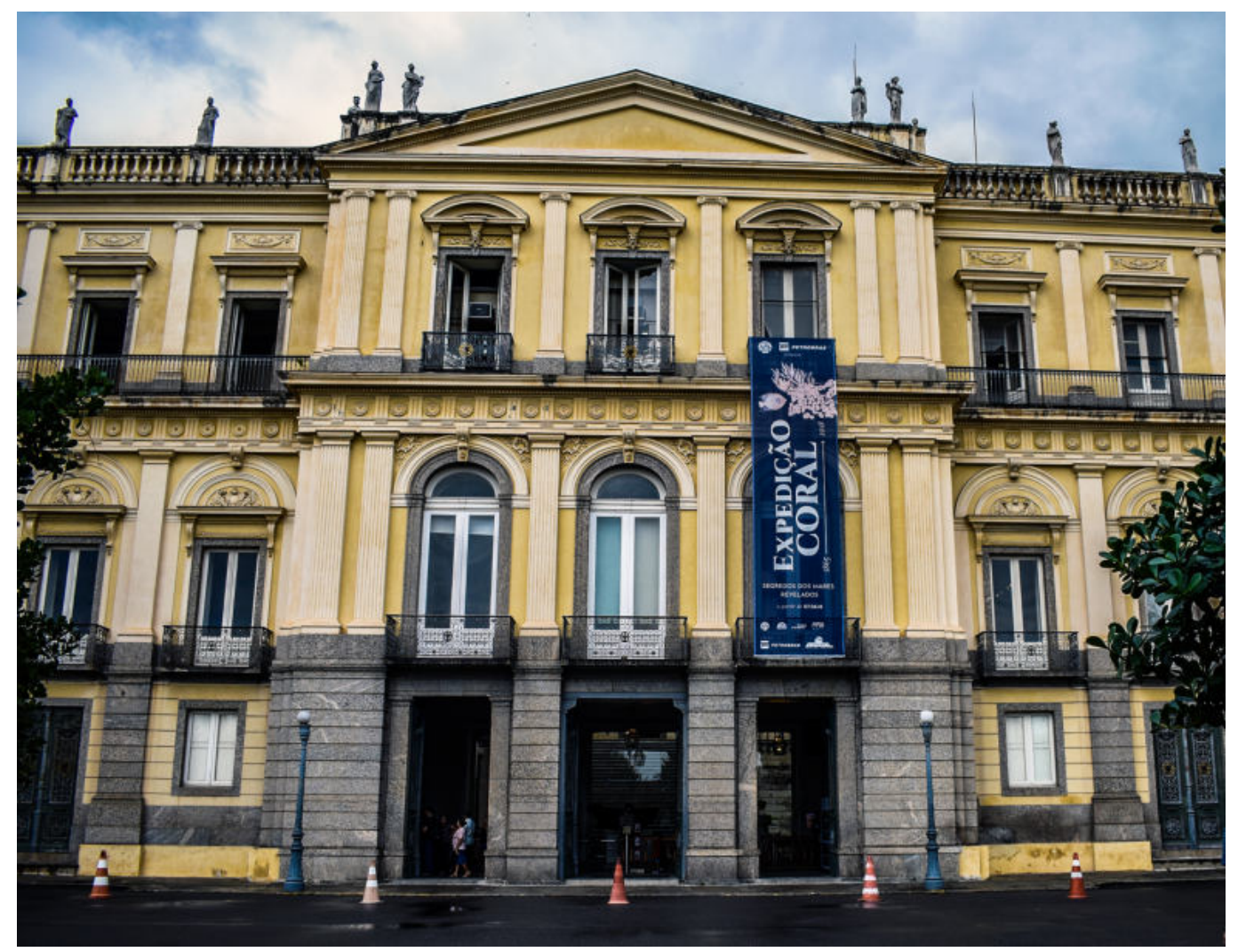

FIGURA 9: Exemplos da inclusão de elementos característicos do padrão museográfico Espetacular. Utilização de grandes faixas de divulgação das exposições que cobrem parte da fachada dos museus. Ressalta-se que a expressão do padrão museográfico Espetacular em países como Brasil e Portugal é proporcional ao baixo investimento público e privado em ações científicas e culturais. Embora os elementos estejam presentes, em geral, são mais simples ou adaptações de materiais e ações de tradicionais museus. Fotos: Mariana Galera Soler, obtidas em visita técnica em Agosto de 2018. 
Secord (1996) também critica a premissa do visitante como consumidor e o conhecimento como um commodity, uma vez que consumidores esperam produtos finalizados e que tenha alguma garantia. Quando o conhecimento falha em entregar o que se espera, oferecendo respostas incertas ou controvérsias, pode ocorrer a desilusão dos diferentes públicos.

Counts (2009) revisa a museografia do espetáculo (tradução nossa para termo original "spetacular design") a partir de experiências em museus e parques temáticos estadunidenses. De acordo com o autor, essa museografia é um método para a produção de exposições que pretendem transportar o visitante para novos locais, engaja-lo uma história contada e causar impacto duradouro. Ademais, o autor identifica quatro técnicas associadas com o design do espetáculo: (i) efeitos dramáticos (iluminação, áudio, vídeo e/ou escuridão) [INDICADOR 65, Tabela 9]; (ii) narrativa (principalmente por meio do desenvolvimento de uma história com clímax) [INDICADOR 66, Tabela 9]; (iii) elementos museográficos em grande escala (mais do que o tamanho da exposição, busca-se inserir o visitante no espaço, como por exemplo o uso de IMAX ou telas gigantes) [INDICADOR 67, Tabela 9]; e (iv) autenticidade, que não necessariamente passa pela presença de objetos reais, mas sim na credibilidade dos efeitos usados e da instituição promotora, ou a capacidade de tocar em objetos, assistir performances, inserir-se em ambientes realísticos ou experiências físicas [INDICADOR 68, Tabela 9] (Counts, 2009).

Nas exposições desenvolvidas a partir década de 1980, espera-se que os visitantes naveguem entre vários tipos de informação e modos de representação. Conexões poéticas, visuais e semelhanças são tão possíveis quanto comparações científicas. Em resumo:

\footnotetext{
"What is interesting is that these apparently decorative arrangements of specimens replace the simulation of the visible habitat and appearance of animals (which we find in the dioramas) with a simulation of larger principles relating to biodiversity and new theories of biological life. Or rather, the arrangement corresponds to the visual forms associated with these theories" (M. Henning, 2006, p. 146, grifo nosso)
}

Dois exemplos incontornáveis para a compreensão do padrão museográfico Espetacular são as exposições: Grand Galerie de l'Evolução do Muséum national d' Histoire Naturelle (MNHN) e Hall of Biodiversity (AMNH). 
Inaugurada em 1994, a Grand Galerie de l'Evolução do Muséum national d' Histoire Naturelle (MNHN) sintetiza diversos dos elementos supracitados e buscou tornar o sólido e centenário edifício da instituição francesa em um dinâmico centro de comunicação da cultura científica. A exposição busca ser uma janela para a ciência, mostrar aos visitantes a força dos questionamentos e da verificação de hipóteses na construção da teoria da evolução, apelando para a combinação de abordagem simbólica/filosófica das diversas formas de vida, que apela aos sentidos e as emoções ${ }^{49}$ (Paddon, 2014).

Seguindo o mesmo padrão museográfico, em 1998, o AMNH inaugurou o Hall of Biodiversity, uma exposição dedicada a ser um retrato dinâmico da beleza e da abundância da vida na Terra, como destaque para a biodiversidade e múltiplas histórias sobre as espécies extintas ou ameaçadas de extinção (Paddon, 2014) (Figura 10).

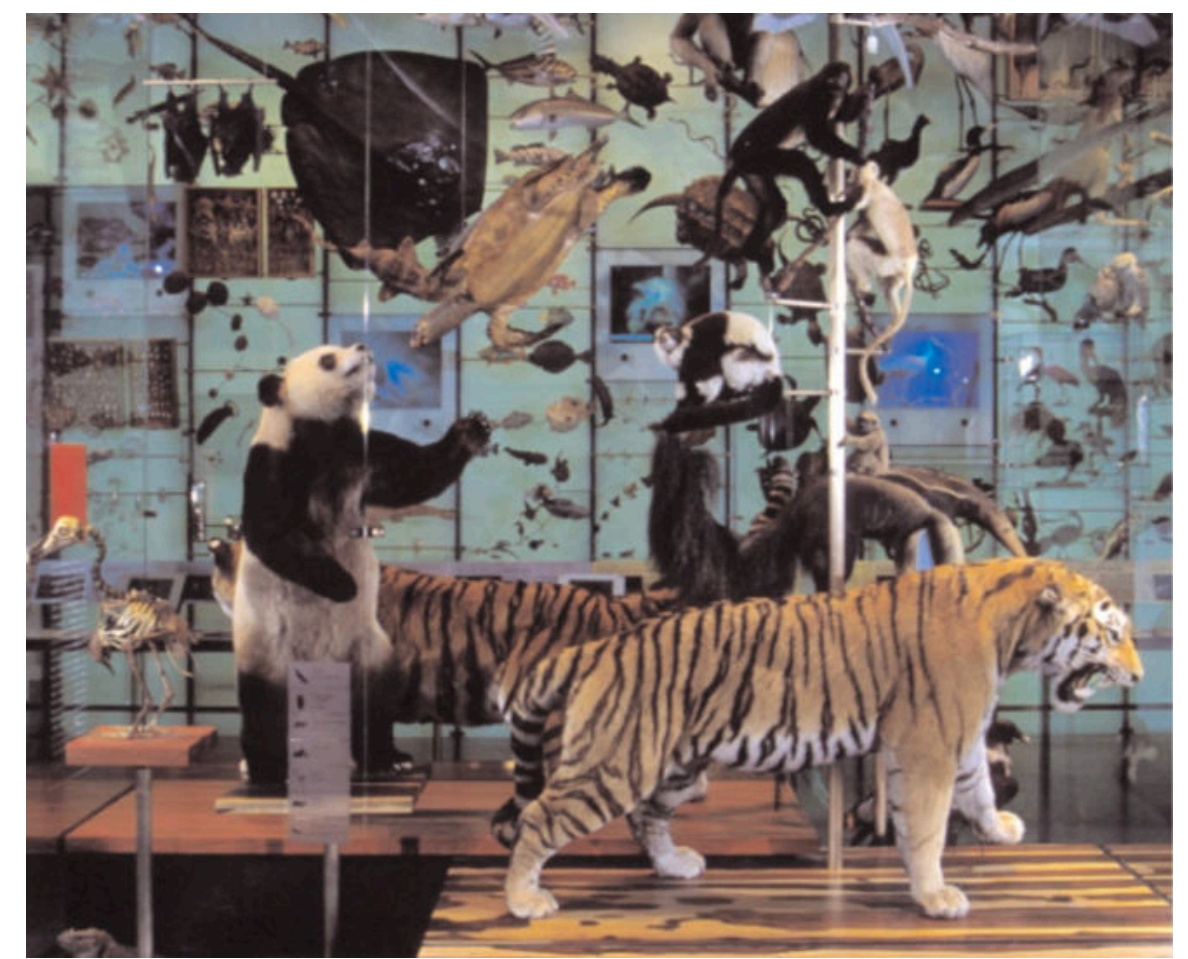

FIGURA 10. Exemplo de exposição que promove o Padrão Museográfico Espetacular. Spectrum of Life Wall, vitrine com destaque para as espécies ameaçadas de extinção na Terra. Parte do Hall of Biodiversity, no AMNH. Foto: Hall of Biodiversity Educator's Guide, disponível em: <https://www.amnh.org/exhibitions/permanent-exhibitions/hall-ofbiodiversity/educator-resources>. Acesso em 12 de Fevereiro de 2019.

${ }^{49}$ A conceção sobre as incertezas da ciência refletem a discussão sobre controvérsias científicas, um importante contributo das Social Sciences. Contudo, no padrão museográfico Espetacular o que se ressalta é o poder da ciência em resolver problemas e não o método científico em sua aparente linearidade. 
Em ambos os casos, os espécimes apresentados têm pouca importância individual (embora sejam taxonomicamente identificados), devendo ser considerados dentro de um espectro [INDICADOR 77, Tabela 9] (Maigret, 1996). De acordo com Henning (2006), a forma que os espécimes estão inseridos no padrão museográfico Espetacular exibe interdependência e inter-relações.

Além disso, as mensagens comunicadas pelas exposições desse padrão são consideradas demasiadamente complexas para serem transmitidas por um indivíduo ou um pequeno conjunto de espécimes, sendo os percetíveis por meio do arranjo da luz, do som e do cenário [INDICADOR 65, Tabela 9] (Maigret \& Raulin-Cerceau, 2000). Muitas das escolhas são baseadas na apresentação estética [INDICADOR 71, Tabela 9], alicerçadas mais nas sensações do que nas explicações, e há diversos aparatos multimédia com informações adicionais [INDICADOR 78, Tabela 9] (Maigret \& Raulin-Cerceau, 2000).

Mais recentemente, o Museo delle Scienze em Trento (Norte da Itália) ${ }^{50}$ representou a história da vida e a biodiversidade alpina com elementos que podemos identificar com padrão museográfico Espetacular. Como um projeto cultural que iniciou em 2006 e aberto ao público em 2013, a instituição quis afastar-se da visão de "museu tradicional" ao mesmo tempo que também não se alinhava com centro científico interativo simples, lúdico e descontextualizado (Negra \& Lanzinger, 2014) .Tendo como missão prioritária o diálogo entre natureza, ciência / tecnologia e sociedade [INDICADOR 72, Tabela 9], a museografia articula-se com a arquitetura do edifício na construção de ambientes imersivos [INDICADOR 69, Tabela 9],com acervo esteticamente selecionado [INDICADOR 66, Tabela 9] disposto de modo cenográfico (recriando a distribuição da fauna ao longo dos estratos de uma montanha) [INDICADORES 77, Tabela 9] e com intenso volume de conteúdos apresentados em recursos multimédia [INDICADOR 78, Tabela 9].

No Brasil, em 2015 foi inaugurado o Museu do Amanhã. Autoproclamado como um museu científico pela sua equipa curatorial, apresenta também características do padrão museográfico Espetacular, que vão desde a obra arquitetónica de Santiago Calatrava, o financiamento realizado por diferentes instituições privadas (sendo um banco espanhol seu patrocinador master), exposição

${ }^{50}$ Embora o Museo delle Scienzie não seja citado correntemente na literatura científica que não seja em língua italiana, esta instituição foi apontado como uma referência contemporânea para curadores, técnicos e investigadores entrevistados durante a realização desta tese. Por isso, consideramos importante enquadrá-lo no referencial que será utilizado para o estudo de exposições. 
articulada em módulos [INDICADOR 73, Tabela 9], com grande apelo ao uso de recursos multimédia [INDICADOR 78, Tabela 9] para a criação de ambientes imersivos [INDICADOR 69, Tabela 9]. A ciência é apresentada como verdade única e inequívoca [INDICADOR 70, Tabela 9] que o visitante é convidado a experienciar [INDICADOR 74, Tabela 9].

A museografia dos últimos 30 anos promoveu a criação de espaços cada vez mais sofisticados ao redor dos acervos expostos. Os suportes das exposições como vitrines, iluminação e etiquetas não desapareceram, no entanto se encontram inseridos num conjunto de ferramentas de comunicação integrada, contribuindo para visões ainda mais apuradas do objeto e uma imagem mais coerente do mundo. Os objetos são colocados em um conjunto que indica seu pertencimento a um mesmo tema [INDICADOR 77, Tabela 9](Magnin, 2011).

No inicio do século XXI, mais estadunidenses iam ver museografia e ter experiências, do que passivamente observar coleções, como a principal característica que definia o trabalho do museu (Karen Ann Rader \& Cain, 2014). Assim, se os museus são desde longa data locais de espetáculo e convívio social, o que parece ser novidade é a escala dos empreendimentos e a incessante reprodução de práticas dos medias de massa. O museu espetacular caracteriza-se pela preponderância das imagens, dos eventos e das técnicas (incluindo manobras publicitárias), combinados com o entretenimento. Nas exposições com audiências de sucesso estão presentes representações elegantes e imersivas que funcionam em conjunto com a publicidade para produzir um espetáculo possa ser comercializado como uma forma de legitimidade cultural. De forma que os museus contemporâneos ocupam um lugar único dentro desse processo: lar e a fonte definidora do fenômeno do original, ao mesmo tempo em que promove sua circulação, como parte da commodity culture (Sherman \& Rogoff, 2003, p. xvii). 


\begin{tabular}{|c|c|c|c|c|}
\hline \multirow{16}{*}{ 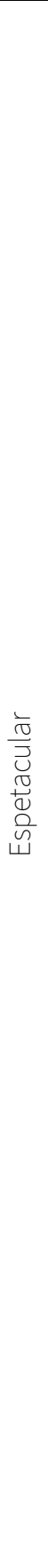 } & $\begin{array}{l}\text { No. Do } \\
\text { Indicador }\end{array}$ & $\begin{array}{c}\text { Padrão } \\
\text { Museográfico }\end{array}$ & Indicador & Autores-Fonte \\
\hline & 65 & $\begin{array}{c}\text { Características } \\
\text { comuns }\end{array}$ & $\begin{array}{l}\text { Efeitos dramáticos, principalmente com uso de luz e } \\
\text { som }\end{array}$ & Prior, 2006; Counts, 2009 \\
\hline & 66 & $\begin{array}{c}\text { Características } \\
\text { comuns }\end{array}$ & $\begin{array}{l}\text { Narrativas com encadeamento de eventos, aparatos ou } \\
\text { histórias (pode haver clímax) }\end{array}$ & $\begin{array}{l}\text { Prior, 2006; Counts, 2009; } \\
\text { Magnin, } 2011\end{array}$ \\
\hline & 67 & $\begin{array}{l}\text { Características } \\
\text { comuns }\end{array}$ & $\begin{array}{l}\text { Recursos expográficos em grande escala (ampliações } \\
\text { de imagens, grandes projeções) }\end{array}$ & Counts, 2009 \\
\hline & 68 & $\begin{array}{l}\text { Características } \\
\text { comuns }\end{array}$ & $\begin{array}{l}\text { "Autenticidade": encontro com objetos reais ou } \\
\text { certificados pela autoridade da instituição, } \\
\text { performance com pessoas (dramatização), } \\
\text { experiências físicas ou inserção em ambiente real }\end{array}$ & Prior, 2006; Counts, 2009 \\
\hline & 69 & $\begin{array}{l}\text { Características } \\
\text { comuns }\end{array}$ & Museografia cria ambientes imersivos & $\begin{array}{l}\text { Sherman \& Rogoff, 2003; } \\
\text { Okan, 2003; Counts, 2009; } \\
\text { Magnin, 2011 }\end{array}$ \\
\hline & 70 & $\begin{array}{l}\text { Características } \\
\text { comuns }\end{array}$ & Visão progressista e inequívoca da ciência & $\begin{array}{l}\text { MacDonald, 2004; } \\
\text { Delicado, } 2010\end{array}$ \\
\hline & 71 & $\begin{array}{l}\text { Características } \\
\text { Comuns }\end{array}$ & Seleção estética do acervo & $\begin{array}{l}\text { Maigret, 1996; Maigret \& } \\
\text { Raulin-Cerceau, } 2000 ; \\
\text { Paddon, } 2014\end{array}$ \\
\hline & 72 & $\begin{array}{l}\text { Características } \\
\text { Comuns }\end{array}$ & $\begin{array}{l}\text { Apresentação da aplicabilidade da ciência para a } \\
\text { sociedade }\end{array}$ & \begin{tabular}{|l|} 
MacDonald, 2004; \\
Delicado, 2010 \\
\end{tabular} \\
\hline & 73 & $\begin{array}{l}\text { Características } \\
\text { Comuns }\end{array}$ & $\begin{array}{l}\text { Facilmente renovada (com estruturas moldáveis, que } \\
\text { não afetam diretamente a arquitetura do edifício) }\end{array}$ & Magnin, 2011 \\
\hline & 74 & $\begin{array}{l}\text { Características } \\
\text { Comuns }\end{array}$ & $\begin{array}{l}\text { Incorporação de elementos do movimento } \\
\text { "edutainment" }\end{array}$ & $\begin{array}{l}\text { Okan, 2003; Balloffet, } \\
\text { Courvoisier, \& Lagier, } 2014\end{array}$ \\
\hline & 75 & $\begin{array}{l}\text { Características } \\
\text { Comuns }\end{array}$ & Ênfase no visitante & Rader e Cain, 2014 \\
\hline & 76 & $\begin{array}{l}\text { Características } \\
\text { Comuns }\end{array}$ & $\begin{array}{l}\text { Centrado no que o visitante quer aprender; aprender } \\
\text { como ato divertido }\end{array}$ & $\begin{array}{l}\text { Okan, 2003; Rader e Cain, } \\
2014\end{array}$ \\
\hline & 77 & $\begin{array}{l}\text { Características } \\
\text { Comuns }\end{array}$ & $\begin{array}{l}\text { Espécimes identificados individualmente, mas } \\
\text { interpretados em conjunto com outros }\end{array}$ & $\begin{array}{l}\text { Maigret, 1996; Maigret \& } \\
\text { Raulin-Cerceau, 2000; } \\
\text { Henning, 2006; Magnin, } \\
2011\end{array}$ \\
\hline & 78 & $\begin{array}{l}\text { Características } \\
\text { Comuns }\end{array}$ & $\begin{array}{l}\text { Utilização de aparatos multimédia com informações } \\
\text { adicionais }\end{array}$ & $\begin{array}{l}\text { Maigret \& Raulin-Cerceau, } \\
\text { 2000; }\end{array}$ \\
\hline & 79 & $\begin{array}{l}\text { Características } \\
\text { Comuns }\end{array}$ & $\begin{array}{l}\text { Os objetos são colocados em um conjuntos que } \\
\text { indicam o pertencimento a um mesmo tema }\end{array}$ & Magnin, 2011 \\
\hline
\end{tabular}

Tabela 9: Tabela que resume os indicadores compartilhados pelo Padrão Museográfico Espetacular, que serão aplicados na análise das exposições estudadas nesse trabalho. 
Biodiversidade Musealizada: Formas que Comunicam

2.6.1 Padrão Museográfico baseado em exposições blockbuster

[blockbuster exhibition] "(...) created a paradigm shift in the way museums operate within their communities and public programming"(Turner, 2011)

Blockbusteré um termo alemão que denomina as bombas utilizadas na II Grande Guerra para destruir grandes partes de uma cidade. No contexto museológico, refere-se à exposições poderosas e revolucionárias (Dean, 1994, p. 159). Nesse estudo, consideramos as exposições blockbuster como um tipo de exposição que possui características únicas e que influenciaram outros tipos de exposições, como supracitado por Turner (2011), o que subsidia um subpadrão museográfico. Consideramos que esse subpadrão é uma derivação do padrão museográfico espetacular e, portanto, compartilha suas características comuns descritas no tópico anterior e sumarizadas na Tabela 9, mas acumulam particularidades que servirão de identificadores e que são apresentadas ao longo do texto que se segue e na Tabela 10.

As exposições blockbuster representam um fenómeno recente e bastante controverso no campo da Museologia. Diferentes autores, como por exemplo: Freedberg et.al, (1986), Rectanus (2006), Mairesse (2015) e Zaky (2017), reconhecem a origem desses eventos no final dos anos 1960 e início dos anos 1970, no Metropolitan Museum of Art sob a direção do diretor Thomas Hoving. Hoving foi um dos mais importantes curadores do século XX e introduziu mudanças significativas no MoMA, criando uma plano expositivo que combinava a produção do show business com o prestígio e a aura da fine art, por exemplo com a utilização de grandes painéis de anúncio das exposições nas fachadas [INDICADOR 81, TABELA 10]e melhor acesso físico a instituição. Além disso, foi responsável pela montagem estadunidense da exposição The Treasures of Tutankhamun, o marco inicial das 
exposições blockbuster, em 1972, com 55 objetos da tumba do menino-faraó, muitos dos quais em ouro ou encrustados de pedras preciosas ${ }^{51,52}$.

As exposições blockbuster desde seu início estadunidense, passaram a circular pelo mundo e influenciar também os espaços disponíveis e o modo como eram realizadas as exposições permanentes, uma vez que as primeiras são iminentemente temporárias e itinerantes (Freedberg et al., 1986).

De acordo com Berryman (2013), esse tipo de exposição está baseado em uma fórmula comum: presença de objetos icónicas ou personagens ou temas de grande impacto [INDICADOR 85, TABELA 10], intensa atividade comercial (merchandising) [INDICADOR 84, TABELA 10] e apelo popular de massa [INDICADOR 86, TABELA 10]. Essa rígida fórmula, mais próxima aos espetáculos do que os movimentos identitários do final do século XX, levaram Freedberg e colaboradores (1986) a afirmar que "nineteenth-century-style treasure exhibitions popular again" (Freedberg et al., 1986, p. 358). Essa conexão histórica entre espetáculo, museus e espetadores e recente aproximação estética é retomada por Griffiths (2008), no livro "Shivers Down Your Spine: Cinema, Museums, and the Immersive View".

Alguns entusiastas desse tipo de museografia afirmam que as exposições blockbuster tornaram os museus efetivamente democráticos, evocando audiências novas e maiores (Elsen, 1986). Tendo em vista que são usualmente destinadas para pessoas que normalmente não vão aos museus, apresentam um formato acessível [INDICADOR 87, TABELA 10] e de intenso apelo popular [INDICADOR 86, TABELA 10] (West, 1995). Elsen(1986) resume em: "The blockbuster is the most rapid

${ }^{51}$ A primeira montagem de The Treasures of Tutankhamun foi um esforço diplomático entre os governos da Inglaterra e do Egito. Realizada no British Museum com mais de 70 objetos originais, a exposição é até hoje considerada um dos maiores sucessos da instituição, além de ter propósitos humanitários, uma vez que seus lucros serviram para ajudar a proteção do patrimônio egípcio. Apenas nessa primeira montagem, que teve seis meses de duração, The Treasures of Tutankhamun recebeu mais de 1,5 milhões devisitantes. Aitinerância The Treasures of Tutankhamun foi possível pela articulação diplomática de corporações, fundações e patrocinadores governamentais, cujo trajeto passou porquase uma dezena de países eatraiu mais de 10 milhões devisitantes (Zaky,2017). A cronologia dessa exposição (e outras derivadas) pode ser vista em: http://mww.kingtutart.com (acesso em 02 de Abril de 2018). Uma outra exposição sobre o mesmo tema está atualmente aberta em Lisboa. http://wnw.tutankamon.pt (Acesso em 2 de Novembro de 2019).

${ }^{52}$ Cabe a ressalva que a internacionalização de programas de exposições, circulação de coleções, de curadores e diretores de museus já é uma característica bem estabelecida de muitos museus nacionais, mesmo antes do advento das exposições blockbuster (Rectanus, 2006). Sheets-Pyenson (1988) discutiu a circulação de modelos arquitetónicos e profissionais - diretores e curadores- entre instituições norte-americanas, australianas, argentinas e inglesas. Lopes e Podgorny (2000) descrevem esse movimento desde o final do século XIX entre museus latino-americanos. 
and dramatic way to develop an awareness of understanding of and tolerance for art" (Elsen, 1986, p. 24).

A habilidade de atrair multidões também é entendida como uma oportunidade pedagógica. Por apresentar o conteúdo em um formato acessível [INDICADOR 87, TABELA 10], as exposições blockbuster oferecem diferentes opções de free-choice learning [INDICADOR 88, TABELA 10] (O’Reilly \& Lawrenson, 2014). Igualmente, a maioria dessas exposições são acompanhadas da venda de longos catálogos, que posicionam o conteúdo dentro de um contexto educacional e do currículo escolar [INDICADOR 90, TABELA 10] (O’Reilly \& Lawrenson, 2014; Karen Ann Rader \& Cain, 2014). É ainda possível argumentar que servem para a educação geral e ampliam a missão do museu, uma vez que encorajam os visitantes a explorar outros espaços da instituição, gerando interesses que poderão ressoar mesmo depois da visita, ao longo da vida dos visitantes (Karen Ann Rader \& Cain, 2014)

Outro benefício das exposições blockbuster é promover as trocas entre instituições, o que pode ter dois significados: promover relações interinstitucionais, permitindo o museu hospedar exposições exclusivas e de grande atração pública, e estabelecer a reputação das instituições globalmente, que por sua vez podem divulgar suas coleções, experiências profissionais e práticas profissionais (O’Reilly \& Lawrenson, 2014).

Mesmo diante dessa série de proveitos, as exposições blockbuster são controversas (Shaman, 1995), e a principal crítica está baseada no financiamento das mesmas. Uma vez que se tratam de exposições itinerantes e com acervos de diversas origens, existem altos custos associados ao transportes e seguros de objetos (Barker, 1999a), além de uma crescente preocupação ambiental, com a pegada ecológica desses eventos (Lambert \& Henderson, 2011).

Ademais, o alto custo da museografia, associado ao design e ricamente apoiada em aparatos multimédias [INDICADOR 97, TABELA 10], elevam o custo de produção e exige conhecimentos 
técnicos para além daqueles habitualmente disponíveis nas instituições, tornando os museus dependentes de escritórios de design e informática especializados ${ }^{53,54}$.

Exposições blockbuster assentam a lógica consumista dentro dos museus, compartilhada com shopping centres, parques temáticos e science centres. De acordo com Barker (1999): "in the consumer society of today, it can be argued, the spectacle finds its typical expression in the image that serves to promote consumption” (Barker, 1999a, p. 18).

Designers buscam criar experiências memoráveis, simulando ambientes completos, não necessariamente relacionados aos objetos de coleções. Menos incumbidos da fidelidade das "coisas reais", importaram a estética comercial [INDICADOR 82, TABELA 10], a robótica e animatrônica [INDICADOR 91, TABELA 10] e os blacklights para criar experiências que evocam o espanto e maravilhamento. Por vezes também agregam elementos da cultura popular, trazendo personagens já consagrados e criando espaços onde os visitantes possam tirar fotos interagindo com os mesmos [INDICADOR 95, TABELA 10] (Chu, 2015). De forma que o design tornou-se tão importante quanto o conteúdo e os propósitos educacionais das exposições (Karen Ann Rader \& Cain, 2014).

Com os altos custos associados, as exposições blockbuster tornaram-se possíveis apenas por meio de financiamentos corporativos [INDICADOR 80, TABELA 10], portanto "the blockbuster exhibition is, in essence, a commercial venture" (O’Reilly \& Lawrenson, 2014, p. 159). Esse é um dos aspetos fundamentais da crítica a esse tipo de exposição, uma vez que o financiamento privado contesta a autonomia dos museus. É possível identificar seus reflexos na dinâmica institucional dos museus contemporâneos, pois não apenas as corporações assumem o papel de patronos - o que Ihes fornece dividendos em forma da "imagem" e boa vontade - como também provêm modelos para expansão, profissionalização e reorganização das instituições museais. Com executivos corporativos inseridos nos conselhos administrativos, museus racionalizaram e aumentaram suas

${ }^{53}$ Nesse contexto, a especialização das instituições tornou-se menos significativa, quando diretores de museus e outros profissionais movem-se entre museus etnográficos e science centres, de museus de arte para museus de história natural. Um limitado número de companhias de design e produtores especialistas produzem com alto custo e design espetacular os grandes museus do mundo. Consequentemente, existe grande diversidade em cada museu, embora exista mais homogeneidade entre os museus, mesmo que cada um enfatize uma característica distintiva (M. Henning, 2006).

${ }^{54}$ Pelo menos nos grandes museus, os departamentos de curadoria eeducação também foram profissionalizados e altos níveis de formação tornaram-se regra, compartilhando apresentações, recursos de financiamento e estratégias pedagógicas com outras instituições. O processo de profissionalização da educação em museus reforçou as similaridades entre as instituiç̧̃es, assim como avaliações e métodos de avaliação educacional externos (Karen Ann Rader \& Cain, 2014). 
estratégias de relações públicas e administração de recursos, com a contratação de especialistas na área (Shaman, 1995).

Outras críticas as exposições blockbuster dizem respeito às questões relacionadas ao conhecimento apresentado e a lógica de funcionamento dos museus que as recebem. Nesse sentido, Freedberg e colaboradores (1986) considera que as exposições possuíam valor histórico substancial e baseadas em considerações intelectuais, e não de marketing, foram restringidas ou modificadas, não apenas por muitas das maiores instituições, mas também por museus menores. Os especialistas são convidados pelos museus a contribuir para uma exposição blockbuster, mas sua atuação é pontual na construção de catálogos ou argumentos da narrativa, trabalhando sob prazos curtos e sem uma coordenação cientificamente especializada. Contudo, cabe destacar que a narrativa dessas exposições apresenta-se com um conteúdo académico e uniforme, pouco dialogando com as realidades locais [INDICADOR 96, TABELA 10] (Karen Ann Rader \& Cain, 2014).

Em contrapartida, Wallach (2003) destaca que a ausência de conhecimento em história da arte não é uma barreira para as audiências participarem das exposições artísticas blockbuster e torna-se uma outra expressão do caráter comercial desses empreendimentos. Considerando que também faz parte de sua lógica a promoção de conversas com especialistas, brochuras, vídeos introdutórios, visitas guiadas, palestras, ecrãs táteis, galerias computadorizadas e que os visitantes são encorajados a arrendar áudio-guias [INDICADOR 97, TABELA 10].

No museu que recebe uma exposição blockbuster, os visitantes simplesmente colocam-se nas mãos daqueles que consideram profissionais e especialistas, que fornecem informações e insights. Nessa perspetiva, os visitantes não são muito diferentes de clientes de corporações (consumidores), uma vez que buscam serviços especializados (Wallach, 2003). Cabe aqui novamente a crítica de Secord (1996), sobre o conhecimento como um produto pronto a ser vendido/consumido.

Ainda sobre caráter comercial das exposições blockbuster ou cuja museografia é influenciada por estas, Shaman (1995) destaca que sendo produções projetadas para atrair milhões de visitantes, tais mostras podem ter desempenhado um papel fundamental no avanço da perceção pública da arte (ou qualquer outro conteúdo ou acervo) como uma mercadoria. De acordo com O'Reilly e Lawrenson (2014), dada a grande escala dessas exibições e de seus recursos museográficos, o visitante sente-se fadigado rapidamente. De modo que projetadas para serem consumidas 
rapidamente pelo grande público, é dado pouco espaço para experiências mais íntimas e concentradas com os objetos expostos (O’Reilly \& Lawrenson, 2014; Shaman, 1995).

Além disso, acervos artísticos considerados icónicos, dado ao seu grande valor estético, histórico ou comercial rotineiramente circulam o que, inevitavelmente, prejudica a investigação a cerca desses objetos, uma vez que dificulta o acesso e empréstimo para fins não rentáveis (Freedberg et al., 1986). No que tange as outras funções dos museus, ainda Freedberg e colaboradores (1986) destaca que as exposições blockbuster ocupam os profissionais de museus, removendo-os de suas tarefas quotidianas, o que leva rotineiramente a negligências com as coleção e exposição permanentes. Por fim, o autor considera que a mecanização dos meios de interação com o público, como guias acústicos, ecrãs informativos etc. [INDICADOR 97, TABELA 10], associadas a galerias e corredores lotados podem levar a uma desumanização da experiência na exposição ${ }^{55}$ (Freedberg et al., 1986).

Outro aspeto no processo de debate das exposições blockbuster está relacionado aos desafios de balancear as ambições académicas do discurso [INDICADOR 96, TABELA 10] com as realidades e pressões para gerar grandes números de audiência e ser um competidor de sucesso no mercado do entretenimento (O'Reilly \& Lawrenson, 2014). Essa competição tem levado a uma padronização desse tipo de exposição, com poucos temas, que são frequentemente repetidos [INDICADOR 93, TABELA 10], como: tesouros de culturas antigas e exóticas, arte impressionista e dinossauros(Conn, 2006).

Conn (2006) chama esse movimento "blockbusteritis" e alerta sobre o efeito distorcido que pode causar no público, expulsando outros tipos de exposições que não têm o mesmo apelo ou efeito popular. Os dinossauros são apenas uma pequena parte da pesquisa e das coleções de história natural. Ademais, são as blockbusters - cada vez mais caras - que forçam uma dependência ainda maior do financiamento das grandes corporações, o que também pode ter o efeito de flexibilizar as prioridades institucionais (Conn, 2006).

As controvérsias não possuem espaço nesse tipo de exposição e subpadrão museográfico [INDICADOR 91, TABELA 10] (Conn, 2006). Tendo em vista que, em geral, nas exposições de arte ou

${ }^{55}$ Considerando que a publicação de Freedberg e colaboradores tem mais de trinta anos, um certo "temor" pela tecnologia e uma visão exagerada da sua influência e papel em ocupar o espaço humano está inserido num contexto social que começa a descobrir os computadores domésticos e a world wide web ainda não é uma realidade. 
antropologia, os objetos e textos estão expostos e organizados de acordo com um esquema destinado a construir e transmitir significado, as exposições blockbuster são construídas em uma visão retrospetiva: coleções de trabalhos completos ou compilações que inauguram ou consolidam uma disciplina. Cabe destacar que, embora os curadores desse tipo de exposição reivindicam ser revisões exaustivas do tema/acervo, as mostras sempre incompletas e, muitas vezes, são apenas exaustivas [INDICADOR 89, TABELA 10] (Greenberg, Ferguson, \& Nairne, 1996).

Apesar de populares e mediáticas, as exposições blockbuster tornam a visita aos museus quase indiferenciadas de um centro comercial ou a Disneyland, a partir do esforços de satisfazer os gostos da audiência e a sua check-list interna. Os visitantes escolhem dentro de uma variedade de atividades e experiências possíveis: visitar a coleção permanente ou alguma exposição especial, compra de souvenirs, reproduções de obras ou livros [INDICADOR 84, TABELA 10], comer uma refeição em uma cafetaria ou em um restaurante mais refinado do museu [INDICADOR 83, TABELA 10] (Wallach, 2003).

Desse modo, Barker (1999b) sumariza as exposições blockbuster como um esforço académico que serve para educar e entreter o público, fornecendo prestígio e lucro para a instituição anfitrião. West (1995) é persuasivo ao questionar as exposições de arte produzidas dentro desse subpadrão museográfico, o que pode ser extrapolado para outros tipos de exposições, ao substituirmos os termos como "great artists" por "cientistas notáveis" ou "great works" por "grandes invenções":

\footnotetext{
"This form of 'double-coding' makes the art blockbuster a truly post-modern experience: through its academic pretensions, it seems to lure an educated audience, but it is accompanied by commercialization, hyperbole and sensationalism which give it more populist qualities. However, this seeming democratic profile is belied by the fact the 'great artists' represent and the 'great works' shown are allowed to retain their mystique and allure" (West, 1995, p. 90).
}

Claramente, as exposições blockbuster deixaram impressa sua marca no conceito de "museu contemporâneo", que é expresso por: (i) estabelecimento de sistemas integrados ao marketing e produtos licenciados [INDICADOR 84, TABELA 10]; (ii) globalização de troféus de culturas nacionais (por exemplo: "tesouros nacionais"), cânones ou identidades [INDICADOR 85, TABELA 10]; (iii) validação de politicas governamentais para democratização e pesquisa de novas audiências; (iv) 
aspirações tanto para o entretenimento como para a educação e (v) ser um veículo de promoção da imagem do órgão de financiamento (Rectanus, 2006) [INDICADOR 84, TABELA 10]. Exemplos são descritos por Chu (2015), que demonstrou esse impacto no contexto asiático e Turner (2011), Berryman (2013), O 'Reilly e Lawrenson (2014), que trazem exemplos da Austrália.

Diretamente relacionados à temas de história natural, um icónico e contemporâneo exemplo é a exposição Darwin. Construída para comemorar os 200 anos do nascimento do cientista inglês Charles Darwin além de abordar a biografia do investigador, apresenta factos e dados que corroboram a teoria evolutiva por seleção natural, a partir de uma perspetiva histórica. Darwin teve a curadoria de Niles Eldredge (paleontólogo e colaborador de Stephen Jay Gould) e foi produzida pelo AMNH em colaboração com o Field Museum (Chicago, EUA), Museum of Science (Boston, EUA), NHM e Royal Ontario Museum (Toronto, Canadá). Contou também com o apoio da Down House (Downe, Inglaterra), Cambridge University e o acervo pessoal de alguns membros vivos da família Darwin, para gestão do acervo inglês. O financiamento da exposição foi feito por instituições privadas (Ceci, 2009).

Inaugurada em Novembro de 2005 em Nova Iorque (EUA), Darwin viajou entre instituições anglo-saxónicas até 2008. Contudo, devido a diversos pedidos de museus e instituições em outros países, o AMNH passou a vender a propriedade intelectual dessa mostra, fornecendo os conteúdos e/ou recursos físicos para que a exposição fosse apresentada em diferentes museus. Em 2007, o Brasil foi o primeiro país a receber essa nova versão da exposição (a mostra circulou entre São Paulo, Rio de Janeiro, Brasília, Curitiba e Goiânia). Também foram feitas montagens adaptadas as realidades locais na Nova Zelândia, Japão, Portugal (em Lisboa, no museu da Fundação Calouste Gulbenkian) e Itália (Ceci, 2009). Atualmente, o AMNH ainda dispõe dessa exposição no seu catálogo de exposições itinerantes, onde podem ser encontradas informações sobre as especificações técnicas para sua montagem, um catálogo reduzido e um guia de atividades educativas (https:<www.amnh.org/global-business-development/traveling-exhibitions/darwin>. Acesso em 27 de Abril de 2018).

Dentro do escopo das instituições analisadas nesse trabalho, destacamos que a lógica de exposições blockbuster foi fundamental para MUHNAC. Após o catastrófico incêndio de 1978, nas décadas seguintes a instituição esteve em um longo processo de restauro e reforma dos espaços, reorientação das coleções que restaram (a coleção zoológica, por exemplo) foi totalmente perdida), 
restabelecimento da pesquisa e, principalmente, no desenvolvimento de seu papel público (Alves et al., 2014). No histórico dessa instituição, um momento de charneira é a exposição sobre dinossauros em 1992/ 1993, denominada "Dinossauros Regressam a Lisboa". Com modelos robóticos arrendados do NHM , gerou filas e atraiu milhares de visitantes novamente ao museu (Delicado, 2010). Para se ter ideia do sucesso da mostra, o MUHNAC recebeu mais de 350 mil visitantes em pouco mais de um mês ${ }^{56}$ (Mateus, 2015).

\begin{tabular}{|c|c|c|c|c|}
\hline \multirow{14}{*}{ 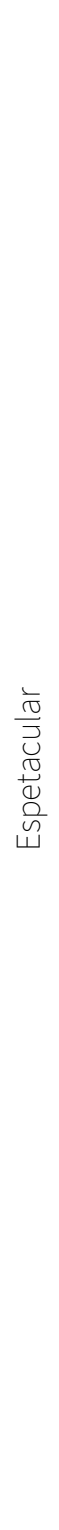 } & $\begin{array}{l}\text { No. Do } \\
\text { Indicador }\end{array}$ & $\begin{array}{l}\text { Subpadrão } \\
\text { Museográfico }\end{array}$ & Indicador & Autores-Fonte \\
\hline & 80 & Blockbuster & Financiamento corporativo & $\begin{array}{l}\text { Freedberg et.al, 1986; West, 1995; } \\
\text { Miller, 1996; Wallach, 2003; Coon, } \\
\text { 2006; Conn, 2010; Rectanus, 2006; } \\
\text { Turner, 2011; Berryman, 2013; } \\
\text { O'Reilly \& Lawrenson, 2014; Rader e } \\
\text { Cain, 2014; Chu, 2015 }\end{array}$ \\
\hline & 81 & Blockbuster & $\begin{array}{l}\text { Propaganda das exposições (grandes painéis na } \\
\text { fachada e outdoors pelas cidades) }\end{array}$ & Rader e Cain, 2014 \\
\hline & 82 & Blockbuster & Estética comercial & $\begin{array}{l}\text { West, 1995; Wallach, 2003; O'Reilly \& } \\
\text { Lawrenson, 2014; Rader e Cain, } \\
\text { 2014; }\end{array}$ \\
\hline & 83 & Blockbuster & $\begin{array}{l}\text { Presença de lojas e cafés nos espaços } \\
\text { expositivos }\end{array}$ & Rader e Cain, 2014; Berryman, 2013 \\
\hline & 84 & Blockbuster & Intensa atividade comercial (merchandising) & $\begin{array}{l}\text { Freedberg et.al, 1986; Berryman, } \\
\text { 2013; Rader e Cain, 2014 }\end{array}$ \\
\hline & 85 & Blockbuster & $\begin{array}{l}\text { Presença de objetos icónicas ou personagens } \\
\text { ou temas de grande impacto }\end{array}$ & Berryman, 2013; Rectanus, 2006 \\
\hline & 86 & Blockbuster & Apelo popular de massa & Berryman, 2013; West, 1995 \\
\hline & 87 & Blockbuster & Formato acessível & $\begin{array}{l}\text { West, 1995; O’Reilly \& Lawrenson, } \\
2014\end{array}$ \\
\hline & 88 & Blockbuster & $\begin{array}{l}\text { Oportunidades de free-choice learning, com uso } \\
\text { de interativos autoguiados }\end{array}$ & $\begin{array}{|lr|}\text { Wallach, 2003; O'Reilly \& } \\
\text { Lawrenson, 2014; }\end{array}$ \\
\hline & 89 & Blockbuster & Narrativa é construída em visão retrospetiva & J. Miller, 1996 \\
\hline & 90 & Blockbuster & $\begin{array}{l}\text { Catálogos à venda, que posicionam conteúdo } \\
\text { da exposição num contexto educacional e } \\
\text { curricular }\end{array}$ & \begin{tabular}{|lr} 
Wallach, 2003; O’Reilly \& \\
Lawrenson, 2014; Rader e Cain, 2014
\end{tabular} \\
\hline & 91 & Blockbuster & Uso de robótica e animatrônica & Rader e Cain, 2014 \\
\hline & 92 & Blockbuster & Ausência de controvérsias & Conn, 2006 \\
\hline
\end{tabular}

56 Uma reportagem do período, com imagens da montagem da exposição pode ser vista em: https://arquivos.rtp.pt/conteudos/dinossauros-em-portugal/. Acesso em 10 de Outubro de2019. 
Continuação Tabela 10:

\begin{tabular}{|c|c|c|c|c|}
\hline \multirow{6}{*}{ 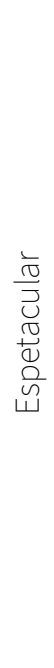 } & $\begin{array}{l}\text { No. Do } \\
\text { Indicador }\end{array}$ & $\begin{array}{l}\text { Subpadrão } \\
\text { Museográfico }\end{array}$ & Indicador & Autores-Fonte \\
\hline & 93 & Blockbuster & Padronização de temas e abordagens & Conn, 2006 \\
\hline & 94 & Blockbuster & $\begin{array}{l}\text { Promoção de atividades paralelas } \\
\text { associadas ao tema da exposição } \\
\text { (palestras, visitas guiadas) }\end{array}$ & Wallach, 2003 \\
\hline & 95 & Blockbuster & $\begin{array}{l}\text { Áreas para tirar fotos ("photo-taking } \\
\text { exhibition") }\end{array}$ & Chu, 2015 \\
\hline & 96 & Blockbuster & $\begin{array}{l}\text { Narrativa construída com conteúdo } \\
\text { académico e distante das realidades } \\
\text { locais }\end{array}$ & Rader e Cain, 2014 \\
\hline & 97 & Blockbuster & Uso intenso de suportes multimédia & $\begin{array}{l}\text { Freedberg et.al, 1986; Shaman, 1995; } \\
\text { Wallach, 2003; Berryman, 2013; Rader } \\
\text { e Cain, } 2014\end{array}$ \\
\hline
\end{tabular}

Tabela 10: Tabela que resume os indicadores compartilhados pelo subpadrão museográfico baseado nas exposições blockbuster, que serão aplicados na análise das exposições estudadas nesse trabalho.

\subsection{Padrão "Retorno à Curiosidade"}

"The return to curiosity is not a return to the hierarchical universe of the original age of curiosity, but a turn to a plurality of perspectives, of ways of attending to objects, and of narratives. The curiosity cabinet and curiosity museum are now associated with challenges to traditional hierarchies of objects and information" (M. Henning, 2006, p. 154).

Como anteriormente citado, Bann (2003) afirma que os museus contemporâneos não são uma evolução direta dos gabinetes de curiosidade, do século XVII, uma ideia que tem sido lugar comum em diferentes tipos de publicações. De acordo com o autor, embora exista a continuidade dada pelas coleções, os embasamentos epistemológicos aos quais esses objetos correspondem mudaram radicalmente.

Os gabinetes do século XVII utilizavam a mesma rubrica de "curiosidade" para diferentes tipos de acervos - raros, exóticos, antigos ou recentes - destacando a presença da múltiplas narrativas e relações com diversas áreas do conhecimento, associações pessoais, questões da materialidade e, mesmo, flexibilidade de uso (Bann, 2003). Já o conceito e a instituição frequentemente reconhecida como "museu" é fruto do Iluminismo e remonta as tabelas classificatórias do século XVIII (Forster, 
2014). O século XIX assistiu ao crescimento exponencial das instituições museais, bem como as respetivas estruturas, sistematização e organização de acervos e espaços, sendo o período conhecido como a "era dos museus". (Lopes, 2009). Exatamente quando a historiografia considerou que as disciplinas da Biologia saíam do museu, afastando-se da História Natural, voltando-se para pesquisas de laboratório, os museus experimentaram um crescimento, notadamente além das fronteiras europeias (Lopes \& Podgorny, 2000).

Desse modo, os objetos suportaram diferentes status epistemológicos ao longo dos séculos, o que é simultaneamente expresso em novas formas de museografia. Adamopoulou e Solomon (2016) apontam que, especialmente nos museus que não estão associados aos acervos artísticos, existe uma tendência contemporânea a criar exposições que remetem aos gabinetes de curiosidades. Além de celebrados como objetos de pesquisa de campos como a História da Ciência e a Museologia, esses espaços tem adquirido um status "a playful space of investigation and interaction. It is applauded for speaking to all the senses, involving the visitor, transgressing disciplinary boundaries, fostering new ways of knowing and for acting as a powerful 'contact zone' " (Collet, 2014, p. 47$)^{57}$.

Em contrapartida, nos dias correntes, ainda encontramos referências aos antigos gabinetes de curiosidades nos museus de história natural. Em Madrid, temos dois exemplos de exposições inseridas nesse padrão. No Museo Nacional de Ciencias Naturales, "El Gabinete de Historia Natural" foi reinaugurado em Novembro de 2016, em comemoração de uma dupla efeméride: 300 anos de nascimento de Pedro Franco Dávila (primeiro diretor e responsável pela organização dessa coleção real) e $240^{\circ}$ aniversário da Fundación del Gabinete de Historial Natural (Figura 11Ce 11D) ${ }^{58}$. No Museo de America, a exposição de longa-duração encontra-se estruturada em cinco grandes áreas: o conhecimento da América; a realidade da América; a sociedade; a religião; e a comunicação. Na área destinada ao conhecimento, parte dos objetos de História Natural das antigas colónias espanholas

57 Sobre a multiplicidade de sentidos e narrativas suportadas pelos objetos dos museus de história natural, um conceito fundamental é proposto por Star e Griesemer (1989), ao defini-los como boundary objects: "boundary objects are both adaptable to different viewpoints and robustenough to maintain identity across them" (Star \& Griesemer, 1989, p. 387)

58 Uma visão mais detalhada desse espaço está em uma exposição virtual disponível no site institucional: <http://mncngabinete.s3.amazonaws.com/scb/MNCNGabineteES_LOCAL.html>. Acesso em 20 de Fevereiro de 2019. Há também uma visita dentro na plataforma Google Arts\&Culture: <https://artsandculture.google.com/partner/museo-nacional-de-ciencias-naturalesmncn-cesic > . Acesso de 20 de Fevereiro de 2019. 
estão apresentadas em vitrines que buscam representar um gabinete de história natural, como espaço do colecionismo e início das ciências naturais na Espanha (e mesmo na Europa) ${ }^{59}$ (Figura $11 \mathrm{~A}$ e 11B).

Contudo, o que se observa é tendência contemporânea em reabilitar o gabinete de curiosidades como forma de museografia e não a reconstrução desses espaços, como apontado por Bann (2003), Henning (2006), Collet (2014) e Adamapoulou e Solomon (2016). A partir da exaustiva revisão bibliográfica, tal "tendência da museografia" é proposta nesse trabalho como um novo padrão museográfico.

O padrão "Retorno à Curiosidade" traz a centralidade novamente aos objetos [INDICADOR 110, Tabela11] e busca estimular a curiosidade [INDICADOR 105, Tabela11], uma vez que questiona diretamente as ordenações didáticas, hierárquicas ou mesmo as tradicionais cronologias (por anos ou movimentos) históricas [INDICADOR 109, Tabela 11]. Observa-se que esse padrão tem sido aplicado especialmente em exposições temporárias ou em áreas separadas das exposições de longa-duração, geralmente em instituições que possuem acervos que datam o início da era Moderna (Bann, 2003) ou refletem críticas a partes ou objetos mais controversos da coleção (Collet, 2014).

Entre os fundamentos dessa museografia, diversos autores sinalizam a Grand Galerie de Évolucion, do MNHN, como um ponto de viragem (Adamopoulou \& Solomon, 2016a; M. Henning, 2006; Paddon, 2014). Inaugurada em 1994, essa exposição representa a combinação de uma abordagem narrativa filosófica, uma apropriação inovadora da arquitetura do museu e o uso das coleções biológicas em uma museografia com intensidade sensorial e emotiva (Maigret \& RaulinCerceau, 2000). Contudo, há um elemento crucial que faz essa exposição mais próxima ao padrão museográfico Espetacular do que "Retorno à Curiosidade”. Maigret (1996) afirma que os espécimes exibidos têm pouca importância individual e que deveriam ser considerados dentro de um espectro: " in actual fact, the specimens exhibited have little individual importance even if each is identified either by its scientific ou common name, and its position in the classification" (Maigret, 1996, p. 22). De forma que, mesmo sendo citada como uma referência na museografia atual, a exposição parisiense ainda carrega a autoridade do conteúdo vistas nas exposições científicas mais tradicionais.

\footnotetext{
59 No site institucional é possível encontrar a descrição completa da exposição, bem como vídeos e audioguias: <http://muw.culturaydeporte.gob.es/museodeamerica/coleccion/recorrido2.html>. Acesso em 20 de Fevereiro de2019.
} 

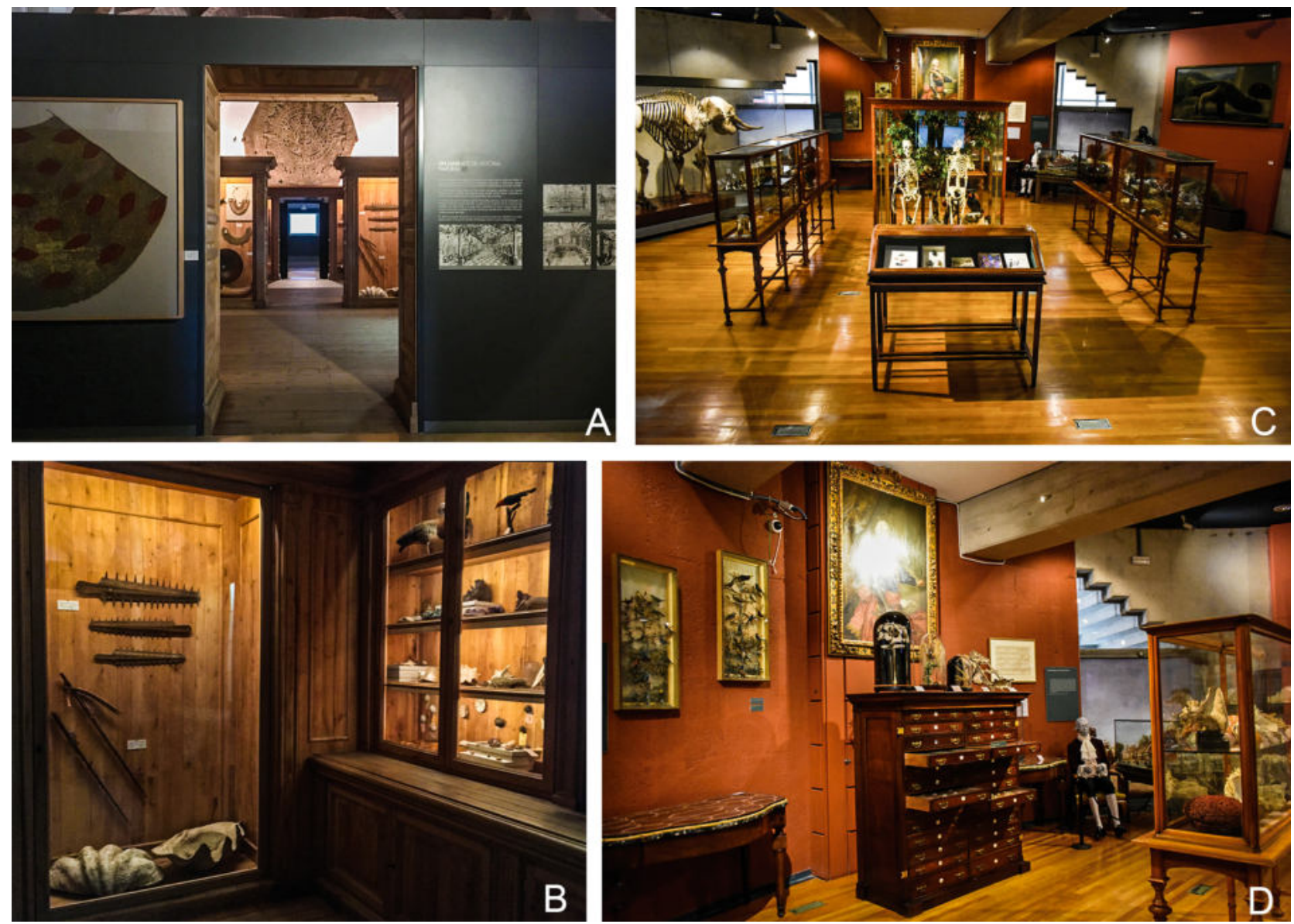

FIGURA 11: Exemplos da utilização do padrão museográfico baseado nos gabinetes de curiosidades, em museus de Madrid (Espanha). Em A, módulo El Conocimento da exposição de longa-duração do Museo de América. Em B, detalhe de vitrines contendo espécimes animais na mesma exposição. Em C, visão geral da remontagem do Real Gabinete de Historia Natural, do século XVIII. Em D, destaque para acervo histórico: mobiliário, pintura e espécimes zoológicos, pertencentes Real Gabinete de Historia Natural. Fotos: Mariana Galera Soler, obtidas durante visita em Abril de 2017 e Junho de 2019.

Na contemporaneidade, podemos destacar o artista plástico Mark Dion no trabalho entre os limites da curadoria científica e da prática artística. Nas palavras de Adamopoulou e Solomon (2016), o artista simula práticas arqueológicas, "escavando" coleções de museus e universidades e dirigindo projetos como curadorem parceria com as equipas de investigação. Suas obras são apresentadas como gabinetes de curiosidades, tanto na forma como no conteúdo. Dentre as quais destaca-se a exposição temporária WeltWissen - World Knowledge montada entre 2010-11, desenvolvida para comemorar os 350 anos de pesquisa e colecionismo em Berlim, sendo esta a primeira grande exposição a celebrar a história científica e cultural de Berlim, depois da reunificação (Adamopoulou \& Solomon, 2016b). 
Um dos elementos icónicos dessa mostra foi uma grande estante de prateleiras curvadas, que cortavam o átrio central do Martin-Groupis-Bau (Berlim) ao meio. Nas prateleiras havia aproximadamente 400 objetos, desde o esqueleto do cavalo favorito de Frederick, o Grande, até objetos de gabinetes e museus, como fósseis, bustos, artefactos arqueológicos e tecnológicos. Os visitantes poderiam abordar os limites dos objetos e, portanto, do conhecimento, a partir de qualquer direção (Laubichler, 2010).

Todos os objetos apresentados eram parte de coleções universitárias ou arquivos de Berlim, com especial enfoque na magnitude dos acervos pós reunificação (Laubichler, 2010), e representavam vários campos da pesquisa científica. A seleção foi feita por Mark Dion e uma equipe de artistas e o modo que foram exibidos buscava ilustrar diferentes pontos de vista e abordagens metodológicas (Adamopoulou \& Solomon, 2016b).

Esta instalação criou uma representação vivida das ciências de modo bastante conceitual, como é o mundo do conhecimento, e causou forte impacto, por meio de sua massiva dimensão, número de objetos acumulados, amplitude do espaço livre, cenografia e iluminação. Funcionando como instalação artística per se, mais do que uma estratégia de exposição de museus científicos, promovia uma experiência de vida real, mais do que simples transmissão do conhecimento ${ }^{60}$ (Figura 12) (Adamopoulou \& Solomon, 2016).

Além disso, demonstrava que as atividades científicas e escolares estão enraizadas em circunstâncias históricas e locais e que continuamente expandem os horizontes de conhecimento, de duas formas: coleta sistemática e ordenada de factos para os museus, publicações acadêmicas e relatos sintéticos e práticas imprevisíveis de pesquisa experimental e teórica, que transcendem caminhos bem estabelecidos (Laubichler, 2010).

Além da instalação proposta Dion, a massiva presença de objetos não necessariamente suportados por uma narrativa é uma realidade historicamente conhecida em museus científicos cujo acervos transcendem as limitações das reservas, como o tradicional exemplo do Musée des Arts et Métiers, em Paris.

\footnotetext{
${ }^{60}$ A documentação, imagens e parte do conteúdo de WeltWissen - World Knowledge está disponível em: http://www.weltwissenberlin.de/index.php/Ueberblick_Dokumentation.html. Acesso em 17 de Março de 2019.
} 


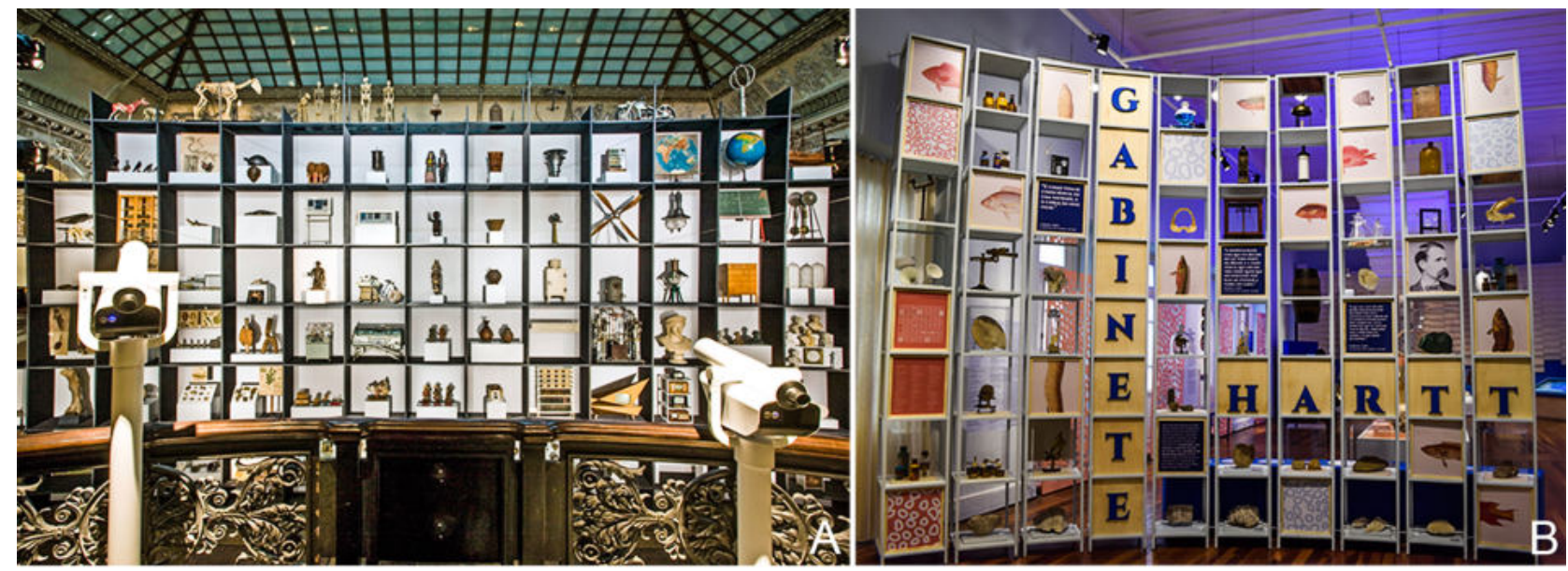

FIGURA 12: Exemplos do padrão museográfico "Retorno à Curiosidade". Em A, uma visão geral da instalação de Mark Dion, na exposição WeltWissen. Foto: Roman März. Fonte: <http://www.weltwissen-berlin.de/index.php/217.html> Acesso em 17 de Março de 2019. Em B, instalação de abertura da exposição "Expedição Coral”, no Museu Nacional do Rio de Janeiro. Novamente a noção de gabinete de curiosidades esteve presente nessa exposição, que foi inaugurada em Junho 2018 e foi a última realizada antes do incêndio da instituição (2 de Setembro de 2018). Foto: Mariana Galera Soler, obtidas durante visita técnica em Agosto de 2018.

De modo que as reservas técnicas visitáveis são uma realidade na museografia de diferentes museus científicos, seja por limitações em salvaguarda do acervo, como também são uma tendência intensificada no padrão museográfico "Retorno à Curiosidade". Neste último caso, dispõe de princípios estéticas, como iluminação e mobiliário, para criar ambientes altamente tecnológicos em que os objetos científicos tal qual são estudados são expostos (Adamopoulou \& Solomon, 2016b). Kara Blond (2018) afirma que uma tendência para a museografia dos museus de história natural do futuro são as reservas técnicas visitáveis, permitindo uma experiência "behind the scenes". 0 resultado é um ambiente que segue os princípios do design contemporâneo, com grande apelo estético ao mesmo tempo que cumpre as exigências dos princípios museológicos e científicos de preservação, tornando-se um gabinete de curiosidades com significado científico e valor artísticocultural (Figura 13) (Adamopoulou \& Solomon, 2016). 


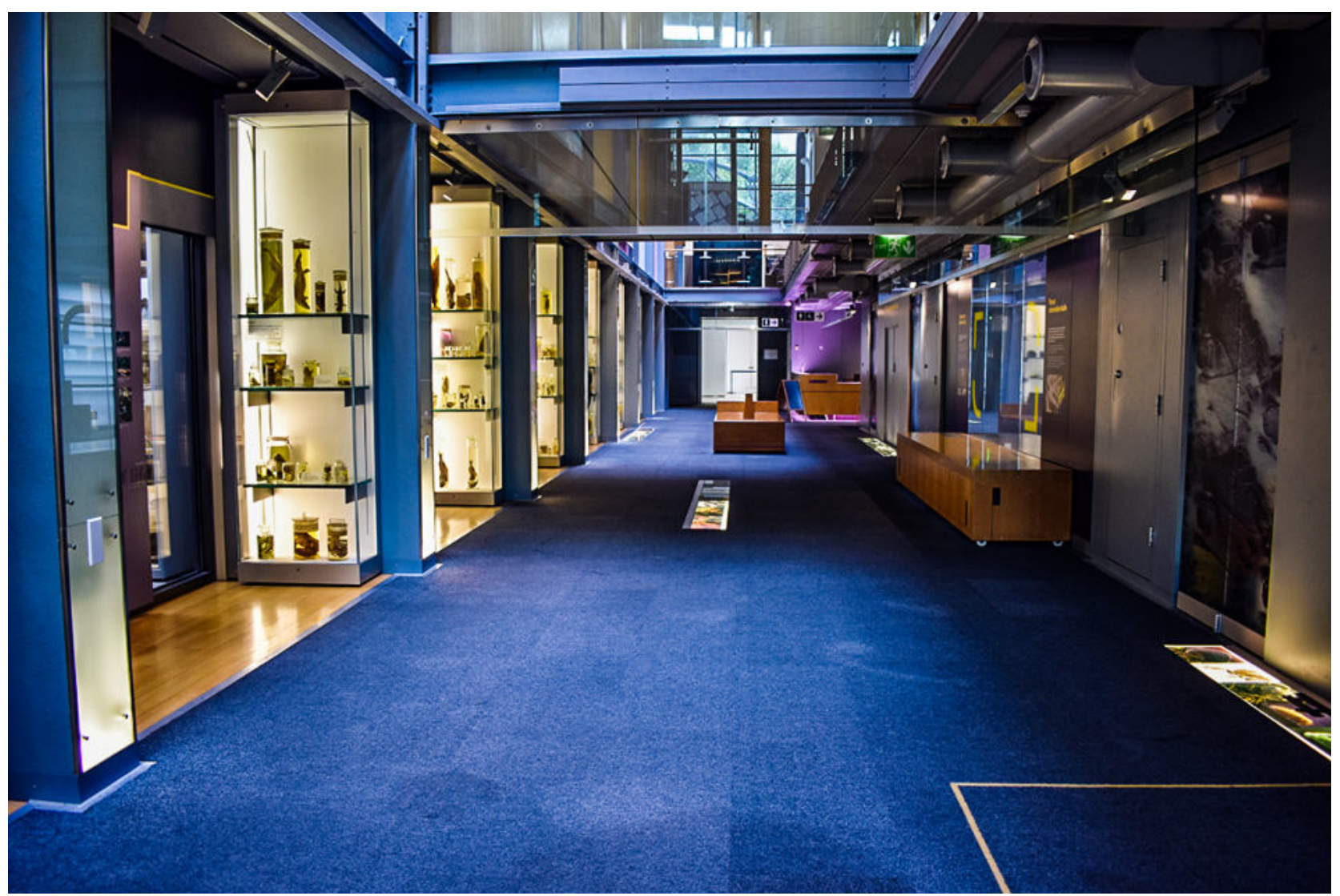

FIGURA 13: As reservas técnicas visitáveis são consideradas uma das representações do padrão museográfico "Retorno à Curiosidade". Spirit Collection, no Darwin Centre, NHM. Foto: Mariana Galera Soler, obtidas durante visita técnica em Maio de 2018.

Bann (2003) considera que o fenómeno do "Retorno à Curiosidade" é ainda uma resposta ao enfraquecimento do paradigma da organização cronológica e sequencial dos factos. Em resposta aos movimentos do lluminismo e Romantismo, as narrativas episódicas e a classificação dominaram a organização da museografia os museus de arte ocidentais ao longo do século XIX. O autor destaca que o culto a "curiosidade" foi característico dos dois séculos anteriores, mas o culto a linearidade promoveu um modo de conciliar objetos heterogêneos dentro de um espaço e tempo comum. De forma que, se nas primeiras décadas do século XIX ordenações lineares correspondiam a uma abordagem experimental, na viragem para o século XX estava normalizado como prática museológica, expressa nos "period room”, característicos dos museus de arte e de história .

A normatização da museografia por meio de linhas cronológicas que fornecem uma noção progressista de escolas, movimentos ou nações - aspira a utopia da museografia sem autor: "In other words, authority is vested in the objectivity of History itself' (Bann, 2003, p. 123). Tais considerações 
sobre os museus de arte podem também ser aplicadas aos museus científicos, como apontado por Henning (2006).

A utopia da museografia sem autor pode ser compreendida como uma representação de uma ciência sem autor, mas com autoridade (Stengers, 1991) nos museus de história natural. Cabe aqui explicitarmos essa ideia: A segunda metade do século XIX e o início do XX assiste o desenvolvimento da objetividade como um qualitativo (e, posteriormente, como quase sinónimo) da prática científica. Desconfiados da mediação humana entre a natureza e a sua representação, os investigadores buscavam produzir suas imagens mecanicamente, com a utilização de diferentes suportes e equipamentos, como a fotografia, o microscópio/telescópio ou modelos, o que Daston e Galison (2007) definiram como objetividade mecânica.

A objetividade mecânica implica na busca por reprimir a intencional intervenção do artistaautor-curador-investigador na construção de representações da natureza, substituindo-o por conjuntos de procedimentos que, idealmente, poderiam transferir perfeitamente a natureza para as páginas de atlas ou bancadas dos laboratórios, a partir de protocolos estritos. O investigador possuía autoridade e policiava o ilustrador (Lorraine Daston \& Galison, 2007).

A ciência apresentada como objetiva, ou a história como uma narrativa cronológica e linear de factos, representa um investigador (que também é curador) como trabalhador diligente e contido em suas interpretações. "Let nature speaks for itself" é a expressão que coloca em contacto as obras de Stengers (1991) e Daston e Galison (2007) ao tratar da objetividade. Contudo, ambos trabalhos evidenciam a utopia dessa qualidade epistemológica, uma vez que " 'Methodological' discourse therefore tends to occult the role of debates, that is to say, the irreducibly collective character of the practice of the sciences" (Stengers, 1991, p. 3).

Em outro lugar, Stengers (1994) considera a objetividade científica como a busca das ciências em se tornarem objetos das ciências experimentais, entendidas como uma atitude neutra, desprovida de julgamento. No entanto, a autora evidencia que a objetividade científica não depende de um tipo de metodologia científica, mas da invenção, da criação ativa de novos modos de responder sobre um fenómeno. Tendo em vista que os fenómenos não falam, os fenómenos experimentais são criados para testar e provar uma hipótese, contra outras. Logo, a objetividade científica não é produto de uma ação neutra, mas uma apaixonada e inventiva busca por fenómenos que façam a diferença entre as interpretações humanas: "The invention of an experimental device is 
the invention of having the phenomenon talk, in a limited way: it does not tell the truth but it makes the difference among opponents" (Stengers, 1994, p. 24).

Em contrapartida, a curiosidade está presente nas instituições que fogem do regime de um único objeto/experimento, com suas inevitáveis camadas hierárquicas de valor, em favor dos lugares que convergem entre os múltiplos objetos e interpretações. A curiosidade permite a múltiplas interpretações de valor, com o objeto sendo associado a algo imaterial ou uma associação pessoal, bem como afirmando sua própria materialidade em termos animais, vegetais ou minerais (Bann, 2003).

Todavia, o modo como a "curiosidade" e as "obsessões pessoais" estão por trás de todas as formas de colecionar (e, portanto, de todos os museus) é subestimado naquelas instituições que seguem fielmente o paradigma historicista. A curiosidade que tem um papel especialmente indicativo e sintomático do que é que valorizado, quando o modo de apresentação historicista não mais mostra a autoridade inquestionável e possui valioso papel de sinalizar-nos que o objeto exposto é, invariavelmente, um complexo de significados inter-relacionados e que podem ser até mesmo discordantes [INDICADOR 99; INDICADOR 101, Tabela 11] (Bann, 2003).

De modo que a curiosidade retoma as característica dos objetos expostos e revela o que há em comum entre os acervos artísticos e as coleções altamente diversificadas de um museu de arqueologia ou história natural (Bann, 2003). Além disso, invariavelmente pressupõe uma exibição autoral ou uma museografia aberta ao ato subjetivo de interpretação [INDICADOR 108, Tabela 11]. 0 gabinete de curiosidade é creditado por habilidades patentemente ausentes nas instituições modernas: o encorajamento de representações respeitosas, abertas e equitativas de diferentes culturas [INDICADOR 107, Tabela 11] (Collet, 2014).

Desde reservas visitáveis a exposições temporárias, curadores de museus e designers frequentemente têm preferido a estética da densidade do artefacto, com justaposições não-usuais, com ênfase na agência de cada objeto e na sua interação em conjunto, o que Adamopolou e Solomon (2016a) denominaram "typological exhuberance" [INDICADOR 106, Tabela11].

Assumir do papel ativo do visitante do museu, não apenas na compreensão das exposições, mas como co-autor dos significados das narrativas advém da perceção do museu como espaço polissémico e dialógico. Nesse museu contemporâneo - ou em transição e emergente, nas palavras de Cury (2014) - em que não existem estruturas necessariamente explicativas e didáticas para a 
disposição do acervo [INDICADOR 101, Tabela 11], é apenas possível quando a exposição (como meio de comunicação) permite a abordagens multivocais, em que a diversidade é representada de forma respeitosa e equitativa [INDICADOR 107, Tabela 11]. Sendo assim, o padrão museográfico "Retorno à Curiosidade" embora remonte aos arranjos estéticos [INDICADOR 103, Tabela 11] e sobrecarregados [INDICADOR 106, Tabela 11] dos espaços aristocráticos e reais do século XVI e XVII, só foi possível diante de uma conceção contemporânea da instituição museu e da Museologia enquanto ciência aplicada.

Tendo em vista o enquadramento dos padrões museográficos acima descritos, é possível observar que quando as exposições não são centradas nos objetos (subpadrões museográficos: taxonómico, séries evolutivas ou dioramas), tem-se a centralidade das narrativas ou do espetáculo, subvertendo ordenações cronológica e/ou triunfalista (ou progressista e idealizada) em favor de associações de ideias mais pontuais ou temáticas . O "Retorno à Curiosidade" implica num padrão museográfico que representa uma diferente construção do conhecimento nos museus, com a rejeição ou questionamento de organizações lineares ou históricas dos objetos [INDICADOR 109, Tabela 11].

Considerando que desde a segunda metade do século XIX as exposições foram consideradas dentro de uma estrutura cognitiva como ferramentas educativas, a intenção de seus curadores esteve claramente associada ao controle e direção dos significados que os visitantes iriam adquirir durante uma visita.

Em contrapartida, em exposições orientadas esteticamente [INDICADOR 100; INDICADOR 103, Tabela 11] objetivam trabalhar predominantemente com os níveis emocionais e efetivos. No século XXI tem assistido a uma maior consciência das equipas curatoriais das limitações de algumas das abordagens anteriores para a compreensão pública da ciência e há maior disponibilidade em abordar as múltiplas facetas e potenciais do museu. Embora ainda exista um grande pedido para a necessidade de o público compreender melhor a ciência, certamente há evidências nos museus de que o "entendimento" não está sendo mais compreendido de forma restrita, mas que os museus possam explorar mais suas habilidades particulares para despertar interesse e múltiplos entendimentos e significados [INDICADOR 103, Tabela 11] (MacDonald, 2004).

Dentro do contexto atual de produção do conhecimento, os objetos servem como evidência para resultados académicos sólidos, disseminados por meio das publicações científicas. No entanto, 
quando exibidos, muitas vezes eles são acrescidos de longos textos explicativos, que servem como mediadores entre os objetos e o visitante (Bann, 2003). Já nos "gabinetes contemporâneos" permitese que os objetos sejam vistos como estruturas de artefactos abertos a qualquer interpretação, sendo possível reescrever a história da cultura material. A metáfora e a imitação também são critérios para a seleção de objetos nesse padrão [INDICADOR 108, Tabela 11]. Como não existe um significado fixado para este tipo de instalação, é mais fácil demonstrar que existem múltiplas - na verdade, infinitas - leituras possíveis para os espectadores [INDICADOR 100, Tabela11]. Por sua própria definição, os gabinetes contemporâneos proclamam que qualquer sistema de classificação, descrição ou representação é parcial, defeituoso ou tendencioso [INDICADOR 109, Tabela11] (Bann, 2003).

O padrão museográfico que marca o retorno à curiosidade é representado por um design que promove o maravilhamento e favorecem o reencantamento pelos objetos [INDICADOR 98, Tabela11](Adamopoulou \& Solomon, 2016a). Contudo, os padrões museográficos "Espetaculares" também possuem algumas referências aos gabinetes contemporâneos, uma vez que os últimos também utilizam amplamente aparatos multimédia [INDICADOR 104, Tabela11] que permitem criar conectividade, deslumbramento e disponibilizar diferentes conteúdos [INDICADOR 101, Tabela11] e as instalações são decorativas e estéticas [INDICADOR 103, Tabela11]. A ênfase na conectividade e correspondências representa uma mudança no paradigma nas formas em que o conhecimento é estruturado e como os visitantes são abordados em diferentes tipos de museus. Tendo em vista que contribuem para aumentar a popularidade e acessibilidade dos museus, oferecem uma estrutura interpretativa que permite às audiências criarem suas próprias conexões e utilizarem amplo espectro de medias (M. Henning, 2006).

Por apresentarem inúmeras alternativas de representação [INDICADOR 102, Tabela11], os gabinetes contemporâneos encorajam não somente uma abordagem diferente do conhecimento, mas também um interdisciplinar - se não participativo - caminho para o aprendizado. O padrão museográfico "Retorno à Curiosidade" dispõe de um conjunto totalmente diferente de princípios organizacionais das taxonomias do lluminismo e as relações textualmente codificadas entre os objetos, espécies e espécimes. Como um espaço de conversa, troca e compartilhamento de conhecimento entre pessoas, o gabinete torna a produção de significado mais (ou ao menos) 
poético (Adamopoulou \& Solomon, 2016a). O retorno a curiosidade é, portanto, visto como um meio de tornar os museus mais dialógicos e polissêmicos (M. Henning, 2006).

\begin{tabular}{|c|c|c|c|c|}
\hline \multirow{14}{*}{ 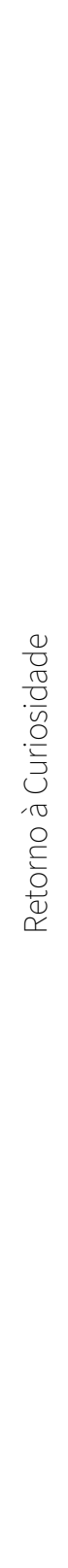 } & $\begin{array}{l}\text { No. Do } \\
\text { Indicador }\end{array}$ & $\begin{array}{c}\text { Padrão } \\
\text { Museográfico }\end{array}$ & Indicador & Autores-Fonte \\
\hline & 98 & $\begin{array}{l}\text { Características } \\
\text { comuns }\end{array}$ & $\begin{array}{l}\text { Promover o reencantamento com os } \\
\text { objetos }\end{array}$ & $\begin{array}{l}\text { Bann, 2003; Henning, 2006; } \\
\text { Adamopoulou \& Solomon, } 2016\end{array}$ \\
\hline & 99 & $\begin{array}{l}\text { Características } \\
\text { comuns }\end{array}$ & Características comuns & $\begin{array}{l}\text { Bann, 2003; MacDonald, 2004; } \\
\text { Henning, 2006; Adamopoulou \& } \\
\text { Solomon, 2016 }\end{array}$ \\
\hline & 100 & $\begin{array}{l}\text { Características } \\
\text { comuns }\end{array}$ & $\begin{array}{l}\text { Ausência de estruturas } \\
\text { necessariamente explicativa ou } \\
\text { didáticas para organização do acervo }\end{array}$ & MacDonald, 2004; Henning, 2006 \\
\hline & 101 & $\begin{array}{l}\text { Características } \\
\text { comuns }\end{array}$ & $\begin{array}{l}\text { Diferentes tipos de informação ao } \\
\text { longo de uma mesma exposição }\end{array}$ & Henning, 2006 \\
\hline & 102 & $\begin{array}{c}\text { Características } \\
\text { comuns }\end{array}$ & $\begin{array}{l}\text { Diferentes tipos de representação ao } \\
\text { longo de uma mesma exposição }\end{array}$ & Henning, 2006 \\
\hline & 103 & $\begin{array}{c}\text { Características } \\
\text { comuns }\end{array}$ & Instalações decorativas e estéticas & $\begin{array}{l}\text { MacDonald, 2004; Henning, 2006; } \\
\text { Adamopoulou \& Solomon, } 2016\end{array}$ \\
\hline & 104 & $\begin{array}{l}\text { Características } \\
\text { comuns }\end{array}$ & $\begin{array}{l}\text { Utilização de multimédia para criar } \\
\text { museografias espetaculares }\end{array}$ & Henning, 2006 \\
\hline & 105 & $\begin{array}{c}\text { Características } \\
\text { comuns }\end{array}$ & Estimular a curiosidade & $\begin{array}{l}\text { Bann, 2003; MacDonald, 2004; } \\
\text { Henning, 2006; }\end{array}$ \\
\hline & 106 & $\begin{array}{l}\text { Características } \\
\text { comuns }\end{array}$ & $\begin{array}{l}\text { "Typological exuberance": } \\
\text { justaposição de diferentes tipos de } \\
\text { objetos e ênfase na agência e na } \\
\text { interação }\end{array}$ & $\begin{array}{l}\text { Bann, 2013; Adamopoulou \& } \\
\text { Solomon, } 2016\end{array}$ \\
\hline & 107 & $\begin{array}{c}\text { Características } \\
\text { comuns }\end{array}$ & $\begin{array}{l}\text { Representações respeitosas, abertas e } \\
\text { equitativas de diferentes culturas }\end{array}$ & Collet, 2014 \\
\hline & 108 & $\begin{array}{l}\text { Características } \\
\text { comuns }\end{array}$ & $\begin{array}{l}\text { Museografias que apresentam } \\
\text { metáforas e temas alegoricamente e } \\
\text { visualmente. }\end{array}$ & Adamopoulou \& Solomon, 2016 \\
\hline & 109 & $\begin{array}{l}\text { Características } \\
\text { comuns }\end{array}$ & $\begin{array}{l}\text { Sistema de classificação, descrição ou } \\
\text { representação apresentados como } \\
\text { parciais, defeituosos ou tendenciosos }\end{array}$ & Adamopoulou \& Solomon, 2016 \\
\hline & 110 & $\begin{array}{l}\text { Características } \\
\text { comuns }\end{array}$ & Ênfase no objeto. & $\begin{array}{l}\text { Bann, 2003; MacDonald, 2004; } \\
\text { Henning, 2006; Adamopoulou \& } \\
\text { Solomon, 2016 }\end{array}$ \\
\hline
\end{tabular}

Tabela 11: Tabela que resume os indicadores compartilhados pelo padrão museográfico "Retorno à Curiosidade", que serão aplicados na análise das exposições estudadas nesse trabalho. 


\subsubsection{Biografia dos Objetos}

"as sociedades restringem ambos esses mundos simultaneamente e da mesma forma, construindo objetos da mesma forma que constroem pessoas"(Kopytoff, 2008, p. 121)

De acordo com Jacomy (2007) os objetos têm recebido ênfase reforçada nos museus contemporâneos por duas razões: à necessidade de se agarrar a algo concreto e tangível e, por sua vez, dotado de uma presença carregada de um fator emocional e outro de curiosidade; e, por outro lado, o fator da tridimensionalidade - uma dimensão não disponível nos ecrãs da televisão ou dos computadores. De modo que o objeto é, e continuará a ser, para o referido autor, o suporte mais adaptado para rememorização, assim como um discurso inovador. Devido a sua familiaridade ou ao seu exotismo, sua modéstia ou nobreza, o objeto enriquece todos os discursos, todas as demonstrações com a condição de não se reduzir ao estado de simulacro ou de simples contexto (Jacomy, 2007).

A nova centralidade dos objetos nas exposições [INDICADOR 110, Tabela 11] carrega além da perspetiva do encantamento [INDICADOR 98, Tabela 11], os fundamentos teóricos de um campo relativamente recente e bastante efervescente na história da ciência: a biografia dos objetos de coleções [INDICADOR 111, Tabela 12]. Esse crescente campo de estudo fornece novas perspetivas em narrativas locais e globais em história da ciência, tecnologia e medicina. Os objetos podem fornecer importantes apontamentos dentro do desenvolvimento de um experimento, especulação teórica, práticas de ensino e pesquisa, aplicações técnicas e motivações, interações entre produtores, técnicos de laboratórios e cientistas, bem como amplia os contextos históricos, sociais e políticos. Para os museus, o aumento do uso das coleções para estudos históricos é benéfico não apenas para o cuidado da coleção, pesquisa e conservação, mas também enriquece exposições, programas educacionais e publicações (Lourenço \& Gessner, 2014).

Os objetos são fontes. As "museological sciences” reconhecidas por Pickstone (1994) são aquelas cujas práticas implicam na classificação e categorização, a partir da análise e comparação de espécimes de coleções. Na perspetiva de Kohlen (2007), tais ciências são consideradas “collecting 
sciences", uma vez que representam aquelas associadas a procura e recolha de objetos em campo, geralmente em grandes quantidades.

Contudo, Alberti (2005) aponta que a biografia dos objetos é construída a partir de diferentes áreas do conhecimento [INDICADOR 112, Tabela 12], desde suas áreas diretamente relacionadas (associadas à materialidade do objeto), como também os aspetos epistemológicos desses, como por exemplo o estudo sobre os atlas científicos desde o século XVIII até a contemporaneidade, realizado por Daston e Galison (2007).

Adicionalmente, como citado na abertura desse tópico, há uma abordagem essencial da Antropologia sob a perspetiva da "vida cultural das coisas" (Kopytoff, 2008). Os objetos movem-se através do mundo público e das arenas privadas, dentro e fora dos bens e commodities, nascem numa fábrica, em um estúdio artístico, em uma oficina de artesanato, ou são encontrados no ambiente; podem acabar ou serem sucateados, como podem ser a peça central de um museu, vistos através de montras de vidro. Ao longo do seu curso, os objetos ganham significados nos vários ambientes (sociais, económicos, políticos e culturais) pelos quais passam e essas passagens podem, por sua vez, iluminam aqueles ambientes que ainda não são conhecidos (Silverstone, 1992).

De acordo com Kopytofff (2008), existem diferentes modelos biográficos, mas o modelo dotado de maior consciência teórica é aquele baseado num número razoável de histórias verdadeiras: apresenta uma variedade de possibilidades biográficas oferecidas pela sociedade em questão e examina a maneira pela qual essas possibilidades são concretizadas nas histórias de vida de várias pessoas (ou de objetos).

Examinar as biografias dos objetos pode ainda revelar facetas que de outra forma seriam ignoradas, como situações de contato cultural entre populações, como a adoção de objetos e ideias estrangeiras (um exemplo pode servisto em Pires \& Soler, 2018). Além disso, por serem culturalmente informados e formatados, o objeto é uma entidade culturalmente construída, dotada de significados culturalmente específicos, classificada e reclassificada em categorias culturalmente constituídas (Kopytoff, 2008).

A abordagem material em história da ciência também fornece uma excelente oportunidade de incluir mais história nos museus de ciência. Mais História da Ciência não significa menos "ciência”, ao contrário, mais e melhor ciência e melhor entendimento para os visitantes (Lourenço \& Gessner, 2014). 
Considera-se um dos momentos inaugurais da perspetiva da biografia dos objetos em história da ciência, a criação da publicação Journal of the History of Collections, por Arthur MacGregor (que mantém-se como editor), após um seminário em celebração do tricentenário do Ashmolean Museum, em 1983. Para J. Bennett (2005) esta perspetiva permite relacionar inúmeras abordagens que são particularmente importantes para a história da ciência, uma vez que os objetos coletadas no campo estão seguramente associados às instituições e as práticas dos centros metropolitanos, por meio da identidade e do significado que lhe são acrescidos durante a sua trajetória. Central na cultura dos museus, o estudo das biografias dos objetos pode ser uma ferramenta poderosa para entender o conjunto de premissas, ambições e crenças que o museu encorpa e como isso muda ao longo do tempo (J. Bennett, 2005).

No entanto, a capacidade dos objetos em representar suas próprias histórias é entendida por diferentes enfoques. Enquanto Lorraine Daston (2000) traz a própria materialidade como argumento para a compreensão do objeto: "[os objetos] do not need to be discovered or investigated; they possess the self-evidence of a slap in the face. These are the solid, obvious, sharply outlined, in-the-way things of quotidian experience" (Lorraine Daston, 2000, p. 2)".

Em contraponto, Alberti (2005) destaca que os objetos são sempre inanimados, mesmo que solicitados ou alterados, e constituem meio que é relacionado às pessoas, especialmente suas práticas e instituições. Macdonald (2004) traz uma perspetiva intermédia ao reconhecer a capacidade dos objetos em "falar", mas considera que nem todos os visitantes têm as habilidades e sejam capazes de "escutar" o que eles tem a dizer. Para a autora, mais do que somente objetos de ciência, eles são simultaneamente objetos de curiosidades, capazes de promover o maravilhamento [INDICADOR 113, Tabela 12] (MacDonald, 2004).

Ressalta-se ainda que a biografia dos objetos e seus significados não estão estagnados. Ao se tornarem musealia ${ }^{61}$, os objetos tornam-se espécimes, que são adicionados a coleções (que também

${ }^{61}$ O processo de musealização não consiste meramente na transferência de um objeto para os limites físicos de um museu. Independentemente de sua natureza, como um objeto de culto, utilitário ou de deleite, animal ou vegetal, ou mesmo algo que não seja claramente concebido como objeto, uma vez dentro do museu, este assume o papel de evidência material ou imaterial dos humanos e do seu meio, e uma fonte de pesquisa e de exibição, adquirindo, assim, uma realidade cultural específica. Stránský, em 1970, propõe o termo musealia para designar os elementos que passaram pelo processo de musealização e adquiriram o status de objetos de museus (Desvallées \& Mairesse, 2013) 
são dinâmicas), preservados, expostos, decompostos, descartados e, até mesmo, destruídos (Alberti, 2005) [INDICADOR 111, Tabela 12].

Ao longo de suas "vidas", são atribuídos variados significados aos objetos de museus: colecionadores, curadores e audiências encontraram objetos de maneiras muito diferentes, uma vez que pessoas imbuem os objetos de interpretações e valores, manipulando e contestando o seu significado ao longo do tempo [INDICADOR 113, Tabela 12](S. J. M. M. Alberti, 2005).

Existem alguns aspetos metodológicos (inaugurados por Fleming, 1974), dos quais destacamos o trabalho de Alberti (2005), que é exemplificado na sequência de casos expostos em Alberti (2011), o "Lisbon toolkit”, proposto por Lourenço e Gessner (2014), bem como as biografias de objetos que permitiram o acesso aos atores invisíveis da arqueologia no Alentejo (e em todo Portugal), na investigação de Pereira (2017).

Considerando que "a museum objects can be a prism through which to view various publics' experience of science" (Alberti, 2005, p. 561), um subpadrão museográfico baseado na biografia dos objetos pressupõe a presença de diferentes narrativas, nem sempre pacificadas, a cerca de um mesmo espécime [INDICADOR 111; INDICADOR 112, Tabela 12]. Essa multiplicidade de vozes pode deixar curadores desconfortáveis, uma vez que desvela as contingências da natureza das coleções espécimes (J. Bennett, 2005), bem como as intrincadas histórias e as contingências históricas e locais da pratica científica [INDICADOR 114; 115, Tabela 12]. Tais contingências proveem singularidade para cada museu uma instituição singular, para os objetos do respetivo acervo (Lourenço \& Gessner, 2014). Contudo, também evidencia a impossibilidade da objetividade e neutralidade da prática científica e museológica [INDICADOR 116, Tabela 12] (J. Bennett, 2005).

Exposições inteiramente construídas no subpadrão museográfico "Biografia dos Objetos" ainda são raras, mas podemos citar alguns exemplos de países anglo-saxões. Em Londres, a exposição Treasures, no Cadogan Gallery do NHM foi inaugurada em 2012 e mostra 22 objetos do acervo da instituição que possuem grande valor científico, histórico e cultural ${ }^{62}$. A descrição presente no guia de visitantes a resume como: "an intimate celebration of the Museum'collection, twenty-two

62 Há também uma versão itinerante dessa exposição, que foi inaugurada em 2018, em Taiwan. Mais informações e imagens estão disponíveis em: <http://wnw.nhm.ac.uk/press-office/press-releases/treasures-of-the-natural-world-opens-in-taiwan-.html> e <http://mww.nhm.ac.uk/business-services/touring-exhibitions/treasures.html>.Acesso em 19 de Março de2019. 
specially selecionated objects that are either unique, valuable, famous or susprising" (Natural History Museum, 2018).

Dessa forma, a narrativa proposta nesta exposição está centrada na seleção dos objetos em si: "this elite array has been selected from more tah 70 million specimens, books and artworks" (texto de abertura da exposição), e o que eles representam perante as respetivas coleções, história do museu ou investigação, e não uma narrativa textual didática que articula objetos ou conceitos e objetos. Os objetos são expostos em vitrines individuais, com iluminação de realce nas vitrines e difusa na sala (com paredes escurecidas e 20 detalhados vitrais), de modo que os objetos tornam-se ícones (assim como estão em uma sala nobre da instituição).

Além de uma pequena legenda, todos os objetos dispõem de telas táteis ao lado, em que há mais informações sobre o espécime em si e/ou a espécie que representa, a coleção em que está inserido, sobre onde podem ser encontrados temas relacionados em outras exposições do NHM ("Around the museum") e links para materiais complementares presentes no site institucional (“Mobile \& on-line”) (Figura 14).

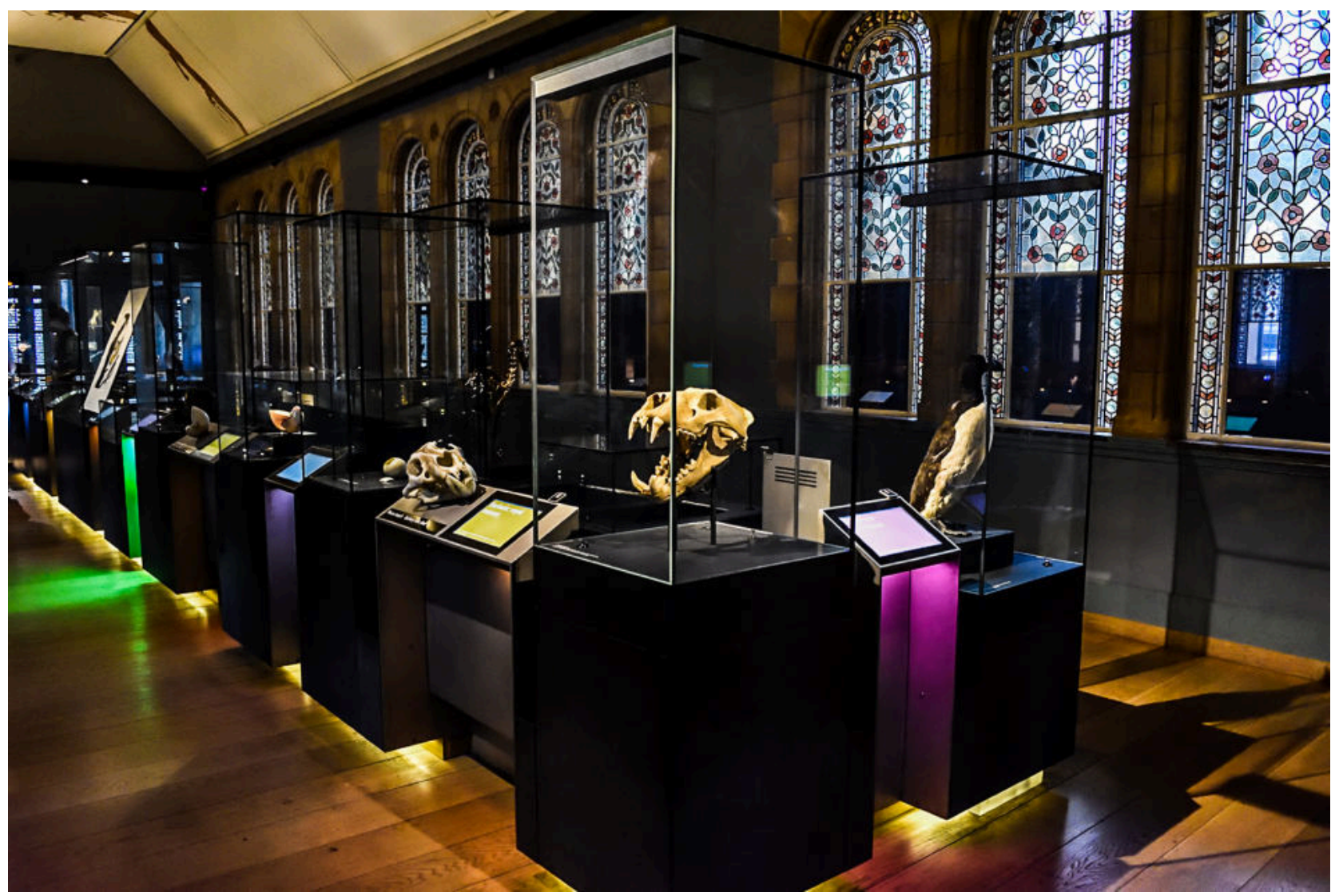

FIGURA 14: Vista geral da exposição Treasures, no NHM. Foto: Mariana Galera Soler, obtidas durante visita técnica em Maio de 2018. 
Ainda no NHM, a substituição da réplica do saurópode Diplodocus “Dippy”63 pelo esqueleto de uma jovem baleia-azul (Balaenoptera musculus) "Hope"64 implicou também numa expressiva reforma do espaço. Inaugurada em 13 de Julho de 2017, uma nova mostra propõe uma abordagem diferente para o saguão de entrada do museu, em que a tradicional ideia de um "índex taxonómico" dos seres vivos (que data ainda de Richard Owen) é substituída por objetos representativos e fundamentais para a compreensão da origem e evolução do sistema solar e da vida na Terra.

Desse modo, Hope foi suspensa ao teto desse saguão e ao seu redor estão expostos outros dez objetos (ou conjunto de objetos) em alcovas, que são considerados destaques para valorização e compreensão das coleções científicas da instituição (Figura 15 e Figura 16).

Nos EUA, duas exposições temporárias inauguradas também em 2017 foram estruturadas de modo a destacar os objetos e reconhecê-los como entidades que causam maravilhamento e possuem percursos particulares: Objects of Wonders, no NMNH, e Specimen: unlocking the secrets of life, no The Field Museum (Chicago).

\section{Ground Floor}

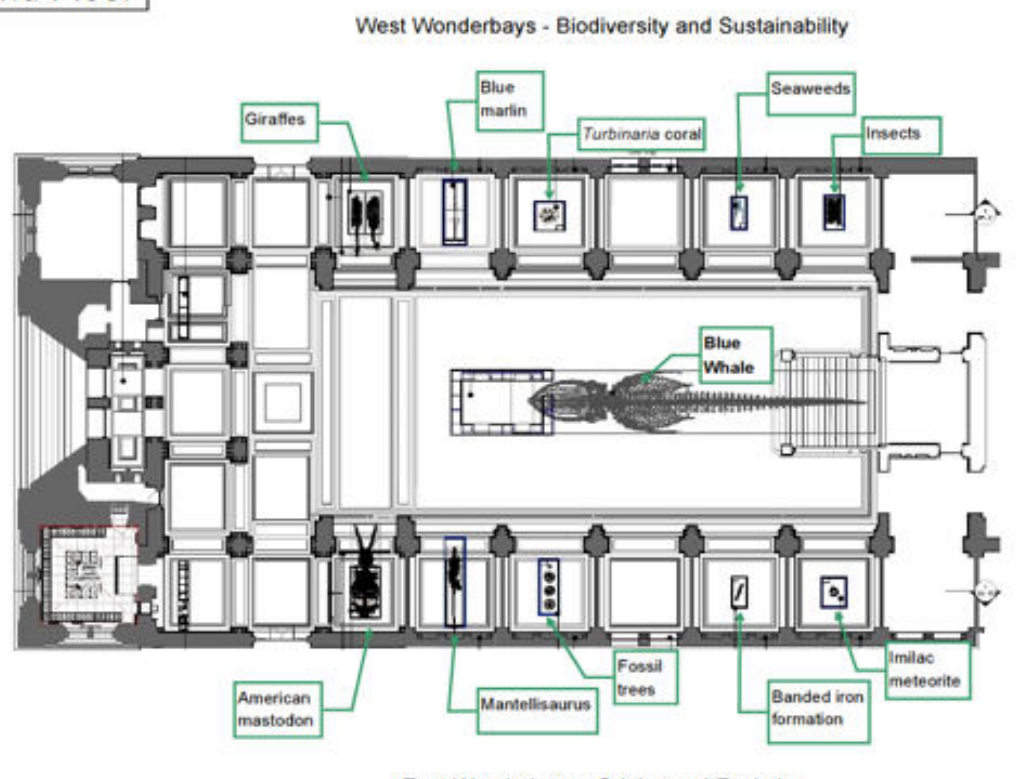

Figura 15: Planta baixa do Hintze Hall, NHM. Fonte: Informações disponibilizadas por Susan Holmes, Exhibitions and Interpretation Manager do NHM, por e-mail, em 6 de Julho de 2018 (S. Holmes, personal communication, 7 de Junho de 2018).

${ }^{63}$ Atualmente o carismático espécime encontra-se em itinerância entre museus e centros de ciência ao longo de toda Inglaterra. 0 roteiro e atividades educativas associadas estão disponíveis em: < http://mww.nhm.ac.uk/take-part/dippy-on-tour.html>. Acesso em 19 de Março de2019.

${ }^{64}$ Hope também teve sua bibliografia explorada pelo NHM, contudo tais informações estão especialmente concentradas no site institucional, como por exemplo em: <http://mww.nhm.ac.uk/discover/news/2018/march/a-cetacean-relation.html> Acesso em 20 de Março de2019. 

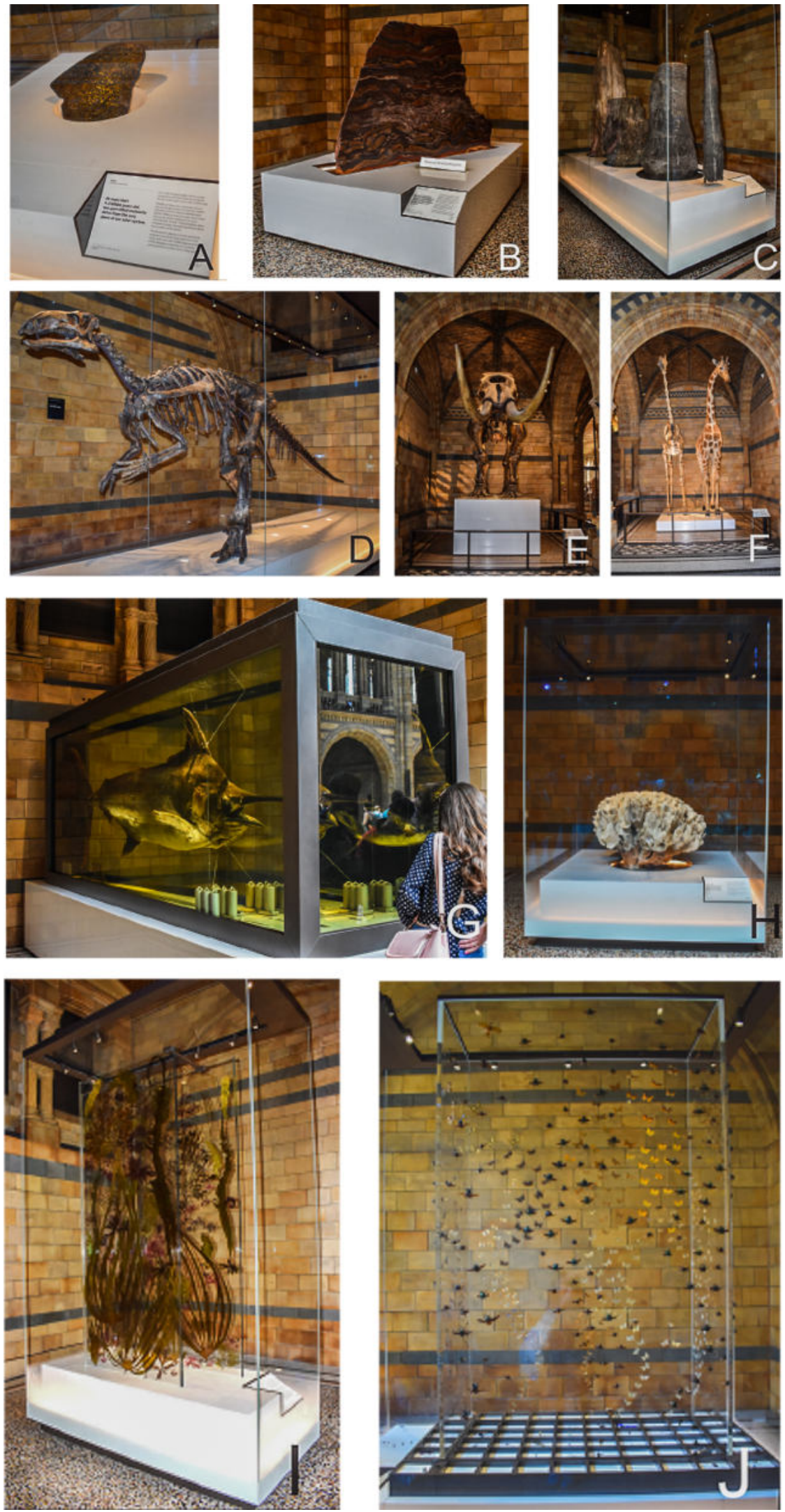

FIGURA 16: Objetos destacados no Hintze Hall, saguão central do NHM. Em A, um meteorito "Imilac" datado da origem do Sistema Solar. Em B, um fragmento de rocha de 2,5 toneladas com bandas de ferro e datação de 2,6 bilhões de anos da Austrália (marcando o surgimento dos primeiros organismos fotossintetizantes e a liberação de grandes quantidades de oxigénio na atmosfera). Em C, um conjunto de quatro troncos fossilizados em períodos geológicos diferentes (Devoniano, Carbonífero, Jurássico e Paleógeno). Em D, o esqueleto mais completo de dinossauro encontrado na Inglaterra (Mantellisaurus atherfieldensis). Em E, um mastodonte (Mammut americanum). Em F, um par composto por um esqueleto (Giraffa camelopardalis camelopardalis) e uma taxidermia (Giraffa reticulata). Em G, um marlim-azul (Makaira nigricans) exposto em um tanque com solução de glicerina. Em $\mathrm{H}$, um grande espécime de coral australiano (Turbinaria bifrons). Em I, um conjunto de vitrines com espécimes de algas vermelhas, verdes e castanhas, separadas por vitrinas. Em J, uma vitrine e gavetas entomológicas que servem de suporte para a exposição de centenas insetos de seis distintas ordens (Odonata, Diptera, Hymenoptera, Lepidoptera, Coleoptera e Orthoptera). Fotos: Mariana Galera Soler, obtidas durante visita técnica em Maio de 2018. 
Inaugurada em 10 de Março de 2017, Objects of Wonders apresenta objetos icónicos utilizados pelos investigadores do Smithsonian Institute, de modo que o acervo conta a história da prática científica histórica e contemporânea da instituição, por meio da biografia dos seus objetos. No texto de divulgação dessa exposição, destaca-se seu objetivo: "From their astonishing scale to surprising form to awe-inspiring rarity - experiencing these objects in person creates moments of wonder and curiosity that can't be found elsewhere" (National Museum of Natural History, sem data) ${ }^{65}$.

Em Chicago, Specimen: unlocking the secrets of life narrou a história de objetos importantes para investigação científica da instituição e/ou que possuem percursos inesperados. Propunha a valorização dos objetos de história natural como fonte e das coleções e museus como recursos de conhecimento (BLOUIN ARTINFO, 2017) 66,67.

Há também exemplos pontuais da utilização da biografia dos objetos, inseridas dentro de outras exposições. Pode-se destacar o exemplo marcante do urso polar Knut, uma personagem mediático do zoológico de Berlim, fenómeno conhecido como "Knutmania". Com apenas quatro anos de vida, o animal morreu repentinamente em frente ao público (autópsia revelou ataque epilético) e houve grande debate sobre o que seria feito com o corpo, com a sugestão inclusive da realização de um enterramento ("Polar bear Knut died of brain damage, tests suggest" 2011). Contudo, o corpo foi taxidermizado e atualmente em exposição no Museum für Naturkunden, também em Berlim (Van Mensch, 2011), cuja inauguração atraiu novamente grande atração dos medias.

No Museo de La Plata na sala Osteología Comparada encontra-se o esqueleto de um bovino identificado como "vaca ñata". Em sua legenda o espécime é identificado como um animais que pastava nas áreas externas da instituição (Figura 17). Outros espécimes famosos que estão em exposição em museus de história natural são descritos em Alberti (2011) e Van Mensch (2011).

\footnotetext{
65 Mais informações sobre a exposição estão disponíveis em: https://naturalhistory.si.edu/exhibits/objects-wonder . Acesso em 8 de Outubro de 2019.

66 Website com animações e informações a respeito de Specimen: unlocking the secrets of life. https://www.fieldmuseum.org/discover/on-exhibit/specimens/. Acesso em 8 de Outubro de 2019.

${ }^{67}$ Essa exposição contou ainda com a participação do criativo português, Luís Carlos Marques, senior art director da Leo Burnett, de Chicago. A agência criou uma cabine acústica de gravação que passou por diversas ruas da cidade de Chicago em busca de vozes para contar histórias relacionadas com os 200 espécimes expostas nessa exposição. As gravações recolhidas agora fazem parte da coleção permanente do museu e podem ser ouvidas porvisitantes pode meio de uma aplicação de telemóvel (Ana Marcela, 2017).
} 

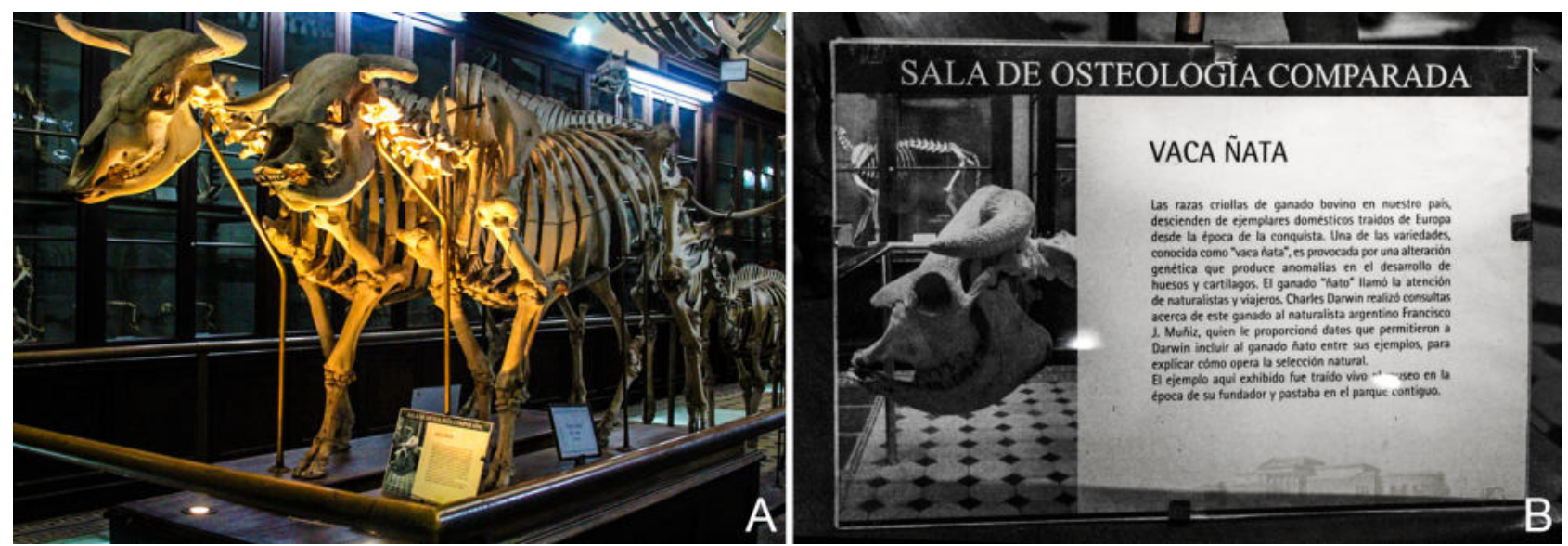

FIGURA 17: Espécime "Vaca Ñata” em exposição na sala Osteología Comparada, no Museo de La Plata. Em A, vista geral do espécime de raça crioula bovina (direita), com outro esqueleto ao lado (esquerda). Em B, detalhe da legenda, com destaque para a biografia do objeto. Foto: Mariana Galera Soler, obtida em visita técnica em Fevereiro de 2014.

Para além da biografia dos objetos, uma outra questão científica contemporânea tem sinalizado a centralidade dos objetos nos museus de história natural. A crise da biodiversidade e seus efeito das mudanças climáticas na distribuição das espécies, o estudo de doenças consideradas extintas que agora voltam a assolar as sociedades, rotas de migração alteradas e os serviços ecossistêmicos são temas na agenda científica da contemporaneidade e os museus de história natural possuem um papel de relevo nessas questões urgentes (Conn, 2010; Dorfman, 2017).

No entanto, essas questões estão associadas as coleções utilizadas para estudos evolutivos e ecológicos e pouco mudam a relação do público com os acervos. Nesse sentido o museu volta a ser valorizado como espaço de salvaguarda de acervos, porém sob uma nova luz: os objetos preservados foram coletados pelo seu papel representativo. E considerando a destruição de muitos ambiente, o valor de muitos desses objetos vem agora justamente por conta da sua crescente raridade. Animais taxidermizados, classificados e preservados agora representam as últimas e melhores informações sobre espécies e sobre os seus respetivos ecossistemas. Em uma era de aquecimento global, esses objetos tem alcançado uma sombria singularidade(Conn, 2010). 


\begin{tabular}{|c|c|c|c|c|}
\hline \multirow{7}{*}{ 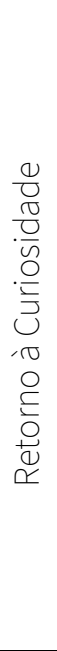 } & $\begin{array}{l}\text { No. Do } \\
\text { Indicador }\end{array}$ & $\begin{array}{l}\text { Subpadrão } \\
\text { Museográfico }\end{array}$ & Indicador & Autores-Fonte \\
\hline & 111 & $\begin{array}{l}\text { Biografia dos } \\
\text { Objetos }\end{array}$ & Utilização da biografia dos objetos & Alberti, 2005 \\
\hline & 112 & $\begin{array}{l}\text { Biografia dos } \\
\text { Objetos }\end{array}$ & Abordagem interdisciplinar & Alberti, 2005 \\
\hline & 113 & $\begin{array}{c}\text { Biografia dos } \\
\text { Objetos }\end{array}$ & Promovem diferentes relações com a audiência & $\begin{array}{l}\text { MacDonald, 2004; Alberti, } \\
\text { 2005; }\end{array}$ \\
\hline & 114 & $\begin{array}{c}\text { Biografia dos } \\
\text { Objetos }\end{array}$ & Contingências históricas & $\begin{array}{l}\text { Bennett, 2005; Lourenço e } \\
\text { Gessner, } 2014\end{array}$ \\
\hline & 115 & $\begin{array}{l}\text { Biografia dos } \\
\text { Objetos }\end{array}$ & Contingências locais & $\begin{array}{l}\text { Bennett, 2005; Lourenço e } \\
\text { Gessner, } 2014\end{array}$ \\
\hline & 116 & $\begin{array}{c}\text { Biografia dos } \\
\text { Objetos }\end{array}$ & $\begin{array}{l}\text { Impossibilidade da objetividade e neutralidade } \\
\text { da prática científica e museológica }\end{array}$ & Bennett, 2005 \\
\hline
\end{tabular}

Tabela 12: Tabela que resume os indicadores compartilhados pelo subpadrão museográfico "Biografia dos Objetos", que serão aplicados na análise das exposições estudadas nesse trabalho.

\subsection{Exposições e padrões museográficos: outras interpretações}

Os padrões museográficos caracterizados mostram que quando as exposições quando não são centradas nos objetos do acervo, têm suas centralidade em narrativas propostas por determinados grupos dentro das instituições (em geral, os investigadores) ou buscam aproximar-se das experiências memoráveis e acríticas do espetáculo (financiadas por patronos), subvertendo ordenações enciclopédicas, cronológica e/ou triunfalista em favor de associações de ideias pontuais ou temáticas de grande apelo popular. Na contemporaneidade, há ainda outra possibilidade de construção de discursos museológico, retomando a estética dos gabinetes de curiosidade, há a rejeição ou questionamento de organizações lineares ou históricas dos objetos, o que pode promover o reencantamento pelos objetos e sua materialidade e permite que os mesmos estejam abertos a outras interpretações.

Nota-se, portanto, uma nova aproximação das esferas do entretenimento e da cultura científica: no século XIX os panoramas de Louis Daguerre foram incorporados aos planos de fundo dos dioramas, trazendo movimento e profundidade a esses recursos; o aumento do uso da televisão pós-II Guerra Mundial foi marcado nas exposições com a utilização de narrativas contadas por textos expositivos, ilustradas por objetos e os primórdios dos aparatos interativos, com reprodução do som de animais, por exemplo. A popularidade dos jogos eletrónicos dos anos 1970-1980 expressa-se na 
onda promovida pelos interativos do Public Understanding of Science, culminando com exposições espetaculares blockbuster e todos os produtos licenciados que imitam objetos de coleções que são vendidos. As reservas técnicas visitáveis adaptam-se através da escolha do visitante e a ênfase com a seleção pessoal pode ser relacionada à cultura do consumismo. De acordo com Michelle Henning (2006), a transferência de responsabilidade do autor ou o meio de comunicação para o leitor, consumidor ou visitante é similar ao que encontramos em outros medias, como as televisões interativas ou a internet.

Adamapoulou e Solomon (2016) associam a tendência de reconstrução dos gabinetes de curiosidades (padrão museográfico "Retorno à Curiosidade" com a experiência contemporânea da World Wide Web (WWW), que em 2019, completou 30 anos. A navegação na internet permitiu o acesso simultâneo aos mais diversos conteúdo, como história, ciência, arte, literatura entre outros, nos mais diversos formatos (texto, vídeo, som e, mais recentemente, realidade aumentada), remontando a experiência com um mundo universal do conhecimento, antes de sua divisão em categorias disciplinares especializadas (especialmente depois da segunda metade do século XIX). Os internautas são livres para fazer suas escolhas e criar suas "taxonomias" pessoais. Desse modo, os autores sugerem que a WWW transformou seus usuários em novos “colecionadores de conteúdos”, selecionados com ou sem critérios científicos e classificados de forma racional, simbólica ou simplesmente idiossincrática em pastas no Ambiente de Trabalho.

A experiência com o mundo virtual tornou plausível uma museografia mais heterogénea do que hierárquica e é mais um dos resultados da hibridização dos museus com outros medias. Os museus de história natural têm aumentado seu repertório para poder competir com o mercado de entretenimento atual, ao explorar a plasticidade da ideia de museu combinado com amplas coleções depositadas em edifícios de arquitetura espetacular e elaboradas configurações, como locais para comer e passear, bem como usufruir de exposições (M. Henning, 2006).

Os museus virtuais não necessariamente estão associados a essa perspetiva, embora autores comentem sobre a maneira pela qual a internet reescreve as estruturas de memória e conhecimento, desafiando a ordenação hierárquica do arquivo e aparecendo muito mais como um gabinete de curiosidades. Esses websites, que muitas vezes são projetos de arte, site de colecionadores ou projetos de pesquisa, cresceram a partir da tradição dos museus, porém representam uma virada 
para o conhecimento em rede e descentralizado e o privilégio por associações arbitrárias e ressonantes (M. Henning, 2006).

Pickstone (2001) também relaciona a internet (e a sua possibilidade de trabalho em rede e em tempo real) com mudanças na prática científica, associando a WWW como a invenção da imprensa no século XV, ou as publicações em massa do século XIX, com as práticas científicas dos períodos respetivos. A prensa de Gutenberg transformou a distribuição de textos e permitiu a representação pictórica um instrumento fundamental das ciências descritivas. Depois permitiu a popularização da história natural, por meio da criação de manuais domésticos. Até o final do século XX, tecnologias computacionais expandiram enormemente o potencial de acumulação de informação, onde métodos de recolha de dados puderam ser padronizados e espécies ou detalhes de catálogos podem ser comparados virtualmente. De acordo com o autor, vivemos num maravilhoso caos, onde procuramos ainda por palavras índex, mas não de acordo com um sistema hierárquico, e sim por palavras-chaves (Pickstone, 2001).

Em contrapartida, ao analisarmos as práticas individuais com a internet, ao mesmo tempo que permite o contato com múltiplas realidades e distâncias, é também facto que ela promove o isolamento. A busca contemporânea constante pelo "e-factor", que associa entretenimento a experiência, aponta para uma busca pelo retorno a realidade e, nesse sentido, os objetos de museus são únicos:

"Whatever else can be said of them, objects endure. And in that endurance they offer people the simple pleasure of looking at and the thrill of being in the presence of real things, made by human hands through time and across space or fashioned by nature in all its astonishing variety. Museums filled with objects may provide an education or lessons in moral uplift, but perhaps more than anything they offer the opportunity to see things in three dimensions-things that are beautiful or odd or horrifying or consoling"(Conn, 2010, p. 57)

Quando o público possui um papel chave na seleção das histórias apresentadas e na museografia dos acervos, a comunidade local é entendida como tomadora de decisão e essa é uma das mais radicais ideias do museu pós-moderno (Paddon, 2014). De modo que há, pelo menos, duas perspetivas no recente desenvolvimento dos museus: uma observa os museus moldados aos 
mercados globais, onde a diversidade e as múltiplas histórias significam um meio de atrair audiências; outra analisa os museus como instituições que têm se tornado acessíveis e democráticas, comprometidas com o pluralismo e endereçadas a mais diversas audiências (M. Henning, 2006).

Sob essa última perspetiva, podemos discutir como na teoria museológica, as declarações promovidas nas Assembleias Gerais e Encontros do ICOM têm desempenhado um papel decisório sobre o campo dos museus e são orientadores tanto para políticas públicas sobre essas instituições em diversos países ${ }^{68}$, como para a museografia aplicada a cada nova exposição. No século XX, são destacados cinco documentos norteadores do pensamento museológico contemporâneo: documentos produzidos no Seminário Regional da UNESCO sobre a Função Educativa dos Museus, ocorrido no Rio de Janeiro no ano de 1958; a Declaração de Santiago, em 1972; Declaração de Québec, produzida no I Atelier Internacional da Nova Museologia, realizado em Québec, no ano 1984 e na Reunião de Oaxtepec, ocorrida no México, no mesmo ano; e, por fim, e na Declaração de Caracas, em 1992 (Primo, 1999).

Desses documentos, de acordo com Antunes (2015), na Museologia há um antes e um depois de Santiago do Chile, em 1972. Naquele ano, o ICOM organizou, a pedido da UNESCO, a "Mesa Redonda sobre o Desenvolvimento e o Papel dos Museus no Mundo Contemporâneo", em Santiago do Chile, de 20 a 31 de maio de 1972, onde foi aprovada a Declaração de Santiago, que marcou uma verdadeira rutura epistemológica, por assumir que o museu como instituição a serviço do meio (Antunes, 2015). Esse documento propõe que o museu seja entendido como instrumento e agente de transformação social - o museu integral (Primo, 1999).

O Documento de Oaxtepec é redigido em 1984, no mesmo ano da Declaração de Québec e reafirma muitas das questões apontadas e recomendadas na Mesa Redonda de Santiago do Chile e em Québec. Na Declaração de Québec não há em si novidades conceituais, mas a sua importância

${ }^{68}$ Um exemplo bastante óbvio é a definição de museus presente na Lei Quadro dos Museus Portugueses (Lei nº 47/2004 Artigo $3^{\circ}$ ) eno Estatuto dos Museus Brasileiros (Lei 11.904 de 14 de Janeiro de 2009), ambas inspiradas na definição aprovada na $20^{2}$ Assembleia Geral do ICOM que ocorreu em Barcelona, Espanha em 6 de Junho de 2001 (e que voltou a ser discutida na Conferência Mundial de 2019, em Kyoto). 
deve-se reconhecimento da existência do Movimento da Nova Museologia ${ }^{69}$, tendo assim legitimado uma pratica museológica mais ativa, socializadora, dialógica e internacionalmente autônoma.

Na Declaração de Caracas, em 1992, tem-se a evolução do conceito de museu integral para o conceito de museu integrado. Propõe, então, uma releitura do documento produzido em Santiago, e é em Caracas que a comunidade é entendida como "co-gestora" do património, constatando a vigência de muitos de seus postulados e as suas influências no conceito de museu (Primo, 1999).

Se numa perspetiva de uma museografia "tradicional" o objeto é o centro da atividade do profissional que se concretiza num espaço chamado museu, que é visitado por determinados tipos de públicos, que devem ser educados e informados; numa perspetiva da "Nova Museologia", emergem novos objetos museológicos (não apenas o que é tipológico e exemplar), os museus alargam-se para os territórios e assumem diferentes configurações e formas de organização a serviço das comunidades. A Nova Museologia possui premissas inclusivas e assume que todos somos portadores de saber e que os saberes são múltiplos. Considera, portanto, que todos temos o direito e o dever de participar na construção do nosso presente (Primo \& Leite, 2015).

De modo mais evidente, o padrão museográfico "Retorno à Curiosidade" está alinhado com tais perspetivas mais contemporâneas da Museologia. A partir de uma coletânea de trabalhos sobre o que se espera dos museus do futuro (museus emergentes) e a realidade museológica atual (museus em transição), Cury (2014) indica que nas últimas décadas observa-se um paradigma emergente nos museus, entendido como lugar que promove o diálogo entre o contexto de vida do visitante e aquilo que o museu propõe como experiência de visitação. Os objetivos da visita tornamse múltiplos e escolhas, os significados são construções sociais, a experiência museal é simbólica, subjetiva e intersubjetiva, alcança as dimensões ritualísticas e lúdicas, provoca as emoções, é multissensorial e transcende o espaço do museu, o visitante é ativo e autônomo. Entre diversos itens apontados em um quadro comparativo, destaca-se que o discurso expositivo do museu em transição (ou seja, o museu que vivemos hoje) é um discurso sinérgico de múltiplas vozes e narrativas [INDICADOR 99, Tabela 11], a curadoria é realizada por equipas multidisciplinares (como citamos

\footnotetext{
${ }^{69}$ O MINOM (Movimento Internacional para uma Nova Museologia) foi constituído em Lisboa durante o II Atelier Internacional de Nova Museologia “Ecomuseus e museologia local”, por Escritura Pública de 23 de Junho de 1995 (Antunes, 2015).
} 
acima o exemplo do artista Mark Dion trabalhando em conjunto com equipas de investigadores), e uma noção de património como ponte de aproximação entre sociedades e culturas distintas, tempos e espaços [INDICADOR 107, Tabela 11].

O subpadrão museográfico "Biografia dos Objetos" também representa uma metodologia contemporânea dos estudos museológicos. A Nova Museologia parte premissa teórica de adequação das estruturas e processos museológicos aos ritmos e às necessidades das sociedades contemporâneas. Nesse sentido, reconhece as narrativas biográficas associadas ao acervos na busca por produzir um saber emancipatório e solidário, como um método que adequado ao resgate dos conhecimentos e memórias das comunidades (Primo \& Leite, 2015).

Além disso, o questionamento sobre o sentido dos objetos que estão nas coleções de dos museus, funções para a comunidade é uma preocupação que começou a surgir com o fim da II Guerra Mundial. A interrogação sobre para que serve a Museologia, ao mesmo tempo que a distinção entre primitivos e civilizados deixou de ser usada (categorias comuns em museus tradicionais), conduziu a uma consciência de que a Museologia e os museus devem construir um processo dialógico. Como citado anteriormente, os documentos produzidos no seio das assembleias gerais e reuniões internacionais promovidas pelo ICOM são fundamentais, especialmente a "Declaração de Santiago", de 1972. No contexto dos intensos movimentos sociais da América do Sul, esta declaração atenta para a necessidade dos museus estarem ao serviço do desenvolvimento da comunidade e dos territórios e introduz no vocabulário da Museologia as questões do ambiente e território, por meio do conceito do ecomuseu e do museu integral (Primo \& Leite, 2015). 


\section{CAPÍTULO II: Análise das exposições: museografia categorizada por padrões}

\subsection{Métodos de investigação}

A partir da exaustiva revisão na literatura científica e museológica realizada no Capítulo 2, foram sinalizadas séries de indicadores que caracterizam cada um dos padrões e sub-padrões museográficos propostos nesse trabalho. Tais padrões assinalam traços do design e arquitetura, escolha de acervo e recursos museográficos e quantidade de narrativa textual que podem facilmente ser observados em visitas à exposições.

Além disso, como discutido em cada um dos padrões caracterizados também pressupõem epistemologias do conhecimento científico e práticas museológicas subjacentes as equipas curatoriais que desenvolveram as exposições, ao momento histórico em que foram propostas, as instituições em que estão alocadas, as respetivas agências de fomento, entre outros fatores.

Os indicadores descritos ao longo do texto foram congregados em tabelas (Tabelas 1 - 12) no capítulo anterior e estão sumarizados em uma Matriz de Indicadores, apresentada no APÊNDICE 2. A Matriz de Indicadores é uma ferramenta de análise construída nesse trabalho, de modo a permitir o reconhecimento inicial da museografia presente em exposições de museus de história natural e que permite a articulação entre museografia (design), ciência (epistemologias, conceções e representações) e público (relação com o acervo e narrativa).

Essa matriz propiciou uma análise estatística simples de agrupamento (também conhecida como análise de cluster), em que cada agrupamento refere-se a um subpadrão, inserido em um padrão museográfico, a saber: (i) "Centrado em Objetos", (ii) "Centrado numa Narrativa”; (iii) "Espetacular" e (iv) "Retorno à Curiosidade".

A Matriz de indicadores foi aplicada da seguinte forma: para cada indicador é conferido o valor "1" caso esteja presenta na exposição estudada ou "0" quando está ausente. Calculou-se o índice numérico EPM (Enquadramento em Padrão Museográfico), a partir da seguinte expressão: $\mathrm{EPM}=\frac{\Sigma \mathrm{n}}{\mathrm{T}}$

Em que $n$ é o número de indicadores que foram identificados (atribuído valor 1) na exposição estudada e T é o total de indicadores existentes para cada padrão. Sendo assim, a expressão deve 
ser calculada com a somatória dos indicadores identificados e dividida pelo total de indicadores reconhecidos em um determinado padrão museográfico.

Considerando que todos os indicadores têm o mesmo peso, a partir dessa matriz de dados realizou-se um teste de propensão, que avaliou como cada uma das exposições analisadas aderiram (ou "são similares") aos agrupamentos propostos. O resultado foi um índice que variou entre 0 e 1 e que foi convertido em percentagem, para evitar conflitos com o EPM.

Nesse trabalho os cálculos e planilhas de trabalho foram realizadas com auxílio do software Microsoft Excel ${ }^{\circledR}$, aplicando-se as funções somatória condicional SOMA.SE, utilizada para somar os valores ( 0 e 1) num intervalo que correspondem aos critérios especificados (indicadores) e a função estatística CONTAR.SE, que permitiu contar o número de células que correspondem a um critério, gerando a seguinte fórmula ${ }^{70}$ :

\section{= SOMA.SE $([$ intervalo de critérios];[critério]; [intervalo de valores a serem somados])/CONTAR.SE([intervalo de critérios];[critério])}

EPM é o valor obtido e insere a exposição analisada em um dos quatro grandes grupos de padrões museográficos: "Centrado no Objeto", "Centrado numa Narrativa", "Espetacular" e "Retorno à Curiosidade". Para uma compreensão mais detalhada de como as exposições estão propensas a aderirem a cada um dos dez subpadrões museográficos identificados, foi calculado a percentagem da adesão da exposição a cada padrão museográfico mais específico. Por exemplo: uma exposição pode ser centrada em objetos e composta apenas por dioramas e não possuir séries taxonómicas. 0 EPM apontará a centralidade do objeto como padrão geral, e a percentagem informa qual subpadrão museográfico essa exposição foi aderente.

Claramente, por se tratarem de índices numéricos os resultados deverão ser analisados individualmente e contextualmente. A presença ou ausência dos indicadores esteve associada a diferentes fatores, como escolhas curatoriais, orçamento, acervo disponível, pressupostos educativos etc. Contudo, propõe-se tal ferramenta para caracterizações iniciais de identificação, a

\footnotetext{
70 Aplicação da fórmula teórica elaborada, dentro da linguagem proposta pelo software Microsoft Excel ${ }^{\circledR}$.
} 
serem utilizadas inclusive "em campo" (em museus e/ou exposições científicas) e que pôde orientar análises mais detalhadas nesta tese, bem como poderá subsidiar outras investigações.

\subsection{Estudos de Caso: descrição de exposições e enquadramento nos diferentes padrões museográficos}

\subsubsection{Museu Nacional do Rio de Janeiro: "Conchas, corais e borboletas"}

\subsubsection{Contextualização:}

A exposição "Conchas, corais e borboletas" foi aberta ao público em 01 de Outubro de 2013 e constituía uma remontagem das exposições de longa-duração do Departamento de Invertebrados e do Departamento de Entomologia do MNRJ. Parte da exposição anterior, denominada "Exposição dos Insetos" foi inaugurada em 1960, planejada e executada pelos professores José Cândido de Melo Carvalho e Roger Pierre Hypolite Arlé. A presença de objetos históricos, textos e elementos museográficos na exposição contemporânea apontavam referências históricas (Figura 18).

O processo de desenvolvimento da exposição foi intenso e multidisciplinar, uma vez que congregou curadores científicos oriundos de diferentes laboratórios de pesquisa dos departamentos envolvidos, equipa do setor de Museologia, designers, artistas e outros profissionais externos ao MNRJ. Foram realizadas reuniões com o grupo geral de curadores e, mais sistematicamente, reuniões individuais entre o curador de cada setor da exposição e a museóloga Thereza Baumann, coordenadora geral do projeto expositivo.

Uma estratégia desenvolvida pela referida coordenadora, junto com designer Glauco Campelo - co-responsável pelo projeto expositivo - foi a elaboração de "Fichas de Catalogação de Material em Exposição" (ficha museográfica), em que cada curador científico especificava individualmente o tipo do recurso expográfico que desejava expor (por exemplo: espécime, modelo, esquema, multimédia ou texto) e o contexto em que se inseria o recurso escolhido (Figura 19). 


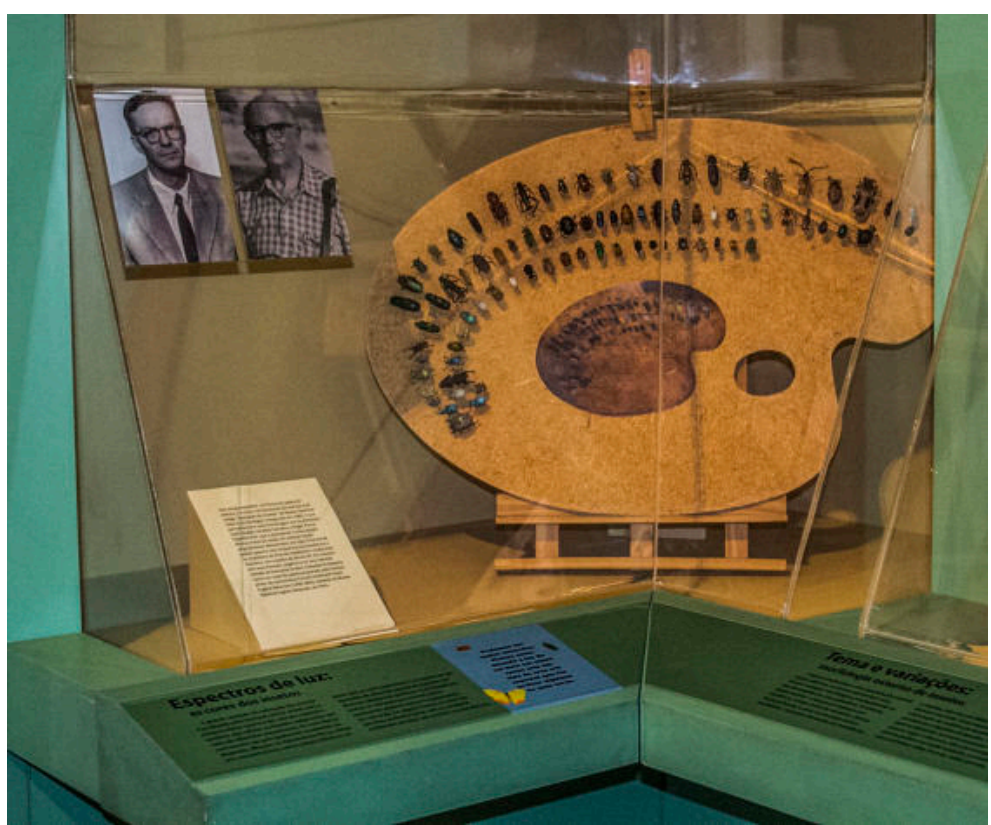

FIGURA 18: Vitrine com reprodução de um paleta de aquarela. Besouros estavam expostos no lugar de tinta, sinalizando a diversidade de cores do grupo. Na legenda, era possivel ler: "Este antigo expositor, em forma de paleta de pintura, é o único remanescente da estrutura da antiga "Exposição de Insetos" do Museu Nacional (Sala III da Zoologia), inaugurada em 1960. A sua permanência é uma homenagem aos professores José Cândido de Melo Carvalho e Roger Pierre Hypolite Arlé, que a planejarame executaram. Muitos materiais ainda em exibição foram originalmente selecionados por eles. A forma da paleta aparece com frequência na arquitetura e no mobiliário do final do movimento modernista brasileiro, em meados do século XX. Em sintonia com esse formato, organizou-se uma colorida coleção de besouros (ordem Coleoptera) dispostos como nas cores da paleta preparada pelo famoso pintor do romantismo francês Ferdinand Victor Eugène Delacroix (1798-1863), exposta no Musée National Eugène Delacroix, em Paris". Fotografia: Mariana Galera Soler, obtida em visita técnica em Junho de 2014.

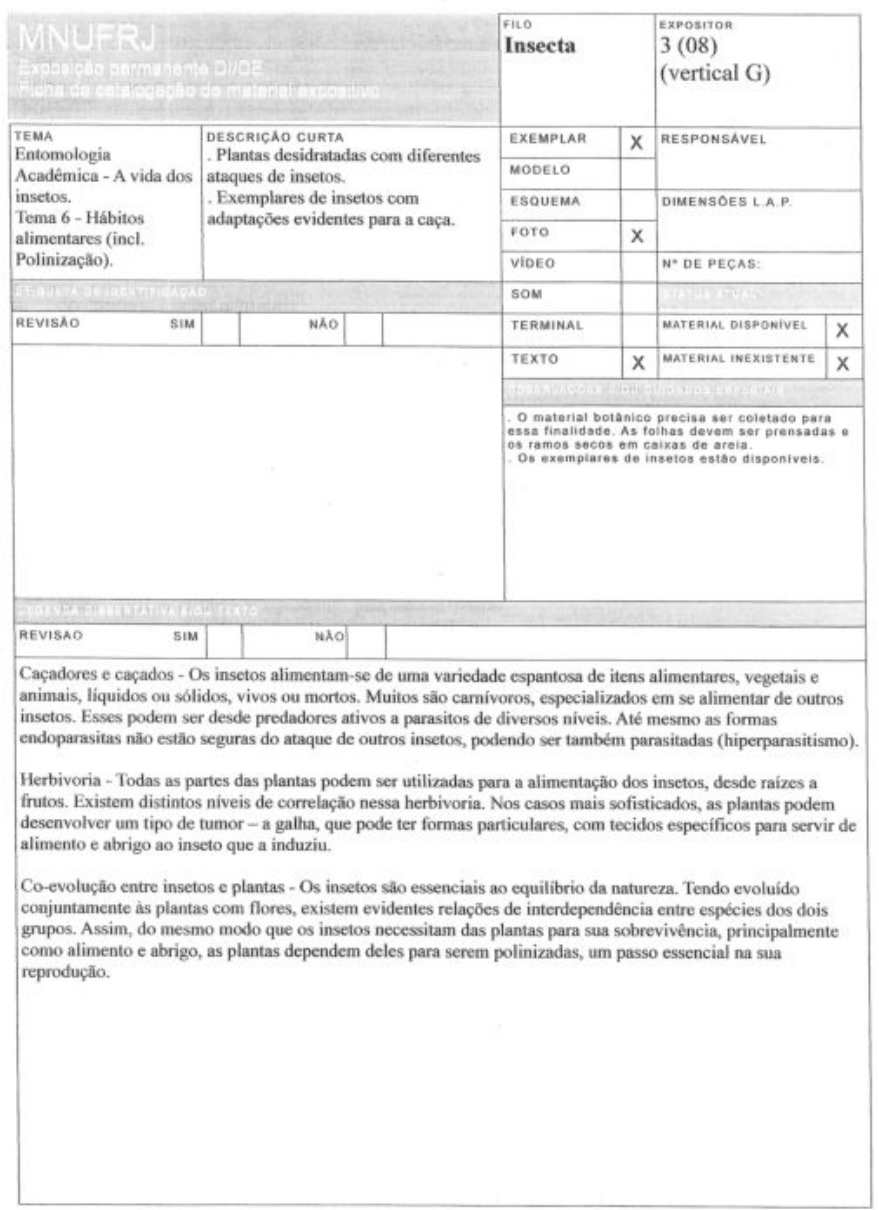

FIGURA 19: Exemplo de uma Ficha de Catalogação de Material em Exposição. Fonte: Acervo do Setor de Museologia, visitado em Junho de 2014 e Julho de 2018. 
A partir destas fichas foram criados roteiros, que listavam e hierarquizavam os assuntos a que se relacionavam, e a ordem em que apareceram na exposição. Os investigadores tiveram total liberdade para selecionar o acervo em exposição e definir seu discurso, facto que possibilitou a maior participação desses profissionais como curadores da exposição ${ }^{71}$. Além disso, a equipe do setor de Museologia sugeriu algumas peças do acervo da exposição antiga que foram consideradas fundamentais pelo reconhecimento do público, valor estético e/ou histórico.

De acordo com a gestão curatorial acima descrita, o início da elaboração da exposição ocorreu em 2008, com a previsão original de conclusão em Dezembro de 2009 (facto que ocorreu apenas quatro anos depois).O principal motivo do atraso foi o difícil acordo por parte dos curadores científicos (investigadores) a respeito da seleção de objetos e a distribuição de espaços para compor a exposição (Campelo, 2010). Evidencia-se esse conflito pela demarcação clara (e proporcional) dos espaços dos setores da exposição e os respetivos departamentos de investigação (organizados por grupos taxonómicos) (Figura 20), bem como praticamente a ausência de espaços em que sejam representados organismos de grupos zoológicos diferentes. Nas entrevistas, os membros científicos e técnicos da equipa relataram unanimemente os entraves e discussões sobre espaços.

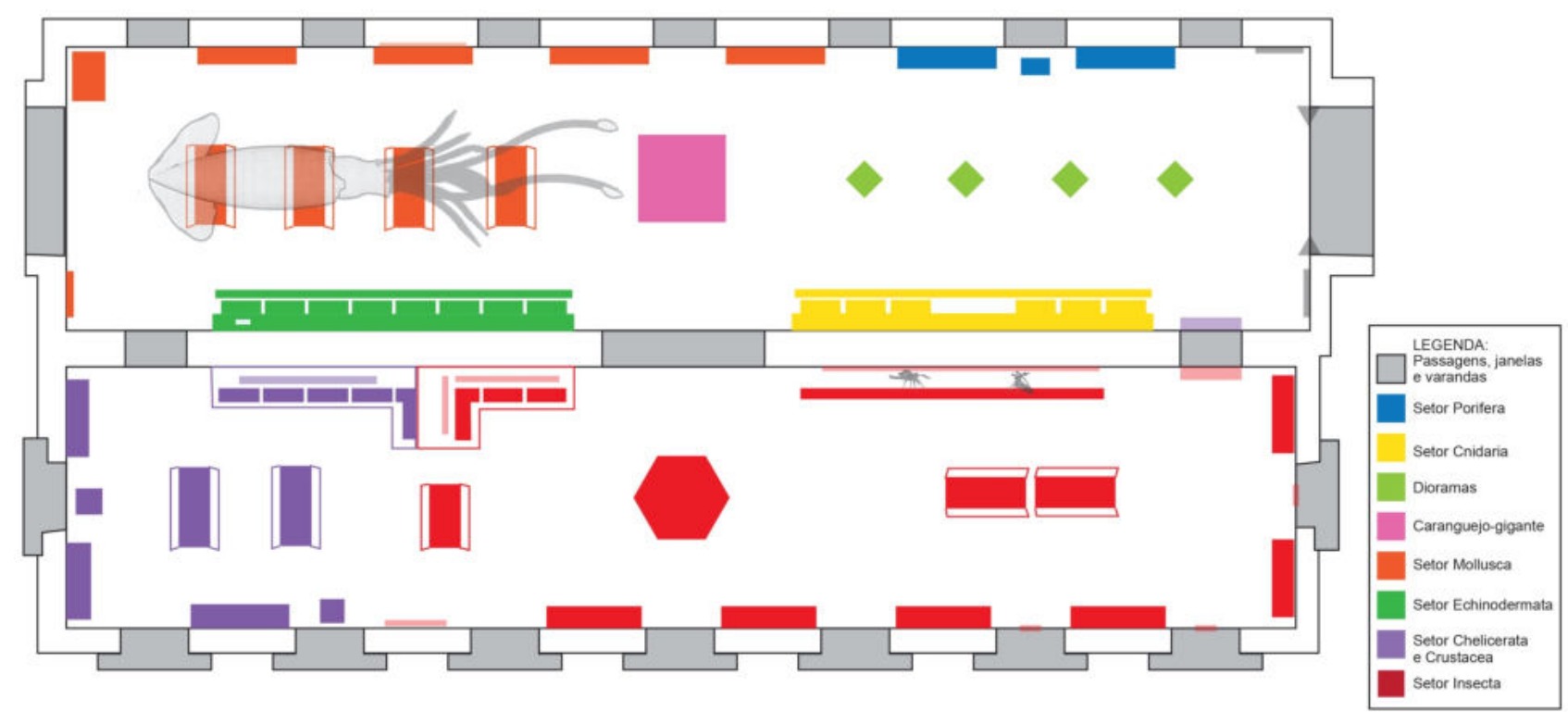

FIGURA 20: Planta baixa da exposição "Conchas, corais e borboletas". Fonte: Arquivo digitalizado do Setor de Museologia. Imagem editada pela autora.

${ }^{71}$ Comunicação pessoal de ALVES, em 23 de Junho de 2014 e corroboradas BAUMANN e CAMPELO, em 1 de Agosto de 2018. 
A estes questionamentos internos foram somadas discussões num âmbito mais geral do MNRJ, posto que foi sugerida a alteração das salas onde foi desenvolvida a exposição. Em princípio, os objetos e conteúdos sobre animais invertebrados eram expostos em quatro salas segmentadas e com pouca continuidade de paredes. A proposta expositiva de "Conchas, corais e borboletas" efetivamente ocupou o espaço anteriormente destinada aos grandeza vertebrados, que correspondia a duas grandes galerias, com vistas para os jardins nobres do MNRJ e ampla perspetiva, que permitiram a maior utilização dos meios museográficos e de soluções mais arrojadas (Campelo, 2010). Contudo, mesmo nesse espaço nobre, a obra também esteve parada por meses devido a manutenção do piso, que sofria uma infestação de insetos ${ }^{72}$.

Até mesmo o mobiliário interferiu nos prazos de execução do projeto, uma vez que se tentou reaproveitar o mobiliário existente na instituição, desenhando-se adaptações para reforma e atualização destes componentes. No entanto, as condições de manutenção e as alterações necessárias para adequação e especificações técnicas tornaram a alternativa economicamente inviável. Por isso optou-se pela elaboração de projetos originais de vitrines e equipamentos, destinados aos conteúdos e objetos especificados por seus curadores (CAMPELO, 2010).

O desenho de vitrines e apresentação de maquetes e perspetivas, associados às alternativas de recursos de ambientação para contextualização dos módulos e reorganização do espaço, foram realizados durante o período de Setembro a Dezembro de 2009, pela empresa carioca UNIDESIGN Programação Visual LTDA (Figura 21).

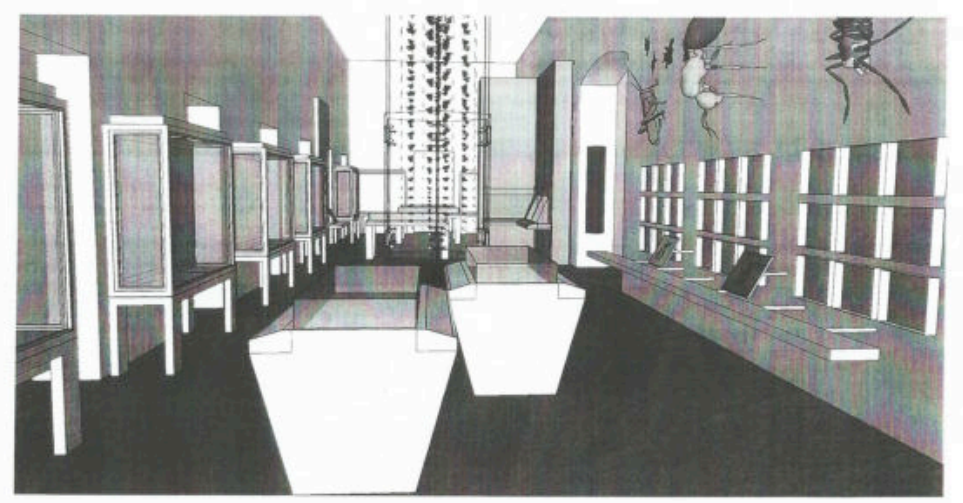

${ }^{72}$ BAUMANN e CAMPELO , comunicação pessoal, 1 de Agosto de 2018.
FIGURA 21: Uma das perspetivas que faziam parte do projeto expositivo de "Conchas, corais e borboletas”, com distribuição do mobiliário e alguns objetos do acervo, na segunda galeria. Fonte: Acervo do Setor de Museologia, visitado em Junho de 2014 e Julho de 2018. 
A produção cenotécnica iniciou em Fevereiro de 2010, durou mais de 15 meses, e foi desenvolvida pela empresa também carioca CENOMAX (CAMPELO, 2010). A disposição do acervo nas vitrines e preparação de suportes mais finos ficou a cargo da equipa de Museologia do MNRJ, principalmente na figura da museóloga Marilene de Oliveira Alves e dos curadores e técnicos dos respetivos setores científicos, destacando-se o trabalho de alguns curadores científicos que pessoalmente engajaram-se na montagem, como Alcimar do Lago Carvalho (Entomologia) e Alexandre Dias Pimenta (Malacologia).

No que diz respeito ao financiamento, a exposição "Conchas, corais e borboletas" dispôs de diferentes fontes de recursos, mas que essencialmente constituiu-se por montantes financeiros provenientes de editais públicos federais para divulgação da ciência. Ainda foram necessários aportes pontuais de verba que foram obtido por doações (Associação de Amigos do Museu Nacional) ou de financiamentos de projetos de investigação de professores e investigadores da UFRJ.

A ficha técnica da exposição "Conchas, corais e borboletas" encontra-se no ANEXO 1.

\subsubsection{Tratamento Museográfico}

O contexto conflituoso em que foi concebida a exposição "Conchas, corais e borboletas" estava refletido em seu discurso expositivo. Assim, observavam-se setores unificados pelo projeto museográfico, especialmente a comunicação visual e mobiliário comum, mas que pouco dialogam entre si. Havia também ainda um texto introdutório sobre o reino Animalia, que introduzia o visitante no universo zoológico.

Inseridos em duas grandes galerias, os setores da exposição foram organizados taxonomicamente, de modo linear e representam os grandes grupos (filos) de invertebrados, tal como eram organizadas as coleções científicas e os departamentos da instituição: Porifera, Cnidaria, Mollusca, Echinodermata, Arachnida, Crustacea e Insecta (Figura 20).

Mesmo diante da especificidade de cada setor, foi possível identificar algumas similaridades quanto ao conteúdos e acervos: (i) introdução geral sobre grupo zoológico (filo) e diferenciação de suas classes; (ii) número de espécies no grupo e representatividade dento da diversidade conhecida; (iii) relações entre humanos e o grupo, especialmente quanto a temas relacionados à conservação 
ambiental e saúde (prevenção de acidentes e bioprospecção de fármacos); e, principalmente, (iv) expressivo aporte de objetos que evidenciam a diversidade dentro de cada grupo representado.

Em sequência ao texto introdutório sobre Animalia, estava presente o setor Porifera, representado pelas esponjas-do-mar e esponjas-de-água-doce. Internamente, este setor também estava organizado taxonomicamente. As classes de Porifera eram diferenciadas, estavam disponíveis textos informativos sobre a história natural do grupo, curiosidades (mitos). Alguns espécimes dispunham de pormenores de sua biografia, especialmente associados ao momento da recolha, realizada por expedições de investigação e/ou pela empresa PETROBRAS ${ }^{73}$. Ainda eram apresentados os usos dos poríferos pela espécie humana: importância econômica, bioprospecção e algumas de suas representações culturais, como um vaso zoomórfico indígena (Figura 22).
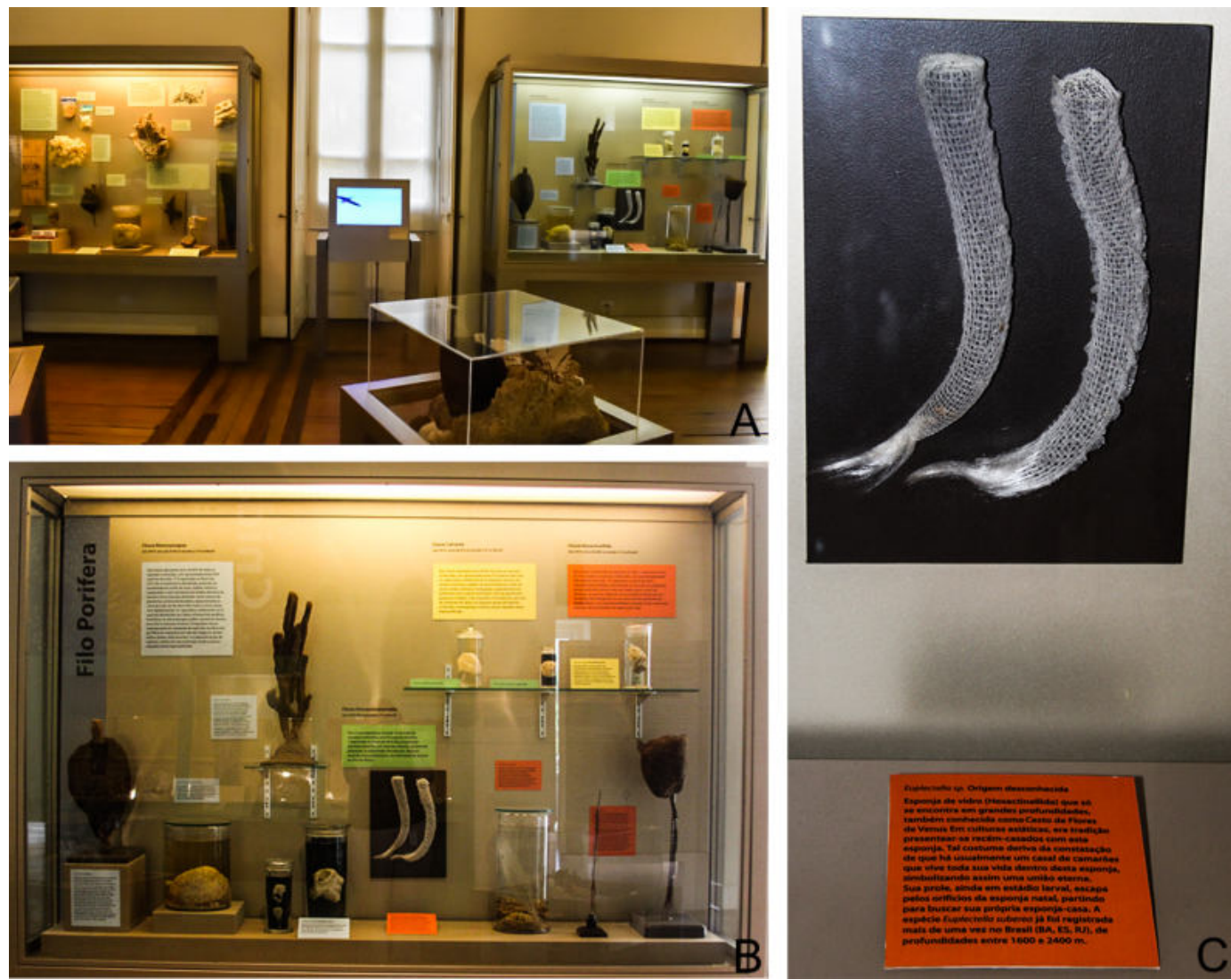

FIGURA 22: Exposição "Conchas, corais e borboletas" - Setor Porifera. Em A visão geral do setor, com vitrines, vídeo com imagens do trabalho em campo dos investigadores. Em B vitrine "Filo Porifera", com espécimes preservados em via seca e húmida dos grupos poríferos viventes. Em C destaque para objeto histórico, duas esponjas-de-vidro (Euplectella sp.). Fotografia: Mariana Galera Soler, obtida em visita técnica em Junho de 2014 (B e C) e Agosto de 2018 (A).

${ }^{73}$ Empresa de capital aberto, cujo o principal acionista é o governo brasileiro, constituindo-se assim como uma empresa estatal de economia mista, no seguimento da energia, prioritariamente nas áreas de prospeção, exploração, produção, refino e distribuição de petróleo e derivados. 
O segundo setor era Cnidaria, filo representado na exposição por corais, águas-vivas, anêmonas-do-mar e gorgônias. O contexto evolutivo do grupo iniciava do setor, apresentando também quem são os animais do filo. Associado a esta apresentação, eram mostradas características gerais dos cnidários, como anatomia, hábitos de vida, ambiente, alimentação e comportamento. Considerando que o tipo de ciclo de vida, em geral, diferencia as classes de Cnidaria, tais ciclos estão representados por meio de esquemas impressos e as classes apresentadas por animais preservados em via húmida. Ainda neste setor, havia grande destaque os recifes de coral (grande painel apresentado na imagem e conteúdos do vídeo)74 (Figura 23).

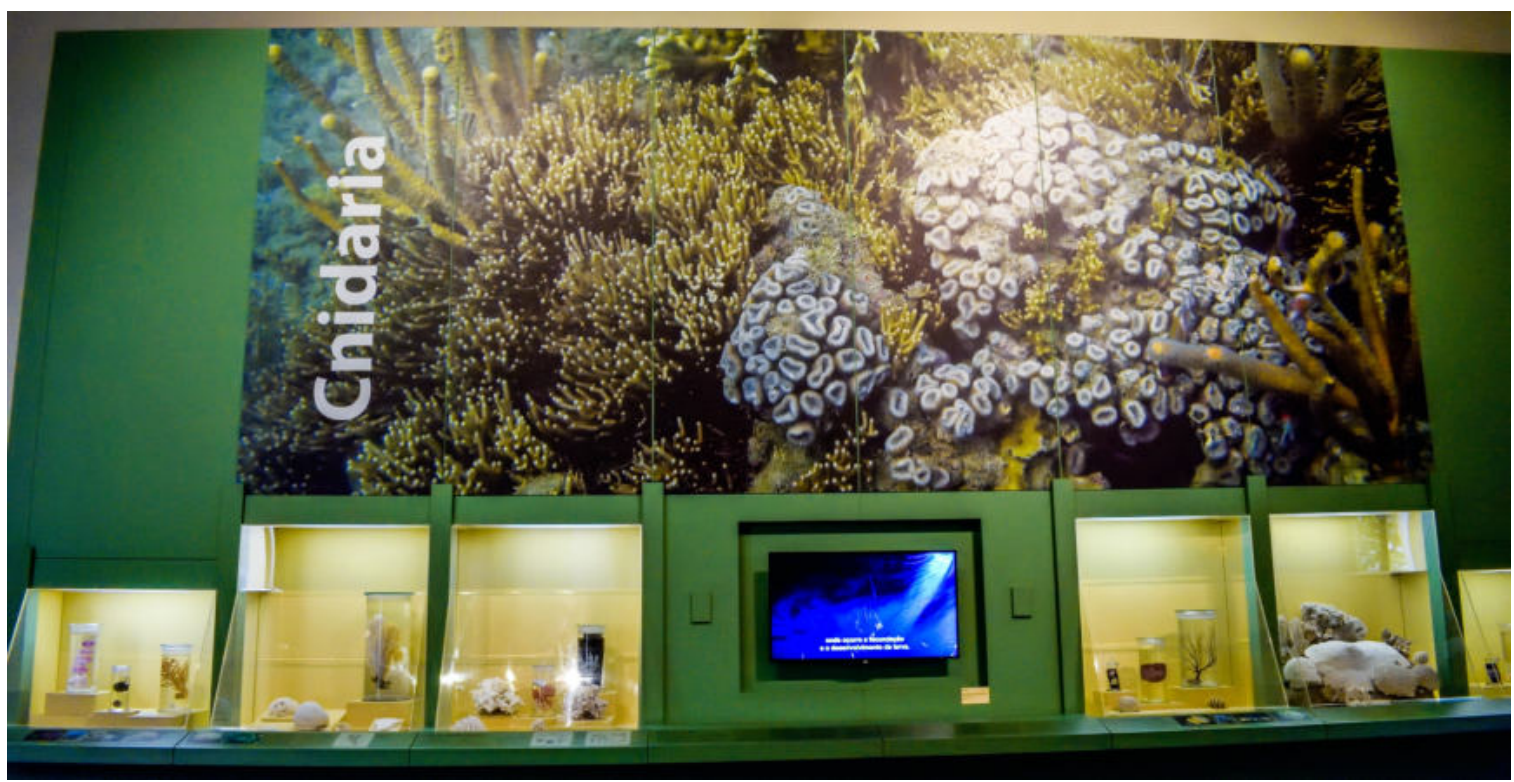

FIGURA 23: Exposição "Conchas, corais e borboletas" - Setor Cnidaria. Em A visão geral do setor, com vitrines e vídeo sobre ações do Projeto Coral Vivo. Fotografia: Mariana Galera Soler, obtida em visita técnica em Agosto de 2018.

Entre esses dois primeiros setores, era possível observar um conjunto de quatro pequenos dioramas, que representam biomas marinhos: bioma inconsolidado raso, bioma consolidado raso, bioma inconsolidado fundo, bioma consolidado fundo. Estes biomas possuíam essencialmente invertebrados e representavam os únicos pontos da exposição em que animais de diferentes grupos taxonómicos eram apresentados juntos e representando as condições em que viviam em ambiente natural (Figura 24 A-E). A seguir e antes do início do próximo setor, encontrava-se em exposição um dos mais icônicos objetos de história natural do MNRJ: um caranguejo-gigante (Macrocheira

74 O grande destaque para os corais em "Conchas, corais e borboletas" também está associado à investigação realizada na instituição, uma vez que investigadores do respetivo departamento são os fundadores do Projeto Coral Vivo, financiado, pela Petrobras desde 2003. Mais informações em: http://coralvivo.org.br. Acesso em 11 de Abril de2019. 
kaempferi) preservado em via seca. Este objeto, que também estava em exposição anteriormente, foi restaurado para "Conchas, corais e borboletas" e, embora estivesse exposto fora do contexto taxonómico, sua montra formava um contínuo com os dioramas de biomas, uma vez que caranguejos-gigantes vivem em águas profundas do Pacífico e os biomas representados não possuem referências a que oceanos pertencem (Figura 4B e 24A).

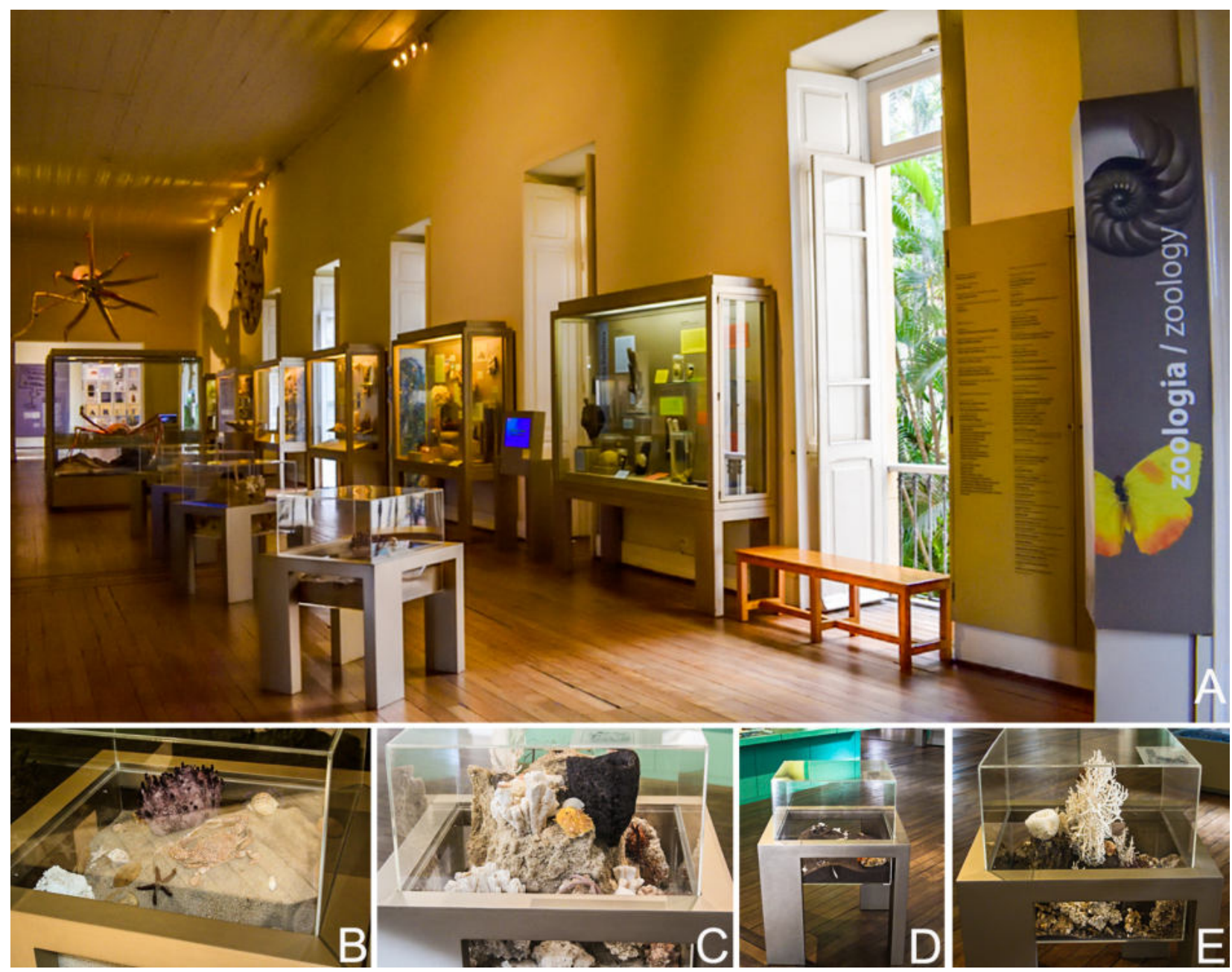

FIGURA 24: Dioramas da exposição "Conchas, corais e borboletas". Em A visão geral da primeira sala da exposição, com destaque para os quatro pequenos dioramas no centro da sala. Em B diorama "bioma inconsolidado raso". Em C diorama "bioma consolidado raso. Em D diorama "bioma inconsolidado fundo. Em E diorama "bioma consolidado fundo. Fotografia: Mariana Galera Soler, obtida em visita técnica em Agosto de 2018.

O setor Mollusca ocupava a metade final da primeira galeria da exposição (Figura 17). Possuía estratégias expográficas únicas na exposição, como uma réplica de uma lula-gigante com cerca de 
8,5m de comprimento presa ao teto ${ }^{75}$, uma mesa com lupas para observação de micromoluscos e imagens de microscopia eletrônica dos mesmos (Figura 25B-C).

A primeira vitrine desse setor apresentava a pergunta: "Quem são e o que são os moluscos?", pergunta respondida por meio de textos ilustrados por espécimes sobre a principal característica do grupo (presença de concha calcária) e o sucesso evolutivo dos moluscos em diferentes ambientes marinhos e terrestres.

Os conteúdos zoológicos e taxonómicos mais detalhados sobre as principais classes de moluscos (bivalves, cefalópodes e gastrópodes) eram presentes nas vitrines laterais. Já nas vitrines centrais estavam disponíveis grande quantidade de espécimes (mais de 500) de espécies diferentes e eram abordadas essencialmente questões relacionadas à morfologia e às variações morfológicas ou de hábito de vida (Figura 25A).
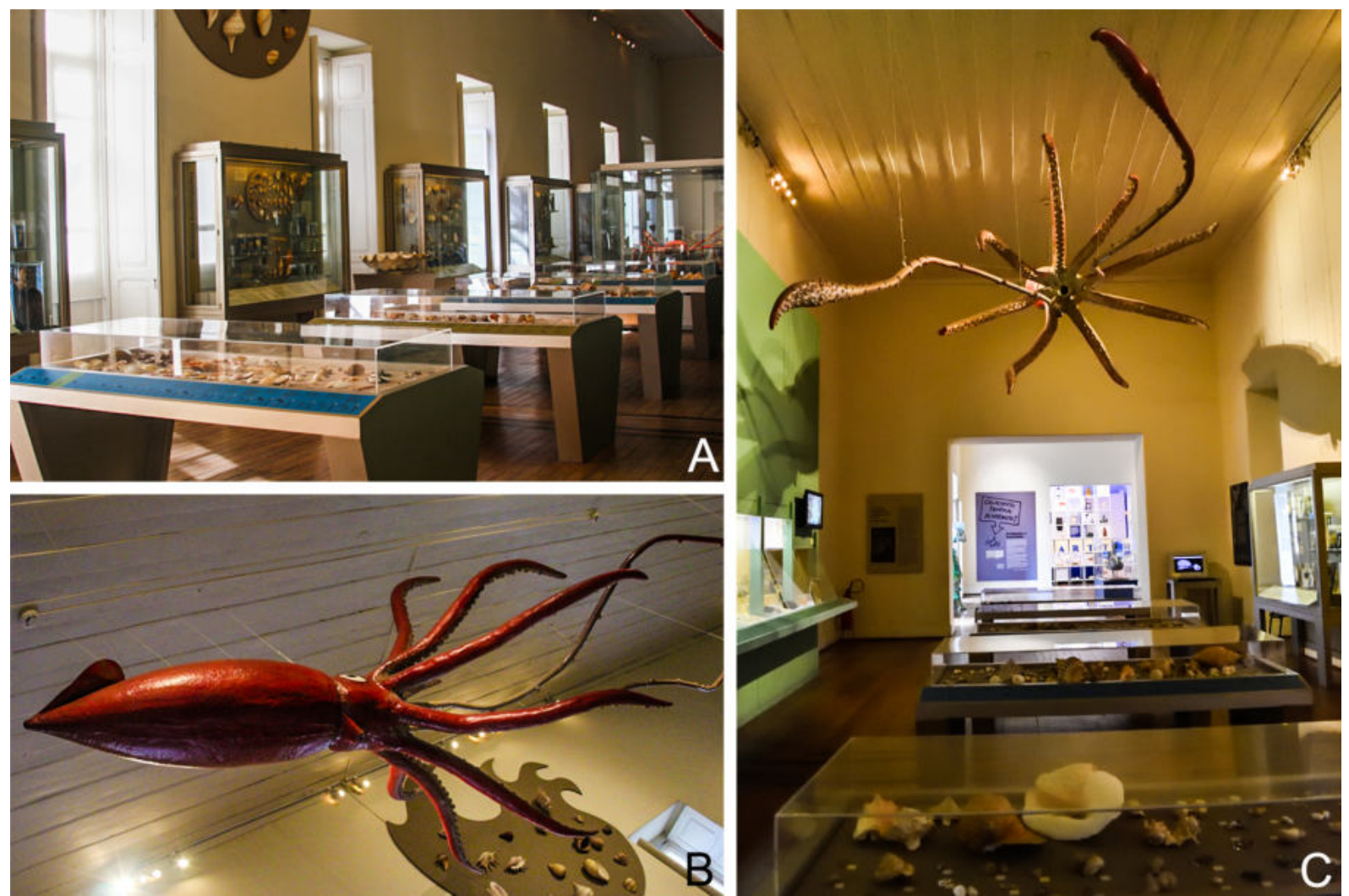

FIGURA 25: Exposição "Conchas, corais e borboletas" - Setor Mollusca. Em A visão geral do setor. Em B réplica de lula-gigante (Architeuthis dux). Em C vista geral da exposição e ao fundo as últimas salas de exposições abertas para comemoração dos 200 anos do MNRJ. Fotografia: Mariana Galera Soler, obtida em visita técnica em Agosto de 2018.

75 Modelos semelhantes de lulas-gigantes presas no teto podem vistos nas exposições do Natural History Museum, em Londres, e Museo Natural de Ciencias Naturales, em Madrid. 
Ainda na metade final da primeira galeria de "Conchas, corais e borboletas", junto ao setor dos moluscos, havia um conjunto de vitrines laterais que constituíam o Setor Echinodermata. Neste setor, estrelas-do-mar, ouriços-do-mar, holotúrias, crinóides e ofiurídeos também estavam organizados taxonomicamente. O discurso proposto pautava-se nas características morfológicas únicas dos equinodermos (simetria pentarradial na fase adulta, sistema de canais e esqueleto internos e parede corporal) e naquelas que diferenciam as respetivas classes. Tais características foram apresentadas dentro de um contexto evolutivo apresentado por textos e gráficos e que contava parte da história do grupo, que surgiu há 600 milhões de anos atrás. Ainda sobre os equinodermos estavam disponíveis informações textuais sobre a história natural do grupo: hábitos de vida, alimentação, anatomia e comportamento (Figura 26).

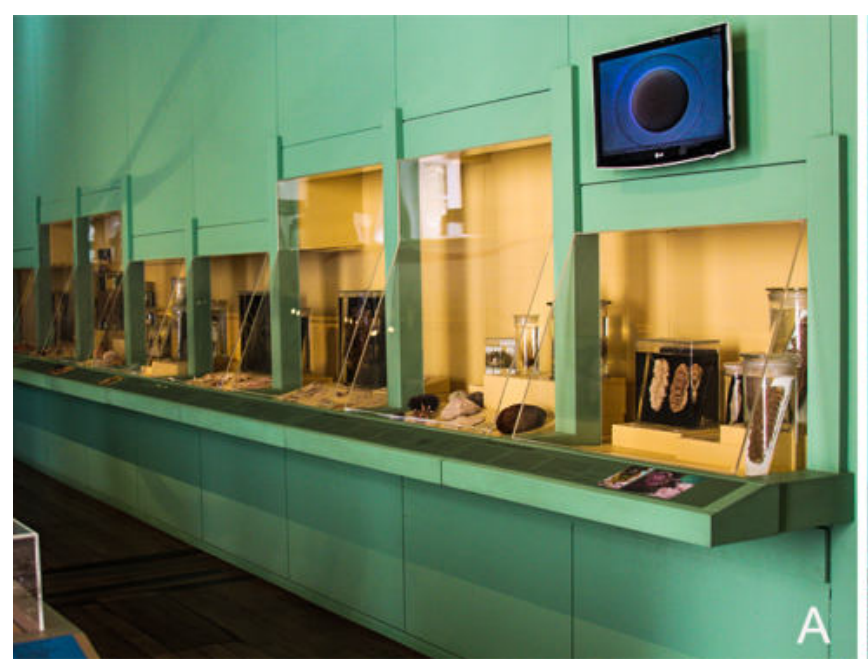

FIGURA 26: Exposição "Conchas, corais e borboletas" - Setor Echinodermata. Em A vitrines do setor, com equinodermos preservados em vias seca e úmida, fósseis, fotografias e vídeo (vídeo intitulado "Vida de Bolacha", com legendas e sem som, conta o desenvolvimento embrionário e reprodução das bolachas-da-praia. Produzido por Bruno C. Vellutini e Alvaro E. Migotto, Centro de Biologia Marinha da USP. Duração: 4'05). Em B vitrine "Filo Echinodermata" com fósseis e representantes viventes dos equinodermos. Fotografia: Mariana Galera Soler, obtida em visita técnica em Junho de 2014.

A segunda galeria de "Conchas, corais e borboletas" estava destinada aos artrópodes. A partir de um texto introdutório, eram descritas algumas características comuns aos grupos zoológicos que estavam expostos nos três setores desta galeria (aracnídeos, crustáceos e insetos) com abordagem evolutiva, como a presença do exoesqueleto e o corpo formado por segmentos e apêndices articulados (Figura 27). 


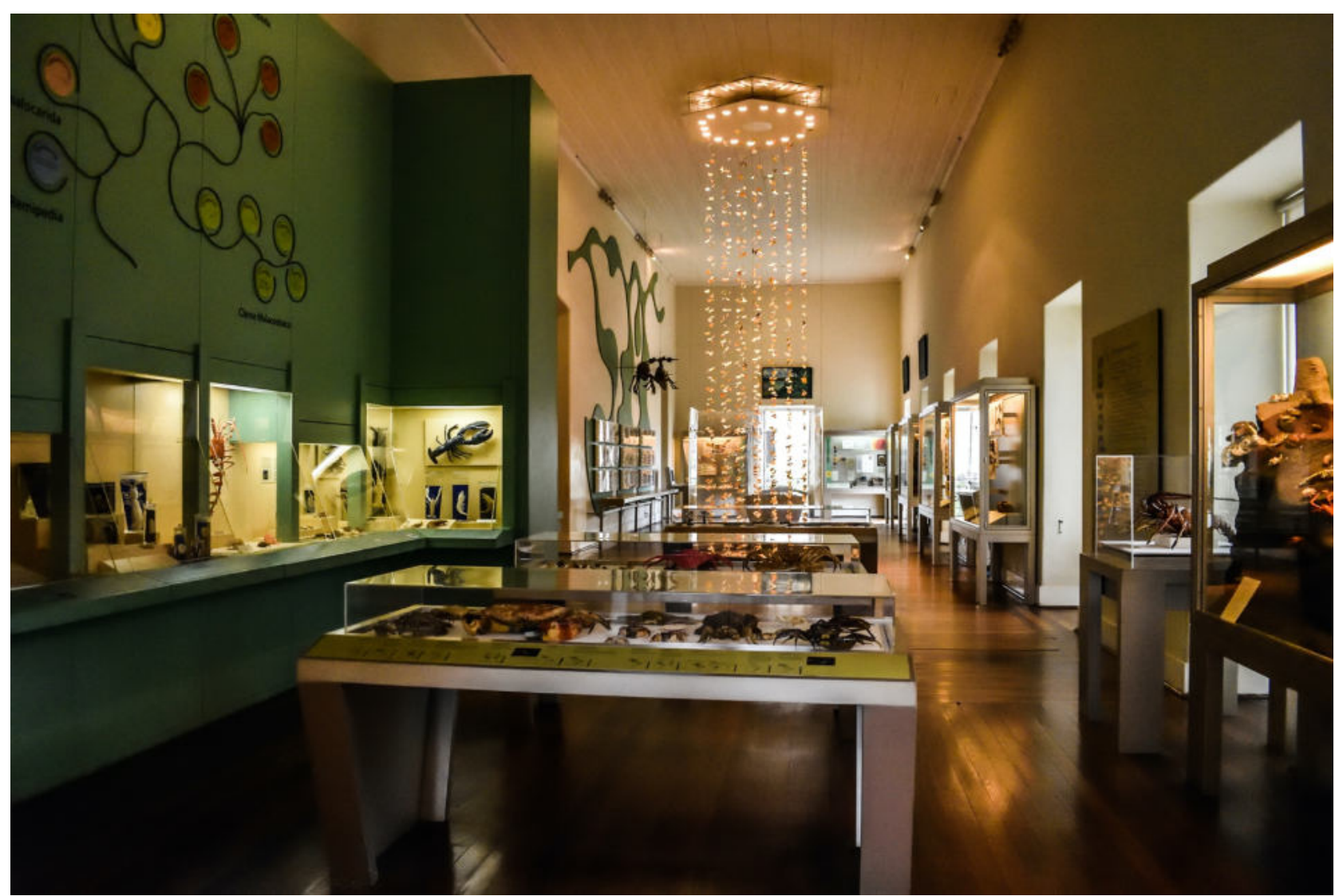

FIGURA 27: Exposição "Conchas, corais e borboletas" - Visão geral da segunda galeria. Fotografia: Mariana Galera Soler, obtida em visita técnica em Agosto de 2018.

O Setor Arachnida abria a segunda galeria, sendo o menor setor de "Conchas, corais e borboletas". Essencialmente foi exposto o mesmo acervo da antiga exposição do grupo, organizado em apenas duas vitrines. No entanto, mesmo com espécimes datados da metade do século passado, o discurso era contemporâneo, uma vez que exibia uma hipótese filogenética ${ }^{76}$ recente dos grupos de Chelicerata, citando as principais características de cada um de seus grupos internos e a importância e o reconhecimento de Arachnida como um grupo zoológico natural (monofilético).

Tratando-se especificamente de aracnídeos (aranhas e escorpiões), eram expostos principalmente aqueles de interesse médico (espécies que podem causar alguma moléstia à saúde humana). Ainda associada à saúde pública, exibiam-se as ceroplastias de uma mão e um braço com feridas ocasionadas por acidentes com aranhas e infeção por ácaros (opção da equipa de Museologia dado o reconhecimento público desse acervo) e uma ampola do soro anti-escorpiônico produzido pelo Instituto Vital Brazil (Rio de Janeiro, Brasil) (Figura 28).

\footnotetext{
${ }^{76}$ Os métodos de análise filogenética de grupos de organismos passaram a ser propostos a partir de Willi Henning (1966).
} 

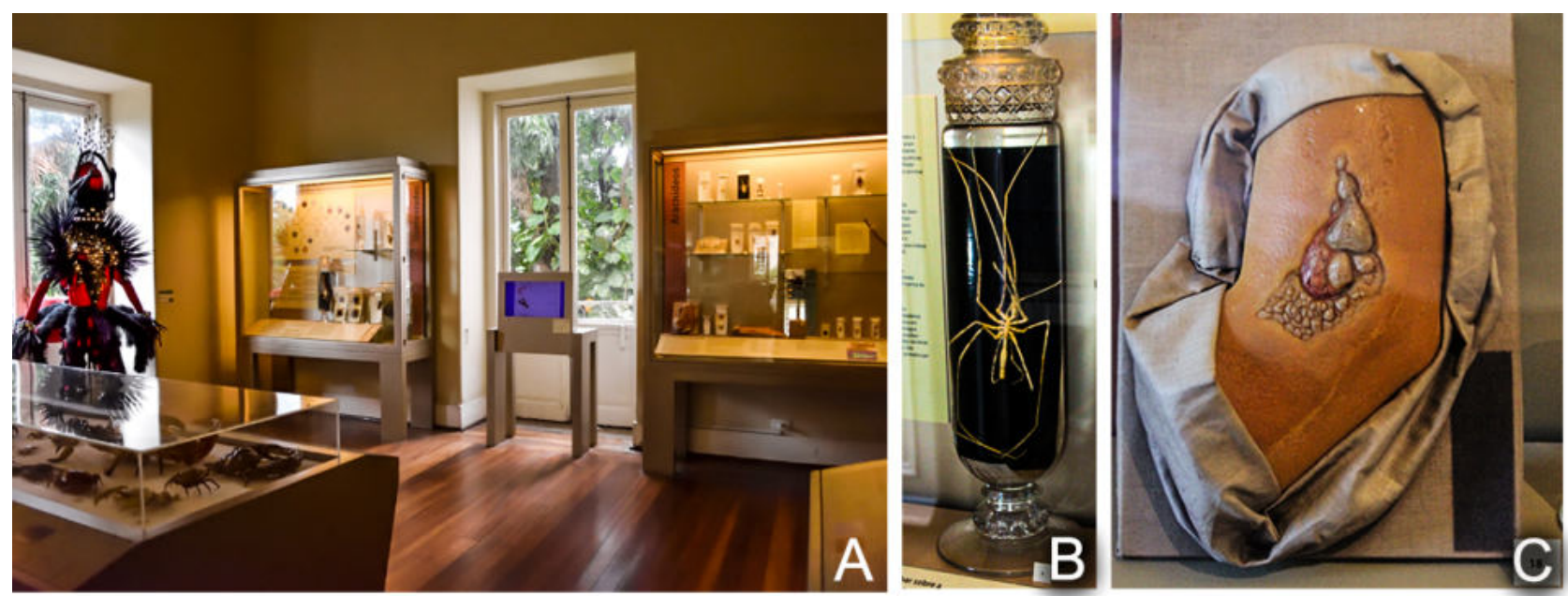

FIGURA 28: Exposição "Conchas, corais e borboletas" - Setor Arachnida. Em A vitrines do setor. O vídeo entre as vitrines pertence ao Setor Crustacea. Em B aranha-do-mar (Pycnogonida) preservado em via húmida e vidro da antiga exposição. Em C peça em cera do acervo histórico, réplica de braço humano em cera, mostrando lesões necróticas por picada de aranha-marrom, Loxosceles sp. Fotografia: Mariana Galera Soler, obtida em visita técnica em Agosto de 2018.

Em seguimento, ocupando o da primeira metade dessa segunda galeria encontrava-se o Setor Crustacea. Novamente inseridos dentro de uma perspetiva evolutiva, os crustáceos estavam organizados quanto as características que definem o grupo e os grupos taxonómicos internos (classes e ordens), surgimento e registro fóssil, evolução da forma em diferentes grupos internos, distribuição geográfica e a conquista de diferentes ambientes (Figura 29).

Outro aspeto ainda presente neste setor era a importância econômica dos crustáceos. Cerca de vinte espécies de crustáceos são exploradas para alimentação na costa brasileira e, devido a problemas de sobre-exploração, atualmente existe uma regulamentação legislativa nacional sobre os períodos do ano em que a pesca é permitida e o período de defeso, quando é proibida a pesca para que haja a reprodução dos indivíduos das espécies exploradas.

Nesse sentido, três animações de curta-duração tratam dos temas presentes na exposição, principalmente relacionados à conservação, mas com linguagem e ilustrações voltadas ao público infantil. Vale ressaltar que essas obras em tão diferente linguagem (do restante da exposição) foram produzidos pela parceria do MNRJ com o curso de graduação em Comunicação Visual Design da Universidade Federal do Rio de Janeiro, por meio das docentes Irene Peixoto e Dóris Kosminsky, no ano de 2012 (Figura 28A). 


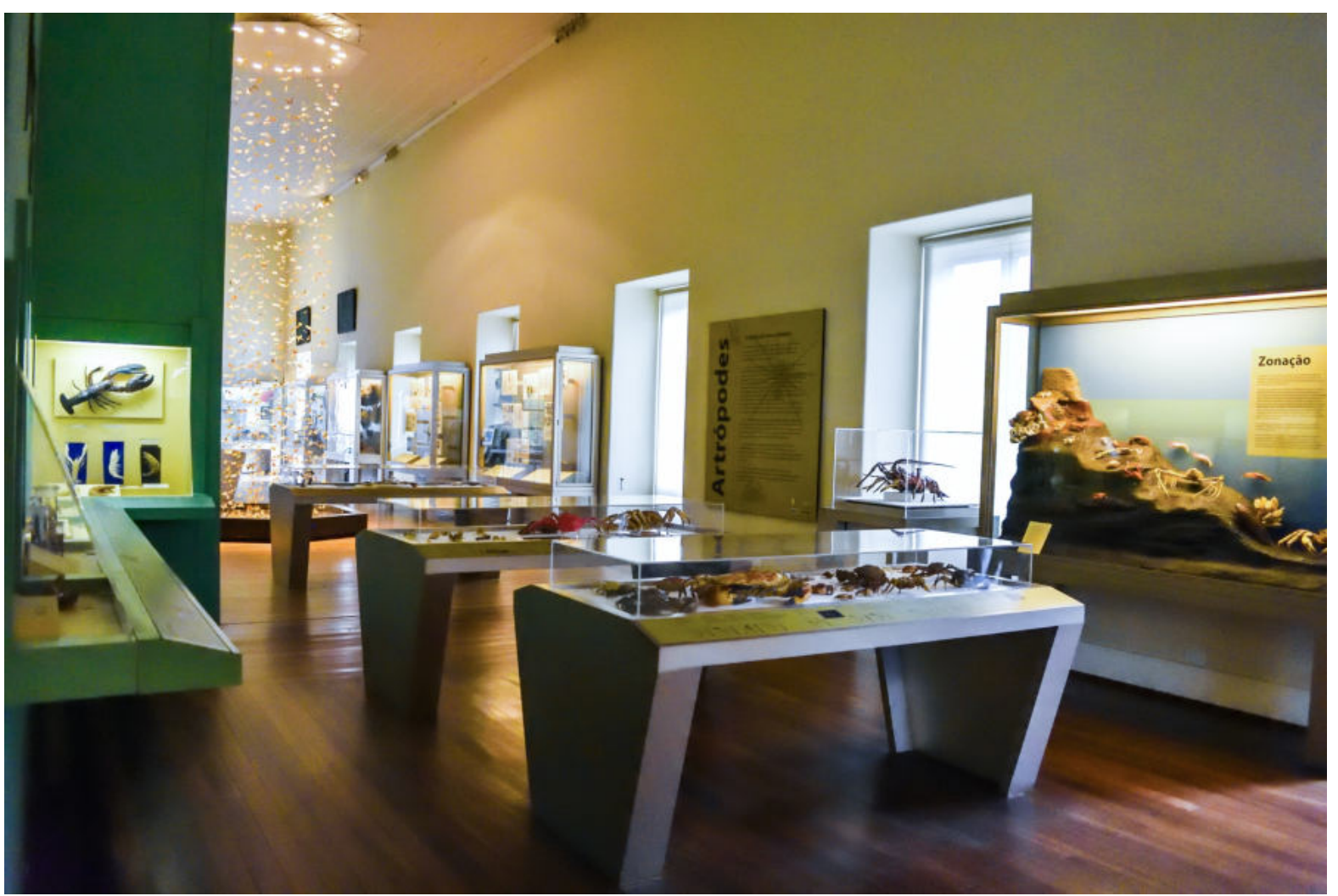

FIGURA 29: Exposição "Conchas, corais e borboletas" - Setor Crustacea. Fotografia: Mariana Galera Soler, obtida em visita técnica em Agosto de 2018.

Encerrava o Setor Crustacea a remontagem de uma vitrine da exposição antiga, que aborda a zonação do ambiente marinho. A diversidade de crustáceos evidencia que os animais que vivem em ambiente marinho, assim como qualquer ambiente, não possuem distribuição uniforme. Essa vitrine remontava a uma imagem também clássica de livros didáticos da Biologia, como destacado em entrevista pela curadora Irene Azevedo Cardoso (Figura 30). 

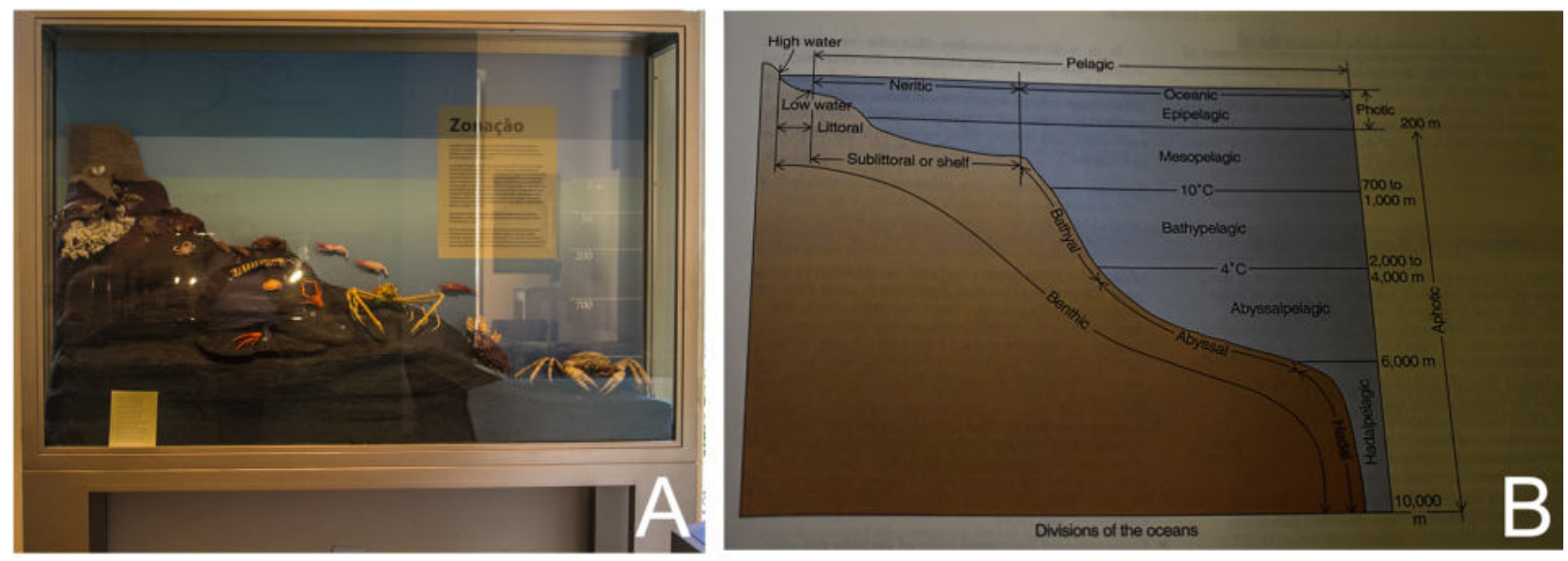

FIGURA 30: Exposição "Conchas, corais e borboletas" - Setor Crustacea. Comparação entre vitrine "zonação do ambiente marinho" (A) e ilustração do livro "Marine Biology: an ecological approach" de James Nybakken e Mark D. Bertness, $6^{a}$ Edição, 2004, apontado como referência em entrevista pela curadora Irene Azevedo Cardoso (B). Fotografia: Mariana Galera Soler, obtida em visita técnica em Agosto de 2018.

O último setor da exposição de "Conchas, corais e borboletas" foi destinado aos insetos e ocupava a metade final da segunda galeria. De acordo com o texto escrito pelo curador e corroborado em sua entrevista, para a exposição foram selecionados materiais relativos à três vertentes do conhecimento: entomologia acadêmica, centrada em estudos científicos que envolvem a elaboração e teste de hipóteses sobre os mais diferentes aspetos da vida desses animais; entomologia econômica ou aplicada, relacionada à aplicação prática desse conhecimento na promoção do desenvolvimento socioeconômico; e a entomologia cultural, que engloba todas as demais vertentes de influência do conhecimento ou imaginário sobre insetos nos demais campos do saber (sendo essa última tema da livre docência do curador Alcimar do Lago Carvalho).

De acordo com estas vertentes, as vitrines combinavam essencialmente a história natural de diferentes grupos de insetos (entomologia acadêmica) e informações sobre a relação deles com a espécie humana (entomologia aplicada). A entomologia cultural esteve restrita às vitrines centrais e finais da exposição (Figura 31).

A representação de um panapaná, revoada de milhares de borboletas machos em áreas abertas de solo húmido à procura de água e determinados sais minerais, utilizando como referência oito espécies de borboletas brasileiras que comumente participam deste fenômeno no Brasil, compunha o elemento mais atrativo do setor, posicionado em seu centro (Figura 32). 
Havia a grande quantidade de conteúdos científicos, que vão desde informações sobre a variação da forma, ciclo de vida, organização social e evolução dos grupos internos de Insecta, até os problemas com pragas agrícolas e transmissão de doenças. Ademais, estavam expostos o maior número de exemplares de todos os setores de "Conchas, corais e borboletas", como uma mostra da diversidade do grupo - apenas neste setor, foram expostos mais de 1800 espécimes preservados em via seca ou via húmida.

Quase cinco anos após sua abertura, a exposição "Conchas, corais e borboletas" ganhou novos objetos. Tendo em vista que em Fevereiro de 2018, a Escola de Samba Imperatriz Leopoldinense fez seu desfile inspirado no MNRJ, com o samba enredo "Uma noite real no Museu Nacional", diversos profissionais e estudantes do museu participaram do evento e estiveram envolvidos em sua produção. Assim, ao final dos desfiles de carnaval, a Escola doou modelos de todas as fantasias desenvolvida, que estavam distribuídas ao longo das salas do MNRJ, e alguns exemplos eram mostrados em "Conchas, corais e borboletas" (Figura 33). 

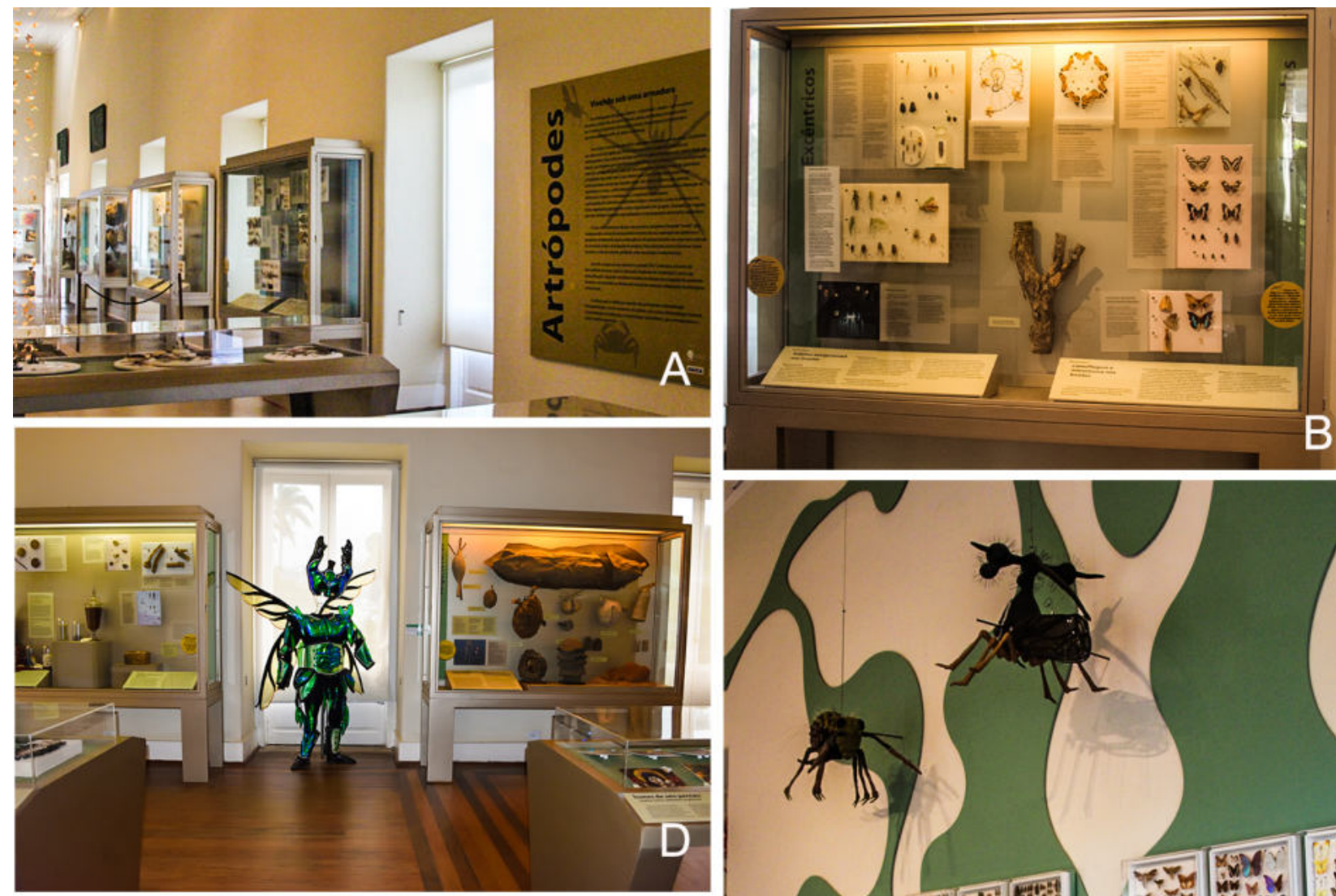

B
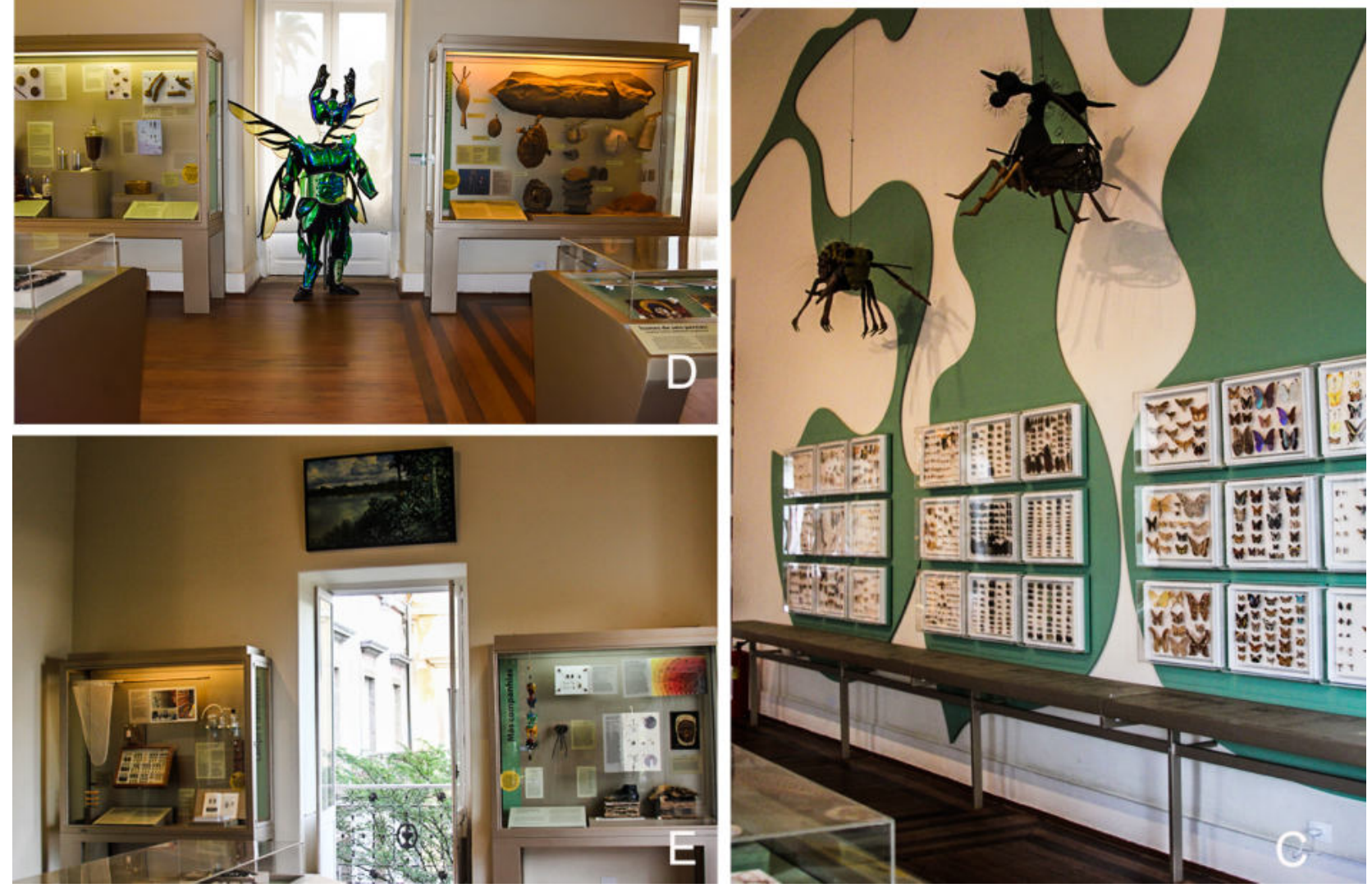

FIGURA 31: Exposição "Conchas, corais e borboletas" - Setor Insecta. Em A visão vista geral da segunda sala da exposição. Em B vitrine "Excêntricos" e "Comes e bebes". Em C a diversidade do grupo dos insetos é representada em 27 quadros que simulam gavetas entomológicas, os insetos estão preservados em via seca e transpassados por alfinetes entomológicos. Dois modelos ampliados cem vezes de insetos, um da família Sminthuridae (ampliado 500x) e Bocydium tintinnabuliferum (ampliado 100x). Em D vitrines sobre entomologia aplicada. Em E a direita vitrine sobre o trabalho do entomólogo e a esquerda vitrine sobre entomologia aplicada. Fotografia: Mariana Galera Soler, obtida em visitas técnicas em Junho de 2014 e Agosto de 2018. 

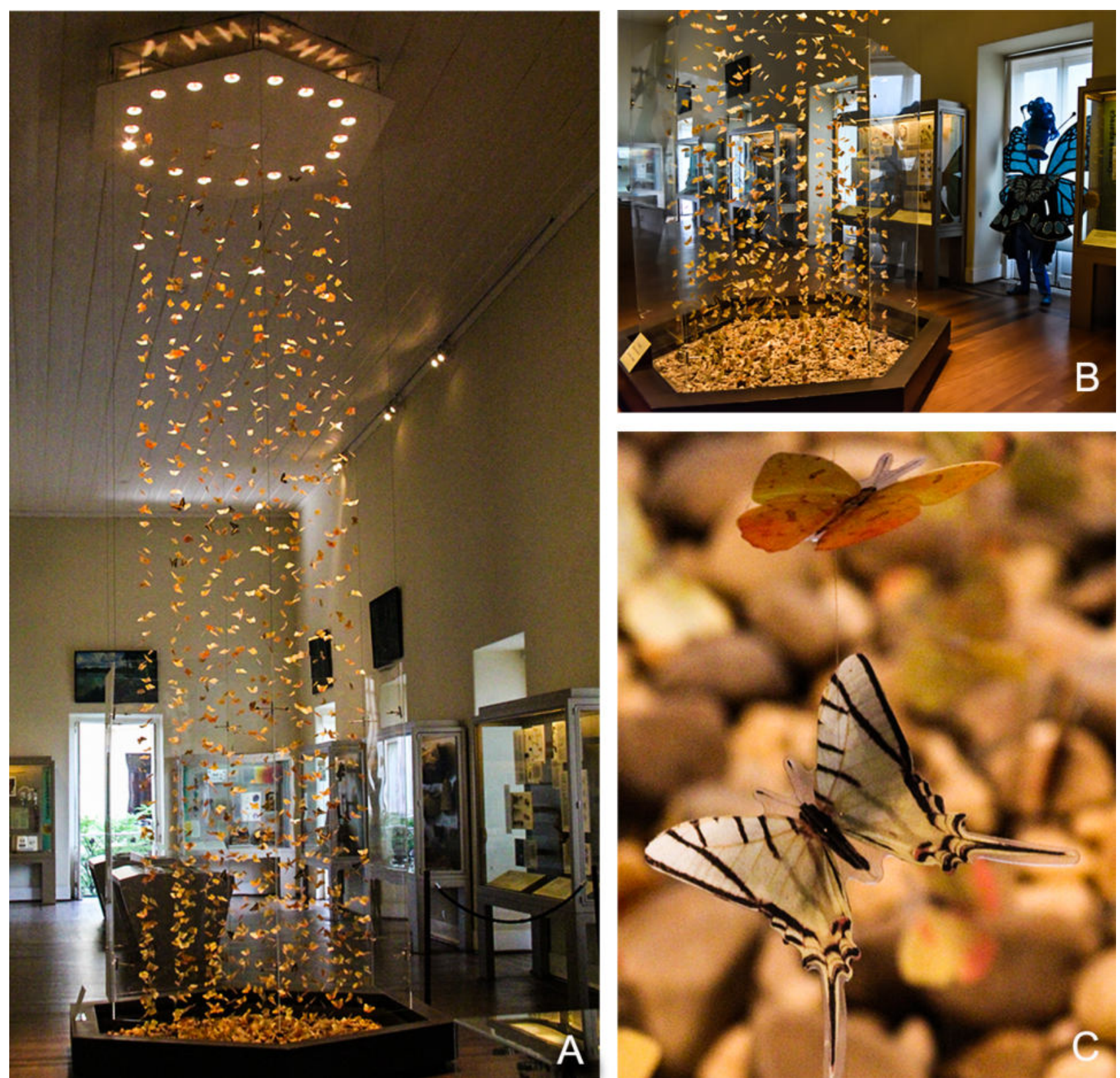

FIGURA 32: Exposição "Conchas, corais e borboletas" - Setor Insecta. Em A montagem de um panapaná com centenas de impressões em acetato das espécies de borboletas: Anteos clorinde, Anteos menippe, Aphrissa statira statira, Phoebis argante argante, Phoebis philea philea e Phoebis sennae sennae, Heraclides thoas brasiliensis e Protesilaus protesilaus nigricornis. Em B detalhe da base do panapana e ao fundo uma fantasia carnavalesca inspirada em borboletas. Em C uma das borboletas do panapana (Protesilaus protesilaus nigricornis), como exemplo de como o panapana foi montado, a partir da impressão individual em acetado frente e verso de cada uma das borboletas e presas em fio de nylon. Fotografia: Mariana Galera Soler, obtida em visita técnica em Junho de 2014 e Agosto de 2018. 

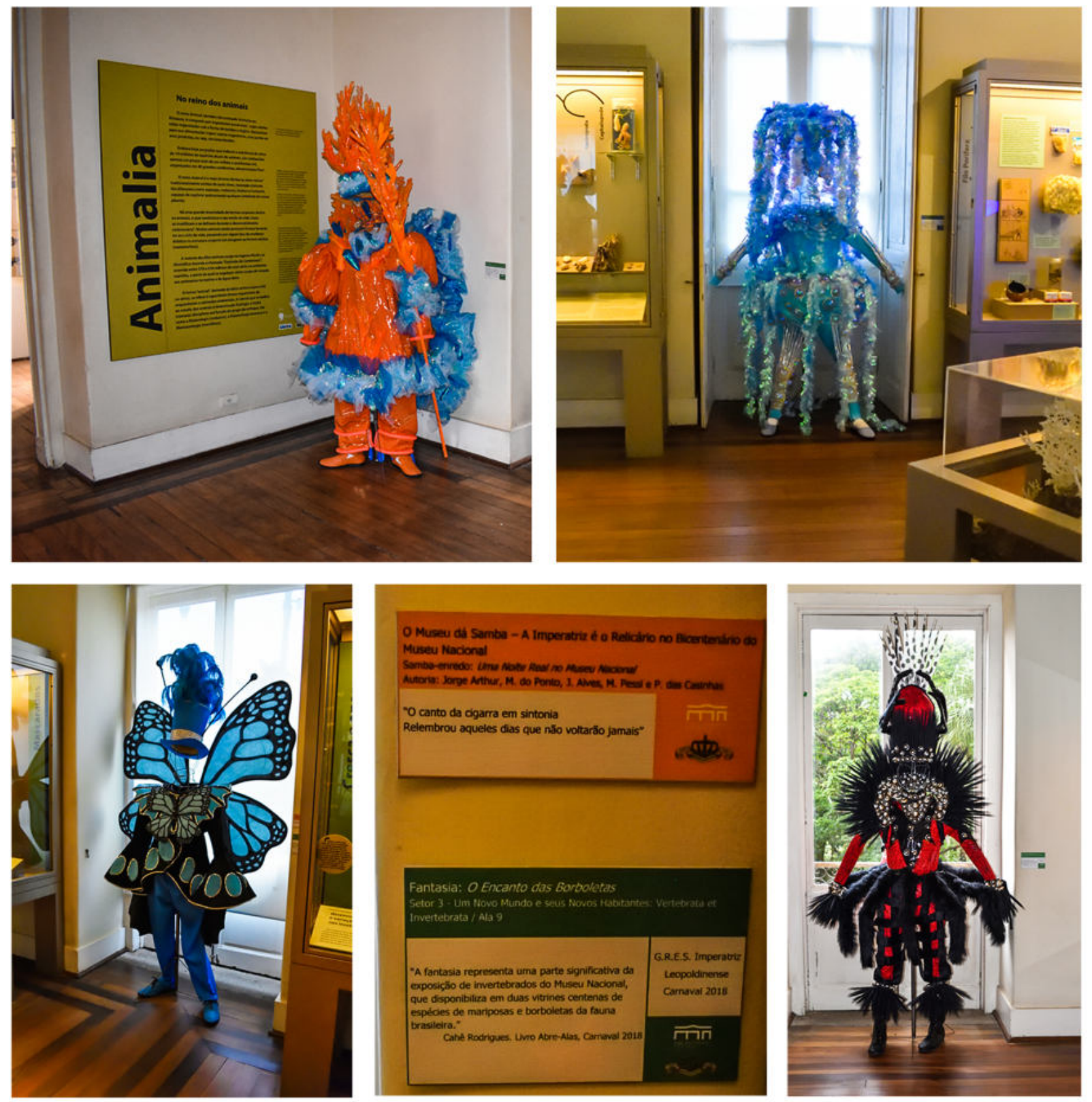

FIGURA 33: Algumas das fantasias doada pela Escola de Samba Imperatriz Leopoldinense e associadas ao acervo exposto em Exposição "Conchas, corais e borboletas". Fotografia: Mariana Galera Soler, obtida em visita técnica em Agosto de 2018. 
Biodiversidade Musealizada: Formas que Comunicam

3.2.2 Museu Nacional de História Natural e da Ciência - Universidade de Lisboa

\title{
3.2.2.1 Reis da Europa Selvagem: os nossos últimos carnívoros
}

\subsection{Contextualização:}

A exposição "Reis da Europa Selvagem: os nossos últimos grandes carnívoros" foi inaugurada em 2 de Março de 2017 e encerrou em 29 de Setembro de 2019. Ocupava uma área de 486 m² (sala 57 do MUHNAC).

Tal exposição representou uma parceria entre o Grupo $\mathrm{LOBO}^{77}$ e MUHNAC e possuía a narrativa centrada na coexistência de populações humanas e a conservação dos quatro principais grupos de grandes carnívoros europeus: (i) lobos, representados pelo lobo-ibérico (Canis lupus signatus, o último grande predador da fauna portuguesa) e lobo-europeu (Canis lupus); (ii) ursopardo (Ursus arctos); linces, representados pelo lince-euro-asiático (Lynx lynx, o maior felino europeu) e lince-ibérico (Lynx pardinus, o felino mais ameaçado do mundo); e (iv) glutão (a hiena do Ártico, Gulo gulo).

Um resumo bastante ilustrativo dessa exposição estava presente no folder produzido para sua divulgação:

\begin{abstract}
"Ao longo de seus módulos, esta emblemática exposição permite contemplar exemplares naturalizados imersos num cenário expositivo de imagens, sons e novas tecnologias que conduzem o público a uma viagem pelas áreas geográficas onde vivem estes animais e conhecer seus habitats, biologia, organização social, hábitos alimentares, ameaças e projetos que promovem a sua conservação"
\end{abstract}

(informação disponível no folder distribuído na bilheteira do MUHNAC e no site institucional: https://www.museus.ulisboa.pt/pt-pt/reis-da-europa-selvagem . Acesso em 04 de Junho de 2019).

A proposta dessa exposição surgiu com o pedido do Grupo LOBO para a utilização de um dos espaços destinados a exposição temporária do MUHNAC, para apresentar painéis impressos com os

\footnotetext{
77 Organização não-governamental em prol da conservação do lobo-ibérico (Canis lupus signatus) e seu ecossistema. Mais informaações disponíveis em: http://lobo.fc.ul.pt. Acesso em 02 de Abril de 2018.
} 
resultados de suas investigações (necessidade apontada pelas agências financiadoras do Grupo LOBO e um produto comum as instituições parceiras do projeto), que constituíam uma pequena mostra itinerante.

Contudo, ao entrar em contato com o MUHNAC, a então do museu, na figura do investigador José Pedro Sousa Dias, encaminhou a proposta para investigadora e curadora de mamíferos Cristiane Bastos-Silveira, curadora da coleção de mamíferos e, portanto, especialista científica na temática da exposição proposta. Então, a investigadora do museu reconheceu a oportunidade de ampliar a narrativa para as outras espécies de grandes carnívoros europeus, que também estão sob ameaça, a partir dos dados de relatórios de investigação de outros grupos europeus, ligados ao Projeto LIFE MED-WOLF e Large Carnivore Initiative for Europe (LCIE). Tais dados são mais expressivos desde 2006 até o presente.

Outro elemento fundamental para a elaboração de "Reis da Europa Selvagem" foi a possibilidade dessa narrativa permitir a utilização de um acervo de uma coleção privada bastante rica, a coleção Valentim Fernandes dos Santos ${ }^{78}$. Essa foi a primeira experiência em expor cerca de duas dezenas de espécimes dessa coleção, que está em comodato no MUHNAC, para o público, configurando-se como um exercício institucional de burocracia (para assegurar os termos do comodato), transporte e conservação do acervo (os espécimes estavam na casa da família do antigo proprietário) e fortemente articulada com a missão do museu, na salvaguarda e comunicação de coleções de história natural (Entrevista Cristiane Bastos-Silveira - Comissária Científica da Exposição Reis da Europa Selvagem, 2017).

Nas palavras de Bastos-Silveira essa exposição foi um importante "balão de ensaio" tanto para o MUHNAC, ao exercer todas as suas valências para receber uma coleção externa e privada, para os proprietários da coleção, que estavam dispondo do seu acervo pela primeira vez, e dentro de um cenário da montagem de uma exposição em parceria com outra instituição, nesse caso, o Grupo Lobo (Bastos-Silveira, comunicação pessoal, 28 de Março de 2018).

Além dos aspetos relacionados ao acervo, havia três elementos museográficos marcantes nessa exposição: a conceção da museografia foi realizada totalmente externa do MUHNAC, uma vez

\footnotetext{
78 A coleção privada do Senhor Valentim Fernandes dos Santos é uma coleção privada do caçador português que dá nome a coleção, falecido em 1997. Atualmente, a família gere os espólios do caçador e negocia os termos do comodato com o MUHAC (BastosSilveira, comunicação pessoal, 28 de Março de 2018).
} 
que ficou a cargo do Grupo Lobo e de uma empresa de sua confiança contratada (Laranja Mecânica, que atua também como consultora do Projeto LIFE MED-WOLF), o uso de dioramas e a realidade aumentada.

A realização da museografia externa a equipa do MUHNAC causou alguns desentendimentos entre a proposta feita pelos curadores científicos da instituição e desadequação em termos do uso de materiais e qualidade gráfica dos recursos aplicados em "Reis da Europa Selvagem" e as demais exposições do museu lisboeta (Dias, comunicação pessoal, 6 de Abril de 2018).

Em contrapartida, os dioramas foram inteiramente construídos por dois membros da equipe técnica do MUHNAC, os taxidermistas Pedro Andrade e Ana Campos. A construção dos dioramas de ambientes portugueses representam um desejo desses profissionais e equipa do MUHNAC, que realizaram desde a conceção dos espaços, pesquisa, escolha do acervo e montagem.

A introdução da realidade aumentada na exposição foi uma escolha da curadoria para introduzir "tecnologia" no discurso expositivo e atrair a atenção do público mais jovem. O dispositivo foi desenvolvido também pela empresa externa do museu, embora a equipa do MUHNAC não considere satisfatório o resultado final (Dias, comunicação pessoal, 6 de Abril de 2018).

O financiamento da exposição foi feito pelo orçamento do MUHNAC e os seguros de transporte e manutenção do acervo da coleção Valentim Santos foram obtidos por parcerias com entidades privadas (Corretora de Seguros Caravelas e COTAI Companhia Técnica De Administração E Investimentos, S.A.)

A ficha técnica da exposição "Reis da Europa Selvagem” encontra-se no ANEXO 2.

\subsection{Tratamento Museográfico:}

A exposição "Reis da Europa Selvagem" tem como público-alvo famílias e grupos intergeracionais. De acordo com a curadora Cristiane Bastos-Silveira a palavra-chave da exposição é coexistência. No caso, entre a espécie humana e os grandes carnívoros europeus.

Na Figura 34 apresentamos a planta da exposição, tal como foi concebida pela equipa curatorial do MUHNAC. 


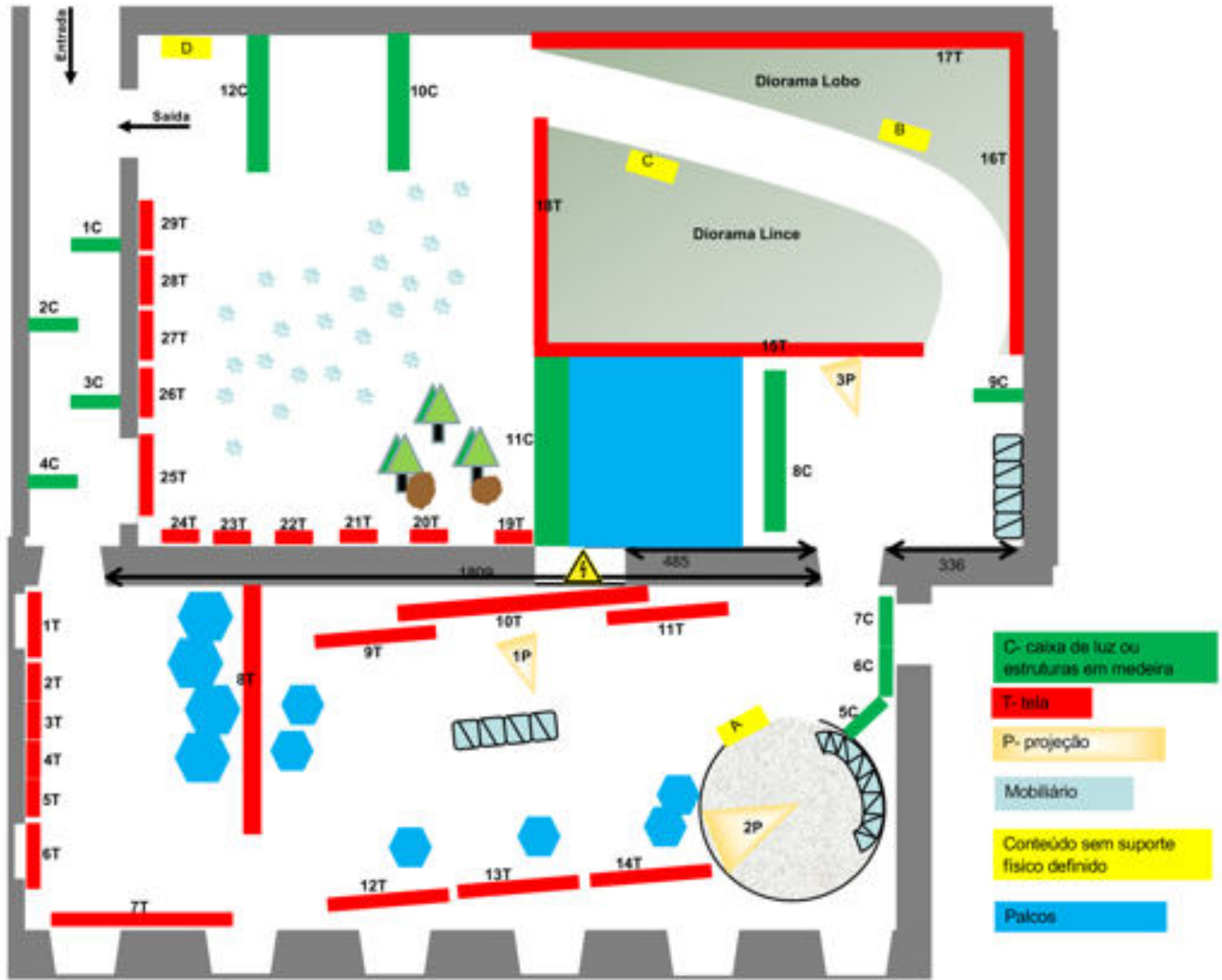

FIGURA 34: Planta-baixa da exposição "Reis da Europa Selvagem". Fonte: Documento digital disponibilizado pela investigadora e curadora científica Cristiane Bastos-Silveira, em 21 de Junho de 2019.

Já na entrada da exposição, o visitante deparava-se com uma série de quatro painéis, onde eram apresentados os nomes científicos das espécies centrais dessa exposição, bem como uma frase com alguma curiosidade ou pergunta que promova o interesse pelas referidas espécies. A escolha dos nomes em latim visaram estimular a curiosidade sobre o seu significa e, em visitas mais específicas, promover discussões sobre a nomenclatura zoológica.

Nesses painéis também estavam expressas as respetivas pegadas de cada espécie (uma característica fundamental para identificação taxonómica de carnívoros e sinais de sua presença no ambiente). Esse primeiro espaço foi utilizado como área de acolhimento de grupos em visitas 
guiadas e os painéis eram posicionados de tal modo que impedia que o visitante pudesse ver os módulos seguintes, novamente buscando estimular a curiosidade e simular a dificuldade de encontrar esses animais na natureza (Figura 35).

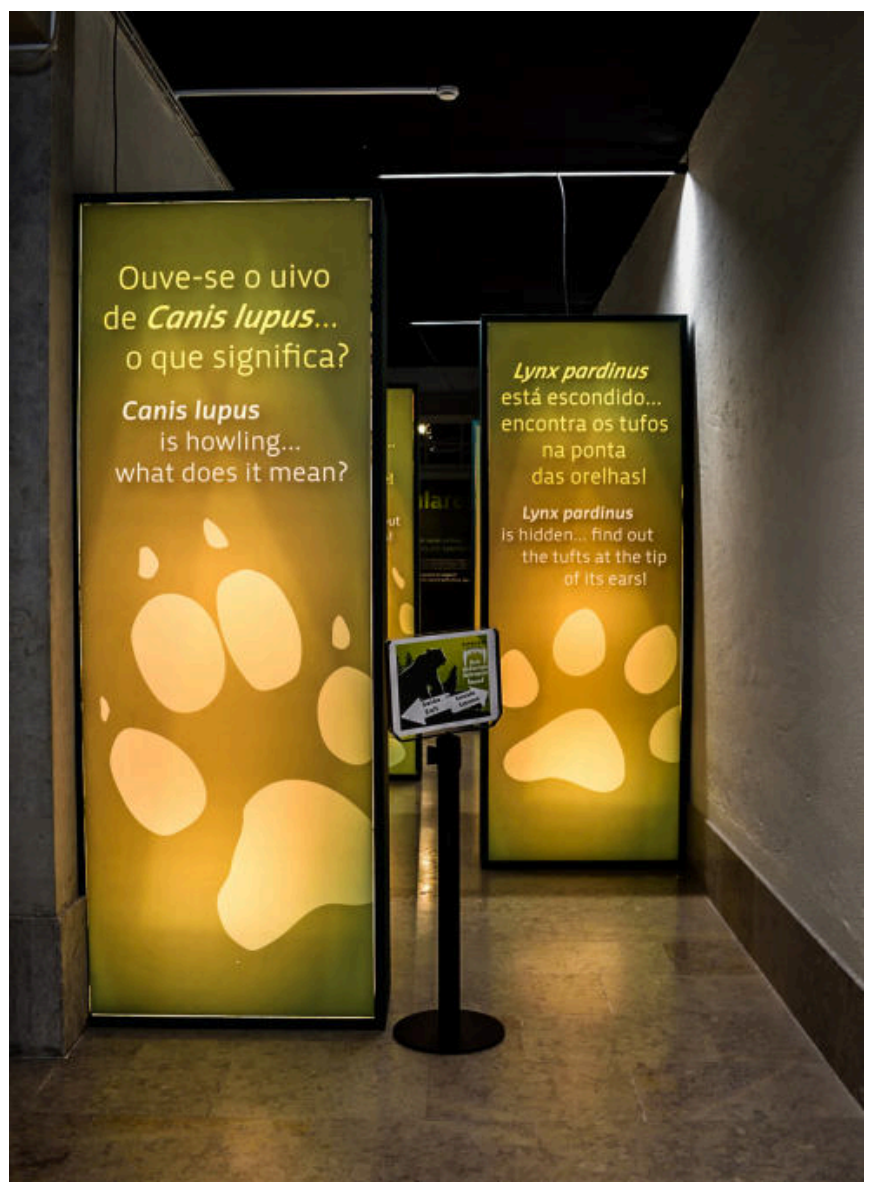

FIGURA 35: Painéis na entrada da exposição "Reis da Europa Selvagem". Ao total são quatro painéis intercalados, cada um com o nome científico (Canis lupus, Lunx pardinus, Ursus arctus e Gulo gulo), nome popular (em Portugal), uma pergunta ou uma curiosidade e o desenho da respetiva pegada, uma característica fundamental para o reconhecimento de mamíferos em campo. Fotografia: Mariana Galera Soler, obtida em visita técnica em Julho de 2018.

No primeiro módulo eram efetivamente apresentados os quatro grupo de espécies de grandes carnívoros europeus os quais a exposição estava centrada. Tais espécies foram expostas individualmente, por meio de espécimes naturalizados (dois espécimes oriundos da coleção privada de Valentim dos Santos e dois da coleção do MUHNAC) (FIGURA 36CB. e painéis com a silhueta dos animais e textos sobre características biológicas, tais como: época de nascimento, longevidade, peso (macho e fêmeas), tamanho da prole, altura e organização social (FIGURA 36C). 
Biodiversidade Musealizada: Formas que Comunicam

Havia ainda um texto inicial, em que o visitante era informado sobre o objetivo da exposição e proposta a seguinte reflexão, obtida por meio das conclusões dos relatórios científicos: o preconceito da espécie humana é a principal ameaça à extinção das espécies de grandes carnívoros):

"nessa exposição você irá conhecer as espécies de grandes carnívoros que habitam a Europa, aprender sobre seus habitats, comportamento, dieta e as causas e consequências do conflito com o homem. Podemos transformar preconceito em respeito? Podemos aceitar coexistir com estas espécies?” (FIGURA 36 A)
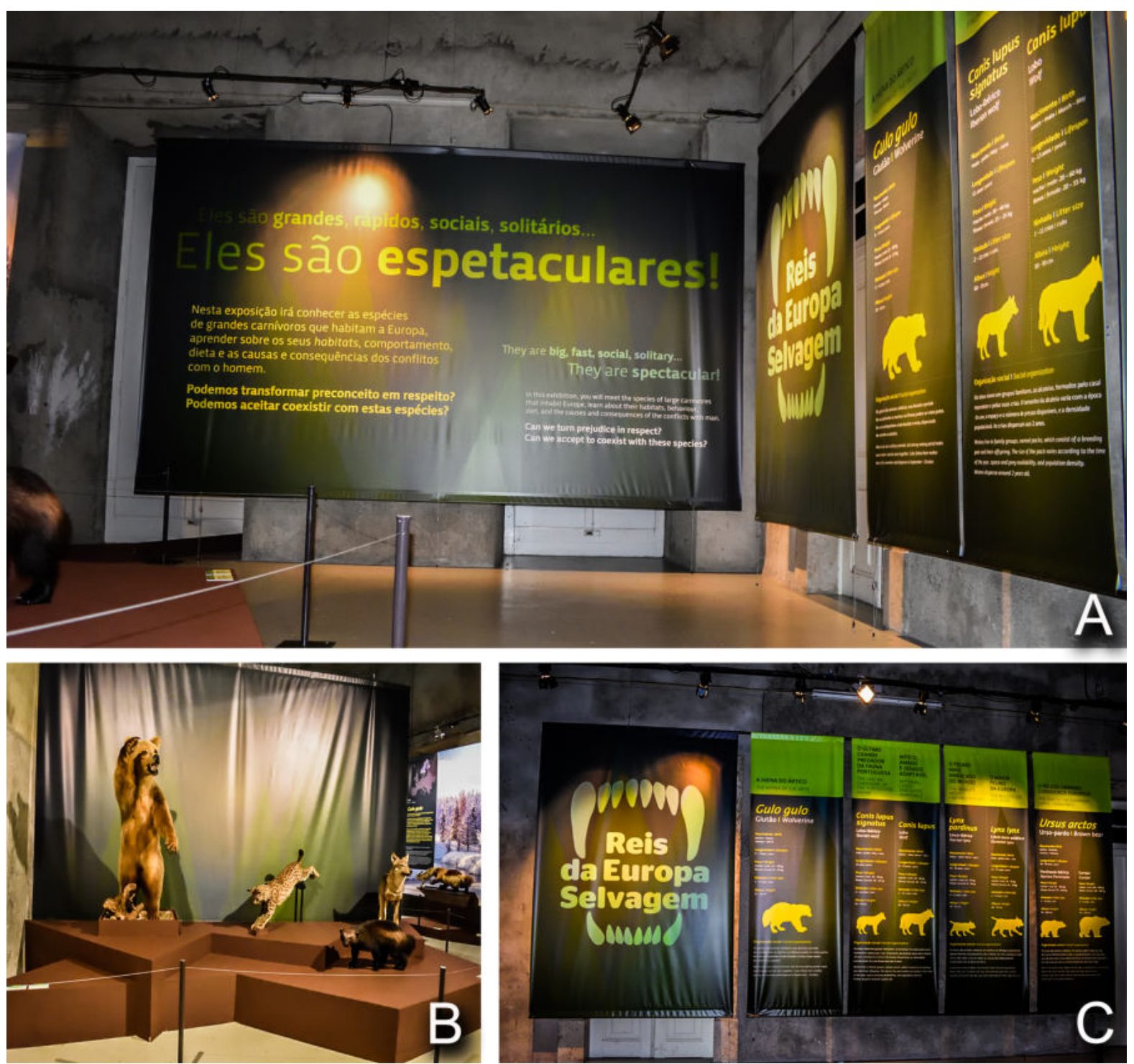

FIGURA 36: Primeiro módulo da exposição "Reis da Europa Selvagem". Em A, painel de apresentação. Em B, a esquerda do painel de apresentação encontra-se um palco com quatro espécimes naturalizados da espécies que serão discutidas na exposição (da coleção Valentim dos Santos: Lynx pardinus e Ursus arctus e da coleção MUHNAC: Canis lupus e Gulo gulo), nome popular (em Portugal). Em C, a direita do painel de apresentação, painéis com informações sobre a história natural daqueles animais. Fotografia: Mariana Galera Soler, obtida em visita técnica em Julho de 2018. 
O módulo seguinte mostrava a Ecologia e distribuição geográfica dos carnívoros, principalmente informações relacionadas ao habitat, populações (com mapas) e textos sobre comportamentos, como a marcação de território. A partir das distribuições geográficas, também foram diferenciadas as sub-espécies dos grandes carnívoros europeus, ou seja, o lince-ibérico (Lynx pardinus) e lince-euro-asiático (Lynx lynx), e o lobo-europeu (Canis lupus) e lobo-ibérico (Canis lupus signatus).

A ideia fundamental foi demonstrar que os limites geopolíticos entre os países não se adequam a distribuição das espécies, de modo que tais espécies devem ser monitoradas considerando o espaço europeu e os ecossistemas em que vivem. Nesse sentido, cada espécie era apresentada individualmente, com espécimes naturalizados e painéis com texto e um mapa europeu de distribuição das populações (FIGURA 37A,D). Esse módulo também possuía ambientação sonora que transcendia para outros espaços da exposição.

Compunham também esse módulo três diferentes projeções. A primeira, junto aos espécimes e acompanhada de painéis de textos, apresenta uma série de 27 fotografias de diferentes habitats dos carnívoros, inclusive com imagens de zonas agrícolas, mostrando a proximidade dessas espécies e das populações humanas. Tais imagens tinham identificação do ecossistema ao qual se referem (taiga, por exemplo) e autoria. A duração da projeção era de 2:30 minutos (FIGURA 37B).

As duas projeções seguintes dividiam o mesmo espaço, embora em lados opostos. Sob um construção em formato oval79 , em seu lado externo foi exibida uma sequência de mapas europeus e a situação das populações das quatro espécies (representadas por suas silhuetas), com os dados a partir de um senso realizado entre 2010 e 2012 (FIGURA 37C). A duração da projeção foi de 2:35 minutos.

Na parte interna dessa estrutura oval foi projetado um pequeno vídeo com imagens (fotos e vídeos curtos) e frases de impacto sobre as principais ameaças para a sobrevivência dos grandes carnívoros (caça, território retalhado e pecuária) e possíveis soluções para a coexistência deles com

79 A estrutura em formato oval é remanescente de uma antiga exposição realizada nessa sala sobre sons da natureza, com maior aporte de acervo ornitológico. A equipe responsável por “Reis da Europa Selvagem” optou por reaproveitar a construção, obviamente não mais associado aos ovos e as aves, mas criando um espaço reservado e de reflexão, com a projeção de imagens com maior apelo, como animais mortos em atropelamentos ou caça ou animais sendo liberados para vida livre novamente (BASTOS-SILVEIRA, comunicação pessoal, 28 de Março de 2018). 
as populações humanas (regresso a métodos tradicionais de proteção dos rebanhos, como cercas e pastoreio com cães, estudo das reais ameaças dos territórios e oportunidades de gerar receitas com o turismo). O curta-metragem foi uma produção do Grupo Lobo, MUHNAC - Universidade de Lisboa e tem a duração de 3 minutos (FIGURA 37F).

Três painéis informativos encerravam esse módulo, em que são apresentadas as principais ameaças a sobrevivência dos grandes carnívoros europeus e as possíveis medidas para a conservação dessas espécies, por meio de textos e imagens em infográficos (FIGURA 37E).

No terceiro módulo contava com um grande palco, onde foi exposta a diversidade de presas dos grandes carnívoros. Ao total, eram representadas 23 espécies, por meio de 25 espécimes taxidermizados em posição natural ou como troféus de caça, e identificados individualmente. A construção desse módulo foi proposta como maneira de otimizar o processo de comodato de peças da coleção privada, mas também de mostrar mais diversidade das faunas europeias (especialmente devido aos ungulados). Em painel de texto foi descrita a importância dos carnívoros para o equilíbrio do ambiente e a alimentação preferencial do urso-pardo, lince-ibérico, lince-euro-asiático, glutão, lobo-europeu e lobo-ibérico (Figura 38) 

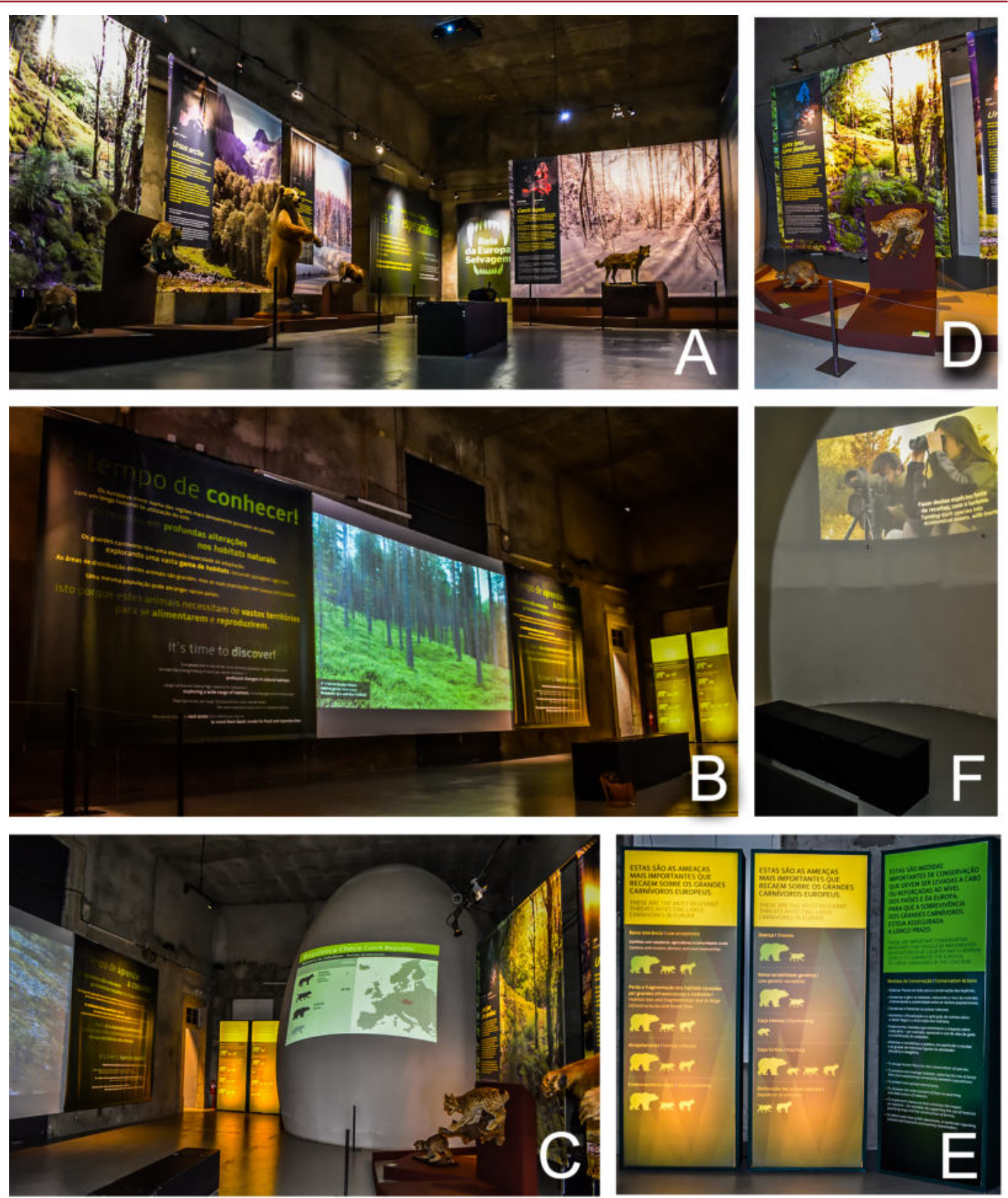

FIGURA 37: Segundo módulo da exposição "Reis da Europa Selvagem". Em A, vista geral dos animais taxidermizados e apresentados individualmente. Junto aos espécimes, há impressões de seus ambientes naturais, mapas de distribuição na Europa, informações sobre habitat, área de distribuição e comportamento de demarcação de território. Em B, projeção de 27 ambientes europeus onde podem ser encontrados grandes carnívoros, acompanhada por dois textos estáticos sobre a distribuição e coexistência entre nossa espécie e os grandes carnívoros. Em C, parte da área externa da estrutura oval, onde ocorre a projeção de 31 mapas de países europeus, associado aos números de indivíduos identificados de grandes mamíferos e/ou o que têm acontecido com essas populações (extinção, retorno ou reintrodução).. Em D, detalhe da museografia das espécies Lynx lynx e Lynx pardinus. Em E, Painéis que encerram o módulo, em que são apontadas as principais ameaças de cada espécie e medidas de conservação. Em E, ambiente interno da estrutura oval, com projeção de curta-metragem sobre as principais ameaças e possíveis soluções para a coexistência de populações humanas e de grandes carnívoros, em território europeu. Fotografia: Mariana Galera Soler, obtida em visita técnica em Julho de 2018. 


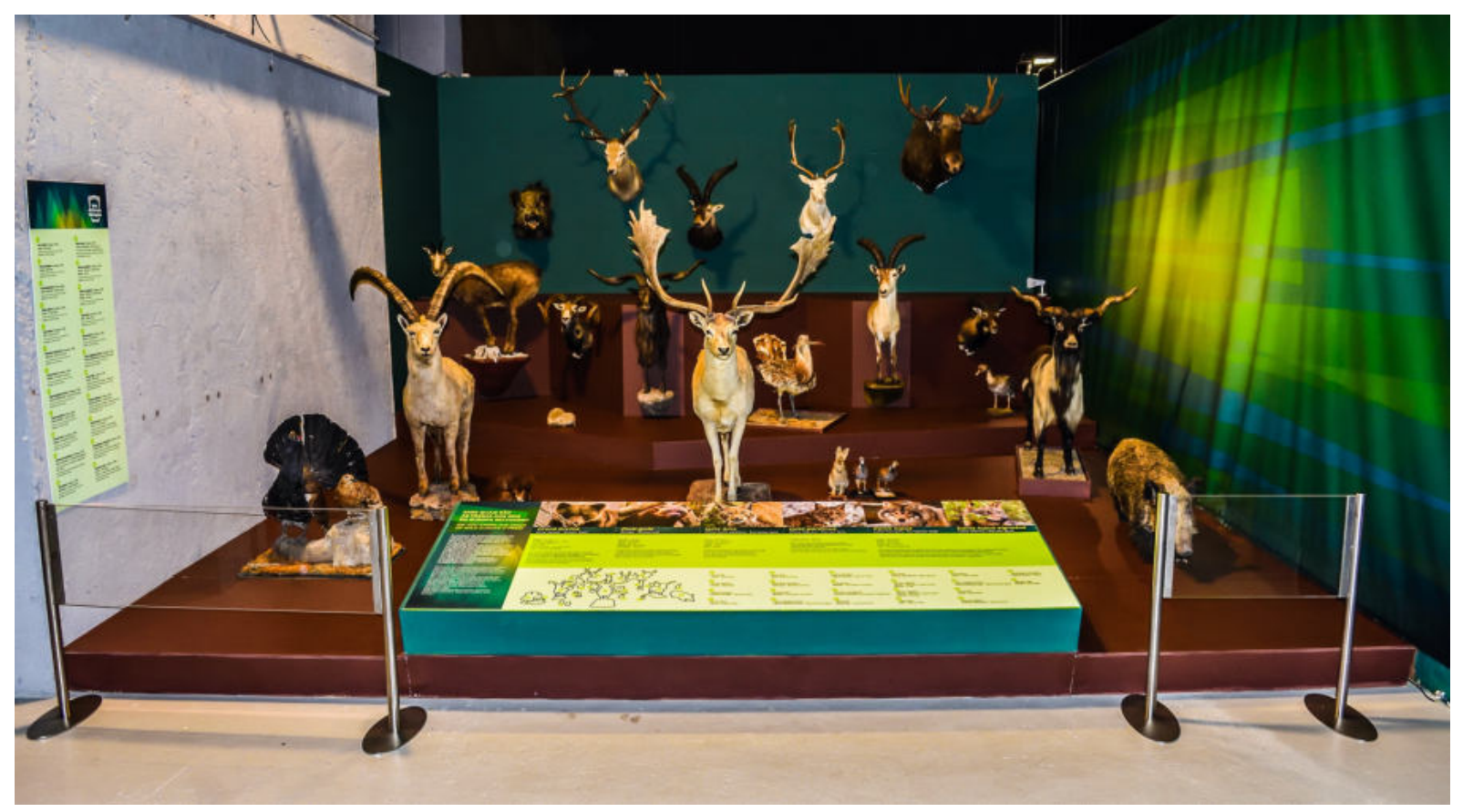

FIGURA 38: Palco com os espécimes naturalizados de presas dos grandes carnívoros europeus. 0 painel à frente indica quais são as presas preferenciais de cada uma das espécies de carnívoros e possui um esquema com silhuetas numeradas das presas, cuja legenda está no painel preso na parede, a direita. Fotografia: Mariana Galera Soler, obtida em visita técnica em Julho de 2018.

O módulo seguinte era constituído por dois dioramas de imersão de ambientes portugueses: o montado de azevinho (ambiente em que pode ser visto o lince-ibérico) e a serra (característico do norte de Portugal e habitat do lobo-ibérico), posicionados em paralelo (Figura 39A). Além dos tradicionais espécimes naturalizados e vegetação associada, os dioramas tinham o fundo ambientado com fotografias ampliadas dos ambientes escolhidos e um texto introdutório de cada ecossistema. Os espécimes representados pertencem todos a coleção do MUHNHAC, mas não estão identificados. Na representação da serra, há dois espécimes naturalizados de lobo-ibérico (um uivando e outro rebolando na relva - Figura 39C), bem como outros animais, como um furão e duas aves, e plantas, como urze e carqueja, que são característicos desse ambiente. Já o diorama do montado de azinho representava uma cena de caça entre um lince-ibérico e um coelho e também outros animais (três aves e dois mamíferos) e vegetação característicos do sub-bosque desse ecossistema, como rosmaninho, tojo e azinheiras (Figura 39B).

O último módulo da exposição começava com a seguinte frase: "Os grandes carnívoros têm um passado, ainda estão presentes e merecem um futuro!” e foi proposto para trazer alguns 
elementos culturais em que as espécies de grandes carnívoros estão inseridos (Figura 40A). Desse modo, foi criado um espaço de leitura, onde estavam disponíveis 13 obras da literatura infantil, em português, que tem como personagens os carnívoros (maioritariamente livros com lobos entre os personagens) ${ }^{80}$. Há ainda três grandes painéis com ditados populares em diversas línguas europeias (português, inglês, alemão, francês, espanhol e italiano) sobre os carnívoros ${ }^{81}$ (Figura 40B).

Em uma das paredes laterais desse módulo são encontradas silhuetas em tamanho real dos carnívoros, de onde partiam pegadas no chão que associavam essas silhuetas a outros painéis, posicionados no lado oposto da sala, com fotografias ampliadas e os diversos nomes populares das espécies, que podem ser utilizados nos diferentes países da Europa. As pegadas seguem as cores das silhuetas, possuem o tamanho e estão posicionadas de acordo com a morfologia e passada do respetivo animal (Figura 40A).

Por fim, havia uma experiencia de realidade aumentada (cuja a proposta já estava presente no guião oferecido pelos curadores científicos a empresa responsável pela museografia) que reproduz a cena de uma fêmea de urso-pardo, com a sua cria. Nessa experiência, os visitantes puderam interagir com a mãe urso, que se coça em uma árvore, fica em pé, brame e corre com o filhote (Figura 40A, 41).

\footnotetext{
${ }^{80}$ Nesse espaço também haveria a projeção de dois textos literários nas paredes e duas árvores para ambientar o espaço (já que os livros estão em mesas que representam pedras e os visitantes sentam em pedaços de troncos). Contudo, durante visitas em 2017, 2018 e2019 esses recursos não estavam disponíveis (em reparação pela equipe técnica do MUHNAC), sendo apenas citados pela investigadora Cristiane Barros-Silveira.

${ }^{81}$ Deacordo com o documento contendo o plano original proposto pela empresa Laranja Mecânica propunha-se a construção de um labirinto com ecrãs para apresentar histórias e imagens e alguns objetos de história natural. Contudo, esse espaço não foi produzido.
} 

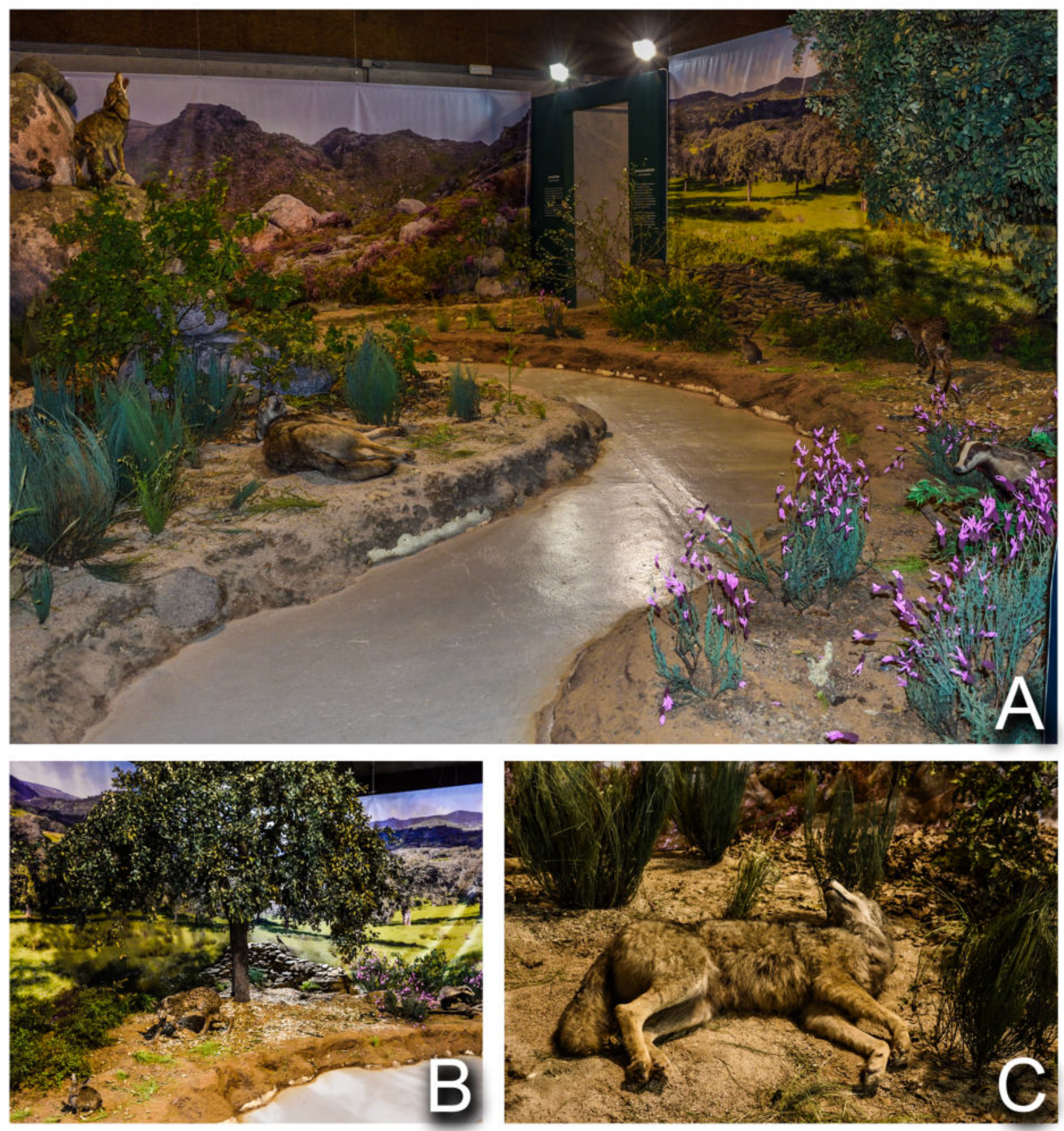

FIGURA 39: Dioramas da exposição "Reis da Europa Selvagem". A. Vista geral de dois dioramas de imersão, construídos em paralelo, com passagem no meio para os visitantes. Não há barreiras físicas entre o acervo e os visitantes, apenas a indicação do percurso. B. "Um dia na serra". Diorama que ilustra a paisagem das serras da região norte de Portugal, onde podem ser encontradas as últimas populações do lobo-ibérico, em Portugal. Destaque para lobo roçando na relva. C. "Um dia no montado". Diorama que ilustra o ecossistema do montado de azinho, habitat do lince-ibérico, na parte sul de Portugal. Destaque para a cena de caça entre o lince e uma lebre. Fotografia: Mariana Galera Soler, obtida em visita técnica em Julho de 2018. 

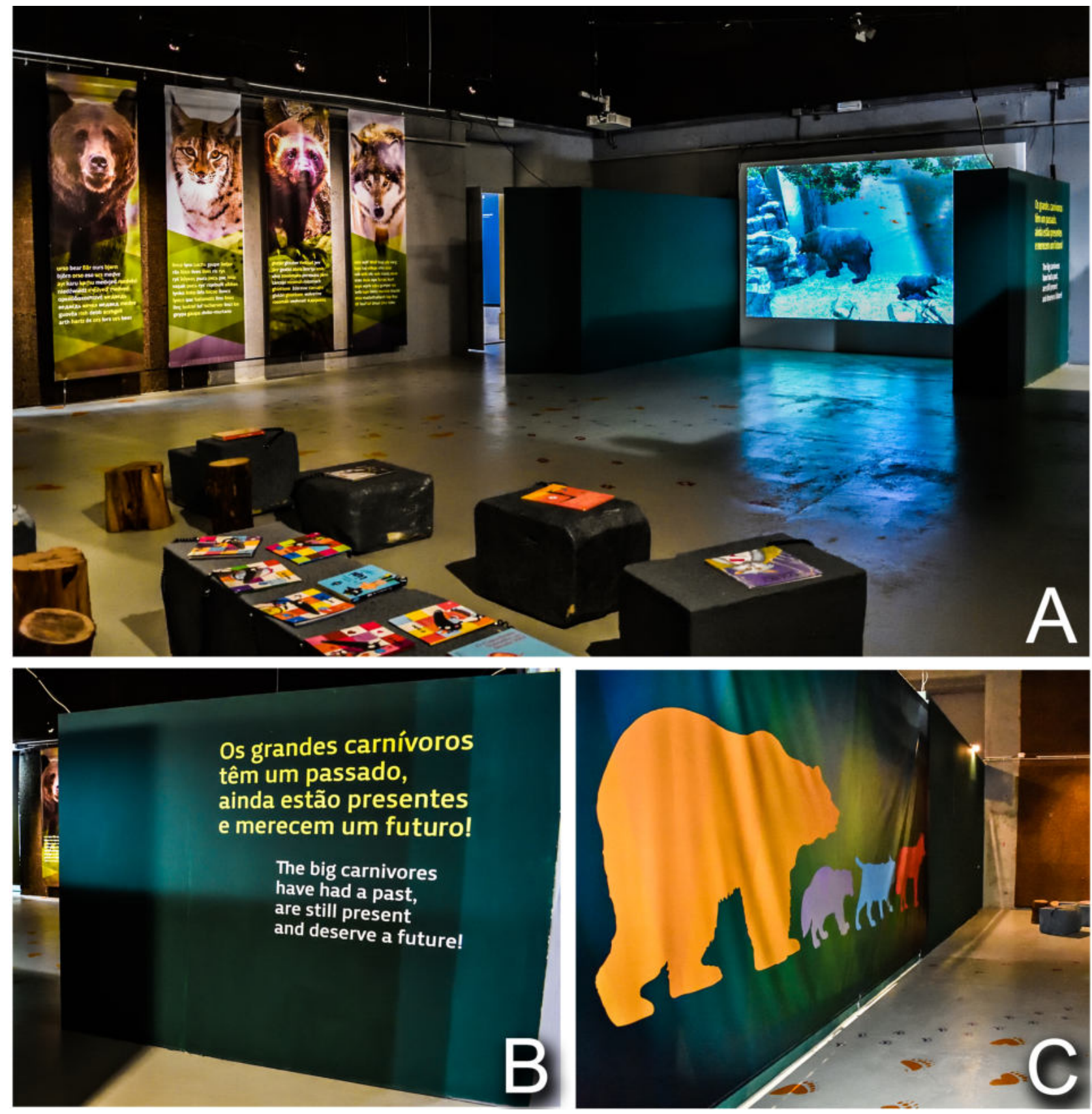

FIGURA 40: Módulo final da exposição "Reis da Europa Selvagem”. Em A, vista geral do quinto módulo da exposição, com espaço de leitura ao centro e painéis com fotos e nomes populares. Em B Painel introdutório do módulo, marcando a passagem entre os dioramas e o módulo final. Em C, painel onde é possível identificar as silhuetas dos carnívoros à esquerda, suas pegadas no chão. Ao fundo o espaço de leitura. Fotografia: Mariana Galera Soler, obtida em visita técnica em Julho de 2018. 


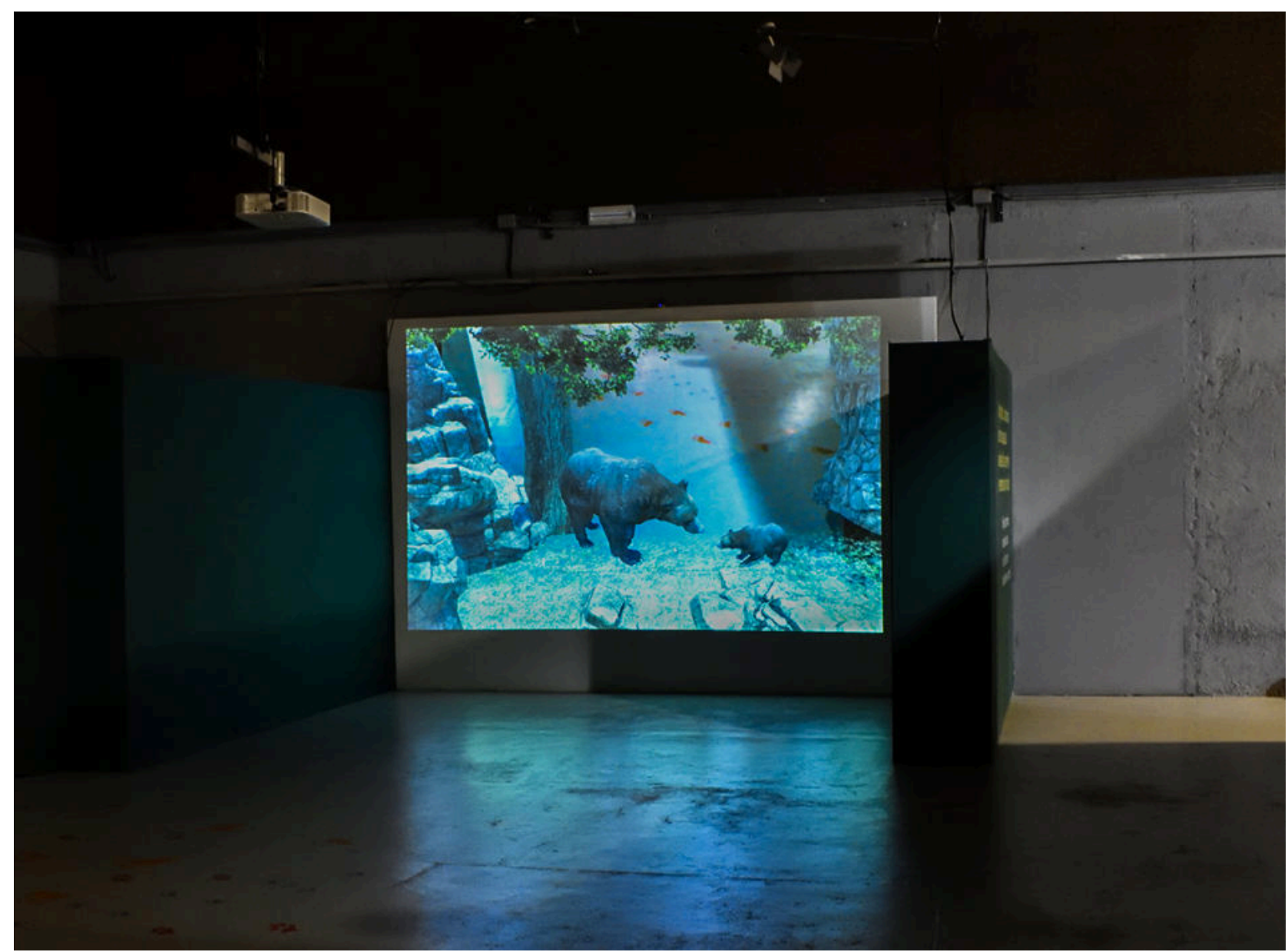

FIGURA 41: Realidade aumentada, com fêmea de urso-pardo e sua cria. De acordo com a investigadora Cristiane Bastos-Silveira, a introdução de elementos tecnológicos, como a realidade aumentada, tem como objetivo cativar o público mais jovem e criar espaços de interação com o visitante (comunicação pessoal, 28 de Março de 2018). Fotografia: Mariana Galera Soler, obtida em visita técnica em Julho de 2018. 


\subsubsection{2 "Specere"}

\subsection{Contextualização:}

A exposição "Specere" foi inaugurada em 28 de Março de 2018 e tem como objetivo:

"dar a conhecer ao público a diversidade das coleções de história natural do MUHNAC e do Instituto de Investigação Científica Tropical (IICT), mas também o trabalho diário de preparação e preservação necessários para a sua manutenção e, acima de tudo, destacar a importância e utilidade que têm para a ciência". (Informações fornecidas na página institucional do MUHNAC. Disponível em: http://www.museus.ulisboa.pt/pt-pt/node/2176. Acesso em 17 de Abril de 2018)

"Specere" foi desenvolvida durante dois anos ${ }^{82}$ e corresponde a uma parceria que envolveu os curadores de diversas especialidades da História Natural do MUHNAC, a equipa técnica da instituição e filósofos da ciência, no âmbito do projeto de investigação "Which biodiversity definition for biodiversity conservation?", coordenado por Elena Casetta. O referido projeto de investigação tem como objetivo principal "to put forward the formal and material constrains that a definition of biodiversity satisfy in order to be effective in conservation actions" e "Specere" responde ao seguinte objetivo "to organize a series of events at -in collaboration with - the National Museum of Natural History of Lisbon to inform the general public about biodiversity, particularly the practical and conceptual challenges posed by its conservation"83.

Maria Judite Alves, coordenadora científica da exposição no MUHNAC, durante seu discurso no evento de abertura de "Specere", afirmou que um dos objetivos era apresentar as coleções científicas do MUHNAC, utilizando a expressão: "dos bastidores aos corredores".

Além disso, dar mais visibilidade aos objetos pertencentes as coleções científicas da instituição, especialmente de História Natural, foi uma das diretrizes fundamentais da exposições da gestão de José Pedro Dias, diretor da instituição desde Fevereiro de 2014 até Maio de $2019^{84}$.

\footnotetext{
${ }^{82}$ Casseta, E. Discurso de abertura da exposição “Specere”, em 28 de Abril de 2018.

83 Informações disponíveis em: http://biodecon.campus.ciencias.ulisboa.pt/?page_id=16. Acesso em 17 de Maio de 2018.

${ }^{84}$ Dias, comunicação pessoal, 17 deAbril de 2018.
} 
Em entrevista realizada em 6 de Abril de 2018, Dias afirmou que "Specere" é um exemplo de exposição construída a partir de demandas internas do MUHNAC. Nesse caso, tratava-se da invisibilidade das coleções de História Natural no espaço expositivo. Assim como Judite Alves, Dias reforça a necessidade de criar instrumentação para que o público possa perceber o que existe e acontece atrás das portas fechadas do museu. Com essa demanda interna foi somado o interesse da equipa de filosofia da ciência em desenvolver o output de seu respetivo projeto de investigação, o que promoveu o estímulo para o encerramento do projeto, que teve parado por diversos períodos (Bastos-Silveira, comunicação pessoal, 28 de Março de 2018).

Dias comentou ainda que "Specere" teve a preocupação de "dar um highlight da coleção inteira, sem despejar tudo, (...) e ao mesmo tempo criando uma narrativa de explicação do papel das coleções. Ou seja, não separar o conteúdo, em termos de conteúdo científico, nesse caso de explicação do papel das coleções de História Natural na ciência moderna. Não separar isso da própria exposição dos objetos" (Dias, comunicação pessoal, 6 de Abril de 2018).

Nesse sentido, a exposição já em seu título (e painel de abertura) faz referência a "espécime", palavra que é pouco visita nas galerias dos museus, mas fundamental nas coleções de história natural: espécime vem do latim specimen, que é formada pela raiz do verbo specere (olhar) e o sufixo -men, significando o "resultado de olhar". O título "Specere” pretende, por um lado, convidar o público a "olhar" a diversidade do mundo natural representada nas nossas coleções e, por outro lado, refletir a importância do "olhar" na construção do conhecimento científico (Figura 42).

Outros dois elementos são simbólicos na conceção de "Specere": o mobiliário e o espaço em que foi montada. O mobiliário utilizado na museografiada referida exposição remete ao património científico português, uma vez que é essencialmente composto pelas antigas estantes da biblioteca do Instituto Bacteriológico Câmara Pestana, em Lisboa (uma estratégia para preservar de maior número de estantes no acervo da instituição) ${ }^{85,86}$ (Figura 42). E o espaço escolhido para a montagem da exposição também é muito emblemático e representativo: corresponde ao corredor que liga o

85 Na tese de Marques (2019) encontram-se plantas e descrições detalhadas do espaço em que funcionava o Instituto Bacteriológico Câmara Pestana.

86 Dias, comunicação pessoal em 06 de Abril de 2018. 
antigo Museu de Ciência da Universidade de Lisboa, com o Museu Nacional de História Natural87 (Figura 43).

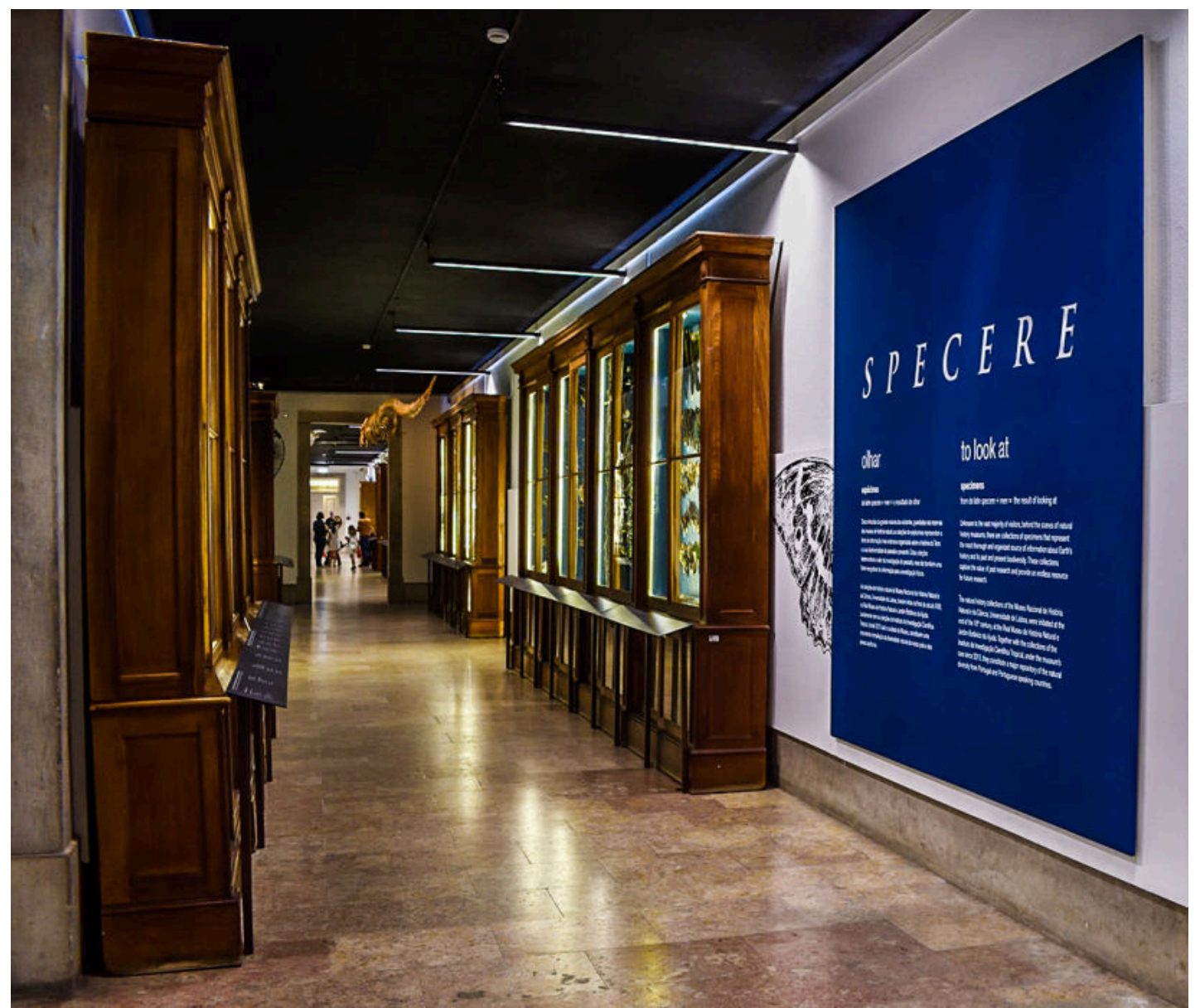

FIGURA 42: Painel de abertura da exposição "Specere" e visão geral dos armários e painéis. No texto desse painel é possível ler: "Olhar. Espécimes. Do latim specere + men = o resultado do ol har. Desconhecidas da grande maioria dos visitantes, guardadas nas reservas dos museus de história natural, as coleções de espécimes representam a fonte de informação mais extensa e organizada sobre a história da Terra e sua biodiversidade do passado e presente. Estas coleções testemunham o valor da investigação do passado, mas também uma fonte inesgotável de informação para investigação futura. As coleções de história natural do Museu Nacional de História Natural e da Ciência, Universidade de Lisboa, tiveram início no final do século XVIII, no Real Museu de História Natural e Jardim Botânico da Ajuda. Juntamente com as coleções do Instituto de Investigação Científica Tropical, desde 2015 sob o cuidado do Museu, constituem uma importante compilação da diversidade natural do nosso país e dos países lusófonos". Na Figura 44, esse painel equivale ao P2. Fotografia: Mariana Galera Soler, obtida em visita técnica em Julho de 2018.

87 O Museu de Ciências da Universidade de Lisboa foi criado em 1985 e a sua exposição de longa-duração abriu ao público em Março de 1993. Essa instituição partilhou o espaço da antiga Faculdade de Ciências, junto com o Museu Nacional de História Natural. Ambos são frequentemente designados como "Museus da Politécnica” (Lourenço, 2010). Em Outubro de 2011, o Conselho Geral da Universidade de Lisboa criou a Unidade Museus da Universidade de Lisboa, com a designação pública de Museu Nacional de História Natural e da Ciência. Este Museu sucedeu ao Museu Nacional de História Natural e ao Museu de Ciência, integrando as suas coleções, os antigos edifícios da Escola Politécnica, o Jardim Botânico de Lisboa e o Observatório Astronómico da Ajuda. 
Assim como em "Reis da Europa Selvagem", parte do financiamento da exposição foi coberto pelo orçamento do MUHNAC. Além disso, foi aplicada parte da verba destinada para output e disseminação dos resultados do projeto de investigação de Elena Casetta "Which biodiversity definition for biodiversity conservation?", financiado pela Fundação para a Ciência e a Tecnologia FCT (I\&D Project. Ref. PTDC/IVC-HFC/1817/2014).

A ficha técnica da exposição "Specere" encontra-se no ANEXO 3.

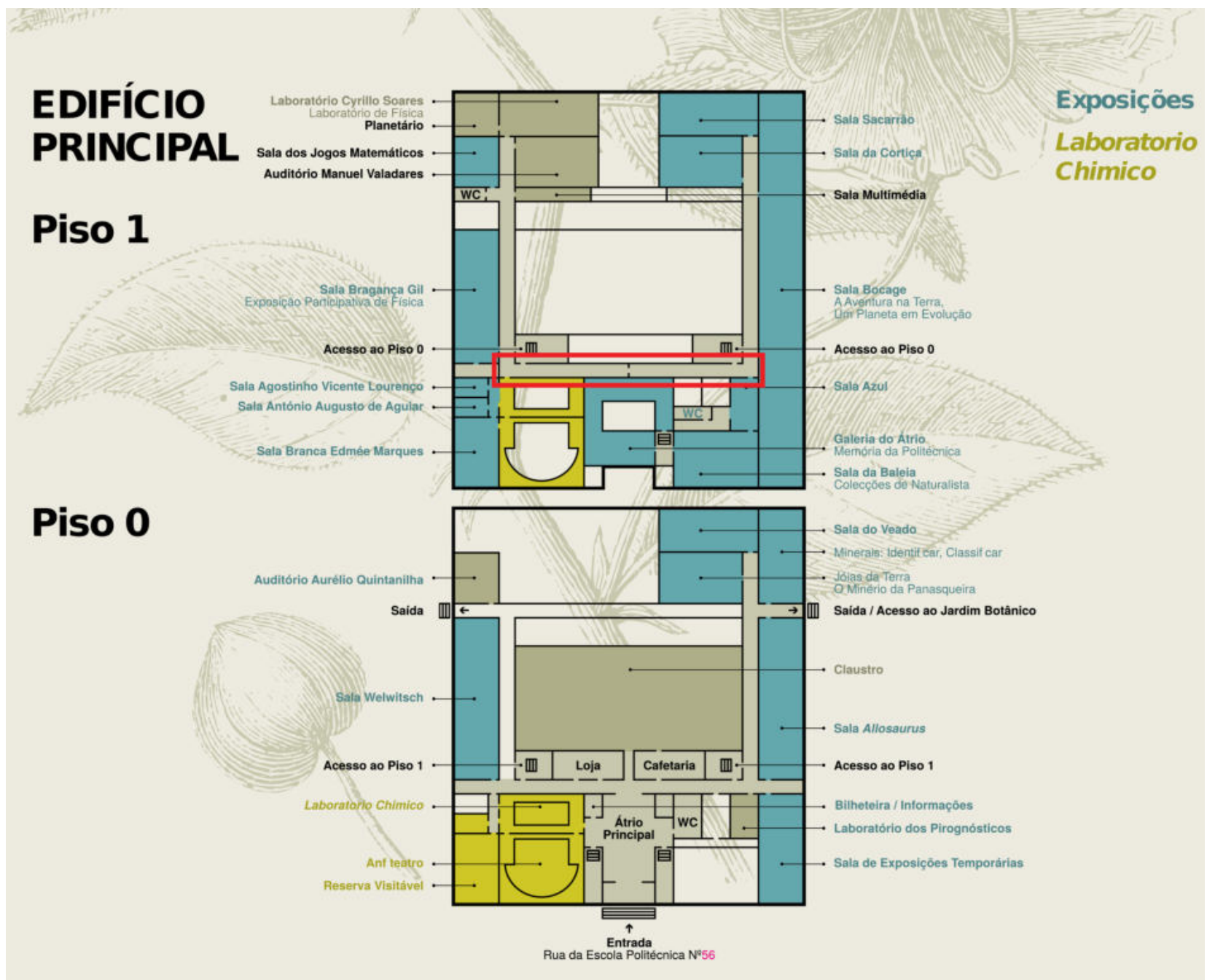

FIGURA 43: Mapa do Museu Nacional de História Natural e da Ciência, Universidade de Lisboa. O retângulo destacado em vermelho marca o espaço em que é realizada a exposição "Specere". Disponível em: https://museus.ulisboa.pt/sites/default/files/PLANTA_PUBLICO_MUHNAC_PT.pdf. Acesso em 4 de Junho de 2019. 


\subsection{Tratamento Museográfico}

A exposição "Specere" foi construída em um corredor com pouco menos de 60m de comprimento (totalizando uma área expositiva de aproximadamente $185 \mathrm{~m}^{2}$ ), um longo espaço que não possuía caráter museográfico até então, mas de importância simbólica na instituição. Como corredor de passagem, possui portas que dão acesso a salas de trabalho (seis, ao total) e janelas que permitem a entrada de luz exterior (protegida por cortinas) e as escadas para o andar inferior.

A exposição é modular e embora o extenso espaço pareça impor narrativa progressiva ou ordenação taxonómica, essa não está presente, uma vez que os visitantes podem entrar na exposição pelas duas extremidades do corredor (uma que dá acesso a Sala Bocage e outra a Sala Bragança Gil), sem qualquer prejuízo a compreensão da narrativa; inclusive, painéis introdutórios estão disponíveis em ambos os extremos (Figura 44).

A narrativa construída com o objetivo de "dar a conhecer ao público a diversidade das coleções de história natural do MUHNAC e do Instituto de Investigação Científica Tropical" encontrase articulada e distribuída em seis painéis de texto, que são iluminados individualmente, decorados com ilustrações científicas e posicionados entre os armários de acervos e portas (indicados pela letra T, na Figura 44). Nesses textos, é destacada a importância dos espécimes nas coleções, como pode ser visto nos títulos "Únicos e insubstituíveis" (T8, na Figura 44) ou "A história da Terra dentro do museu" (T3, na Figura 44) e seu uso em diversas práticas científicas, como "Espécimes antigos, novas descobertas" (T2, na Figura 44), "Todos iguais? Todos diferentes!" (T4, na Figura 44) e "Tesouros preciosos: os espécimes tipo" (T7, na Figura 44 e Figura 45). 


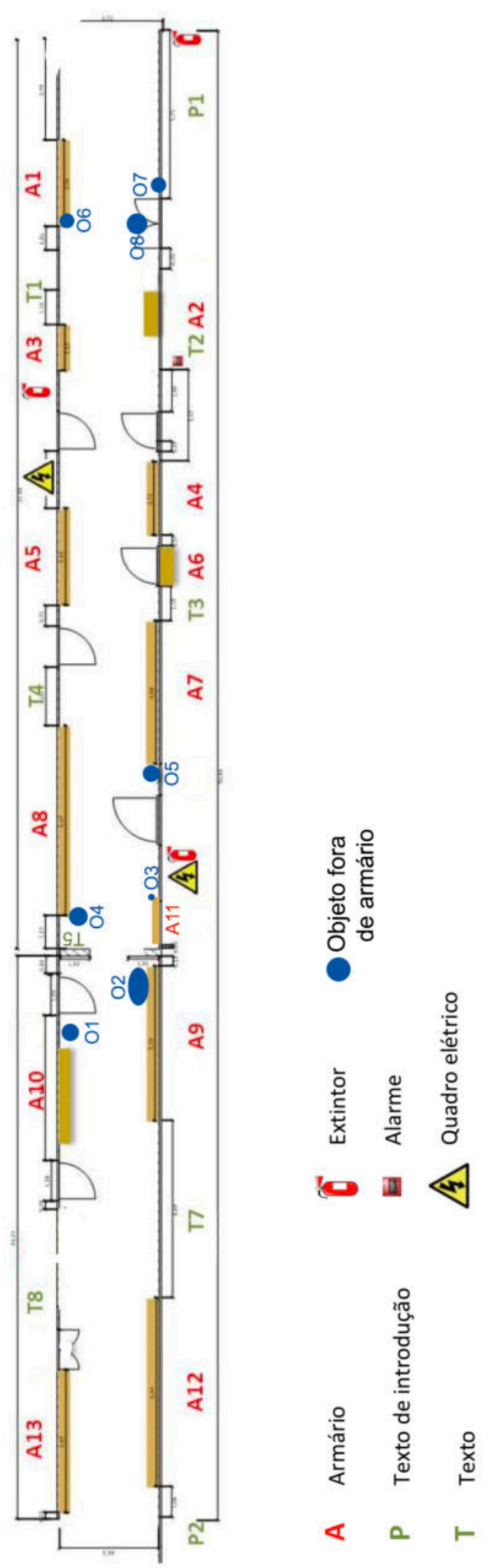

FIGURA 44: Planta baixa da exposição "Specere", adaptada do guião expositivo disponibilizado por Jorge Prudêncio, por e-mail, em 23 de Maio de 2018. Foram realizadas edições no documento original, para que a planta se aproximasse da exposição que efetivamente foi realizada. 


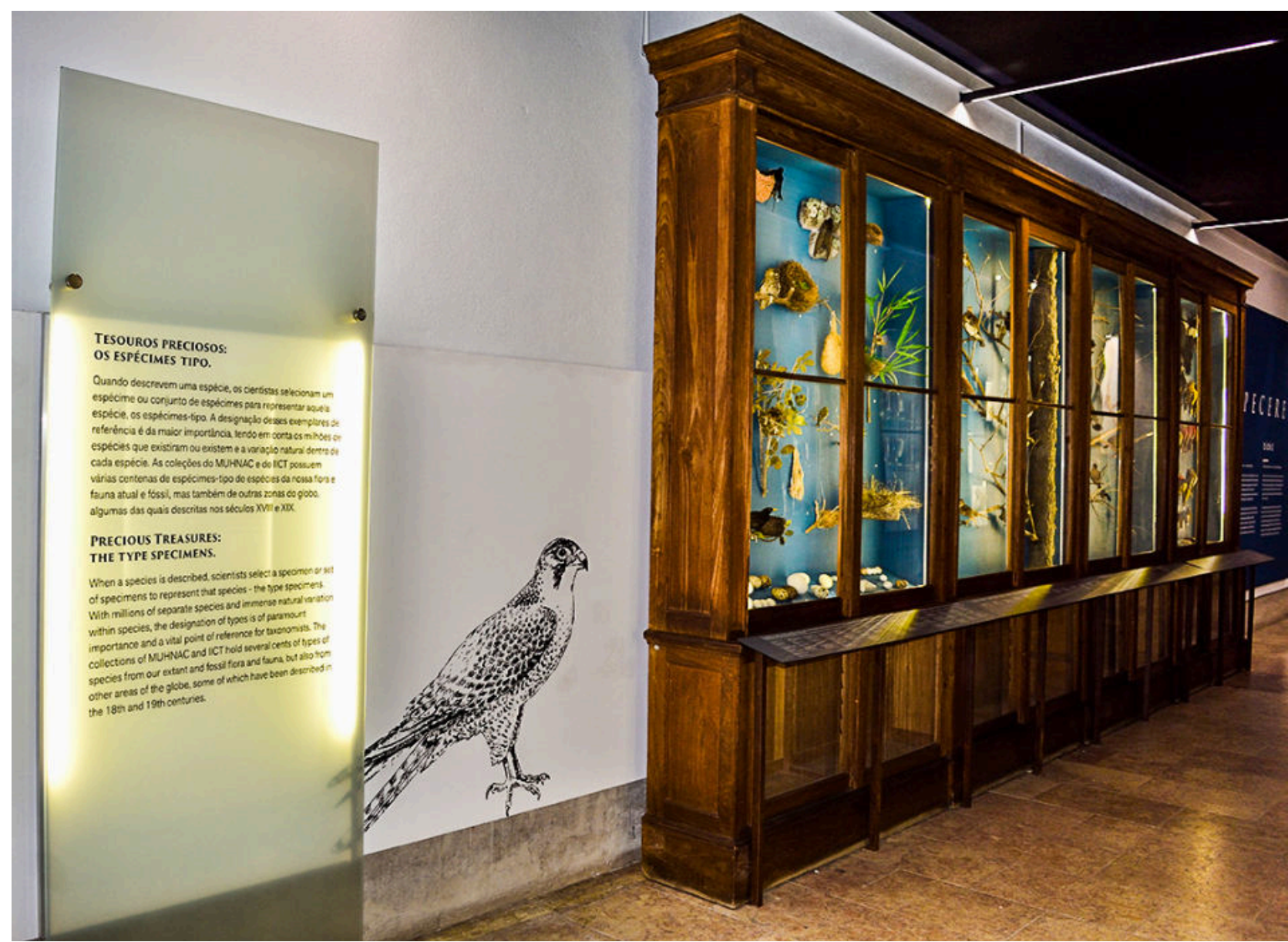

FIGURA 45: Painel com o texto "Tesouros Preciosos: os espécimes tipos. Quando descreve uma espécie, os cientistas selecionam um espécime ou um conjunto de espécimes para representar aquela espécie, os espécimes-tipo. A designação de desses exemplares de referência é da maior importância, tendo em conta os milhões de espécies que existiram ou existem e a variação natural dentro de cada espécie. As coleções do MUHNAC e do IICT possuem várias centenas de espécimes-tipo de espécies da nossa flora e fauna atual, mas também de outras zonas do globo, algumas das quais descritas nos séculos XVIII e XIX”. Destaca-se a importância de determinado tipo de objeto das coleções de história natural. Ao lado um armário com ninhos e ovos. Na Figura 44, este painel equivale ao T7 e ao armário A12. Fotografia: Mariana Galera Soler, obtida em visita técnica em Julho de 2018.

Quanto ao mobiliário, "Specere” é composta por 28 armários que fazem parte do património do MUHNAC e uma vitrina. Esses móveis estão organizados em 12 módulos, que correspondem as coleções de história natural da instituição, a saber: herbário LISU (briófitas) e LISC (plantas vasculares) (A13, na Figura 44), mineralogia (A10, na Figura 44), petrologia (A10, na Figura 44), paleontologia (fósseis e réplicas) (A7, na Figura 44), mamíferos (espécimes naturalizados, taxidermia científica e osteologia) (A2, A9 e A11, na Figura 44), aves (espécimes naturalizados, taxidermia científica e osteologia, além da coleção de ninhos e ovos) (A1, A9 e A12, na Figura 44), entomologia (espécimes em via seca e via húmida) (A4, na Figura 44), malacologia (espécimes em via seca conchas, e via húmida) (A5, na Figura 44) e antropologia (vitrina já presente no espaço expositivo 
com dois esqueletos: homem Homo sapiens sapiens e chimpanzé-comum fêmea Pan troglotydes) (A6, na Figura 44).

Além disso, há um módulo destinado as coleções em via húmida (nesse caso, preservadas em álcool) com espécimes representantes dos seguintes filos: Porifera, Cnidaria, Mollusca, Annelida, Sipuncula, Arthropoda (especialmente crustáceos), Echinodermata e Vertebrata (representados por peixes, anfíbios e répteis) (A8 na Figura 44).

Em cada um desses módulos, há informações fundamentais e comuns (exceção da coleção de Antropologia), como: o número de espécies e espécimes presentes na coleção do MUHNAC, abrangência geográfica (em geral, os espécimes são representantes da diversidade portuguesa e territórios africanos lusófonos - antigas colónias) e relevância histórica (espécimes que registram os primórdio científicos em determinadas áreas, como a paleontologia, por exemplo).

Além disso, as coleções são utilizadas para representar práticas científicas que ocorrem em museus de história natural (museological science, de acordo com Pickstone, 1994 ou collecting science, como definido por Kohler, 2007) seja no processo de preparação de espécimes, como métodos para sua conservação em coleções. Na Figura 47B ilustra-se a preparação de espécimes entomológicos em via seca, além da importância dos dados em etiquetas para gestão de coleções. A Figura 46 mostra a utilização álcool para preservar espécimes e a Figura 45 ressalta o uso de espécimes naturalizados para investigação e exposições. Tais informações são explicitadas por meio dos texto expositivo, além da informação a coleta de tecidos para estudos genéticos (conteúdo abordado apenas em texto). 


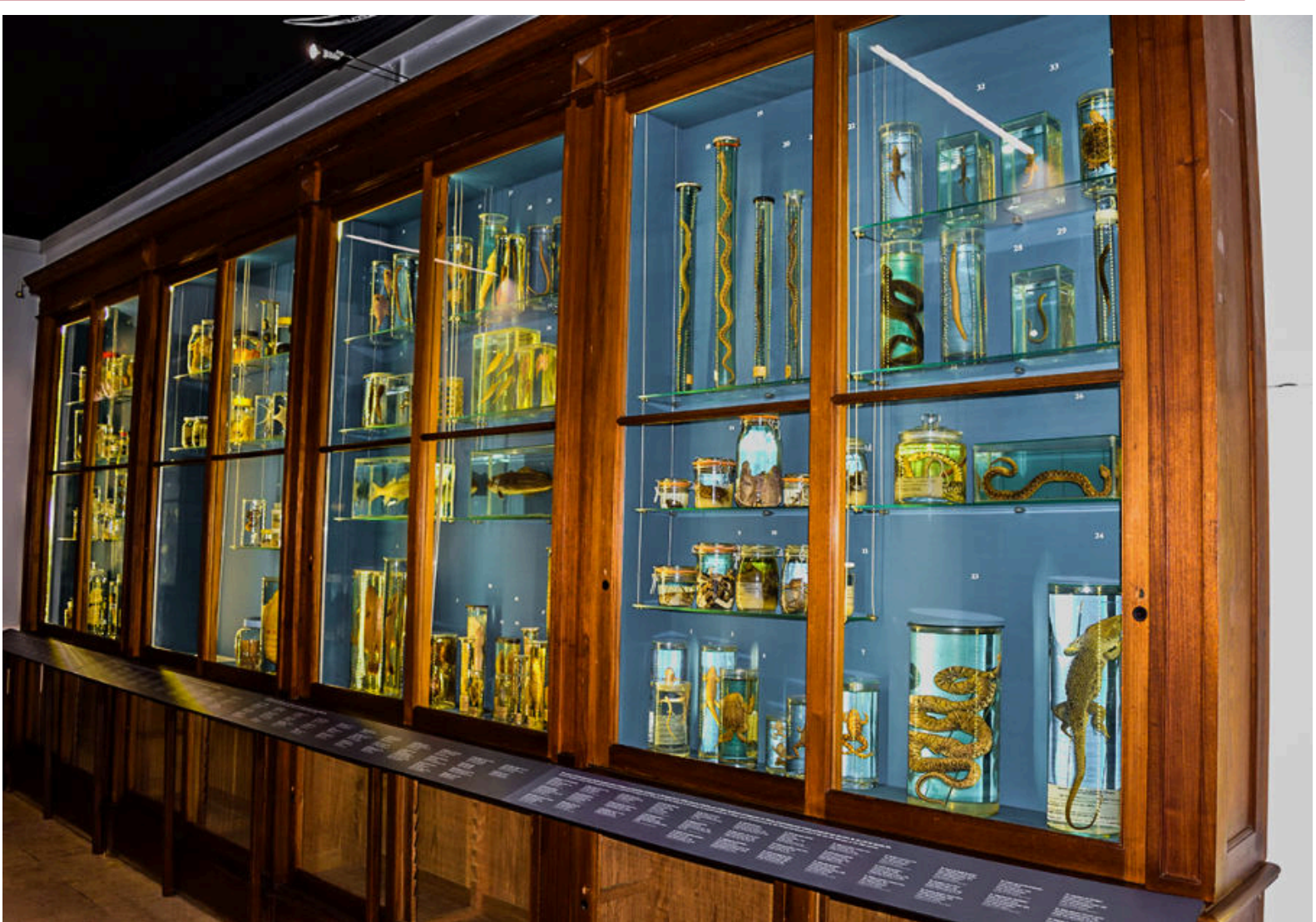

FIGURA 46: Conjunto de armários que apresentam as coleções preservadas em via húmida. Embora exista grande diversidade zoológica presente nesse módulo, todos os espécimes estão organizados de acordo com seus respetivos grupos taxonómicos. Na Figura 44, este é armário A8. Fotografia: Mariana Galera Soler, obtida em visita técnica em Julho de 2018.
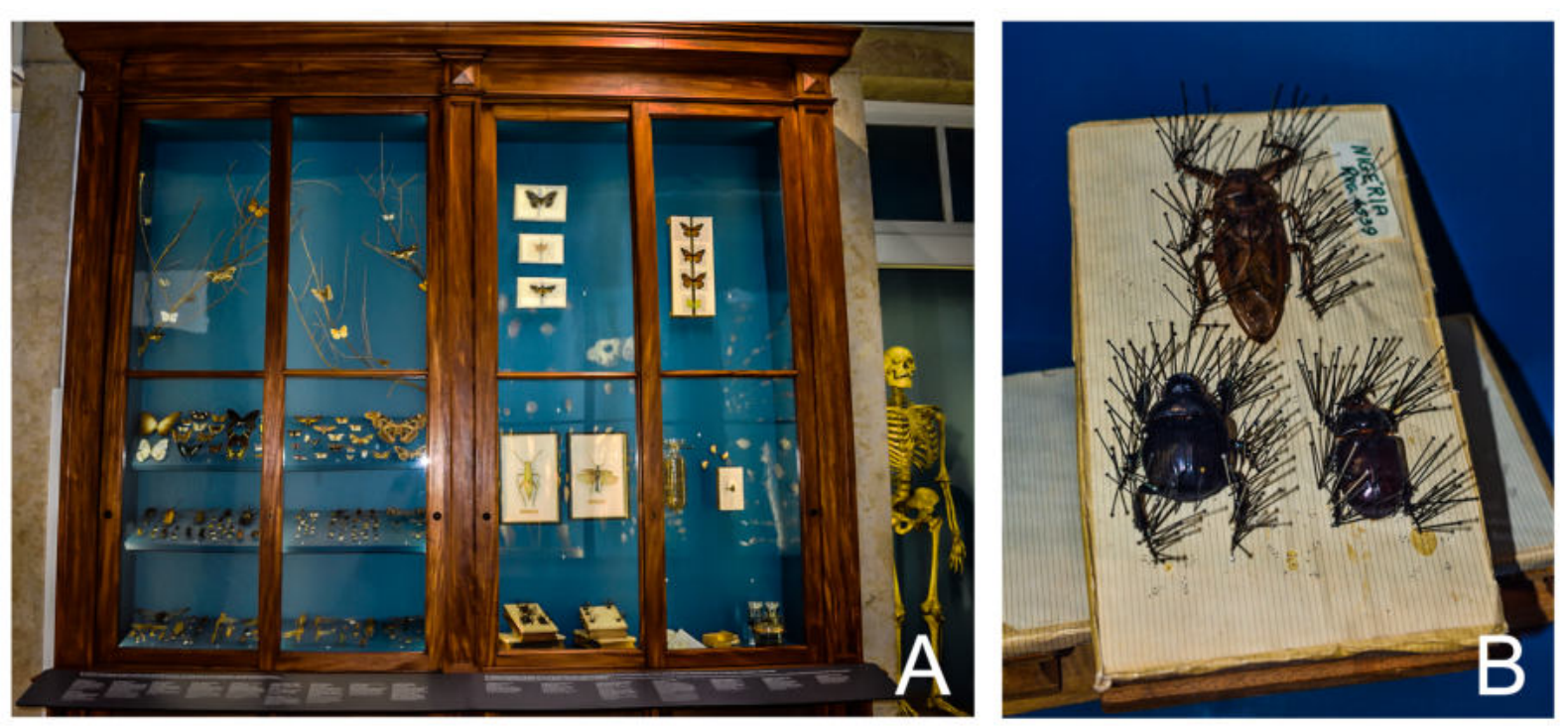

FIGURA 47: Conjunto de armários que apresentam as coleções entomológicas. Em A uma visão geral dos armários, com espécies preservados em via seca (em sua grande maioria) e organizados taxonomicamente do lado esquerdo e representando o trabalho de preparação dos espécimes de insetos, no lado direito. Em B, detalhe de espécime em preparação. Na Figura 44, este é armário A4. Fotografia: Mariana Galera Soler, obtida em visita técnica em Julho de 2018. 

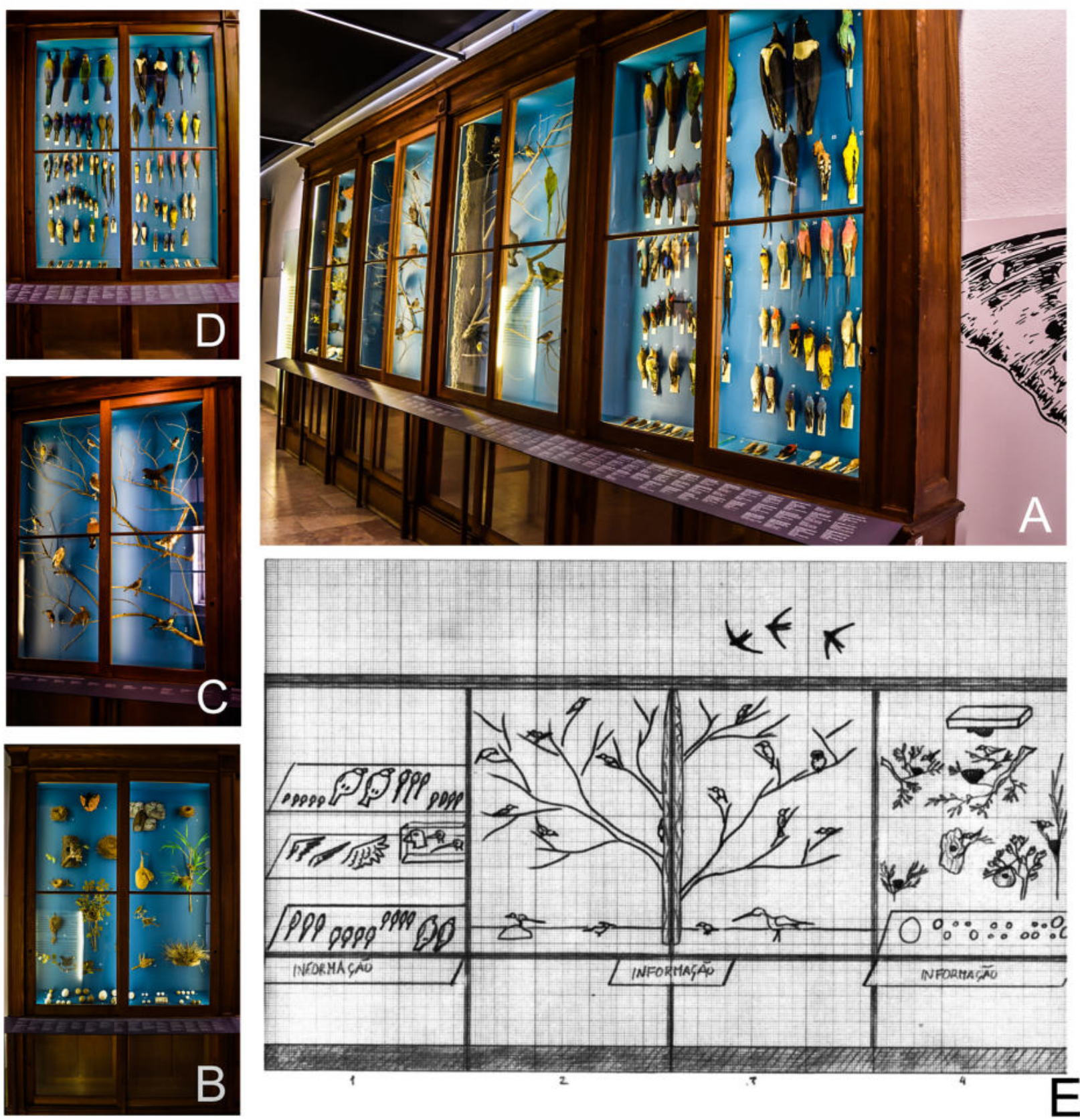

FIGURA 48: Conjunto de armários que apresentam as coleções ornitológicas. Em A uma visão geral dos armários, com espécies preservados em via seca. Em B, detalhe para coleção de ovos e ninhos. Em C, espécimes de aves naturalizados. Em D, espécimes ornitológicos organizados taxonomicamente e preservados para fins científicos. Em E, esquema inicial de disposição dos objetos no armário (Documento digital disponibilizado via e-mail por Jorge Prudêncio, em 23 de Maio de 2018). Na Figura 44, este é armário A12. Fotografia: Mariana Galera Soler, obtida em visita técnica em Julho de 2018. 
Há objetos que estão fora dos armários, no entanto suas legendas e contextos expositivos estão inseridos na lógica modular da exposição. Pode-se exemplificar com a presença de um esqueleto de roaz-corniveiro (Tursiops truncatus) preso ao teto da exposição, ao lado da coleção osteológica (Figura 49F), alguns roedores e aves e até um crânio de dinossauro que parecem "fugir" das gavetas da coleções (Figura 49 B, C, D), ou ainda como um prisma de basalto ao lado da coleção de petrologia (Figura 49) ${ }^{88}$. De acordo com entrevista realizada com Jorge Prudêncio, biólogo responsável pela museografia e coordenação geral desse projeto, em 13 de Maio de 2018, optou-se por ter objetos fora dos armários para quebrar a "linearidade da exposição" (sequência de armários e um longo corredor), sendo que a coerência dentro e fora dos armários demonstra que o conteúdo textual e objetos estão associados ao objetivo expresso da narrativa expositiva.

No entanto, os discursos internos dos módulos são diversificados e não necessariamente correspondentes ao discurso. Como propostas individuais dos curadores científicos das respetivas coleções, encontram-se abordagens distintas como: o ecossistema Fagosilva (representado pela coleção do Herbário LISC) (Figura 50C), características anatômicas (representadas por coleções osteológicas de peixes e tetrápodes, coleção ornitológica e coleção de moluscos em via seca) (Figura 50 A, D e E), ameaças a conservação (apontada na legenda da coleção de mamíferos de médio porte) (Figura 50B), importância económica e ecológica (ilustrada na coleção de micromamíferos e coleção de moluscos em via seca) (Figura 50D), ou estudos evolutivos (coleção paleontológica) ${ }^{89}$ (Figura 49B).

Tais diferenças também são observadas também na museografia dentro de cada um dos armários e vitrina. Como relatado por Jorge Prudêncio, a conceção museográfica dos módulos foi

\footnotetext{
88 Exceção é um grande exemplar de Welwitschia mirabilis que encontra-se sem nenhuma informação, para além da identificação (Figura 49A) e duas aves naturalizadas suspensas na exposição (teto e parede junto a um dos painéis introdutórios).

${ }^{89}$ Destaca-sea abordagem escolhida para as coleç̃oes paleontológicas. No módulo em queestão presentes 14 objetos da coleção, 11 não são representantes da paleofauna portuguesa e 5 são réplicas, embora o texto ressalte a importância científica histórica da coleção do MUHNAC.

Os textos ainda relacionam a importância dos fósseis para a compreensão das relações evolutivas e utilizam repetidamente exemplos dos dinossauros, embora sem a exposição de fauna pretérita de dinossauros portugueses. Optou-se por réplicas de espécimes icónicos e fundamentais para a compreensão da evolução dos dinossauros e aves, como Microraptor gui, espécime chinês depositado na coleção do Institute ofVertebrate Paleontology and Paleoanthropology, Chinese Academy ofScience, edescrito porXu ecolaboradores (2003).
} 
desenvolvida individualmente. Os critérios para a museografia foram diversos, como por exemplo: (i) aspetos estéticos e melhor disposição espacial, como os mamíferos de médio porte e paleontologia (Figura 50B e 50B); (ii) escolha dos curadores científicos ou equipas técnicas, como o caso do expositor com insetos que foi inteiramente concebido e elaborado pelo investigador, que manteve uma proposta inicial da exposição em mostrar como era a prática científica nesse tipo de coleção zoológica (Figura 47), o armário com a coleção de mineralogia e petrologia também concebido por investigadores e o armário com ninhos e ovos, desenvolvido pelo taxidermista Pedro Andrade (Figura 48); (iii) inspirados na forma, como as conchas (espécimes da coleção de malacologia preservada em via seca) (Figura 50D); (iv) em uma organização taxonómica, como na coleção húmida (Figura 46); (v) inspirado em antigos expositores, como a montagem das exsicatas proposta por Jorge Prudêncio (Figura 50C), com base na vitrine da árvore da vida, presenta na exposição Aventura da Terra90, nessa mesma instituição.

Posto que a exposição "Specere" não impõe um percurso linear para o visitante, o objetivo central da narrativa não é perdido, mesmo com as múltiplas abordagens dos módulos, uma vez que há unidade entre as informações essenciais e na constante reafirmação da importância das as coleções de história natural.

\footnotetext{
90 Mais detalhes em: https://www.museus.ulisboa.pt/pt-pt/a-aventura-da-terra. Acesso em 12 de Junho de 2019.
} 

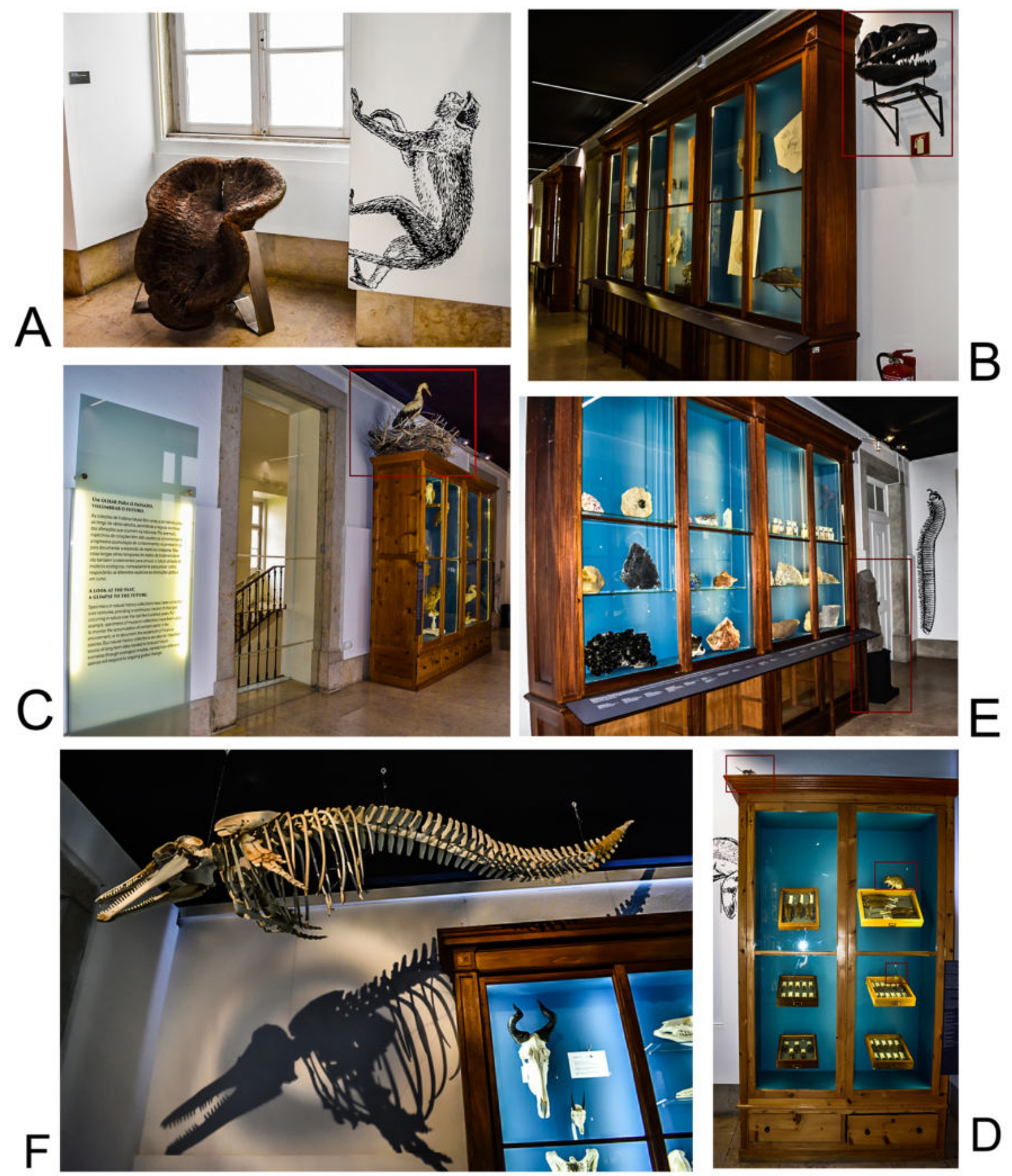

FIGURA 49: Exemplos de objetos apresentados fora de armários. Em A espécime isolado de Welwitschia mirabilis, apenas com identificação do nome científico e popular (O8, na Figura 44). Em B, armário com fósseis e réplicas, com crânio de dinossauro terópode Allosaurus fragilis exposto do lado externo (destacado em quadro vermelho) (05, na Figura 44). Em C, aves de rapina e aves limícolas naturalizadas. Ave indeterminada em ninho na parte superior do armário (06, na Figura 44) . Em D, espécimes de micromamíferos naturalizados (destacados em quadros vermelhos) e taxidermias científicas (03, na Figura 44). Em E, ao lado dos armários com as coleções de mineralogia e petrologia há um fragmento de disjunção prismática de basalto (destacado em quadro vermelho) (O1, na Figura 44). Em F, o esqueleto do Tursiops truncatus preso ao teto, ao lado dos armários que mostram espécimes osteológicos (O2, na Figura 44). Fotografia: Mariana Galera Soler, obtida em visita técnica em Julho de 2018. 

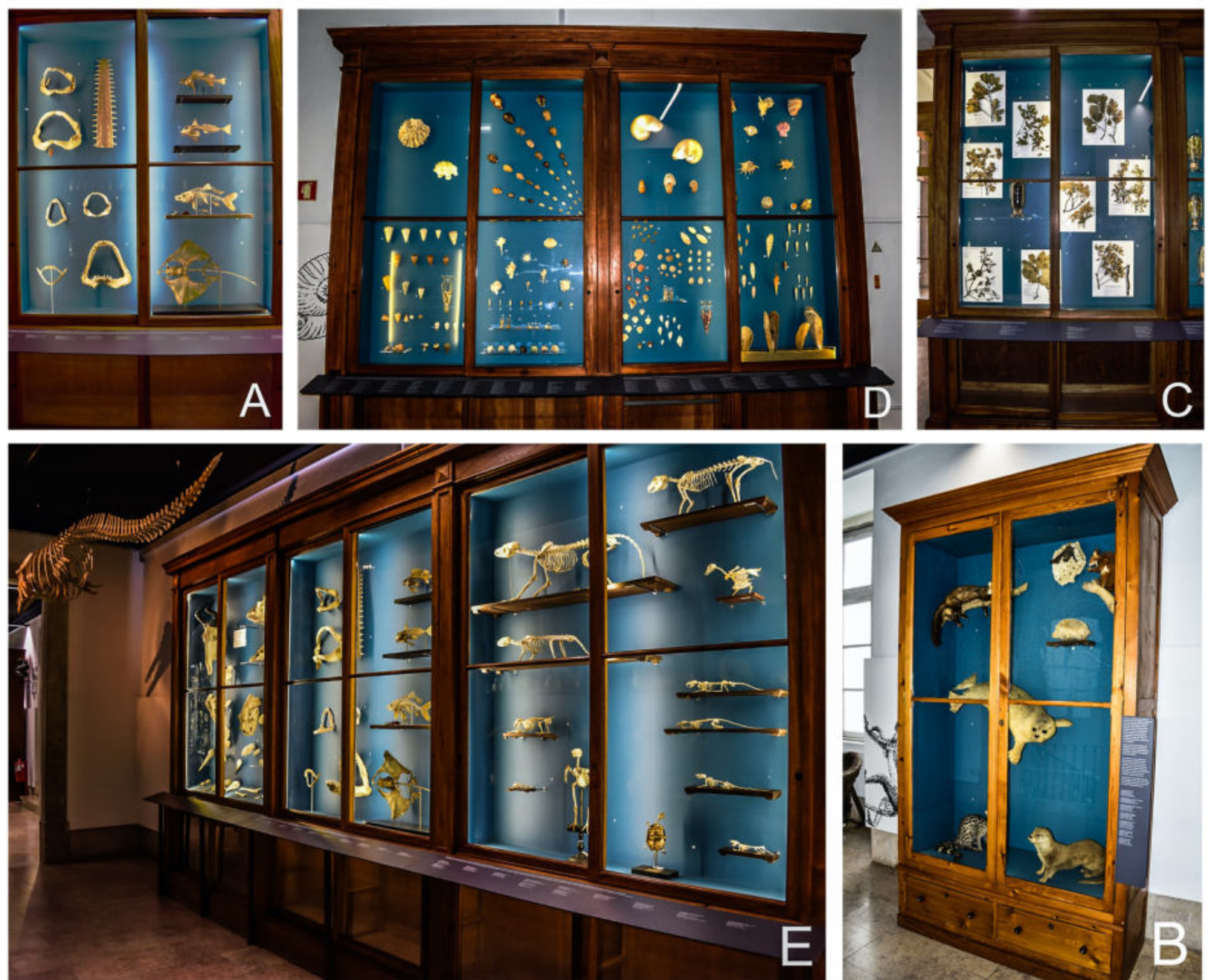

FIGURA 50: Armários com museografias e abordagens diferentes. Em A, armários de osteologia, com destaque para comparações entre mandíbulas de diferentes condrictes e colunas vertebrais (A1, na Figura 44). Em B, armário com mamíferos de médio porte e alguns ameaçados de extinção (A2, na Figura 44). Em C, armário com coleções botânicas, em destaque armário com espécies do ecossistema fagossilva (A13, na Figura 44). Em D coleção de malacologia (A5, na Figura 44). Em E vista geral dos armários com a coleção osteológica (A1, na Figura 44). Fotografia: Mariana Galera Soler, obtida em visita técnica em Julho de 2018. 
3.2.3 Museu de História Natural e da Ciência da Universidade do Porto-Galeria da Biodiversidade

\subsubsection{Contextualização}

"Tudo na casa era desmedidamente grande desde os quartos de dormir onde as crianças andavam de bicicleta até o enorme átrio para o qual davam todas as salas e no qual, como Hans dizia, poderia armar o esqueleto da baleia que há anos repousava, empacotado em numerosos volumes, nas caves da Faculdade de Ciências por não haver lugar onde coubesse armado " (Andersen, 1984, p. 50-51, grifo nosso)

O trecho acima destacado foi escrito por Sophia de Mello Breyner Andresen, no conto "Saga", publicado no livro "Histórias da Terra e do Mar", em 1984. A poetisa portuguesa passou parte de sua infância na quinta de seus avós (antiga Quinta do Campo Alegre), espaço que inspirou essa descrição e que, atualmente, é conhecida como Casa Andresen e abriga a Galeria da Biodiversidade, no Jardim Botânico do Porto.

A Casa Andresen foi o primeiro polo do Museu de História Natural e da Ciência da Universidade do Porto a reabrir ao público, após processo de profunda renovação, iniciado em 2010 (Ferrand, 2017). Esse espaço abrigava um palacete portuense do final do século XIX (espaço de memória de Sophia Andresen, supracitado) e sofreu intervenções para receber a exposição "A evolução de Darwin (exposição blockbuster realizada em por ocasião do segundo centenário do nascimento de Darwin e dos 150 anos da publicação da obra “A origem das espécies”), que em três meses e meio de exibição atingiu os 161 mil visitantes. Após essa exposição, o espaço foi novamente fechado para obras até a inauguração da Galeria da Biodiversidade, em 30 de Junho de 2017. As obras de reabilitação arquitetónica do edifício foram coordenadas pelo arquiteto e docente da Faculdade de Belas Artes da Universidade do Porto, Nuno Valentim (Fonseca \& Santos, 2018) (Figura $51)$. 

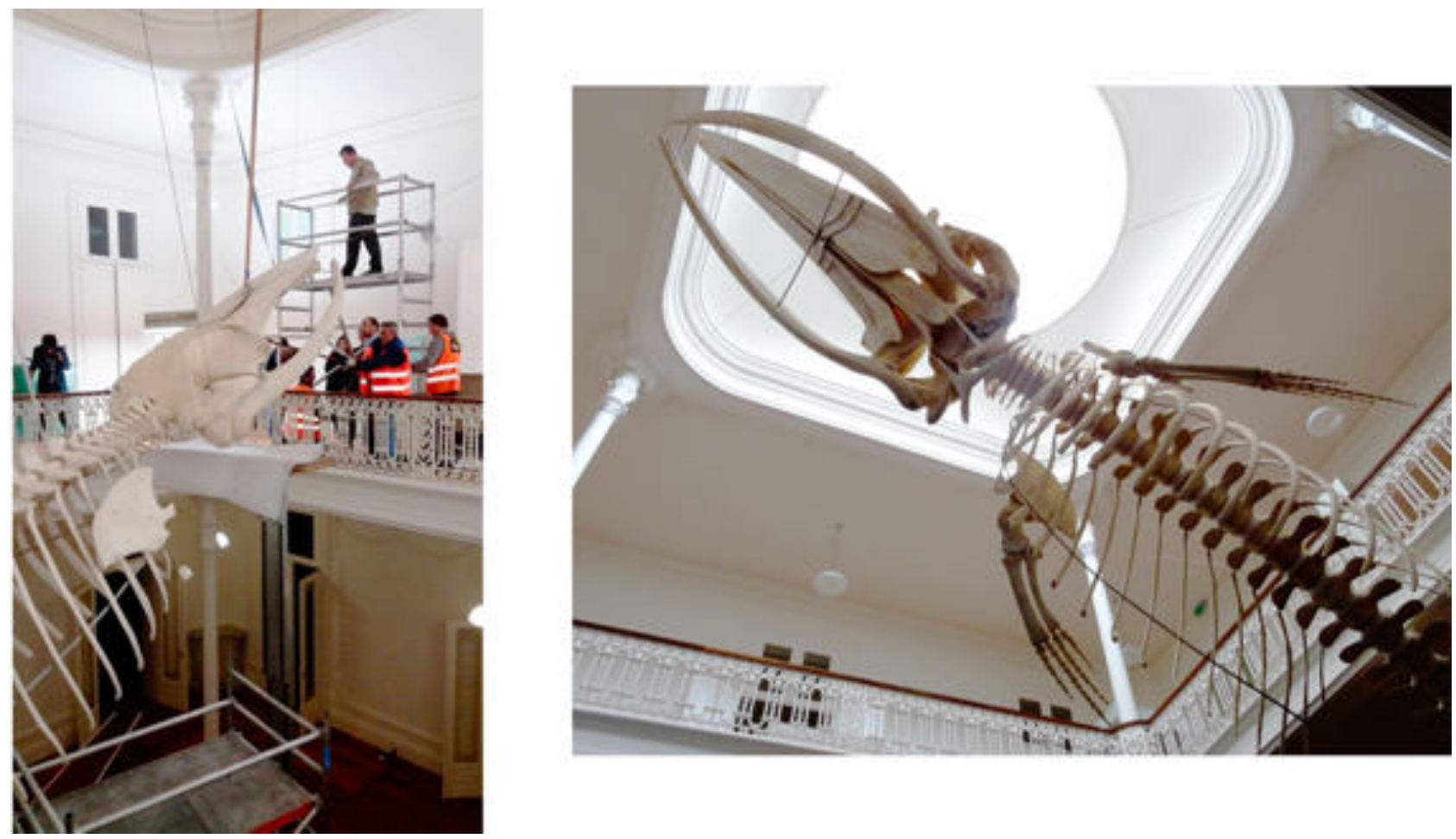

FIGURA 51: "O desejo de Sophia” é como ficou conhecida um dos mais icónicos objetos em exposição na Galeria da Biodiversidade, o esqueleto de baleia que pertencia a Faculdade de Ciências da Universidade do Porto. Estas imagens cedidas pelo arquivo institucional do Museu de História Natural e da Ciência da Universidade do Porto mostram o processo de montagem do esqueleto, que é possivelmente de uma baleia-azul juvenil, que ocupa o vão livre do átrio do antigo palacete, o objeto citado por Sophia Andresen e também imaginado nesse espaço pela poetisa, no conto "Saga". Fonte: Arquivo do Museu de História Natural e da Ciência da Universidade do Porto.

A Galeria da Biodiversidade é o resultado de um projeto em parceria da Universidade do Porto e a Agência Nacional para a Cultura Científica e Tecnológica, sendo esse o primeiro espaço a integrar a Rede Ciência Viva a associar-se diretamente com uma universidade e também o primeiro espaço dessa natureza na cidade do Porto.

Como um "espaço onde a arte se cruza com a Biologia e a História Natural, estimulando uma panóplia de experiências sensoriais, propositada e cuidadosamente concebidas para celebrar a diversidade da vida, a Galeria da Biodiversidade éo primeiro espaço museológico do mundo criado de raiz segundo a filosofia da museologia total"91 e resulta também do encontro de três profissionais: o biólogo e diretor do MP Nuno Ferrand de Almeida, o físico e museólogo Jorge Wagensberg e o designer e criativo Luís Mendonça.

91 Texto de apresentação da Galeria da Biodiversidade, disponível em https://mhnc.up.pt/galeria-da-biodiversidade/. Acesso em 18 de Junho de 2019. 
Nuno Ferrand viajou no ano de 2013 para visitar diversos centros de ciência europeus, até encontrar com Jorge Wagensberg e sua proposta de museologia total. O conceito da "museologia total" considera que os museus de ciências são espaços de "realidade concentrada". São instituições que exibem fenómenos reais e proporcionam a relação dos visitantes com eles, seja interativa, cognitiva ou afetiva - hands-on, minds-on ou heards-on. A premissa é que a audiência é universal, uma vez que não existem diferentes classes diante da missão desse tipo de instituição na contemporaneidade: o estímulo a ciência (Wagensberg, 2005). De modo que as exposições são baseadas nas emoções e não necessariamente em conhecimentos prévios (Wagensberg, 2000).

Os pilares da museologia total são: a possibilidade de encontro com o objeto original (aquele que representa a si próprio); conversa (em sentido amplo, entendendo a interatividade ou pensar sobre também como formas de "conversar"); inteligibilidade ("is the minimum expression of the maximum of what is shared"); e beleza ("The beauty of a piece of reality is the degree of rhythm and harmony that a mind is able to perceive in such a piece ") (Wagensberg, 2005, p. 316).

Um espaço incontornável para a compreensão da museologia total de Wagesberg é o museu científico CosmoCaixa, em Barcelona:

\begin{abstract}
"En aquest projecte es proven noves tècniques, mètodes i criteris museogràfics portats i debatuts durant els darrers anys als fòrums internacionals i provats a les exposicions temporals i itinerants. La nova museologia, que, per animar-nos a nosaltres mateixos, hem anomenat museologia total, és avui visible a CosmoCaixa"
\end{abstract}

(Disponível em: http://www.ub.edu/fisica/fitxersPDF/CursoMuseologia_CAT.pdf. Acesso em 10 de Novembro de 2019).

De acordo com a equipa que trabalhou na conceção e desenvolvimento da exposição do MP, o encontro entre Ferrand e e Wagensberg foi bastante profício e de muitas trocas, uma vez que ambos desejavam "partilhar uma museografia que fosse característica do século XXI". Nesse sentido, Wagensberg trouxe seu conceito de "museologia total" e Ferrand buscava parcerias e inspirações além dos muros universitários (FONSECA; GUSMÃO, comunicação pessoal, 27 de Fevereiro de 2019).

A conceção da Galeria da Biodiversidade propõe "uma vigem pela vida. Mas também um cruzamento entre a arte e ciência em que a exuberância e a beleza de cada objeto ou de cada instalação nos convoca primeiro para uma demorada contemplação, e depois para a compreensão do 
que se procura transmitir" (Ferrand, 2017, p. 2). Em diversas entrevistas e reportagens realizadas na altura da inauguração da exposição, como em jornais portugueses como O Publico! e Visão, são comuns a perspetiva de promover o encantamento com a ciência por meio do estético e a busca por comunicar factos científicos de modo único em Portugal.

O resultado final levou a seguinte declaração de Nuno Ferrand de Almeida:

"A Galeria da Biodiversidade materializa o sonho de construir um espaço único de promoção cultural, aberto a todas as pessoas, assente numa nova forma de comunicar ciência (...) Baseada num inovador conceito museográfico que se distingue pela aposta numa sempre presente dimensão estética associada a um delicado equilibro entre objetos reais e soluções tecnológicas de ponta, a sua exposição permanente surpreende-nos e emociona-nos, mostrando-nos de forma clara que, como produtos da evolução, todos nós somos também agentes dessa mesma evolução, modelando a natureza à nossa volta e, devendo, por isso mesmo, empenhar-nos, com acrescida responsabilidade, na preservação da biodiversidade"

(Declaração em 28 de Setembro de 2018, na altura da em que a Galeria da Biodiversidade recebeu 0 apoio de mecenato da Sonae. Fonte: https://www.sonae.pt/pt/media/press-releases/sonae-torna-se-mecenas-dagaleria-da-biodiversidade-da-universidade-do-porto/. Acesso em 18 de Junho de 2019. Grifo nosso).

Em termos de financiamento, o orçamento da construção da exposição e arranjo do edifício foi obtidos por meio de parcerias públicas (como a Agência Nacional para a Cultura Científica e Tecnológica e Universidade do Porto) e mecenato de algumas entidades privadas, como a Sonae.

A morte de Jorge Wagensberg em 3 de Março de 2018, pouco mais de um semestre após a abertura da Galeria da Biodiversidade, ainda é sentida pela equipa do MP, embora ainda mantenham contactos com a empresa por ele fundada (Total Museology) (FONSECA; GUSMÃO, comunicação pessoal, 27 de Fevereiro de 2019).

A ficha técnica da exposição presente na Galeria da Biodiversidade encontra-se no ANEXO 4. 


\subsubsection{Tratamento Museográfico}

"o sonho de Sophia concretizou-se e o esqueleto da magnífica baleia emerge no Átrio da Casa Andresen e é precisamente o mote que dá origem a toda narrativa da Galeria da biodiversidade"

(Ferrand, 2017, p. 1- 2).

Sem um percurso único e definido para a visitação, a exposição da Galeria da Biodiversidade, ocupa aproximadamente $1000 \mathrm{~m}^{2}$, distribuídos em dois andares. Contudo, o átrio da Casa de Andresen (Piso 0) e suas laterais (Piso 1) são claramente o centro e cerne argumentativo da exposição (Figura 52).

A partir da justaposição entre dois esqueletos e sons de batimentos cardíacos de mamíferos - uma baleia (possivelmente uma baleia-azul juvenil) e um musaranho-pigmeu, respetivamente o maior e o menor mamífero conhecidos (Figura 53), o visitante é convidado a contemplar e refletir sobre a biodiversidade, a partir de quatro princípios principais: ético, estético, comercial e científico (Figura 52 e 54).

A Casa Andresen possui três andares, sendo que a exposição ocupa o parte do primeiro andar (Piso 0) e o segundo andar todo (Piso 1). Passando pelo hall de entrada da instituição e bilheteria, um escada em forma espiral, inspirada na dupla-hélice do DNA, dá acesso ao Piso 1 da Galeria da Biodiversidade, onde se encontra grande parte da exposição (Figura 52, E2). 

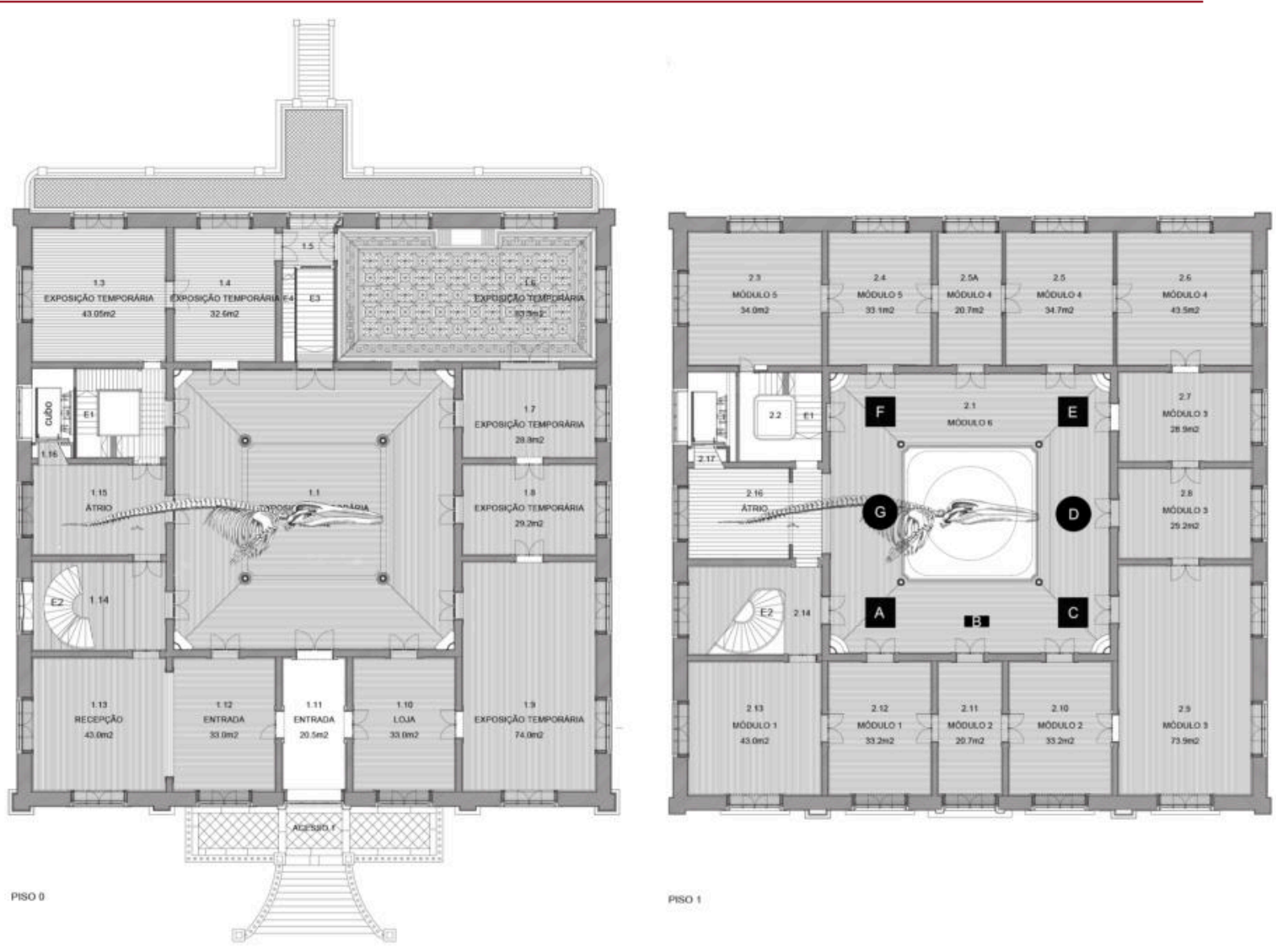

piso!

FIGURA 52: Planta baixa dos espaços expositivos nos Pisos 0 e 1 da Casa de Andresen. No Piso 0 (esquerda), "cubo" representa o módulo Diversidade Humana. No Piso 1 (direita), os quadrados representam os quatro princípios para preservação da biodiversidade: A - Científico; C - Estético; E - Ético; e F - Económico. O retângulo B representa o totem de apresentação do conceito de biodiversidade. O círculo G aponta o local onde é possível identificar a diversidade de cheiros. O círculo D é o recurso interativo Ovo Esférico | Ovo Ovoide. Em G recurso interativo "A que cheira?”. Os módulos numerados são respetivamente (em sentido anti-horário): Módulo 1: Gabinete de Curiosidades e Especiação; Módulo 2: Seleção Natural e Comer e Não Ser Comido; Módulo 3: Diversidade de Formas, Seleção Artificial, Analogia x Homologia; Módulo 4: Teatro dos Sentidos, Diversidade Genética x Incerteza e Diversidade de Cores; Módulo 5: Por Terra, Mar e Ar, Seleção Sexual. E2 refere-se a escada em forma de hélice. Fonte: Arquivo do Museu de História Natural e da Ciência da Universidade do Porto, modificado pela autora. 

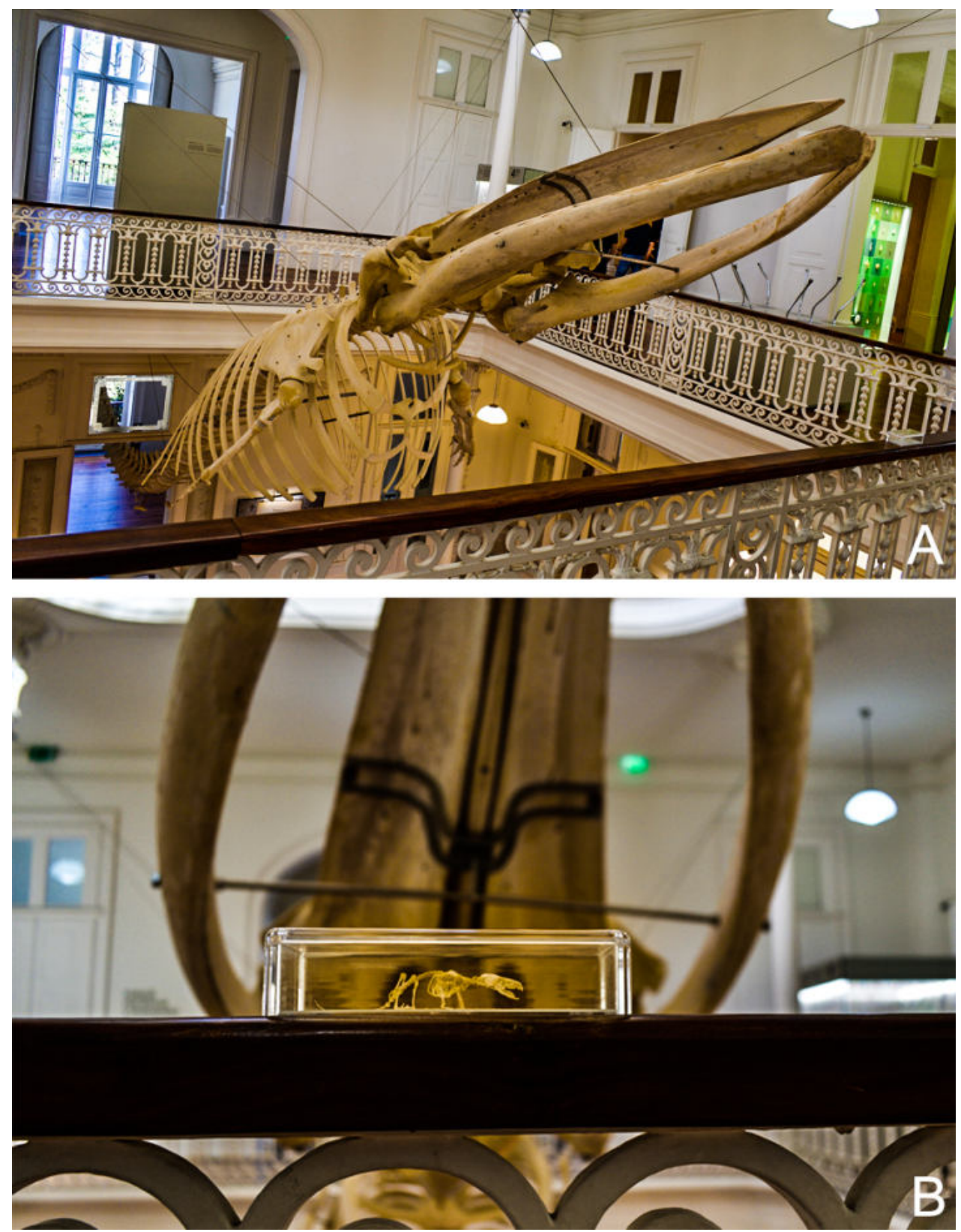

Figura 53: Os esqueletos da Galeria da Biodiversidade. Em A, esqueleto de uma baleia-juvenil, possivelmente uma baleia-azul (Balaenoptera musculus), conhecida pela equipa do MP como "o desejo de Sophia". Em B, esqueleto de musaranho-pigmeu, menor mamífero conhecido. Fotografia: Mariana Galera Soler, obtida em visita técnica em Fevereiro de 2019.

Ao chegar ao Piso 1, um totem pode ser considerado um convite a contemplar a exposição, em que pode ser lido o seguinte texto (Figura 52 retângulo B):

"Porquê preservar a biodiversidade? Nos seus primórdios o Universo foi um caldo homogéneo de partículas. Hoje, passados mais de 13,5 mil milhões de anos, pode afirmar-se que um objeto ou organismo só é idêntico a si próprio. Objetos e organismos podem ser agrupados pelo que partilham (dentro de uma classe) e 
diferenciados pelo que os distingue (variedade de classes). Os planetas chamam-se assim porque têm em comum muitas propriedades (grandes corpos esféricos que orbitam uma estrela...), mas distinguem-se com um nome próprio porque diferem noutros aspetos (composição da atmosfera, temperatura, tamanho, gravidade, etc.). A diversidade é uma medida da distribuição de certos objetos ou organismos pelas diferentes classes possíveis. É mínima se pertence a mesma classe (campo de trigo) e máxima se as diferentes classes estiverem representadas (Jardim Botânico). A biodiversidade é a variedade dos seres vivos, um termo criado pelo biólogo E.O. Wilson. A biodiversidade não está uniformemente distribuída no planeta e nem é constante no tempo. Tende a ser maior nos tópicos e menos nas regiões polares. Notase que os desertos possuem maior biodiversidade do eu aquilo que seria de se esperar. Na escala a evolução biológica, a biodiversidade registou grandes expansões e declínios drásticos, pelo que qualquer decréscimo da diversidade é sinal de alarme. Por que razão nos devemos empenhar em preservar uma espécie? Esta pergunta inspira os quatro princípios fundamentais da preservação da biodiversidade: estético, ético, económico e científico".(Grifo nosso)

Na sequência, os quatro princípios para a preservação da biodiversidade são museografados a partir de objetos e instalações icónicos:

A. Estético: ovos foram eleitos como objetos estéticos representantes da diversidade de vida dos organismos, numa montra em que a diversidade é representada de acordo com três propriedades: cor (escuro para o claro) x forma (esférica para elíptica) x tamanho (do maior para o menor) (Figura 54A);

B. Ético: a domesticação animal é apresentada por meio de uma vitrine com 400 modelos de raças de espécies de cachorros, a primeira domesticação humana, e todas associadas a lobo (Canis lupus), que também é o único modelo com cor e movimento (Figura 54C). Associada a esse vitrine, há um ecrã inserido em uma moldura ornamentada e que apresenta uma série de obras de arte (ou partes de obras) que ilustram cães (Figura 54B).

C. Comercial: novamente no tocante da domesticação, agora abordando plantas, são apresentadas sementes de plantas que foram introduzidas fora de seus países / 
continentes pelos portugueses: feijão, grão-de-bico, lentilhas, aveia, nozes, manga entre outras (Figura 54D);

D. Científico: uma amostra de cada um de todos os comprimidos existentes nas farmácias portuguesas (de acordo com a legenda), apontando a importância da preservação da biodiversidade como estoque de recursos naturais (bioprospecção) (Figura 54E);

Ainda no nas laterais do átrio no Piso 1, são promovidas outras experiências interativas e/ou sensoriais que também discutem a biodiversidade, como a diversidade de cheiros que permitem a identificação de alimentos e vegetais (a partir da vaporização de aromas artificiais) que, posteriormente, são apresentados para que o visitante: canela, pinho, lavanda, cravinho, laranja, chocolate, menta e maçã (Figura 52G).
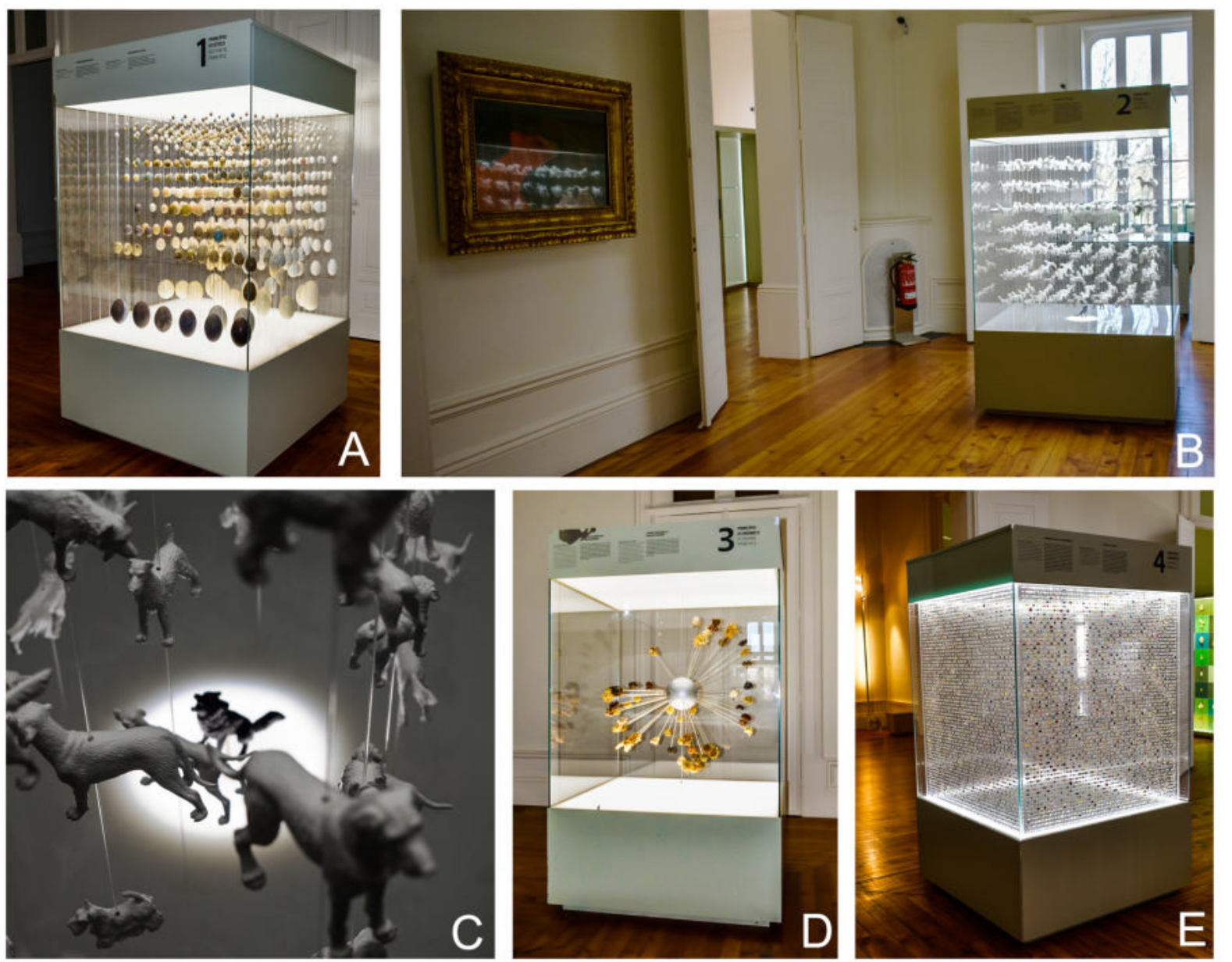

Figura 54: Os quatro princípios para preservação da biodiversidade. Em A, princípio estético. Em B, princípio ético em módulo composto por montra e ecrã. Em C, detalhe das réplicas de cães em branco e lobo em preto, iluminado e único com movimento, na vitrine Princípio Ético. Em D, princípio económico. Em E, princípio científico. Fotografia: Mariana Galera Soler, obtida em visita técnica em Fevereiro de 2019. 
Tais recursos museográficos preenchem o mezanino ao redor do átrio central da Casa Andresen (Piso 1). Há ainda salas e quartos que estão nesse andar e são ocupados por módulos temáticos relacionadas a evolução dos seres vivos na Terra e os primeiros objetos de história natural trazidos por naturalistas e colonizadores portugueses.

Considerando que toda a exposição segue os preceitos da "museologia total", há o suporte do objeto e grande apelo estético e multimédia para representação de um conceito cientifico, que primeiro é contemplado (apelo estético para o maravilhamento) e, posteriormente, pode ser compreendido (por meio da interação ou leitura de legendas). Ilustra-se com o conceitos de diversidade, representado pela ampla variedade de cores e formas de 64 tipos folhas recolhidas no Jardim Botânico do Porto (Figura 55A); pela diversidade genética, apresentada por vitrine com aproximadamente 3 mil caracóis da mesma espécie (Cepaea nemoralis), mas que possuem todos diferenças em seus padrões de cores e listras (Figura 55B). 

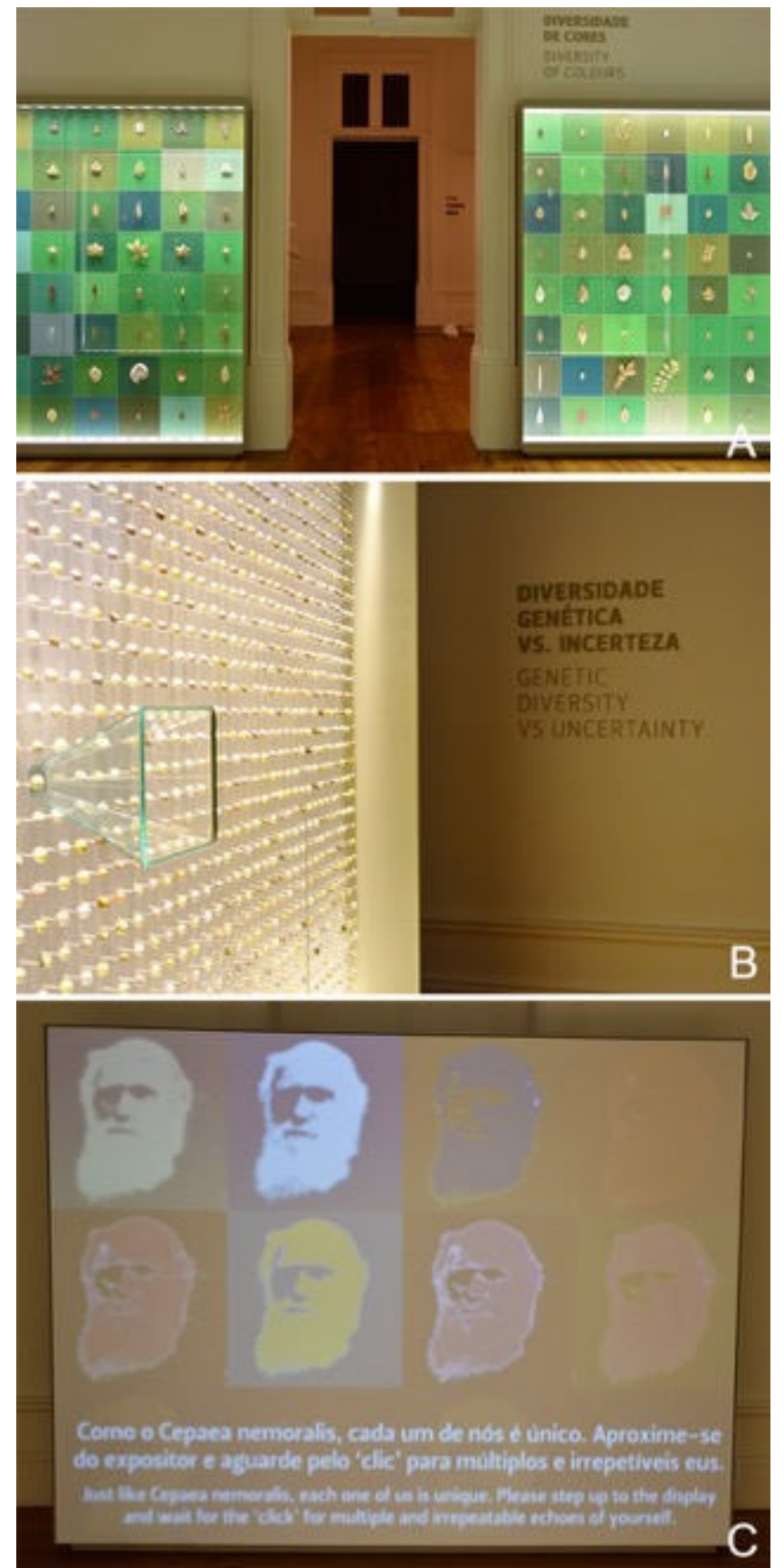

Figura 55: Módulos de grande apelo estético, baseados na conceção da "museologia total". Em A, Módulo Diversidade de Cores. Em B, Módulo Diversidade Genética versus Incerteza, com painel com mais de 3 mil moluscos. Em C, no lado oposto do mesmo módulo, o visitante pode posicionar-se e tirar uma fotografia, que aparecerá em vários formatos, em uma referência a obra de Andy Warhol. Fotografia: Mariana Galera Soler, obtida em visita técnica em Fevereiro de 2019.

As formas na natureza e suas respetivas funções são expostas sob a perspetiva do escocês D’Arcy Thompson, biólogo e matemático cuja pesquisa abordou as formas geométricas mais comuns na natureza e das publicações do próprio Jorge Wagensberg (Wagensberg, 2008, 2014a), em 
que o físico e museólogo propõe um esquema conceitual que relaciona as formas geométricas básicas da natureza (esfera, espiral, hexágono, fractal, catenária, hélice, ponta e onda) com sua função (Figura 56):

"In our conceptual scheme, the concept function is a more intelligible and universal concept than the concept mechanism. In other words, a great variety of different mechanisms perform the same function: to make it possible to continue to belong to the reality we wish to understand" (Wagensberg, 2008, p. 328)
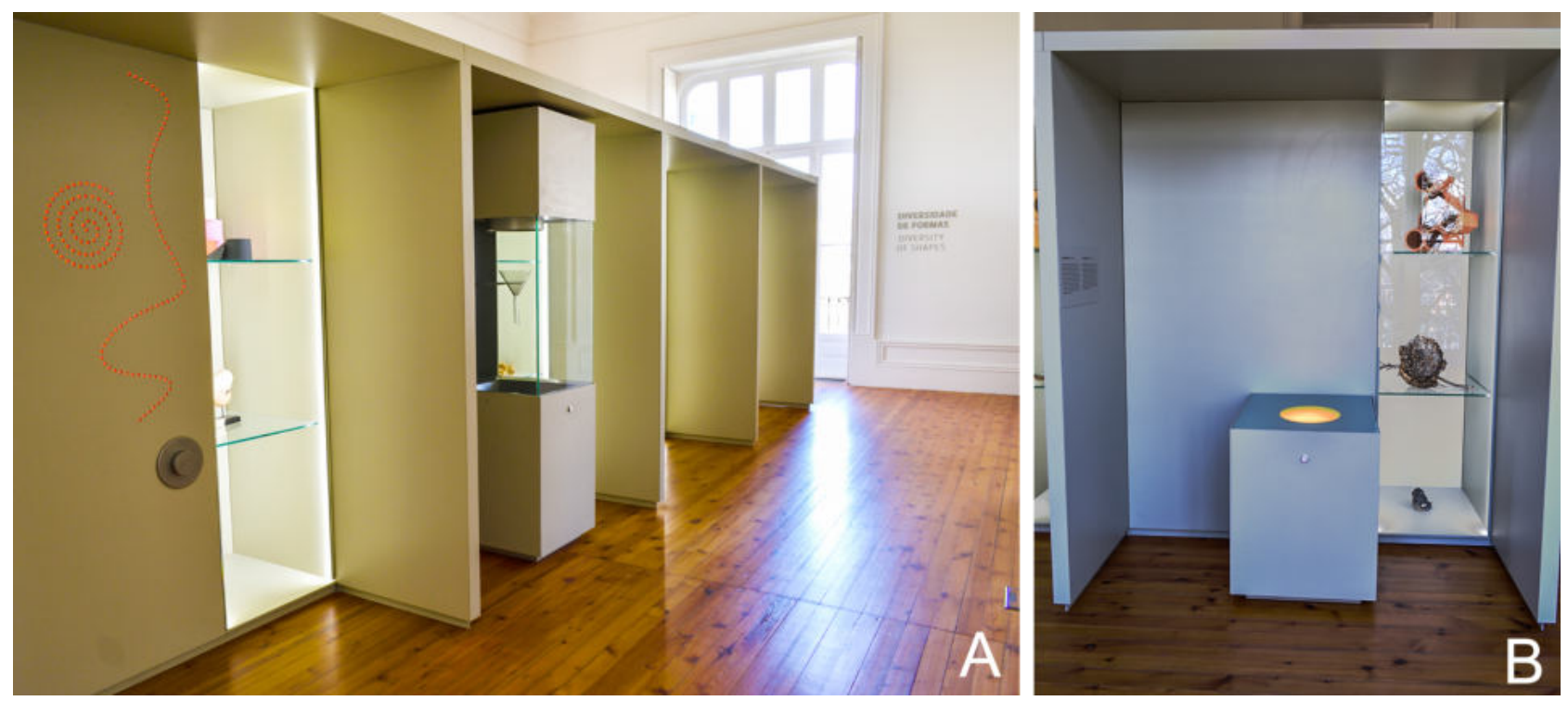

Figura 56: Módulos Diversidade de Formas. Em A. Vista Geral de uma das laterais do cubo museográfico desenvolvido para esse módulo (a manutenção é realizada por cima e internamente, com acesso por escadas). Em B, detalhe de como é apresentada a forma "hexágono", com pequeno texto à esquerda, recurso interativo ao meio e objetos que tem essa forma do lado direito. Fotografia: Mariana Galera Soler, obtida em visita técnica em Fevereiro de 2019.

A evolução das formas também é explorada no módulo "Por terra, mar e ar", em que os membros dos tetrápodes (animais com coluna vertebral e apêndices distintos ligados a cintura escapular e pélvica) são exibidos de acordo com a função adquirida evolutivamente: nadar, caminhar ou voar. Esse módulo é constituído por modelos de animais organizados a partir de suas estratégias de locomoção (nadar, correr, voar) e um ecrã onde são apresentados os conteúdos associados à evolução da forma desses animais, utilizando animações com as mesmas imagens dos modelos em exposição(Figura 57). 

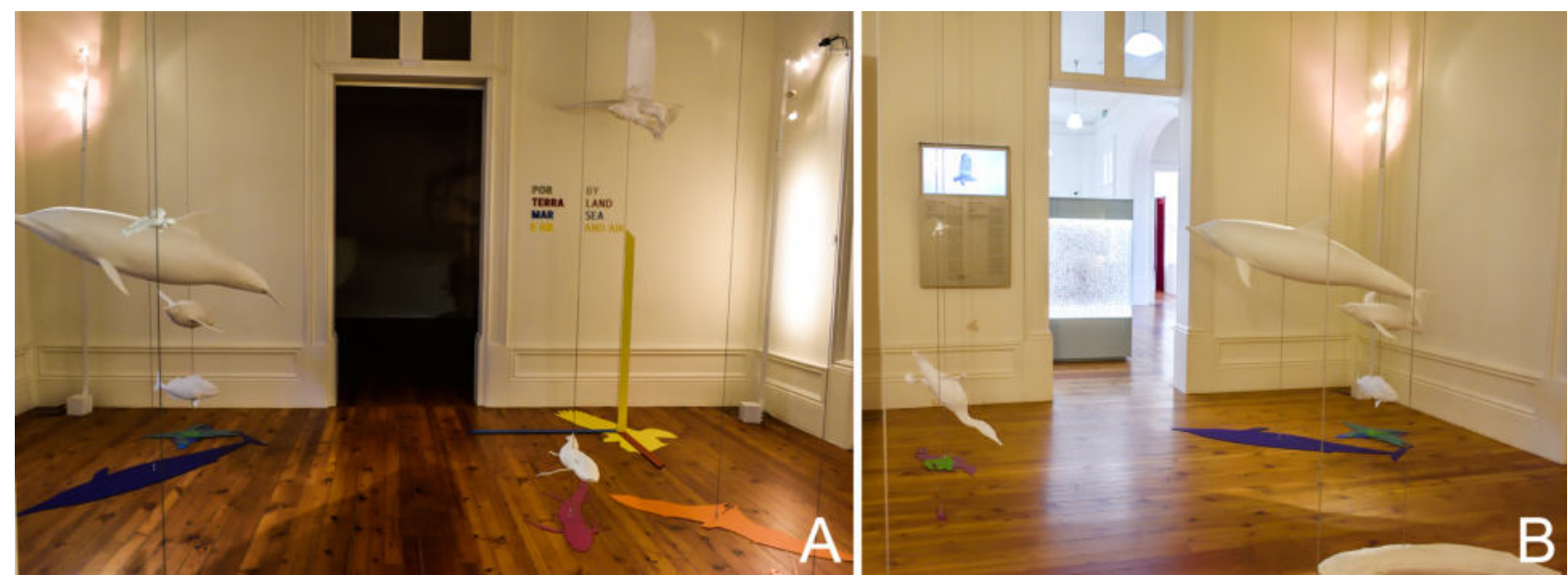

Figura 57: Módulos Por Terra, Mar e Ar. Duas perspetivas diferentes. Fotografia: Mariana Galera Soler, obtida em visita técnica em Fevereiro de 2019.

Um único módulo da Galeria da Biodiversidade possui organismos vivos: "Comer e não ser comido". Nesse módulo estão presentes três terrários com: insetos bicho-pau, que ilustram a camuflagem ("a arte de passar despercebido, dissimulando-se no meio ambiente); salamandras que mostram aposematismo ("a arte de evidenciar características terríveis para dissuadir o predador"); e uma serpente não-venenosa, mas que possui cores que sugerem perigo, o mimetismo (" $a$ arte de parecer o que não se é") ${ }^{92}$ (Figura 58).

Os processos evolutivos de seleção foram explorados em três módulo: um módulo que apresenta a seleção sexual, por meio de espécimes (pavão e cervídeo) animais taxidermizados de espécies que possuem dimorfismo sexual (Figura 59A); a seleção artificial, numa vitrine apresenta centenas de variedades de milho (diversidade natural, diversidade domesticada, diversidade melhorada - hibridização - e diversidade transgénica) (Figura 59B); e a seleção natural em que é reproduzido "em tempo museográfico" o exemplo clássico (comumente encontrado em livros didáticos) das borboletas (Biston betularia) de Manchester e a Revolução Industrial (Figura 59C).

\footnotetext{
92 Os trechos entre aspas foram extraídos dos textos da exposição Galeria da Biodiversidade, módulo "Comer e Não Ser Comido”.
} 


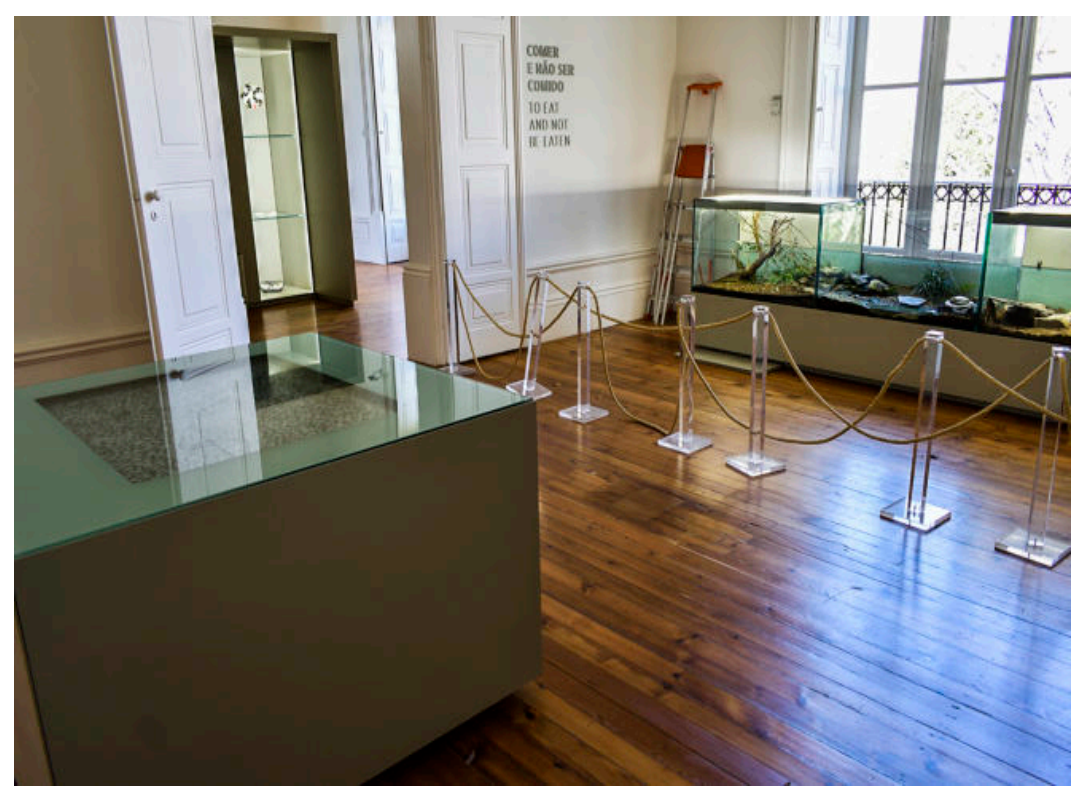

Figura 58: Módulos Comer e Não ser Comida. Esse módulo é composto por três terrários e um recurso interativo mecânico: mesa repleta de pontos negros, em que quando o visitante move uma alavanca destacam-se as silhuetas de três roedores, mas que só são percetíveis quando estão em movimento. Os terrários com animais vivos desse módulo estiveram em manutenção durante todos os dias da visita técnica (vazamento de água). Fotografia: Mariana Galera Soler, obtida em visita técnica em Fevereiro de 2019.
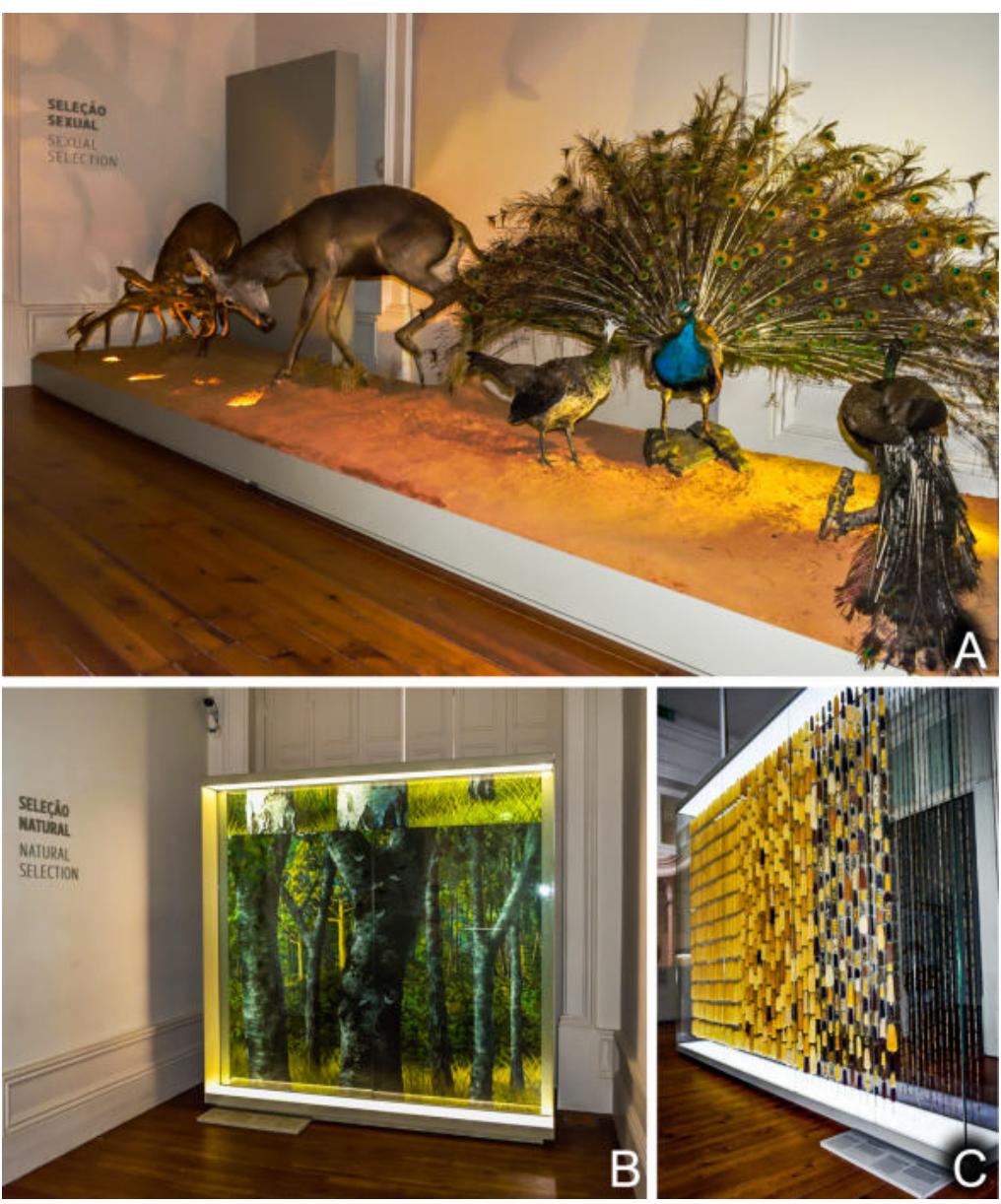

Figura 59: Módulos relacionados às teorias seletivas. Em A, espécimes naturalizados ilustram a Seleção Sexual. Em B, recurso museográfico que representa a seleção natural, reproduzindo o exemplo das mariposas (Biston betularia) de Manchester e como as diferenças em termos de camuflagem em troncos naturais ou cobertos por fuligens, o que levou a uma mudança na frequência da característica melânica na população. Fotografia: Mariana Galera Soler, obtida em visita técnica em Fevereiro de 2019. Em C, uma grande montra mostra a diversidade de variedades de milhos naturais e produzidos por hibridização ou transgénica. 
Dois outros conceitos importantes para a compreensão da árvore evolutiva são: analogia e homologia. Tais conceitos são exibidos em paralelo em um mesmo módulo, com uma vitrine cuja iluminação focal assinala a diversidade de posições dos olhos em modelos de diferentes mamíferos, associando a estratégias de caça a predadores e proteção (Figura 60A), e outra vitrine também com modelos e iluminação destacada, em que são comparadas as formas similares (convergentes) de animais que não possuem histórias evolutivas comuns (analogia) (Figura 60B-C).
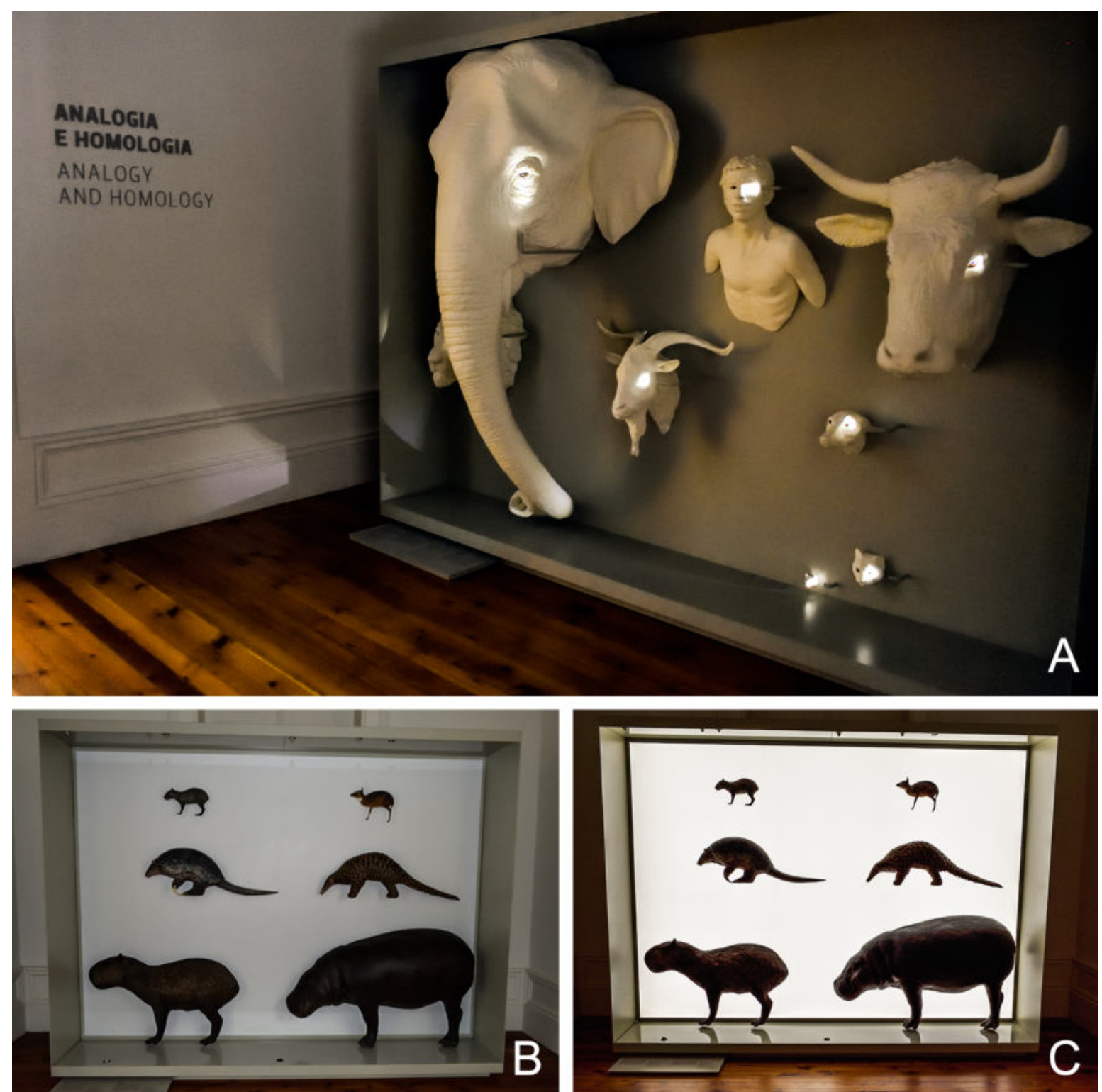

Figura 60: Módulos Analogia e Homologia. Em A, modelos de mamíferos com iluminação focal apontando o posicionamento diferente dos olhos, de acordo com as estratégias de caça e proteção das espécies (homologia). Em $\mathrm{B}$ e $\mathrm{C}$ modelos de mamíferos sul-americanos e africanos que apresentam convergência em suas formas, mesmo sem origem evolutiva direta (analogia). Fotografia: Mariana Galera Soler, obtida em visita técnica em Fevereiro de 2019. 
O processo de especiação é exibido em um módulo único, cuja personagem central é um manequim realista de Charles Darwin com dois coelhos nas mãos, feito pela artista francesa especialista na reconstituição de hominídeos Élisabeth Daynès.

Os visitantes podem sentar-se ao lado do manequim para fotografar e assistir alguns vídeos sobre fenómenos invisíveis a olho nu, assim como os processos evolutivos. A partir da diferenciação dos museus de outros meios de transmissão de conhecimento ("os museus apresentam a realidade, todos os outros meios a representam", novamente em referência a museologia total de Jorge Wagensberg), cinco ecrãs mostram imagens que só são possíveis de ver com a utilização de equipamentos tecnológicos, como raio-x, microscópio, imagens tomadas em câmara lenta, drones ou telescópios (Figura 61A).

Na parede lateral desse módulo há a montra "O coelho de Porto Santo e o sonho de Darwin, onde estão dispostas 34 réplicas que demonstram a variação fenotípica entre algumas espécies de Lagomorfos - lebres e coelhos (18 espécies de Lepus spp., 15 espécies de Syvilalagus spp. e 11 Oryctolagus cuniculus, destacando a homogeneidade dos dois primeiros gêneros, em comparação com a última espécie). Igualmente é relatada a história de como os coelhos tornaram-se pragas na Ilha de Porto Santo (Madeira), após terem sido soltos por navegadores portugueses no século XVI e sua importância para os estudos evolutivos:

"Charles Darwin teve a oportunidade de estudar dois exemplares de coelhos de Porto Santo que foram enviados para o jardim zoológico de Londres. Darwin ficou surpreendido ao constatar que eram bastante mais pequenos que os coelhos domésticos e com uma pequena madeixa. Tinham hábitos exclusivamente noturnos, eram muito mais ativos e indomáveis e, sobretudo, recusavam-se a acasalar com outros coelhos. Estando isolados há séculos, ter-se-ia o coelho insular separado definitivamente do coelho continental? Era o que pensava Ernst Haeckel, célebre biólogo e defensor de Darwin, que, em 1868, em honra de outro admirador de Darwin, descreveu o coelho insular como uma espécie nova: Lepus huxleyi. Os estudos de genética atuais confirmam o interessante deste caso como exemplo de adaptação de uma espécie a uma mudança de ambiente, mas também revelam que o processo de 
Biodiversidade Musealizada: Formas que Comunicam

especiação, embora se encontre em curso, ainda não foi concluído. Talvez dentro de alguns milénios..."93 (Figura 61B).
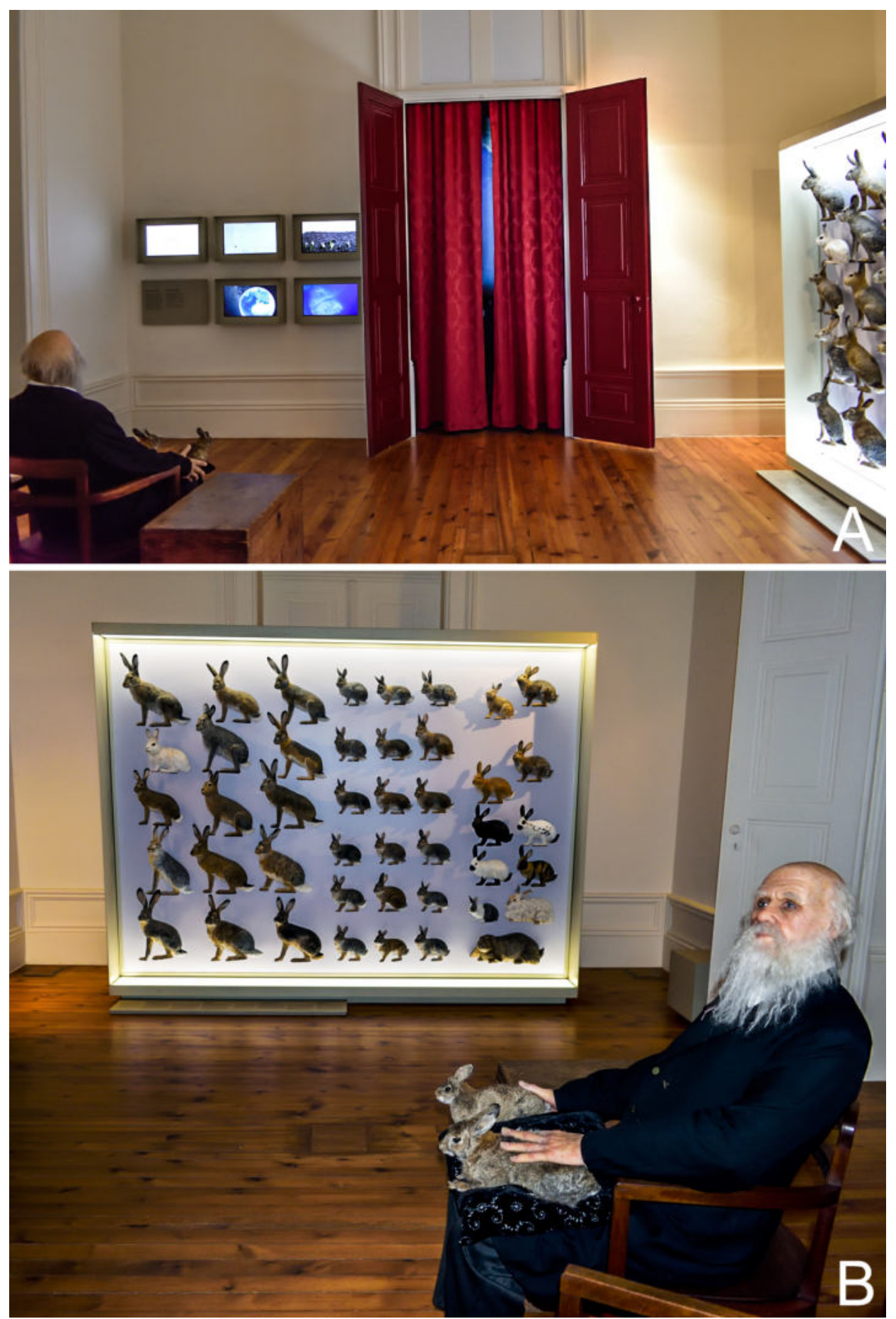

Figura 61: Módulos Especiação, duas perspetivas do módulo. Em A, visão geral com ecrãs. Em B, destaque para o realismo do manequim de Charles Darwin, realizado pela artista francesa Élisabeth Daynès. Fotografia: Mariana Galera Soler, obtida em visita técnica em Fevereiro de 2019.

93 Os trechos entre aspas foram extraídos dos textos da exposição Galeria da Biodiversidade, módulo Especiação. 
Encerra esse piso da exposição um módulo que remonta um gabinete de curiosidades, cuja iluminação está centrada em globo terrestre móvel e interativo no centro da sala. Esse módulo possui as paredes pintadas de vermelho escuro (mesma cor da fachada da instituição) e representa as grandes viagens que foram fundamentais para os avanços científicos, com destaque para as viagens do naturalista Alexandre Rodrigues Ferreira (1756 - 1815) e os primeiros objetos de história natural trazidos naturalistas e colonizadores portugueses (Figura 62A). Nas paredes há quadros com imagens de animais, plantas e paisagens, mas também imagens de cunho etnográfico como tribos indígenas americanas ou representações de populações ocidentais. Há ainda mapas de viagens realizadas pelos portugueses e uma reprodução do famoso rinoceronte de Albrecht Dürer (Figura 62B).

Entre os quadros existem dois armários com portas de vidro e prateleiras que vão do chão até o teto da sala, onde são guardados objetos de história e instrumentos científicos (Figura 62C). Contudo, toda essa riqueza museográfica está obscurecida, pois a sala serve apenas de cenário para um globo terrestre iluminado que gira no centro do espaço.

Nesse globo, a partir das definições realizadas pelo visitante em um terminal multimédia, são projetadas diversas rotas dos navegadores portugueses (Bartolomeu Dias, Vasco da Gama e Fernão Magalhães), migração e domesticação de organismos (incluindo espécie humana) e movimentos da deriva continental, mostrando que a dinâmica e ocupação espacial são condições para a vida "tudo se move" (Figura 62D).

De acordo com informações obtidas nas entrevistas, esse módulo será reestruturado, com intuito de iluminar os objetos e dar mais destaque também as paredes da sala94 (FONSECA; GUSMÃO, comunicação pessoal, 27 de Fevereiro de 2019).

94 O módulo "Teatro dos Sentidos" encontra-se em manutenção durante o período da visita e não pode ser analisado. 

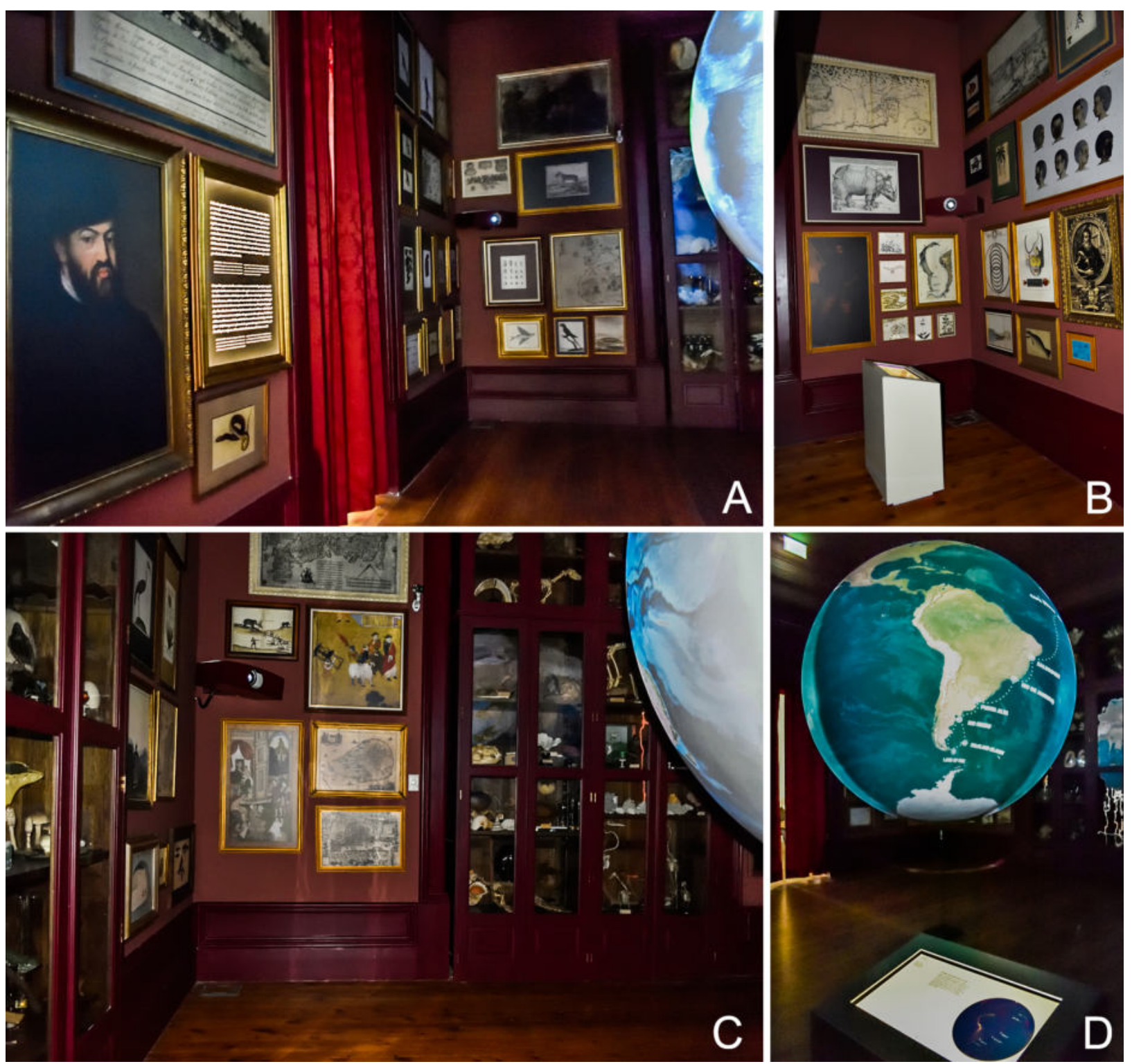

Figura 62: Módulos Gabinete de Curiosidades, diversas perspetivas do módulo. As imagens foram tratadas digitalmente uma vez que a iluminação do local não permitia melhor resolução. Fotografia e Tratamento das Imagens: Mariana Galera Soler.

Descendo a escada em espiral ou uma outra escada mais convencional (parte da estrutura da edificação), tem-se acesso aos dois últimos módulos da exposição, que abordam especificamente a diversidade humana e cultural. Em Diversidade Humana há um cubo composto por 150 fotografias de pessoas, demonstrando que pequenas variações de cor da pele, formato dos olhos e tipo de cabelo possibilitam grande diversidade de biotipos. Essas imagens fazem parte de um catálogo produzido pela fotógrafa brasileira Angélica Dass, no projeto Humanae: "Humanae é um 
inventário cromático, um projeto que reflete sobre as cores além das fronteiras de nossos códigos, usando como referência o sistema de cores PANTONE ${ }^{\circledR} 95$ (Figura 63A).

No lado oposto dessas imagens, há um recurso interativo que captura imagens faciais do visitante e, a partir da identificação do género e da etnia (estão disponíveis apenas "europeu", "africano" e "asiático") desse visitante, faz uma simulação de como seria a face do mesmo nas outras etnias disponíveis. É oferecida a opção de envio da imagem gratuitamente para o email do visitante (Figura 63B-C).
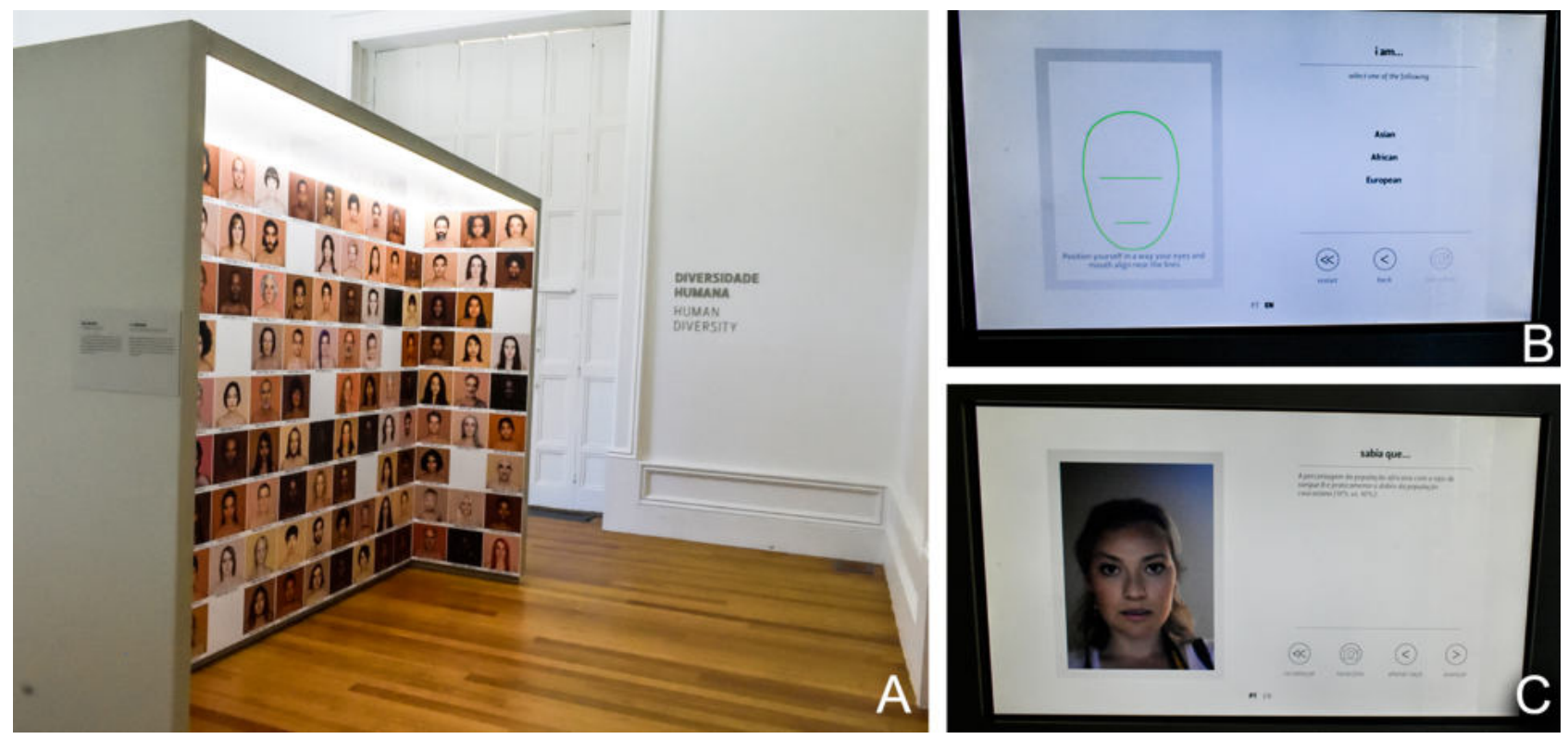

Figura 63: Módulos Diversidade Humana. Em A, cubo museográfico com fotografias de humanos compondo uma escala Pantone ${ }^{\circledR}$. Em B e C imagens das telas do recurso interativo. Fotografia: Mariana Galera Soler, obtida em visita técnica em Fevereiro de 2019.

Por fim, Diversidade da Língua é um módulo com evidentes referências a Sophia de Mello Breyner. Construído como um espaço de leitura, remetendo a um possível espaço onde a poetisa escrevia na casa dos avós, com a iluminaçãoindireta facultada por uma janela coberta por cortinados. Sob uma secretária encontra-se a disposição para a leitura a coletânea "Obra Poética", da mesma autora. Num terminal multimédia está disponível em língua portuguesa e inglesa cinco dos principais poemas de Sophia (O palácio, Quando, Reza da Manhã de Maio, Inscrição, A luz oblíqua), que podem ser lidos e/ou são ouvidas suas narrações.

\footnotetext{
95 Mais imagens e informações estão disponíveis em: https://humanae.tumblr.com. Acesso em 22 de Junho de 2019.
} 
Compõem ainda esse módulo um conjunto de 62 fotos em porta-retratos, que preenchem as outras duas paredes da sala, com imagens de portugueses pelo mundo, em que a ideia é mostrar portugueses um exemplo da dispersão e do encontro de culturas pelo mundo. De acordo com a equipa entrevistada, optou-se por abordar a literatura e a língua portuguesa como forma de diversidade cultural e esse módulo ainda encontra-se em desenvolvimento (FONSECA; GUSMÃO, comunicação pessoal, 27 de Fevereiro de 2019)(Figura 64).

É ainda nesse Piso 0 em que está o grande átrio que Sophia descreveu e onde imaginou a baleia, que atualmente todos os visitantes podem contemplar. Também se localiza a entrada, a loja, todo o tipo de informações sobre a agenda da Galeria, do futuro do Museu e, de uma forma geral, um guia cultural da Universidade do Porto e da cidade (Ferrand, 2017)(Figura 65).

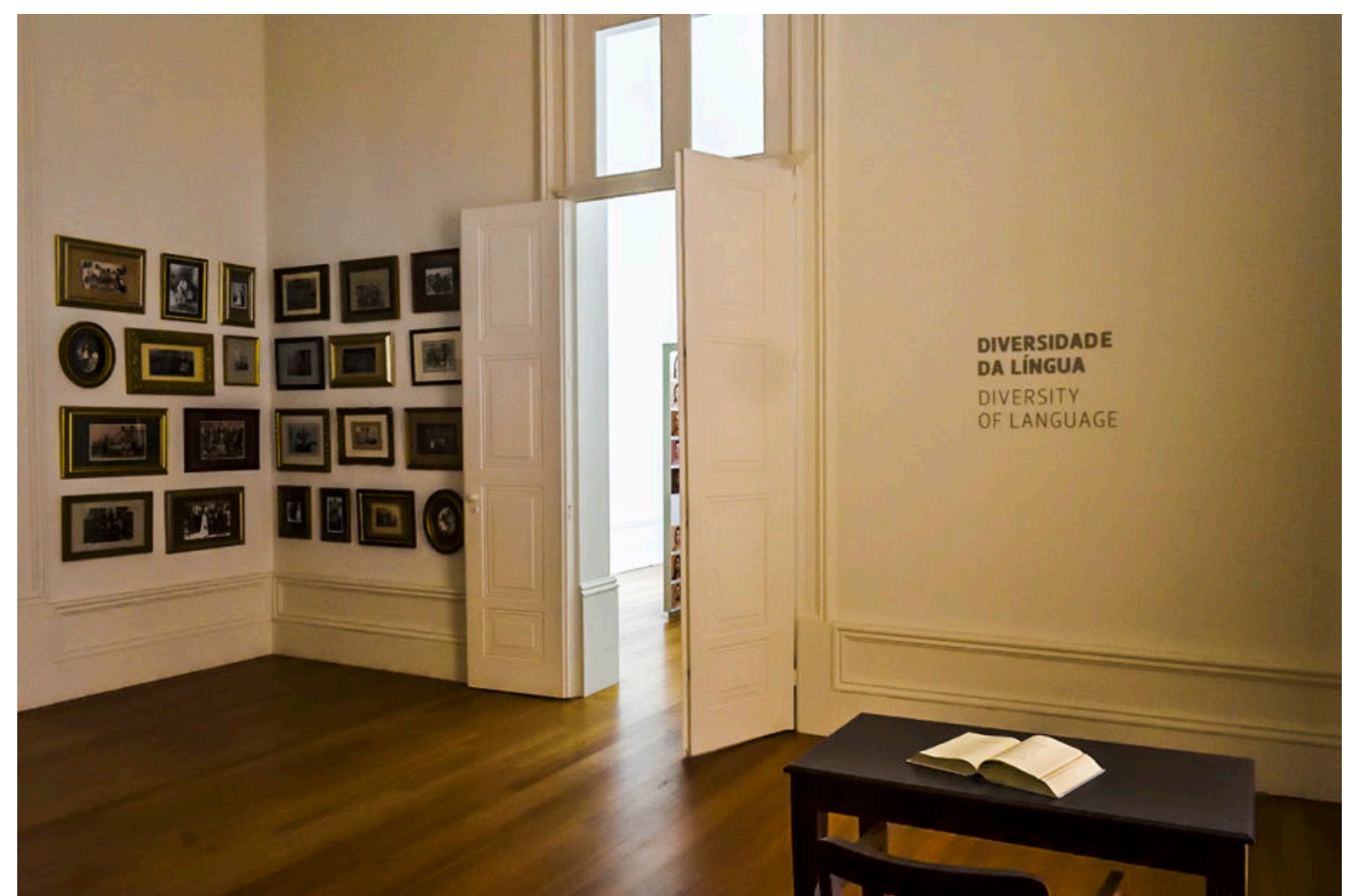

Figura 64: Módulos Diversidade da Língua. Fotografia: Mariana Galera Soler, obtida em visita técnica em Fevereiro de 2019. 


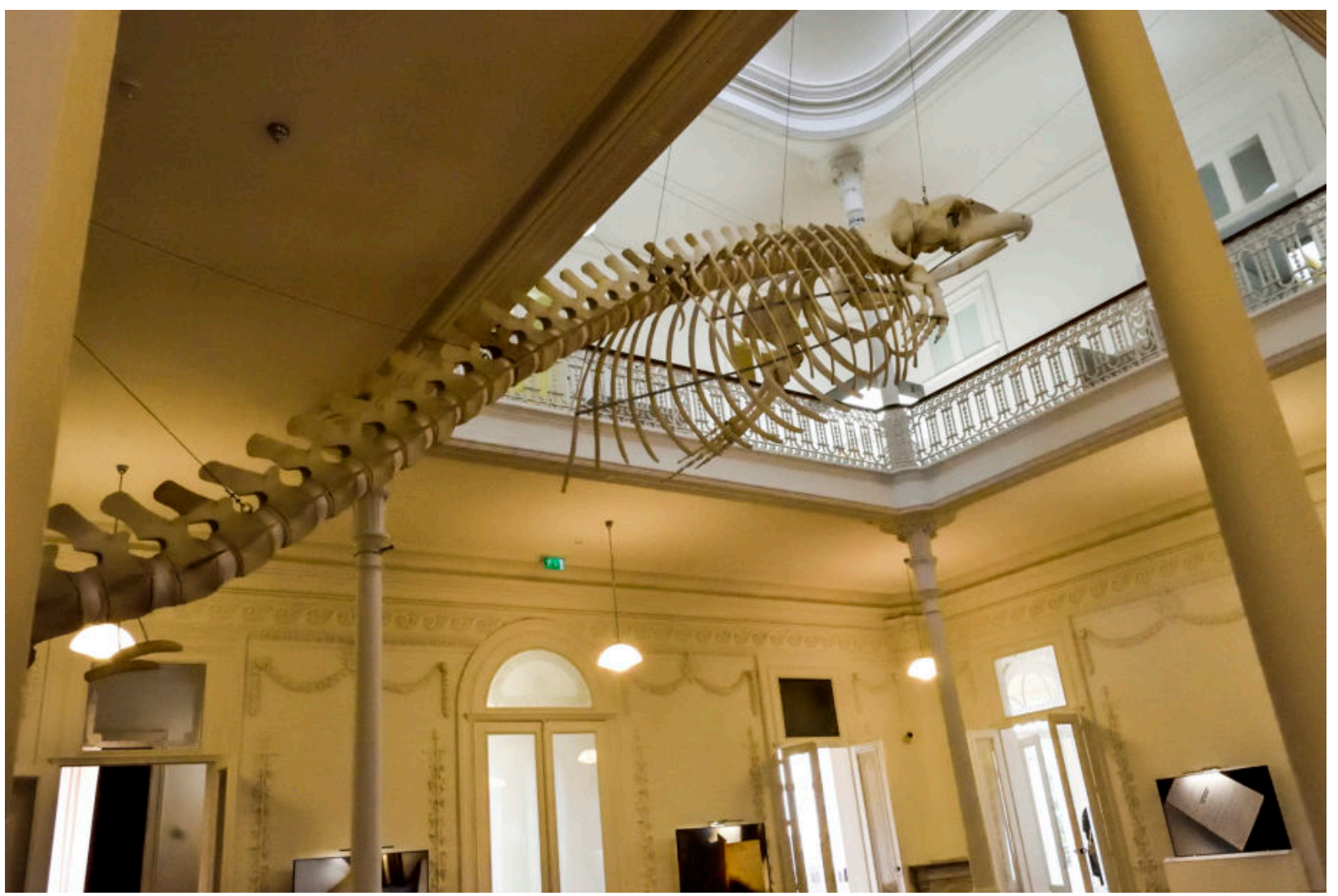

Figura 65: Vista Geral do átrio com o esqueleto de cetáceo. Fotografia: Mariana Galera Soler, obtida em visita técnica em Fevereiro de 2019.

\subsubsection{Museu de Zoologia da Universidade de São Paulo-Biodiversidade: conhecer para preservar}

\subsubsection{Contextualização}

"Durante o esforço coletivo de reestruturação da exposição de longa-duração do MZUSP aproveitamos para renovar o Programa de Comunicação Museológica da instituição alinhavando aos valores, conceitos e estratégias que seriam priorizados em nossas atividades de extroversão" (Landim, 2018, p. 101).

"Como instituição universitária, nosso Programa de Comunicação Museológica está fortemente vinculado à pesquisa em torno de nosso acervo e esta foi a tônica da consulta feita à comunidade durante a elaboração do projeto em suas diversas fases" (Landim, 2018, p. 101).

Os dois trechos acima destacados são da curadora e investigadora da Universidade de São Paulo, Maria Isabel Landim, e destacam uma característica essencial no processo de conceção da 
exposição da exposição "Biodiversidade: conhecer para preservar": o trabalho coletivo com membros dos diversos grupos de estudantes e profissionais do MZUSP.

Em 13 de Agosto de 2018, foi realizada uma entrevista com a referida curadora, quando pudemos recolher os dados referentes ao processo de conceção da exposição, bastante particular e não comparável com as demais instituições em análise.

O primeiro ponto destacado por Landim foi esse processo teve início em 2011 e não esteve diretamente associado ao Plano de Comunicação Museológica da instituição. Naquele ano ocorreu o fechamento do MZUSP, uma vez que a instituição havia sido contemplada com um edital para infraestrutura ${ }^{96}$, quando foi realizada uma grande reforma no setor elétrico, informática e pequenos ajustes prediais no MZUSP (Landim \& Elias, 2012). Para isso, laboratórios de investigação e parte de coleções que estavam nos "bastidores" precisaram ocupar os espaços das galerias de exposição. Então coube a equipa da Divisão de Difusão Cultural (DDC), recém contratada e com pouca experiência institucional e como equipa na época, realizar o inventário de todo o acervo que estava em exposição.

Em 2012, o MZUSP foi convidado a montar uma exposição na Estação Ciência (unidade da Universidade de São Paulo, extinta em 2015). Esse foi o primeiro "ensaio" tanto em termos de trabalhos operacionais da equipa com o acervo destinado à exposição da instituição, como também foi um exercício de construção de uma narrativa mais ampla no que diz respeito a biodiversidade ${ }^{97}$. Com o título "Biodiversidade: fique de olho!", a exposição temporária teve como conceito:

"Partindo da mais remota origem da vida na Terra até o surgimento e estado atual dos biomas brasileiros, o recorte curatorial do projeto 'Biodiversidade: Fique de olho!' foi elaborado de forma a proporcionar ao público uma reflexão sobre os desafios que enfrentamos diante da crise atual da biodiversidade"

(Landim \& Elias, 2012, p. 338).

\footnotetext{
${ }^{96}$ A verba para esses editais de infraestrutura foram liberadas pelo governo do Estado de São Paulo (Brasil) após o incêndio que destruiu mais de 90\% da coleção centenária de herpetofauna e invertebrados do Instituto Butantan.

97 Até 2015, ano que foi aberta a exposição "Biodiversidade: conhecer para preservar" a equipa também esteve envolvida na montagem e itinerância de outras exposições, o que garantiu experiência e coesão entre os profissionais.
} 
Ainda em 2012-2013, a Universidade de São Paulo abriu editais para cultura e extensão universitária, pela Pró-Reitoria de Cultura e Extensão. O MZUSP concorreu com alguns projetos diferentes a esses editais, todos focados em aspetos da abertura da nova exposição de longaduração. O financiamento inicialmente obtido por esses editais havia sido designado para a contratação de uma empresa especializada para realizar a conceção da exposição, em articulação com os diferentes setores do MZUSP.

No entanto, até 2014 as galerias mantiveram-se ocupadas pelos laboratórios de pesquisa, enquanto as reformas previstas atrasaram e novas demandas surgiram, como uma urgente reforma no telhado. Além disso, a crise financeira da Universidade levou a cortes no repasse dos prémios dos editais.

Com corte de cerca de 60\% no orçamento total previsto para o projeto, a equipa da DDC teve de assumir para si a responsabilidade de coordenar o processo de conceção da exposição, mantendo a verba restante para a contratação de uma única empresa especializada em desenvolvimento de exposições (via licitação pública) para construção da museografia (design, iluminação, mobiliário entre outros), uma expertise que não existia (e ainda não existe) nos quadros profissionais da instituição.

Embasada em sua experiência profissional e visitas a outras instituições museológicas do mundo, Landim relata em sua entrevista que seguiu a premissa que existiam dois grupos de investigadores nos museus: um grupo de investigadores que se ressente do facto de que as exposições se profissionalizaram e perderam o contacto direto com a investigação e um segundo grupo que considera isso algo positivo, pois não considera da sua alçada conceber exposições.

Para "orquestrar o processo" de criação do conceito da nova exposição Landim contou com apoio do técnico nível superior da DDC, Felipe Alves Elias. Também foi consultada Mirian David Marques, que era a diretora da DDC na altura que foi desenvolvida a última exposição de longaduração do MZUSP (início dos anos 2000). Tal investigadora ministrou uma palestra sobre os desafios e dificuldades enfrentados em 2002, para a atual equipa da DDC. Nessa palestra, Marques relatou a dificuldade de conseguir a participação dos outros investigadores do MZUSP no processo de conceção e desenvolvimento da exposição, o que gerou muitas críticas a exposição "Pesquisa em 
Biologia: a biodiversidade sob o olhar do zoólogo98" e atritos pessoais que se seguiram ao longo da carreira.

Então, Landim e Elias optaram por partir de uma metodologia de sucesso, que havia sido aplicada pela empresa EXPOMUS em 2009, no processo de conceção da exposição de comemoração dos 75 anos da Universidade de São Paulo, que envolveu todas as unidades da instituição. Eles desenvolveram um calendário com número definido de reuniões (dez) e cada uma delas com tempo de duração determinado (1 hora). Nessas reuniões participavam o Comitê Curatorial, grupo constituído por representantes dos diversos laboratórios de pesquisa, das áreas técnicas (operacional e administrativo) e dos estudantes. Antes das reuniões, eram enviados a todos os membros do MZUSP uma série de perguntas sobre o acervo, investigação e recursos disponíveis na instituição. As respostas deveriam ser encaminhadas ao respetivo representante do grupo. Por conseguinte, nas reuniões eram apresentadas as "tarefas para casa" (respostas das questões compiladas por área), para que fossem consolidadas em decisões coletivas.

Um outro tema abordado nessas reuniões foi o público-alvo. Logo nos primeiros encontros, a educadora da instituição Marcia Fernandes Lourenço, apresentou os relatórios dos visitantes do MZUSP dos últimos anos, bem como quais eram os Parâmetros Curriculares Nacionais +, que são orientações educacionais complementares aos Parâmetros Curriculares Nacionais para o Ensino Médio brasileiro (equivalente ao Ensino Secundário em Portugal), definidos pelo Ministério da Educação. Embora atualmente o público-escolar corresponda a 15\% dos visitantes, ele foi considerado um público prioritário. Os turistas também são considerados como tal, o que justifica o esforço de ter toda a exposição bilingue, seja nas legendas ou por meio de etiquetas de QRCodes espalhados pelo espaço expositivo.

Nas reuniões que se seguiram, de acordo com relatado por Landim, um dos desafios era manter o foco e objetividade e, de modo mais cordial possível, encaminhar as conversas "para que o MZUSP encontrasse sua voz a partir de seu acervo e limitado ao orçamento disponível" " (Landim, comunicação pessoal, 13 de Agosto de 2018) e não de ausências (espécimes raros que deveriam ser replicados, por exemplo) ou ser um livro de Zoologia em três dimensões: "ou então nós iríamos virar

\footnotetext{
98 Informações sobre essa exposição estão disponíveis em: http://unw.mz.usp.br/?page_id=1478. Acesso em 12 de Julho de 2019.
} 
um pastiche de museu, pois não encontramos a nossa voz, nós vamos reproduzir" (Landim, comunicação pessoal, 13 de Agosto de 2018).

A partir desse processo curatorial, duas das principais temáticas que surgiram foram: a importância de abordar o tema evolução e a apresentação do ser humano em contexto. De acordo com dados disponibilizados no Memorial Descritivo da exposição, o conceito gerador foi "dinâmica", e está associado tanto ao funcionamento da instituição (como constantemente atualizada e atuante nos mais diferentes pontos da cadeia curatorial, referência em pesquisa e que reabriu ao público com a inauguração desta exposição), como a produção do conhecimento científico (conhecemos diversos níveis de biodiversidade ao longo do tempo, por meio de diferentes abordagens e tecnologias) e ainda em perspetivas teóricas, como a biodiversidade observada pela por sua distribuição no tempo e espaço, resultado de processos evolutivos, alguns já conhecidos e descritos desde o século XIX e também da relações estabelecidas entre organismos e organismos e paisagem $^{99}$.

Outro tema importante que surgiu nas reuniões do processo curatorial foi a "tradição", não associado ao velho e passado, como é senso comum entre museus, mas como uma instituição séria, fiável e com expertise o suficiente para tratar dos temas que estão observando. Uma das formas de transformar esse conceito em museografia foi manter as vitrines do século XIX mesmo em frente aos modernos dioramas, criando um contraste. Dentro dessas vitrines foram escolhidos "pequenos animais com grandes histórias" (Landim, comunicação pessoal, 13 de Agosto de 2018), acervo que geralmente não são muito visíveis em dioramas, mas que ganharam protagonismo com narrativas históricas inusitadas sobre a investigação de determinados acervos: "a partir do acervo valorizar a pesquisa para justificar a salvaguarda desse acervo na nossa instituição" (Landim, comunicação pessoal, 13 de Agosto de 2018) (Figura 66).

\footnotetext{
${ }^{99}$ Informaç̃̃es disponível no Memorial Descritivo da Exposição. Documento digital disponibilizado por Maria Isabel Landim, em 13 de Agosto de 2018.
} 

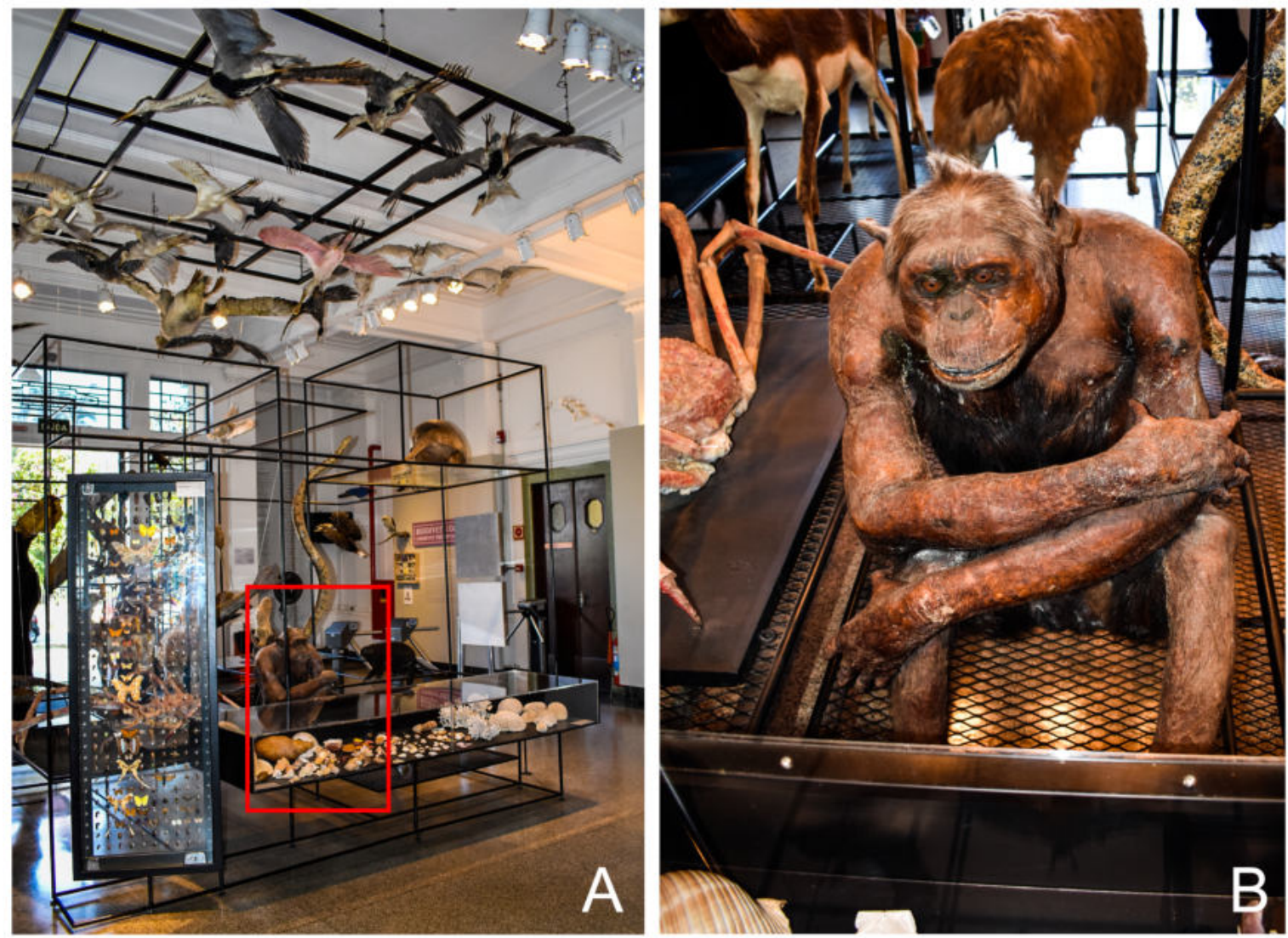

Figura 66: Hall de entrada da exposição "Biodiversidade: conhecer para preservar", com destaque para o chimpanzé Chico. Em A, vista geral do hall com retângulo destacando a posição de Chico. Em B, detalhe da taxidermia do chimpanzé. Fotografia: Mariana Galera Soler, obtida em visita técnica em Agosto de 2018.

Acessibilidade física também foi um elemento considerado na conceção dessa exposição, sendo parte da verba destinada para a construção de uma rampa de acesso ao MZUSP (FIGURA 67). Não há audiodescrição da exposição, mas o Setor Educativo possui um conjunto importante de materiais acessíveis ao toque, com animais taxidermizados, modelos do edifício e de dioramas e outros materiais afins.

A partir da definição do público-alvo, conceito-gerados, premissas, valores e conceitos explicitados no processo curatorial interno do MZUSP foi elaborado um Memorial Descritivo pela equipa da DDC. Esse documento foi disponibilizado a empresa EXPOMUS foi contratada para desenvolver e realizar o projeto museográfico. Então, em 28 de Agosto de 2015 foi inaugurada a exposição "Biodiversidade: conhecer para preservar".

A ficha técnica da exposição "Biodiversidade: conhecer para preservar" encontra-se no ANEXO 5. 


\subsubsection{Tratamento Museográfico}

A exposição "Biodiversidade: conhecer para preservar" é a atual exposição de longa-duração que ocupa a maior parte da área expositiva do edifício do Museu de Zoologia da Universidade de São Paulo: "Estaremos no Ipiranga pelos próximos anos e esse projeto de longa duração foi concebido para este edifício, muito especial, construído especificamente para abrigar o nosso museu" (Maria Isabel Landim, em entrevista para Zucchi, 2015).

Assim, seus módulos foram concebidos em harmonia com a arquitetura do prédio, proposta pelo reconhecido arquiteto Christiano Stockler das Neves no final da década de 1930 - 1949. 0 edifício possui alguns diálogos com o seu entorno (Eixo Monumental ou "locus histórico do Ipiranga”, junto ao Museu Paulista da Universidade de São Paulo), como também busca preservar referências patrimoniais da Zoologia neotropical (com vitrais, painéis e esculturas de animais presentes) e teve sua construção pautada pela lógica organizacional de ocupação e distribuiç̧ão de espaços, segundo a função a ser desempenhada (exposição, laboratórios, coleções, secções administrativas etc.) (Silva, 2006).

Outro elemento fundamental para a conceção museográfica dessa exposição foi o papel do acervo: "Entendemos que é justamente a nossa relação com o acervo que nos caracteriza enquanto instituição e este relação deve transparecer ao público. Todos os demais meios de apresentação e recursos narrativos devem ser auxiliares"100.

Diante da imposição arquitetónica (apenas um terço do edifício é destinado a exposição) e da premissa curatorial, "Biodiversidade: conhecer para preservar" está estruturada em três módulos temáticos, além de um espaço de "Introdução" e uma "Sala de Descobertas", onde são realizadas atividades educativas (FIGURA 67).

Ao entrar pela entrada principal do MZUSP, o visitante depara-se com uma estrutura metálica sob a qual estão apoiados diversos animais, sendo a primeira mostra da diversidade de formas, tamanhos e cores presentes no reino animal. De acordo com a curadora Maria Isabel Landim: "mostrando que somos parte de um todo maior" (Leão, 2015) (FIGURA 68).

\footnotetext{
100 Informações disponível no Memorial Descritivo da Exposição. Documento digital disponibilizado por Maria Isabel Landim, em 13 de Agosto de 2018.
} 
Nesse parte introdutória são apresentados conceitos fundamentais para a narrativa proposta, como biodiversidade (incluindo diversidade genética e de ecossistemas) e os processos evolutivos ("todos os seres vivos surgiram de um ancestral comum que se diversificou ao longo do tempo"101) que a geram: seleção natural, seleção sexual, seleção artificial e isolamento reprodutivo (especiação) (FIGURA 69). Ainda nesse módulo há um conjunto de ecrãs que transmitem imagens de animais e paisagens, com uma narração sobre a origem e diversificação da vida na Terra. A ficha técnica e o texto curatorial também encontram-se nesse saguão de entrada.

A galeria central do edifício do MZUSP abriga o Módulo 1 da exposição, que corresponde a biodiversidade no espaço e no tempo. Nesse módulo são abordas questões relacionadas a Geologia, como as mudanças nas distribuições dos continentes ao longo do tempo geológico. Sob o título "A História da Biodiversidade" são apresentados os fósseis como registos da vida pretérita e as grandes extinções como fenómenos recorrentes e fundamentais para a diversificação de novas espécies. A evolução química na Terra primitiva é citada como a origem da vida (FIGURA 70). Encerra esse módulo a grande extinção do Holoceno, como evento mais recente que permitiu a diversificação de muitas espécies que conhecemos atualmente (FIGURA 71).

\footnotetext{
101 Trecho extraído do módulo de introdução da exposição “Biodiversidade: conhecer para preservar”.
} 


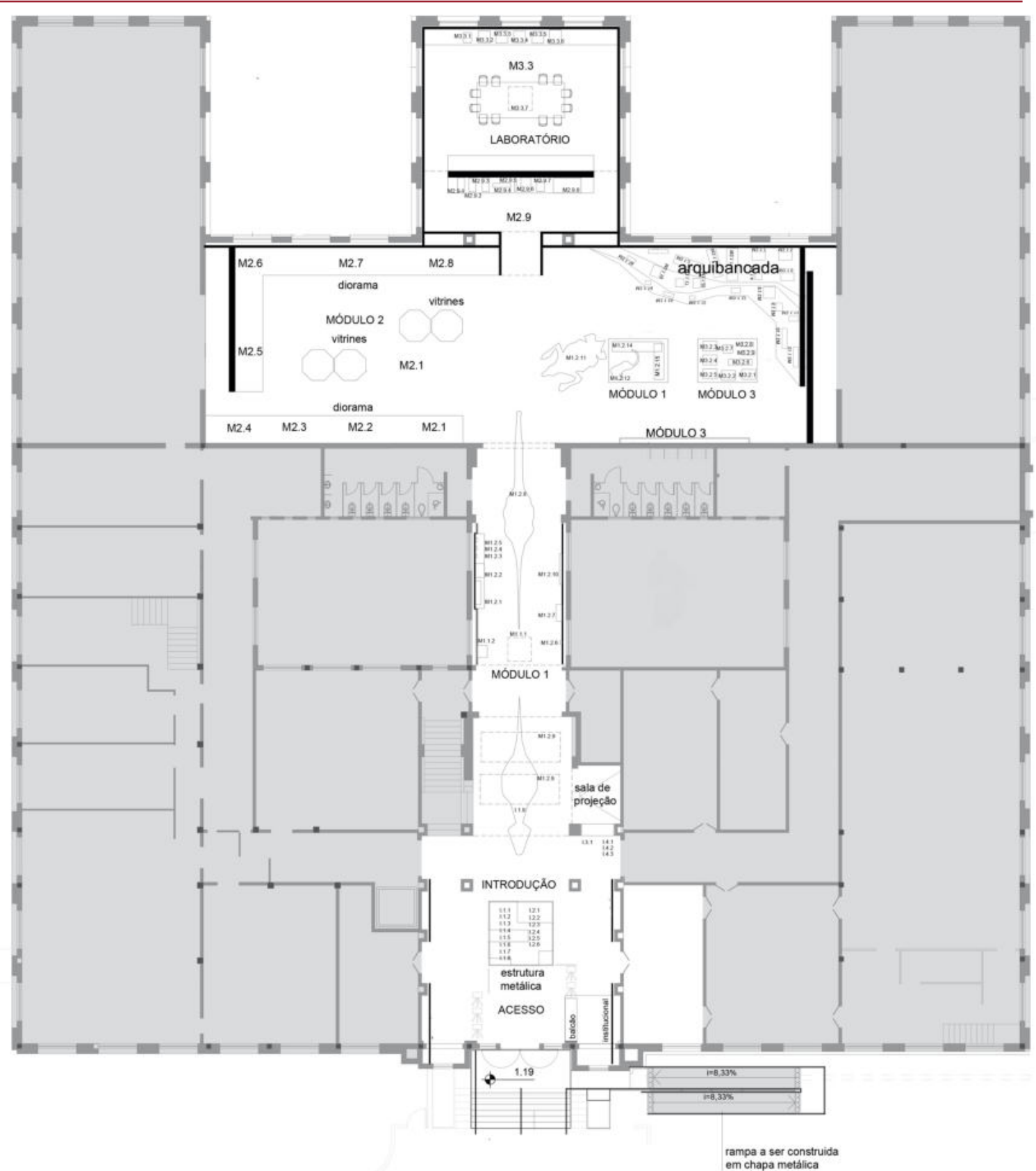

FIGURA 67: Planta baixa da exposição "Biodiversidade: conhecer para preservar". Arquivo modificado para adequação das modificações implementadas na instalação da exposição. Fonte: Projeto de Arquitetura e Expografia. EXPOMUS. Arquivo digital disponibilizado por Maria Isabel Landim, em 13 de Agosto de 2018. 

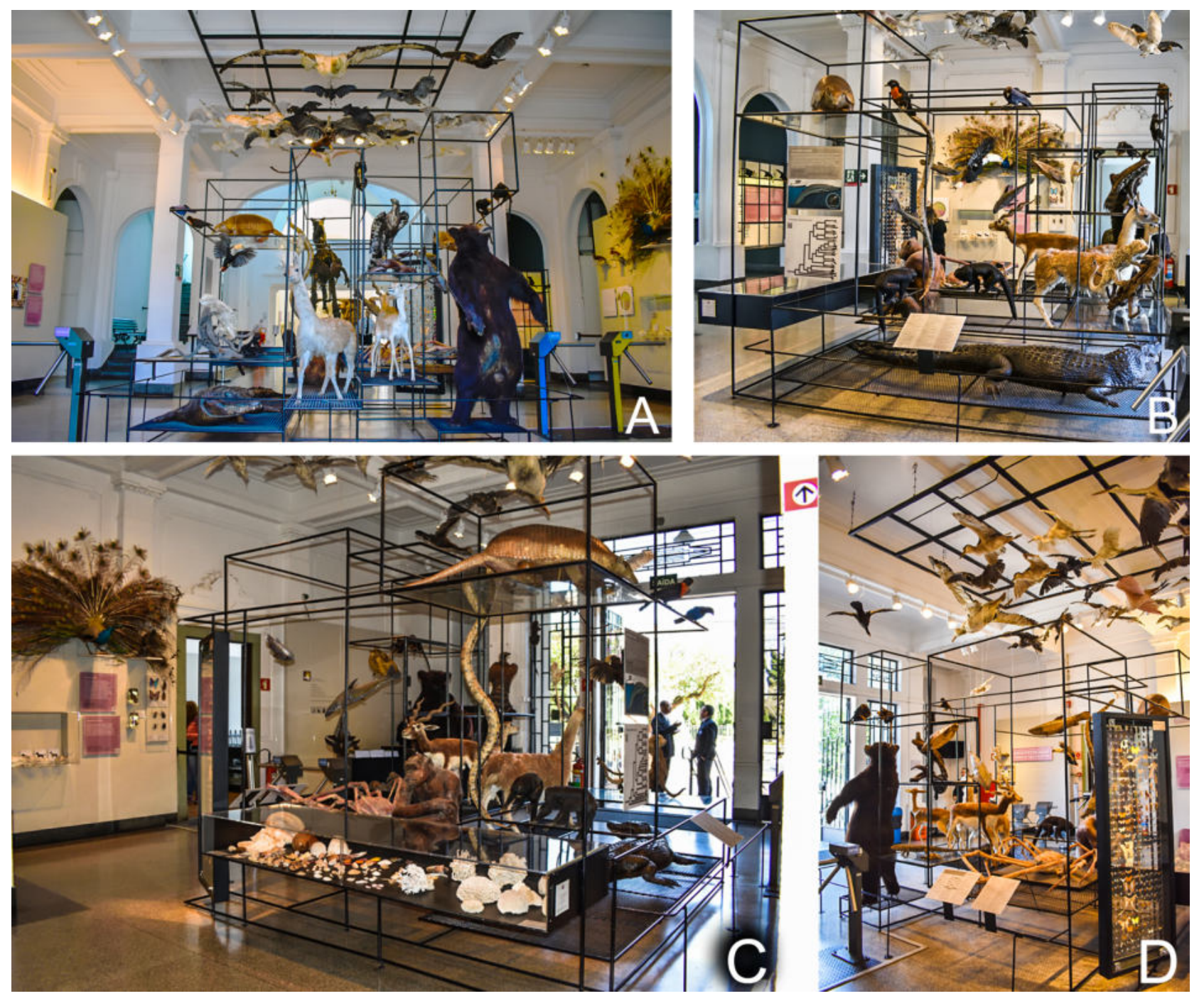

FIGURA 68: Quatro perspetivas diferentes do hall de entrada da exposição "Biodiversidade: conhecer para preservar". O visitante pode circular por todas as faces dessa estrutura metálica e aproximar-se do acervo (sem tocar), uma vez que não há vidros ou paredes acrílicas de separação. Fotografia: Mariana Galera Soler, obtida em visita técnica em Agosto de 2018.

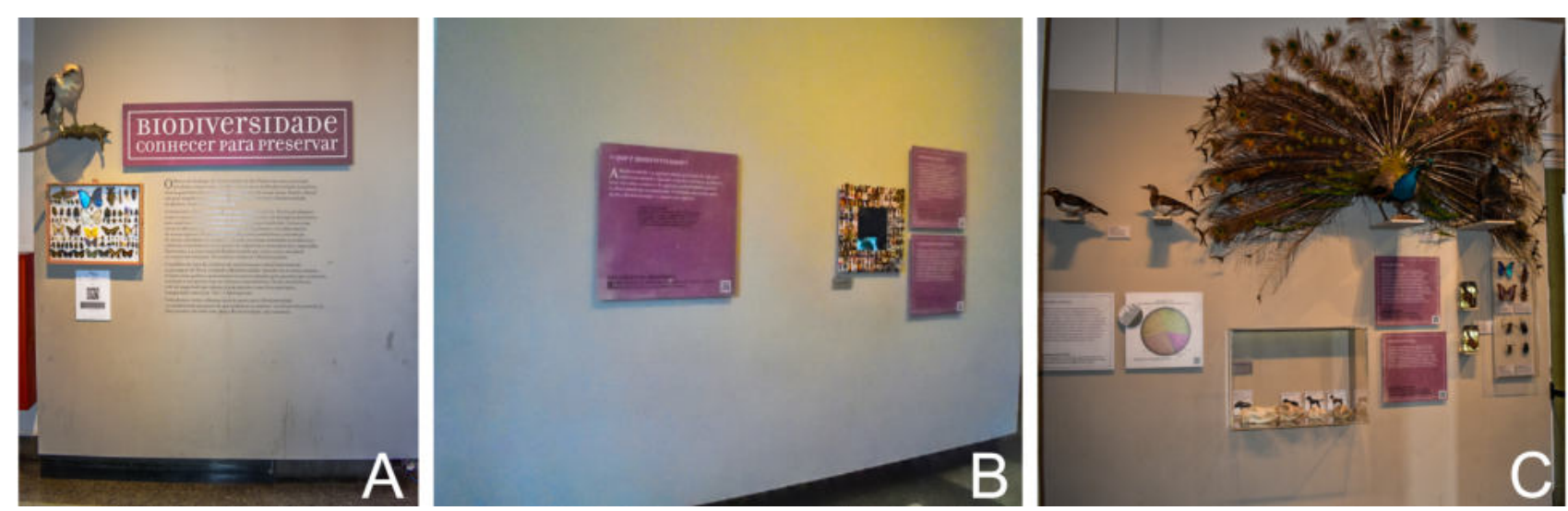

FIGURA 69: Paredes laterias do hall de entrada da exposição "Biodiversidade: conhecer para preservar". Em A, painel com título da exposição e texto curatorial. Em B, conceito de biodiversidade, biodiversidade de ecossistemas e biodiversidade genética. Em C, os principais mecanismos do processo evolutivo (seleção e isolamento). Fotografia: Mariana Galera Soler, obtida em visita técnica em Agosto de 2018. 

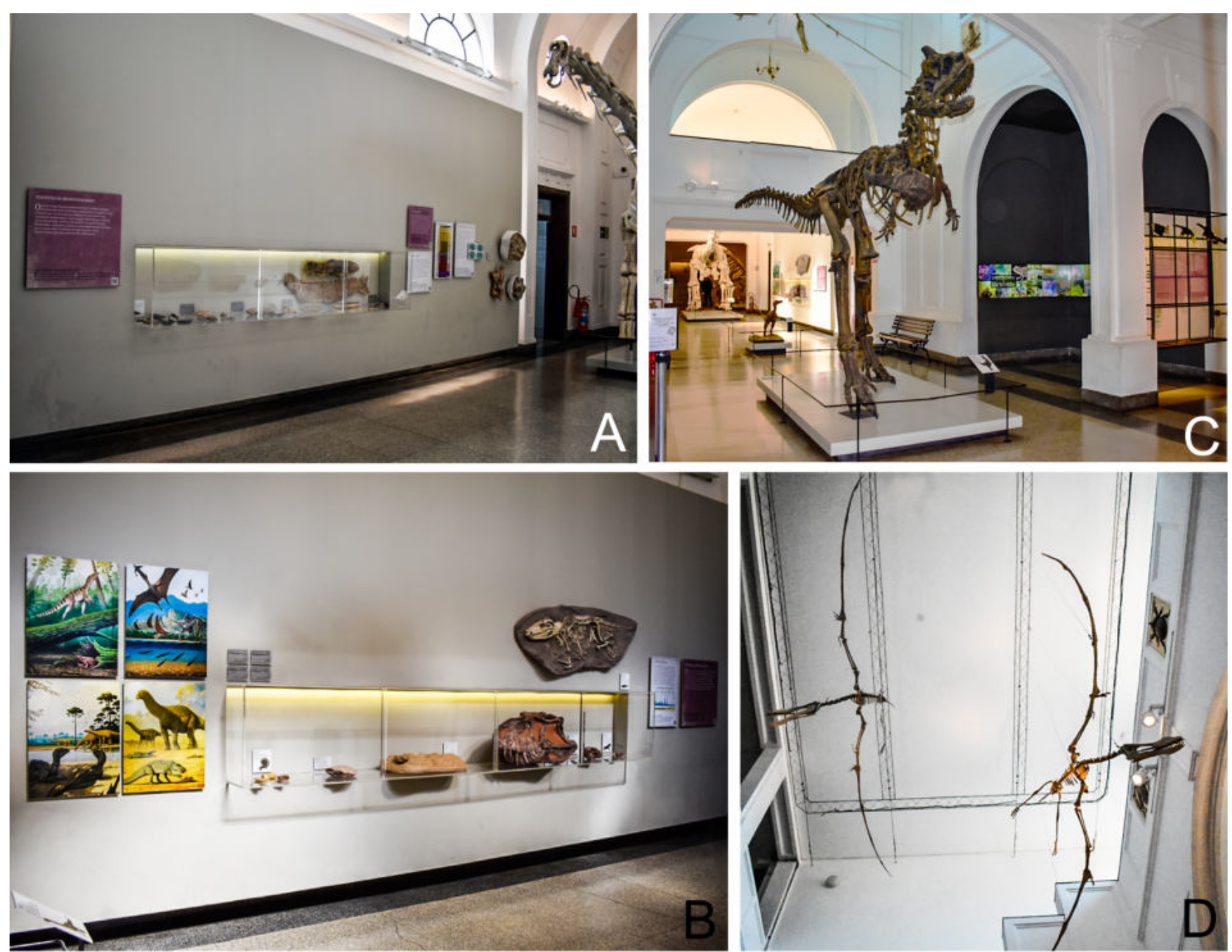

FIGURA 70: Módulo 1 da exposição "Biodiversidade: conhecer para preservar", cujo tema é a história geológica da biodiversidade. Em A, paredes com textos sobre a origem da vida na Terra e o tempo geológico. Réplicas de fósseis posicionados de acordo com o surgimento de cada grupo no linha do tempo. Em B, paredes com textos sobre grandes extinções e montra com réplicas de fósseis de grupos extintos. Em C, no meio do corredor há duas réplicas de esqueletos de dinossauros completos: Carnotaurus e Tapuiasaurus macedoi e uma reconstituição em vida de um Velociraptor. Em D, réplicas de pterossauros estão suspensas no teto, presas no terceiro andar. Fotografia: Mariana Galera Soler, obtida em visita técnica em Agosto de 2018. 


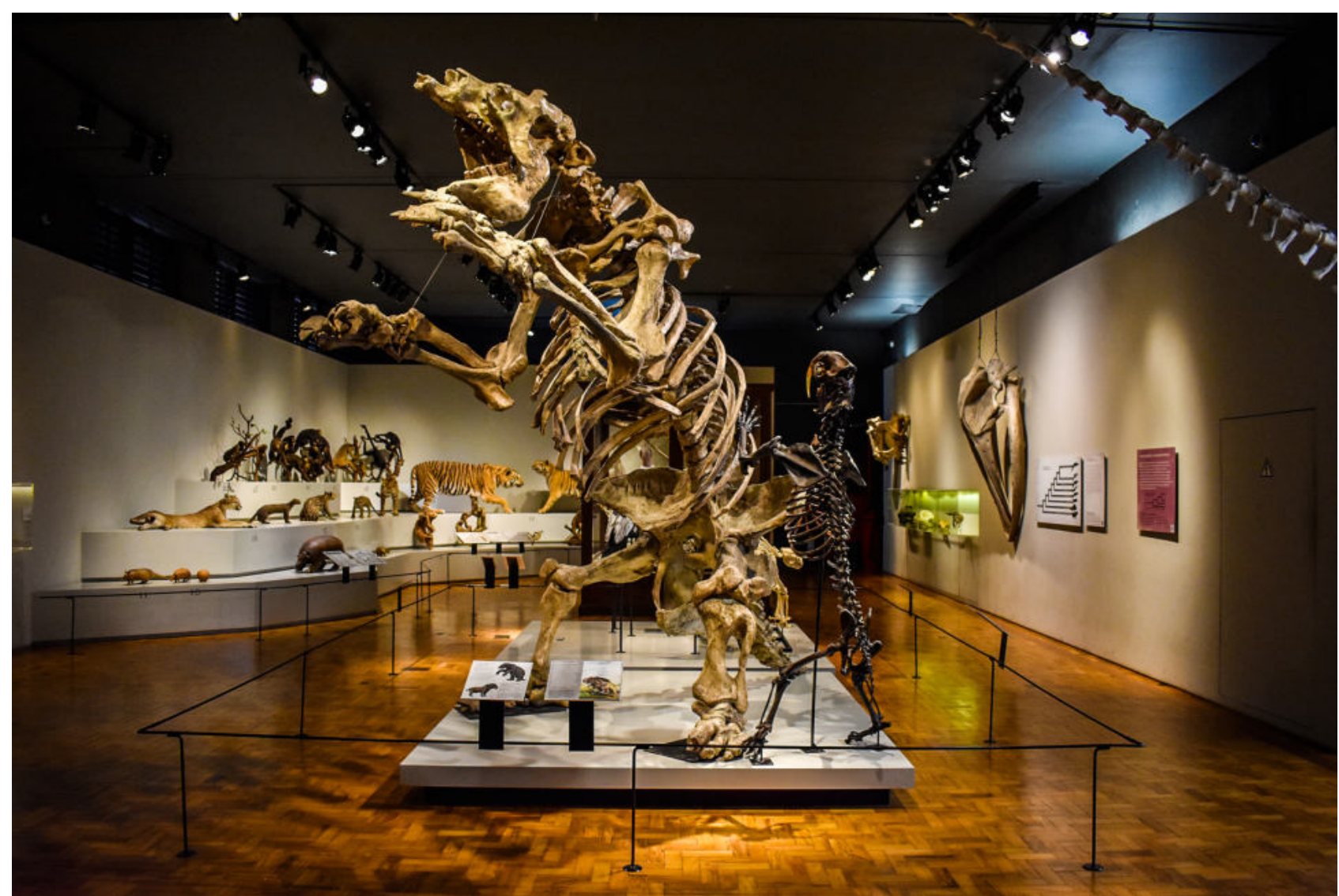

FIGURA 71: Fechamento do Módulo 1 da exposição "Biodiversidade: conhecer para preservar", com representantes da megafauna, que foram extintos na mais recente grande extinção. Fotografia: Mariana Galera Soler, obtida em visita técnica em Agosto de 2018.

O Módulo 2 aborda a biodiversidade contemporânea, com especial enfoque para o contexto brasileiro. Para tanto, foram construídos dioramas dos principais ecossistemas brasileiros, associados à mapas com distribuição original desses ambientes ${ }^{102}$ (FIGURA 72).

Entre os dioramas, vitrines sextavadas em vidro e madeira, foram expostos os invertebrados que não são facilmente visíveis se inseridos nas grandes paisagens. A seleção desses animais foi

102 Os dioramas de "Biodiversidade: conhecer para preservar" possuem uma conceção diferente de todos os demais observados durante a realização desta investigação. Ao invés de paisagens impressas ou pintadas ao fundo, para criar uma noção de profundidade, optou-se por uma solução "teatral" e atuais, com fotografias em alta resolução impressas sobre tecidos translúcidos com os animais interpostos para retratar estas paisagens (Landim, 2018). Essa cenografia cria uma série de "camadas" no ambiente que, associadas à transparência do tecido e iluminação focal, dão destaque para as formas e silhuetas dos animais, que estão naturalizados. Tal solução cenográfica foi desenvolvida a partir da falta de profissionais qualificados na produção de grandes dioramas no Brasil eem sua viabilidade financeira (Landim, comunicação pessoal, 13 de Agosto de 2018). 
Biodiversidade Musealizada: Formas que Comunicam

baseada em expor espécies que têm histórias interessantes do ponto de vista da pesquisa científica ou casos quotidianos, como as ostras mais consumidas no Brasil ou a seleção de espécies que podem ser vistas facilmente avistadas (Leão, 2015)(FIGURA 72A).
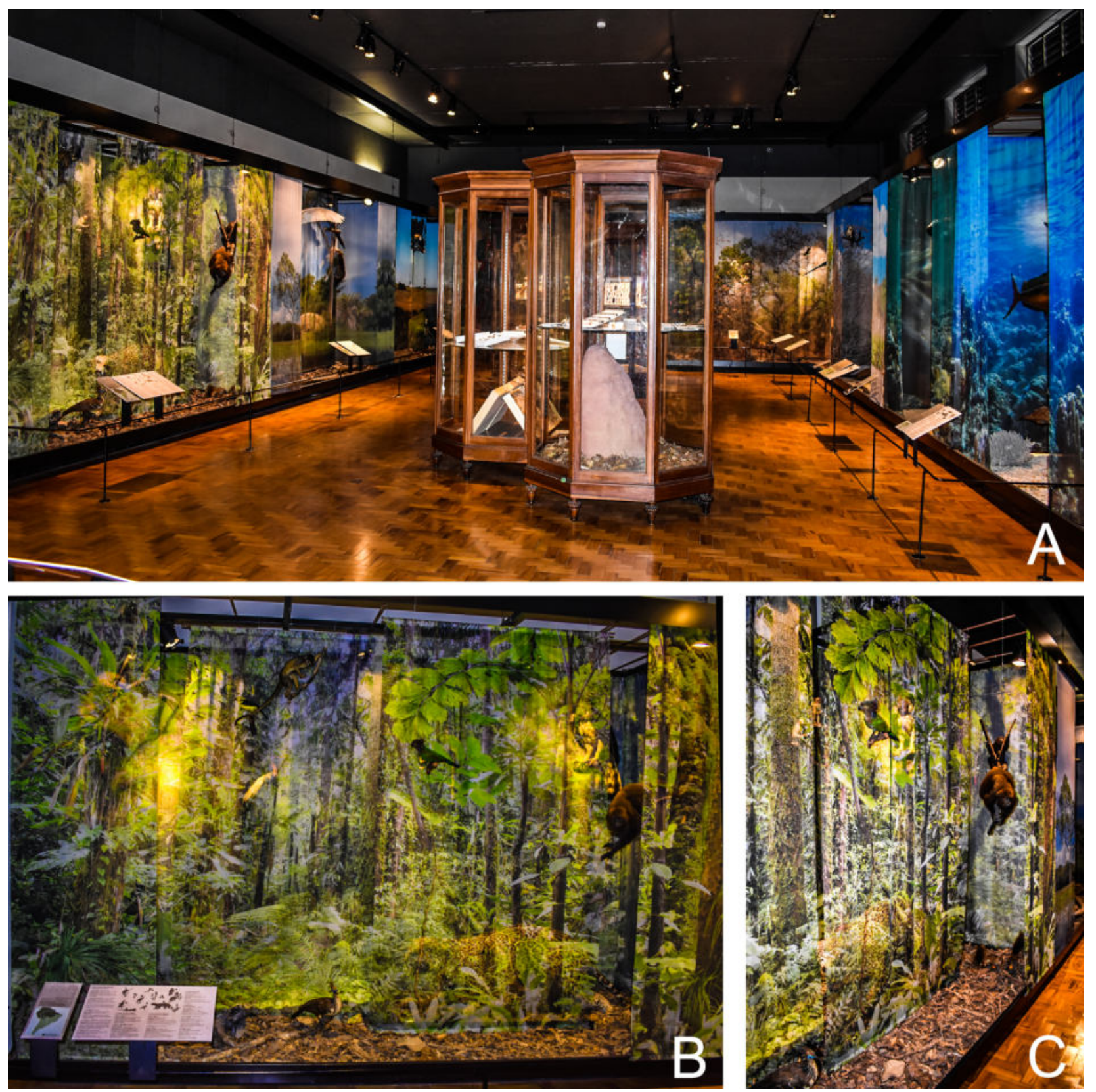

FIGURA 72: Módulo 2 - "Paisagens da Biodiversidade". Em A, visão geral dos dioramas construídos um ao lado do outro. As vitrines no meio mostram estudos desenvolvidos pelo Museu de Zoologia da Universidade de São Paulo. Em B, o diorama da Floresta Amazónia. Em C, detalhes dos tecidos translúcidos e o efeito de "camadas" criado pelo uso de tecidos e iluminação especializada. Fotografia: Mariana Galera Soler, obtida em visita técnica em Agosto de 2018. 
Esse módulo também estende-se para a entrada da "Sala de Descoberta", onde são explorados os ecossistemas urbano, rural e costeiro, tendo como referência a cidade de São Paulo (cidade onde está situado o MZUSP) e o litoral e interior paulista (FIGURA 73). Considerando que a fauna brasileira também é o principal objeto de estudo do MZUSP, nesse módulo também são apresentadas diversas pesquisas realizadas e publicadas, como estudos de caso sobre a importância dos museus de história natural e, destacadamente, do MZUSP (FIGURA 75D).

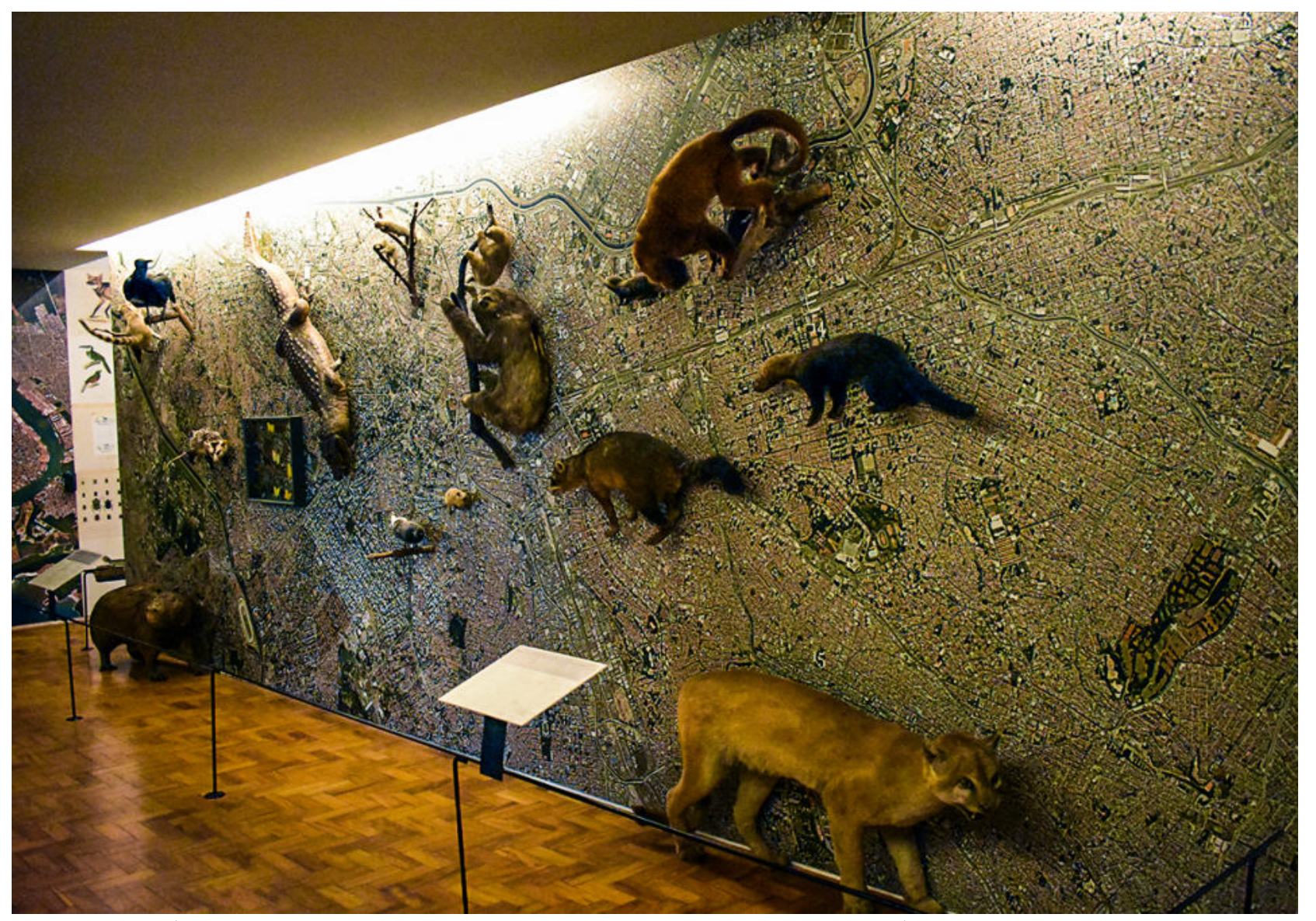

FIGURA 73: Módulo 2 - Paisagens humanas, com destaque para fotografia aérea de São Paulo e alguns animais distribuídos de acordo com os locais na metrópole que podem (raramente) ser encontrados. Fotografia: Mariana Galera Soler, obtida em visita técnica em Agosto de 2018.

Retomando os conceitos evolutivos apresentados na Introdução, o Módulo 3 tem como título "Todos parentes, todos diferentes", onde são exploradas mais detalhadamente questões relacionadas ao parentesco de diferentes grupos zoológicos. Inicia o módulo um texto e o exemplo da evolução do crânio dos cetáceos (Figura 74B). 
Onde na Figura 67 está apontado "arquibancada" trata-se de um suporte em três níveis, onde em cada nível é apresentada a diversidade e as relações filogenéticas entre as espécies, a saber (de cima para baixo): primatas, felinos e xenartros (tamanduás, preguiças e tatus)(FIGURA 74A).

Outras histórias evolutivas também são contadas nesse módulo, como a volta ao ambiente aquático dos mamíferos, no caso da história evolutiva dos cetáceos (FIGURA 74B), e a evolução humana, como exemplo de diversificação dos primatas do Velho Mundo (FIGURA 74A - direita).
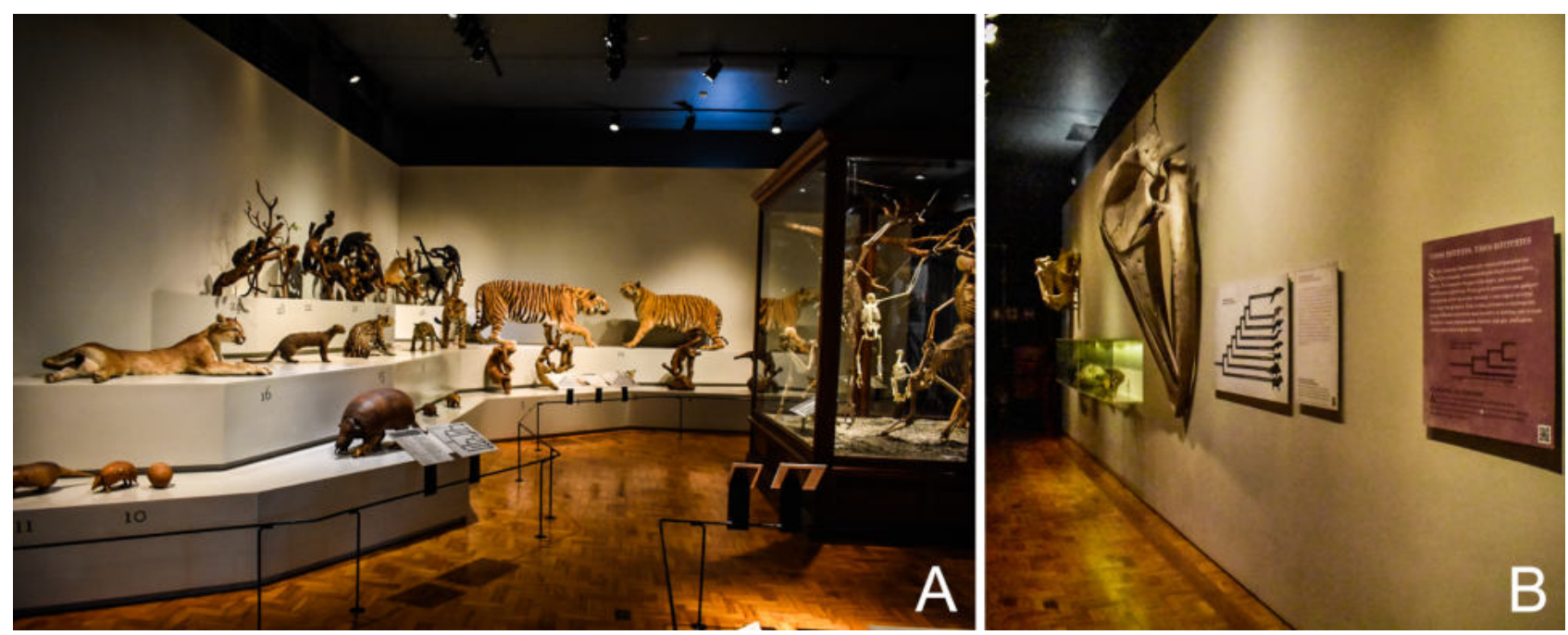

FIGURA 74: Módulo 3 - "Todos parentes, todos diferentes" traz exemplos de histórias evolutivas de diversos grupos. Em A "arquibancada" onde animais nativos e exóticos são apresentados de acordo com seus contextos taxonómicos e evolutivos. Ainda em A, à direita vitrine com esqueletos completos de primatas do Velho Mundo e relacionados à árvore evolutiva humana. Em B, painel introdutório sobre as árvores filogenéticas e a história evolutiva dos cetáceos. Fotografia: Mariana Galera Soler, obtida em visita técnica em Agosto de 2018

Encerra a exposição "Biodiversidade: conhecer para preservar" a "Sala de Descobertas", que busca reproduzir de modo estilizado os bastidores da instituição e novamente destacar a importância dos museus de história natural. Esse espaço traz referências às coleções; ao rico acervo da biblioteca da instituição (forneceram as pranchas que foram utilizadas como papel de parede); às bancadas de pesquisa na forma de uma grande mesa e equipamentos para as atividades com o público (Landim, 2018) (FIGURA 75 A-C ).

Ainda nesta sala, uma vitrina intitulada de "novinhos em folha" apresenta os resultados recentes de nossa pesquisas do MZUSP , mostrando os espécimes utilizados no estudo e os artigos científicos resultantes (Landim, 2018) (FIGURA 75D). 

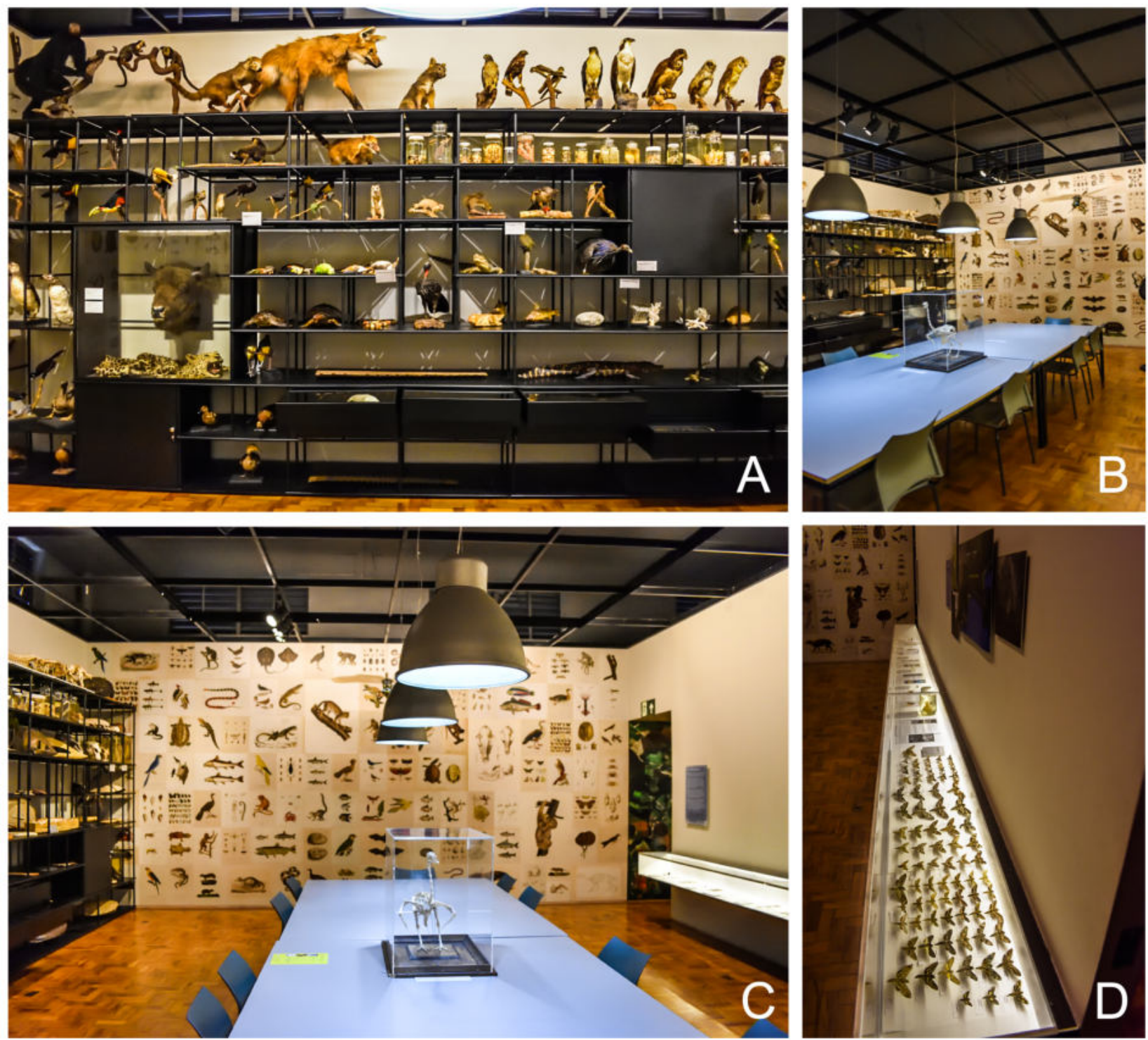

FIGURA 75: Sala da Descoberta. Em A, armário com espécimes animais em diferentes formas de preservação (via húmida, seca, peles, osteologia, busto etc.), com explicações sobre a importância das coleções de história natural e de tais tipos de preservação. Em B e C, visão geral da sala, com armário, decoração nas paredes com ilustrações científicas de obras raras da biblioteca do Museu de Zoologia da Universidade de São Paulo. Em D, vitrine "novinhos em folha”, em que espécimes utilizados na investigação realizada na instituição e recém-publicados artigos científicos sobre eles são colocados lado-a-lado. Fotografia: Mariana Galera Soler, obtida em visita técnica em Agosto de 2018 


\section{CAPÍTULO III - Enquadramento em Padrão Museográfico (EPM): números que ajudam explicar padrões}

A Tabela 13 apresenta os resultados da aplicação do índice numérico EPM (Enquadramento em Padrão Museográfica), descrito no capítulo anterior. No APÊNDICE 2 encontra-se a Matriz de Indicadores completa, onde está disponível a relação de presença e ausência de cada um dos indicadores descritos em cada uma das exposições.

\begin{tabular}{|c|c|c|c|c|c|c|c|c|c|c|c|}
\hline \multicolumn{2}{|c|}{$\begin{array}{l}\text { Enquadramento em Padrão Museográfico } \\
\text { (EPM) }\end{array}$} & 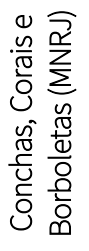 & 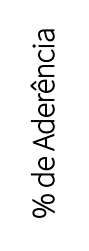 & 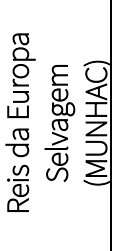 & 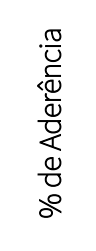 & 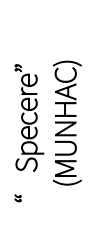 & 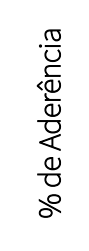 & 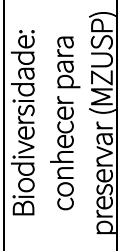 & 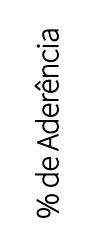 & 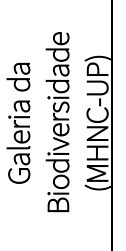 & 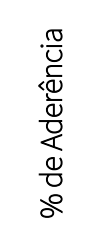 \\
\hline \multirow{5}{*}{ 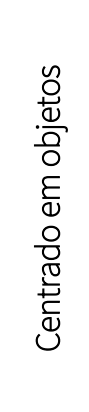 } & Características comuns & 0,15 & 100 & 0,04 & 25,00 & 0,12 & 75,00 & 0,15 & 100 & 0,08 & 50,00 \\
\hline & Séries Taxonómicas & 0,19 & 100 & 0,04 & 20,00 & 0,12 & 60,00 & 0,15 & 80,00 & 0,08 & 40,00 \\
\hline & $\begin{array}{c}\text { Séries Evolutivas / } \\
\text { Progressistas }\end{array}$ & 0,15 & 66,67 & 0,00 & 0,00 & 0,04 & 16,67 & 0,19 & 83,33 & 0,15 & 66,67 \\
\hline & Dioramas & 0,19 & 45,45 & 0,42 & 100 & 0,04 & 27,27 & 0,38 & 90,91 & 0,08 & 54,55 \\
\hline & EPM & 0,69 & 69,23 & 0,50 & 0,50 & 0,38 & 38,46 & 0,88 & 88,46 & 0,54 & 53,85 \\
\hline \multirow{5}{*}{ 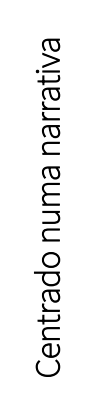 } & Características comuns & 0,05 & 40,00 & 0,11 & 80,00 & 0,03 & 20,00 & 0,08 & 60,00 & 0,11 & 80,00 \\
\hline & Quotidiano & 0,08 & 87,50 & 0,11 & 50,00 & 0,05 & 25,00 & 0,13 & 62,50 & 0,11 & 50,00 \\
\hline & Ecológico & 0,16 & 55,56 & 0,24 & 100 & 0,05 & 22,22 & 0,16 & 66,67 & 0,00 & 0,00 \\
\hline & $\begin{array}{c}\text { Public Understanding of } \\
\text { Science }\end{array}$ & 0,13 & 31,25 & 0,08 & 18,75 & 0,16 & 37,50 & 0,18 & 43,75 & 0,34 & 81,25 \\
\hline & EPM & 0,42 & 42,11 & 0,53 & 0,53 & 0,29 & 28,95 & 0,55 & 55,26 & 0,55 & 55,26 \\
\hline \multirow{3}{*}{ 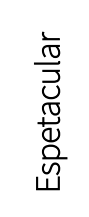 } & Características comuns & 0,21 & 57,14 & 0,24 & 53,33 & 0,24 & 33,33 & 0,27 & 60,00 & 0,36 & 53,33 \\
\hline & Blockbuster & 0,13 & 22,22 & 0,18 & 33,33 & 0,12 & 27,78 & 0,24 & 44,44 & 0,33 & 50,00 \\
\hline & EPM & 0,34 & 34,21 & 0,42 & 42,42 & 0,36 & 36,36 & 0,52 & 51,52 & 0,70 & 69,70 \\
\hline \multirow{3}{*}{ 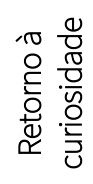 } & Características comuns & 0,32 & 46,15 & 0,11 & 15,38 & 0,37 & 61,54 & 0,42 & 61,54 & 0,37 & 53,85 \\
\hline & Biografia dos Objetos & 0,11 & 33,33 & 0,00 & 0,00 & 0,00 & 0,00 & 0,11 & 33,33 & 0,11 & 10,53 \\
\hline & EPM & 0,42 & 42,11 & 0,11 & 10,53 & 0,37 & 42,11 & 0,53 & 52,63 & 0,47 & 47,37 \\
\hline
\end{tabular}

Tabela 13: Tabela que resume os valores de EPM (Enquadramento em Padrão Museográfico), um índice numérico calculado de acordo com a presença ou ausência dos indicadores. 


\subsection{Discussão dos Padrões Identificados}

\subsection{1 "Conchas, corais e borboletas" (MNRJ)}

Em "Conchas, corais e borboletas" nota-se que o valor de EPM mais alto associa a exposição ao padrão museográfico "Centrado em Objeto". Nesse padrão, as "Séries Taxonómicas" e as "Séries Evolutivas/Progressistas" foram aquelas com maior expressão (maior percentagem de aderência), para além de serem encontradas todas as características comuns desse padrão.

Entre as características comuns, destacamos o indicador 1 "Promover o aprendizado por meio da observação dos objetos ("lição das coisas")" como ponto de partida, uma vez que trata-se de uma exposição essencialmente contemplativa. Embora existam outros meios de representação para além dos objetos do acervo (como vídeos, lupas e animações), em geral não havia recursos museográficos que permitissem que o visitante pudesse tocar, interagir ou foram propostas outras atitudes de mediação.

Há duas exceções, ambas orientadas para o público infantil: (i) a proposição de uma "conversa" com o visitante no setor Insecta. Por meio de pequenas placas de cores chamativas coladas nas vitrines, eram propostas algumas perguntas ou textos apresentados como se o acervo "falasse" com o visitante. Essa foi uma iniciativa pessoal e individual do curador do respetivo setor, Alcimar do Lago Carvalho (Figura 76A); (ii) animações sobre a conservação dos crustáceos em período reprodutivo. Por meio de desenhos animados, os visitantes são convidados a refletir sobre a importância dos períodos de recesso da recolha de crustáceos (caranguejo e tatuí), para a sobrevivência das espécies. Como citado anteriormente, esse media não foi desenvolvido pelas diferentes equipas do MNRJ, mas por uma parceria com os alunos do curso de Comunicação Social da UFRJ (Figura 76B). 

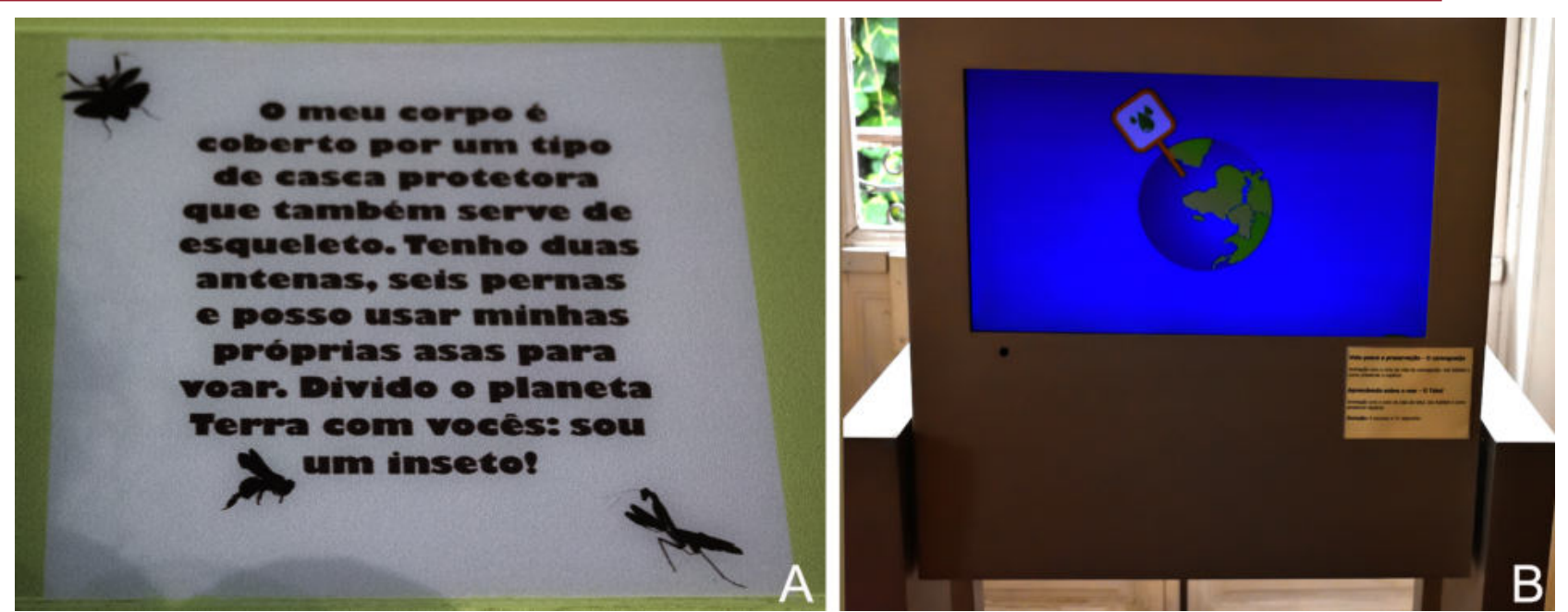

FIGURA 76: Recursos museográficos destinados à crianças em "Conchas, corais e borboletas". Em A, texto expositivo presente no setor Insecta. Em B, ecrã com duas animações de curta-duração no setor Crustacea. Fotografia: Mariana Galera Soler, obtida em visita técnica em Agosto de 2018.

Considerando que os espécimes que estavam expostos em "Conchas, corais e borboletas" pertenciam as coleções científicas dos respetivos grupos taxonómicos, a forma que estavam dispostos refletia, em geral, também o modo como eram salvaguardado nas coleções ou que eram utilizados para a investigação. Assim, há uma prevalência da exibição de formas anatómicas externas [INDICADOR 2] e da comparação entre as formas a partir das seguintes [INDICADOR 3].

Tendo em vista que esta exposição estava no mais importante museu de história natural brasileiro (MNRJ), pode-se sugerir que se trata de um reflexo das práticas do que Pickstone (1994) reconhece como "museological sciences", em que a Zoologia encontra-se inscrita. De acordo com o autor, as "museological sciences" constituem práticas que exigem grande quantidade de espécimes, de modo que cada um deles é entendido como um composto e analisado em elementos, de modo a procurar mecanismos explicativos para tal organização (no caso de "Conchas, corais e borboletas", de modo genérico, a teoria evolutiva).

Ainda inserido na discussão das "museological sciences" o modo como os espécimes eram cuidadosamente preparados, identificados individualmente e localizados geograficamente apontam para formas de conhecimento que são únicas de profissionais da Zoologia, diferenciandoos dos amadores por terem autoridade sobre as coleções (tanto pelo número de espécimes que tinham disponíveis como por os terem profundamente analisados), pela sua capacidade de apresentar a natureza em determinada ordem, classificada por diagnoses que posicionam os espécimes diante da diversidade [INDICADORES 4, 10, 11, 12 e 15] (Figura 77). 
Das diferentes abordagens possíveis da Zoologia, os estudos taxonómicos são aqueles que mais aproximam-se das "museological sciences". Tais estudos também enquadram a Zoologia como "ciência de coleção", ou seja, depende da coleta de campo e extensos conjuntos de amostras e tem como características principais: a materialidade dos objetos de pesquisa, a documentação de procedência e a necessidade de armazenamento permanente de seus testemunhos (Kohler, 2007).

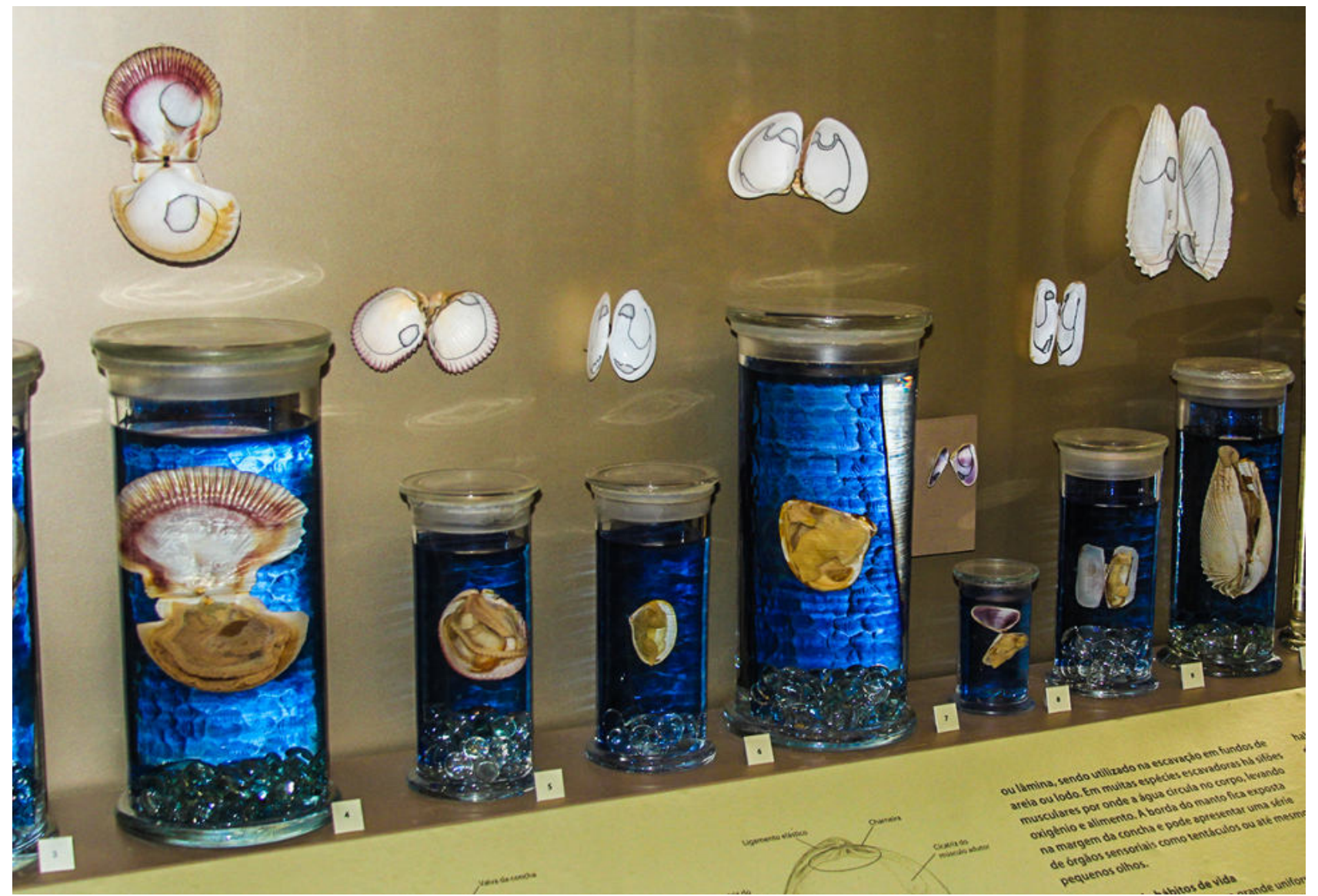

FIGURA 77: Vitrine com bivalves em Conchas, corais e Borboletas. Destaque para valvas preservadas em via seca e com marcações da musculatura animal, realizadas por especialistas e que evidenciam um caráter taxonómico. Fotografia: Mariana Galera Soler, obtida em visita técnica em Junho de 2014.

Embora "Conchas, corais e borboletas" tenha sido elaborada por uma equipa multidisciplinar, composta por investigadores, técnicos, museólogos e designers, nota-se o papel decisório dos investigadores-curadores na escolha do acervo e da abordagem desse. Além dos relatos obtidos nas entrevistas, as fichas museográficas desenvolvidas pelo Serviço de Museologia do MNRJ (Figura 19) foram preenchida pelas equipas científicas de cada um dos setores da exposição. Nessas fichas, foram definidos os tipos de acervo em exposição, o tema em que se insere e a proposta de legenda. O papel crucial dos investigadores dá mais indícios que a escolha da museografia centrada nos objetos, especialmente ordenada em "Séries Taxonómicas", pois trata-se 
de uma forma de representação da natureza diretamente associada à prática científica dos investigadores da instituição, ou seja, existe uma associação evidente entre a prática científica e a representação da natureza.

Em uma visão mais abrangente, a escolha de uma museografia orientada as séries taxonómicas também pode ser entendida como um reflexo da missão institucional dos departamentos de Entomologia e Invertebrados, setores científicos do MNRJ diretamente relacionados à exposição. Nos sites institucionais dos respetivos departamentos, podemos encontrar suas missões:

“(...) Atuando na pesquisa, ensino e extensão, suas principais missões relacionam-se a manutenção, preservação e estudo da Coleção Entomológica do Museu Nacional (...) No Departamento, diversas linhas de pesquisa envolvendo insetos vêm sendo desenvolvidas, com enfoque na Sistemática, Morfologia, Biologia, Ecologia, Biodiversidade e História Natural"

(Departamento de Entomologia).

\begin{abstract}
“(...) Ser um centro de excelência de pesquisa em biodiversidade de invertebrados marinhos e Aracnologia, capacitado para identificar, descrever e caracterizar a biologia e a ecologia das espécies animais de todos os filos de invertebrados em todos os habitats marinhos, com especial ênfase no Mar Profundo"
\end{abstract}

(Departamento de Invertebrados).

Desse modo, aquele que define a representação da natureza - o curador científico, ou seja, o investigador especializado - faz como ele a interpreta em sua prática profissional.

A presença dos quatro pequenos dioramas em "Conchas, corais e borboletas", que pouco dialogam com os setores da exposição, sendo elementos isolados no discurso expositivo e mínimos diante de outros recursos museográfico, justifica o facto de que estes não configuram um subpadrão museográfico de grande aderência em nosso modelo [INDICADORES 16, 18, 21 e 24] (Figura 24).

Outro padrão museográfico sinalizado, mas com menor representatividade foi "Retorno à Curiosidade". Em "Retorno à Curiosidade" estão presentes aqueles indicadores diretamente 
associados à valorização dos objetos e a promoção do encontro e encantamento dos visitantes com a diversidade materializada por animais preservados [INDICADORES 98, 106 e 110]. A presença pontual de objetos históricos e que contavam como era a antiga exposição do MNRJ (Figura 18 e Figura 28C) e animais utilizados em contextos culturais trazem narrativas diferentes da científica para a exposição [INDICADOR 99] (Figura 78 e Figura 79C).

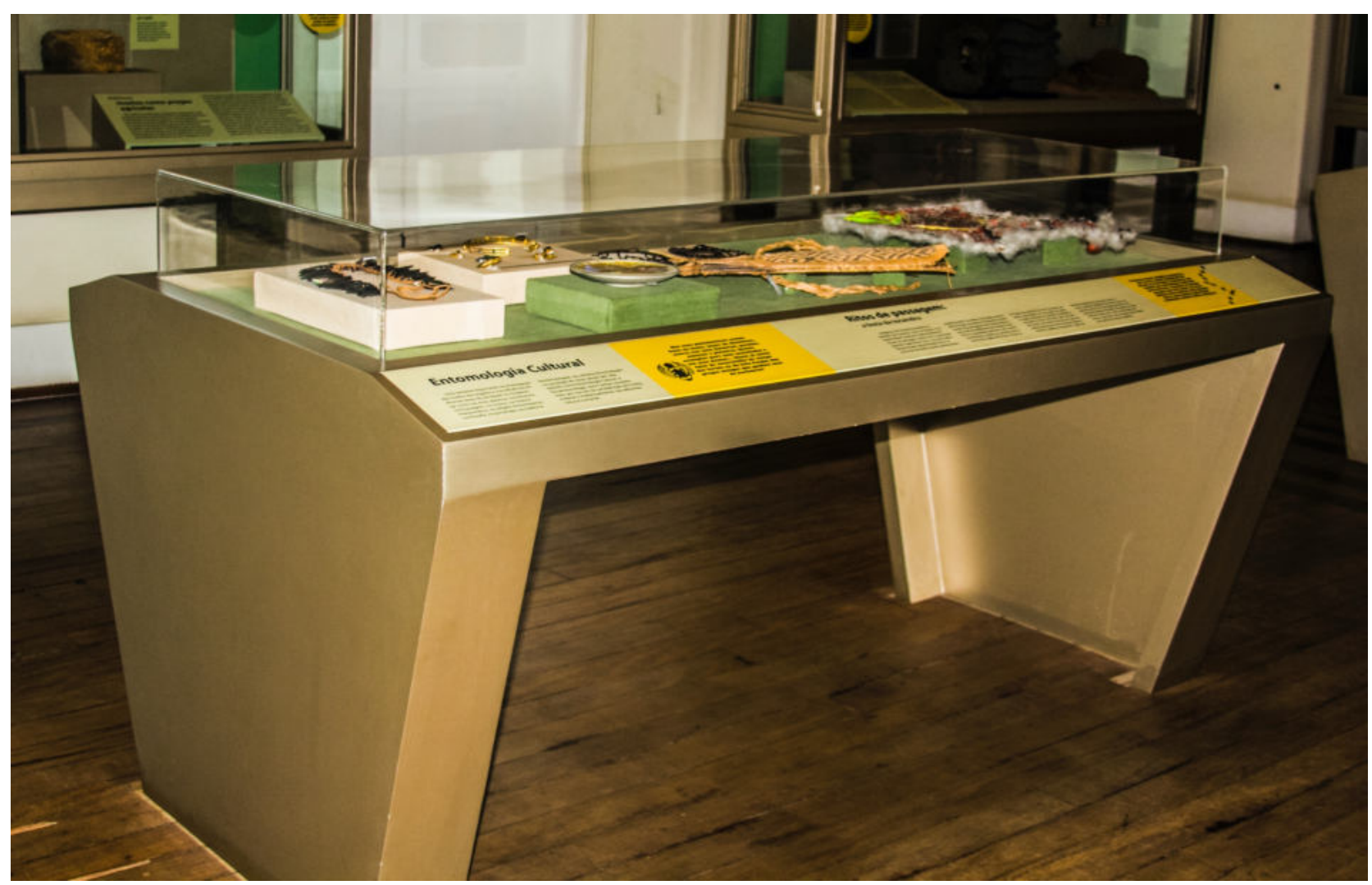

FIGURA 78: Vitrine com artefactos indígenas e joias construídos com insetos, na parte de Entomologia Cultural do Setor Insecta. Fotografia: Mariana Galera Soler, obtida em visita técnica em Junho de 2014.

No setor Porifera, há sete objetos cujas legendas trazem a história da recolha e chegada ao MNRJ [INDICADOR 111 e 113], sendo exemplos únicos do subpadrão "Biografia dos objetos" (Figura 79). Destaca-se que as biografias descritas trazem informações relevantes sobre a expertise das equipas de coleta e financiamento das expedições pela PETROBRAS. 

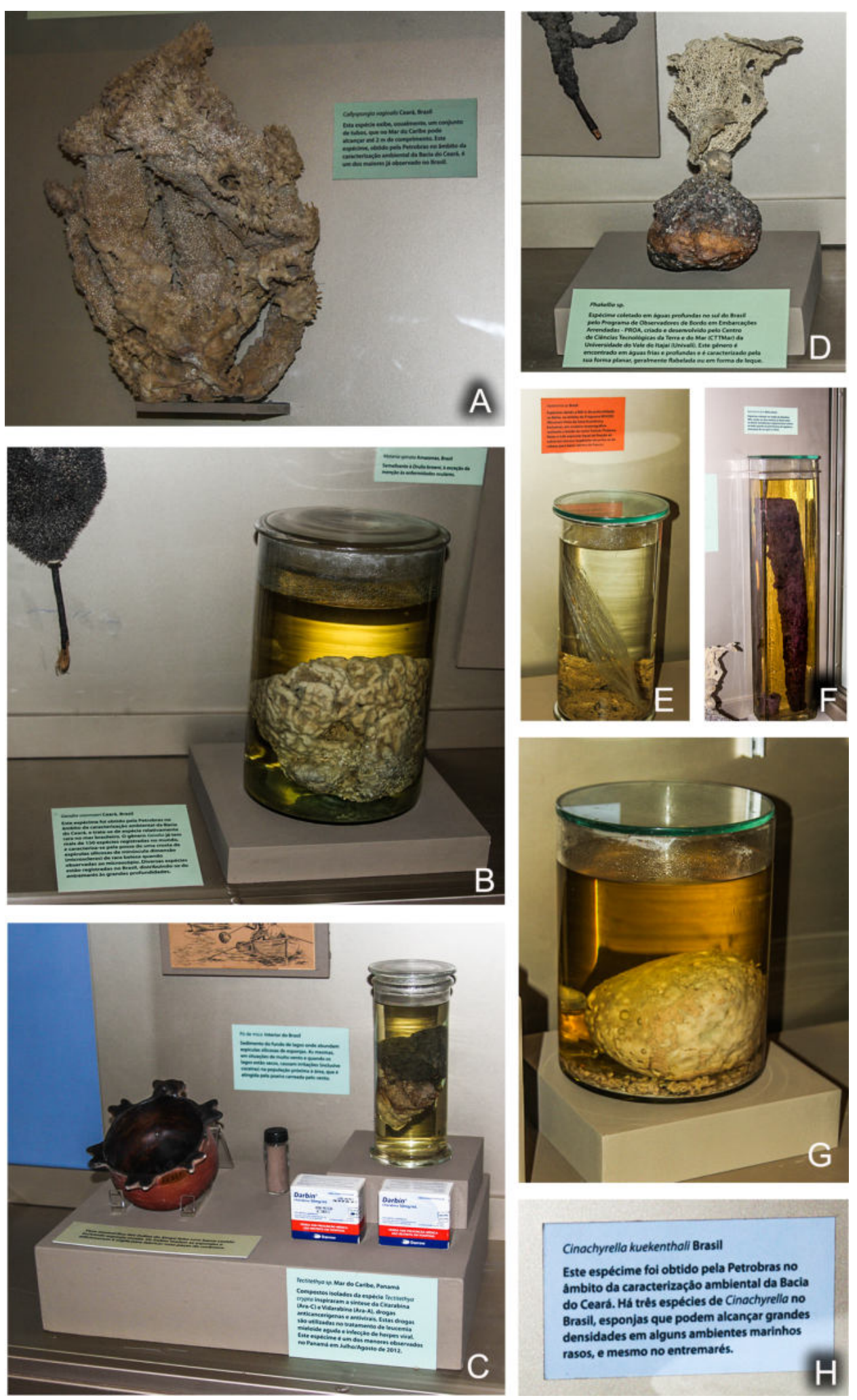

FIGURA 79: Espécimes de poríferos que narram seus procedimentos de recolha em ambiente natural. A Callispongia vaginalis. B Geofia vosmaeri. C. Espécime de Tectitethya sp. em via húmida, vaso zoomórfico dos índios do Xingu, recipiente com "pó de mico" (argila com espículas silicosas) e duas embalagem de medicamentos cujo composto ativo foi sintetizado de poríferos. D. Phakellia sp. E. Hyalonemasp. F. Aplysina fulva. G. Cinachyrella kukenthali.Fotografia: Mariana Galera Soler, obtida em visita técnica em Agosto de 2018. 
Os padrões museográfico "Centrado numa narrativa" $(0,42)$ e "Espetacular" $(0,34)$ foram aqueles que indicadores foram menos encontrados em "Conchas, corais e borboletas".

Destaca-se que em "Centrado numa narrativa” houve uma maior adesão especialmente pela abordagem de temas relacionados à conservação da espécies (subpadrão Ecológico), uma vez que esse foi recorrente na maioria dos setores, com especial destaque para o Setor Cnidaria (com vídeo e textos relacionados ao projeto Coral Vivo), as animações presentes no Setor Crustacea e o desequilíbrio ambiental que leva a pragas agrícolas, ilustradas em Insecta.

Quanto ao subpadrão museográfico Quotidiano, destaca-se o caráter didático da exposição com textos explicando conceitos científicos [INDICADOR 34], a utilização de termos não-científicos em alguns textos e a discussão de problemas domésticos e de saúde pública, como pragas e transmissão de doenças [INDICADORES 32, 34 e 63].

Indicadores do subpadrão Public Understanding of Science referem-se ao uso, mesmo que pontual, de aparatos multimédias [INDICADOR 61] e ausência de perspetivas históricas (em grande parte da exposição) e/ou críticas da ciência e dos conceitos expostos [INDICADORES 51 e 53].

Por fim, considerando o caráter mercadológico, corporativo e mediático das exposições que caracterizam o padrão museográfico Espetacular, "Conchas, corais e borboletas" apresentou o menor número de indicadores desse padrão. Entre as características gerais desse padrão, identificamos o uso de recursos em grande escala, como ampliações de fotografias e de microscopias [INDICADOR 67]. Numa perspetiva de show business a ciência é apresentada como uma verdade inequívoca e de direta aplicabilidade pública [INDICADORES 70 e 72].

A intensa presença de objetos de coleções científicas garantiam a autenticidade dos conteúdos e certificava o MNRJ como instituição científica e produtora de conhecimento [INDICADOR 68]. Para além da organização taxonómica, os objetos, nesse caso animais preservados, também estavam dispostos de acordo com temas [INDICADORES 77e 79] e eram selecionados de acordo com critérios estéticos, um desafio acrescido uma vez que os invertebrados não são animais de grande popularidade, considerados por alguns como disgusting animals.

A ausência de financiamentos corporativos (o financiamento dessa exposição foi realizado por editais de instituições públicas brasileiras ou verbas de projetos de pesquisa individuais), um dos elementos fulcrais das exposições do subpadrão blockbuster levaram a praticamente ausência dos seus indicadores, com exceção do uso de aparatos que causam impacto no público, como grandes 
faixas de divulgação da exposição na fachada da instituição [INDICADOR 81] e a presença de objetos do acervo marcantes, como o caranguejo-gigante (Macrocheira kaempferi) e a réplica da lula-gigante, com mais de 8m de comprimento [INDICADOR 85] (Figuras 9, 24A e 25B, C).

\subsection{2 "Reis da Europa Selvagem"}

Na exposição "Reis da Europa Selvagem: os nossos últimos carnívoros" encontramos maior EPM associado ao padrão museográfico "Centrado numa narrativa”, embora um índice muito próximo seja identificado em "Centrado em objetos". Em um primeiro momento esse resultado pode parecer contraditório, mas observado ao detalhe é possível a compreensão. A prevalência a esses padrões está relacionada a aderência total (100\%) a dois sub-padrões: "Dioramas", no caso "Centrado em objetos" e as "Características Comuns" e "Subpadrão Ecológico", no caso "Centrado numa Narrativa".

Considerando que as "características comuns" são aqueles indicadores fundamentais na definição dos grupos de padrões, pois é a partir do acúmulo delas e outras particulares que identificamos efetivamente os padrões museográficos, fica evidente nos termos propostos para esse método que "Reis da Europa Selvagem" é uma exposição "Centrada numa Narrativa", uma vez que apenas 25\% das características comuns às exposições "Centradas em Objetos" sejam associadas à referida exposição.

Além disso, a percentagem relativa a "Centrada em Objetos" refere-se a existência de apenas um indicador: "privilégio de formas anatómicas externas" [INDICADOR 2], o que pode ser analisado sob o ponto de vista histórico dos museus de história natural e da constituição do acervo expositivo de "Reis da Europa Selvagem". Pelo viés histórico, tradicionalmente as coleções de museus de história natural privilegiaram a preservação da morfologia, especialmente a externa. Isso decorre da herança do desenvolvimento das técnicas de taxidermia, que data da emergência das primeiras coleções de história natural na Europa, no século XVI. Desde esse período inicial, peles eram preservadas a partir da combinação e diferentes elementos (de pimentas a sabão de arsénico) e, eventualmente, cobriam estruturas que simulavam a forma em vida do animal (Péquignot, 2006). De modo que a forma externa similar ao animal em vida é algo que, tradicionalmente, se buscava preservar no contexto dos museus de história natural. 
Em “Reis da Europa Selvagem”, o acervo em exposição advém de duas coleções: a coleção mastozoológica do MUHNAC e a coleção privada Valentim dos Santos. Os espécimes da coleção institucional foram selecionados a partir de suas qualidades estéticas e capacidade de comunicação de conceitos [INDICADORES 27 e 71]. Tendo em vista o discurso expositivo focado na história natural e conservação dos grandes carnívoros europeus, foram escolhidos aqueles que pudessem melhor comunicar os hábitos de vida das espécies destacadas, de modo que houve uma preferência por espécimes que privilegiavam formas anatómicas externas e representação de comportamentos. Já os espécimes oriundos de uma coleção privada, cujo proprietário era um antigo caçador que expunha suas conquistas, é esperada a exaltação dos animais como troféus e, portanto, a conservação estética da anatomia externa [INDICADOR 2].

Dioramas foi um subpadrão museográfico com adesão total de "Reis da Europa Selvagem". A partir da revisão bibliográfica realizada nesse trabalho, consideremos os dioramas um subpadrão museográfico "Centrado em Objeto". Contudo, nas palavras de Marandino e colaboradores (2015), os dioramas representam um género de exposição "eco-centrado", de modo que, a partir de uma leitura mais conceitual e menos "museográfica" a existência desses recursos expositivos corroboram a narrativa da exposição de uma abordagem ecológica (FIGURA 39).

Como uma exposição "Centrada numa Narrativa", "Reis da Europa Selvagem" possui explicações explicitas da narrativa proposta [INDICADOR 30], como demonstrado no painel central do primeiro módulo da exposição (FIGURA 36), onde é possível ler: "Nesta exposição irá conhecer as espécies de grandes carnívoros que habitam a Europa, aprender sobre seus hábitos, comportamento, dieta e as causas e consequências do conflito com o homem".

Os espécimes em exposição também não deixam dúvidas sobre sua "utilidade" na construção da narrativa, sempre contextualizados e identificados (individualmente ou em grupo) [INDICADOR 29], servindo de suporte material para ilustrar conceitos presentes nos textos ou vídeos [INDICADOR 27], como por exemplo o palco em que as presas dos grandes carnívoros são apresentadas (Figura 38).

Mesmo que o contexto de surgimento do subpadrão museográfico Ecológico tenha sido principalmente o movimento ambientalista dos anos 1960-70, algumas das marcas ainda são expressas em "Reis da Europa Selvagem", dos quais destacamos a busca de novos contextos de uso 
a acervos que apresentavam a natureza de forma estática e estética, como no caso de espécimes oriundos de uma coleção privada [INDICADOR 40] (FIGURA 36, 38 e 80).

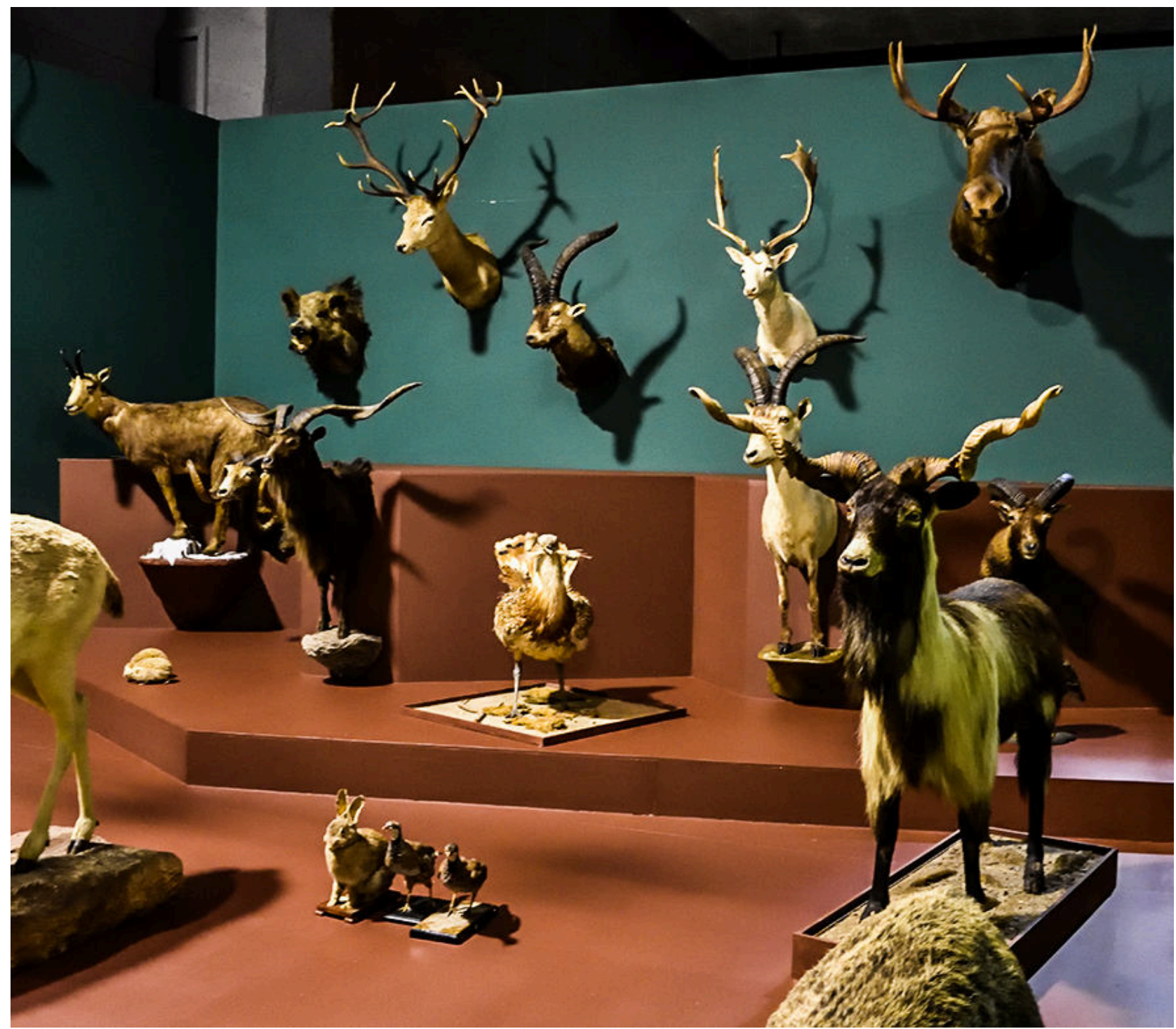

FIGURA 80: Detalhe do terceiro módula da exposição "Reis da Europa Selvagem", em que ungulados foram taxidermizados como bustos, uma forma frequentemente associada aos troféus de caça. Fotografia: Mariana Galera Soler, obtida em visita técnica em Julho de 2018

Outra marca importante, como reflexo de um movimento ativista, é a busca por envolver o visitante com a natureza e a exposição, seja pela criação de ambientes imersivos (Figura 81). 

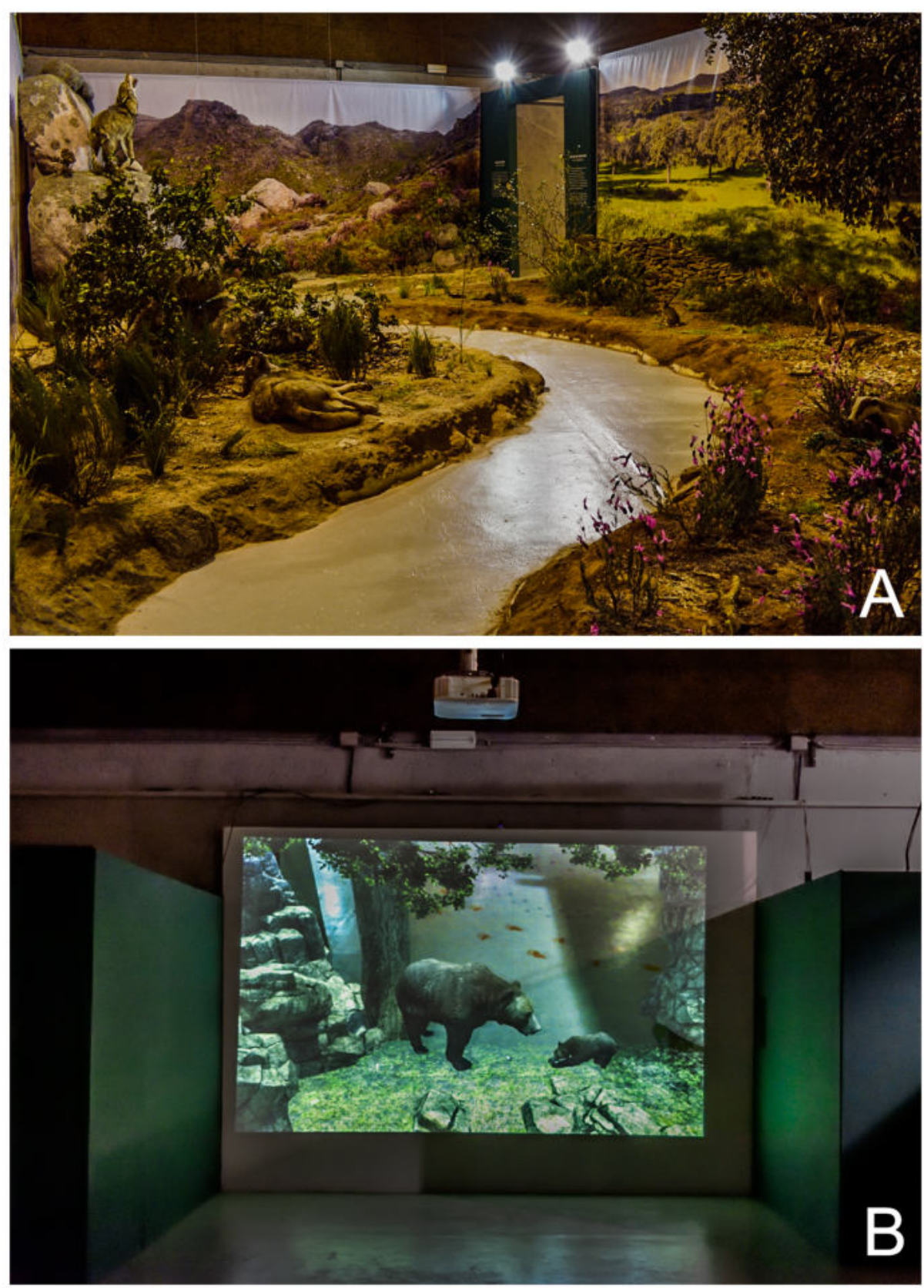

FIGURA 81: Dois ambientes imersivos criados pela museografia de Reis da Europa Selvagem. Em A, os dioramas construídos em paralelo e sem vidros, permitem que o visitante literalmente transite por dois diferentes ecossistemas. Em B, a utilização do recurso da realidade aumentada promove a sensação do visitante estar dentro do ambiente e interagindo com as personagens, no caso, uma mãe e uma cria de urso-pardo. Fotografia: Mariana Galera Soler, obtida em visita técnica em Julho de 2018.

A interpretação da exposição é controlada pela narrativa e percurso. Algumas mensagens escritas buscam promover a reflexão, permitindo maior proximidade e um caráter mais personalizado e propositivo do visitante perante à exposição [INDICADOR 31, 43 e 46]. Destacamos os seguintes exemplos: 
"Há mais de um século grandes carnívoros dominavam a Europa, e hoje?" (vídeo projetado no interior)

"Podemos transformar preconceito em respeito?

Podemos aceitar coexistir com essas espécies?” (Painel no primeiro módulo da exposição)

"É tempo de aprender a coexistir" (Painel ao lado da projeção de habitats, no segundo módulo)

"Estas são medidas importantes de conservação que devem ser levadas a cabo ou reforçadas ao nível dos países e da Europa: para que a sobrevivência dos grandes carnívoros esteja assegurada a longo prazo" (Painéis que encerram o segundo módulo)

"Os grandes mamíferos têm um passado, ainda estão presentes e merecem um futuro!" (Frase de abertura do último módulo da exposição).

Por fim, o uso de linguagem quotidiano e uma estética associada aos gráficos e notícias jornalísticas também foram aplicados nessa exposição (INDICADOR 47) (FIGURA 82). O apelo ao uso de uma imagem gráfica marcante aparece no documento ${ }^{103}$ apresentado pela empresa Laranja Mecânica como proposta de trabalho: "Enquadrados por uma linguagem gráfica marcante".

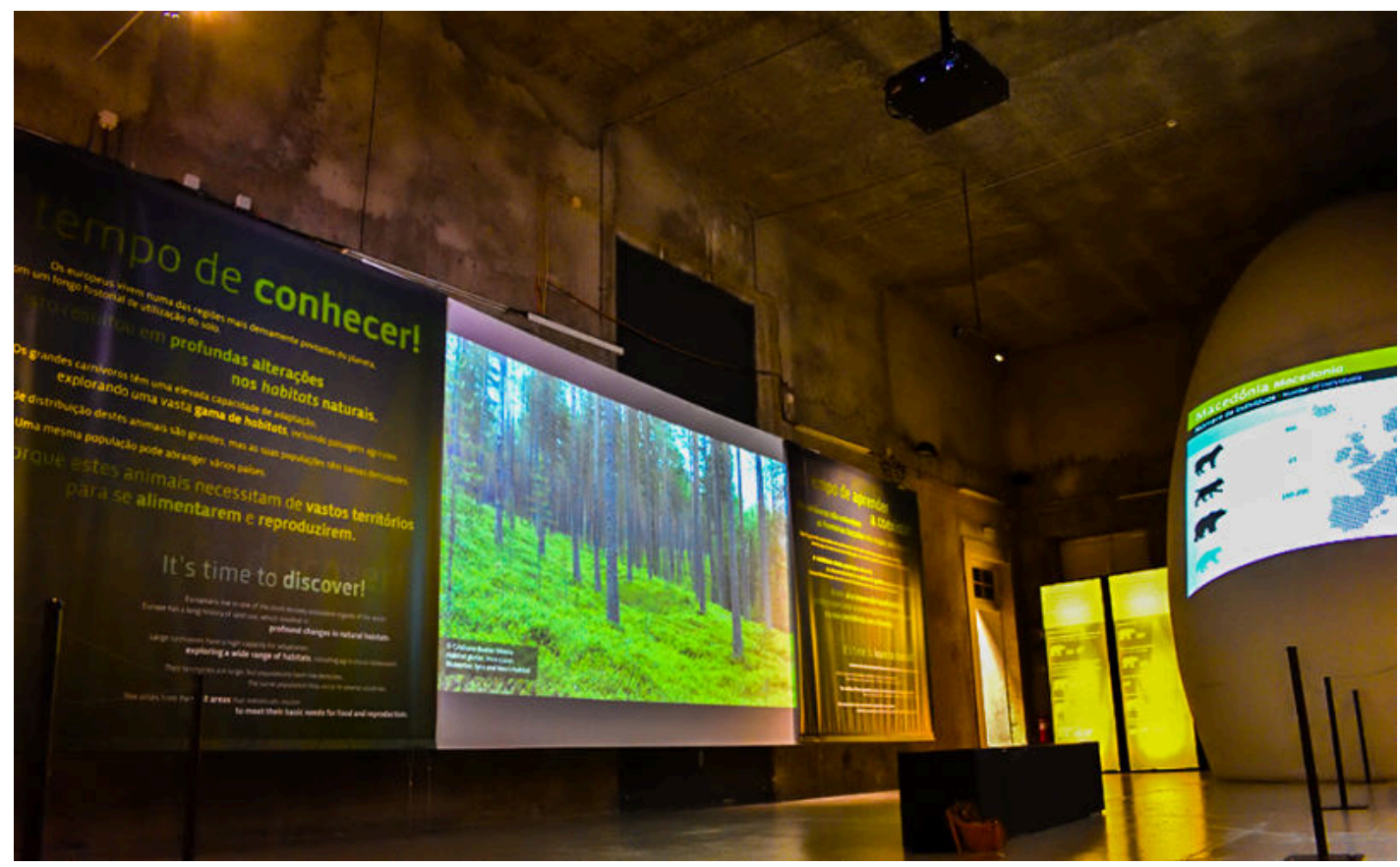

FIGURA 82: No segundo módulo da exposição "Reis da Europa Selvagem" encontramos o uso de imagens pictóricas (projeção e painéis), gráficos (projeção), frases curtas (painéis) e com formatação diferenciada, uma estética similar a utilizada em jornais e revistas. Fotografia: Mariana Galera Soler, obtida em visita técnica em Julho de 2018.

103 Documento digital disponibilizado por Cristiane Bastos-Silveira, em 21 de Junho de 2019. 
Assim como em "Conchas, corais e borboletas", os conteúdos e os curadores científicos também marcaram a forma de expor (museografia). "Reis da Europa Selvagem" surgiu da parceria do Grupo LOBO - associação não-governamental de ambiente cuja missão é "trabalhar em prol da conservação do lobo e do seu ecossistema em Portugal e fomentar o interesse pelo lobo e pelas ciências que the respeitam através da informação da opinião pública"104 - e o MUHNAC (unidade da Universidade de Lisboa e instituição de pesquisa científica em história natural). Sendo assim, a seleção do subpadrão museográfico Ecológico retrata a associação entre forma e conteúdo.

Os documentos fundamentais que originaram essa exposição foram relatórios científicos obtidos com resultados de grupos de investigação relacionados à conservação de grandes carnívoros da Europa (Large Carnivore Initiative for Europe - LCIE) e os resultados do Projeto LIFE MED-WOLF - Boas práticas para a Conservação do Lobo em Regiões Mediterrânicas - e Grupo LOBO, projetos de investigação baseados em estudos ecológicos e biogeográficos. Portanto, diretamente relacionado a tal conteúdo científico, observa-se grande quantidade de mapas de distribuição presente na exposição, bem como uma série de instruções normativas indicando medidas para a conservação das espécies e quantificando as ameaças sofridas para cada uma das espécies (Figura $37 C)$.

Mesmo tratando-se de parte de um acervo de museu de história natural, questões relacionadas a taxonomia das espécies (problemática inclusive, dado que tanto o lobo quanto o lince possuem sub-espécies, uma categoria taxonómica controversa para alguns taxonomistas) não estão presentes. Esse facto pode ser explicado por dois argumentos: em primeiro lugar, o MUHNAC sofreu um grande incêndio em 1978 e as coleções zoológicas foram as principais afetadas. De forma que a coleção de mamíferos foi "re-iniciada" apenas em 1983, possuindo atualmente cerca de 5000 exemplares provindos de diversas localidades de Portugal, de outros países europeus e alguns países africanos e sua importância reside na representação de endemismos ibéricos, destacam-se os pequenos mamíferos, como Galemys pyrenaicus e Microtus cabrera (Alves et al., 2014). Considerando que as espécies de grandes carnívoros em exposição foram descritas em datas anteriores a essa coleção (a mais recente subespécie é Canis lupus signatus, descrita por Cabrera em 1907) e não por

104 Informação disponível em: http://mww.grupolobo.pt/sobre-o-grupo-lobo/quem-somos/missao-valores. Acesso em 4 de Junho de 2019 . 
investigadores da instituição, não há a prevalência de espécimes taxonomicamente relevantes nessa coleção (série tipo: holótipos, parátipos, neótipos entre outros) para as espécies expostas. O tema taxonomia também não aparece nos documentos produzidos para a exposição, seja pelo comissariado científico, seja pela empresa responsável pela museografia.

Quanto aos curadores científicos de "Reis da Europa Selvagem", a curadora científica e responsável por essa exposição no MUHNAC, Cristiane Bastos-Silveira, possui uma carreira académica baseada em análises filogenéticas com dados moleculares de diversos grupos de mamíferos, que não carnívoros. Contudo, a curadora trouxe os dados dos relatórios científicos supracitados e entendeu essa exposição como uma oportunidade de otimizar o processo de comodato com a coleção privada de Valentim dos Santos. Já o outro curador científico, Francisco Petrucci Fonseca, além de presidente do Grupo LOBO e coordenador português do projeto LIFE MED-WOLF, construiu sua trajetória académica em Ecologia, com foco na Ecologia e Conservação dos lobos. O perfil académico desse comissariado científico sugere a prevalência do subpadrão museográfico Ecológico, bem como a adesão, pelo menos em parte, do padrão museográfico "Centrado em objetos" (preocupação fundamental com as coleções científicas).

A aderência parcial a outros padrões museográficos ("Espetacular" e "Retorno à Curiosidade") deve-se principalmente a utilização de recursos museográficos em pontos específicos da exposição ou podem ser associados às características contextualizadas em outros padrões. Por exemplo, o efeito dramático de luz e som [INDICADOR 65] está presente apenas no segundo módulo de "Reis da Europa Selvagem" (embora o som perpasse para outros espaços). Já características como utilização de recursos expográficos em grande escala [INDICADOR 67], grandes propagandas da exposição na fachada do MUHNAC [INDICADOR 81] e estética comercial [INDICADOR 82] estão mais próximas a busca por uma linguagem jornalística [INDICADOR 47]. Tais propostas aparecem como referências no documento entregue pela empresa Laranja Mecânica, como proposta de projeto museográfico.

A opção por estruturas móveis e que não afetaram a estrutura do edifício [INDICADOR 73] nessa exposição não esteve relacionada a uma possível itinerância, mas a restrições orçamentárias e desacordos entre as equipas do museu e as empresa Laranja Mecânica e Soul Pepper (Dias, comunicação pessoal, 6 de Abril de 2018) (Figura 83). 

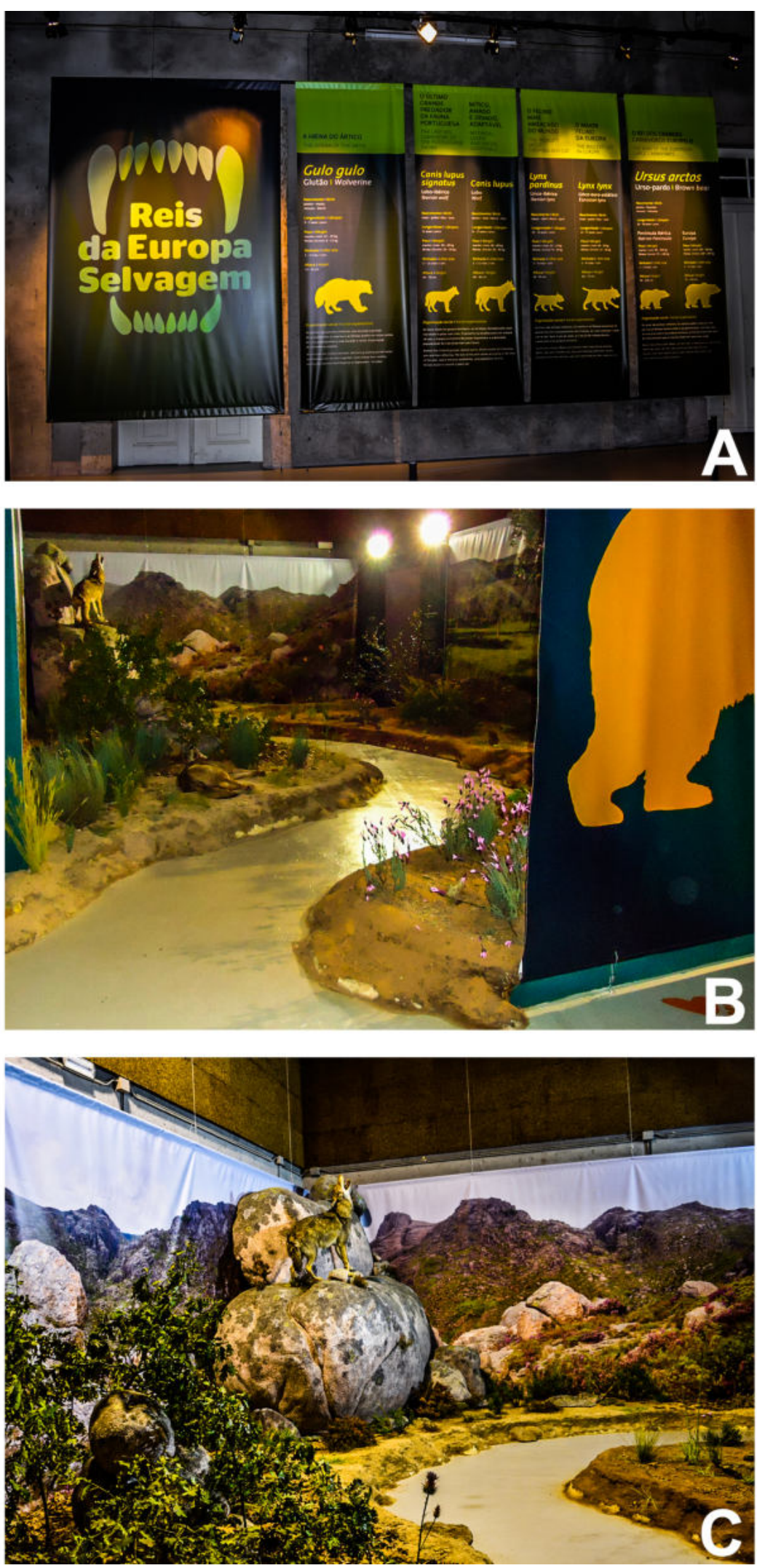

FIGURA 83: Detalhes exposição "Reis da Europa Selvagem" em que podem ser vistas estruturas de montagem simples e que não afetam a arquitetura do edifício (menor custo e possibilidade de novas montagens em outros espaços). Fotografia: Mariana Galera Soler, obtida em visita técnica em Julho de 2018. 
Diante das ampla gama de conceções da Ecologia e de seu papel na sociedade contemporânea, a exposição "Reis da Europa Selvagem" apresenta conceções dissonantes em seu discurso. Ao apresentar dioramas em que a espécie humana não está representada, expõe uma visão holística, uma vez que animais de diferentes espécies interagem e respondem ao meio ambiente em que se encontram, mas também retoma uma conceção de natureza intocada e bela, característica da ecologia romântica e dos ideias iniciais do movimento ambientalista dos anos 1960-70. A presença de taxidermias, isoladas ou em dioramas, também prima pela busca da autenticidade, outro valor fundamental dessa corrente da Ecologia.

Em contrapartida, os textos e recursos multimédias expostos posicionam os humanos criticamente diante da preservação espécies de grandes carnívoros europeus. Questiona atitudes e a ocupação humanas, bem como aponta medidas e políticas públicas para a conservação. Tal visão crítica e engajada, nos remete a ecologia política.

Considerando que o MUHNAC é uma instituição científica e grande parte dos argumentos de "Reis da Europa Selvagem" foram extraídos de relatórios de projetos de investigação, temos que os mapas de distribuição ao longo do tempo, textos sobre e a representação dos animais com comportamentos que teriam em vida e os dados que correlacionam práticas humanas e as ameaças a preservação dos grandes carnívoros europeus são exemplos essenciais da ecologia científica.

As abordagens e correntes ecológicas identificadas em "Reis da Europa Selvagem" carregam consigo conceções de ciência e de cientistas opostas: enquanto os dioramas e outros ambientes imersivos evocam noções de investigadores como gentlemen, que buscam uma inserção em plenitude com a natureza, por meio da observação distanciada, utópica e descontextualizada do crescimento urbano, o uso de imagens reais da investigação em campo e o compartilhamento de resultados da investigação associam-se a investigadores especializados e profissionais, cujo trabalho é a produção de conhecimento.

A Ecologia não está entre as museological sciences propostas por Pickstone (1994, 2001), pois possui um forte componente associado às experimental sciences. Ao criar o termo "ecologia", Ernst Haeckel buscou estruturar um campo da Biologia que estudava o organismo no ambiente, em oposição ao estudo no organismo em laboratório, que provinha da fisiologia (Keller \& Golley, 2000). Embora a investigação em laboratório seja uma das premissas as "experimental sciences", Pickstone (2001) entende que a Ecologia contemporânea abarca diversos tipos de estudos, que vão desde o 
trabalho de identificação e quantificação de espécies em ecossistemas (analítico), mas que também podem buscar o controle da natureza, subordinando os métodos analíticos aos experimentais. A busca por uma consciência ecológica e as preocupações com questões associadas à conservação da natureza estão também nos museus, que representam, a priori, espécimes mais próximos de sua forma em vida do que em séries taxonómicas (Pickstone, 2001).

Por fim, as múltiplas abordagens ecológicas identificadas em "Reis da Europa Selvagem" podem sugerir que, uma vez que a instituição científica não seja altamente especializada nos conteúdos científicos expostos (como os conteúdos taxonómicos em "Conchas, corais e borboletas" no MNRJ), é possível certo distanciamento e maior liberdade de abordagens tanto da equipa científica, que busca diferentes dados e não apenas aqueles quotidianamente relacionados à sua prática e a sua representação de prática profissional, como da equipa técnica, que possivelmente permitiu maior liberdade na proposição de formas da museografia.

\subsection{3 "Specere"}

Na exposição "Specere" é a mostra mais recente analisada nesse estudo e teve, na voz de seus comissariados técnico e científico, a clara missão de mostrar os "bastidores" ou as "reservas escondidas" do MUHNAC. Tendo em vista que, nas palavras de Dias (comunicação pessoal, 17 de Abril de 2918) as coleções de história natural eram aquelas que estavam mais escondidas na instituição.

Corroborando o discurso dos curadores com o método proposto de análise, constatamos que os valores de EPM mais altos e, portanto, padrões museográficos de maior aderência, foram aqueles cuja ênfase está nos objetos. Essa foi a primeira evidência em "Specere" da proximidade do discurso curatorial e da forma de expor.

Novamente ressaltando a importância das características comuns na definição de um padrão museográfico, temos 75\% dessas características dos padrões “Centrados em Objetos" identificadas em "Specere", bem como aproximadamente 70\% de presença dos indicadores das características comuns de "Retorno à Curiosidade".

Os contextos de surgimento desses dois grandes grupos de padrões museográficos encontram-se em extremos opostos da linha temporal da museografia de museus científicos, como 
discutido no capítulo anterior. As exposições centradas em objetos foram as primeiras a surgirem nos museus de história natural, em um momento em que a história natural era institucionalizada e reconhecida "ciências dos museus", sendo os museus centros de desenvolvimento científico, na Europa do século XIX (Lopes, 2009). Os museus eram locais de investigação que permitiam explorar a ordem da natureza e contemplar as maravilhas naturais (Lopes \& Murriello, 2005), sendo espaços de articulação e formação do olhar dos naturalistas e transformando-se em instituições de produção e disseminação de conhecimentos, nos moldes que Ihes exigiam as conceções científicas vigentes (Tony Bennett, 2004).

Evidentemente, as coleções operam um papel central nessa visão de instituição museológica (padrão museográfico "Centrado em objetos"). De modo que, ao buscar uma museografia que valorize e reconheça a importâncias das coleções de história natural, formas de organização do acervo são recuperadas, promovendo do aprendizado por meio da observação dos objetos [INDICADOR 1]. Outro indicador marcante desse padrão é a de grande aporte de objetos organizados hierarquicamente, que privilegiam as formas anatómicas externas [INDICADOR 2, o viés histórico desse indicador foi explicado anteriormente, em sua aplicação na exposição "Reis da Europa Selvagem"].

Além disso, remonta também a perspetiva histórica a reutilização de mobiliário característico do século XIX, com o aproveitamento das estantes da biblioteca do Instituto Bacteriológico Câmara Pestana (Figura 85).

Em contrapartida, especialmente nos últimos 40 anos, os museus têm assumido um papel socialmente responsável, posições mais criticamente engajada dos curadores e suportado equipas multidisciplinares. A busca para que o visitante seja autónomo e que, ao mesmo tempo, interaja física, afetiva e intelectualmente com a exposição permitiu novas práticas museográficas, que provocassem o "reencantamento" com as objetos. O uso de estética e a rubrica da curiosidade foram então recuperados, destacando a presença da múltiplas narrativas e relações com diversas áreas do conhecimento, associações pessoais, questões da materialidade, de forma cada vez mais distanciado de explicações diretas e rígidas ou hierarquias únicas e fixas (M. Henning, 2006). Esse contexto mais democrático e inspirador foi fundamental para a constituição do padrão museográfico "Retorno à Curiosidade". 


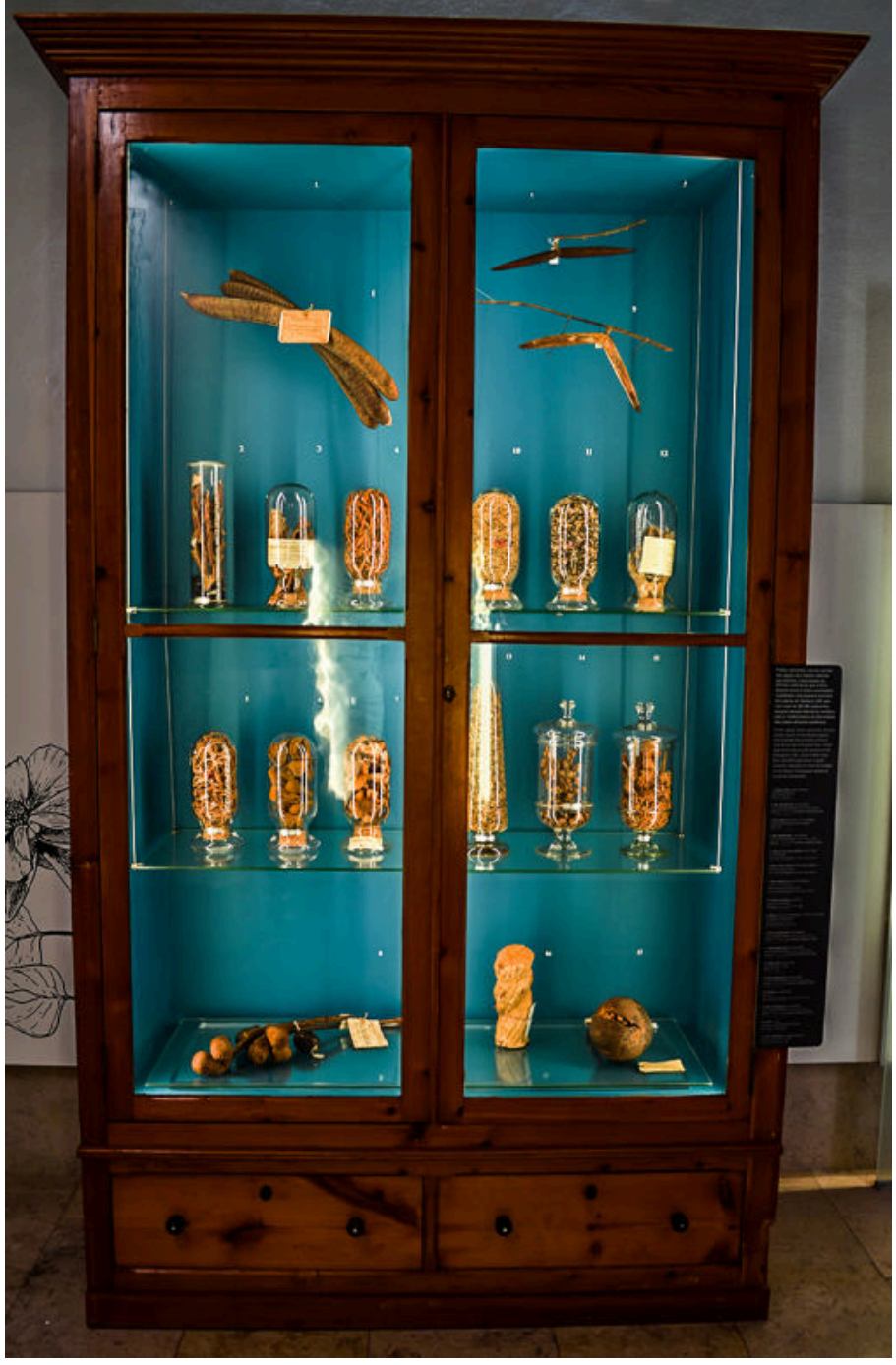

FIGURA 84: Armário da exposição "Specere", cujo mobiliário foi reaproveitado das estantes da biblioteca do Instituto Bacteriológico, contendo espécimes histórica de botânica que atualmente fazem parte do Herbário LISC. Destaca-se a forma particular dos vidros em que são inseridos os espécimes, etiquetas antigas e a diversidade das procedências dentro dos países lusófonos, como: Índia, Angola, Moçambique, Guiné-Bissau, Tomé e Príncipe. Fotografia: Mariana Galera Soler, obtida em visita técnica em Julho de 2018.

Em "Specere", a busca pelo reencantamento com os objetos [INDICADOR 98] foi o fator fundamental para a construção da exposição. Quando a equipa curatorial se preocupou em dar visibilidade às coleções de história natural, também busca junto ao público um reconhecimento da importância do seu trabalho e da instituição. Portanto, a escolha desse padrão museográfico é também uma escolha em prol da prática científica dos museus, na contemporaneidade.

Entre os armários de maior apelo estético, destacam-se o armário com a coleção de conchas e o armário das aves. De acordo com Jorge Prudêncio (2018, comunicação pessoal, 13 de Maio de 2018), a partir de uma escolha inicial de mais uma centena de conchas em uma coleção que ultrapassa os milhares, a equipa da Museologia agrupou os espécimes, buscando uma ordenação estética, associando formas e cores (Figura 50D). Já no armário das aves, Prudêncio ainda afirma que a investigadora Maria Judite Alves fez a seleção dos espécimes não naturalizados (taxidermia 
científica), buscando aqueles mais coloridos, destacados e oriundos de diferentes procedências, pertencentes a coleção recém-agregada ao MUHNAC do IICT (Figura 48).

Outro aspeto estético que marca este subpadrão museográfico é a justaposição de diferentes espécimes e formas de representação [INDICADOR 106]. Nesse sentido, os armários que apresentam as diferentes coleções preservadas em via húmida, onde há diferentes grupos zoológicos (embora organizados internamente pelos seus respetivos grupos taxonómicos), a escolha de uma única forma de preservação e distintas formas de espécimes, recipientes e etiquetas promove a "typological exuberance".

Além disso, a exposição The Wet Collections, do Museum für Naturkunde (Berlim), considerada um dos marcos iniciais do padrão museográfico "Retorno à curiosidade" (Adamopoulou \& Solomon, 2016a), mostra várias similaridades com o módulo desenvolvido em "Specere" (considerando-se as proporções devidas em termos de financiamento e quantidade de acervo, pode-se encontrar semelhanças no tipo de iluminação, recipientes, espécimes e preservação) (Figura 85).
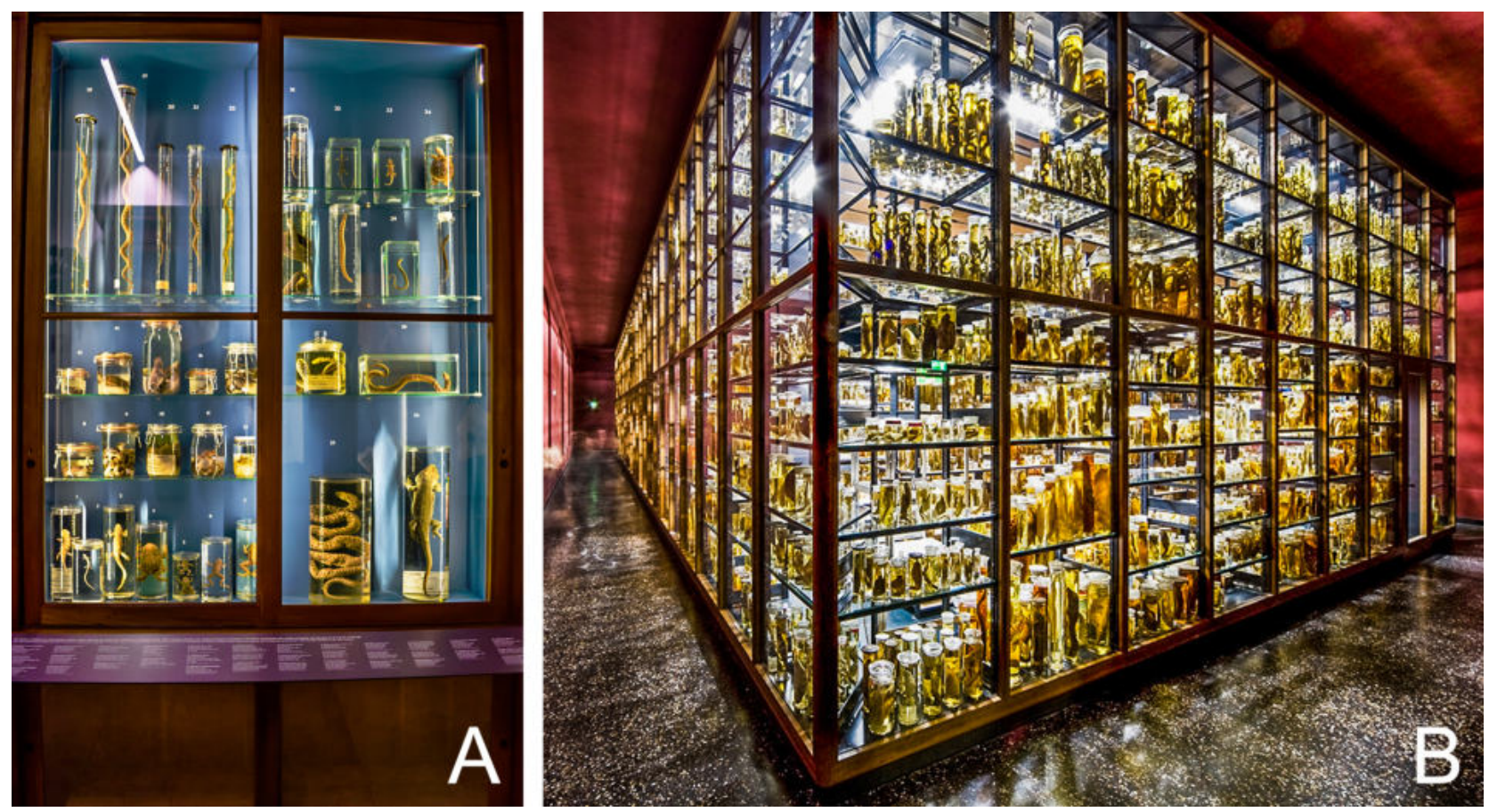

FIGURA 85: Visão comparada de duas museografias inspiradas em "typological exuberance". Em A, Armário da exposição "Specere" contendo espécimes herpetológicos preservados em via úmida. Fotografia: Mariana Galera Soler, obtida em visita técnica em Julho de 2018. EM B, módulo da exposição The Wet Collections, do Museum für Naturkunde (Berlim). Disponível em: https://www.museumfuernaturkunde.berlin/en/museum/exhibitions/wetcollections. Acesso em 14 de Junho de 2019. 
Outro elemento utilizado em "Specere" para buscar o encantamento dos visitantes, foi a utilização de réplicas [INDICADOR 108] de fósseis de grande importância para o estudo evolutivo dos dinossauros ou grupo de grande apelo mediático. Contudo, os fósseis que foram encontrados em afloramentos portugueses ou pertenciam a coleção da instituição não estavam representados. Outros fósseis escolhidos para a exposição também destacam-se por sua boa preservação ou grande tamanho, não necessariamente estando associados à biota pretérita local (Figura 86).

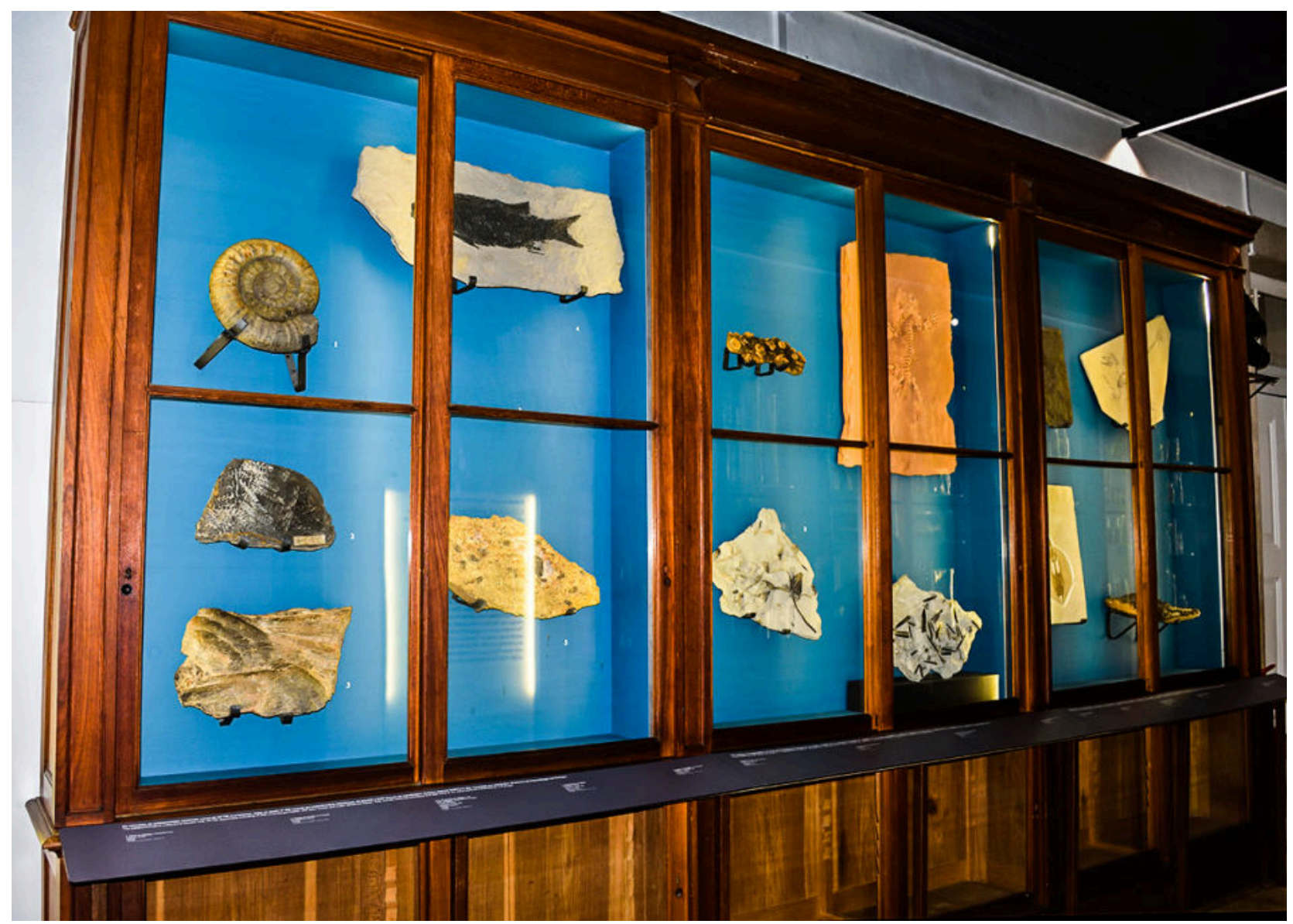

FIGURA 86: Armário da exposição "Specere" contendo réplicas de fósseis relacionados à evolução de dinossauros e outros fósseis autênticos, com destacada qualidade de preservação ou tamanho. Fotografia: Mariana Galera Soler, obtida em visita técnica em Julho de 2018.

No tocante aos outros padrões museográficos identificados em "Specere", notam-se alguns elementos das características comuns tanto de padrões "Centrados numa Narrativas", como "Espetacular", com maior EPM no último.

Destacamos que os indicadores do padrão museográfico "Espetacular" foram também identificadas na outra exposição da mesma instituição - "Reis da Europa Selvagem" - como: a 
utilização de uma narrativa explicativa explícita [INDICADOR 30], em que textos orientam o visitante; grandes painéis de propaganda [INDICADOR 67] na fachada da instituição, como divulgação; a utilização de móveis modulares, que facilmente permitem que a exposição seja renovada [INDICADOR 73]; objetos organizados dentro do mesmo tema [INDICADOR 79], mesmo que não exista grande articulação entre os temas de cada um dos módulos (armários); seleção estética do acervo, como claramente evidenciado na exposição malacológica [INDICADOR 71] e busca por objetos reais [INDICADOR 68], certificando a autoridade institucional).

Dessarte pode-se sugerir que sejam características mais gerais de exposições contemporâneas em museus de história natural, influenciados por museografias da segunda metade do século XX, como formas de comunicação e marketing institucional utilizando grandes painéis para divulgar as exposições e, especialmente nos casos analisados, exposições com orçamentos mais modestos, cuja museografia não interfere na arquitetura do prédio (muitas vezes registados como património, o que dificulta ainda mais modificações), mas podem ser facilmente desenvolvidas.

Já analisando-se subpadrões museográficos específicos, como "Quotidiano", "Ecológico” ou "Public Understanding of Science, verificamos valores de EPM e percentagem de aderência similares, todos entre 0,05-0,2 | 20-30\%. Essa ampla distribuição nos padrões, sem elevada representatividade de cada um individualmente, o que também aconteceu em certa medida em "Conchas, corais e borboletas", pode ser justificada pela multiplicidade de curadores científicos associados ao projeto expositivos e que tiveram uma voz decisiva. Coube aos setores associados à exposição (Museologia) fazer a gestão entre equipas científicas

Em ambas instituições (MNRJ e MUHNAC), as equipas científicas foram livres para suas criar seus conteúdos e selecionar acervos dentro do respetivo setor/armário da exposição. Mesmo trabalhando dentro de uma mesma instituição e tendo como objeto de estudo as coleções científicas de história natural, existem diferentes práticas realizadas e abordagens possíveis, o que pode ser evidenciado por narrativas tão discrepantes quanto a conservação de mamíferos de médio porte e as adaptações das aves ao voo. Ou por armários sobrecarregados de frascos organizados taxonomicamente e uma vitrine com apenas dois esqueletos antropomorfos em posição anatómica. 


\subsection{4 "Galeria da Biodiversidade"}

A exposição permanente presente na Galeria da Biodiversidade parte de premissas diferentes das demais exposições analisadas nesse estudo. Na voz da equipa do MP esse espaço pretende "ir além do conceito de museu" (FONSECA; GUSMÃO, comunicação pessoal, 27 de Fevereiro de 2019), o que é refletido em opções museográficas únicas, promovidas pela escolha largamente propagada conceção de "museologia total", de Jorge Wagensberg.

Além disso, também em termos institucionais a Galeria da Biodiversidade difere-se das demais, uma vez que mesmo sendo parte de um museu de história natural (Museu de História Natural e da Ciência da Universidade do Porto), a Galeria integra a Rede Nacional de Centros Ciência Viva, um importante conjunto de mais de 20 centros de ciências concebidos a partir dos anos 1990, em Portugal.

"Museologia total" e os centros de ciência são os referenciais da Galeria da Biodiversidade que influíram diretamente nas escolhas da museografia e, portanto, são evidenciadas nos padrões museográficos encontrados. Embora tenham sido indicadores em praticamente todos os padrões, há maior propensão (valor mais alto de EPM) no Padrão Museográfico "Centrado numa Narrativa”, especialmente no subpadrão Public Understanding of Science, e no Padrão Museográfico Espetacular.

De acordo com as premissas da "museologia total" o museu de ciências "es un espacio dedicado a crear, en el visitante, estímulos a favor del conocimiento y del método científicos (...) y a promover la opinión científica en el ciudadano (...)" (Wagensberg, 2000, p. 15), o que evidencia a ênfase no visitante [INDICADORES 28, 50 e 75] nesse tipo de museografia.

Na Galeria da Biodiversidade o discurso científico é preponderante em todos os textos da exposição [INDICADOR 34] (com raras exceções onde são encontrados excertos poéticos, especialmente de Sophia Andresen), o que é também uma característica da museologia total: "La ciencia es la forma de conocimiento que más influye en la vida del ciudadano" (Wagensberg, 2000, p. 15). Embora o mesmo autor afirme mais a frente nessa publicação: "no se deben enviar mensajes especiales garantizados o blindados por la tradición o la autoridad científica” (Wagensberg, 2000, p. 16), os textos presentes são bastante resumidos e restritos a conceitos científicos ou explicações de 
processos e fenómenos. Outras narrativas, como a biografia dos objetos, conhecimentos locais ou referenciais culturais são pouco presentes ou ausentes nos módulos.

Corrobora também a importância do discurso científico e do texto a seguinte citação de Wagensberg (2000, p. 16): "Ios objetos reales ilustran, los fenómenos reales demuestran y las escenografías y emblemas sitúan". Os objetos não têm, pois, uma voz ativa, e sim servem de ilustração ou demonstração de uma narrativa ou contexto proposto por seus curadores [INDICADORES 27, 29, 30] (Figura 87).

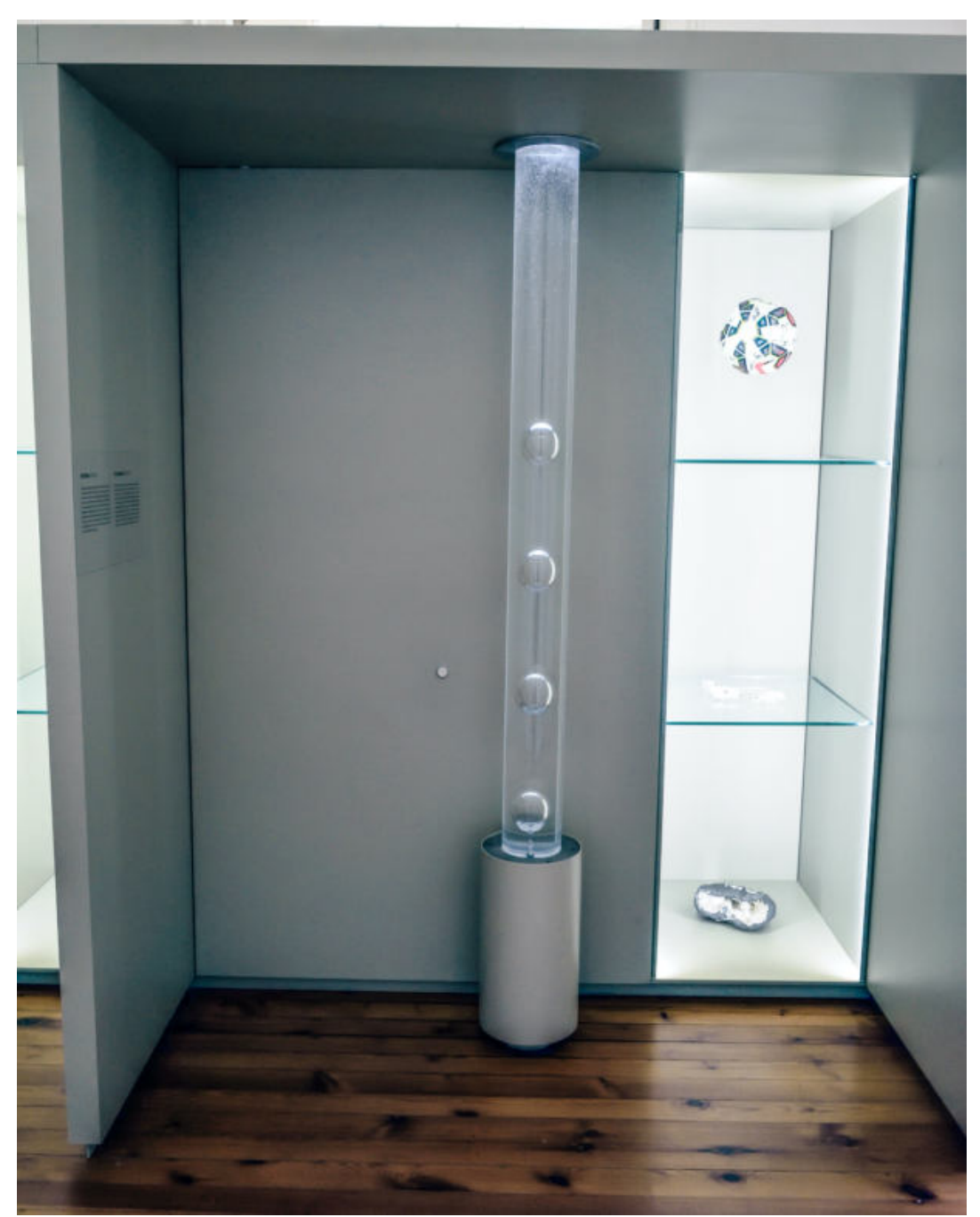

FIGURA 87: No Módulo Diversidade de Formas, destaque para a forma "Esfera", que é descrita em texto (na parede à esquerda), demonstrada em aparato interativo que cria bolhas de ar em gel e ilustrada por objetos (bola de futebol, pérolas e formações rochosas). Fotografia: Mariana Galera Soler, obtida em visita técnica em Fevereiro de 2019.

Ressalta-se ainda que a conceção de "museologia total” foi proposta para museus e espaços científicos e que seu autor - Jorge Wagensberg - é físico e realizou uma série de publicações científicas no campo da Física, Biologia (Wagensberg, 2008) e Filosofia da Ciência (Wagner, 2004). A presença de dois curadores que também são investigadores (Nuno Ferrand e Jorge Wagensberg) 
justifica, como também ocorreu nas outras exposições analisadas, o forte caráter científico da exposição e do modo como foi pensada: "El mejor método para imaginar, diseñar y producir instalaciones museográficas en un Museo de Ciencias es el propio método científico (basado en los principios de objetividad, inteligibilidad y dialéctica)"(Wagensberg, 2000, p. 16).

Há ainda um outros vieses importantes na "museologia total" de Wagensberg: (i) a busca por evidenciar o real (museus como "realidade concentrada", nas palavras do autor) por meio de objetos autênticos (sempre que possível); (ii) a promoção do encantamento do visitante, seja pelo apelo estético ou pelo estímulo à curiosidade: "immersion in the reality of the world is to be fostered. Or to put it another way, remoteness from reality is to be avoided" (Wagensberg, 2014b, p. 345); e (iii), constantemente, propor uma museografia contemporânea e diferente do que é conhecido até então. Tais perspetivas podem ser evidenciados pelas características marcadas tanto pelas características comuns do padrão museográfico Espetacular, como a utilização de efeitos de luz e som [INDICADOR 65], no Gabinete de Curiosidades (Figura 62), ou a seleção estética do acervo [INDICADOR 71], como mostrado na vitrine que ilustra a diversidade de ovos (Figura 55 e 86).

Embora o subpadrão museográfico blockbuster tenha sido recentemente estabelecido no âmbito dos museus, este têm figurado marcadamente nas exposições analisadas, como a utilização de grandes propagandas [INDICADOR 81], ou ainda associados a alguns aspetos da "museologia total", como oportunidades de "free-choice learning" [INDICADOR 88] por meio de módulos expositivos independentes uns dos outros (Figura 52), áreas para tirar fotos [INDICADOR 95] como o manequim de Darwin (Figura 61), e apelo popular de massa [INDICADOR 86], com peças icónicas como o esqueleto da baleia preso ao teto (Figura 53).

Ainda sobre a "museologia total", também respondem a essa busca por uma museografia única, estética e contemporânea algumas características associadas ao padrão museográfico "Retorno à Curiosidade" - o mais contemporâneo padrão proposto nessa tese - especialmente no que diz respeito a promoção do reencantamento com os objetos [INDICADOR 98] (Figura 88). 


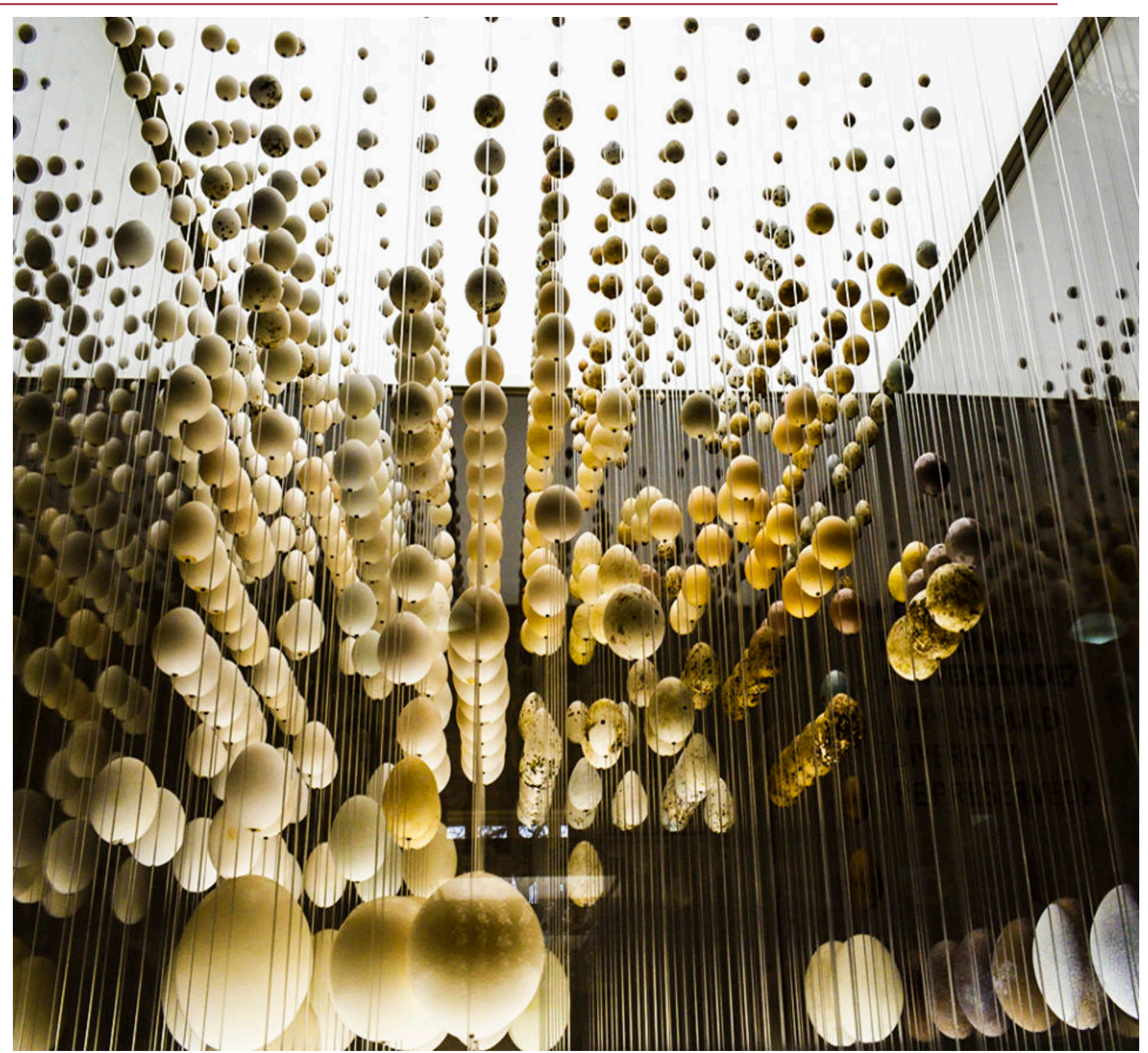

FIGURA 88: Uma das vitrines mais aclamadas pelas publicações na abertura da exposição permanente da Galeria da Biodiversidade é aquela que ilustra a diversidade de ovos na natureza. Nessa vitrine uma coleção de ovos preservados em via seca (apenas a casca) são distribuídos de acordo com sua cor $X$ tamanho $X$ presença de ornamentações. O resultado garantiu excelentes fotos de divulgação. Fotografia: Mariana Galera Soler, obtida em visita técnica em Fevereiro de 2019.

As vitrines que representam os quatro princípios para preservação da biodiversidade (Figura 54) são bons exemplos da utilização da museografia como metáfora de temas alegoricamente e visualmente [INDICADOR 108] e na utilização de uma abordagem interdisciplinar [INDICADOR 112], uma vez que: "objeto o al fenómeno real para cuyo conocimiento se usa luego la disciplina científica que convenga, porque "la naturaleza no tiene la culpa de los planes de estudio previstos en escuelas y universidades" (Wagensberg, 2000, p. 16). 
Os recursos interativos são também uma parte destacada da "museologia total" de Wagensberg. Contudo, mesmo antes desta recente proposição museológica, os recursos interativos já faziam parte do universo dos museus de ciências, a partir da influência do movimento do Public Understanding of Science e da popularização dos centros de ciência (e ainda mais anteriormente se considerarmos as feiras internacionais e museus de ciências e técnicas). Assim, a interatividade que marca a Galeria da Biodiversidade responde tanto a proposta museológica, como pelo tipo de instituição que está relacionada (Rede Nacional de Centros Ciência Viva) [INDICADOR 49, 88] (Figura 89).
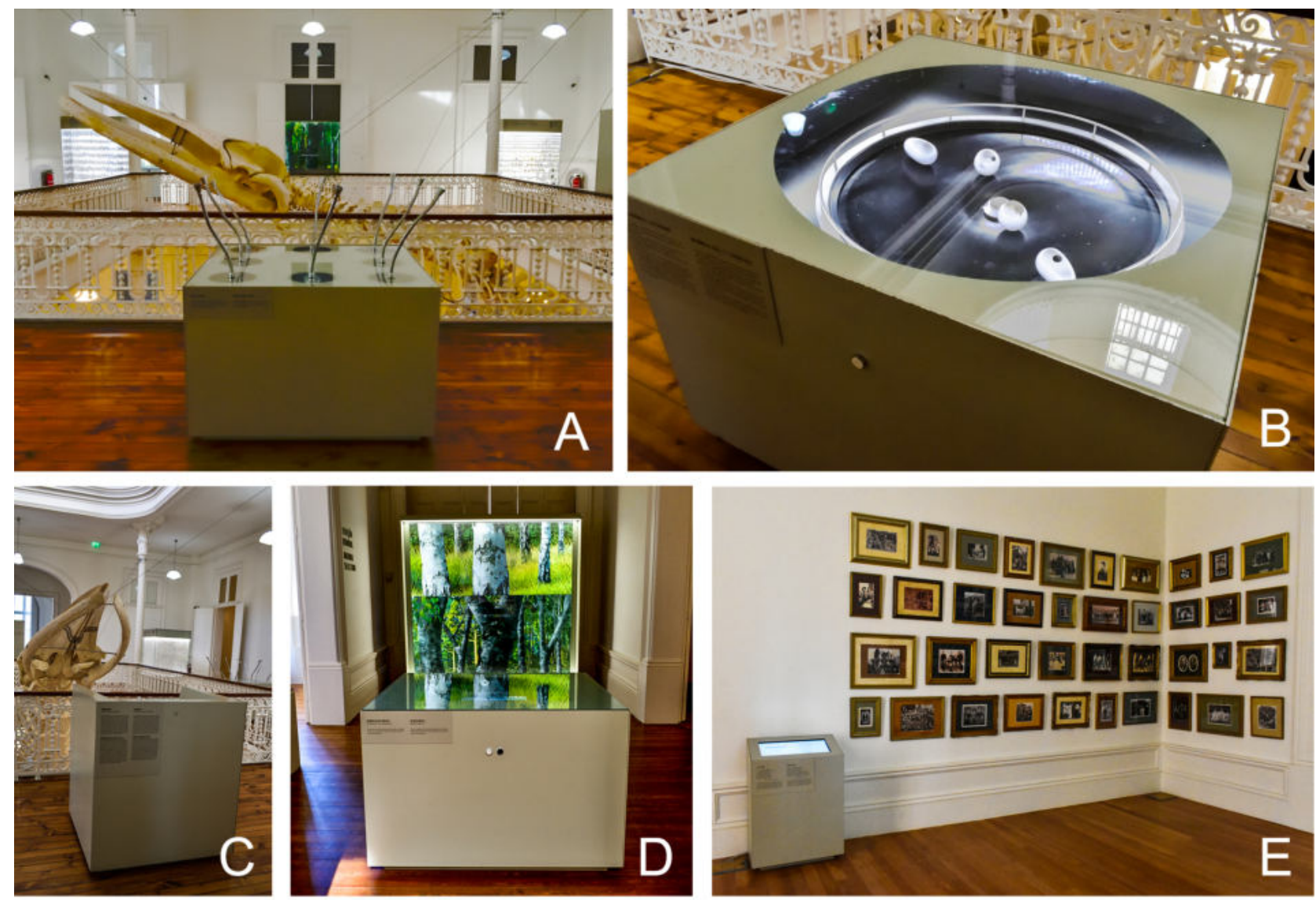

FIGURA 89: Exemplos de recursos interativos da Galeria da Biodiversidade. Em A, módulo interativo "A que cheira?", presente junto com os princípios da Biodiversidade. Em B, módulo interativo “Ovo Ovóide e Ovo Esferóide”, presente junto com os princípios da Biodiversidade. Em C, numa cadeira colocada a frente do esqueleto do musaranhopigmeu e o crânio da baleia é possível acionar um dispositivo para ouvir os batimentos cardíacos desses dois animais e ainda o humano. Em D, módulo interativo em que o visitante pode observar o aumento ou a diminuição da frequência de bolas de cores preta e branca, associado à mudança da frequência de indivíduos melânicos e claros, no exemplo das borboletas de Manchester (aparato ao fundo). Em E, totem multimédia em que o visitante pode escolher ouvir ou ler cinco dos poemas mais famosos de Sophia de Mello Andresen. Fotografia: Mariana Galera Soler, obtida em visita técnica em Fevereiro de 2018. 
Public Understanding of Science foi um movimento educacional chegou a Europa nos anos 1980, com a publicação de um influente relatório da Royal Society of London (1985), com o mesmo título. Em Portugal, sua expressão pode ser identificada na publicação do Manifesto para a Ciência em Portugal de Mariano Gago, em 1990, base sobre a qual se assentou diversas mudanças na política científica portuguesa e o lançamento do programa Ciência Viva (Conceição, 2011).

A Rede Nacional dos Centro Ciência Viva não têm, regra geral, como propósito a preservação, pesquisa e comunicação de patrimónios. Por princípio baseiam-se na disponibilização de dispositivos interativos, orientando-se segundo um modelo de science centres tal como concebido de forma pioneira por Frank Oppenheimer, no Exploratorium de São Francisco (Conceição, 2011). Desse modo, mesmo mais de 30 anos após o lançamento do programa, a preocupação com o estímulo a cultura científica da população ainda se mantém e a Galeria da Biodiversidade. Em uma perspetiva formativa e escolarizada ${ }^{105}$, baseada em princípios científicos [INDICADOR 58], mesmo que descontextualizados das realidades locais [INDICADOR 56, 96], como exemplificar a seleção natural com borboletas inglesas ou a seleção artificial com o milho sul-americano (Figura 59B-C).

Influenciado pelo movimento educacional e museológico, o proposto subpadrão museográfico Public Understanding of Science foi aquele com maior aderência a exposição permanente da Galeria da Biodiversidade, confirmando a associação entre o tipo de instituição e museografia. Para além dos recursos interativos, as instituições e exposições inseridas nesse subpadrão buscam demonstrar os princípios científicos básicos [INDICADOR 51], o que é evidenciado pela seleção dos conteúdos de diversos módulos da Galeria, onde cada um explora um conceito científico, como: seleção natural, artificial ou sexual, especiação, migrações entre outros.

Por fim, ressalta-se que características associadas ao padrão museográfico "Centrado em objetos" são aquelas também alinhadas com a "museologia total", tais como o grande apelo estético, privilegiando formas anatómicas externas [INDICADOR 2] e a prevalência de espécimes representativos e regulares [INDICADOR 9].

Outras características como a iluminação destacada [INDICADOR 26] e a relação de dependência entre as formas para sua compreensão [INDICADOR 3] estão associadas à criação de

105 Quase 50\% do público da rede de Centros Ciência Viva é escolar, de acordo com o Relatório "O Público da Rede Nacional de Centros Ciência Viva”. Disponível em: http://umw.cienciaviva.pt/img/upload/estudo.PDF. Acesso em 10 de Junho de2019. 
reproduções cenográficas [INDICADOR 37] e proposição de ambientes imersivos [INDICADOR 69], na busca de promover emoções nos visitantes (interatividade minds on e heart on, Wagensberg, 2000), outra premissa desse conceção museológica.

Assim, a "museologia total" proposta por Jorge Wagensberg não pode ser considerada um padrão museográfico, uma vez que está circunscrito nas produções curatorias de Wagensberg e seu grupo e pelo facto de reproduzir diversas referências de padrões museográficos já estabelecidos e reproduzidos globalmente. Trata-se mais de uma expressão particular da museografia de grupo de profissionais de museus e centros de ciência do que um padrão sob os quais estão subjacentes epistemologia e práticas científicas e museológicas.

\subsection{5 "Biodiversidade: conhecer para preservar"}

A última exposição analisada neste trabalho é "Biodiversidade: conhecer para preservar", do MZUSP. Partindo o Memorial Descritivo ${ }^{106}$ da exposição, o conceito gerador é: "O conhecimento sobre a biodiversidade tem origem na pesquisa sobre acervos e é a base para compreensão de processos evolutivos e da preservação da natureza" e as suas palavras-chave são: biodiversidade, zoologia, evolução, conservação, acervo, pesquisa, seres-humanos em contexto" (grifo nosso).

Na altura da inauguração da exposição, em entrevista ao jornal Estadão (O Estado de São Paulo, 28 de Agosto de 2015), a curadora Maria Isabel Landim afirmou: "A visita vale pela bela exposição e para uma reflexão sobre o papel que desempenhamos na crise atual da biodiversidade e sobre a contribuição de nossa instituição na produção de conhecimento relevante que visa em última instância a sua preservação" (Zucchi, 2015).

Em ambas passagens destaca-se os papéis predominantes do seguintes aspetos: (i) conhecimento científico; (ii) do acervo; (iii) da investigação do Museu de Zoologia da Universidade de São Paulo; (iv) da evolução; e (v) da preservação da natureza. Tais temas, para além do discurso expositivo, estão expressos na museografia, uma vez que maiores valores de EPM (e, portanto, padrões com maior adesão) são encontrados em Padrões Museográficos "Centrados em Objetos",

\footnotetext{
106 Documento digital disponibilizado por Maria Isabel Landim, em 13 de Agosto de 2018.
} 
especialmente, "Séries Evolutivas/Progressistas" e "Séries Taxonómicas"107, e "Centrado numa Narrativa", subpadrão museográfico "Ecológico", respetivamente.

A importância dada as coleções científicas do MZUSP é reforçada no Memorial Descritivo como: "Oferecer um olhar sobre a biodiversidade que nenhuma outra instituição poderia produzir por estar radicalmente relacionado à pesquisa desenvolvida no MZ. Os grupos aqui estudados são citados nas narrativas" e é também reproduzida na museografia, como por exemplo no Módulo 2, onde numa série de quatro vitrines sextavadas (mobiliário antigo e que faz parte do património da instituição), três abordam a importância do trabalho da instituição e outra a diversidade de besouros, a partir de gavetas entomológicas repletas de espécimes presentes nas coleções científicas (Figura 88 C e D).

Nessas vitrines há ainda o núcleo "Novas Identidades”, onde são apresentadas espécies recentemente descritas por investigadores e projetos de pesquisa associados à instituição. Nesse caso são apresentadas novas espécies de cupins (Isoptera), moscas e melgas (Diptera), besouros (Coleoptera), caramujo (Mollusca) e peixes (Osteichtyes). Para mostrar as espécies descritas pelos investigadores da instituição são utilizados espécimes individualmente identificados [INDICADOR 4] e preservados em via húmida ou via seca, de forma a privilegiar a anatomia externa [INDICADOR 2].

As informações estão explícitas nos textos [INDICADOR 30], mas a presença dos espécimes de coleções científicas conferem autoridade a instituição e materialidade ao conteúdo [INDICADOR 68](Figura 90).

Tal como "Conchas, corais e borboletas" (MNRJ), em "Biodiversidade: conhecer para preservar" a acentuada importância ao acervo e a investigação realizada na instituição é também representada pelo grande suporte de espécimes de coleções científicas.

No Memorial Descritivo da exposição paulista parte-se da seguinte premissa sobre o acervo:

"A narrativa de nossa exposição estará centrada na apresentação de nosso acervo em toda a sua diversidade (...). Entendemos que é justamente a nossa relação com o acervo que nos caracteriza enquanto instituição e esta relação deve transparecer ao

\footnotetext{
107 Dioramas compõe um subpadrão museográfico de alta aderência também, contudo esse recurso museográfico está circunscrito apenas no Módulo 2 de "Biodiversidade: conhecer para preservar" e será discutido mais a frente no texto.
} 
Biodiversidade Musealizada: Formas que Comunicam

público. Todos os demais meios de apresentação e recursos narrativos devem ser auxiliares".

O que é corroborado no comunicado a imprensa (press release) disponível no site institucional ${ }^{108}$ :

"O MZUSP é considerado um centro de referência em pesquisa relacionada à biodiversidade, sistemática e taxonomia animal - o reconhecimento de sua tradição e excelência vem atrelado à responsabilidade de disseminar o conhecimento que produz"
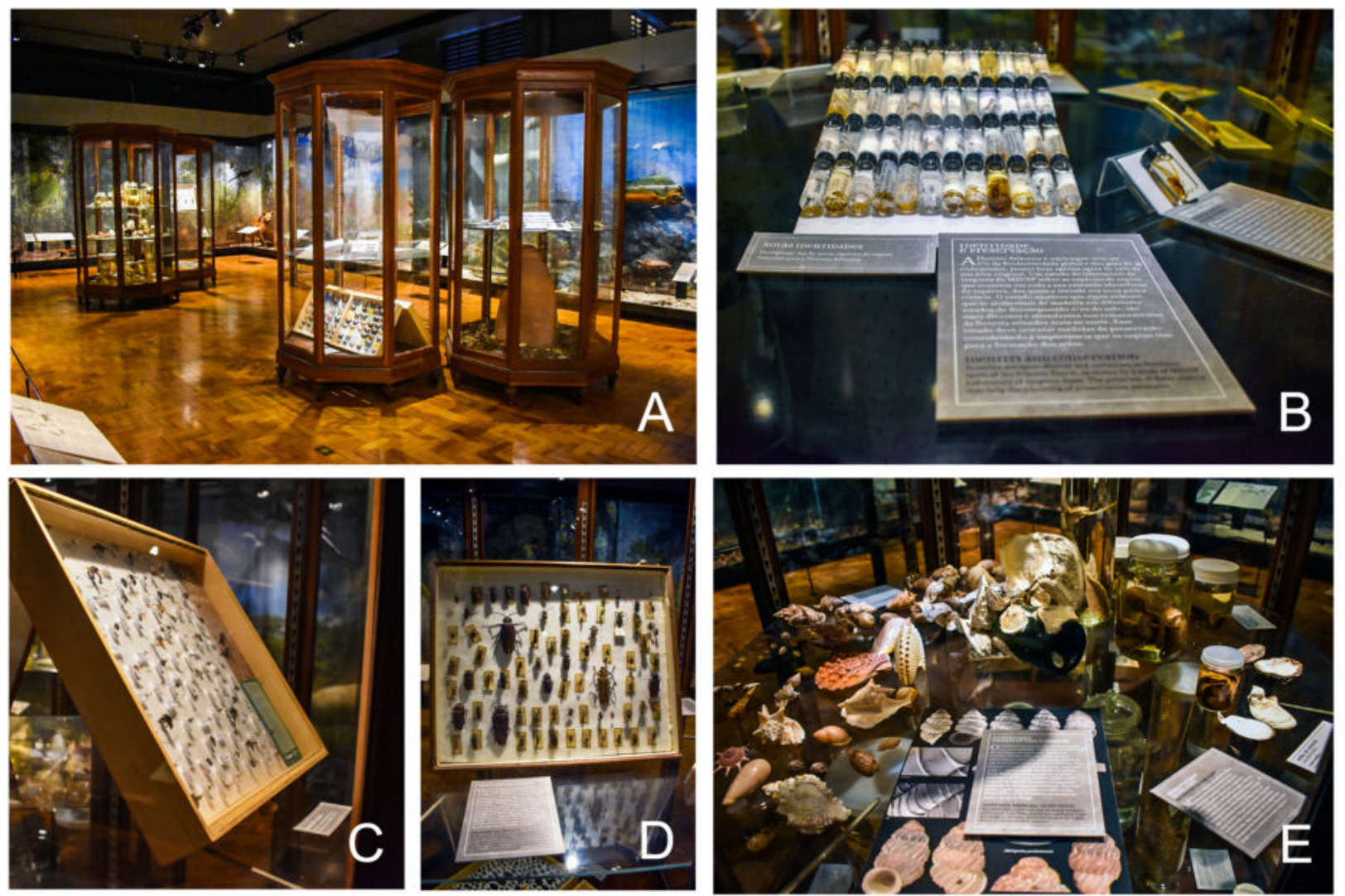

FIGURA 90: Vitrines com coleções do MZUSP, na exposição "Biodiversidade: conhecer para preservar". Em A, visão geral das 4 vitrines, posicionadas entre os dioramas. Em B, detalhe para "Diversidade de cupins - Ordem Isoptera"; Em C, moscas e melgas recolhidas pelo proto SIS-Biota. Em D, diversidade de besouros, em homenagem ao falecimento do investigador Ubirajara Martins Pereira, que como taxonomista de besouros identificou mais de duas mil espécies. Em E, diversidade do grupo de moluscos, evidenciando diversas formas de preservação (úmida e seca) e representação (fotografia e microscopia eletrónica). Fotografia: Mariana Galera Soler, obtida em visita técnica em Agosto de 2018.

108 Disponível em: http://muw.mz.usp.br/?page_id=1481. Acesso em 1 de Julho de 2019. 
E em entrevista com Landim: "a partir do acervo valorizar a pesquisa para justificar a salvaguarda desse acervo na nossa instituição" (Landim, comunicação pessoal, 13 de Agosto de 2018).

Portanto, novamente apontamos que essa escolha reflete a prática científica definida por Pickstone (1994) como "museological sciences", baseada em grandes coleções e séries de espécimes, em que os espécimes são estudados como partes de um complexo mecanismo, processo ou sistema. Ou, nas palavras de Koher (2007), estamos diante de uma “ciência de coleção", isto é, a investigação parte da materialidade dos objetos e necessita que sejam preservados a documentação de procedência e armazenados permanentemente seus testemunhos.

A museografia expressa o conhecimento taxonómico (e as "ciências de coleção", de Koher, 2007) pelo uso de espécimes cuidadosamente preparados, identificados individualmente e localizados geograficamente, inclusive mantendo suas etiquetas das coleções científicas (como no exemplo das vitrines supracitadas). Assim, o uso de espécimes preparados como em coleções científicas ressalta a prática dos taxonomistas, aqueles profissionais que registam, catalogam, preservam, etiquetam, selecionam, escrevem listas e descrições (Kohler, 2007).

Daston e Galison (2007) ao discutir as representações da natureza ao longo dos últimos três séculos, relacionam o uso de espécimes selecionados ("tipos”) com uma prática dos naturalistas e taxonomistas, ou seja, profissionais de grande memória, capazes de analisar e sintetizar impressões, bem como paciência e talento para extrair o que é típico. Por conseguinte, o taxonomista é o profissional suscitado a partir da análise de "Biodiversidade: conhecer para preservar", um sábio capaz de distinguir a espécies genuínas a partir de uma miríade de variedades, identificar a verdadeira característica específica e separar a característica acidental da essencial (D_aston_on \& \& Galison, 2007).

Ainda de acordo com esses autores, os espécimes selecionados por sintetizarem um conjunto de características que definem o grupo compõem uma imagem racional da natureza, inseridos numa ontologia universal, onde não há espaço para irregularidades ou anomalias

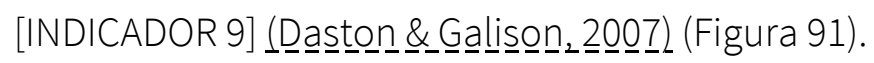




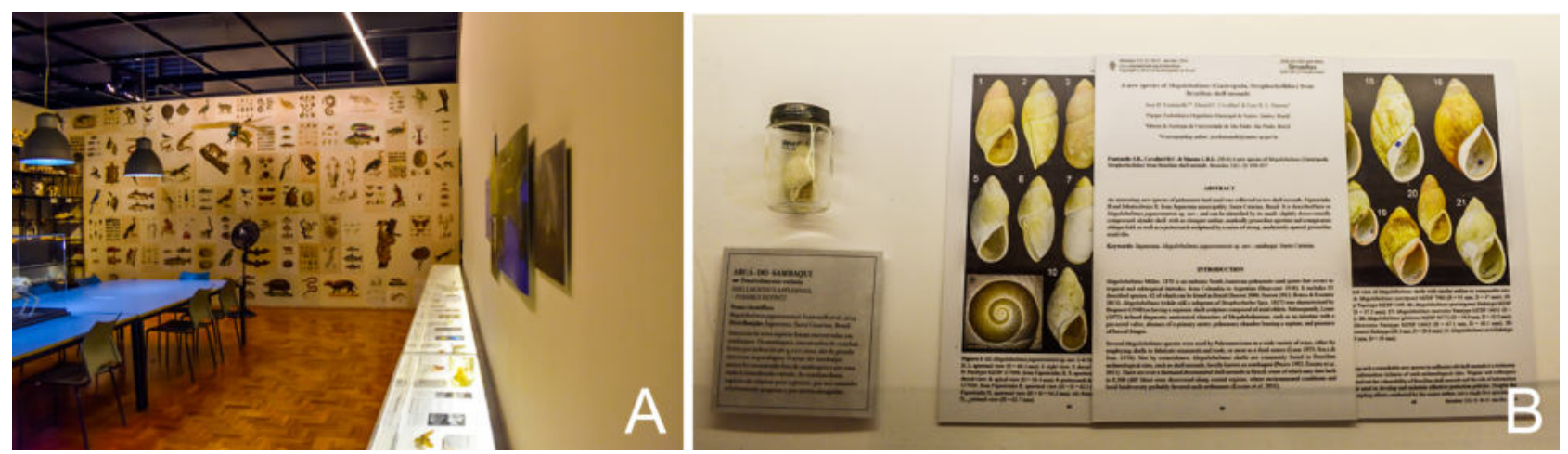

FIGURA 91: Vitrines "novinhos em folha", na Sala de Descobertas da exposição "Biodiversidade: conhecer para preservar”. Em A, visão geral da vitrine na sala. Em B, representação da espécie de molusco Megalobulimus jaguarunensis, utilizando espécime da coleção científica e o artigo científico original, com fotografia dos tipos designados. Fotografia: Mariana Galera Soler, obtida em visita técnica em Agosto de 2018.

Registamos também adesão ao subpadrão "Séries Evolutivas/Progressistas", onde, em geral, os espécimes são apresentados desde as formas mais simples até as formas mais complexas [INDICADOR 14]. Considerando que a conceituação original desse arranjo museográfico foi realizada na organização da coleção arqueológica e etnográfica de Pitt Rivers (Chapman, 1985), uma evidência da circulação dos padrões museográficos entre instituições é a utilização de uma imagem das vitrines do PittRivers Museum presente no Projeto de Arquitetura e Expografia entregue pela empresa EXPOMUS, como uma referência para a exposição "Biodiversidade: conhecer para preservar" (FIGURA 92).

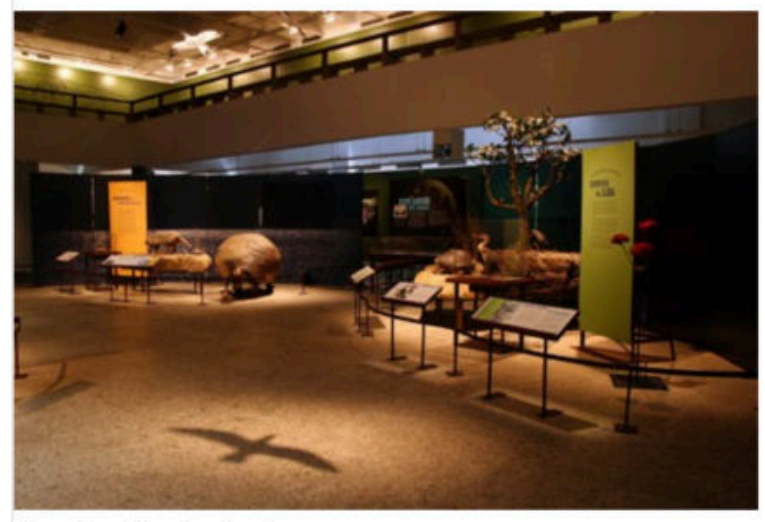

Iluminação de destaque
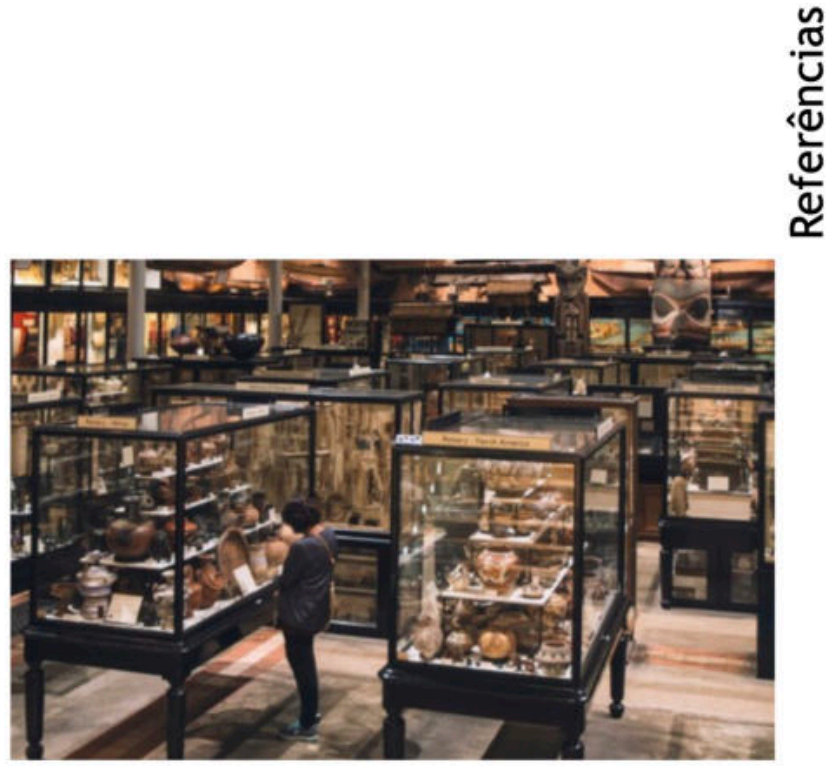

Iluminação embutida

FIGURA 92: Imagens de referência para a arquitetura e museografia da exposição "Biodiversidade: conhecer para preservar". Na imagem à direita exposição Darwin. Na imagem à esquerda vitrines do Pitt Rivers Museum. Fonte: Projeto de Arquitetura e Expografia, realizado pela empresa EXPOSMUS, p. 28. 
Ademais, de acordo com Landim (2018):

"Desde o seu início, a pesquisa no MZUSP esteve focada na taxonomia, sistemática e biogeografia de animas neotropicais, com algumas abordagens ecológicas. Para tais estudos o ambiente em que os organismos vivem é menos relevante do que as linhagens evolutivas às quais estão vinculados "

(Landim, 2018, p. 95, grifo nosso)

Sob a ótica evolucionista, o curador deve agrupar os objetos de diversas regiões geográficas e a classificá-los de acordo com seus critérios relacionados à semelhança hereditária [INDICADOR 15], de modo que o espécime é uma evidência que serve de confirmação e oferece reconhecimento das pressuposições e pressupostos dos curadores científicos [INDICADOR 11]. A Figura 93A exemplifica o subpadrão museográfico "Séries evolutivas/progressistas" presentes em "Biodiversidade: conhecer para preservar":.

Outra passagem do texto de abertura de exposição confirma tal subpadrão: "A taxonomia sofreu transformações ao longo da história. Novos paradigmas, como a teoria evolutiva mudaram a sua característica de disciplina descritiva para analítica" (grifo nosso). Além disso, o uso de diversos cladogramas $^{109}$ para ilustrar as relações de parentesco entre os animais em exposição, evidencia o discurso evolutivo, em que as espécies (ou grupos supra-específicos) são apresentadas inseridas em relações ancestral - descendente [INDICADOR 15] (Figura 93B).

\footnotetext{
${ }^{109}$ De acordo com Amorim (2005) cladogramas são dendrogramas que expressam relações filogenéticas (ou genealógicas) entre táxons terminais, marcados por características únicas do grupo (sinapomorfias).
} 

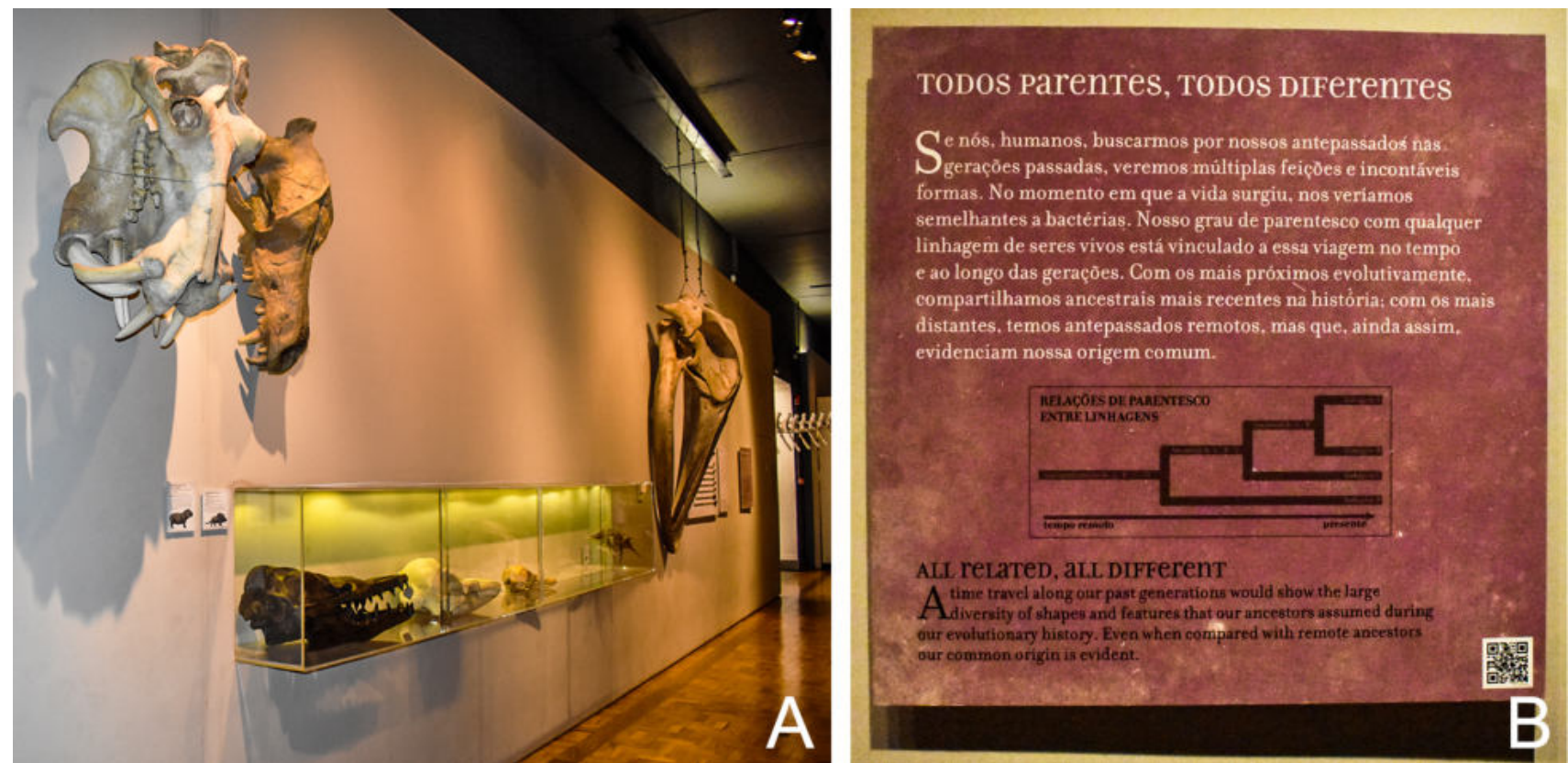

FIGURA 93: Módulo 3 da exposição "Biodiversidade: conhecer para preservar". Em A, uma série de réplicas e crânios originais dispostos em uma ordem evolutiva ilustram os ancestrais que deram origem aos mamíferos aquáticos, intitulada "Da terra a o mar: a história dos cetáceos.. Em B, painel com título do módulo "Todos parentes, todos diferentes" e explicação sobre cladogramas. Fotografia: Mariana Galera Soler, obtida em visita técnica em Agosto de 2018.

Ainda nos subpadrões museográficos "Centrados em objetos”, a presença de oito dioramas no Módulo 2, justifica a aderência ao subpadrão museográfico Dioramas, embora não totalmente ( 90\% de adesão), pois as representações de ambientes apresentadas são alusões genéricas a biomas brasileiros e não locais específicas de um determinado espaço em definido momento histórico [INDICADOR 25] (Figura 72).

Tais dioramas são elementos importantes da exposição por dois aspetos: (i) era desejo do Comitê Curatorial manter esse tipo de museografia, tão característica de museus de história natural e da própria história da instituição, embora o orçamento fosse bastante limitado para a realização desse tipo de montagem; (ii) são uma solução de design única, baseada em pesquisa histórica, criada pela equipa da empresa Expomus para essa exposição.

Nas palavras da arquiteta responsável Ana Helena Villena:

"Havia uma preocupação grande em relação aos dioramas, nosso desejo era não reproduzir os dioramas do sec. XIX e fazer uma cenografia contemporânea, mas não tínhamos verba para usar tecnologia. Após uma longa pesquisa retomamos a origem do diorama que vem dos adereços cenográficos de teatro que remontam a uma paisagem para dar profundidade ao palco, estava foi a chave para repensar o projeto. 
Depois encontrei o lindo trabalho de uma artista japonês Nobihiro Nakanishi que trabalha com sobreposição de paisagens impressas em vidro/acrílico, que levou a proposta de impressão da paisagem de cada bioma em tecido voal. A partir disso pensamos em criar uma base com substrato de cada bioma para inserção dos animais. Com a proposta conseguimos realizar um diorama sem tecnologia e contemporâneo dentro do orçamento da mostra"

"Havia uma diretriz do MZUSP de expor diversos animais taxidermizados em dioramas. O MZUSP já era reconhecido por este aspecto que deveria ser mantido na nova mostra. Em um primeiro momento fizemos, Eu e Eduardo Colonelli, uma outra proposta sem os dioramas que não foi aceita, depois ficou entendido que esta era uma questão central para o MZUSP"

"Uma dificuldade que tivemos com a equipe do Museu é que havia uma relação afetiva com antiga exposição e um desejo de manter diversos aspectos dela, mas à medida que as propostas eram apresentadas e defendidas o projeto foi sendo acolhido. O diorama foi um projeto que teve uma resistência em ser aceito, o que nos pareceu natural por seu caráter inovador, mas fizemos um protótipo 1:1 que foi fundamental para entender seu funcionamento e conseguimos que fosse aprovado"

(Villena, correspondência por e-mail, 03 de Julho de 2019).

Paralelamente ao discurso evolutivo, existe uma constante preocupação com a preservação dos ambientes e com o aumento da perda de espécies no período recente, especialmente ocasionada pela espécie humana (crise da biodiversidade/Antropoceno). Essa preocupação encontra-se expressa desde o título da exposição "Biodiversidade: conhecer para preservar", como em documentos, exemplificado pelo comunicado a imprensa e texto de abertura da exposição:

"Somos guardiões de uma das maiores coleções da nossa fauna. Sendo o Brasil um país megadiverso, que abriga cerva de 20\% de toda Biodiversidade do planeta nossa tarefa não é trivial. (...) Entretanto, é a crise atual da Biodiversidade que coloca nossa atividade no centro das atenções. Precisamos conhecer a Biodiversidade.

O sustento de mais de 7 bilhões de seres humanos altera radicalmente as paisagens da Terra, erodindo a Biodiversidade. Quando ela se torna escassa, ficamos mais 
pobres e precisamos encontrar soluções para garantir que a natureza continue a nos prover serviços ecossistêmicos. Nossa interferência é de tal magnitude que é equiparada a uma força geológica, inaugurando uma nova 'era': o Antropoceno."

E no Memorial Descritivo: "Relevância da pesquisa para preservação ressaltando os valores institucionais". Tais argumentos expressam-se na museografia por meio da adesão que quase 70\% ao subpadrão museográfico Ecológico.

Ainda corrobora esse subpadrão museográfico o posicionamento crítico da instituição, como o exemplo pontual que pode ser visto em frente ao diorama de águas continentais, nu, texto sobre o crítico sobre impacto das hidrelétricas [INDICADOR 44] (Figura 94):

\begin{abstract}
"Atualmente, 70\% da matriz energética do Brasil provém das hidrelétricas. A construção de barragens para essa finalidade contribuiu para a diminuição da correnteza dos rios, causando alterações na qualidade da água e também impede o trânsito de organismos, promovendo o isolamento de populações. Para os peixes em particular, as barragens prejudicam a piracema, que é a migração rio acima na época da desova. Causam também impactos sociais, como a remoção compulsória de grandes contingentes populacionais do local a ser inundado, levando à degradação social nas comunidades atingidas"
\end{abstract}

Destacamos ainda na entrada da "Sala das Descobertas”, o núcleo “Paisagens Humanas”, em que o ser humano é colocado em contexto, como agente modificador da paisagem, trazendo exemplos de áreas com grande impacto ambiental como a cidade de São Paulo e as regiões litorâneas e interiores paulistas (Figura 72).

Os elementos da museografia associados ao padrão museográfico Espetacular foram propostos tanto pela empresa responsável pelo projeto museográfico, como pela narrativa entregue pela equipa do MZUSP. Destacamos que o projeto de iluminação criado pela especialista Fernanda Carvalho (contratada especificamente para esse fim) permitiu a criação de efeitos dramáticos e ambientes imersivos [INDICADOR 65 e 69] (Figura 95). 

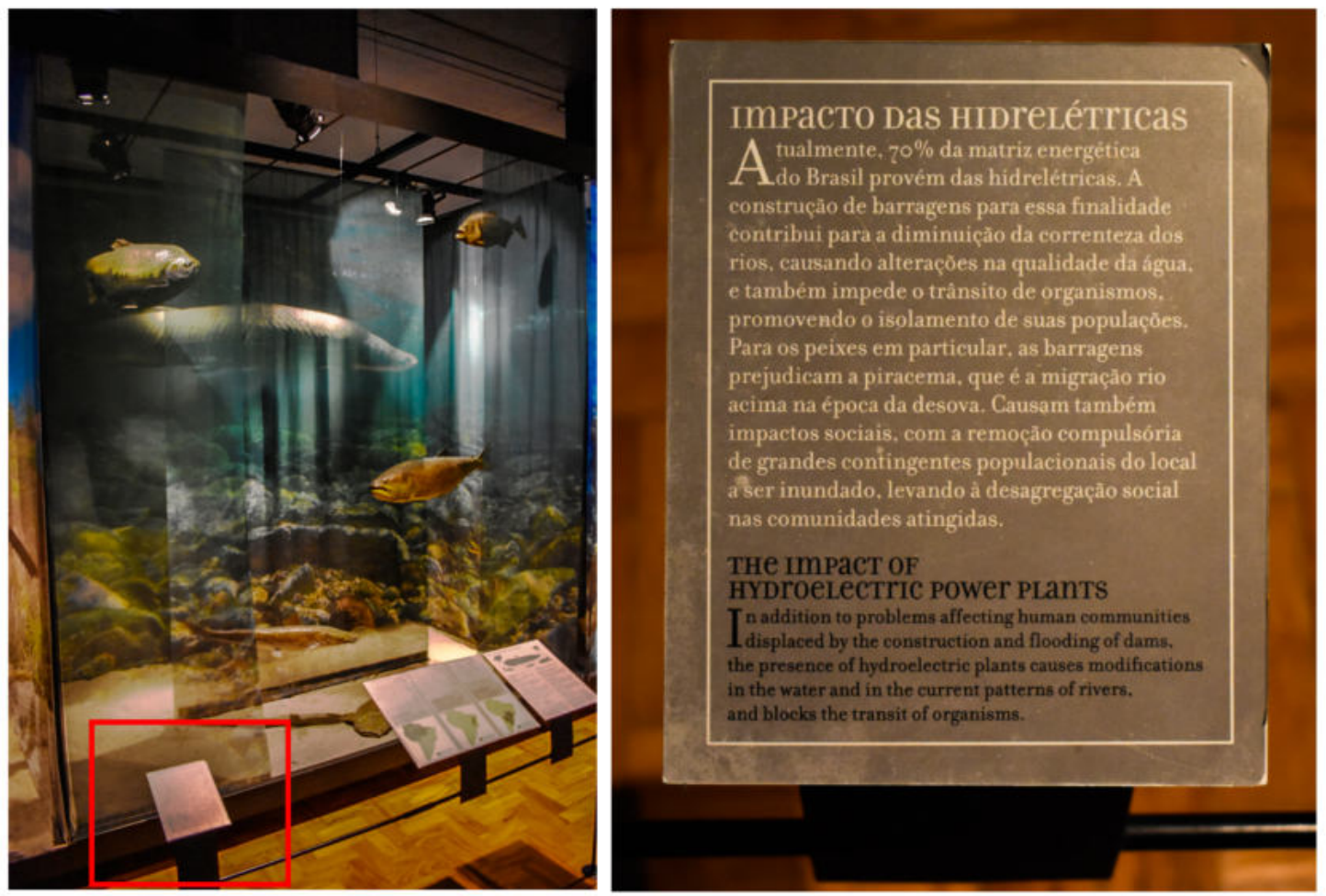

FIGURA 94: Dioramas, no Módulo 2 da exposição "Biodiversidade: conhecer para preservar". Em A, diorama de águas continentais. O retângulo vermelho indica o local do texto que encontra-se ampliado em B e transcrito acima. Fotografia: Mariana Galera Soler, obtida em visita técnica em Agosto de 2018.

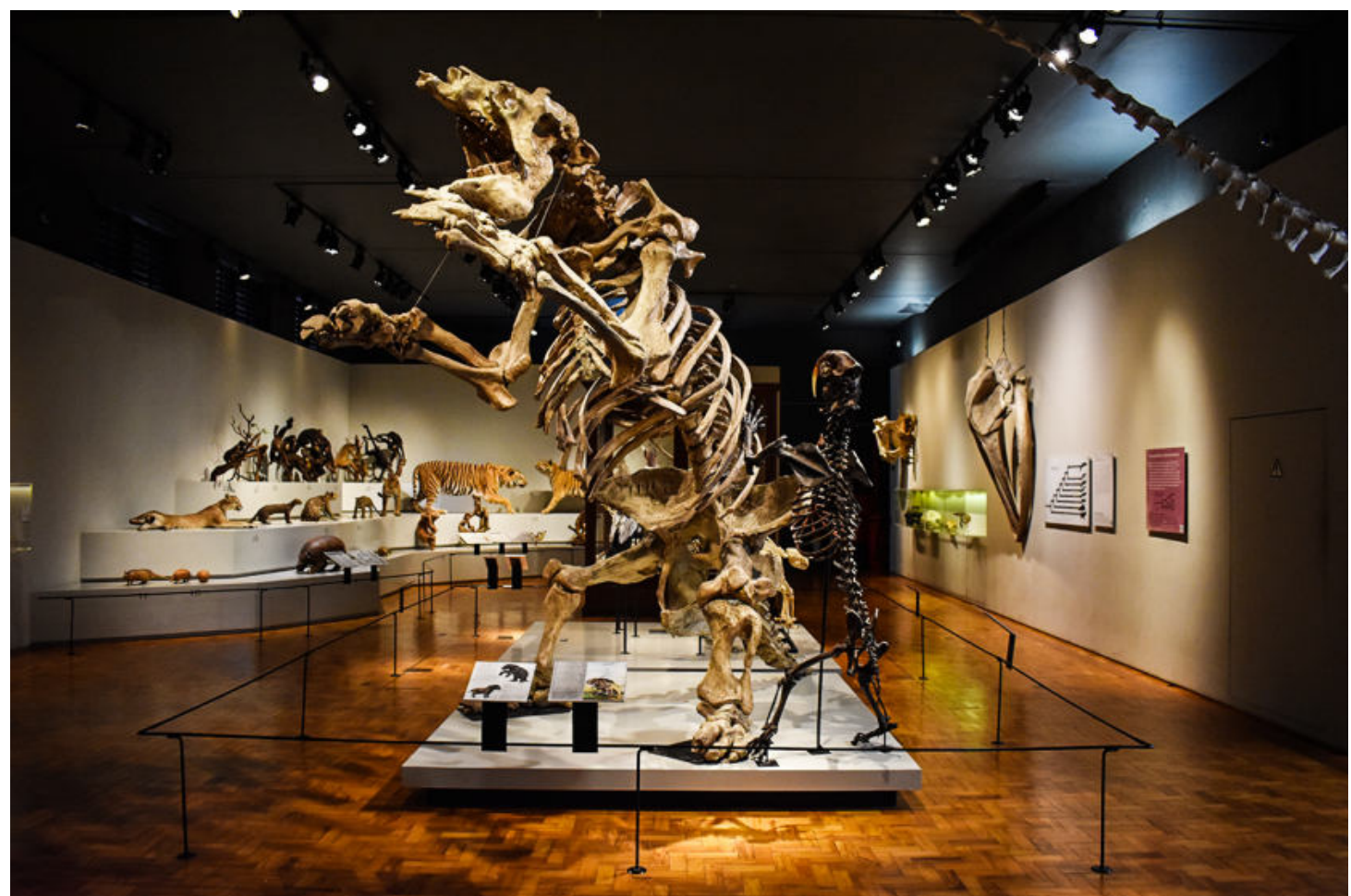

FIGURA 95: Módulo 2 e 3 da exposição "Biodiversidade: conhecer para preservar"., com destaque para iluminação focal e opção por manter spots de luz e calhas com fios elétricos evidentes. Fotografia: Mariana Galera Soler, obtida em visita técnica em Agosto de 2018. 
Ainda sugerido pela EXPOMUS, as exposições citadas pela arquiteta Ana Helena Villena como referências e inspirações para museografia, como: Grand Galerie de l'Évolution (exemplo fundador do padrão museográfico Espetacular), as exposições cenográficas e tecnológicas de Neichatel Natural History Museum, com diferentes aparatos tecnológicos e cenográficos, e Melborne Museum, em que os animais estão em vitrines/cenários são muito similares as "arquibancadas" construídas no museu paulistano (Figura 67 e 74).

A forte relação com a história da instituição seu edifício e mobiliário, novamente remete ao padrão museográfico "Centrado em objetos”, especialmente nas séries taxonómicas e séries evolutivas, também está presente em outra referência, como Galerie de Paléontologie et d’Anatomie comparée (França). Além da tradição de instituições universitárias, exemplificadas pelas inspiração nas seguintes instituições: The Grant Museum of Zoology (Inglaterra), Zoology Museum Babes-Bolyai University-Cluj (Romênia) (exemplos citados por diferentes membros da equipa curatorial em entrevista).

Além disso, imagens de Darwin - exposição itinerante coordenada pelo American Museum of Natural History e exemplo fundamental de exposição blockbuster - foram utilizados como referências para a museografia de "Biodiversidade: conhecer para preservar". Como indicadores associados ao subpadrão museográfico Blockbuster, temos a utilização de grandes painéis na entrada da instituição [INDICADOR 81], a presença de peças icónicas [INDICADOR 85], como a diversidade de formas, tamanhos e cores nos espécimes que compõem o saguão de entrada da instituição ou esqueletos de dinossauros, áreas para que o visitante possa tirar fotos ou se ver na exposição[INDICADOR 95], como em “Diversidade Genética” e as paredes cobertas por ilustrações da "Sala de Descobertas".

Uma vez que toda a exposição foi unicamente desenhada por uma empresa e conteúdos produzidos e acervos selecionados em um processo curatorial coeso e coordenado pela equipa do setor de Museologia do MZUSP (descrito anteriormente), há a padronização do design, linguagem e abordagens [INDICADOR 93]. Contudo, também são reflexos desse processo curatorial que agregou apenas os atores internos da instituição, o uso do discurso académico e distante das realidades locais [INDICADOR 96] ou ausência de controvérsias [INDICADOR 92].

As referências ao padrão museográfico "Retorno à curiosidade" estão, principalmente, circunscritas à "Sala de Descobertas", onde é possível visualizar a "typological exuberance", no 
armário em que diferentes espécimes das variadas coleções do MZUSP são apresentadas juntas [INDICADOR 106] (Figura 75A). Esse tipo de museografia favorece o reencantamento pelos objetos (como ocorre com os espécimes no saguão de entrada) [INDICADOR 98] e o estímulo a curiosidade, ao buscar transparecer "os bastidores" da instituição [INDICADOR 95]. Nesse caso encontramos imagens da exposição alemão The Wet Collections, do Museum für Naturkunde (Berlim), considerada um dos marcos iniciais do padrão museográfico "Retorno à curiosidade" (Adamopoulou \& Solomon, 2016a), igualmente entre as referências de museografia no documento entregue pela empresa EXPOMUS.

Considerando os padrões museográficos identificados, a exposição "Biodiversidade: conhecer para preservar" mostra que, assim como "Conchas, corais e borboletas", embora diversos profissionais tenham composto a equipa para a realização da exposição, os curadores científicos tiveram papel fundamental na escolha do acervo e da abordagem desse. Esta conclusão é corroborada pela seguinte citação: "Como instituição universitária, nosso Programa de Comunicação Museológica está fortemente vinculado à pesquisa em torno de nosso acervo e esta foi a tônica da consulta feita à comunidade durante a elaboração do projeto em suas diversas fases" (Landim, 2018, p. 101).

Além disso, a maior prevalência de museografias centradas nos objetos, cuja representação da natureza é dada por meio de espécimes (ou ilustrações) selecionados com características que são típicas, está diretamente associada à prática científica dos investigadores taxonomistas, em que a pesquisa é promovida pela visão e manuseio dos objetos, ou seja, o método de investigação intuitivo (embora muitos taxonomistas tenham dificuldade de admitir que seu trabalho é tão rigoroso e padronizado como práticas experimentais) (Kohler, 2006). A partir desse método é privilegiada uma imagem de natureza reconhecida como selva, labirinto, um desconhecido e infinito oceano, onde para se orientar é necessária observação paciente, os experimentos repetidos, as descrições e as classificações (Lopes, 2005).

Por fim, a baixa aderência ao subpadrão "Biografia dos Objetos" é justificada em entrevista por Landim: 
"nem sempre a vida dos animais que aqui estão foram dignas como todo mundo gostaria que fosse (...) Se a gente contasse a história do Chico ${ }^{110}$, de que forma ela seria lida? Ela poderia ser interpretada de várias formas por diferentes pessoas e a gente não queria criar suscetibilidade para fechar o desejo das pessoas de conhecer um pouco mais sobre nosso acervo e nossa pesquisa. Isso é algo que nós dependemos de muito estudo de público para saber se algum dia nós vamos abordar ou não".

(Landim, comunicação pessoal, 13 de Agosto de 2018).

Essa decisão foi ratificada coletivamente nas reuniões do Comitê Curatorial do MZUSP.

\subsection{Entre padrões: aproximações e distanciamentos entre realidade observada, documentos e entrevistas}

"Thus 'curiosity' was not originally a psychological attribute, but part of an early modern practice of collecting and display. The roots of our contemporary situation are to be found in a material history of practices, and any understanding will have to emerge from a recognition of the historical depth of current dilemmas"

(Secord, 1996, pg. 457)

Até o momento caracterizamos e discutimos como foram estabelecidos diferentes formas de expor coleções de história natural, especialmente as zoológicas, desde o século XIX até a contemporaneidade, em museus de história natural e de ciências. Tais museografias, associadas aos contextos científico, institucional e político em que surgiram e foram replicadas, permitiram a identificação do que chamamos de padrões museográficos, ou seja, conjuntos de características de design, iluminação, organização de acervo, texto, posicionamento e tipo de público, estratégias de comunicação, abordagem do conteúdo científico e uso de interativos e multimédia que relacionam o modo de expor as coleções com conceções e práticas científicas e museográficas.

${ }^{110}$ Chico é um chimpanzé que viveu toda a sua vida no Zoológico de São Paulo e um animal que foi muito querido nessa instituição. 
Quatro grupos de padrões museográficos foram elencados e, inseridos nesse, subpadrões museográficos mais específicos, compondo assim um modelo teórico de padronização da museografia de museus de história natural:

\author{
Padrão Centrado em Objetos \\ Subpadrão: Séries Taxonómicas \\ Subpadrão: Séries Evolutivas / Progressistas \\ Subpadrão: Dioramas \\ Padrão Centrado numa Narrativa \\ Subpadrão: Quotidiano \\ Subpadrão: Ecológico \\ Subpadrão: Public Understanding of Science \\ Padrão Espetacular \\ Subpadrão: Blockbuster \\ Padrão "Retorno à curiosidade" \\ Subpadrão: Biografia dos Objetos
}

Embora não exista uma estratigrafia, em que um padrão museográfico substitui o outro, os padrões foram descritos de acordo com tempo que surgiram e expressam diferentes momentos históricos e conjunturas científicas, políticas e institucionais de suas origens e influências.

De modo que, os padrões "Centrados em objetos" e "Centrados numa narrativa" (exceção Public Understanding of Science) emergem de museus de história natural com grande poder e prestígio, cujos curadores eram também investigadores especialistas nos acervos e autoridade máxima do conhecimento em seus respetivos campos.

No século XVIII e início do XIX, os museus organizavam suas coleções de modo a reproduzir de forma mais completa possível a Cadeia dos Seres, por meio de grupos artificias e naturais reconhecidos por características morfológicas externas. O naturalista era o profissional capaz de identificar características e espécimes típicos e que “completavam” tal cadeia.

O paradigma evolucionista da segunda metade do século XIX, associado ao grande acúmulo de objetos em galerias empoeiradas, a crescente especialização do conhecimento e profissionalização da carreira de investigador, promoveram a separação de coleções para exposição e acervos salvaguardados em reservas técnicas, destinadas unicamente à pesquisa científica. Os 
objetos que se mantiveram em exposição já não buscavam corroborar as maravilhas da diversidade criada por um ser divino, mas sim séries que representavam a diversificação das formas mais simples de vida até formas mais complexas. Tal museografia implicava obrigatoriamente também num posicionamento dos visitantes, que perante a uma escala evolutiva, era igualmente, hierárquica.

Ainda ao longo do século XIX, com o surgimento da fotografia e dos panoramas e os respetivos usos como meio de entretenimento permitiram o acesso a imagens e paisagens localizadas no tempo e no espaço, mas distantes das realidades urbanas. Concomitantemente, a arte romântica buscava retratar os componentes do belo e a natureza intocada e bucólica. Ainda no final daquele século, paralelamente aos estudos evolutivos, os estudos ecológicos haviam iniciado, contudo ainda numa perspetiva que apenas evidenciava as relações de dependência entre os organismos e o ambiente que os rodeiam. Esses elementos culminam no desenvolvimento dos dioramas, que congregam diferentes elementos do mundo natural e da arte (pintura e teatro) para compor um artefacto de maravilhamento e um dos elementos da museografia mais característicos dos museus de história natural até a atualidade.

Nas primeiras décadas do século XX, Conn (1998) aponta que os objetos deixaram de ser persuasivos, a medida que o visual já não era a única evidência para o conhecimento e a experimentação ganhava cada vez mais espaço e especialização, com a mecânica quântica, eletromagnetismo, relatividade ou ADN. As narrativas contam as teorias que explicam o mundo e são ilustradas por objetos que, por sua vez, são extraídos da realidade.

Desde período entre guerras, a ciência tornou-se amplamente dominadas pelas redes tecnocientíficas - associações entre industriais, academias e governos - que produzem commodities baseados em conhecimento científico. Nesse contexto, uma visão crítica, temporal e política, da ciência tem sido problemática, uma vez que é necessário assegurar o financiamento de investigadores e proteger as empresas patronais das adversidades do julgamento social (Pickstone, 2001).

Nas décadas pós - II Grande Guerra os símbolos de "modernidade" eram os princípios científicos, modos de produção racionais, estética funcional, proezas na área médica, profissionalismo e políticas de bem-estar. As redes tecnocientíficas foram fundamentais para formatar esta imagem e forma de civilidade, que subentendia também o estilo de vida estadunidense (Pickstone, 2001). O movimento do Public Understanding of Science é uma expressão 
clara desse período histórico, quando os science centres ganharam prestígio por apresentarem princípios de ciência de modo interativo, lúdico e espetacular, mas descontextualizados, atemporais, anónimos e como verdades inequívocas.

As redes tecnocientíficas também marcaram a diminuição do financiamento/influência governamental na produção científica, abrindo espaço para os interesses comerciais, que se tornaram globais. Se o conhecimento científico passou a ser entendido como um commodity, a comunicação da ciência torna-se uma tarefa para profissionais especializados (Pickstone, 2001). Nos museus, como espaços de comunicação científica, novos profissionais passam a fazer parte das equipas como designers, arquitetos, jornalistas e outros profissionais de cenografia, iluminação e comunicação.

A presença desses novos profissionais, associada à nova ordem mundial estabelecida desde a segunda metade do século XX (com a predominância cultural, política e econômica dos EUA), os questionamento do mundo conservador (iniciados no Maio de 1968 na França) e a discussão sobre a função social dos museus (no âmbito do ICOM desde 1972) levaram para o discurso museológico conteúdos e formas de representação que transcendiam as abordagens exclusivas do conhecimento científico produzido nos bastidores por curadores-investigadores. Na contemporaneidade, podem ser vistas exposições que transmitem mensagens ativistas em favor da preservação da natureza, ao mesmo tempo que incorporam elementos do show business, como ambientes imersivos, cenográficos e experiências de realidade aumentada.

Assim, os complexos tecnocientíficos descritos por Pickstone (2001) são expressos por novos públicos, cenários e usos dos acervos nos tradicionais museus de história natural. Algumas exposições tornam-se grandes eventos com uma agenda de itinerância programada, tal como os concertos ou as grandes feiras.

Em outra perspetiva, há também mudanças nas políticas de aquisição de acervos e seus usos. Se a origem do espólio dos tradicionais museus de história natural do eixo EUA-Europa vieram da exploração de colónias ou de territórios longínquos, tais práticas não são mais possíveis na atualidade. Novos usos são descobertos para as antigas coleções de história natural, entendendo tais acervos também como testemunhos, por exemplo de rotas de migração e distribuição de espécies em tempos remotos, portadores de agentes patogénicos, contaminantes ambientais. Tais dados têm sido fundamentais para os estudos do Antropoceno, alterações climáticas, saúde pública, 
biogeografia e outros afins, especialmente quando os espécimes de museus passam do status de tipológico e representativo de uma espécie que existe no ambiente, para o sombrio "último registo" (Dorfman, 2007).

Em contrapartida, esses objetos também são repositórios de narrativas únicas, que descrevem tanto as histórias das realidades locais de onde foram extraídos, até as políticas de aquisição e circulação de acervos, práticas cientificas e museológicas de profissionais e de amadores (como caçadores, comerciantes, taxidermistas e conservadores). Tais estudos inaugurados pelos estudos de cultura material na Antropologia, por E.M. Fleming (1974), mais recentemente foram analisados sob o ponto de vista socioantropológico em A Vida Social das Coisas, Appadurai (2008) e, especificamente sobre objetos salvaguardados em museus científicos, pelas metodologias propostas por Alberti (2005) e Lourenço e Gessner (2014) e aplicadas por exemplo em Alberti (2011) e Pereira (2017).

A análise de exposições de museus de história natural portuguesas (três) e brasileiras (duas) permitiu-nos concluir que as exposições contemporâneas não se adequam a um único padrão museográfico, ao contrário, são constituídas de elementos e discursos propostos em diferentes momentos e arcabouços científicos, culturais e sociais, para a construção de discursos únicos ou com múltiplas vozes. A preponderância de um grupo de profissionais, conteúdos relacionados a uma determinada conceção ou design inspirado a determinadas exposições mostram que as exposições são arenas transespitêmicas, aplicando-se o termo proposto por Knoor-Cenita (1982), espaços em que investigadores e outros profissionais negociam e as decisões passam por uma disputa de argumentações e preocupações de natureza técnica, mas também administrativa, política, social, ou seja, as exposições são construções contingentes.

Diante dos diversos atores, interesses e disputas, reconhecemos alguns elementos como fundamentais na definição da museografia das exposições:

1. Natureza da instituição: o tipo de instituição (museu, science centre, zoológico, galeria, parque, museu universitário, jardim público etc.) determina o uso de alguns tipos de acervos e recursos museográficos, de forma a contribuir de modo decisivo na seleção do padrão museográfico. Nos casos estudados temos que a Galeria da Biodiversidade está inserida na lógica da Rede Nacional Ciência Viva, uma rede formada por mais de 20 centros de ciência em Portugal. De modo que, mesmo 
fazendo parte de um museu de história natural (Museu de História Natural e da Ciência da Universidade do Porto), essa foi a exposição que apresentou maior aderência ao subpadrão museográfico Public Understanding of Science, uma museografia que tem sua origem nos centros de ciência interativos criados a partir do Exploratorium de São Francisco. Em contrapartida, "Biodiversidade: conhecer para preservar" e "Conchas, corais e borboletas" são exposições alocadas"111 em instituições de referência em investigação em taxonomia (inclusive com cursos de pós-graduação na área) e salvaguarda dos maiores acervos de história natural entre as instituições analisadas, o que foi expresso nas exposições com diversos indicadores presentes nos padrões museográficos "Centrados em objetos".

2. Temática escolhida: considerando que os padrões museográficos surgiram em diferentes momentos históricos e instituições, sendo representantes de mudanças nas práticas científicas ou museológicas, agências de fomento ou políticas institucionais ou públicas, a definição da temática para uma exposição responde a esses elementos e pode ser expressa em formas de museografia particulares. De modo que o destaque da teoria evolutiva no discurso e museografia de "Biodiversidade: conhecer para preservar" e na "Galeria da Biodiversidade" são assinalados com maiores índices de adesão para o subpadrão museográfico "séries evolutivas/progressistas"112 e é uma temática considerada fundamental pelas equipas curatoriais entrevistadas. Em "Reis da Europa Selvagem", a temática claramente conservacionista está registada com aderência total dessa exposição ao subpadrão museográfico Ecológico. A importância das coleções de história natural em "Specere" está evidenciada pelos maiores valores de EPM em padrões museográficos que são centrados nos objetos ("Centrado em objetos" e "Retorno à Curiosidade").

\footnotetext{
${ }^{111}$ Como citado anteriormente, a exposição "Conchas, corais e borboletas" fez parte do MNRJ, o museu que possuía o maior acervo de história natural da América Latina.

112 "No caso da "Galeria da Biodiversidade", embora os maiores valores de EPM estejam associados à centralidade na narrativa e no espetáculo, as séries evolutivas evidenciam indicadores centrados em objetos.
} 
3. Constituição da equipa curatorial: embora grande parte das exposições analisadas tenham suas museografias realizadas em parcerias com empresas externas (com exceção "Specere" que foi inteiramente concebida e construída pela equipa do MUHNAC), a presença de curadores-investigadores e suas respetivas especialidades deixam marcas profundas nas exposições dos museus de história natural. A forte presença de taxonomistas em "Biodiversidade: conhecer para preservar" e "Conchas, corais e borboletas" está evidenciada na escolha do subpadrões museográfico Série Taxonómica. Em contrapartida, a presença de Jorge Wagensberg e a sua conceção da “museologia total", propiciou que a "Galeria da Biodiversidade" expressasse mais os indicadores relacionados ao padrão museográfico Espetacular, o qual ressalta perspetivas estéticas e afetivas que Wagensberg continuamente destacou em suas publicações (Wagensberg, 2000, 2005, 2014a). Por outro lado, a presença de um ecólogo e a utilização de relatórios de estudos ecológicos para a conceção de "Reis da Europa Selvagem" é evidenciada por adesão total ao subpadrão museográfico ecológico.

4. Objetivo da Exposição: os objetivos definidos pela exposição definem o modo que ela será construída. Assim, "Specere” e "Biodiversidade: conhecer para preservar", na voz de suas equipas curatoriais são exposições que buscam destacar a importância dos acervos das respetivas instituições, o que é evidenciado porvalores mais altos de EPM em padrões museográficos que dão maior visibilidade aos objetos, como "Centrado em objetos" e "Retorno à Curiosidade". A preocupação ambiental e a ótica conservacionista de "Reis da Europa Selvagem" fornecem subsídios para adesão total ao subpadrão museográfico ecológico, enquanto as preocupações em apresentar a biodiversidade em uma perspetiva evolutiva e temporal, são apontadas com maior aderência ao subpadrão museográfico "Séries evolutivas/progressistas" em "Biodiversidade: conhecer para preservar" e "Galeria da Biodiversidade" e também sinalizado pelas equipas curatoriais em entrevistas.

5. Tipo de Acervo: o tipo de acervo escolhido para construção de uma exposição também contribui fortemente para o padrão museográfico que se pretende. Desse modo, o investimento de aparatos multimédia tecnológicos e interativos, como em 
"Galeria da Biodiversidade" fomentam a aderência a um subpadrão museográfico Public Undestanding of Science. Já o uso de mobiliário patrimoniado e grande suporte de objetos em "Specere", "Biodiversidade: conhecer para preservar" ou em "Conchas, corais e borboletas" materializam-se em maior aderência em padrões museográficos "Centrados em objetos".

Paddon (2014) analisou o processo de renovação da museografia de três museus do Reino Unido, partindo de uma mesma nova fonte de recursos financeiros: as lotarias inglesas. A autora considerou que os três principais elementos que definem o sucesso de um projeto museográfico são: processo de tomada de decisão, composição das equipas de trabalho e processos de comunicação entre os membros das equipas de trabalho.

Tais elementos elencados por Paddon (2014) são corroborados pelos dados apresentados nesse trabalho. Tanto de forma direta, como em "Teamwork will influence the design of the exhibitions and interpretations" (Paddon, 2014, p. 144) está expresso no fator "3. Constituição da equipa curatorial". Como a influência dos objetos da exposição na museografia são expressos em "teams must carefully consider how a decision about design, for example, might impact the specimens on display or access for visitors" (Paddon, 2014, p. 144).

O papel decisório dos curadores-investigadores também é evidenciado pela autora, contudo ela afirmar que os curadores foram aqueles profissionais que experimentaram a maior mudança em seu papel no desenvolvimento de exposições ao longo dos últimos dois séculos. Para a Paddon:

"They [curators] act as mini-project managers to coordinate the intricacies of their designated galleries. Curators will undoubtedly have personal agendas, a specific interest in one area of their collection or their opinion on the perfect gallery, but these agendas need to be moderated to fit with the overall goals of the project. Curators need to accept change and understand that the team is not trying to work against suggestions they make. (...). Equally, other team members need to make full use of the curator's expertise, ensuring a factually correct interpretation of objects and knowledge of local collections"

(Paddon, 2014, p. 145). 
Ainda de acordo com Paddon (2014), a museografia contemporânea reconhece a necessidade de um equilíbrio entre a interpretação enciclopédica, excessivamente zelosa e a interpretação parcial e minimalista. Um equilíbrio precisa ser alcançado entre o design e as coleções.

De forma simplificada, a partir das exposições analisadas algumas questões sintetizam os fatores determinantes museografia de museus de história natural contemporâneos: (i) Onde? ; (ii) Sobre?; (iii) Por que?; (iv) O quê?; e, principalmente, (v) Quem fez?.

As questões estão relacionadas com os fatores 1, 2, 4, 5 e 3, respetivamente. No entanto, um fator previamente considerado determinando, não foi sinalizado em nossa investigação: o públicoalvo. As exposições analisadas não possuíam um público-alvo expressamente definido, apenas indicações como "grupos intergeracionais" (Bastos-Silveira, comunicação pessoal, 28 de Março de 2018), como no caso de "Reis da Europa Selvagem", ou "nosso objetivo é um público bem genérico" (Landim, comunicação pessoal, 13 de Agosto de 2018), como em "Biodiversidade: conhecer para preservar".

Se na literatura da Museologia e da Educação em museus a partir do século XX o público passa ser o elemento central dos museus, isso parece mais uma afirmação retórica do que a realidade impressa nos corredores e galerias analisados.

Assim, a partir do que Freire (2017) denominou como "arqueologia das exposições"113, analisamos em detalhe cada uma das exposições, desde sua conceção até o retrato mais atualizado do que o público poderá encontrar e verificamos que os contextos e as epistemologias dos conhecimentos científicos dos curadores estão claramente expressas, conferindo para além do conteúdo científico a forma de expor os acervos.

O papel decisório dos investigadores na forma como as exposições são desenvolvidas também representa aspetos institucionais. Considerando que as exposições analisadas estão em museus universitários, essa tipologia de instituição possui especificidades, como destacadas por Bragança-Gil (2005). que provém da integração dos museus nas universidades e da participação ativa daqueles nas atividades culturais, incluindo as científicas. De acordo com a recente publicação do UMAC (International Committee for University Museums and Collections of the ICOM) (2018), os

113 Essa denominação foi utilizada no contexto da História da Arte, mas é igualmente adequada nas perspetivas museológicas e históricas discutidas nesse estudo. 
museus universitários são locais únicos para apresentação da pesquisa académica e o processo de ensino no passado e no presente e para interpretação pública de suas coleções. Tais instituições são especialmente apropriados e possuem uma longa tradição em mobilizar relações efetivas entre a comunidade universitária e o amplo público.

A tradição em servir como "janela" para investigação subsidia a importância da voz do curador-investigador na conceção das exposições, uma vez que a instituição entende-se como um espaço de apresentação da ciência produzida. A análise das missões das instituições em estudo corrobora essa afirmação, como abaixo destacamos trechos:

Museu de Zoologia da Universidade de São Paulo:

"Contribuir com o avanço científico e o estabelecimento de políticas públicas em Biodiversidade através da pesquisa científica de qualidade integrada ao ensino e referenciada por padrões internacionais.

Formar docentes pesquisadores de excelência através dos seus programas de pósgraduação e pós-doutoramento e contribuir com o ensino de graduação de forma indissociável de suas atividades de pesquisa.

Oferecer produtos culturais e educação não formal (extensão) aos diversos segmentos da sociedade através de suas exposições públicas de longa duração, temporárias e itinerantes."

(Disponível em: http://www.mz.usp.br/?page_id=232. Acesso em 2 de Agosto de 2019)

Museu Nacional do Rio de Janeiro - Departamento de Entomologia:

"Atuando na pesquisa, ensino e extensão, suas principais missões relacionam-se a manutenção, preservação e estudo da Coleção Entomológica do Museu Nacional"

(Disponivel em: http://www.museunacional.ufrj.br/entomologia/. Acesso em 2 de Agosto de 2019) 
Museu Nacional do Rio de Janeiro - Departamento de Invertebrados:

"Ser um centro de excelência de pesquisa em biodiversidade de invertebrados marinhos e Aracnologia, capacitado para identificar, descrever e caracterizar a biologia e a ecologia das espécies animais de todos os filos de invertebrados em todos os habitats marinhos, com especial ênfase no Mar Profundo;

Divulgar e transmitir os conhecimentos gerados pela pesquisa para a comunidade científica, estudantes e o público leigo"

(Disponível em: http://www.museunacional.ufrj.br/invertebrados_dp/. Acesso em 2 de Agosto de 2019)

Museu Nacional de História Natural e da Ciência da Universidade de Lisboa (única instituição que não aponta a investigação científica em primeiro lugar em sua missão):

"O MUHNAC/Museus da Universidade de Lisboa tem como missão promover a curiosidade e a compreensão pública sobre a natureza e a ciência, aproximando a Universidade à Sociedade. Essa missão é atingida através da valorização das suas coleções e do património universitário, da investigação, da realização de exposições, conferências e outras ações de carácter científico, educativo, cultural e de lazer. "

(Disponivel em: https://www.museus.ulisboa.pt/pt-pt/missao. Acesso em 2 de Agosto de 2019).

Museu de História Natural e da Ciência da Universidade do Porto:

"missão fundamental promover a construção e difusão do conhecimento sobre a evolução, diversidade e a convergência entre o mundo natural e cultural. Nesse sentido, o MHNC-UP compromete-se a preservar, valorizar, estudar e divulgar um vasto património associado às ciências naturais, exactas e humanas, edificado através de actividades educativas e de investigação desenvolvidas no seio da Universidade do Porto ao longo de mais de dois séculos"

(Disponivel em: https://mhnc.up.pt/sobre-o-mhnc-up/. Acesso em 2 de Agosto de 2019). 
Biodiversidade Musealizada: Formas que Comunicam

Sendo assim, nas exposições analisadas a biodiversidade é representada sob a perspetiva do investigador que a estuda, sendo o museu palco para exaltação das práticas científicas realizadas na instituição e dos conhecimentos produzidos.

Com a intersecção de diferentes padrões museográficos em uma única exposição, há possibilidade do visitante partilhar de diferentes conceções e práticas científicas e museológicas, mas sempre no papel de expectador abstrato, a quem cabe contemplar e seguir. Ainda que a discussão da Museologia há mais de quarenta anos tenha se voltado para a importância dos públicos e do museu como agente de transformação social e mesmo a ciência reconheça no cidadão um agente importante na recolha de dados e preservação dos ambientes (como nos projetos de citzen science), os museus de história natural ainda consideram o público como aqueles que precisam ser "maravilhado" com "scandalous revelations". 


\section{CONSIDERAÇÕES FINAIS}

"Salvaguarda" e "comunicação" representam conjuntos de procedimentos essenciais da cadeia operatória da Museologia (Bruno, 2006). Estes são os alicerces dos processos de musealização que descrevem a trajetória de um objeto desde o momento em que é selecionado do seu contexto original até ser elevado a categoria de musealia, ou seja, um "objeto de museu", e toda a sua "vida" dentro da instituição (Desvallées \& Mairesse, 2013).

Evidentemente a abordagem do estudo da História Natural e, mais recentemente da Biologia, interfere na escolha dos procedimentos de salvaguarda, seja na seleção de quais espécimes deverão ser recolhidos, a preservação de determinadas partes em detrimento de outras e o tipo de informação associada ao espécime.

Nesta tese abordamos o outro alicerce da musealização, a "comunicação". Com o foco nas exposições - meio de comunicação dos museus por excelência - discutimos de que forma estas construções sociais servem de registo de práticas científicas e museológicas nos museus de história natural. Tal perspetiva conta ainda com poucas investigações, como demonstrado ao longo desta investigação e nos raros exemplo, como a análise dos museus científicos estadunidenses por Rader e Cain (2008; 2014), de instituições científicas alemães por Nyhart (2009) e museus ingleses de história natural por Paddon (2014).

Partimos de uma detalhada revisão na literatura, principalmente nos campos da História da Ciência e da Museologia, buscando informações referentes aos modos de expor acervos científicos desde o século XIX até a contemporaneidade e os respetivos contextos científicos, institucionais e sociais em que estavam inseridos. Concomitante à recolha de dados bibliográficos, realizamos mais de duas dezenas de visitas técnicas a exposições em instituições europeias e brasileiras, construindo assim uma importante base de dados e imagens sobre a museografia de museus de história natural.

Este foi o arcabouço teórico que nos permitiu a construção um modelo teórico de padrões museográficos, ou seja, formas de expor acervos científicos associadas ao design, tipo de acervo, textos e legendas, iluminação, recursos audiovisuais e multimédia e o posicionamento do acervo e do visitante perante o discurso museológico. Consideramos que os padrões elaborados têm surgido em contextos políticos, científicos e institucionais, são propostos por grupos de profissionais (investigadores que imprimem seus referenciais para representação do conhecimento, técnicos, 
arquitetos e designers que transmitem esse conhecimento em forma, patronos e administradores que usam as exposições como respostas a demandas político-económicas) e apresentados para públicos determinados.

Os padrões museográficos propostos nesta tese serviram como plataforma de interface entre a Museologia e a História da Ciência, uma vez que partimos de elementos técnicos da museografia (ramo "prático" da Museologia) que refletem diferentes abordagens do conhecimento científico, epistemologias e suas práticas, representadas pelo modo como as exposições são construídas.

Assente nesses padrões, analisamos cinco exposições com acervos científicos, particularmente compostos por espécimes zoológicos, de instituições portuguesas e brasileiras. Selecionamos exposições concebidas após 2010, de modo a registar quase uma década de museografia nas instituições estudadas e acesso ao maior volume possível de documentação e profissionais envolvidos nos projetos.

Ademais, também para garantir uma análise comparativa adequada, elegemos exposições que têm (ou tinham) como fundamento do discurso expositivo o conceito científico "biodiversidade", servindo igualmente como um marcador de contemporaneidade. Nossa premissa é que o conceito "biodiversidade" tem sido vastamente utilizado tanto pela comunidade académica, como também pelos diferentes medias, desde o final dos anos 1980, quando também já eram grandes as preocupações sobre a perda de habitats naturais, associado ao medo da superpopulação humana (especialmente com o crescimento económico dos países em desenvolvimento e os danos ambientais promovidos pelo uso irrestrito de agrotóxicos) e ao esgotamento dos recursos.

Tendo em vista que tal modelo teórico não representa uma estratigrafia de museografias, em que um novo modo de expor substitui completamente o antecedente, foi possível identificar em exposições concebidas nos dias correntes, diferentes padrões em um mesmo museu de história natural, até mesmo em uma mesma exposição.

Embora tenham sido desenvolvidos em tempos e locais específicos, foi possível ainda observar modos de expor similares em diferentes momentos e instituições museológicas no mundo, o que evidenciou o contacto entre essas instituições, ou seja, a circulação de conhecimento, ideias, objetos e profissionais. Por exemplo, durante as entrevistas com as equipas curatoriais das exposições analisadas, o Hall ofBiodiversity (AMNH) e a Grand Galerie de l'évolution (MNHN) e o Museo delle Scienze (Trento, Itália) foram citados como referenciais para praticamente todas as instituições. 
Evidenciamos que elementos externos aos museus de história natural também marcam a reprodução de padrões, como vemos a forte influência da mass media com a incorporação de recursos de multimédia. Nota-se a utilização de realidade aumentada na exposição "Reis da Europa Selvagem" para que o visitante possa interagir com a "mãe urso e seu filhote", ao mesmo tempo que ao longo da mostra o visitante pode aproximar-se de pelo menos duas taxidermias de ursos; ou a utilização de vídeos com animações de crustáceos, ao lado de vitrinas repletas de espécimes preservados em via seca ou húmida.

Podemos ainda analisar mais ao detalhe, quando conceitos científicos são representados de modo tridimensional, mas reproduzem exemplos comuns da literatura, como as mariposas de Manchester para explicar seleção natural na "Galeria da Biodiversidade", ou a utilização de pavões machos taxidermizados nas exposições "Biodiversidade: conhecer para preservar" e "Galeria da Biodiversidade" para ilustrar o conceito de seleção sexual, (e que também está presente na Grand Galerie de l'évolution - MNHN).

De acordo com a autora Michelle Henning (2006) nos museus de história natural a ênfase em espécies ameaçadas de extinção, ambientalismo e biodiversidade têm mudado os critérios do agrupamento das espécies, por museografias que expressam a interdependência e inter-relações das espécies. No rastro dessa proposta, Paddon (2014) parte de grandes exposições, como a Grande Galerie de l'Évolucion (MNHN) e Hall of Biodiversity (AMNH) para sumarizar: a diversidade visual e a similaridade tornaram-se meios para comunicar biodiversidade.

Todavia, verifica-se que os padrões museográficos "Centrados numa narrativa" "Quotidiano", "Ecológico", ou “Public Understanding of Science” - não permitem a multiplicidade de interpretações dos objetos, já que os espécimes são selecionados a partir da sua capacidade de comunicar conceitos científicos: mesmo que os objetos não estejam mais presos em séries taxonómicas ou evolutivas, quando a aprendizagem está baseada na "lição das coisas", sua interpretação está diretamente inserida na narrativa expositiva, destacando acima de tudo o caráter material e ilustrativo do objeto.

Mesmo no caso de exposições construídas sob os padrões museográficos espetaculares, os objetos estão a serviço da construção de uma experiência e, eventualmente, inseridos em narrativas académicas, percursos pré-definidos e distante da realidades locais. 
De modo que, mesmo concebidos em diferentes momentos históricos e instituições, a maioria dos padrões museográficos elaborados apresentam uma abordagem que evidencia a marcante presença do olhar do investigador/curador-científico. No entanto, para comunicar sobre biodiversidade para apenas uma abordagem científica é insuficiente, sendo necessários outros modos de expor, outras vozes dentro do discurso, que são igualmente constituintes do referido conceito.

Nos estudos de caso lusófonos realizados também verifica-se a preponderância do curadorcientífico: vemos a biodiversidade sob a lente dos investigadores que compõem as equipas curatoriais, considerando especialmente a suas áreas de especialização, o que por vezes também definiu o padrão museográfico.

Como visitantes, somos convidados a nos maravilhar com a natureza, tal qual os primeiros naturalistas ao chegar numa floresta. Todavia, dado que não somos "sábios" ou "dotados de grande capacidade de síntese e memória" como os profissionais que fazem as seleções e ordenações dos tipos estão nas exposições, cabe-nos contemplamos séries de "coisas" que tem "lições" pré-definidas para nos contar.

Em outros casos, somos convidados a ler textos, ver imagens capturadas por diferentes instrumentos, experienciar multimédias e jogarmos com aparatos interativos que explicam e emulam processos e teorias já propostas. São propostas leituras "anónimas" e "mecânicas" numa utópica museografia objetiva, por não ter designado um autor, mas com a autoridade institucional conferida aos museus e coleções científicas.

Para além do silenciamento das demais esferas que constituem o conceito de biodiversidade, a perspetiva científica é também abreviada, uma vez que são desconsideradas suas práticas e autores enquanto práticas humanas circunstancialmente definidas. Tais informações não foram representadas em nenhuma das exposições analisadas. Contudo, poderiam encontrar lugar no padrão museográfico "Retorno à curiosidade".

Apenas inserido no padrão museográfico "Retorno à curiosidade" temos um contexto propício (pluridisciplinar) e possível para a representação da biodiversidade. Portanto, ainda mais recente que o termo biodiversidade é a criação de padrão museográfico que permite experienciá-lo. Reafirmamos que viabilizar exposições sobre biodiversidade é prover as múltiplas perspetivas de sua crise e permitir o posicionamento do visitante. 
Se ainda no século XIX a separação de coleção e exposição esteve associada ao crescimento das coleções e à especialização da investigação (Nyhart, 2009), bem como com a organização de exposições temáticas (Van Praët, 1996), observamos ao longo do século XX e na atualidade que o acervo em exposição deixou de ser objeto de pesquisa, transformando-se num instrumento de autoridade para disseminar resultados já estabelecidos. Todavia, como um meio tridimensional e construído por diferentes personagens, as exposições de museus de história natural compõem cenários complexos, de onde emergem outras conceções.

Especialmente ao longo do século XX, ganha relevo na construção de discursos museográficos e sua relação com as epistemologias, práticas científicas e a conceção que apenas a materialidade dos objetos de história natural já não expressa a "olho nu" seus processos de origem e diversificação. Considerando que as teorias mais recentes partem de estruturas tão pequenas que são precisos equipamentos específicos para analisá-las (seja por meio de potentes microscópios eletrónicos ou por exaustivos procedimentos de extração de ADN) ou tão grande/distantes no espaço e no tempo, que exigem clusters de computadores para criar modelos e fazer datações geológicas, o acervo em exposição é escolhido pelo investigador para representar suas ideias e conceções, sendo sua seleção um atestado tanto da função cívico-didática das exposições, como o desenvolvimento de teorias sintéticas (Van Praët, 1996).

Particularmente relacionado ao conceito analisado neste estudo, partimos do alerta de Caseta e colaboradores (2018), ao apontar que natureza e biodiversidade não são sinónimos. Dado que no conceito de biodiversidade estão imbuídas ideias que não necessariamente estão presentes em outros termos: a noção de hierarquia dos elementos vivos (desde as organelas até os ecossistemas), além da noção de que se trata de "algo" que estamos a perder (Caseta et al., 2018).

Não obstante, tais conceitos são passíveis de musealização? Silva (2013) discutiu sobre os processos e conceções filosóficas que levaram a "musealização da natureza”, elencando cinco temas recorrentes na construção contemporânea dos discursos expositivos de museus de história natural: "origem da vida”, "evolução", "classificação", "extinção" e "biodiversidade”.

Mas é possível musealizar a biodiversidade? Para Kohler (2006) o "knowledge of biodiversity was the end to which museums were built" (Kohler, 2006, p. 227), consequentemente o museu de história natural é o espaço ideal para institucionalização do conhecimento sobre a biodiversidade, uma vez que sua compreensão é o fim deste tipo de instituição. 
Em contrapartida, "a biodiversidade surgiu com a sua própria crise, como algo que deve ser preservado" (Caseta et al., 2018, p. 11). Nesse caso, uma vez que o termo "biodiversidade" foi difundido como mote para atração de diferentes atores sociais para o rápido decréscimo do número de espécies causado pelas atividades humanas (Caseta et al., 2018), seu futuro não pode ser resumido a um problema técnico de inventário, ou resolvido por hierarquias estabelecidas por séries taxonómicas e evolutivas; musealizar a biodiversidade depende também do registo e reflexão das escolhas económicas, políticas e sociais que as sociedades têm realizado ao longo do tempo (Lévêque \& Mounolou, 2003).

Assim, limitar o papel dos museus de história natural a um repositório do testemunho de existência de espécies no tempo e no espaço (Mehrhoff, 1997) restringe o papel dessas instituições para a compreensão da biodiversidade. Nesse contexto, Davallon e colaboradores (1992) apontam que a "entrada" do meio ambiente nos museus causou mudanças na museografia e Museologia, pois colocou estas entidades à frente de tópicos que pertencem ao tempo presente e solicita que seja emitido um posicionamento crítico. Já Fortin-Debart (2003) questionou se tal abordagem crítica é coerente com a missão educacional dos museus de história natural e concluiu que ao se tornarem espaços públicos, os museus sujeitam a esfera científica às preocupações da sociedade.

Dado que nesta tese estudamos comparativamente exposições, como componente da "comunicação" dentro dos processos de musealização, foram identificados diferentes modos de expor dentro de uma mesma exposição. Esta aparente incoerência entre os modos de expor e práticas científicas e museológicas assinala que diferentes estilos de pensamento não são estanques ou fechados, mas interagem, na medida em que compõem a construção do pensamento científico e é essa relação que nos permitiu compreender os distintos enfoques sobre a biodiversidade que permeiam as práticas dos museus de história natural (Ribeiro, Carneiro, \& Cavassan, 2016).

Concordamos com Kohler (2006): "The history of our knowledge of biodiversity is first and foremost a history of collecting and collections (Kohler, 2006, p. 2). Porém, a partir dos resultados desta investigação, acrescentamos que para além da salvaguarda (recolha e preservação em coleções científicas), os processos comunicacionais (em especial, as exposições) registam o histórico das práticas, epistemologias e conceções a cerca da biodiversidade, ainda que apenas sob a perspetiva dos investigadores. Assim, corroboramos Alberti (2008), quanto a inseparabilidade da produção e disseminação do conhecimento, e sugerimos que ainda no caso dos museus de história natural e 
biodiversidade há ainda a inseparabilidade entre tipo de instituição - práticas científicas e museológicas - comunicação.

"Before we can have meaning, we must have form" (Kubler, 1962), retomamos a epígrafe desta tese, com proposição do historiador de arte George Kubler. O autor questiona os baluartes da História da Arte (e, marginalmente, da História da Ciência) organizados em períodos progressistas e lineares, movimentos artísticos e na biografia de artistas-génios, propondo sequências mais fluidas e coexistentes, em que o artista-inventor busca soluções e ferramentas para problemas. Partindo das formas houve o reencontro com o conteúdo, propósito e produto, utilidade e conveniência estética (Colt, 1963). Elegemos essa citação, que anteriormente foi utilizada por Conn (1998), como referência para discutir a museografia como locus de estudo na interface entre a História da Ciência e a Museologia, em que o modo de expor carrega tanto significado quanto o conteúdo.

Embora os processos de musealização tenham silenciado as múltiplas vozes que compõem o conhecimento sobre a biodiversidade, ao analisarmos detalhadamente os modos de expor podemos reconhecer conjuntos de epistemologias e práticas científicas e museológicas. Tais conceções não estão explícitas nos textos ou nos objetos, mas são comunicadas por meio das formas, disposição dos objetos, mobiliário, abordagem dos textos e legendas e são criadas e replicadas ao longo do tempo e em diferentes instituições. O silêncio seletivo de determinadas práticas, profissionais e conhecimentos reafirmam a autoridade das ciências naturais e dos museus, por conseguinte, dos investigadores perante a assistência. O público é historicamente convidado a contemplar as maravilhas da ciência, descrita em códigos científicos (mesmo estes insuficientes) não partilhados, de modo que a biodiversidade musealizada nos museus de história natural urbanos é domesticada e nos posiciona tão longe estamos da natureza silvestre de florestas isoladas. 


\section{REFERÊNCIAS BIBLIOGRÁFICAS}

Achiam, M., \& Marandino, M. (2014). A framework for understanding the conditions of science representation and dissemination in museums. Museum Management and Curatorship, 29(1), 6682.

Adamopoulou, A., \& Solomon, E. (2016). Artists-as-Curators in Museums: Observations on Contemporary Wunderkammern. THEMA. La Revue des Musées de la Civilisation, (4), 35-49.

Adelman, L. M., Falk, J. H., \& James, S. (2000). Impact of National Aquarium in Baltimore on visitors' conservation attitudes, behavior, and knowledge. Curator: The Museum Journal, 43(1), 33-61.

Adom, D., Umachandran, K., Ziarati, P., Sawicka, B., \& Sekyere, P. (2019). The Concept of Biodiversity and its Relevance to Mankind: A short review. Journal of Agriculture and Sustainability, 12(2), 219-231.

Alberti, S. J. M. M. (2005). Objects and the Museum. Isis, 96(4), 559-571.

Alberti, S. J. M. M.(2008). Constructing nature behind the glass. Museum and Society, 6(2), 73-97.

Alberti, S. J. M. M. (2011). The Afterlives Animals: a museum menagerie. Charlottesville: University of Virginia Press.

Allison-Bunnell, S. W. (1998). Making nature 'real' again: Natural history exhibits and public rhetorics of science at the Smithsonian Institution in the early 1960s. In S. MacDonald (Org.), The Politics of Display: Museums, science, culture (p. 67-84). London: Routledge.

Almeida, A. M. (1995). A relação do público com o Museu do Instituto Butantan: Análise da exposição "Na Natureza Não Existem Vilões” (Dissertação de Mestrado). Universidade de São Paulo, São Paulo.

Alves, M. J., Bastos-Silveira, C., Carvalho, D., Catry, T., Correia, M. A., Granadeiro, J. P., \& Rebelo, R. (2014). As coleções zoológicas do Museu Nacional e História Natural e da Ciência. In M. J. Alves, A. Cartaxana, M. A. Correia, \& L. F. Lopes, Professor Carlos Almaça (1934-2010)_Estado da Arte em Áreas Científicas do Seu Interesse (p. 289-301). Lisboa.

Amorim, D. de S. (2005). Fundamentos de sistemática filogenética (2nd ed). Ribeirão Preto: Holos.

Ana Marcela. (2017, julho 18). E se pudesse dar voz a um dinossauro? Português ajuda-o a contar a sua história Disponível em: https://www.dinheirovivo.pt/marketing-pub/e-se-pudesse-dar-voz-a-umdinossauro-portugues-ajuda-o-a-contar-a-sua-historia/

Andersen, C., Bek-Thomsen, J., \& Kjærgaard, P. C. (2012). The Money Trail: A new historiography for networks, patronage, and scientific careers. Isis, 103(2), 310-315.

Andersen, S. de M. B. (1984). Histórias da terra e do mar. Lisboa: Salamandra.

Andrade, R. M. (2016). Indumentária nos museus brasileiros: A invisibilidade das coleções. Revista MUSAS, (7), 10-31.

Antunes, M. de A. (2015). Pelos Caminhos da Museologia em Portugal. Revista Iberoamericana de Turismo RITUR, (Número Especial), 142-156.

Appadurai, A. (Org.). (2008). A vida social das coisas: As mercadorias sob uma perspectiva cultural. Niterói: EDUFF. 
Aragão, T. Z. B. (2013). Concepções de ciência presentes na divulgação e na prática de instituições não formais de Ensino de Ciência (Dissertação de Mestrado). Universidade de Campinas, Campinas.

Aranha Filho, J. M. (2011). Guia da Impermanência das Exposições: Uma investigação sobre transformações do Museu Nacional do Rio nos anos 1940 (Tese de Doutoramento). Instituto de Filosofia e Ciências Sociais, Universidade Federal do Rio de Janeiro, Rio de Janeiro.

Asensio, M., \& Pol, E. (1996). Siguen siendo los dioramas uma alternativa efectiva de montaje? Revista de Museologia, (8), 11-20.

Ash, D. (2004). How families use questions at dioramas: Ideas for exhibit design. Curator: The Museum Journal, 47(1), 84-100.

Asma, S. T. (2001). Stuffed animals and pickled heads: The culture and evolution of natural history museums. New York: Oxford University Press.

Azevedo, M., Selles, S., \& Lima-Tavares, D. (2016). Relações entre os movimentos reformistas educacionais do ensino de ciências nos Estados Unidos e Brasil na década de 1960. Educação em Foco, 21(1), 237.

Balloffet, P., Courvoisier, F. H., \& Lagier, J. (2014). From Museum to Amusement Park: The opportunities and risks of edutainment. International Journal of Arts Management 16(2), 4-18.

Bann, S. (2003). The Return to Curiosity: Shifting Paradigms in Contemporary Museum Display. In A. McClellan (Org.), Art and its Publics (p. 117-132).

Barker, E. (1999a). Contemporary Cultures of Display. New Haven: Yale University Press.

Barker, E. (1999b). Exhibiting the Canon: The blockbuster show. In E. Barker (Org.), Contemporary Cultures of Display (p. 127-146). New Haven: Yale University Press.

Barry, A. (1998). On interactivity: Consumers, citizens and culture. In S. MacDonald (Org.), The Politics of Display: Museums, science, culture (p. 85-102). New York: Routledge.

Barry, A. (2001). Political Machines: Governing a technological society. London: A\&C Black.

Bastos-Siqueira, C. (2017, abril 28). Entrevista Cristiane Bastos-Silveira - Comissária Científica da Exposição Reis da Europa Selvagem (L. V. Alves). Retrieved from http://www.museus.ulisboa.pt/en/node/1668

Bayer, H. (1961). Aspects of Design of Exhibitions and Museums. Curator: The Museum Journal, IV (3), 257288.

Bennett, T. (1995). The Birth of the Museum history, theory, politics. New York: Routledge.

Bennett, T. (2004). Pasts Beyond Memory: Evolution, museums, colonialism. London: Routledge.

Bennett, J. (2005). Museums and the History of Science: Practitioner's postscript. Isis, 96(4), 602-608.

Bergers, L., \& Trijp, D. van. (2017). Science Museums: A Panoramic View. Isis, 108(2), 366-370.

Berkowitz, C., \& Lightman, B. (2017). Introduction. In C. Berkowitz \& B. Lightman (Orgs.), Science Museums in Transition: Cultures of display in nineteenth-century Britain and America (p. 1-12). Pittsburg: University of Pittsburgh Press.

Berryman, J. (2013). Art and national interest: The diplomatic origins of the "blockbuster exhibition" in Australia. Journal of Australian Studies, 37(2), 159-173. 
Betts, J., Dunn, R., Higgitt, R., Hutchinson, G., Kukula, M., \& McEvoy, R. (2012). Royal Observatory Greenwich: Souvenir guide. London: Belmont Press.

Blond, K. (2018). Imagining the future of natural history exhibitions. In E. Dorfman (Org.), The Future of Natural History Museums (p. 103-118). New York: Routledge.

Blouin, A. (2017, julho 24). 'Specimens: Unlocking the Secrets of Life' at The Field Museum, Chicago. Disponivel em BLOUINARTINFO International website: https://www.blouinartinfo.com/news/story/2379400/specimens-unlocking-the-secrets-of-life-atthe-field-museum

Blyth, R., Colville, Q., Gaschke, J., Graves, J., Hutchinson, G., McAller, J. Warrior, C. (2012). National Maritime Museum Greeenwich: Souvenir guide (2nd ed). London: Belmont Press.

Bragança, G, F. (1988). Museums of science or science centers: Two opposite realities? In M. M. A. Ferreira \& J. F. Rodrigues, Museums of Science and Tecnology (p. 21-39). Lisboa: Fundação Oriente \& Museu de Ciências da Universidade de Lisboa.

Bragança, G, F. (2005). Museus Universitários: Sua especificidade no âmbito da Museologia. In Colecções de ciências físicas e tecnológicas em museus universitários: Homenagem a Fernando Bragança Gil (p. 33-52). Porto: Universidade do Porto.

Bramwell, A. (1989). Ecology in the 20th century: A history. New Haven and London: Yale University Press.

Brigola, J. (2000). Colecções, gabinetes e museus em Portugal no século XVIII (Tese de Doutoramento). Universidade de Évora, Évora.

Brigola, J. (2008). Domenico Vandelli - um naturalista italiano a serviço de Portugal e do Brasil. In O gabinete de curiosidades de Domenico Vandelli (p. 41-52). Rio de Janeiro: Dantes Editora.

Bruggeman, S. C. (2015). "A Most Complete Whaling Museum”: Profiting from the past on Nantucket Island. Museum History Journal, 8(2), 188-208.

Bruno, C. (2006). Museologia e Museus: Os inevitáveis caminhos entrelaçados. Cadernos de Sociomuseologia, (25), 5-20.

Buckingham, D., \& Scanlon, M. (2000). That is edutainment: Media, pedagogy and the market place. Apresentado em International Forum of Researchersb on Young People and the Media, Sydney.

Burns, T. W., O'Connor, D. J., \& Stocklmayer, S. M. (2003). Science Communication: A Contemporary Definition. Public Understanding of Science, 12(2), 183-202.

Bynum, W. F., Browne, J., \& Porter, R. (1981). Dictionary of the History of Science. Princeton University Press.

Cameron, F. (2005). Contentiousness and shifting knowledge paradigms: The roles of history and science museums in contemporary societies. Museum Management and Curatorship, 20(3), 213-233.

Cameron, F., Hodge, B., \& Salazar, J. F. (2013). Representing climate change in museum space and places: Climate change in museum space and places. Willey Interdisciplinary Reviews: Climate Change, 4(1), 9-21.

Campelo, G. (2010). Exposição Etnomologia/Invertebrados Circuito Permanente. Rio de Janeiro. Arquivos do Setor de Museologia do Museu Nacional do Rio de Janeiro (material perdido em incêndio de 2 de Setembro de 2018).

Carson, R. (1969). Primavera Silenciosa (2a Edição; R. Pollilo, Trad.). Pórtico. 
Carvalho, G. S. (2009). Literacia científica: Conceitos e dimensões. In F. Azevedo \& M. da G. Sardinha, Modelos e Práticas em Literacia (p. 179-194). Lisboa: Lidel.

Caseta, E., Di Marco, S., Silva, J. M., Silva, C. V., Vecchi, D., \& Vicente, L. (2018). Biodiversidade: O que é e porque é importante. Lisboa: Gradiva.

Cavalcanti, C. C. B., \& Persechini, P. M. (2011). Science Museums and the Popularization of Science in Brazil. Field Actions Science Reports, (Special Issue 3). Disponível em: http://factsreports.revues.org/1063

Ceci, C. (2009). Darwin: Origin and Evolution of an Exhibition. Evolution: Education and Outreach, 2(3), 560563.

Challoner, J. (2015). Science Museum: Souvenir guide. London: SCMG Enterprises Ltda / Carlton Books Ltda.

Chapman, W. R. (1985). Arranging ethnology: A.H.L.F. Pitt Rivers and the typological tradition. In G. W. Stocking (Org.), Objects and others: Essays on museums and material culture (p. 15-48). Madison: University of Wisconsin Press.

Cherry, D., \& Cullen, F. (2007). Spectacle and Display: Settings the terms. Art History, 30(4), 475-480.

Chicone, S. J., \& Kissel, R. A. (2014). Dinosaurs and dioramas: Creating natural history exhibitions. Walnut Creek: Left Coast Press.

Chu, J. C.J. (2015). The relationship between museums and blockbuster exhibitions: A case study of Taiwan. Museum 2015 Tokyo: the Agile Museum, 1-16. Tokyo: Muiji University.

Collet, D. (2014). Staging separation: Distant worlds in early museums. In L. Forster (Org.), Transforming Knowledge Orders: Museums, collections and exhibitions (p. 47-71). Paderborn: Wilhelm Fink Vrlg.

Conceição, C. P. (2011). Promoção da Cultura Científica: Análise teórica e estudo de caso do programa Ciência Viva (Tese de Doutoramento). Instituto Universitário de Lisboa, Lisboa.

Conn, S. (1998). Museums and American Intellectual Life 1876-1926. Chicago, Ill.: University of Chicago Press.

Conn, S. (2006). Science Museums and the Culture Wars. In S. MacDonald (Org.), A Companion to Museum Studies (p. 494-508). London: Blackwell Publishing Ltd.

Conn, S. (2010). Do museums still need objects? Philadel phia: University of Pennsylvania Press.

Cookson, C. (2017, junho 30). The Natural History Museum's new hall of wonders. 06 de julho de 2018, Financial Times. Disponivel em: https://www.ft.com/content/b5d17b84-5b89-11e7-b553e2df1b0c3220

Cooper, G. J. (2007). The Science of the Struggle for Existence: on the foundations of ecology. New York: Cambridge University Press.

Corral-Guillé, G. (2015). El nuevo esquema expositivo del museo de historia natural de Londres, 1968-1981. Una perspectiva histórica. (Tese de Doutoramento) Universitat Autònoma de Barcelona, Bellaterra.

Counts, C. M. (2009). Spectacular design in museum exhibitions. Curator: The Museum Journal, 52(3), 273288.

Couto, M. de F. M. (2011). A arte de vanguarda no Brasil e seus manifestos. Revista IEB, (53), 89-106.

Cury, M. X. (2014). Museologia e conhecimento, conhecimento museológico - Uma perspectiva dentre muitas. Museologia e Interdisciplinaridade, III(5), 55-73. 
Cuvier, G. F. (1803). Notice sur l'établissement de la collection d'anatomie comparée du Muséum. Annales du Muséum National d'histoire naturelle, 2, 409-414.

Cypriano, F., \& Oliveira, M. M. (2017). História das Exposições: Casos exemplares. São Paulo: EDUC.176p.

Daston, L. (1988). Review on artifact and experiments. The factual sensibility. Isis, 79(3), 452-470.

Daston, L. (Org.). (2000). Biographies of Scientific Objects. Chicago: The University of Chicago Press.

Daston, L., \& Galison, P. (2007). Objectivity. New York: Cambridge, Mass: Zone Books; Distributed by the MIT Press.

Daston, L., \& Galison, P. (2007a). Epistemologies of the eye. In Objectivity. New York: Zone Books.

Daston, L., \& Galison, P. (2007b). Representation to Presentation. In Objectivity (p. 363-415). New York: Zone Books.

Daston, L., \& Galison, P. (2007c). Truth-to-nature. In Objectivity (p. 55-114). New York: Zone Books.

Davallon, J., Grandmont, G., \& Schiele, B. (1992). L'Environnement entre au musée. Québec: Presses universitaires de Lyon.

Dean, D. (1994). Museum Exhibition: Theory and practice. New York: Routledge.

Deléage, J. P. (1993). História da Ecologia: Uma ciência do homem e da natureza. Lisboa: Publicações Dom Quixote.

Delicado, A. (2008). Microscópios, batas brancas e tubos de ensaio: Representações da ciência nas exposições científicas. Revista Crítica de Ciências Sociais, (83), 79-98.

Delicado, A. (2009). A Musealização da Ciência em Portugal. Lisboa: Fundação Calouste Gulbenkian/Fundação para a Ciência e Tecnologia.

Delicado, A. (2010). For scientists, for students or for the public? Host: Journal of History of Science and Technology, 4, 1-20.

DeLong, D. C. (1996). Defining Biodiversity. Wildlife Society Bulletin, 24(4), 738-749.

Demski, C. E. (2009). Museum Discovery Rooms Engaging Families Using Learning Theories (Dissertação de Mestrado). Seton Hall University, New Jersey.

Desvallées, A., \& Mairesse, F. (Orgs.), Soares, B. B., \& Cury, M. X. (Trads.). (2013). Conceitos-chave de museologia. São Paulo: Comitê Brasileiro do Conselho Internacional de Museus: Pinacoteca do Estado de São Paulo: Secretaria de Estado da Cultura.

Dias, N. (1994). Looking at objects: Memory, knowledge in nineteenth-century ethnographic displays. In G. Robertson, M. Mash, L. Tickner, J. Bird, B. Curtis, \& T. Putnam (Orgs.), Travellers' Tales: Narratives of home and displacement (p. 162-174). London: Routledge.

Dicker, E. (2007). The Transparent Woman. Disponivel: https://collection.maas.museum/object/244414

Dolák, J., \& Šobáňová, P. (2018). Museum presentation. Olomouc: Palacký University Olomouc.

Dorfman, E. (Org.). (2017). The future of natural history museums. New York: Routledge.

Duncan, C. (1995). The art museum as a ritual. In Civilizing Rituals: Inside public art museums (p. 7-20). New York: Routledge. 
Durant, J. (1992). Introduction. In J. Durant (Org.), Museums and the Public Understanding of Science (p. 7 15). London: Science Museum and Museums and the Public Understanding of Science.

Eidelman, J., \& Van Praët, M. (2000). La muséologie des sciences et ses publics: Regards croisés sur la Grande Galerie de l'évoltuon du Muséum national d'histoire naturelle. Paris: Presses Universitaires de France.

Elsen, A. (1986). Museum Blockbusters: Assessing the pros and cons. Art in America, June, 24-27.

Entradas, M. (2015). Science and the public: The public understanding of science and its measurements. Portuguese Journal of Social Science, 14(1), 71-85.

Fabian, J. (2014). Time and the other: How anthropology makes its object. New York: Columbia University Press.

Farro, M. (2009). La Formación del Museo de La Plata: Coleccionistas, comerciantes, estudiosos y naturalistas viajeros a fines del siglo XIX. Rosario: Prohistoria Ediciones.

Fernandes, B. B. (2015). A institucionalização da Ecologia no Brasil: Contribuições científicas do Museu Nacional e da FIOCRUZ. Anais do XXVIII Simpósio Nacional de História. Apresentado em XVIII Simpósio Nacional de História, Florianópolis. Disponível em: http://www.snh2015.anpuh.org/resources/anais/39/1434137707 ARQUIVO AINSTITUCIONALIZA CAODAECOLOGIANOBRASIL-CONTRIBUICOESCIENTIFICASDOMUSEUNACIONALEDAFIOCRUZ.pdf

Ferrand, N. (2017). A Galeria da Biodiversidade. Revista de Ciência Elementar, 5(2), 24.

Findlen, P. (1994). Possessing nature: Museums, collecting, and scientific culture in early modern Italy. Berkeley: University of California Press.

Fleming, E. M. (1974). Artifact Study: A Proposed Model. Winterthur Portfolio, 9, 153-173.

Flower, W. H. (1898). Essays on museums and other subjects connected with natural history. London: Routledge.

Fonseca, M. J., \& Santos, R. (2018, maio 27). Galeria da Biodiversidade premiada pela Associação de Museologia. Notícias Universidade do Porto Disponível em: https://noticias.up.pt/galeria-dabiodiversidade-galardoada-com-premio-da-associacao-de-museologia/

Forgan, S. (1994). The Architecture of Display: Museums, universities and objects in nineteenth-century Britain Museus and Universities. History of Science, xxxii, 139-162.

Forster, L. (2014). Introduction. In L. Forster (Org.), Transformind knowledge orders: Museums, collections and exhibitions (p. 7-20). Paderborn: Wilhelm Fink Vrlg.

Fortin-Debart, C. (2003). Le Musee de Sciences Naturelles, un partenaire de l'école pour une education relative a l'environnement: Du message scientifique au débat de société. 4(2). Disponível em http://journals.openedition.org/vertigo/4494

Franco, J. L. de A. (2013). O conceito de biodiversidade e a história da biologia da conservação: Da preservação da wilderness à conservação da biodiversidade. História (São Paulo), 32(2), 21-48.

Freedberg, S. J., Jackson-Stops, G., \& Spear, R. E. (1986). Art history and the "blockbuster exhibition". Art Bulletin, 68(3), 358-359.

Freire, C. (2017). Por uma arqueologia das exposições. In F. Cocchiarle, A. Severo, \& M. Panitz, Artes Visuais (p. 81-87). FUNARTE. 
Friedman, A. J. (2007). The Extraordinary Growth of the Science-Technology Museum. Curator: The Museum Journal, 50(1), 63-75.

García, S. V., \& Podgorny, I. (2001). Pedagogía y nacionalismo en la Argentina: Lo internacional y lo local en la institucionalización de la enseñanza de la arqueología. Trabajos de Prehistoria, 58(2), 9-26.

Gay, H. (2013). The Silwood Circle: A history of ecology and the making of scientific careers in late twentiethcentury Britain. London: Imperial College Press.

Gippoliti, S. (2005). Historical Museology Meets Tropical Biodiversity Conservation. Biodiversity and Conservation, 14(13), 3127-3134.

Girault, Y. (2003). Le musée de science: D’un parti pris épistémologique à la prise en compte des publics. In Y. Girault (Org.), L'accueil des publics scolaires dans les muséums, aquariums, jardins botaniques, parcs zoologiques (p. 15-50). Paris: L'Harmattan.

Golinski, J. (2005). Making natural knowledge: Constructivism and the history of science. Chicago: University of Chicago Press.

González-Perez, C. F. (2012). Referencias historicas del Museo de La Plata, Facultad de Ciencias Naturales y Museo: Trayectorias necesarias para entender su presente. Aletheia, 3(5), 17.

Goode, G. B. (1891). The Museums of the Future. Washington: Government Printng Office.

Goode, G. B. (1895). The principles of museum administration. York: Coultas \& Volans, Exchange Printing Works.

Greenberg, R., Ferguson, B. W., \& Nairne, S. (1996). Thinking about exhibitions. London: Routledge.

Gregory, W. K. (1936). The museum of things versus the museum of ideas. Science, 83(2164), 585-588.

Griffiths, A. (2008). Shivers Down Your Spine: Cinema, Museums, and the Immersive View. New York: Columbia University Press.

Guarnieri, W. R. C. (2010). Projeto para a Estação Ciência: Centro de Ciências para a Juventude (1986). In C. Bruno (Org.), Waldisa Rússio Camargo Guarnieri: Textos e contextos de uma trajetória profissional (Vol. 1, p. 280-300). São Paulo: Pinacoteca do Estado de São Paulo.

Haraway, D. (1984). Teddy Bear Patriarchy: Taxidermy in the Garden of Eden, New York City, 1908-1936. Social Text, (11), 20.

Hein, G. E. (1986). The Exploratorium: The Museum as laboratory. Washington: Smithsonian Institution Press.

Hein, G. E. (1998). Learning in the Museum (1st Edition). London: Routledge.

Hendry, A. (2017, Janeiro 19). The whale story: Richard Owen. Disponível em: http://www.nhm.ac.uk/discover/the-whale-story-richard-owen.html

Henning, M. (2006). Museums, media and cultural theory. Maidenhead, England; New York: Open University Press.

Henning, W. (1966). Phylogenetic systematics. Urbana: University of Illinois Press.

Henson, P. M. (2017). "A Nursery of Living Thoughts": G. Brown Goode's Vision for a National Museum in the Late Nineteenth-Century United States. In C. Berkowitz \& B. Lightman (Orgs.), Science Museums in Transition: Cultures of display in nineteenth-century Britain and America. Pittsburg: University of Pittsburgh Press. 
Holzmeyer, C. A. (2012). Displaying "The Natural World" for Public Curiosity: U.S. science museum transformations, from Lewis \& Clark to the Exploratorium (Tese de Doutoramento). University of California, Berkeley.

Hooper-Greenhill, E. (1992). Museums and the Shaping of Knowledge. Routledge.

Huang, H. (2008). Mapping of knowledge in the natural history museum: Richard Owen's naturalistic ideas and spatial layouts of the Natural History Museum of London. Collection and Research, 21, 51-77.

Impey, O., Macgregor, A. (1985). The Origins of Museums: the Cabinet of Curiosities in Sixteenth and Seventeenth Century-Europe. Oxford Clarendon.

Jacobi, P. R. (2005). Educação ambiental: O desafio da construção de um pensamento crítico, complexo e reflexivo. Educação e Pesquisa, 31(2), 233-250.

Jacomy, B. (2007). Instrumentos, máquinas e aparatos interativos de ciência e tecnologia exibidos nos museus. In M. E. Valente (Org.), Museus de Ciência e Tecnologia: Interpretações e ações dirigidas ao público (p. 15-24). Rio de Janeiro: MAST.

Jamison, A. (2001). The Making of Green Knowledge: Environmental politics and cultural transformation. Cambridge: Cambridge University Press.

Jamison, A. (2011). Ecology and the Environmental Movement. In A. Schwarz \& K. Jax (Orgs.), Ecology Revisited: Reflecting on concepts, advancing science (p. 195-204). Dordrecht: Springer.

Janes, J. (2016). Remembering Juno on the 80th anniversary of the Cleveland Health Museum. Disponivel em: https://www.cmnh.org/juno\#

Jatobá, S. U. S., Cidade, L. C. F., \& Vargas, G. M. (2009). Ecologismo, ambientalismo e ecologia política: Diferentes visões da sustentabilidade e do território. Sociedade e Estado, 24(1), 47-87.

Jax, K., \& Schwarz, A. (2011). The Early Period of Word and Concept Formation. In K. Jax \& A. Schwarz (Orgs.), Ecology Revisited: Reflectiong on concepts, advancing science (p. 149-154). Dordrecht: Springer.

Julião, L., Neves, M. E. M., \& Segantini, V. C. (2018). Domingos Vandelli: Mediador de dois mundos. Anais Museu Histórico Nacional, 50, 52-68.

Kamcke, C., \& Hutterer, R. (2015). History of Dioramas. In S. D. Tunnicliffe \& A. Scheersoi, Natural History Dioramas: History, construction and educational role (p. 7-22). London: Springer.

Keller, D. R., \& Golley, F. B. (2000). The Philosophy of Ecology: From science to synthesis. Athens: University of Georgia Press.

Kjærgaard, P. C. (2012). The Fossil Trade: Paying a Price for Human Origins. Isis, 103(2), 340-355.

Knorr-Cetina, K. D. (1982). Scientific Communities or Transepistemic Arenas of Research? A Critique of Quasi-Economic Models of Science. Social Studies of Science, 12(1), 101-130.

Kohler, R. E. (2006). All Creatures: Naturalists, Collectors, and Biodiversity, 1850-1950. New Jersey: Princeton University Press.

Kohler, R. E. (2007). Finders, keepers: Collecting sciences and collecting practice. History of Science, (45), 428-454.

Kohler, R. E. (2013). Reflections on the history of systematics. In The Evolution of Phylogenetic Systematics (p. 17-46). University of California Press. 
Kopytoff, I. (2008). A biografia cultural das coisas: A mercantilização como processo. In A. Appadurai (Org.), A Vida Social das Coisas: As mercadorias sob uma perspectiva cultural (p. 89-125). Niterói: Editora da Universidade Federal Fluminense.

Koster, E. (2004). If we could start again... ASTC Dimensions, (May/June), 3.

Kraft, A., \& Alberti, S. J. M. M. (2003). 'Equal though different': Laboratories, museums and the institutional development of biology in late-Victorian Northern England. Studies in History and Philosophy of Science Part C: Studies in History and Philosophy of Biological and Biomedical Sciences, 34(2), 203236.

Kubler, G. (1962). The Shape of Time: Remarks on the history of things. New Haven and London: Yale University Press.

Kulik, G. (1989). Designing the past: History-museum exhibitions from Peale to the present. In W. Loren \& R. Rosenzweig (Orgs.), History Museums in the United States: A critical assessment (p. 1-39). Urbana: University of Illinois Press.

Kury, L. B., \& Camenietzki, C. Z. (1997). Ordem e Natureza: Coleções e cultura científica na Europa Moderna. Anais Museu Histórico Nacional, 29, 57-85.

Lambert, S., \& Henderson, J. (2011). The carbon footprint of museum loans: A pilot study at Amgueddfa Cymru - National Museum Wales. Museum Management and Curatorship, 26(3), 209-235.

Landim, M. I., \& Elias, F. A. (2012). Biodiversidade: Fique de olho! Revista do EDICC (Encontro de Divulgação de Ciência e Cultura), 1, 336-345.

Landim, M. I. (2018). Um oceano de desconhecimento sobre a biodiversidade. Museologia e Interdisciplinaridade, 7(14), 88-106.

Laubichler, M. D. (2010). The Agora of Knowledge. Science, 330(6003), 451-452.

Leão, I. (2015). Museu de Zoologia abre exposição "Biodiversidade - Conhecer para Preservar". Jornal da USP. Disponível em: https://www5.usp.br/97990/museu-de-zoologia-abre-exposicaobiodiversidade-conhecer-para-preservar/

Leão, I. (2016, maio 17). Estação Ciência não voltará para antigo prédio e equipamentos são distribuídos. 02 de maio de 2019, Jornal da USP. Disponível em:: https://jornal.usp.br/universidade/estacaociencia-nao-voltara-para-antigo-predio-e-equipamentos-sao-distribuidos/

Lévêque, C., \& Mounolou, J.C. (2003). Biodiversity. Chichester, England: John Wiley \& Sons, Ltd.

Lockyer, A. (2007). The logic of spectacle c. 1970. Art History, 30(4), 571-589.

Lopes, M. M. (2005). Culturas das Ciências Naturais. Ciência \& Educação (Bauru), 11(3), 457-470.

Lopes, M. M. (2009). O Brasil Descobre a Pesquisa Científica: Os museus e as ciências naturais no século XIX $\left(2^{\mathrm{a}}\right)$. Brasília: Editora Hucitec / Editora Universidade de Brasília.

Lopes, M. M., \& Murriello, S. E. (2005). Ciências e educação em museus no final do século XIX. História, Ciências, Saúde-Manguinhos, 12(suppl), 13-30.

Lopes, M. M., \& Podgorny, I. (2000). The shaping of Latin American museums of natural history, 1850-1990. Osiris, 15, 108-118. 
Lopes, M. M., \&Valente, M. E. (2009). Negotiations of meanings, audiences and apparatuses in the Museums and Science Centres of the 21st century. CIMUSET CONFERENCE. Proceedings... Serbia, Belgrado:[sn].

Lourenço, M. C. (2010). O Museu de Ciência da Universidade de Lisboa: Patrimônio, coleções e pesquisa. In Coleções científicas Luso-Brasileiras: Patrimônio a ser descoberto. Rio de Janeiro, RJ: MAST.

Lourenço, M. C., \& Dias, J. P. S. (2017). "Time Capsules" of Science: Museums, Collections, and Scientific Heritage in Portugal. Isis, 108(2), 390-398.

Lourenço, M. C., \& Gessner, S. (2014). Documenting Collections: Cornerstones for More History of Science in Museums. Science \& Education, 23(4), 727-745.

Lovejoy, T., \& Hannah, L. (Orgs.). (2019). Biodiversity and Climate Change: Transforming the biosphere. New Haven and London: Yale University Press.

MacDonald, S. (1998). Exhibitions of power and powers of exhibition: An introduction to the politics of display. In S. MacDonald (Org.), The Politics of Display: Museums, science and culture (p. 1-21). London: Routledge.

MacDonald, S. (2002). Behind the Scenes at the Science Museum. Oxford: Berg.

MacDonald, S. (2004). Exhibitions and the public understanding of Science Paradox. The Pantaneto Forum, 13. Disponível em: http://pantaneto.co.uk/exhibitions-and-the-public-understanding-of-scienceparadox-sharon-macdonald/

MacFadden, B. J., Dunckel, B. A., Ellis, S., Dierking, L. D., Abraham-Silver, L., Kisiel, J., \& Koke, J. (2007). Natural History Museum Visitors' Understanding of Evolution. BioScience, 57(10), 875-882.

Magnin, P. H. (2011). Una aproximación de la história de las colecciones públicas: De la exposición erudita a la sociedade del espetáculo. Bogotá: Sistema de Patimonio Cultural y Museos. Universidade Nacional de Colombia.

Maigret, J. (1996). Aesthetics in the service of science: The Grande Galerie de l'Évolution in Paris. Museum International, 190(2), 19-22.

Maigret, J., \& Raulin-Cerceau, F. (2000). Les collections mises en scène. In J. Eidelman \& M. Van Praët (Orgs.), La Muséologie des sciences et ses publics: Regards croisés sur la Grande Galerie de l'Évolution du Muséum national d'Histoire naturelle (Presses Universitaires de France, p. 31-52). Paris.

Mairesse, F. (2015). Comunicação, Mediação e Marketing. Museologia e Interdisciplinaridade, IV(57-73), 17.

Marandino, M., Achiam, M., \& Oliveira, A. D. (2015). The diorama as a means for biodiversity education. In S. D. Tunnicliffe \&A. Scheersoi (Orgs.), Natural History Dioramas: History, construction and educational role. Dordrecht: Springer.

Marandino, M., Oliveira, A. D., \& Mortensen, M. (2009). Discussing biodiversity in dioramas: A powerful tool to museum education. Natural History Museum Newsletter. International Council of Museums/ICOM., 29, 30-36.

Marques, A.I.G. O Instituto Bacteriológico Câmara Pestana. Ciência Médica e Cuidados de Saúde (18921930). (Tese de Doutoramento). Universidade de Évora, Évora.

Mateus, S. (2015). Exposições de Dinossauros em Portugal Comunicar Paleontologia, Métodos e Problemáticas. Estudos em Comunicação, (21), 165-175. 
Matthews, M. (1989). A brief review. Synthese, 80, 1-8.

Mayr, E. (1998). O Desenvolvimento do Pensamento Biológico: Diversidade, evolução e herança. Brasília: Editora Universidade de Brasília.

McClellan, A. (2007). Museum studies now. Art History, 30(4), 566-570.

McLean, K. (2007). Do Museum Exhibitions Have a Future? Curator: The Museum Journal, 50(1), 109-121.

Mehrhoff, L. J. (1997). Museums, Research Collections, and the Biodiversity Challenge. In M. Reaka-Kudla, D. E. Wilson, \& E. O. Wilson (Orgs.), Biodiversity II: understanding and protecting our biological resources (p. 447-466). Washington: Joseph Henry Press.

Miles, R. (2007). A Natural History Museum in Transition: Reflections on visitor studies in practice. Visitor Studies, 10(2), 129-135.

Miles, R. S., \& Tout, A. F. (1978). Human Biology and the New Exhibition Scheme in the British Museum (Natural History). Curator: The Museum Journal, 21(1), 36-50.

Miles, R. S., \& Tout, A. F. (1992). Exhibitions and public understanding of science. In J. Durant, Museums and the Public Understanding of Science (p. 27-33). London: Science Museum and Museums and the Public Understanding of Science.

Miller, B., Conway, W., Reading, R. P., Wemmer, C., Wildt, D., Kleiman, D., Hutchins, M. (2004). Evaluating the Conservation Mission of Zoos, Aquariums, Botanical Gardens, and Natural History Museums. Conservation Biology, 18(1), 86-93.

Miller, J. (1996). The show you love to hate: A psychology of the mega-exhibition. In R. Greenberg, B. W. Ferguson, \& S. Nairne (Orgs.), Thinking about exhibitions (p. 192-196). London: Routledge.

Miller, J. D. (1992). Toward a scientific understanding of the public understanding of science and technology. Public Understanding of Science, 1(1), 23-26.

Monaco, L. M., \& Marandino, M. (2010). Biodiversidade nos museus: Discussões sobre a (in)existência de um discurso relativo à conservação em ações educativas dos museus de ciências. In M. Marandino, L. M. Monaco, \&A. D. Oliveira (Orgs.), Olhares sobre os diferentes contextos da biodiversidade: Pesquisa, divulgação e educação (p. 13-29). São Paulo: GEENF/FEUSP/INCTTOX.

Moraes, E. M. A., Santos, C. F. M., \& Campos, R. D. da S. (2011). Filosofia Natural Lusa: A Viagem Philosophica e a Política Iluminista na América Portuguesa Setecentista. Confluenze, 4(1), 75-91.

Morar, N., Toadvine, T., \& Bohannan, B. J. M. (2015). Biodiversity at Twenty-Five Years: Revolution Or Red Herring? Ethics, Policy \& Environment, 18(1), 16-29.

Mouliou, M., Soubiran, S., Talas, S., \& Wittje, R. (Orgs.). (2018). Turning Inside Out European University Heritage:collections, audiences, stakeholders. Athens: National and Kapodistrian University of Athens Press.

Müsch, I. (2015). Coleção de espécimes naturais de Albertus Seba e seu inventário ilustrado. In Bibliotheca Universalis. Albertus Seba-Cabinet of Natural Curiosities (p. 52-75). Koln: Taschen.

Myers, C. W. (2000). A History of Herpetology at the American Museum of Natural History. Bulletin of the American Museum of Natural History, 252, 1-231.

Nair, S. M. (1996). L'écologie entre au musée. Museum International (Edition Francaise), 48(2), 8-13. 
Naish, D. (2014, agosto 8). After 75 Years, 6-Ton Blue Whale Model Still Excites London Museum. Recuperado 7 de julho de 2018, de Tetrapod Zoology (Scientific American). Disponível em: https://blogs.scientificamerican.com/tetrapod-zoology/after-75-years-6-ton-blue-whale-modelstill-excites-london-museum/

National Museum of Natural History. (s.d.). Objects of Wonder. Disponível em https://naturalhistory.si.edu/exhibits/objects-wonder

Natural History Museum. (2018a). Natural History Museum Souvenir Guide. London: Natural History Museum.

Natural History Museum. (2018b). Natural History Museum Souvenir Guide. London: Natural History Museum.

Neurath, O. (1933). Museums of the future. Survey Graphics, 22, 458-463.

Nicholls, H. (2011). The Afterlife of Chi-Chi. In S. J. M.M. Alberti, The Afterlives Animals: a museum menagerie (p. 169-185). Charlottesville: University of Virginia Press.

Nordenskiold, E. (1929). The History of Biology: A survey. New York: Kegan Paul, Trench, Trubner \& Co. Ltd.

Nucci, J. C. (2007). Origem e desenvolvimento da Ecologia e da Ecologia da Paisagem. Revista Geografar, 2(1), 77-99.

Nunes, M. de F. (2016). Science and culture, collections and museums: A new perspective on «Portugal and the european culture», in the 20th century.... Revista de História das Ideias, 34, 267-286.

Nyhart, L. K. (2009). Modern Nature: The rise of the biological perspective in Germany. Chicago: The University of Chicago Press.

Nyhart, L. K. (2016). Interpreting Visual Cultures of Science. Annals of Science, 73(4), 442-446.

Office of Policy and Analysis. (2002). Exhibition Concept Models. Disponível em https://repository.si.edu/bitstream/handle/10088/17299/opanda WPEx ConceptsFinal.pdf

Ogawa, R. T., Loomis, M., \& Crain, R. (2009). Institutional history of an interactive science center: The founding and development of the Exploratorium. Science Education, 93(2), 269-292.

Okan, Z. (2003). Edutainment: Is learning at risk? British Journal of Educational Technology, 34(3), 255-264.

Oppenheimer, F. (1968). Rationale For A Science Museum. Curator: The Museum Journal, 1(3), 206-209.

O'Reilly, C., \& Lawrenson, A. (2014). Revenue, relevance and reflecting community: Blockbusters at the Art Galley of NSW. Museum and Society, 12(3), 157-170.

Orosz, J. J. (1990). Curators and Culture: The museum movement in America, 1740-1870. Tuscaloosa: The University of Alabama Press.

Paddon, H. (2014). Redisplaying museum collections: Contemporary display and interpretation in British museums (Vol. 30). Farnham: Ashgate Publishing Limited.

Padovan, Thiago Lourenço. (2016)Teoria Crítica e indústria museal: reflexões contemporâneas para pensar as ciências e os museus do tempo presente. (Dissertação de Mestrado). Universidade de São Paulo..

Papavero, N., \& Abe, J. M. (1992). Categorias do ser e biologia. Estudos Avançados, 6(14), 143-156.

Parr, A. E. (1963). Concerning Whales and Museums. Curator: The Museum Journal, 6(1), 65-76. 
Pavid, K. (2018b, abril 17). Indexing Earth's wonders: A history of the Museum.

Payne, W. W. (1978). A glossary of plant hair terminology. Brittonia, 30(2), 239-255.

Pekarik, A. J., Doering, Z. D., \& Karns, D. A. (1999). Exploring Satisfying Experiences in Museums. Curator: The Museum Journal, 42(2), 152-173.

Pekarik, A. J., Schreiber, J. B., Hanemann, N., Richmond, K., \& Mogel, B. (2014). IPOP: A Theory of Experience Preference. Curator: The Museum Journal, 57(1), 5-27.

Péquignot, A. (2006). The History of Taxidermy: Clues for Preservation. Collections, 2(3), 245-255.

Pereira, E. J. S. (2017). Actores, colecções e objectos: coleccionismo arqueológico e redes de circulação do conhecimento - Portugal, 1850-1930. (Tese de Doutoramento). Universidade de Évora, Évora.

Perks, S. (2015). Transforming the Natural History Museum in London: Isotype and the New Exhibition Scheme. In S. Macdonald \& H. Rees Leahy (Orgs.), The International Handbooks of Museum Studies (p. 389-418).

Pickstone, J. V. (1994). Museological Science? The Place of the Analytical/Comparative in NineteenthCentury Science, Technology and Medicine. History of Science, xxxii, 111-138.

Pickstone, J. V. (2001). Ways of knowing: A new history of science, technology, and medicine. Chicago: University of Chicago Press.

Pimentel, J. (2010). El Rinoceronte y el Megaterio: U ensayo de morfología histórica. Madrid: Abada Editores.

Pitt Rivers, A. H. L. F. (1874). On the principles of classification adopted in the arrangement of his anthropological collection, now exhibited in the Bethnal Green Museum. Journal of the Royal Anthropological Institute, 6, 293-308.

Pitt Rivers, A. H. L. F. (1875). On the evolution of culture. In J. L. Myres (Org.), The evolution of culture and other essays (p. 20-44). Clarendon Press.

Pitt Rivers, A. H. L. F. (1891). Typological museums, as exemplified by the Pitt-Rivers Museum at Oxford, and his provincial museum at Darnham, Dorset. Journal of the Society of Arts, 40, 115-122.

Podgorny, I. (1995). De razón a facultad. Ideas acerca de las funciones del Museo de La Plata entre 1880 y 1920. Runa, 22, 89-104.

Polar bear Knut died of brain damage, tests suggest. (2011, março 22). BBCNews Disponível em: https://www.bbc.com/news/world-europe-12823466

Pombo, O. (1998). Da classificação dos seres à classificação dos saberes. Revista da Biblioteca Nacional de Lisboa, 2, 19-33.

Porcedda, A., Landry, J., \& Lepage, L. (2006). Musées de sciences et développement durable: Militantisme ou changement de paradigme? In A.-M. Émond (Org.), L'éducation muséale vue du Canada, des États-Unis et d’Europe: Recherche sur les programmes et les expositions (p. 279-292). Québec: Éditions MultiMondes.

Poulot, D. (2013). Museus e Museologia. Belo Horizonte: Autêntica.

Póvoas, L., Lopes, C., Melo, I., Correia, A. I., \& Alves, M. J. (2016). O Museu Nacional de História Natural: Uma história atribulada e uma questão em aberto. Estudos do Quaternário, 14, 105-113.

Prestes, M. E. B. (1996). A Natureza Despida: De Aristóteles a ciência moderna. Revista Hypnos, 1(2), 46-57. 
Primo, J. S. (1999). Pensar contemporaneamente a museologia. Cadernos de Sociomuseologia, (16), 5-38.

Primo, J. S., \& Leite, P. P. (2015). Olhares biográficos em museologia: Os desafios da intersubjetividade. Cadernos de Sociomuseologia, 5, 129-144.

Prior, N. (2006). Postmodern Restructurings. In S. MacDonald (Org.), A Companion to Museum Studies (p. 509-524). Oxford, UK: Blackwell Publishing Ltd.

Quinn, S. C. (2006). Windows on Nature: The great habitat dioramas of the American Museum of Natural History (ABRAMS). New York.

Rader, K. A., \& Cain, V. E. M. (2008). From natural history to science: Display and the transformation of American museums of science and nature. Museum and Society, 6(2), 152-171.

Rader, K. A., \& Cain, V. E. M. (2014). Life on display: Revolutionizing U.S. museums of science and natural history in the twentieth century. Chicago, Ill.: The University of Chicago Press.

Rectanus, M. W. (2006). Globalization. In S. Macdonald (Org.), A Companion to Museum Studies (p. 381-397).

Reiss, M. J. (2015). The Cultural History and Learning Affordances of Natural History Dioramas. In S. D. Tunnicliffe \& A. Scheersoi, Natural History Dioramas (p. 279-289). London: Springer.

Ribeiro, J. A. G., Carneiro, G. do A., \& Cavassan, O. (2016). Os estilos de pensamento sobre a biodiversidade na História da Ecologia. Filosofia e História da Biologia, 11(2), 221-239.

Richards, T. (1993). The Imperial Archive: Knowledge and the fantasy of empire. London: Verso.

Rieppel, O. (2010). New essentialism in biology. Philosophy of Science, 77(5), 662-673.

Rocha, L. M. (2015). Patrimônio, Meio Ambiente e Museologia de Relações: Reflexões sobre um patrimônio no devir. Museologia e Interdisciplinaridade, IV(8), 107-128.

Roschelle, J. (1995). Learning in interactive environments: Prior knowledge and new experience. In J. H. Falk \& L. D. Dierking (Orgs.), Public institutions for personal learning: Establishing a research agenda. (p. 37-51). Washington: American Association of Museums.

Rossi, M. (2008). Modeling the unknown: How to make a perfect whale. Endeavour, 32(2), 58-63.

Royal Society Science Policy Centre. (2011). Knowledge, Networks and Nations: Global scientific collaboration in the 21st century. Disponivel em: https://royalsociety.org/ /media/Royal Society Content/policy/\%20publications/2011/4294976 134.pdf

Sarkar, S. (2002). Defining “Biodiversity”; Assessing Biodiversity: Monist, 85(1), 131-155.

Schaeffer, B., \& Patsuris, M. B. (1958). Exhibits and Ideas. Curator: The Museum Journal, 1(2), 25-33.

Schelbauer, A. R. (2005). O método intuitivo e lições de coisas no Brasil no século XIX. In Histórias e Memórias da Educação no Brasil: Vol. 2 (p. 132-149). Petrópolis: Vozes.

Schwarcz, L. M., \& Dantas, R. (2008). O Museu do Imperador: Quando colecionar é representar a nação. Revista do Instituto de Estudos Brasileiros, (46), 123.

Secord, J. A. (1996). The crisis of nature. In N. Jardine, J. A. Secord, \& E. C. Spary (Orgs.), Cultures of Natural History (p. 447-459). Cambridge University Press.

Shaman, S. S. (1995). Education, sunflowers and the new vulgarity in art museums. In E. Hooper-Greenhill (Org.), Museum, Media, Message (p. 100-108). London: Routledge. 
Sheets-Pyenson, S. (1988). Cathedrals of Science: The Development of Colonial Natural History Museums during the Late Nineteenth Century, Kingston, Ontario.

Sherman, D. J., \& Rogoff, I. (2003). Museum Culture: Histories, discourses, spectacles (2nd Edition). London: Routledge.

Silva, M. C. (2006). Chistiano Stockler das Neves e o Museu de Zoologia da Universidade de São Paulo (Dissertação de Mestrado). Faculdade de Arquitetura e Urbanismo - Universidade de São Paulo, São Paulo.

Silva, M. C. (2013). Musealização da natureza: Exposições em museus de história natural como representação cultural (Tese de Doutoramento). Universidade de São Paulo, São Paulo.

Silverstone, R. (1992). The medium is the museum: On objects and logics in times and spaces. In J. Durant, Museums and the Public Understanding of Science (p. 34-42). London: Science Museum and Museums and the Public Understanding of Science.

Sloan, P. R. (1976). The Buffon-Linnaeus Controversy. Isis, 67(3), 356-375.

Smith, C. S. (2007). Narratives of display at the National Gallery, London. Art History, 30(4), 611-627.

Soares, B. C. B. (2008). RESENHA: O Meio Ambiente Entra no Museu. Revista Eletrônica Jovem Museologia, 3(3), 108-111.

Soler, M. G. (2015). Musealização da zoologia: Narrativas evolutivas construídas com animais (Dissertação de Mestrado), Universidade de São Paulo, São Paulo.

Soler, M. G. (2019). Diversidade que se expõe mas não se representa: O cada da exposição «Conchas, Corais e Borboletas» (MNRJ, 2013-2018). Ventilando Acervos, especial(1), 49-70.

Soler, M. G., \& Landim, M. I. (2017). O silêncio dos inocentes: O papel dos animais em narrativas expositivas. Anais do Museu Paulista: História e Cultura Material, 25(2), 269-289.

Soler, M. G., \& Landim, M. I. (2018). Mute polysemy: Animals in exhibition narratives. 71. Disponível em: https://therai.org.uk/images/rai2018.pdf

Soler, M. G., Nunes, M. de F., \& Lopes, M. M. (2018). Profundezas no céu: As fronteiras enter a técnica e os significados das baleias em museus de história natural. Museologia \& Interdisciplinaridade, 7(14), 151-164.x

Staniszewski, M. A. (2001). The power of display. A History of Exhibition Installations at the Museum of Modern Art (2nd ed). The MIT Press.

Star, S. L., \& Griesemer, J. R. (1989). Institutional Ecology, 'Translations' and Boundary Objects: Amateurs and Professionals in Berkeley's Museum of Vertebrate Zoology, 1907-39. Social Studies of Science, 19(3), 387-420.

Stauffer, R. C. (1957). Haeckel, Darwin, and Ecology. The Quarterly Review of Biology, 32(2), 138-144.

Stengers, I. (1991). La question de l’auteur dans les Sciences Modernes. Littérature, 82, 3-15.

Stengers, I. (1994). From describing falling bodies to understanding people: What is scientific objectivity? Gender-Nature-Culture - Feminist Research Network Working-Paper, 7, 5-28.

Taquet, P. (2008). Estabilishing the paradigmatic museum: Georges Cuvier's Cabinete d'anatomie comparée in Paris. In S. J. Knell, S. MacLeond, \& S. Watson (Orgs.), Museum Revolutions: How Museums Change and are Changed (p. 3-14). New York: Routledge. 
Tresch, J. (2017). Afterword. In C. Berkowitz \& B. Lightman (Orgs.), Science Museums in Transition: Cultures of display in nineteenth-century Britain and America (p. 261-278). Pittsburg: University of Pittsburgh Press.

Trofanenko, B. (2015). Karen A. Rader \& Victoria E. M. Cain Life on Display: Revolutionizing U.S. Museums of Science and Natural History in the Twentieth Century. Chicago, IL: University of Chicago Press, 2014. 459 pp. Cloth \$45.00. History of Education Quarterly, 55(3), 396-399.

Tunnicliffe, S. D. (Org.). (2015). Natural history dioramas: History, construction and educational role. Dordrecht: Springer.

Turner, C. (2011). International exhibitions. In D. Griffin \& L. Paroissien (Orgs.), Understanding Museums: Australian museums and museology. Disponível em: https://www.nma.gov.au/research/understanding-museums/CTurner 2011.html\# edn2

Urbain, A., \& Rode, P. (1948). French Natural History Collections. Museum International, 1(1-2), 67, 110-111.

Valente, M. E. A. (2014). Interseções necessárias: História, museologia e museus de ciências e tecnologia. Museologia \& Interdisciplinaridade, 3(5), 37-53.

Van Gelder, R. G. (1970). Whale on my back. Curator: The Museum Journal, 13(2), 95-119.

Van Mensch, P. (2011). The musealisation of Knut. Dilemmas in the relationship between zoos and museums. ICOMCOL NEWSLETTER, (13), 4-7.

Van Praët, M. (1996). Cultures scientifiques et musées d'histoire naturelle en France. Hèrmes, 20, 143-149.

Van Praët, M. (2004). Las ciencias y el patrimonio natural: Lo intangible en el museo. Museum International, 221/222, 116-125.

Van Praët, M. (2013, agosto 2). Évolution des expositions du muséum.Disponível em:: https://objethistoire.hypotheses.org/300

Van Praët, M., Démaret, H., \& Drouin, J. M. (2000). L'esprit du lieu, un concept muséologique. In J. Eidelman \& M. Van Praët, La muséologie des sciences et ses publics: Regards croisés sur la Grande galerie de l'Evólution (p. 15-30). Paris: Presses Universitaires de France.

Van Praët, M., \& Poucet, B. (1992). Les Musées, Lieux de Contre-Éducation et de Partenariat Avec L’École. Education \& Pédagogies - dés élèves au musée, 16, 21-29.

Van Weelie, D., \& Wals, A. (2002). Making biodiversity meaningful through environmental education. International Journal of Science Education, 24(11), 1143-1156.

Vogel, F. (2014). Notes on exhibition history in curatorial discourse. Zurich: On-Curating.Org, (21), 10.

Wagensberg, J. (2000). Principios fundamentales de la museología científica moderna. Alambique: Didáctica de las ciencias experimentales, (26), 15-20.

Wagensberg, J. (2005). The "total" museum, a tool for social change. História, Ciências, Saúde-Manguinhos, 12 (suppl), 309-321.

Wagensberg, J. (2008). Understanding Form. Biological Theory, 3(4), 325-335.

Wagensberg, J. (2014a). La rebelión de las formas o cómo perservar cuando la incertidumbre aprieta. Tusquets. 
Wagensberg, J. (2014b). On the Existence and Uniqueness of the Scientific Method. Biological Theory, 9(3), $331-346$.

Wallach, A. (2003). Norman Rockwell at the Guggenheim. In A. McClellan (Org.), Art and its Publics: Museum studies at the millennium (p. 97-116). Oxford, UK: Blackwell Publishing Ltd.

West, S. (1995). The devaluation of "cultural capital": Post-modern democracy and the art blockbuster. In S. Pearce (Org.), Art in Museums (p. 74-93). London: The Athlone Press.

Whitehead, P. J. (1971). Museums in the history of zoology. Museums Journal, 70(2/4), 50-57 / 155-160.

Wilson, E. O. (Org.). (1988). Biodiversity. Washington: National Academic Press.

Wonders, K. (1989). Exhibiting Fauna- From Spectacle to Habitat Group. Curator: The Museum Journal, 32(2), $131-156$.

Worster, D. (1977). Nature's Economy: A history of ecological ideas. Cambridge: Cambridge University Press.

Xu, X., Zhou, Z., Wang, X., Kuang, X., Zhang, F., \& Du, X. (2003). Four-winged dinosaurs from China. Nature: $421,8$.

Zaky, A. A. (2017). Tutankhamun Exhibition at the British Museum in 1972 a historical perspective. Journal of Tourism Theory and Research, 3(2), 107-107.

Zucchi, G. (2015, agosto 28). Museu de Zoologia reabre no Ipiranga. Recuperado de Estadão. Disponível em:

https://sao-paulo.estadao.com.br/noticias/geral,museu-de-zoologia-reabre-noipiranga, 1752725 
Biodiversidade Musealizada: Formas que Comunicam

\section{7. ÍNDICE REMISSIVO}

$\mathrm{AMNH}$

3, $17,34,47,48,58,63,69,70,81,82,86,100$, $101,112,280,281$

anfíbios

182

animais vivos

$51,58,90,202$

arquitetura

3, 8, 32, 56, 64, 102, 104, 116, 136, 141, 144, 216, $218,241,248,259,300$

aves

$28,52,170,181,184,187,245,248$

blockbuster

8, 9, 22, 23, 97, 98, 105 - 112, 114, 136, 189, 233, $251,265,268$,

Charles Darwin

$13,33,34,36,45,75,76,112,120,189,204,205$, $251,259,265,289$

coleção

$1,3,4,5,7,9,10,12,13,14,16,20,21,22,24,29$, $31,32,33,34,35,38,43,44,45,54,57,60,61,65$, $69,71,79,80,84,87,88,90,91,97,103,106,107$, $108,110,111,112,114,115,116,117,118,122$, $126,128,129,130,131,133,134,136,140,144$, $147,162,163,165,166,168,170,175,176,177$, $179,181,182,183,184,185,186,187,188,211$, $216,224,225,228,229,230,233,234,235,236$, $239,240,243,244,245,246,247,248,252,256$, $257,258,259,262,266,267,268,270,272,275$, 276, 277, 282, 283, 284, 286, 288, 291, 294, 296, 298, 299

comunicação

$13,15,20,64,79,80,83,85,90,96,101,103,115$, $123,136,147,210,211,213,227,235,248,254$, 266, 267, 270, 274, 279, 284, 285, 295,

curador

$16,20,22,37,38,44,45,50,51,57,59,70,88$, $102,105,106,111,121,122,123,129,143,145$, $146,147,155,156,162,163,164,165,171,175$, $185,186,210,211,216,227,229,230,239,240$, $243,244,248,250,256,260,266,268,270,273$, $274,275,276,282$ 
Biodiversidade Musealizada: Formas que Comunicam

design

$1,3,6,8,12,14,16,17,18,50,64,65,77,90,91$, $95,100,107,108,119,121,128,141,146,154$,

$177,181,190,212,229,259,261,265,267,270$, $271,274,275,279,280,282,287$

diorama

1 - 3, 8, 23, 42 - 54, 56 - 59, 64, 69, 70, 80, 96, 100, $123,135,142,149,150,163,170,172,173,214$, 215, 221, 222, 226, 230, 234, 235, 237, 242, 257, 261 - 264, 268, 269, 287, 289, 293, 295, 299, 301

$\begin{array}{r}21,41,45,51,55,57,72-77,80,167,230,240, \\ 242,277,290,291,293,297,299 \\ \hline\end{array}$

esqueleto

25, 32, 56, 59, 118, 131, 132, 133, 134, 152, 182, $185,187,189,190,193,195,210,220,224,248$, $251,253,265$

Evolução

21, 34, 36, 37, 40, 42, 73, 78, 100, 101, 132, 154, $157,185,192,196,198,200,201,214,217,223$, $225,247,255,277,283,296$

fóssil 32, 33, 35, 38, 39, 79, 79, 98, 112, 118, 132, 152, 154, 181, 185,187, 191, 213, 217, 220, 247, 261, $262,267,293$

gabinete de curiosidades

$15,23,32,35,47,123,124,126,127,128,131$, $147,148,149,208,220,221,268,308$

ICOM $1,9,18,81,138,140,270,275,295,301$

iluminação

$2,8,43,48,50,52,53,100,103,118,119,130$, 203, 206 - 208, 212, 221, 222, 246, 254, 263, 264, $267,270,279$

interativo

$58,65,69,84,87,88$ - 92, 94, 97, 98, 102, 113, 135, $136,194,200,202,206,208,250,252-254,267$, $270,272,273,282,293$

invertebrados

7, 30, 36, 143, 146, 147, 149, 221, 230, 233, 277, 288

Jorge Wagensberg

190 - 192, 199, 200, 204, 249 - 253, 255, 273, 301 , 302

mamíferos

$31,39,40,162,165,169,170,181,185$ - 188, 193, 195, 203, 224, 238 - 240, 248, 261, 
Biodiversidade Musealizada: Formas que Comunicam

meio ambiente

78 - 80, 201, 242, 284, 299, 300

MNHM

$15,16,28,30,100,101,116,280,281$

MNRJ

$7,11,58,143,146,147,149,151,154,157,226$ -

$233,243,248,256,272,300$

moluscos

30, 31, 151, 152, 185, 199, 257, 259,

MP

190, 195, 249

MUHNAC

$113,161,163,168,175,179,181,235,239,240$, 242, 246

multimedia

2, 16, 17, 20, 51, 90, 95, 98, 102 - 104, 107, 114,

$124,125,143,198,206,208,233,242,253,267$.

$273,279,281,282$

musealização

$128,279,283,284,285,290,300$

Museologia

$1,8,9,64,77,78,105,115,123,138$ - 140, 143 -

$147,153,229,245,248,275,278$ - 280, 284 - 290,

$294,295,298-301$

"museologia total"

190, 191, 198, 199, 204, 249 - 255, 273,

museological science

$35,126,182,228,229,242,258,298$

MZUSP

$11,91,210$ - 213, 215, 216, 223, 224, 226, 255 $257,260,262,263,265-267$

narrativa

3, 8, 11, 17, 20 - 23, 42, 53, 59, 61, 64 - 66, 68, 69,

$72,83,88,94,95,100,104,109,113,114-116$,

118,120 - 123, 126, 129, 130, 135, 139 - 142, 161, $162,176,179,185,186,193,211,214,217,226$, 231, 234, 235, 237, 244, 247 - 250, 255, 256, 263, 268, 269, 271, 272, 281, 300,

NHM $59,96,112,113,129,130$

peixes 182

Pitt Rivers

21, 26, 34 - 37, 40, 259, 289, 298

público

2 - 4, 9, 13 - 15, 17, 17 - 19, 22, 25, 46, 49, 54 - 56, 58, 59, 61 - 63, 70, 72, 77 - 79, 81, 84, 85, 93, 96 $100,102,110,111,113,123,127,133,134,137$. 
Biodiversidade Musealizada: Formas que Comunicam

139, 141, 143, 145, 147, 153, 154, 161 - 163, 174 $177,179,189,211,213,214-216,224,227,233$, $245,254,257,267,270,271,275-278,280,284$, 285, 286, 293,

\begin{tabular}{lr}
\hline realidade aumentada & 182 \\
\hline répteis & $91,136,163,171,174,237,270,281$ \\
\hline seleção natural & $34,112,194,201,202,217,254,281$ \\
\hline Smithsonian & $17,20,33,87,97,133,286,292$ \\
\hline som & $16,43,52,58,102,135,136,240,251$ \\
\hline taxidermia & $3,47,132,181,215,245$ \\
\hline taxonomia & $27,33,69,239,240,257,260,272$, \\
\hline Zoologia & $14,35,73,74,144,213,216,222,228,229,255$, \\
& 300 \\
\hline
\end{tabular}




\section{APÊNDICES}

\subsection{APÊNDICE 1: Tabela de Indicadores e respetivos autores}




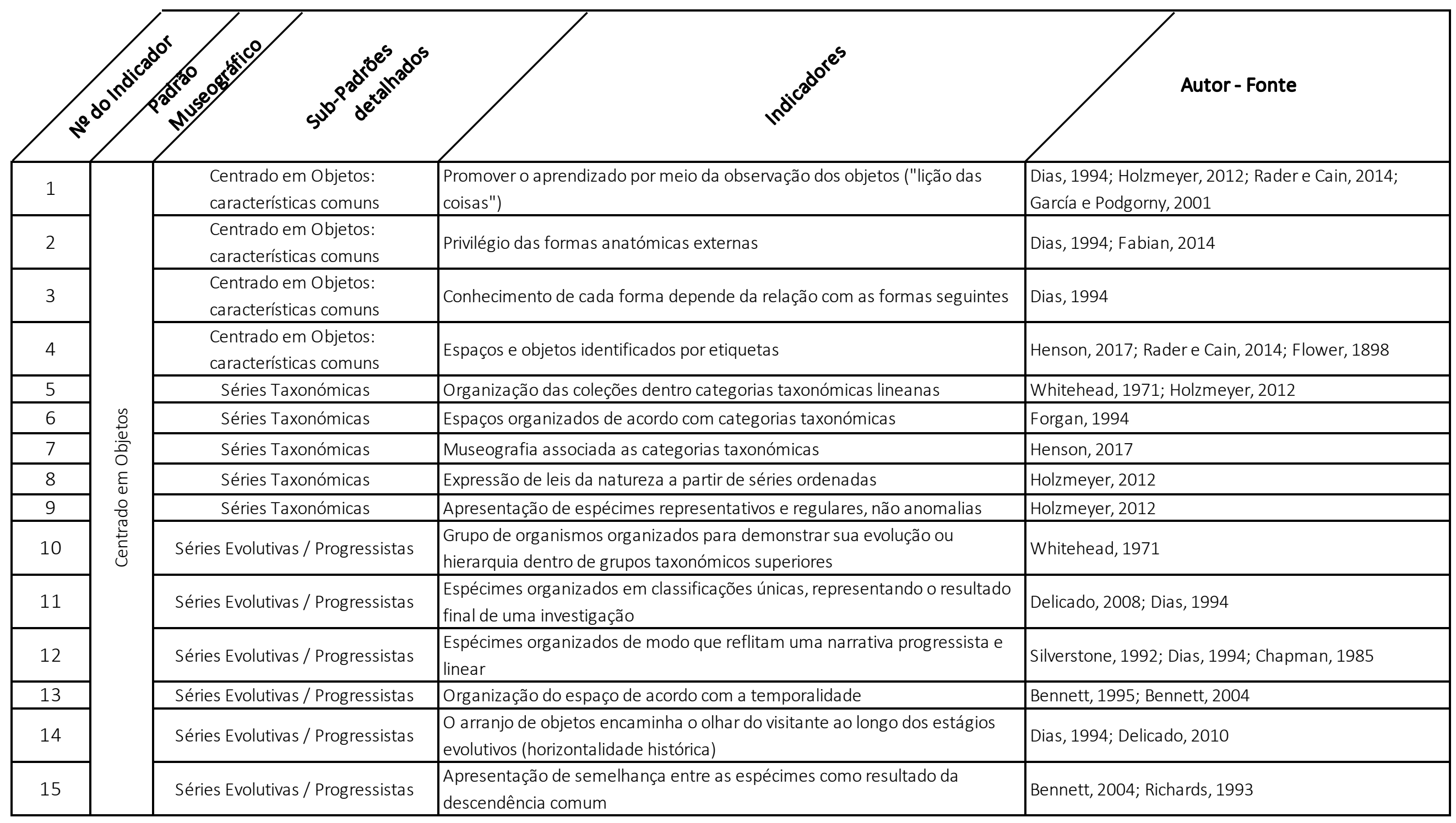




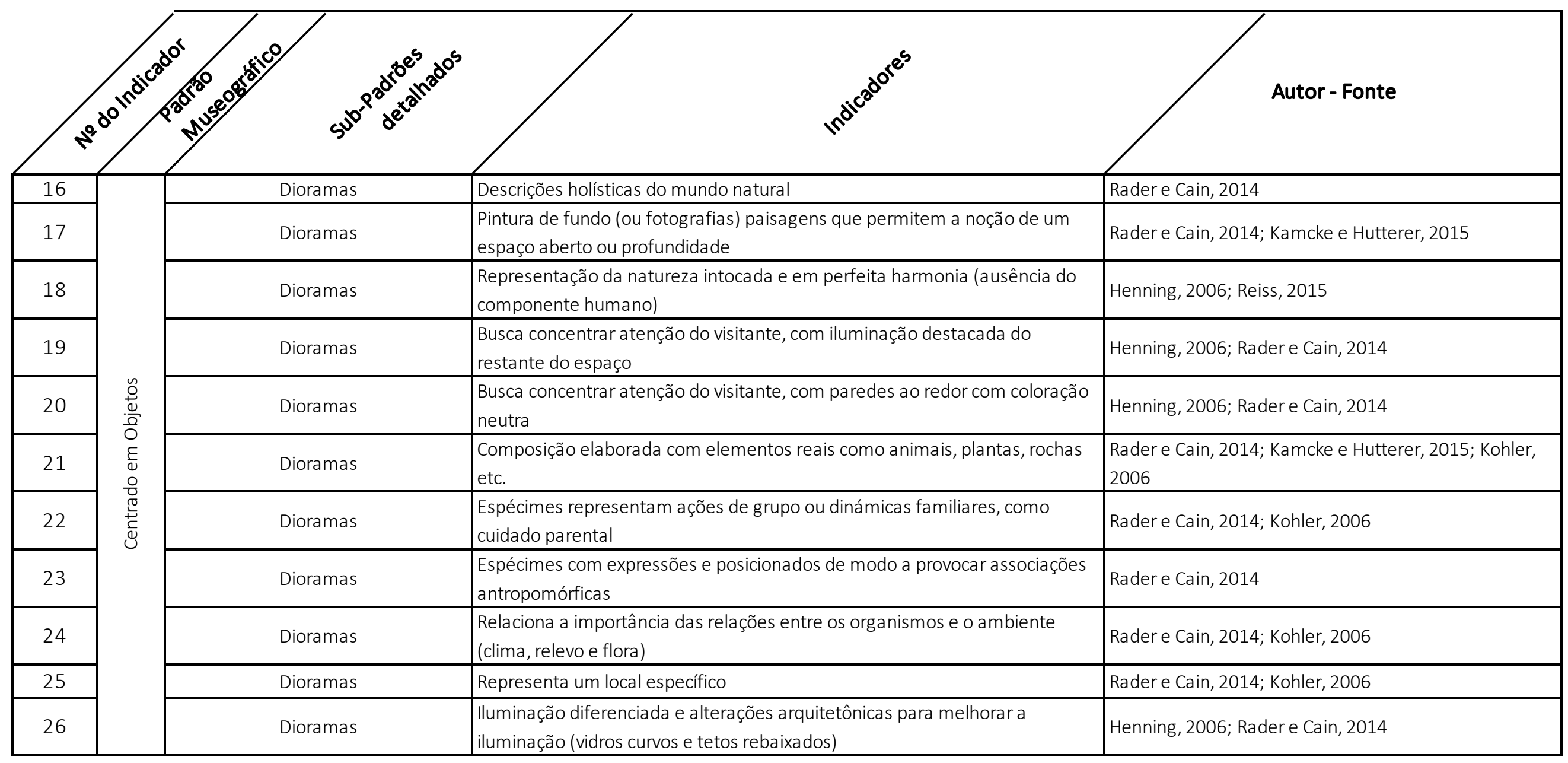




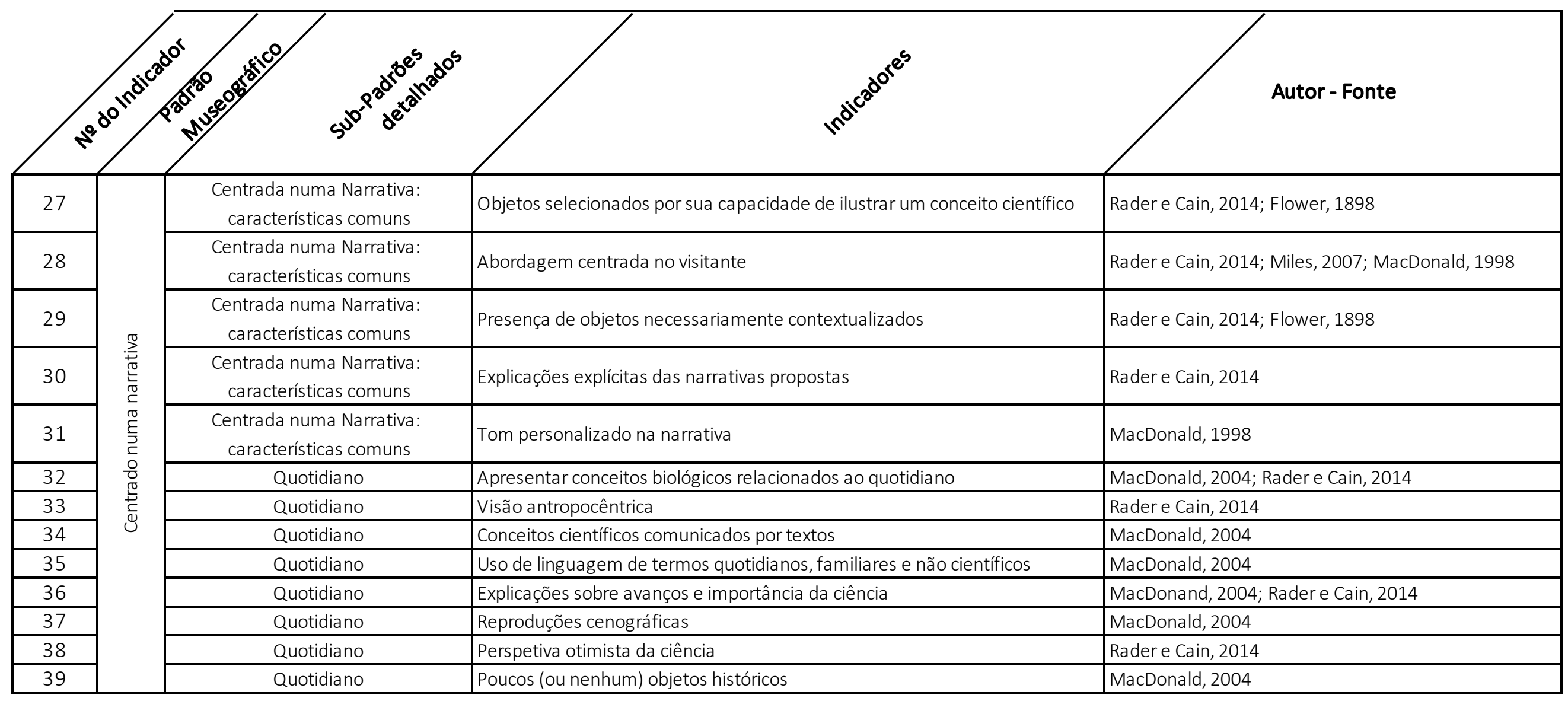




\begin{tabular}{|l|l|l|}
\hline 41 \\
\hline 42
\end{tabular}




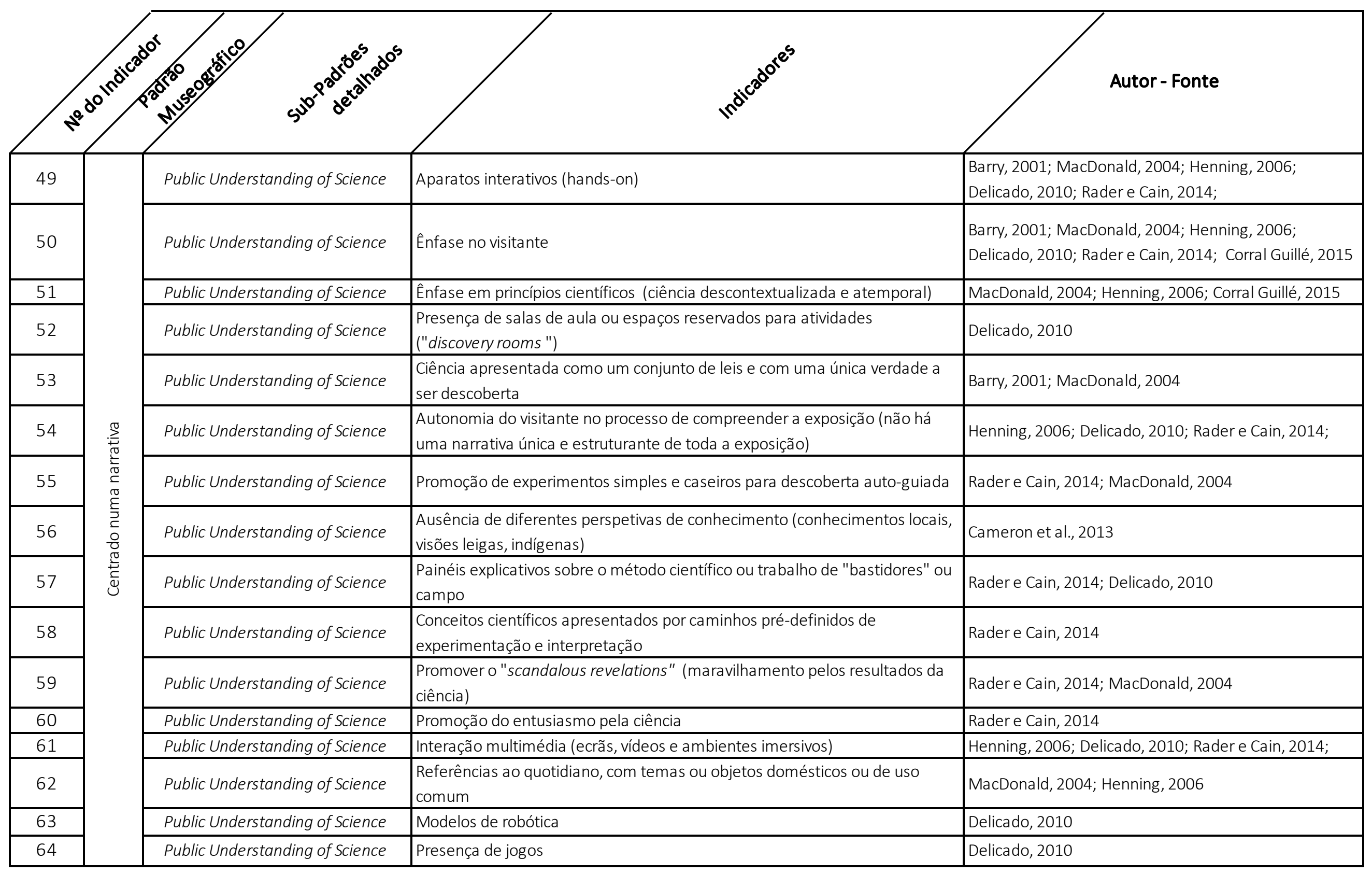




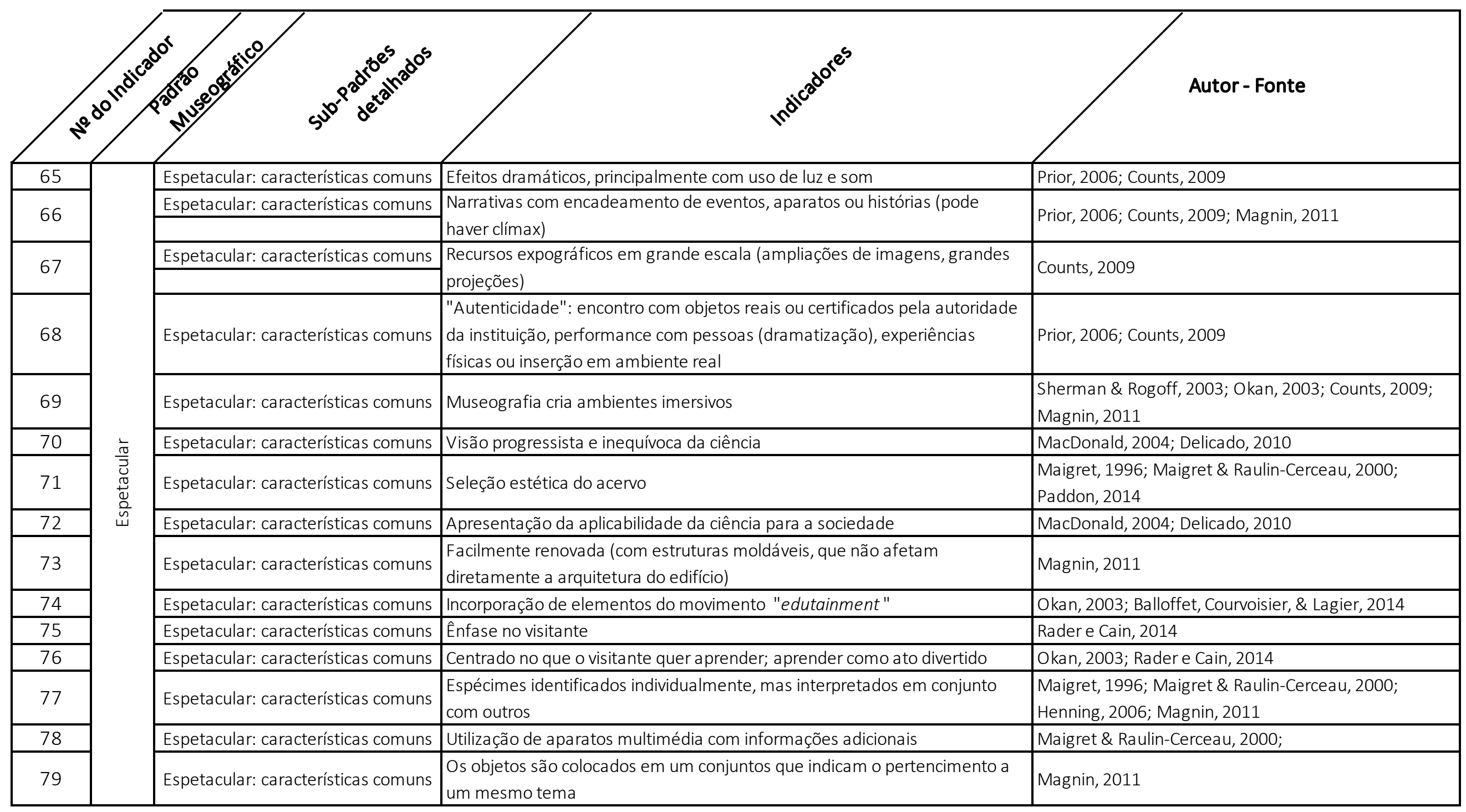




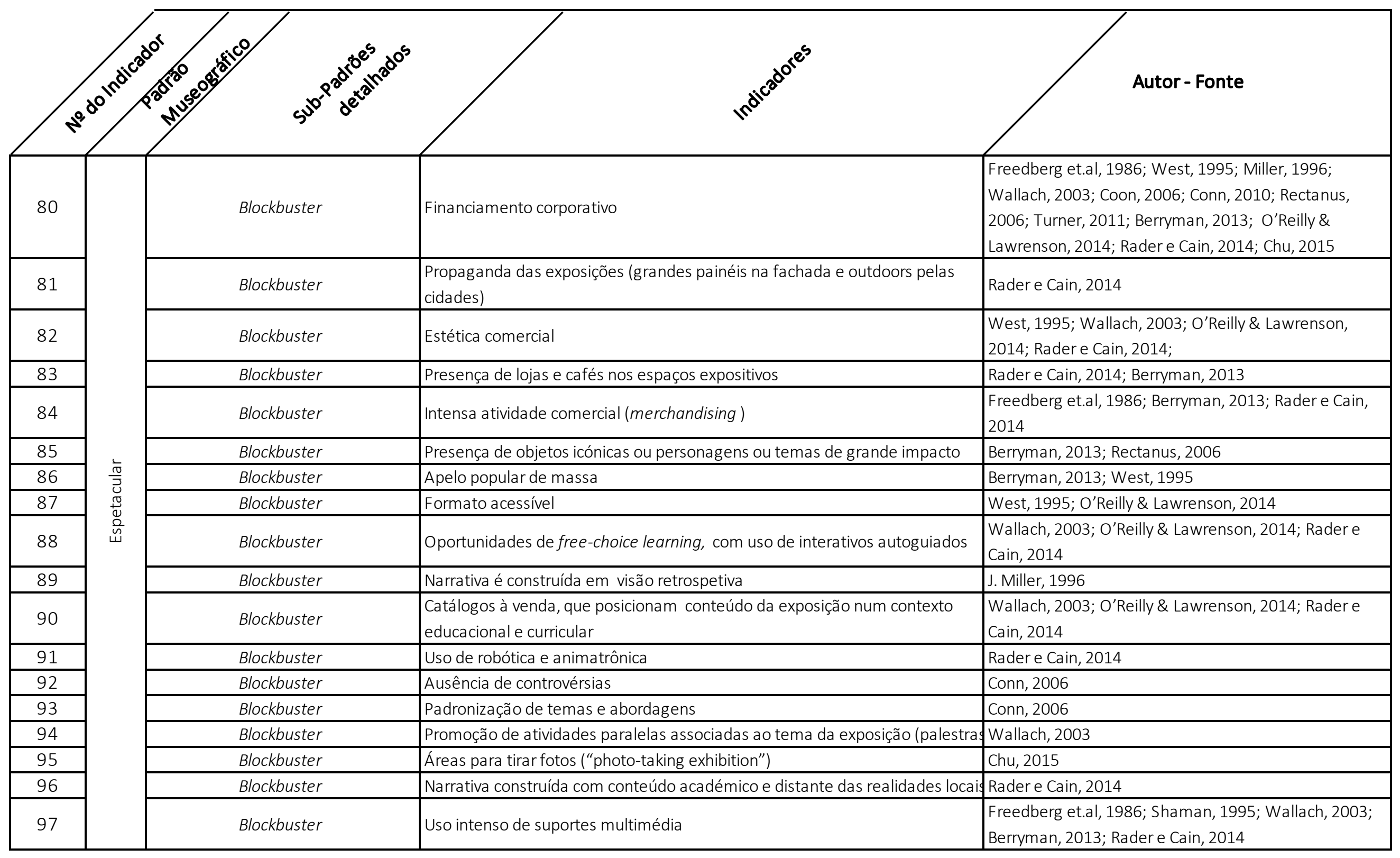




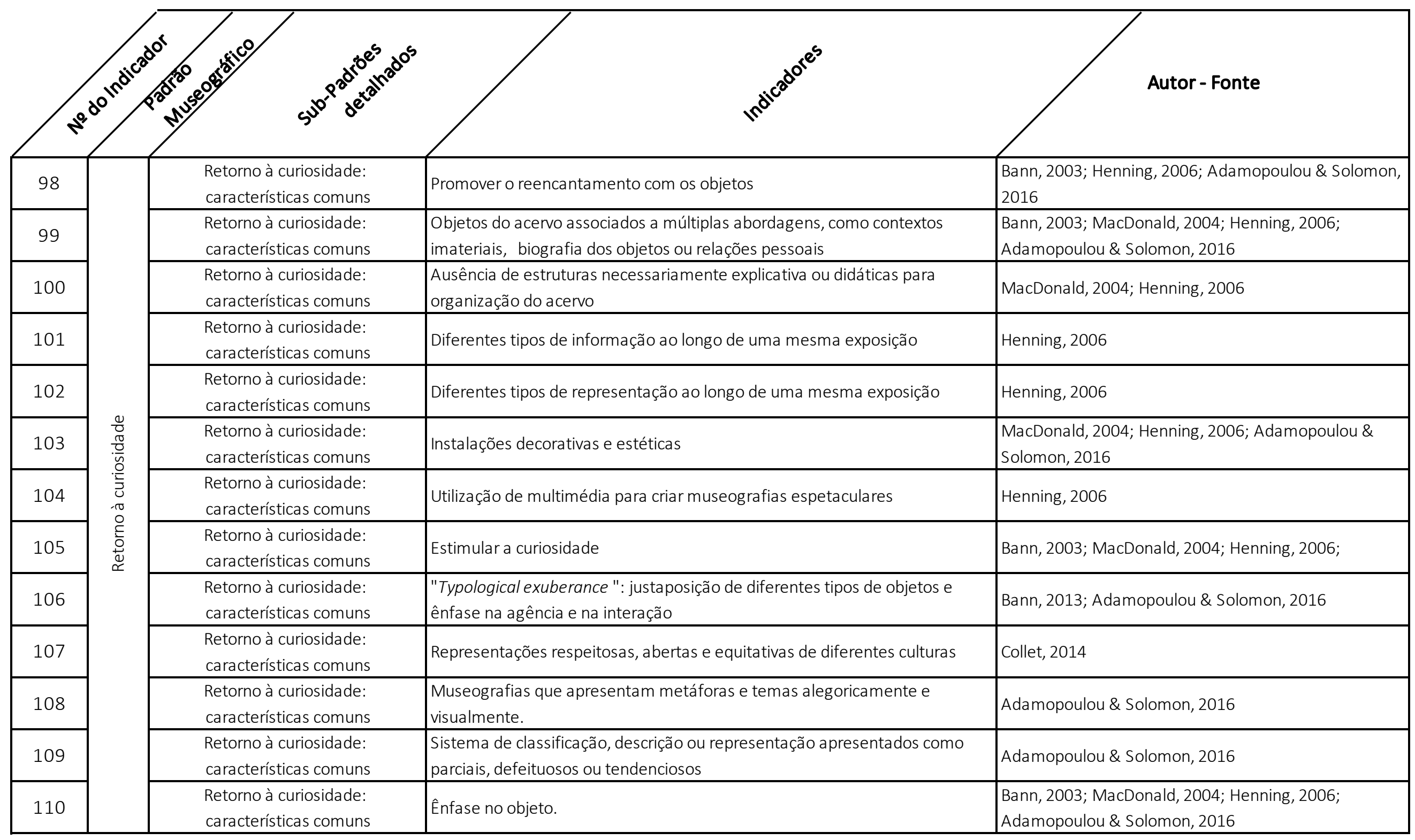




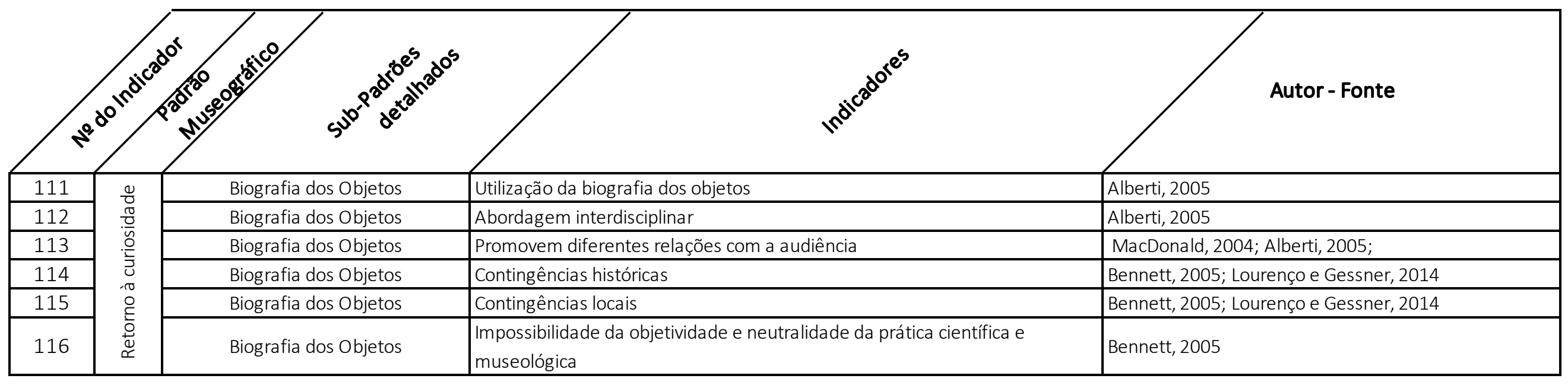


8.2 APÊNDICE 2: Matriz de Indicadores 


\begin{tabular}{|c|c|c|c|c|c|c|c|c|}
\hline $\begin{array}{l}\text { № do } \\
\text { Indicador }\end{array}$ & $\begin{array}{c}\text { Padrão } \\
\text { Museográfico }\end{array}$ & $\begin{array}{c}\text { Sub-Padrões } \\
\text { detalhados }\end{array}$ & Indicadores & $\begin{array}{l}\text { Conchas, } \\
\text { Corais e } \\
\text { Borboletas } \\
\text { (MNRJ) }\end{array}$ & $\begin{array}{l}\text { Reis da } \\
\text { Europa } \\
\text { Selvagem } \\
\text { (MUHNAC) }\end{array}$ & $\begin{array}{c}\text { Specere } \\
\text { (MUHNAC) }\end{array}$ & $\begin{array}{c}\text { Galeria da } \\
\text { Biodiversidade } \\
\text { (MHNUP) }\end{array}$ & $\begin{array}{l}\text { Biodiversidade } \\
\text { conhecer } \\
\text { para preservar } \\
\text { (MZUSP) }\end{array}$ \\
\hline 1 & \multirow{5}{*}{ 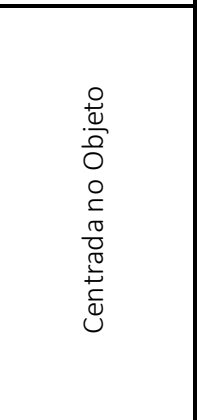 } & $\begin{array}{c}\text { Características } \\
\text { comuns }\end{array}$ & $\begin{array}{l}\text { Promover o aprendizado por meio da observação dos } \\
\text { objetos ("lição das coisas") }\end{array}$ & 1 & 0 & 1 & 0 & 1 \\
\hline 2 & & $\begin{array}{l}\text { Características } \\
\text { comuns }\end{array}$ & Privilégio das formas anatómicas externas & 1 & 1 & 1 & 1 & 1 \\
\hline 3 & & $\begin{array}{c}\text { Características } \\
\text { comuns }\end{array}$ & $\begin{array}{l}\text { Conhecimento de cada forma depende da relação com as } \\
\text { formas seguintes }\end{array}$ & 1 & 0 & 0 & 1 & 1 \\
\hline 4 & & $\begin{array}{c}\text { Características } \\
\text { comuns }\end{array}$ & Espaços e objetos todos identificados por etiquetas & 1 & 0 & 1 & 0 & 1 \\
\hline 5 & & Séries Taxonómicas & $\begin{array}{l}\text { Organização das coleções dentro categorias taxonómicas } \\
\text { lineanas }\end{array}$ & 1 & 0 & 1 & 0 & 1 \\
\hline 6 & \multirow{14}{*}{ 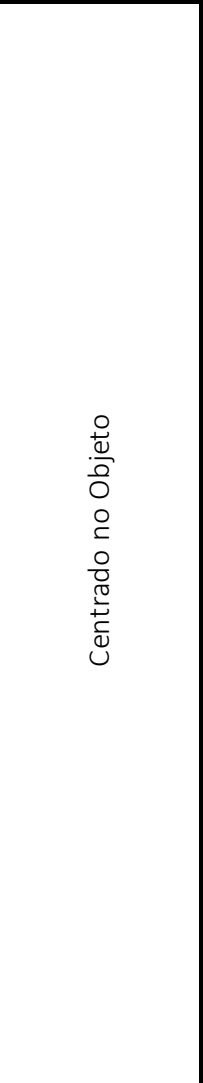 } & Séries Taxonómicas & $\begin{array}{l}\text { Espaços organizados de acordo com categorias } \\
\text { taxonómicas }\end{array}$ & 1 & 0 & 1 & 0 & 0 \\
\hline 7 & & Séries Taxonómicas & Museografia representa as categorias taxonómicas & 1 & 0 & 0 & 0 & 1 \\
\hline 8 & & Séries Taxonómicas & Expressão de leis da natureza a partir de séries ordenadas & 1 & 0 & 0 & 1 & 1 \\
\hline 9 & & Séries Taxonómicas & $\begin{array}{l}\text { Apresentação de espécimes representativos e regulares, não } \\
\text { anomalias }\end{array}$ & 1 & 1 & 1 & 1 & 1 \\
\hline 10 & & $\begin{array}{c}\text { Séries Evolutivas / } \\
\text { Progressistas }\end{array}$ & $\begin{array}{l}\text { Grupo de organismos organizados para demonstrar sua } \\
\text { evolução ou hierarquia dentro de grupos taxonómicos } \\
\text { superiores }\end{array}$ & 1 & 0 & 0 & 1 & 1 \\
\hline 11 & & $\begin{array}{c}\text { Séries Evolutivas / } \\
\text { Progressistas }\end{array}$ & $\begin{array}{l}\text { Espécimes organizados em classificações únicas, } \\
\text { representando o resultado final de uma investigação }\end{array}$ & 1 & 0 & 1 & 1 & 1 \\
\hline 12 & & $\begin{array}{c}\text { Séries Evolutivas / } \\
\text { Progressistas }\end{array}$ & $\begin{array}{l}\text { Espécimes organizados de modo que reflitam uma } \\
\text { narrativa progressista e linear }\end{array}$ & 1 & 0 & 0 & 0 & 0 \\
\hline 13 & & $\begin{array}{c}\text { Séries Evolutivas / } \\
\text { Progressistas }\end{array}$ & Organização do espaço de acordo com a temporalidade & 0 & 0 & 0 & 1 & 1 \\
\hline 14 & & $\begin{array}{c}\text { Séries Evolutivas / } \\
\text { Progressistas }\end{array}$ & $\begin{array}{l}\text { O arranjo de objetos encaminha o olhar do visitante ao } \\
\text { longo dos estágios evolutivos (horizontalidade histórica) }\end{array}$ & 0 & 0 & 0 & 0 & 1 \\
\hline 15 & & $\begin{array}{c}\text { Séries Evolutivas / } \\
\text { Progressistas }\end{array}$ & $\begin{array}{l}\text { Apresentação de semelhança entre as espécimes como } \\
\text { resultado da descendência comum }\end{array}$ & 1 & 0 & 0 & 1 & 1 \\
\hline 16 & & Dioramas & Descrições holísticas do mundo natural & 1 & 1 & 0 & 0 & 1 \\
\hline 17 & & Dioramas & $\begin{array}{l}\text { Pintura de fundo (ou fotografias) paisagens que permitem } \\
\text { a noção de um espaço aberto ou profundidade }\end{array}$ & 0 & 1 & 0 & 0 & 1 \\
\hline 18 & & Dioramas & $\begin{array}{l}\text { Representação da natureza intocada e em perfeita } \\
\text { harmonia (ausência do componente humano) }\end{array}$ & 1 & 1 & 0 & 0 & 1 \\
\hline 19 & & Dioramas & $\begin{array}{l}\text { Busca concentrar atenção do visitante, com iluminação } \\
\text { destacada do restante do espaço }\end{array}$ & 0 & 1 & 0 & 1 & 1 \\
\hline
\end{tabular}




\begin{tabular}{|c|c|c|c|c|c|c|c|c|}
\hline $\begin{array}{l}\text { № do } \\
\text { Indicador }\end{array}$ & $\begin{array}{c}\text { Padrão } \\
\text { Museográfico }\end{array}$ & $\begin{array}{c}\text { Sub-Padróes } \\
\text { detalhados }\end{array}$ & Indicadores & $\begin{array}{l}\text { Conchas, } \\
\text { Corais e } \\
\text { Borboletas } \\
\text { (MNRJ) }\end{array}$ & $\begin{array}{l}\text { Reis da } \\
\text { Europa } \\
\text { Selvagem } \\
\text { (MUHNAC) }\end{array}$ & $\begin{array}{c}\text { Specere } \\
\text { (MUHNAC) }\end{array}$ & $\begin{array}{c}\text { Galeria da } \\
\text { Biodiversidade } \\
\text { (MHNUP) }\end{array}$ & \begin{tabular}{|c} 
Biodiversidade \\
conhecer \\
para preservar \\
(MZUSP)
\end{tabular} \\
\hline 20 & \multirow{7}{*}{ 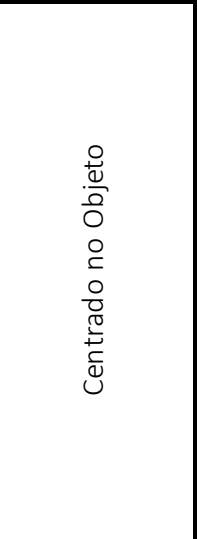 } & Dioramas & $\begin{array}{l}\text { Busca concentrar atenção do visitante, com paredes ao } \\
\text { redor com coloração neutra }\end{array}$ & 0 & 1 & 0 & 1 & 1 \\
\hline 21 & & Dioramas & $\begin{array}{l}\text { Composição elaborada com elementos reais como animais, } \\
\text { plantas, rochas etc. }\end{array}$ & 1 & 1 & 0 & 0 & 1 \\
\hline 22 & & Dioramas & $\begin{array}{l}\text { Espécimes representam ações de grupo ou dinámicas } \\
\text { familiares, como cuidado parental }\end{array}$ & 0 & 1 & 1 & 1 & 1 \\
\hline 23 & & Dioramas & $\begin{array}{l}\text { Espécimes com expressões e posicionados de modo a } \\
\text { provocar associações antropomórficas }\end{array}$ & 0 & 1 & 1 & 1 & 1 \\
\hline 24 & & Dioramas & $\begin{array}{l}\text { Relaciona a importância das relações entre os organismos e } \\
\text { o ambiente (clima, relevo e flora) }\end{array}$ & 1 & 1 & 0 & 1 & 1 \\
\hline 25 & & Dioramas & Representa um local e tempo específicos & 0 & 1 & 1 & 0 & 0 \\
\hline 26 & & Dioramas & $\begin{array}{l}\text { Iluminação diferenciada e alterações arquitetônicas para } \\
\text { melhorar a iluminação (vidros curvos e tetos rebaixados) }\end{array}$ & 1 & 1 & 0 & 1 & 1 \\
\hline
\end{tabular}




\begin{tabular}{|c|c|c|c|c|c|c|c|c|}
\hline $\begin{array}{l}\text { Ne do } \\
\text { Indicador }\end{array}$ & $\begin{array}{c}\text { Padrão } \\
\text { Museográfico }\end{array}$ & $\begin{array}{c}\text { Sub-Padrões } \\
\text { detalhados }\end{array}$ & Indicadores & $\begin{array}{l}\text { Conchas, } \\
\text { Corais e } \\
\text { Borboletas } \\
\text { (MNRJ) }\end{array}$ & $\begin{array}{l}\text { Reis da } \\
\text { Europa } \\
\text { Selvagem } \\
\text { (MUHNAC) } \\
\end{array}$ & $\begin{array}{c}\text { Specere } \\
\text { (MUHNAC) }\end{array}$ & $\begin{array}{c}\text { Galeria da } \\
\text { Biodiversidade } \\
\text { (MHNUP) }\end{array}$ & \begin{tabular}{|c|} 
Biodiversidade \\
conhecer \\
para preservar \\
(MZUSP) \\
\end{tabular} \\
\hline 27 & \multirow{16}{*}{ 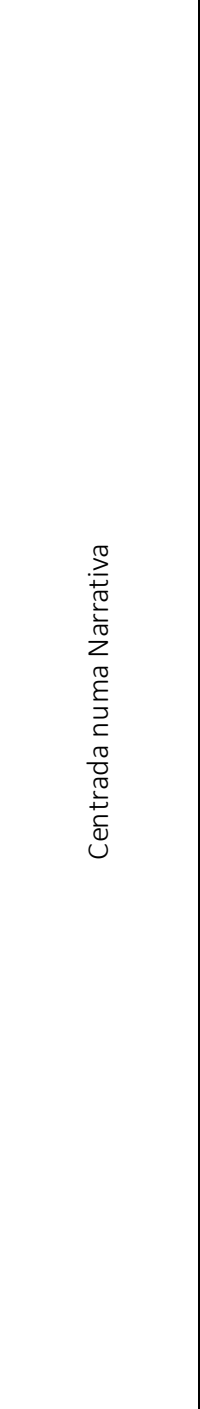 } & $\begin{array}{c}\text { Características } \\
\text { comuns }\end{array}$ & $\begin{array}{l}\text { Objetos selecionados por sua capaciade de ilustrar um } \\
\text { conceito científico }\end{array}$ & 1 & 1 & 0 & 1 & 1 \\
\hline 28 & & $\begin{array}{c}\text { Características } \\
\text { comuns }\end{array}$ & Ênfase no visitante & 0 & 0 & 0 & 1 & $\underline{0}$ \\
\hline 29 & & $\begin{array}{c}\text { Características } \\
\text { comuns }\end{array}$ & Presença de objetos necessariamente contextualizados & 0 & 1 & 0 & 1 & 1 \\
\hline 30 & & $\begin{array}{c}\text { Características } \\
\text { comuns }\end{array}$ & Explicações explícitas das narrativas propostas & 1 & 1 & 1 & 1 & 1 \\
\hline 31 & & $\begin{array}{c}\text { Características } \\
\text { comuns }\end{array}$ & Tom personalizado na narrativa & 0 & 1 & 0 & 0 & 0 \\
\hline 32 & & Quotidiano & Apresentar conceitos biológicos relacionados ao & 1 & 1 & 0 & 0 & 1 \\
\hline 33 & & Quotidiano & Visão antropocentrica & 0 & 0 & 0 & 0 & 0 \\
\hline 34 & & Quotidiano & Conceitos cientificos comunicados por textos & 1 & 1 & 1 & 1 & 1 \\
\hline 35 & & Quotidiano & $\begin{array}{l}\text { Uso de linguagem de termos quotidianos, familiares e não } \\
\text { científicos }\end{array}$ & 0 & 1 & 0 & 0 & 0 \\
\hline 36 & & Quotidiano & Explicações sobre avanços e importância da ciência & 1 & 0 & 1 & 1 & 1 \\
\hline 37 & & Quotidiano & Reproduções cenográficas & 0 & 0 & 0 & 1 & 1 \\
\hline 38 & & Quotidiano & Perspetiva otimista da ciência & 0 & 0 & 0 & 1 & 1 \\
\hline 39 & & Quotidiano & Poucos (ou nenhum) objetos históricos & 0 & 1 & 0 & 0 & 0 \\
\hline 40 & & Ecológico & $\begin{array}{l}\text { Manutenção de museografia e espécimes antigos, } \\
\text { utilizando etiquetas e pequenos textos com novas } \\
\text { contextualizações }\end{array}$ & 1 & 1 & 1 & 0 & 1 \\
\hline 41 & & Ecológico & Indicações de espécies extintas ou ameaçadas de extinção & 1 & 1 & 1 & 0 & 1 \\
\hline 42 & & Ecológico & $\begin{array}{l}\text { Integração do visitante com a exposição, na qual ele é } \\
\text { convidado a desempenhar um papel social na resolução de } \\
\text { problemas ambientais }\end{array}$ & 0 & 1 & 0 & 0 & 0 \\
\hline
\end{tabular}




\begin{tabular}{|c|c|c|c|c|c|c|c|c|}
\hline $\begin{array}{l}\text { № do } \\
\text { Indicador }\end{array}$ & $\begin{array}{c}\text { Padrão } \\
\text { Museográfico }\end{array}$ & $\begin{array}{l}\text { Sub-Padrões } \\
\text { detalhados }\end{array}$ & Indicadores & $\begin{array}{l}\text { Conchas, } \\
\text { Corais e } \\
\text { Borboletas } \\
\text { (MNRJ) } \\
\end{array}$ & $\begin{array}{l}\text { Reis da } \\
\text { Europa } \\
\text { Selvagem } \\
\text { (MUHNAC) } \\
\end{array}$ & $\begin{array}{c}\text { Specere } \\
\text { (MUHNAC) }\end{array}$ & $\begin{array}{c}\text { Galeria da } \\
\text { Biodiversidade } \\
\text { (MHNUP) }\end{array}$ & \begin{tabular}{|c|} 
Biodiversidade \\
conhecer \\
para preservar \\
(MZUSP) \\
\end{tabular} \\
\hline 43 & \multirow{13}{*}{ 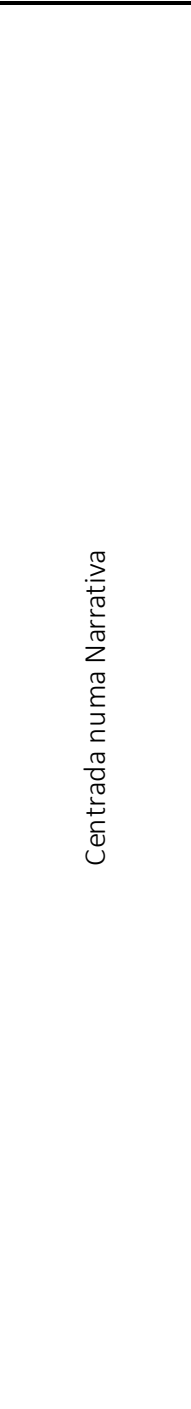 } & Ecológico & $\begin{array}{l}\text { Promover a reflexão do visitante e condições para } \\
\text { mudanças de atitudes relacionadas aos problemas } \\
\text { ambientais }\end{array}$ & 1 & 1 & 0 & 0 & 1 \\
\hline 44 & & Ecológico & $\begin{array}{l}\text { Posicionamento crítico dos museus em questões } \\
\text { ambientais }\end{array}$ & 1 & 1 & 0 & 0 & 1 \\
\hline 45 & & Ecológico & $\begin{array}{l}\text { Ampliar a compreensão da interdependência da vida e de } \\
\text { sua diversidade no planeta }\end{array}$ & 1 & 1 & 0 & 0 & 1 \\
\hline 46 & & Ecológico & $\begin{array}{l}\text { Painéis e gráficos que transmitem mensagens empolgantes } \\
\text { e propostas factíveis para a conservação }\end{array}$ & 0 & 1 & 0 & 0 & $\underline{0}$ \\
\hline 47 & & Ecológico & $\begin{array}{l}\text { Fatos reportados de diversas fontes, similar a linguagem } \\
\text { jornalística }\end{array}$ & 0 & 1 & 0 & 0 & 0 \\
\hline 48 & & Ecológico & $\begin{array}{l}\text { Negação de qualquer discurso ou atitudes relativas a } \\
\text { superioridade humana e dominação sobre a natureza }\end{array}$ & 1 & 1 & 0 & 0 & 1 \\
\hline 49 & & $\begin{array}{l}\text { Public } \\
\text { Understanding of } \\
\text { Science }\end{array}$ & Aparatos interativos (hands-on) & 0 & 0 & 0 & 1 & 0 \\
\hline 50 & & $\begin{array}{c}\text { Public } \\
\begin{array}{c}\text { Understanding of } \\
\text { Science }\end{array} \\
\end{array}$ & Ênfase no visitante & 0 & 0 & 0 & 1 & 0 \\
\hline 51 & & $\begin{array}{c}\text { Public } \\
\text { Understanding of } \\
\text { Science } \\
\end{array}$ & $\begin{array}{l}\text { Ênfase em princípios científicos (ciência } \\
\text { descontextualizada e atemporal) }\end{array}$ & 1 & 0 & 1 & 1 & 1 \\
\hline 52 & & $\begin{array}{c}\text { Public } \\
\begin{array}{c}\text { Understanding of } \\
\text { Science }\end{array} \\
\end{array}$ & $\begin{array}{l}\text { Presença de salas de aula ou espaços reservados para } \\
\text { atividades ("discovery rooms") }\end{array}$ & 0 & 0 & 0 & 0 & 1 \\
\hline 53 & & $\begin{array}{c}\text { Public } \\
\text { Understanding of } \\
\text { Science }\end{array}$ & $\begin{array}{l}\text { Ciência apresentada como um conjunto de leis e com uma } \\
\text { única verdade a ser descoberta }\end{array}$ & 1 & 0 & 1 & 1 & 1 \\
\hline 54 & & $\begin{array}{c}\text { Public } \\
\text { Understanding of } \\
\text { Science }\end{array}$ & $\begin{array}{l}\text { Autonomia do visitante no processo de compreender a } \\
\text { exposição (não há uma narrativa única e estruturante de } \\
\text { toda a exposição) }\end{array}$ & 0 & 0 & 1 & 1 & 1 \\
\hline 55 & & $\begin{array}{c}\text { Public } \\
\text { Understanding of } \\
\text { Science }\end{array}$ & $\begin{array}{l}\text { Promoção de experimentos simples e caseiros para } \\
\text { descoberta auto-guiada }\end{array}$ & 0 & 0 & 0 & 1 & 0 \\
\hline
\end{tabular}




\begin{tabular}{|c|c|c|c|c|c|c|c|c|}
\hline $\begin{array}{l}\text { Ne do } \\
\text { Indicador }\end{array}$ & $\begin{array}{c}\text { Padrão } \\
\text { Museográfico }\end{array}$ & $\begin{array}{l}\text { Sub-Padrões } \\
\text { detalhados }\end{array}$ & Indicadores & $\begin{array}{l}\text { Conchas, } \\
\text { Corais e } \\
\text { Borboletas } \\
\text { (MNRJ) }\end{array}$ & $\begin{array}{l}\text { Reis da } \\
\text { Europa } \\
\text { Selvagem } \\
\text { (MUHNAC) }\end{array}$ & $\begin{array}{c}\text { Specere } \\
\text { (MUHNAC) }\end{array}$ & $\begin{array}{c}\text { Galeria da } \\
\text { Biodiversidade } \\
\text { (MHNUP) }\end{array}$ & $\begin{array}{c}\text { Biodiversidade } \\
\text { conhecer } \\
\text { para preservar } \\
\text { (MZUSP) }\end{array}$ \\
\hline 56 & \multirow{9}{*}{ 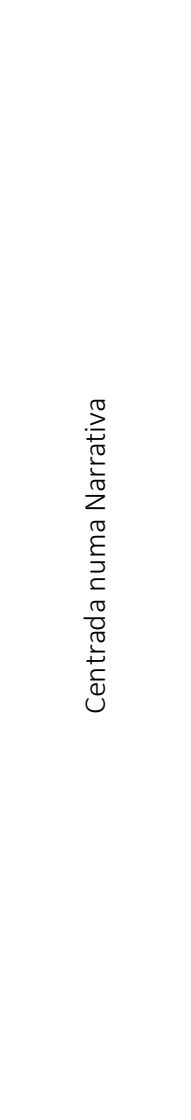 } & $\begin{array}{c}\text { Public } \\
\text { Understanding of } \\
\text { Science } \\
\end{array}$ & $\begin{array}{l}\text { Ausência de diferentes perspetivas de conhecimento } \\
\text { (conhecimentos locais, visões leigas, indígenas) }\end{array}$ & 0 & 1 & 1 & 1 & 1 \\
\hline 57 & & $\begin{array}{c}\text { Public } \\
\text { Understanding of } \\
\text { Science }\end{array}$ & $\begin{array}{l}\text { Painéis explicativos sobre o método científico ou trabalho } \\
\text { de "bastidores" ou campo }\end{array}$ & 1 & 0 & 1 & 0 & 1 \\
\hline 58 & & $\begin{array}{c}\text { Public } \\
\text { Understanding of } \\
\text { Science }\end{array}$ & $\begin{array}{l}\text { Conceitos científicos apresentados por caminhos pré- } \\
\text { definidos de experimentação e interpretação }\end{array}$ & 0 & 0 & 0 & 1 & 0 \\
\hline 59 & & $\begin{array}{c}\text { Public } \\
\text { Understanding of } \\
\text { Science }\end{array}$ & $\begin{array}{l}\text { Promover o "scandalous revelations" (maravilhamento } \\
\text { pelos resultados da ciência) }\end{array}$ & 0 & 0 & 0 & 1 & 0 \\
\hline 60 & & $\begin{array}{c}\text { Public } \\
\text { Understanding of } \\
\text { Science } \\
\end{array}$ & Promoção do entusiasmo pela ciência & 0 & 0 & 1 & 1 & 0 \\
\hline 61 & & $\begin{array}{c}\text { Public } \\
\text { Understanding of } \\
\text { Science } \\
\end{array}$ & Interação multimédia (ecrãs, vídeos e ambientes imersivos) & 1 & 1 & 0 & 1 & 1 \\
\hline 62 & & $\begin{array}{c}\text { Public } \\
\text { Understanding of } \\
\text { Science }\end{array}$ & $\begin{array}{l}\text { Referências ao quotidiano, com temas ou objetos } \\
\text { domésticos ou de uso comum }\end{array}$ & 1 & 1 & 0 & 1 & 0 \\
\hline 63 & & $\begin{array}{c}\text { Public } \\
\text { Understanding of } \\
\text { Science }\end{array}$ & Modelos de robótica & 0 & 0 & 0 & 0 & 0 \\
\hline 64 & & $\begin{array}{c}\text { Public } \\
\text { Understanding of } \\
\text { Science }\end{array}$ & Presença de jogos & 0 & 0 & 0 & 1 & 0 \\
\hline
\end{tabular}




\begin{tabular}{|c|c|c|c|c|c|c|c|c|}
\hline $\begin{array}{c}\text { Ne do } \\
\text { Indicador }\end{array}$ & $\begin{array}{c}\text { Padrão } \\
\text { Museográfico }\end{array}$ & $\begin{array}{c}\text { Sub-Padrões } \\
\text { detalhados }\end{array}$ & Indicadores & $\begin{array}{l}\text { Conchas, } \\
\text { Corais e } \\
\text { Borboletas } \\
\text { (MNRJ) }\end{array}$ & $\begin{array}{l}\text { Reis da } \\
\text { Europa } \\
\text { Selvagem } \\
\text { (MUHNAC) }\end{array}$ & $\begin{array}{c}\text { Specere } \\
\text { (MUHNAC) }\end{array}$ & $\begin{array}{c}\text { Galeria da } \\
\text { Biodiversidade } \\
\text { (MHNUP) }\end{array}$ & $\begin{array}{l}\text { Biodiversidade } \\
\text { conhecer } \\
\text { para preservar } \\
\text { (MZUSP) } \\
\end{array}$ \\
\hline 65 & \multirow{15}{*}{ 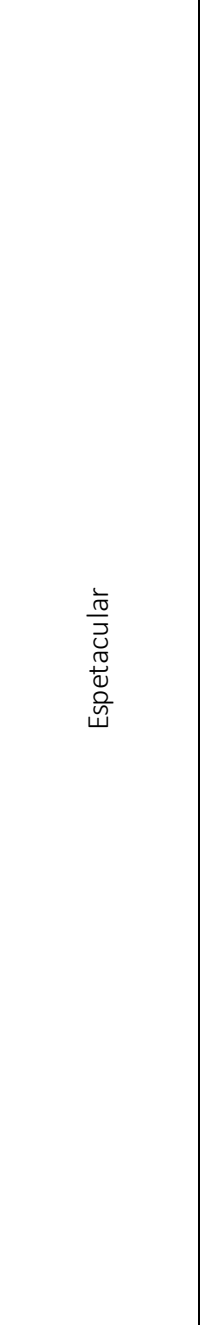 } & $\begin{array}{c}\text { Características } \\
\text { comuns }\end{array}$ & Efeitos dramáticos, principalmente com uso de luz e som & 0 & 1 & 0 & 1 & 1 \\
\hline 66 & & $\begin{array}{c}\text { Características } \\
\text { comuns }\end{array}$ & $\begin{array}{l}\text { Narrativas com encadeamento de eventos, aparatos ou } \\
\text { histórias (pode haver clímax) }\end{array}$ & 0 & 0 & 0 & 0 & 0 \\
\hline 67 & & $\begin{array}{c}\text { Características } \\
\text { comuns }\end{array}$ & $\begin{array}{l}\text { Recursos expográficos em grande escala (ampliações de } \\
\text { imagens, grandes projeções) }\end{array}$ & 1 & 1 & 1 & 1 & 1 \\
\hline 68 & & $\begin{array}{l}\text { Características } \\
\text { comuns }\end{array}$ & $\begin{array}{l}\text { "Autenticidade": encontro com objetos reais ou } \\
\text { certificados pela autoridade da instituição, performance } \\
\text { com pessoas, experiências físicas ou inserção em ambiente } \\
\text { real }\end{array}$ & 1 & 1 & 1 & 1 & 1 \\
\hline 69 & & $\begin{array}{c}\text { Características } \\
\text { comuns }\end{array}$ & Museografia cria ambientes imersivos & 0 & 1 & 0 & 1 & 1 \\
\hline 70 & & $\begin{array}{c}\text { Características } \\
\text { comuns }\end{array}$ & Visão progressista e inequívoca da ciência & 1 & 0 & 1 & 1 & 1 \\
\hline 71 & & $\begin{array}{c}\text { Características } \\
\text { comuns }\end{array}$ & Seleção estética do acervo & 1 & 1 & 1 & 1 & 1 \\
\hline 72 & & $\begin{array}{c}\text { Características } \\
\text { comuns }\end{array}$ & Apresentação da aplicabilidade da ciência para a sociedade & 1 & 0 & 1 & 1 & $\underline{0}$ \\
\hline 73 & & $\begin{array}{c}\text { Características } \\
\text { comuns }\end{array}$ & $\begin{array}{l}\text { Facilmente renovada (com estuturas moldáveis, que não } \\
\text { afetam diretamente a arquitetura do edifício) }\end{array}$ & 0 & 1 & 1 & 0 & 1 \\
\hline 74 & & $\begin{array}{c}\text { Características } \\
\text { comuns }\end{array}$ & Incorporação de elementos do movimento "edutainment" & 0 & 0 & 0 & 1 & 0 \\
\hline 75 & & $\begin{array}{c}\text { Características } \\
\text { comuns }\end{array}$ & Ênfase no visitante & 0 & 0 & 0 & 1 & 0 \\
\hline 76 & & $\begin{array}{c}\text { Características } \\
\text { comuns }\end{array}$ & $\begin{array}{l}\text { Centrado no que o visitante quer aprender; aprender } \\
\text { como ato divertido }\end{array}$ & 0 & 0 & 0 & 1 & 0 \\
\hline 77 & & $\begin{array}{c}\text { Características } \\
\text { comuns }\end{array}$ & $\begin{array}{l}\text { Espécimes identificados individualmente, mas } \\
\text { interpretados em conjunto com outros }\end{array}$ & 1 & 0 & 1 & 0 & 1 \\
\hline 78 & & $\begin{array}{c}\text { Características } \\
\text { comuns }\end{array}$ & $\begin{array}{l}\text { Utilização de aparatos multimédia com informações } \\
\text { adicionais }\end{array}$ & 1 & 1 & 0 & 1 & 0 \\
\hline 79 & & $\begin{array}{c}\text { Características } \\
\text { comuns }\end{array}$ & $\begin{array}{l}\text { Os objetos são colocados em um conjuntos que indicam o } \\
\text { pertencimento a um mesmo tema }\end{array}$ & 1 & 1 & 1 & 1 & 1 \\
\hline
\end{tabular}




\begin{tabular}{|c|c|c|c|c|c|c|c|c|}
\hline $\begin{array}{l}\text { № do } \\
\text { Indicador }\end{array}$ & $\begin{array}{c}\text { Padrão } \\
\text { Museográfico }\end{array}$ & $\begin{array}{c}\text { Sub-Padrões } \\
\text { detalhados }\end{array}$ & Indicadores & $\begin{array}{l}\text { Conchas, } \\
\text { Corais e } \\
\text { Borboletas } \\
\text { (MNRJ) }\end{array}$ & $\begin{array}{l}\text { Reis da } \\
\text { Europa } \\
\text { Selvagem } \\
\text { (MUHNAC) }\end{array}$ & $\begin{array}{c}\text { Specere } \\
\text { (MUHNAC) }\end{array}$ & $\begin{array}{c}\text { Galeria da } \\
\text { Biodiversidade } \\
\text { (MHNUP) }\end{array}$ & \begin{tabular}{|c} 
Biodiversidade \\
conhecer \\
para preservar \\
(MZUSP)
\end{tabular} \\
\hline 80 & \multirow{18}{*}{$\begin{array}{l}\frac{\bar{\pi}}{\frac{\pi}{3}} \\
\overline{0} \\
\frac{0}{0} \\
\frac{0}{山}\end{array}$} & Blockbuster & Financiamento corporativo & 0 & 0 & 0 & 1 & 0 \\
\hline 81 & & Blockbuster & $\begin{array}{l}\text { Propaganda das exposições (grandes painéis na fachada e } \\
\text { outdoors pelas cidades) }\end{array}$ & 1 & 1 & 1 & 1 & 1 \\
\hline 82 & & Blockbuster & Estética comercial & 0 & 1 & 0 & 0 & 0 \\
\hline 83 & & Blockbuster & Presença de lojas e cafés nos espaços expositivos & 0 & 0 & 0 & 0 & 0 \\
\hline 84 & & Blockbuster & Intensa atividade comercial (merchandising) & 0 & 0 & 0 & 0 & 0 \\
\hline 85 & & Blockbuster & $\begin{array}{l}\text { Presença de objetos icónicas ou personagens ou temas de } \\
\text { grande impacto }\end{array}$ & 1 & 0 & 1 & 1 & 1 \\
\hline 86 & & Blockbuster & Apelo popular de massa & 0 & 0 & 0 & 1 & 1 \\
\hline 87 & & Blockbuster & Formato acessível & 0 & 1 & 0 & 1 & 0 \\
\hline 88 & & Blockbuster & $\begin{array}{l}\text { Oportunidades de free-choice learning, com uso de } \\
\text { interativos autoguiados }\end{array}$ & 0 & 0 & 0 & 1 & 0 \\
\hline 89 & & Blockbuster & Narrativa é construída em visão retrospetiva & 0 & 0 & 0 & 0 & 0 \\
\hline 90 & & Blockbuster & $\begin{array}{l}\text { Catálogos à venda, que posicionam conteúdo da } \\
\text { exposição num contexto educacional e curricular }\end{array}$ & 0 & 0 & 0 & 0 & 0 \\
\hline 91 & & Blockbuster & Uso de robótica e animatrônica & 0 & 0 & 0 & 0 & 0 \\
\hline 92 & & Blockbuster & Ausência de controvérsias & 1 & 1 & 1 & 0 & 1 \\
\hline 93 & & Blockbuster & Padronização de temas e abordagens & 0 & 1 & 0 & 1 & 1 \\
\hline 94 & & Blockbuster & $\begin{array}{l}\text { Promoção de atividades paralelas associadas ao tema da } \\
\text { exposição (palestras, visitas guiadas) }\end{array}$ & 0 & 0 & 0 & 1 & 1 \\
\hline 95 & & Blockbuster & Áreas para tirar fotos ("photo-taking exhibition") & 0 & 1 & 0 & 1 & 1 \\
\hline 96 & & Blockbuster & $\begin{array}{l}\text { Narrativa construída com conteúdo académico e distante } \\
\text { das realidades locais }\end{array}$ & 1 & 0 & 1 & 1 & 1 \\
\hline 97 & & Blockbuster & Uso intenso de suportes multimédia & 0 & 0 & 0 & 1 & 0 \\
\hline
\end{tabular}




\begin{tabular}{|c|c|c|c|c|c|c|c|c|}
\hline $\begin{array}{c}\text { Ne do } \\
\text { Indicador }\end{array}$ & $\begin{array}{c}\text { Padrão } \\
\text { Museográfico }\end{array}$ & $\begin{array}{c}\text { Sub-Padrões } \\
\text { detalhados }\end{array}$ & Indicadores & $\begin{array}{l}\text { Conchas, } \\
\text { Corais e } \\
\text { Borboletas } \\
\text { (MNRJ) }\end{array}$ & $\begin{array}{l}\text { Reis da } \\
\text { Europa } \\
\text { Selvagem } \\
\text { (MUHNAC) }\end{array}$ & $\begin{array}{c}\text { Specere } \\
\text { (MUHNAC) }\end{array}$ & $\begin{array}{c}\text { Galeria da } \\
\text { Biodiversidade } \\
\text { (MHNUP) }\end{array}$ & $\begin{array}{l}\text { Biodiversidade } \\
\text { conhecer } \\
\text { para preservar } \\
\text { (MZUSP) } \\
\end{array}$ \\
\hline 98 & \multirow{13}{*}{ 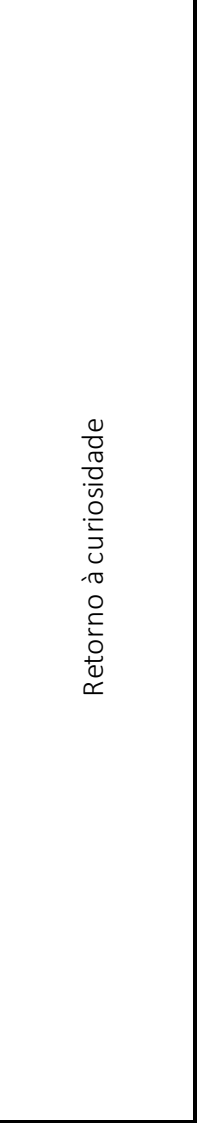 } & $\begin{array}{c}\text { Características } \\
\text { comuns }\end{array}$ & Promover o reencantamento com os objetos & 1 & 0 & 1 & 1 & 1 \\
\hline 99 & & $\begin{array}{l}\text { Características } \\
\text { comuns }\end{array}$ & $\begin{array}{l}\text { Presença de múltiplas narrativas: objetos do acervo } \\
\text { associados a diferentes abordagens, como contextos } \\
\text { imateriais, biografia dos objetos ou relações pessoais }\end{array}$ & 1 & 0 & 1 & 0 & 1 \\
\hline 100 & & $\begin{array}{l}\text { Características } \\
\text { comuns }\end{array}$ & $\begin{array}{l}\text { Ausência de estruturas necessariamente explicativa ou } \\
\text { didáticas para organização do acervo }\end{array}$ & 0 & 0 & 1 & 0 & 0 \\
\hline 101 & & $\begin{array}{c}\text { Características } \\
\text { comuns }\end{array}$ & $\begin{array}{l}\text { Diferentes tipos de informação ao longo de uma mesma } \\
\text { exposição }\end{array}$ & 1 & 0 & 1 & 0 & $\underline{0}$ \\
\hline 102 & & $\begin{array}{c}\text { Características } \\
\text { comuns }\end{array}$ & $\begin{array}{l}\text { Diferentes tipos de representação ao longo de uma mesma } \\
\text { exposição }\end{array}$ & 1 & 1 & 1 & 1 & 1 \\
\hline 103 & & $\begin{array}{c}\text { Características } \\
\text { comuns }\end{array}$ & Instalações decorativas e estéticas & 0 & 0 & 1 & 1 & 1 \\
\hline 104 & & $\begin{array}{c}\text { Características } \\
\text { comuns }\end{array}$ & $\begin{array}{l}\text { Utilização de multimedia para criar museografias } \\
\text { espetaculares }\end{array}$ & 0 & 1 & 0 & 1 & 1 \\
\hline 105 & & $\begin{array}{c}\text { Características } \\
\text { comuns }\end{array}$ & Estimular a curiosidade & 0 & 0 & 0 & 1 & 1 \\
\hline 106 & & $\begin{array}{c}\text { Características } \\
\text { comuns }\end{array}$ & $\begin{array}{l}\text { "Typological exuberance": justaposição de diferentes tipos } \\
\text { de objetos e ênfase na agência e na interação }\end{array}$ & 1 & 0 & 1 & 1 & 1 \\
\hline 107 & & $\begin{array}{c}\text { Características } \\
\text { comuns }\end{array}$ & $\begin{array}{l}\text { Representações respeitosas, abertas e equitativas de } \\
\text { diferentes culturas }\end{array}$ & 0 & 0 & 0 & 0 & $\underline{0}$ \\
\hline 108 & & $\begin{array}{c}\text { Características } \\
\text { comuns }\end{array}$ & $\begin{array}{l}\text { Museografias que apresentam metáforas e temas } \\
\text { alegoricamente e visualmente. }\end{array}$ & 0 & 0 & 0 & 1 & 1 \\
\hline 109 & & $\begin{array}{c}\text { Características } \\
\text { comuns }\end{array}$ & $\begin{array}{l}\text { Sistema de classificação, descrição ou representação } \\
\text { apresentados como parciais, defeituosos ou tendenciosos }\end{array}$ & 0 & 0 & 0 & 0 & 0 \\
\hline 110 & & $\begin{array}{l}\text { Características } \\
\text { comuns }\end{array}$ & Ênfase no objeto. & 1 & 0 & 1 & 0 & 0 \\
\hline
\end{tabular}




\begin{tabular}{|c|c|c|c|c|c|c|c|c|}
\hline $\begin{array}{l}\text { № do } \\
\text { Indicador }\end{array}$ & $\begin{array}{c}\text { Padrão } \\
\text { Museográfico }\end{array}$ & $\begin{array}{l}\text { Sub-Padröes } \\
\text { detalhados }\end{array}$ & Indicadores & $\begin{array}{l}\text { Conchas, } \\
\text { Corais e } \\
\text { Borboletas } \\
\text { (MNRJ) }\end{array}$ & $\begin{array}{l}\text { Reis da } \\
\text { Europa } \\
\text { Selvagem } \\
\text { (MUHNAC) }\end{array}$ & $\begin{array}{c}\text { Specere } \\
\text { (MUHNAC) }\end{array}$ & $\begin{array}{c}\text { Galeria da } \\
\text { Biodiversidade } \\
\text { (MHNUP) }\end{array}$ & $\begin{array}{c}\text { Biodiversidade } \\
\text { conhecer } \\
\text { para preservar } \\
\text { (MZUSP) }\end{array}$ \\
\hline 111 & \multirow{6}{*}{ 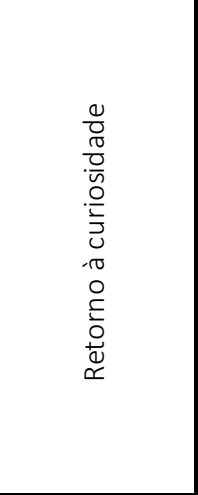 } & $\begin{array}{c}\text { Biografia dos } \\
\text { Objetos }\end{array}$ & Utilização da biografia dos objetos & 1 & 0 & 0 & 0 & 1 \\
\hline 112 & & $\begin{array}{l}\text { Biografia dos } \\
\text { Objetos }\end{array}$ & Abordagem interdisciplinar & 0 & 0 & 0 & 1 & 0 \\
\hline 113 & & $\begin{array}{c}\text { Biografia dos } \\
\text { Objetos }\end{array}$ & Promovem diferentes relações com a audiência & 1 & 0 & 0 & 1 & 1 \\
\hline 114 & & $\begin{array}{l}\text { Biografia dos } \\
\text { Objetos }\end{array}$ & Contingências históricas & 0 & 0 & 0 & 0 & 0 \\
\hline 115 & & $\begin{array}{c}\text { Biografia dos } \\
\text { Objetos } \\
\end{array}$ & Contigências locais & 0 & 0 & 0 & 0 & 0 \\
\hline 116 & & $\begin{array}{c}\text { Biografia dos } \\
\text { Objetos }\end{array}$ & $\begin{array}{l}\text { Impossibilidade da objetividade e neutralidade da prática } \\
\text { científica e museológica }\end{array}$ & 0 & 0 & 0 & 0 & 0 \\
\hline
\end{tabular}




\subsection{APÊNDICE 3: Entrevistas}

Durante a realização da presente investigação foram realizadas nove entrevistas, em sua maioria presencial (8) e com gravação dos áudios (7), totalizando mais de 9h de gravações. Apenas uma das entrevistas foi realizada por e-mail, embora tenham sido enviados documentos complementares por parte dos entrevistados também por e-mail, posteriormente a entrevista.

Em cada uma das instituições que hospedavam as exposições analisadas, foram entrevistados pelo menos dois membros da equipa curatorial: sendo um investigador e outro membro da equipe técnica responsável pela museografia. Assim, foram entrevistados os seguintes profissionais:

Museu Nacional do Rio de Janeiro: Glauco Campelo, Thereza Baumann, Alcimar do Lago Carvalho, Irene Azevedo Cardoso.

Museu de Zoologia da Universidade de São Paulo Maria Isabel Landim e Ana Helena Villela.

Museu Nacional de História Natural e da Ciência da Universidade de Lisboa

Jorge Prudêncio, Cristiane Bastos-Silveira, José Pedro Dias.

Museu de História Natural e da Ciência da Universidade do Porto Maria João Fonseca, Paulo Gusmão Guedes.

As entrevistas ocorreram depois de pelo menos uma visita nas respetivas exposições, de modo que o roteiro abaixo apresentado lista questões mínimas e genéricas, mas que foram contextualizadas com as realidades locais.

1. Identificação do Entrevistado (nome, cargo na instituição / função na equipa curatorial e formação)

2. Qual foi sua participação no processo de conceção e elaboração da exposição?

3. Você poderia descrever o processo de conceção e elaboração da exposição?

4. Quais foram "fontes de inspiração" para a construção da exposição? Se sim, como foi feita a pesquisa?

5. Foram realizadas viagens ou visitas técnicas a outras instituições?

6. Quais critérios para a escolha desse tema? 
7. Houve alguma imposição ou restrição de recursos (interativo, dioramas, vídeos etc.) pela instituição?

8. Houve alguma imposição/restrição temática ou em termos de design da exposição feita pela instituição?

9. Qual a forma de financiamento da exposição?

A partir dessa lista fica evidente que as entrevistas seguiram um modelo semiestruturado, com um conjunto de questões pré-definidas que foram realizadas em forma de diálogo com o entrevistado. Quando oportuno, foram realizadas questões específicas ou perguntas adicionais para elucidar temas que não ficaram claros. Podemos citar alguns exemplos, como o uso de realidade aumentada em "Reis da Europa Selvagem", a montagem do panapaná em "Conchas corais e borboletas", processo de criação dos dioramas de "Biodiversidade: conhecer para preservar!" e a opção pela abordagem da "museologia total” na "Galeria da Biodiversidade". 


\section{ANEXOS}

9.1 ANEXO 1: Ficha Técnica da exposição "Conchas, corais e borboletas"

PRESIDENTE DA REPÚBLICA

Dilma Vana Rousseff

MINISTRO DA FAZENDA

Guido Mantega

PRESIDENTE DA CAIXA ECONÔMICA FEDERAL

Jorge Fontes Hereda

REITOR DA UNIVERSIDADE FEDERAL DO RIO DE JANEIRO

Carlos Levi

MUSEU NACIONAL

DIRETORA

Claudia Rodrigues Ferreura de Carvalho

DIRETOR ADJUNTO DE ADMINISTRAÇÃO

Wagner William Martins

CHEFE DO DEPARTAMENTO DE ENTOMOLOGIA

Maria Cleide de Mendonça

CHEFE DO DEPARTAMENTO DE INVERTEBRADOS

Cristina Silveira Serejo

CHEFIA DA SEÇÃO DE MUSEOLOGIA

Marco Aurélio Marques Caldas / Cleide Maria da Conceição Martins

COORDENAÇÃO GERAL E CURADORIA TÉCNICA

Thereza Baumann

DEPARTAMENTO DE ENTOMOLOGIA

Curadoria e Textos

Alcimar do Lago Carvalho

${ }^{1}$ Nomes e títulos foram mantidos exatamente com a mesma grafia apresentada na exposição. 


\section{Assistente de Curadoria \\ Cátia Antunes de Mello-Patiu}

Assistentes de Execução

Alexandre Soares

Paulo Roberto Magno

\section{Colaboradores (Consultivos ou Executores)}

Edvar Heeren de Oliveira

Felipe Vivalli

Gabriel Luiz Figueira Mejdalani

Marcela Laura Monné Freire

Luis Antônio Alves Costa

Sonia Maria Lopes Fraga

Sueli Maria Pereira

Márcia Souto Couri

Maria Cleide de Mendonça

Miguel Angel Monné Barrios

Valéria Cid Maia

\section{Agradecimentos}

Ângelo Parise Pinto

Editora Holos

Filipe Porto

Mônica Salazar Souza

Rachel Alexandre de Carvalho

Setor de Enologia, Departamento de Antropologia do Museu Nacional

Estagiários e colaboradores do

Departamento de Entomologia do Museu Nacional 


\section{DEPARTAMENTO DE INVERTEBRADOS}

SETOR DE ARACNOLOGIA

Curadoria e textos

Adriano Brilhante Kury

Alessandro Giupponi (Professor Visitante)

\section{Apoio técnico}

Carla Barros

\section{Agradecimentos}

Arthur Anker e Marshal Hedin pela cessão de imagens

\section{SETOR DE CELENTEROLOGIA}

Curadoria e textos

Clóvis Barreira e Castro

Débora de Oliveira Pires

Emiliano Nicolas Calderon (Professor Visitante)

\section{Agradecimentos}

Dr. Álvaro Esteves Migotto e o Projeto Coral Vivo pela cessão de imagens

\section{SETOR DE CRUSTACEA:}

\section{Curadoria e textos}

Cristiana Silveira Serejo

Irene Azevedo Cardoso

\section{Apoio técnico}

Mônica Glória Pereira de Moura

\section{Agradecimentos}

Carlos Secchin pela cessão de imagens

\section{SETOR DE MALACOLOGIA}

\section{Curadoria e textos}

Alexandre Dias Pimenta

\section{Colaboração}

Arnaldo Campos dos Santos Coelho

Cláudio José Fernandes da Costa

Juliana Batista Alvim

Júlio Cesar Monteiro

Maurício Romulo Fernandes 
Norma Campos Salgado

Paulo Marcio Santos Costa

Renata dos Santos Gomes

\section{Agradecimentos}

White Star Publisher pela cessão de desenhos do livro "Shells - Guide to the jewels of the Sea", Autor: Giorgio Gabbi (1999). http://www.whitestar.it

Flavio Dias Passos - UNICAMP - cessão de foto de molusco Aplacóforo

\section{SETOR DE PORIFERA}

Curadoria e textos

Eduardo Carlos Meduna Hajdu

Mariana de Souza Carvalho (bolsista de pós-doutoramento)

\section{Colaboração}

Sula Salani Mota

\section{Agradecimentos pela cessão de imagens}

Álvaro Esteves Migotto (Centro de Biologia Marinha/USP São Sebastião)

Cenpes/Petrobrás

Dirk Schories (Universidade Austral do Chile - Valdívia, Chile)

Fernando Moraes (Museu Nacional/ UFRJ)

Guilherme Muricy (Museu Nacional/UFRJ) - identificação de material biológico

Paulo Pezzuto (UNIVALE) - doação de material biológico

Jeff Rorman (Jeff Rotmam Photography, Nova Jersey, EUA)

João Luis Fraga Carraro (Insstituto de Biociências/UFRGS, Porto Alegre e Museu Nacional/UFRJ)

José Luis Carballo (Universidade Nacional Autônoma do México, Mazatlan, México)

Mário Reis Custódio (Instituto de Biociências/USP São Paulo)

Philippe Willenz (Instituto Real Belga de Ciências Naturais, Bruxelas, Bélgica)

Steven Edward McMurray (Universidade da Carolina do Norte, Wilmington, EUA)

Welington Franklin Vieira Jr. (Alfamar Apoio Marítimo, Rio de Janeiro)

Arquivos do Estado da Flórida (Flórida, EUA)

Gráfica do Instituto Smithsonian (Washington D.C., EUA)

\section{SEÇÃO DE MUSEOLOGIA}

\section{Equipe Técnica:}

Durval Cosme Gonçalves Pinto (in memoriam)

Edina Maria Pereira Martins

Luiz Carlos Menezes

Marco Aurelio Marques Caldas

Marilene de Oliveira Alves

Moana Campos Soto

Rafael Navarro Costa 
Sabrina Damasceno Silva

Mirian Carmo Spitzer Miranda (estagiária)

Thaís Rodrigues Jardim Barreto (estagiária)

Montagem de vitrines e confecção de suportes

Marilene de Oliveira Alves

Preparação de material científico

Cláudio José Fernandes

Edina Maria Pereira Martins

Marco Aurélio Marques Caldas

Mônica Glória de Moura

Desenho de esquemas dos biomas

Luiz Antonio Alves Costa

Higienização de quadros

Angela Rabelo (Departamento de Antropologia/Museu Nacional)

\section{Confecção de Réplicas}

\section{Lula-gigante}

Maurílio de Oliveira (Setor de Museologia)

J oão Carlos Ferreira (Departamento de Paleontologia)

\section{Insetos e ambientação dos biomas}

Ronaldo Rocha

Vídeos

Rogério Bistene (LAPID/Museu Nacional e Projeto Coral Vivo/Cinemar)

Serviços complementares de instalação da exposição:

Equipe da oficina do Museu Nacional

\section{DESIGN}

Glaucio Campelo - Unidesign

\section{Assistentes:}

Aline Mielli

Daniel Palatnik

Priscila Steir

Pedro Burgos

ILUMINAÇÃO

Antonio Mendel 


\section{SUPORTES ESPECIAIS EM ACRÍLICO E METAL}

Studio Regina Barreto

\section{CENOTÉCNICA}

CENOMAX

Agradecimento Especial

Luiz Fernando Dias Duarte

Marilene de Oliveira Alves

REALIZAÇÃO

Universidade Federal do Rio de Janeiro

Museu Nacional

\section{PATROCÍNIO}

SAMN - Associação Amigos do Museu Nacional, CNPq (Conselho Nacional de Desenvolvimento Científico e Tecnológico), Caixa Econômica Federal e Governo Federal 


\subsection{ANEXO 2: Ficha Técnica da exposição "Reis da Europa Selvagem"2}

\section{Organização}

Museu Nacional de História Natura e da Ciência

Grupo Lobo

\section{Comissariado}

Cristiane Bastos-Silveira, Francisco Petrucci-Fonseca

\section{Coordenação Executiva}

Cristiane Bastos-Silveira, Jorge Prudêncio, Judite Alves

\section{Projeto Expositivo}

Cristiane Bastos-Silveira, Jorge Prudêncio, Laranja Mecânica

\section{Design}

Laranja Mecânica

\section{Montagem}

Soul Pepper, Harmonia Urbana, MUHNAC

\section{Iluminação}

Soul Pepper

\section{Diorama}

Pedro Andrade (coord.), Ana Campos, Luís Quinta (Fotografias)

\section{Exemplares}

Coleção Privada Valentim dos Santos, Coleção Zoológica MUHNAC, glutão cedido por Norwegian Institute for Nature Research, lince-ibérico cedido por Instituto da Conservação da Natureza e das Florestas

\section{Banda Sonora}

Portuguese Forest - The Sounfs of Nature, Jon Ryman (CC BY)

\section{Conservação}

Catarina Teixeira (coord.), Catarina Gonçalvez, Conceição Casanova, Laura Moura

\section{Manutenção}

Manuela Carvalho (coord.), Carlos Delgado, Filipe Paiva, José Vicente, Paulo Gabriel

\section{Plano de Comunicação}

\footnotetext{
${ }^{2}$ Nomes e títulos foram mantidos exatamente com a mesma grafia apresentada na exposição.
} 
Lúcia Alves (coord.), Tânia Ferreira

\title{
Mecenato
}

Mafalda Madureira

\section{Agradecimentos}

Alexandra Cartaxana, Alexandra Marçal, Ana Guerreiro, Ana Paula Alonso, Bruno Pinto, Carla Figueiredo, Catarina Mouta, Cécie Delmotte, César Garcia, Claudia Dorea, Daniel Crespo, Diana Carvalho, Diana Tavares, Djuro Huber, Fernando Serralheiro, Frode HolmstrØm, Fundación Oso Pardo, Gerald Heckel, Giesella Cotta, Guilherme Buzzo, Hirundina Andrade, Isabel Ambósio,, Isabel Queiró, Javier Talegón, João Loureiro, Joaquim Pedro Ferreira, Large Carnivore Initiative for Europe (LCIE), Leonor Soaes, Luís Ferreira (www.luis-ferreira.com), Luís Filipe Paula Lopes, Luís Rainha, Margarida Fernandes, Maria José Clarinha, Mariana Marques, Marta Costa, Palmira Carvalho, Paula Cristóvão, Paulo Gaspar, Paulo Marques, Pedro Morais, Petter Wabakken, Rogério Abreu, Sílvia Ribeiro, Teresa Antunes, Terje B $\varnothing$, Tiago Ribeiro, Valeria Salvatori, Vítor Lucas

\section{Apoios}

Chiado Editora

Grupo Leya (Edições Nova Gaia)

Edicare

Porto Editora

Bertrand

Livros Horizonte

Zero a Oito

\author{
Mecenas \\ COTAI \\ CARAVELA - Companhia de Seguros
}

Exposiçãa produzida no âmbito do Projeto Life Med-Wolf 11 NAT/IT/069 MED-WOLF 


\subsection{ANEXO 3: Ficha Técnica da exposição "Specere"3}

Comissariado Maria Judite Alves

Coordenação Geral Jorge Prudêncio

Museografia Rogério Abreu (coord.), Jorge Prudêncio, Marta Costa

Design Gráfico Tiago Ribeiro

Taxidermia Pedro Andrade (cood.), Ana Campos

Conservação e Restauro Catarina Gonçalves, Catarina Teixeira, Laura Moura

Apoio à Conservação e Restauro Ana Marques, Beatriz Brandão, Catarina Pires, Joana Fontes, Marisa Pinheiro, Filipa Correia

Seleção de Espécimes Alexandra Cartaxana, Alexandra Lucas, Alexandra Marçal Correia, Ana Isabel Correia, Bruno Ribeiro, Cecília Sérgio, César Garcia, Cristiane Bastos-Silveira, Cristina Duarte, Diana Carvalho, Elisabete Malafaia Ireneia Melo, João Paulo Lopes, Liliana Póvoas, Luís Ceríaco, Luís Filipe Lopes, Maria Judite Alves, Mariana Marques, Palmira Carvalho, Paula Branco, Susana Garcia, Susana Matos, Vandas Santos

Textos Maria Judite Alves (coord.), Alexandra Cartaxana, Alexandra Marçal Correia, César Garcia, Cristiane Bastos-Silveira, Cristina Duarte, Elisabete Malafaia, Ireneia Melo, Liliana Póvoas, Luís Filipe Lopes, Vanda Santos

Revisão dos Textos Alexandra Marçal Correia, Fernando Serralheiro

Ilustração Científica Pedro Salgado

Montagem e Logística Harmonia Urbana, Manuela Carvalho (coord.), Carlos Delgado, Paulo Gabriel

Apoio à Montagem Catarina Moura, Lina Hall, Luísa Crisóstomo, Sandrine Pontes

Iluminação Filipe Paiva

Produção Gráfica Logotexto, Publifast

Direção e Comunicação Lúcia Alves

Agradecimentos Adolfo Ferrero, Alda Francisco, Ana Guerreiro, Beatriz Amorim, Carla Figueiredo, Hirondina Andrade, Inês Marques, Inês Pinto, João Chora, Leonor Pereira, Paula Alonso, Paula Cristóvão, Pedro Morais, Rui Carvalho, Sofia Pereira

Exposição produzida no âmbito do projeto I\&D BIODECON PTDC/IVC-HFC/1817/2014 Universidade de Lisboa

Museu Nacional de História Natural e da Ciência da Universidade de Lisboa

Fundação para a Ciência e a Tecnologia

\footnotetext{
${ }^{3}$ Nomes e títulos foram mantidos exatamente com a mesma grafia apresentada na exposição.
} 


\subsection{ANEXO 4: Ficha Técnica da exposição "Galeria da Biodiversidade"4}

\section{PROMOTORES}

Universidade do Porto Ciência Viva - ANCCT

\section{CONCEÇÃO E COORDENAÇÃO GERAL}

Nuno Ferrand de Almeida

Luís Mendonça

Jorge Wagensberg

\section{COMISSARIADO EXECUTIVO}

Conselho do MHNC-UP

Conselho Executivo do MHNC-UP

\section{DIREÇÃO ARTÍSTICA E DESIGN}

Luís Mendonça/Gémeo Luís

\section{PRODUÇÃO}

Alexandre Pinheiro

Paula Costa

Carla Morais Pires

Cristiana Vieira

Daniela Coutinho

Hernán Crespo Bermejo luri Frias

Joana Tinoco

João Junqueira

José Manuel Grosso Silva

Luís Mendonça

Maria João Fonseca

Norma Pott

Helena Veloso

\section{EXECUÇÃO}

Álvaro Negrello

Angélica Dass

Elizabeth Daynes

Fernando Correia

F. Azevedos

\section{ARQUITETURA}

Nuno Valentim e Frederico Eça
Paulo Farinha Marques

Paulo Gusmão Guedes

Pedro Almeida

Ricardo Lopes

Rita Gaspar

Rosa Carretero

Simão Mateus
Gema Digital

Karangua Letratec

Linhas Trocadas

Museu Nacional História N. 100 Ferrugem

Portofólio

Quagga Associates

Total Museology

Ciência 


\section{COMUNICAÇÃO}

GCI U.Porto - MHNC-UP

\section{AGRADECIMENTOS E CONTRIBUTOS}

ADAPTA

Albano Beja-Pereira

Ana Margarida Alexandrino

Andreia Magalhães

Andrey A. Lissovsky

António Botelho de Melo

António Cardoso

António Guerner Dias

António Sá Torres Armando

Alves

Arquivo da Família Rodrigues

Associação Antigos

Orfeonistas U.P.

Banco Nacional Ultramarino

Bento Cavadas

Biblioteca Nacional

Biblioteca Nacional do Brasil

Bibliothèque de l'A.N. de

France Blandina Sá Torres

Carlos Alberto

Casimiro Costa

Catarina Fernandes

Cátia Sá

Cidália Duarte

Cláudia Salgueiro

David M. Hillis

David Vieites

Delta Q

Derrick Zwickl

Direção Regional de

Agricultura

Diogo Bessa

Duarte Monteiro

Duarte Vilela

DuPont Pioneer

Eugénia Bastos

Família Correia-Audigane

Família Sousa

Farmácia Lemos

Fátima Valle da Veiga
Federação Portuguesa de

Futebol Fernando Correia

Francisca Trevisan

Francisco Pinto e Margreth

Baden

Francisco Ribeiro Meireles

Fundación Casa Ducal de

Medinaceli

Galeria Navin Kumar

Gracinda Amaro

Hugo Lobo

Hugo Oliveira

Hugo Rebelo

Iñigo Solano

International Maize (CIMMYT)

Isabel Maria Torres da Silva

Pereira

Isabel Tavares

Jardim Zoológico de Lisboa

Joana Torres

João Ferrand

João Monteiro

João Tereso

Joaquim Saramago

Jorge Brito

Jorge Coelho

Jorge Forjaz

Jorge Macedo Rocha

Jorge Magalhães Alves

Jorge Rocha

José Gregório Sá Torres

José Marques dos Santos

José Melo Ferreira

Julieta Rodrigues

Library of Congress

Liliana Farelo

LIPOR

Lusosem

Mami Higuchi

Maria do Carmo Pires
Maria João Falcão

Maria Sá Torres

Maria Teresa Dantas

Martim Pessanha

Miguel Araujo

Miguel Carneiro

Mónica Silva

MUHNAC - U.Lisboa

Museu da Ciência da U.

Coimbra

Museu de Évora |DRCA

Museu de Lamego

Museu Nacional Soares dos

Reis Norma Gomez

Nuno Magalhães

Nuno Queiroz

Parque Biológico Serra da

Lousã

Parque Biológico de Gaia

Parque Ornitológico de S.

M.Feira

Paula Ribas

Paulo Alexandrino

Paulo Célio Alves

Paulo Costa

Paulo Gama Mota

Pedro Cardia

Perpétua Nunes da Silva

Quinta do Pedragal

Quinta dos Penedinhos

Raquel Godinho

Ricardo Ramos

Rita Cunha

Rita Marques 
Biodiversidade Musealizada: Formas que Comunicam

Robin Gutell

Rosa Pinho

Rui Mendonça

Sandra Rodrigues

Sara Lemos Ferreira

Sónia Leitão

Stephen Sabatino

Syngenta

TVU.

Valentim Nabais

VALORMED

Zoo da Maia

Zoo Lourosa

Zoo Santo Inácio

Zoomarine 
9.5 ANEXO 5: Ficha Técnica da exposição “Biodiversidade: conhecer para preservar"5

UNIVERSIDADE DE SÃO PAULO

Reitor

Pró-Reitora

Marco Antonio Zago

Maria Arminda do Nascimento Arruda

Vice-Reitor

Vahan Agopyan

Pró-Reitor Adjunto de Cultura

João Marcos de Almeida Lopes

PRÓ-REITORIA DE CULTURA E EXTENSÃO UNIVERSITÁRIA

Pró-Reitor Adjunto de Extensão Universitária Moacyr Ayres Novaes Filho

MUSEU DE ZOOLOGIA DA USP

Diretor

Marcos Domingos Siqueira Tavares

Chefe da Divisão Científica

Marcelo Duarte da Silva

Vice-Diretor

Chefe da Divisão de Difusão Cultural

Carlos José Einicker Lamas

Maria Isabel Landim

Chefe da Divisão Administrativa

Otávio Gregori Júnior

\section{IDEALIZAÇÃO DA EXPOSIÇÃO BIODIVERSIDADE: CONHECER PARA PRESERVAR MZUSP}

PROJETO

MZUSP \& Expomus

Coordenação Geral do Projeto

Maria Isabel Landim

Felipe Alves Elias

\section{Comitê Curatorial}

Maria Isabel Landim

Mirian David Marques

Marcelo Duarte da Silva

Marcos Domingos Siqueira Tavares

Mario de Vivo

Carlos José Einicker Lamas

Aléssio Datovo

Eliana Marques Cancello

Mário César Cardoso de Pina

Carlos Roberto Ferreira Brandão

Luiz Ricardo Lopes de Simone

Luís Fábio Silveira

\footnotetext{
${ }^{5}$ Nomes e títulos foram mantidos exatamente com a mesma grafia apresentada na exposição.
} 
Felipe Alvez Elias

Otávio Gregori Júnior

Gáulica Aparecida Bio

Jacqueline Battilana

Altair Aparecido Casemiro

Renato de Oliveira Silva

Carlos Campaner

\section{Subcomitê de Textos}

Maria Isabel Landim

Mirian David Marques

Mario de Vivo

Felipe Alves Elias

\section{Tradução}

Mirian David Marques

\section{Subcomitê de Acervos e Imagens}

Dione Seripierri

Vanessa Sakai Gomes Pires

Rosângela Celina Cavalcante

Roseli Viana Retamero

Márcia Fernandes Lourenço

Marina Isabel Lima

\section{Subcomitê Administrativo}

Otávio Gregori Júnior

Marcia Regina Caldino

Gláucia Aparecida Bio

Anderson José Paulino da Silva

Luís Eduardo Massunari Lieu

\section{Divisão de Difusão Cultural}

Maria Isabel Landim

Felipe Alves Elias

Márcia Fernandes Lourenço

Rosângela Celina Cavalcanti

Roseli Viana Retamero

Márcia Regina Galdino dos Santos

Vanessa Sakai Gomes Pires

\section{Taxidermia}

Marina Isabel Lima
Aline Staskowian Benetti

Alberto B. Carvalho

Marcelo Santos Félix

Camila Fernandes Conti

Mónica Antunes Ulyssea

Joice Constantino 


\section{Compras/Finanças/Tesouraria}

Luíza Yuriko Hiraoka

Leopoldine Pascher

Imaculada Conceição Musso

Gláucia Aparecida Bio

Carmela Mohrmann Elias

\section{Equipe Operacional / Manutenção / Motoristas}

Altair Aparecido Casemiro

Vanderlei Tadeu Moreira dos Santos

Eliseu dos Santos Pereira

Anderson José Paulino da Silva

Aparecido Pereira da Silva

Ismael Pereira de Jesus

Rogério dos Santos

Isac Balbino da Silva
Marlene de Fátima Rocha

Maria Cícera A. de Araújo Santos

Jonathan Jorge Zeferino de Almeida

Vânia Lúcia da Silva

Francisco de Assis Brum da Silva

José Fernando Costa

Rosemeire Rodrigues Alves

Sergio Nunes Torres

Augeu Francisco

Valter da Silva Saraiva

Claudio Reberti Servilha

\section{IMPLANTAÇÃO DA EXPOSIÇÃO BIODIVERSIDADE: CONHECER PARA PRESERVAR}

\section{Expomus}

Exposições, Museus, Projetos Culturais

\section{Direção}

Maria Ignez Mantovani Franco

Roberta Saraiva Coutinho

Renato Musa

\section{Comunicação Institucional}

Carla Nieto Vidal

\section{Núcleo de Museologia}

Carolina Vilas Boas

\section{Coordenação Técnica dos Acervos}

Alessandra Labate Rosso

\section{Assistentes Técnicas}

Heloísa Bedicks

Lilian Almeida Rastelli

\section{Produção Local}

Camila Gordillo de Souza 


\section{PROJETO MUSEOGRÁFICO E EXPOGRÁFICO}

Escritório Paulistano de Arquitetura

Metrópole Arquitetos

\section{Equipe}

Ana Helena Villela

Eduardo Colonelli

Izabel Barboni Rosa

Liz Arakaki

Laura Vaniqui

\section{EXECUÇÃO DO PROJETO MUSEOGRÁFICO E EXPOGRÁFICO}

Liz Cenografia

\section{PLANEJAMENTO VISUAL GRÁFICO}

Partícula | Claudia Lammoglia

\section{PLOTAGENS E INSTALAÇÃO}

Olho Digital

\section{FOTÓGRAFOS}

Ivan Strazzer Vilas Boas

Ricardo Rios

TRATAMENTO DAS IMAGENS DOS DIORAMAS

Daniel Renault

\section{INSTALAÇÃO AUDIOVISUAL “BIODIVERSIDADE”}

Estúdio Preto e Branco

\section{Concepção}

Luiz de Franco Neto e Maurício Moreira

Motion Design

Igor Ventura

Direção de Arte

Marise Greice Kieling

Direção Técnica

Murilo Celebrone

Roteiro

Angela Annunciato

Pesquisa e Edição

Cíntia Henriques
Marcos Cintra

Mayra Vescovi

Trilha Sonora

Maurício Domene - Estúdio Next

Locução

Maurício Fernandes

Produção Executiva

Cláudia Vieira Ventura 


\section{Assistente de Produção}

Karine Kotsubo

\section{Imagens}

iStock, by Getty Images

Planet Earth (2006), British Broadcasting

Corporation (BBC) 
PROJETO DE ILUMINAÇÃO

Fernanda Carvalho - Design de Luz Estudio

Assistente de lluminação

Renata Fongaro

Charly Ho

\section{Execução da lluminação}

Liz Cenografia

\section{MONTAGEM FINA}

Manuseio

\section{TAXIDERMIA / OSTEOTECNIA}

José de Campos

Lucas Andrei Campos Siva

Willim Marcus Campos Silva

Márcia Campos Silva

lezo Lettman

Ariel Milaim

Beatriz Beloto

\section{REVISÃO DOS TEXTOS}

Lia Ana Trzmielina

\section{AGRADECIMENTOS}

Vice-Reitoria da Universidade de São Paulo Eduardo Alves (PRCEU)

Fundação Parque Zoológico de São Paulo Parque Ecológico do Tietê

Parque Zoológico Municipal Quinzino de Barros (Sorocaba - SP)

ZooParque Itatiba (Itatiba, SP)

Parque Ecológico Municipal de Paulínia Armando Müller (Paulínia, SP)

Museu de Anatomia Veterinária,
Faculdade de Medicina Veterinária e Zootecnia da Universidade de São Paulo José Coltro Jr. E equipe Femorale Alexandre Rossi

Lívia Pires do Prado Bruno Augusta Osvaldo Oyakawa Monica A. Ulysséa Tiago Carrijo Vinícius S. Ferreira 